

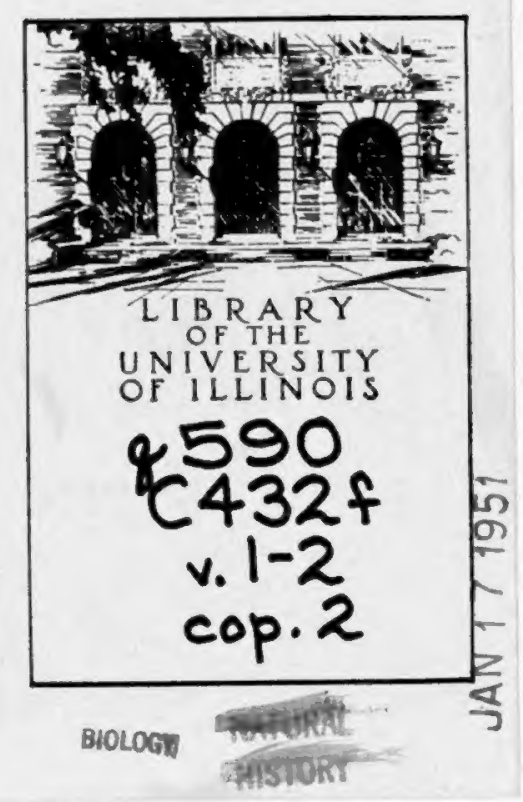




\section{Return this book on or before the}

Latest Date stamped below.

Theft, mutilation, and underlining of books are reasons for disciplinary action and may

result in dismissal from the University.

University of Illinois Library

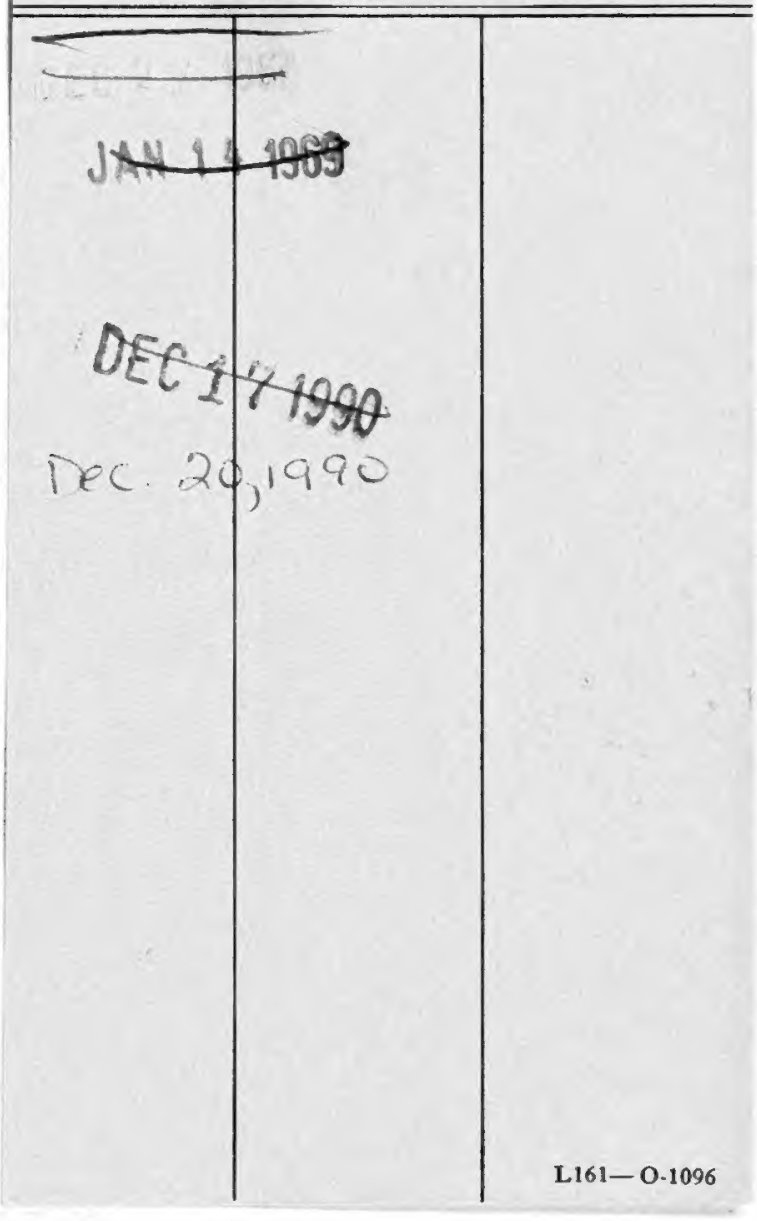





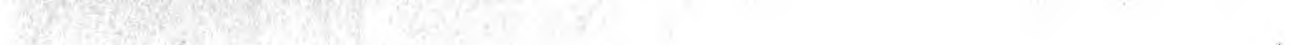




\title{
AMPHIBIANS OF WESTERN CHINA
}

Ch'eng-chao Liu

\author{
5UL 179050
}

Rati?

AIST:

\author{
FIELDIANA: ZOOLOGY MEMOIRS \\ VOLUME 2 \\ Published by \\ CHICAGO NATURAL HISTORY MUSEUM \\ JUNE 15,1950
}




\title{
FIELDIANA: ZOOLOGY MEMOIRS
}

\author{
VOLUME 2
}

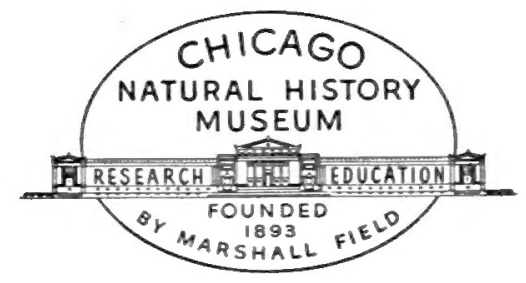

CHICAGO NATURAL HISTORY MUSEUM

CHICAGO, U.S.A.

1950

THE LIBRARY OF THE

JUN $2 \perp 1950$ 


\section{Editors}

KARL P. SCHMIDT

Chief Curator, Department of Zoology

LILLIAN A. ROSS

Associate Editor of Scientific Publications 
AMPHIBIANS OF WESTERN CHINA 


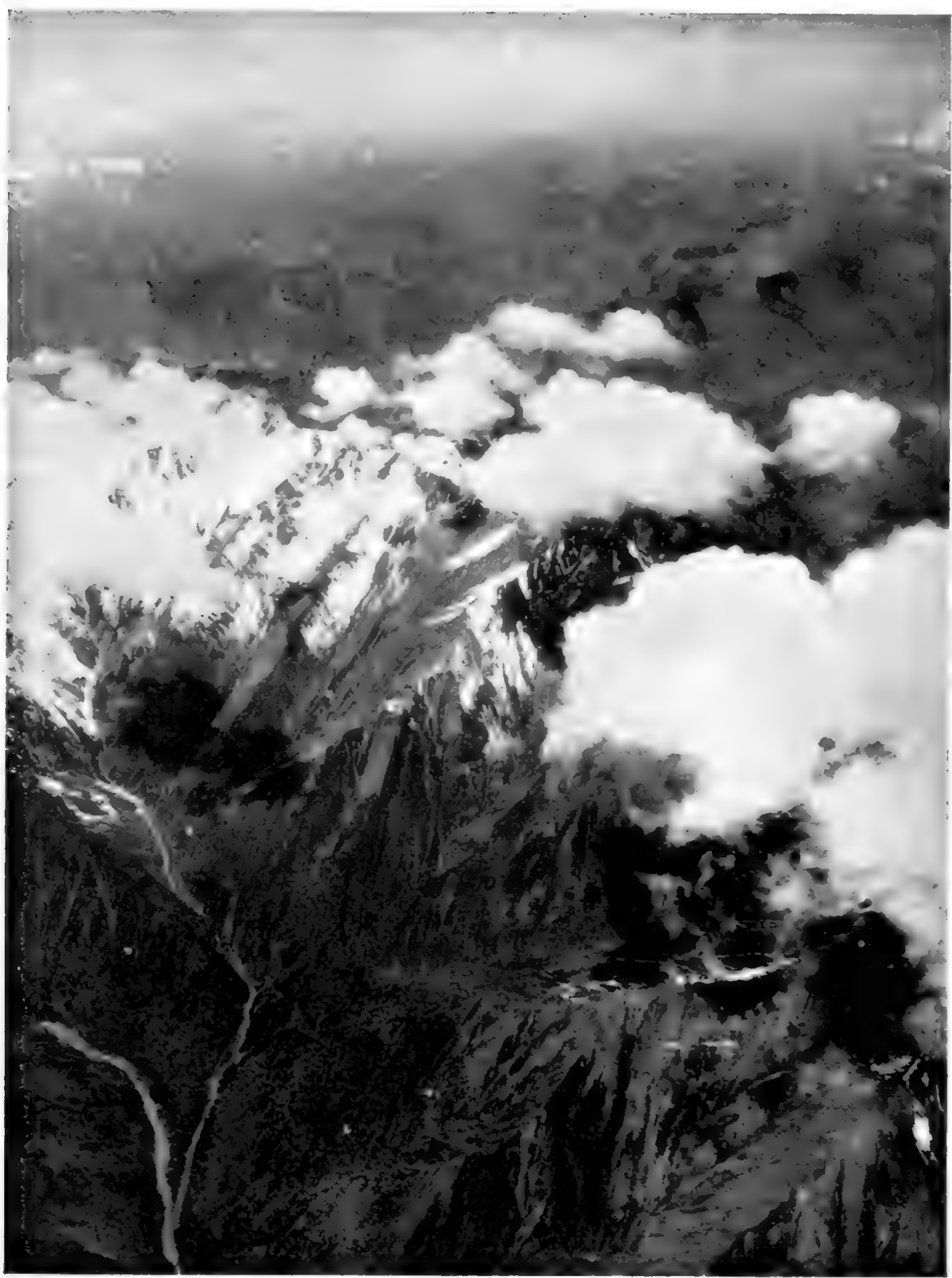

Courtesy of American Geographical Sociely and Dr. Herold J. Wiens, Yale University

THE RUGGED TIBETAN BORDER COUNTRY OF NORTHWESTERN SZECHWAN 


\title{
AMPHIBIANS OF WESTERN CHINA
}

\author{
CH'ENG-CHAO LIU \\ PROFESSOR OF BIOLOGY, WEST CHINA UNION UNIVERSITY \\ RESEARCH ASSOCIATE, DIVISION OF AMPHIBIANS AND REPTILES \\ CHICAGO NATURAL HISTORY MUSEUM
}

FIELDIANA: ZOOLOGY MEMOIRS

VOLUME 2

Published by

CHICAGO NATURAL HISTORY MUSEUM

JUNE 15, 1950 
PRINTED IN THE UNITED STATES OF AMERICA BY CHICAGo NATURAL HISTORY MUSEUM PRESS 


\section{PREFACE}

I have the pleasant duty of expressing my profound gratitude to the numerous institutions and to the host of individuals who have aided me in the studies from which the present volume results. At the head of the list must stand West China Union University, where, under President L. K. Chang, I found a new university sponsor and freedom to engage in research, and where Professor M. C. Chang, Head of the Department of Biology, gave me sympathetic and effective support. Second must come my American scientific haven, Chicago Natural History Museum, where I was made welcome by Colonel Clifford C. Gregg, the Director, and by my colleagues in herpetological studies, Messrs. Karl P. Schmidt, Clifford H. Pope, D. Dwight Davis, and Robert F. Inger. I must, of course, thank the United States of America, through whose Division of Cultural Relations in the State Department I received the opportunity to spend a year in the United States in order to bring together my accumulated data into publishable form. Messrs. Francis J. Colligan and Earl A. Dennis, of the State Department, smoothed my way throughout my stay in America.

I have examined nearly every specimen of Chinese amphibians preserved in American museums and must thank the authorities and my colleagues at the United States National Museum, the Museum of Comparative Zoology, the American Museum of Natural History, the Carnegie Museum, Cornell University, and the Museum of Zoology of the University of Michigan. The notes and manuscripts of the late Leonhard Stejneger, the great pioneer in the critical study of the herpetology of Japan and China, were courteously placed at my disposal by Dr. Doris M. Cochran, Curator of Herpetology at the National Museum. I was received everywhere as a welcome friend and colleague, and I realized that there is to be found in scientific circles the true spirit of the One World of the future.

In the course of visits to various museums and universities I have consulted with Dr. E. R. Dunn, Mr. Charles M. Bogert, Mr. M. Graham Netting, and Mr. Arthur Loveridge. I owe them a large share of my debt of gratitude.

My former teacher at Yenching University, Dr. Alice M. Boring, has my grateful remembrance for her continued encouragement and help during the war years. In China itself, the Institute of Zoology of the Academia Sinica lent me valued support, and especial thanks are due to Dr. H. W. Chang for bibliographic aid.

In western China, my repeated expeditions would have been impossible without the faithful help and encouragement of my wife, who aided me in the study 
of collected specimens, made measurements and calculations, and typed the manuscripts of all of my preliminary papers. In various years I was assisted in field exploration by H. W. Chang, Y. W. Kao, H. C. Chang, P. L. Luh, C. K. Liu, C. T. Chin, K. F. Cheng, and T. T. Liu. But for Dr. T. L. Yü, of Sichang Hospital, who saved my life when I had typhus, these words could not have been written. I was materially aided by Mr. Y. C. Chiao, of the Department of Communications of the Central Government, in travels in Sikang, Kansu, and Shensi. Mr. L. C. Liu, Director of the Sikang-Kantze Highway Construction, aided me in reaching objectives in Sikang and Kansu.

Many salamanders and frogs are intrinsically beautiful creatures, with pleasing colors and harmonious patterns. Their coloration is of great interest for the distinction of the species and still more for its relations to the environment in which the species are found. I was extremely fortunate in finding a capable artist in Chengtu, in the person of Mr. I. S. Wang, young and mostly self-trained, who became my invaluable aid in the field and at home. The illustration of this volume, with the exception of plates 1 and 2 and figures 10 and 82 , is his work. I am therefore very proud to present a series of forty-seven of Mr. Wang's water colors, assembled on eight plates, the publication of which was made possible by a special contribution from Mr. Albert $\mathrm{H}$. Wetten, Trustee of Chicago Natural History Museum. I am profoundly grateful to Mr. Wetten for this colored illustration of my work, and feel certain that its users will be equally indebted to him.

The manuscript, as it grew in the laboratory of the Division of Amphibians and Reptiles at Chicago Museum, was a product of co-operative labors. Mr. Karl P. Schmidt, Chief Curator of the Department of Zoology, had aided me in studies on Chinese amphibians in 1934 and 1935, my reception in Chicago being no doubt the more cordial for our relation as successive students of Dr. A. H. Wright of Cornell University. On my return in September, 1946, we found ourselves old friends. Mr. Schmidt's aid in the organization of the work and in clarifying my English has been generous beyond my power to thank him. Mr. Pope, Curator of the Division of Amphibians and Reptiles, joined Mr. Schmidt in reading the manuscript through successive corrections. Much of the subject matter of the work was discussed jointly by Messrs. Schmidt and Pope and myself, and I had the valuable aid of Mr. Pope's notes on type specimens preserved in European museums.

Mr. Robert F. Inger, Assistant in the Division, was ever helpful, and continued his interest and aid through the preparation of the finally voluminous manuscript for the press. Mr. Davis, Curator of the Division of Vertebrate Anatomy, aided me with translations from the French, as Mr. Schmidt did from the German. Miss Laura Brodie rendered an invaluable service to the manuscript by her careful mounting of the illustrations. Miss Margaret J. Bauer, Mrs. Helen G. Moyer, and Mrs. Howard K. Gloyd shared the tedious work of typing from an extraordinarily interlined and corrected longhand original manuscript, taking a personal interest in the project. 
I wish to mention the fact that the library facilities at Chicago Natural History Museum are especially notable for herpetological material, combining the personal libraries of Messrs. Schmidt and Pope with the general library of the Museum. Mr. Carl W. Hintz, the Librarian, and all the members of his staff, were extremely cordial and helpful to me in the borrowing of books.

CH'ENG-CHAO LIU

November 1, 1948 


\section{CONTENTS}

List OF ILLUSTRATIONS

INTRODUCTION . . . . . . . . . . . . . . . . . . . 17

Preservation and Measurements . . . . . . . . . . . . . . . . 17

List of Localities . . . . . . . . . . . . . . . . . . . . . 20

Zoological Explorations in Western China, 1938-46 . . . . . . . . 23

Emigration of Teachers and Students to Western China . . . . . . . . . 23

Herpetological Exploration of Mount Omei . . . . . . . . . . . 25

Explorations at Muping, Sikang, 1939 . . . . . . . . . . . . . 27

Journey to Northwestern Szechwan . . . . . . . . . . . . . . . . . 29

Journey to Ningshu, Sikang, 1942 . . . . . . . . . . . . . . . . . . . . . 31

Explorations in Kangshu, Sikang, 1943 . . . . . . . . . . . . . . . 36

Discoveries in Western China . . . . . . . . . . . . . . . . . . . . 41

Distribution and Speciation of Amphibia of Western China. . . . . . . 43

Introduction . . . . . . . . . . . . . . . 43

General Relations between Amphibia of Western China and Other Parts of the World . . . . . . 44

General Relations between Amphibia of Western China and Other Parts of China. 45

Distribution of the Amphibia of Western China . . . . . . . . . . . . 46

Discussion of Endemic Genera . . . . . . . . . . . . . . . . . 48

Habitat Isolation . . . . . . . . . . . . . . . . . 50

Provincial Lists of the Species of Amphibia of Western China . . . . . . . . . 53

Adaptations of the Amphibia of Western China . . . . . . . . . . . . . 54

Adaptation in Adults and Tadpoles . . . . . . . . . . . . . . . . . 55

LIST OF SPECIES

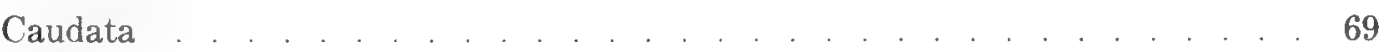

Salientia . . . . . . . . . . . . . . . . 110

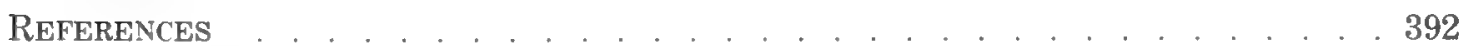

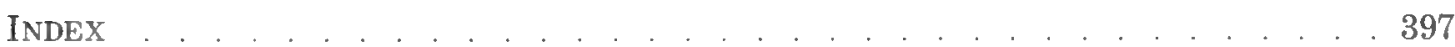





\section{LIST OF ILLUSTRATIONS}

\section{PLATES}

Frontispiece. A view of the rugged Tibetan border country of northwestern Szechwan. Courtesy of American Geographical Society and Dr. Herold J. Wiens, Yale University.

1. Salamanders of western China. Figs. 1-3. Batrachuperus tibetanus. Figs. 4, 5. Batrachuperus pinchonii.

2. Salamanders of western China. Figs. 1-3. Tylototriton kweichowensis.

3. Salamanders of western China. Fig. 1. Batrachuperus pinchonii. Fig. 2. Triturus wolterstorff. Fig. 3. Tylototriton taliangensis.

4. Pelobatid frogs of western China. Fig. 1. Scutiger pingii. Fig. 2. Megophrys omeimontis. Fig. 3. Vibrissaphora boringii. Fig. 4. Aelurophryne tainingensis. Fig. 5. Megophrys minor. Fig. 6. Aelurophryne glandulata.

5. Pelobatid frogs of western China. Figs. 1, 2. Scutiger schmidti. Fig. 3. Megophrys shapingensis. Fig. 4. Megophrys boulengeri. Fig. 5. Scutiger popei.

6. Frogs of western China. Fig. 1. Rana nigromaculata. Fig. 2. Rana chaochiaoensis. Fig. 3. Rana andersonii. Fig. 4. Rana shuchinae. Fig. 5. Nanorana pleskei. Fig. 6. Rana margaretae.

7. Cascade frogs of western China. Fig. 1. Staurois loloensis. Figs. 2, 6. Staurois mantzorum. Fig. 3. Staurois chunganensis. Fig. 4. Staurois kangtingensis. Fig. 5. Staurois lifanensis.

8. Tree frogs of western China. Figs. 1, 2. Rhacophorus chenfui. Fig. 3. Rhacophorus omeimontis. Figs. 4, 5. Rhacophorus bambusicola.

9. Aerial egg-mass of tree frog, Rhacophorus omeimontis.

10. Tadpoles of salientians of western China. Figs. 1, 2. Megophrys minor. Fig. 3. Scutiger rugosa. Fig. 4. Megophrys oshanensis. Fig. 5. Microhyla ornata. Fig. 6. Rana boulengeri. Fig. 7. Aelurophryne glandulata. Fig. 8. Bombina maxima. Fig. 9. Rana adenopleura. Fig. 10. Hyla annectans. Fig. 11. Kaloula macroptica. Fig. 12. Staurois lifanensis. Fig. 13. Scutiger schmidti. Fig. 14. Rhacophorus leucomystax.

\section{TEXT FIGURES}

2. Illustrations of measurements used in this paper. A. Adult. B. Foot of adult. C. Tadpole .

PAGE 16

3. Map of western Szechwan and eastern Sikang, showing localities, mountain ranges, and altitudes

4. Map of Mount Omei, showing routes, temples, and altitudes . . . . . . . . 26

5. Map of Paohsinghsien (Muping), Sikang, showing main rivers and mountain ranges, and routes and localities of collecting trip made in $1939 . . . .28$ 
6. Map of northwestern Szechwan, showing collecting routes, localities, and altitudes

7. Map of Ningshu, Sikang, showing collecting routes, localities, and altitudes.

8. Map of Kangshu, Sikang, from Kangting to Kangtze, showing collecting routes, localities, and altitudes .............. 37

9. Megalobatrachus davidianus. A. Dorsal view of head. B. Ventral view of head. 73

10. Megalobatrachus japonicus. A. Dorsal view of head. B. Ventral view of head . 73

11. Hynobius shihi. A. Adult. B. Oral cavity. C. Ventral view of hand. D. Finger, showing cornified tip. E. Ventral view of foot . . . . . . . . . 78

12. Batrachuperus karlschmidti; adult . . . . . . . . . . . . . . . . . . . . . 88

13. Batrachuperus karlschmidti. A. Egg-case. B. Larva just after hatching. C. Fully developed larva.

14. Batrachuperus yenyuanensis. A. Adult female. B. Oral cavity. C. Ventral view of hand. D. Ventral view of foot

15. Bombina maxima; male

16. Bombina maxima; male. A. Ventral view of head and thoracic region. B. Ventral view of hand. C. Ventral view of foot .............. 11

17. Aelurophryne mammata; male. A. Dorsal view. B. Ventral view . . . . . 121

18. Aelurophryne brevipes; male. A. Ventral view of head and thoracic region. B. Ventral view of hand. C. Ventral view of foot . . . . . . . . . 125

19. Aelurophryne brevipes; male . . . . . . . . . . . . . . 126

20. Aelurophryne brevipes; tadpole. A. Lateral view. B. Mouth . . . . . . 130

21. Aelurophryne tainingensis; male. A. Ventral view of head and thoracic region. B. Ventral view of hand. C. Ventral view of foot ......... 133

22. Aelurophryne maculata. A. Dorsal view. B. Ventral view of hand. C. Ventral view of foot

23. Aelurophryne glandulata; male. A. Ventral view of hand. B. Ventral view of foot 138

24. Aelurophryne glandulata; male. Ventral view of head and thoracic region. . . . 139

25. Aelurophryne glandulata; tadpole. A. Ventral view. B. Mouth . . . . . 142

26. Scutiger pingii; male. A. Ventral view of head and thoracic region. B. Oral cavity. C. Ventral view of hand. D. Ventral view of foot . . . . . . 147

27. Scutiger pingii; tadpole. A. Lateral view. B. Mouth . . . . . . . . . 149

28. Scutiger rugosa. A. Young adult. B. Oral cavity. C. Ventral view of hand. D. Ventral view of foot ................. 152

29. Scutiger rugosa; mouth of tadpole . . . . . . . . . . . . . 153

30. Scutiger popei. A. Oral cavity. B. Ventral view of hand. C. Ventral view of foot

31. Scutiger popei; tadpole. A. Lateral view. B. Mouth . . . . . . . 159

32. Scutiger schmidti. A. Ventral view of head and thoracic region of male. B. Oral cavity. C. Ventral view of hand of male. D. Ventral view of foot . . . . 163

33. Scutiger schmidti. A. Egg-mass. B. Mouth of tadpole . . . . . . . 167

34. Scutiger sp. from Mount Omei; tadpole. A. Lateral view. B. Mouth . . . 172

35. Scutiger sp. from Lungtung; tadpole. A. Lateral view. B. Mouth . . . . 176

36. Vibrissaphora boringii. A. Oral cavity. B. Ventral view of hand. C. Ventral view of foot

37. Megophrys boulengeri. A. Oral cavity. B. Ventral view of hand. C. Ventral view of foot 
38. Megophrys minor; tadpole. A. Tadpole with lips folded. B. Expanded "funnel." "PAGE C. Mouth

39. Megophrys omeimontis. A. Oral cavity. B. Ventral view of hand. C. Ventral view of foot. D. Lateral view of head

40. Megophrys shapingensis. A. Oral cavity. B. Ventral view of hand. C. Ventral view of foot. D. Lateral view of head

41. Megophrys oshanensis. A. Adult. B. Oral cavity. C. Ventral view of hand. D. Ventral view of foot

42. Megophrys oshanensis; mouth of tadpole

43. Bufo raddei. A. Ventral view of hand. B. Ventral view of foot

44. Bufo raddei. A. Segment of a strand of eggs. B. Tadpole. C. Mouth of tadpole

45. Bufo tibetanus; adult male . . . . . . . . . . . . . . . 208

46. Bufo tibetanus. A. Ventral view of hand. B. Ventral view of foot . . . . 209

47. Bufo tibetanus; tadpole. A. Lateral view. B. Mouth . . . . . . . . . . . . 211

48. Bufo bufo wrighti; adult female . . . . . . . . . . . . . . 215

49. Bufo bufo wrighti. A. Ventral view of hand. B. Ventral view of foot . . . . 216

50. Bufo bufo wrighti. A. Segment of a strand of eggs. B. Tadpole. C. Mouth of tadpole . . . . . . . . . . . . 218

51. Bufo bufo gargarizans. A. Ventral view of hand of male. B. Ventral view of foot.

52. Bufo bufo gargarizans; tadpole. A. Lateral view. B. Mouth . . . . . . . 223

53. Hyla annectans. A. Adult male. B. Ventral view of hand. C. Ventral view of foot

54. Hyla annectans; mouth of tadpole . . . . . . . . . . . . . . . 231

55. Calluella ocellata. A. Dorsal view. B. Ventral view . . . . . . . . . . 233

56. Calluella ocellata. A. Ventral view of hand. B. Ventral view of foot . . . . . 234

57. Kaloula rugifera. A. Adult male. B. Ventral view of hand. C. Ventral view of foot of male. D. Top of finger tip . . . . . . . . . . . . . . 236

58. Kaloula rugifera. A. Eggs. B. Lateral view of tadpole. C. Dorsal view of tadpole. D. Mouth of tadpole . . . . . . . . . 240

59. Kaloula macroptica. A. Adult male. B. Ventral view of hand. C. Ventral view of foot . . . . . . . . . . . . . 242

60. Kaloula macroptica. A. Eggs. B. Mouth of tadpole . . . . . . . 245

61. Kaloula verrucosa. A. Adult female. B. Ventral view of hand. C. Ventral view of foot

62. Rana adenopleura; adult female . . . . . . . . . . . . . . . . . . . 254

63. Rana adenopleura. A. Eggs. B. Mouth of tadpole . . . . . . . . 258

64. Rana boulengeri; adult male . . . . . . . . . . . . . . . 263

65. Rana boulengeri; adult male, showing spines on belly . . . . . . . . . . . . 264

66. Rana boulengeri. A. Eggs. B. Mouth of tadpole . . . . . . . . . . . 271

67. Rana phrynoides; male. A. Adult. B. Ventral view . . . . . . . . . 273

68. Rana phrynoides; tadpole. A. Lateral view. B. Mouth . . . . . . . . . 276

69. Rana temporaria chensinensis; adult female . . . . . . . . . . . . . 282

70. Rana temporaria chensinensis; tadpole. A. Lateral view. B. Mouth . . . . . 284

71. Rana japonica; tadpole. A. Lateral view. B. Mouth . . . . . . . . . . 290 
72. Rana choochiaoensis. A. Eggs. B. Lateral view of tadpole . . . . . 295

73. Rana andersonii. A. Ventral view of hand of male. B. Ventral view of foot . . 300

74. Rana andersonii; tadpole. A. Lateral view. B. Mouth . . . . . . . . 302

75. Rana margaretae. A. Ventral view of hand of male. B. Ventral view of foot. 304

76. Rana margaretae; tadpole. A. Lateral view. B. Mouth . . . . . . . . . . 307

77. Rana shuchinae. A. Ventral view of hand. B. Ventral view of foot. . . . 314

78. Rana limnocharis; tadpole. A. Lateral view. B. Mouth . . . . . . . . 317

79. Rana guentheri; tadpole. A. Lateral view. B. Mouth. . . . . . . . . . . 321

80. Nanorana pleskei. A. Oral cavity. B. Ventral view of hand of male. C. Ventral

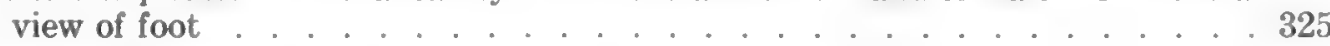

81. Nanorana pleskei; tadpole. A. Lateral view. B. Mouth. . . . . . . . . 327

82. Altirana parkeri. A. Adult. B. Oral cavity. C. Ventral view of hand. D. Ventral view of foot .................... . . . 329

83. Staurois mantzorum. A. Ventral view of hand. B. Ventral view of foot . . 332

84. Staurois mantzorum; tadpole. A. Lateral view. B. Ventral view . . . . . 336

85. Staurois chunganensis. A. Ventral view of hand. B. Ventral view of foot . . 338

86. Staurois chunganensis; tadpole. A. Lateral view. B. Ventral view . . . . . 343

87. Staurois lifanensis. A. Ventral view of hand. B. Ventral view of foot . . . 345

88. Staurois lifanensis; ventral view of tadpole . . . . . . . . . . . 348

89. Staurois kangtingensis. A. Ventral view of hand. B. Ventral view of foot . . 350

90. Staurois kangtingensis; tadpole. A. Lateral view. B. Ventral view . . . . . 352

91. Staurois loloensis. A. Oral cavity. B. Ventral view of hand. C. Ventral view of foot . . . . . . . . . . . . . . 354

92. Staurois ricketti minor; adult male . . . . . . . . . . . . . 357

93. Rhacophorus leucomystax; adult female . . . . . . . . . . . . . . . 361

94. Rhacophorus leucomystax; mouth of tadpole . . . . . . . . . . . 369

95. Rhacophorus dugritei. A. Adult female. B. Ventral view of hand. C. Ventral view of foot . . . . . . . . . . . . . . 371

96. Rhacophorus bambusicola. A. Ventral view of hand. B. Ventral view of foot . 375

97. Rhacophorus bambusicola. A. Egg-mass. B. Lateral view of tadpole. C. Mouth of tadpole . . . . . . . . . . . . . . 378

98. Rhacophorus omeimontis. A. Ventral view of hand. B. Ventral view of foot . 380

99. Rhacophorus omeimontis; tadpole . . . . . . . . . . . . 386

100. Rhacophorus chenfui. A. Ventral view of hand. B. Ventral view of foot . . . 389 



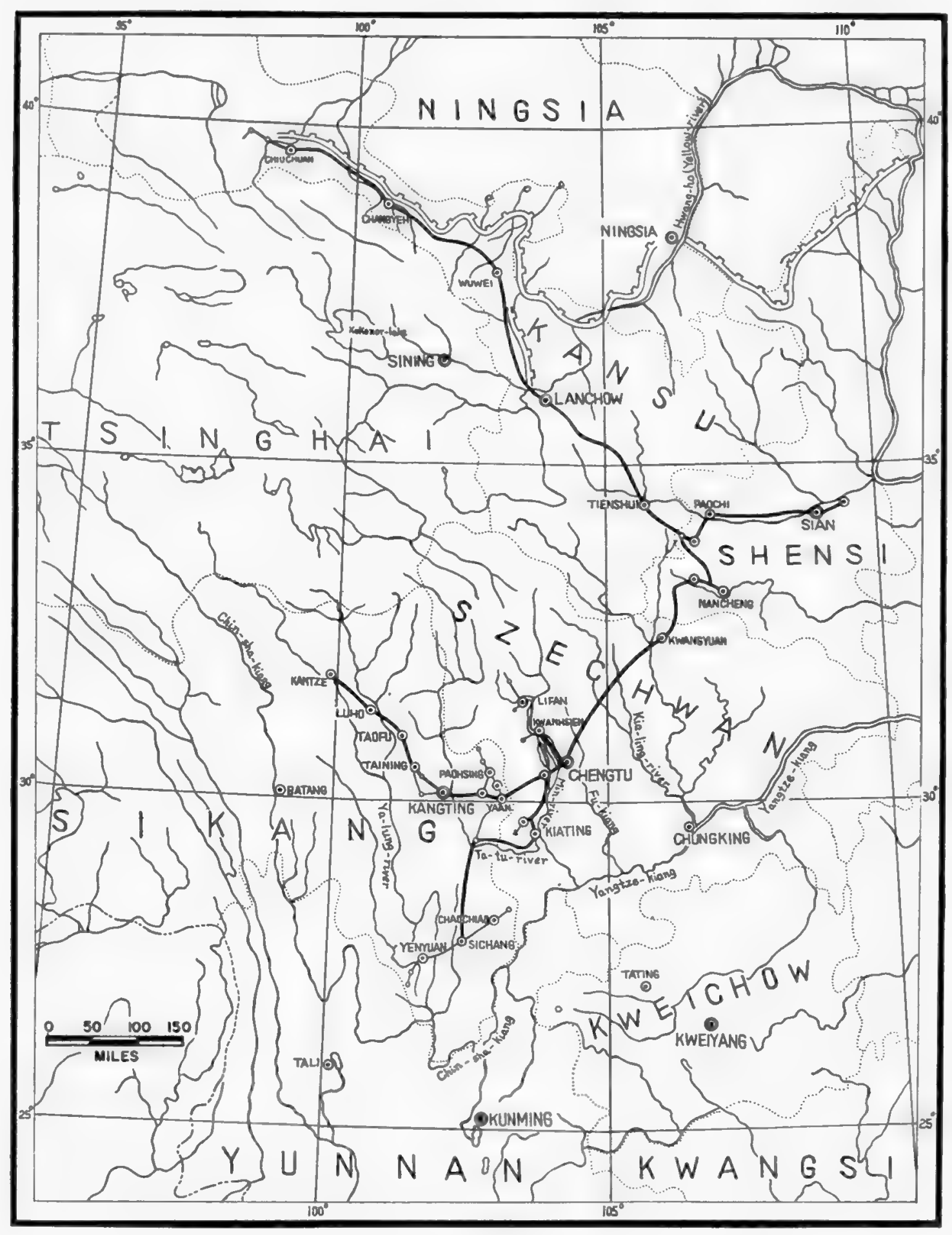

FIG. 1. Map of western China, showing routes of eleven expeditions. 


\section{INTRODUCTION}

My forced emigration to western China in 1938 enabled me to engage in herpetological studies in a region new to me. West China Union University at Chengtu proved to be a most favorable base of operations for repeated field trips into the mountainous regions to the west and south, which really represent the escarpment of the Tibetan Plateau. I was puzzled at the wealth of undescribed species of salamanders and frogs that immediately presented themselves, and addressed myself to the basic zoological work of defining and describing them, engaging at the same time in studies of their life histories and ecological distribution. I can only conclude that the Chinese region bordering on Tibet is a center of speciation for Amphibia comparable with the Appalachian Mountains in the eastern United States. The following report summarizes the results of eight years of field work and observation, and studies of the resulting collections in China. The greater part of my collection has been presented to Chicago Natural History Museum, which has honored me with the title of Research Associate in the Division of Amphibians and Reptiles.

My field work carried me from my base in Szechwan to the recently established province of Sikang, and to Shensi, Kansu, and Tsinghai (fig. 1). The species from Yunnan and Tibet have been added to the list in order to make a reasonably definable unit of "western China." I have quoted original descriptions and amplified them in the hope of broadening the usefulness of the publication. I had an unforgettable lesson in the need for available means of identification when I found that my little handbook of the amphibians of northern China was being used by students at the University of Yunnan in futile attempts to identify specimens from subtropical Yunnan.

\section{Preservation and Measurements}

The dimensions of specimens described in this work are expressed in millimeters. A definite method for taking each dimension was decided upon, and all the measurements were made by myself. A vernier caliper reading to $0.1 \mathrm{~mm}$. was used for measurements up to $150 \mathrm{~mm}$. Beyond this, a steel millimeter rule was used. All the measurements were made on specimens that had been preserved in 10 per cent formalin and transferred, after being well fixed, to 5 per cent formalin.

In order to preserve the specimen in a condition approximating as nearly as possible a normal body position, caution was required at the time of injection 
to avoid deforming the specimen by over-injection. After injection, my specimens were placed in a large amount of solution and crowding of specimens was avoided. It was essential to preserve tadpoles in the field, as soon as they were collected, in order to obtain normally shaped specimens. Eggs were likewise preserved in the field. There is some known shrinkage of specimens in preservation. It is hoped that by uniform procedure in preservation the resulting specimens are comparable from species to species.

In most of the tables of measurements, the extremes and the average are given. Using the body length as standard, I have calculated the ratio to the measurements of other parts in order to produce figures comparable from sizegroup to size-group and from species to species. The adults were always sexed, when possible, and the ratios calculated separately. In order to reduce the inherent error in measurements of amphibians, the specific measurements made were standardized as follows:

\section{CAUDATA}

Total length: From tip of snout to tip of tail.

Body length: From tip of snout to vent.

Head length: From tip of snout to gular fold.

Head width: At angle of jaws.

Head height: At angle of jaws.

Internasal space: From nostril to nostril.

Interorbital space: Taken transversely where inner borders of convex surfaces of orbits approach most closely.

Eye length: From anterior corner to posterior corner of eye.

Arm length: From juncture of arm with body to tip of longest finger.

Trunk length: Axilla to groin, from posterior aspect of base of arm to anterior aspect of base of leg.

Leg length: From vent to tip of longest toe.

\section{SALIENTIA \\ AdULt (fig. 2, A and B)}

Body length: From tip of snout to vent (fig. 2, A1).

Head length: From tip of snout to angle of jaws (fig. 2, A2).

Head width: At angle of jaws.

Internasal space: From nostril to nostril.

Interorbital space: Taken transversely where inner borders of convex surfaces of orbits approach most closely (fig. 2, A3).

Width of upper eyelid: Widest dimension.

Tympanum: Taken horizontally from anterior to posterior.

Length of parotoid gland: Longest dimension.

Width of parotoid gland: Widest dimension.

Arm length: From juncture of arm with body to tip of longest finger.

Diameter of lower arm: Greatest diameter of lower arm.

Hand length: From juncture of arm and hand to tip of longest finger (fig. 2, A5).

Leg length: From vent to tip of longest toe.

Tibia length: From convex surface of knee to convex surface of joint of tibia and tarsus (both joints flexed; fig. 2, A6). 

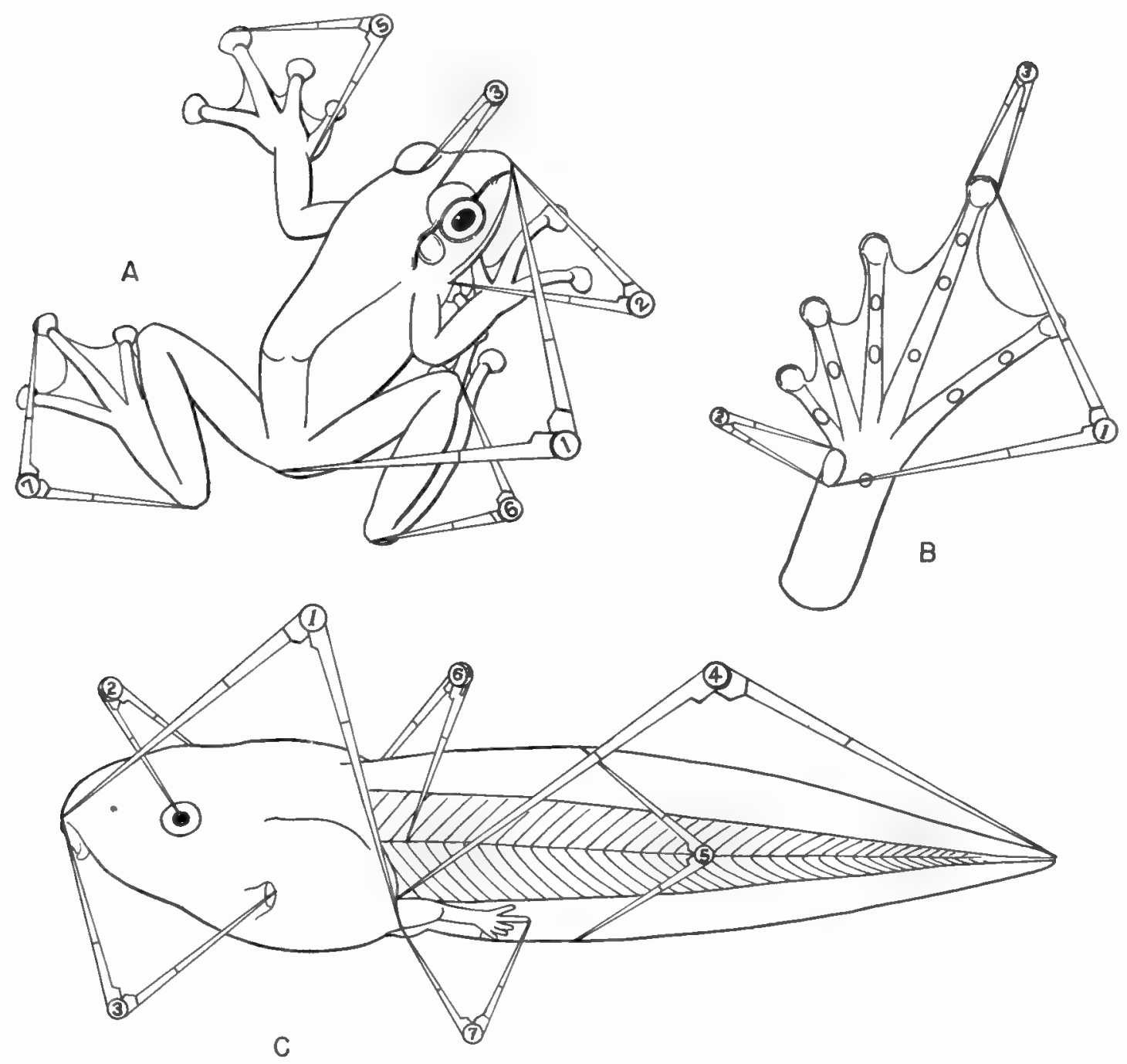

FIG. 2. Illustrations of measurements used in this paper. A. Adult. B. Foot of adult. C. Tadpole.

Length of foot and tarsus: From convex surface of joint of tibia and tarsus to tip of longest toe (fig. 2, A7).

Foot length: From base of inner metatarsal tubercle to tip of longest toe (fig. 2, B1).

Inner metatarsal tubercle: Greatest length (fig. 2, B2).

Width of toe pad: Greatest width (fig. 2, B3).

\section{TADPOLES (fig. 2, C)}

Body length: From tip of snout to vent (fig. 2, C1).

Body height: At highest place.

Body width: At widest place.

Head height: Just posterior to eyes.

Head width: Just posterior to eyes.

Internasal space: From nostril to nostril.

Interocular width: From mid-eye to mid-eye (fig. 2, C2).

Mouth width: From edge of lip of one side of mouth to edge of lip of the other side. 
Snout to spiraculum: From tip of snout to opening of spiraculum (fig. 2, C3).

Tail length: From vent to tip of tail (fig. 2, C4).

Tail height: Highest place of tail fin (fig. 2, C5).

Diameter of tail muscle: Taken at vent region (fig. 2, C6).

Length of hind leg: From base to tip of longest toe (fig. 2, C7).

\section{List of Localities}

Because the same Chinese word has phonetic differences in different parts of China and different modes of expression in the Roman alphabet, great difficulties are often encountered in scientific literature unless maps and itineraries are published. When the local names of small places are used (as is frequently the case with zoological collectors) it is essential that the district be given. Many names are duplicated and reduplicated, for example, Lianghokau, which means "the place where two rivers meet."

The meanings of some of the recurrent suffixes are as follows:

$\begin{array}{lll}\text { chow: large district } & \text { kiang: river } & \text { shan: mountain } \\ \text { hsien: district } & \text { ho: river } & \text { ling: mountain } \\ \text { ch'ang: large village with } & \text { kou: small mountain stream } & \text { sze: temple } \\ \text { market } & & \end{array}$

Though the use of hyphens separates the elements of place names, it has been thought best to follow the precedent of the Chinese Postal Map and write locality names without hyphens. The locality names in Szechwan and Sikang used in the present work are mapped (figs. 1, 3-8) and are listed for reference as follows:

\section{SIKANG}

Batang
Chaochiao
Chêtotang
Chiala
Chilipa
Chiulung
Chuwo
Fuhsienkwan (near Yaan)
Fulinhsien
Hasa
Hlagong (near Yakiang, west of Kangting)
Hosi
Hsintuchiao (near Tungolo)
Hsuanshenpa
Kangting (=Tatsienlu)
Kantze
Kaohouping (near Tienchuan)
Keitaliangsze
Lianghokou
Lianglukou (Tienchuanhsien)
Lingkwan (east of Paohsing)
Lolokou
Luho
Lungtung
Lushan (Tienchuanhsien)

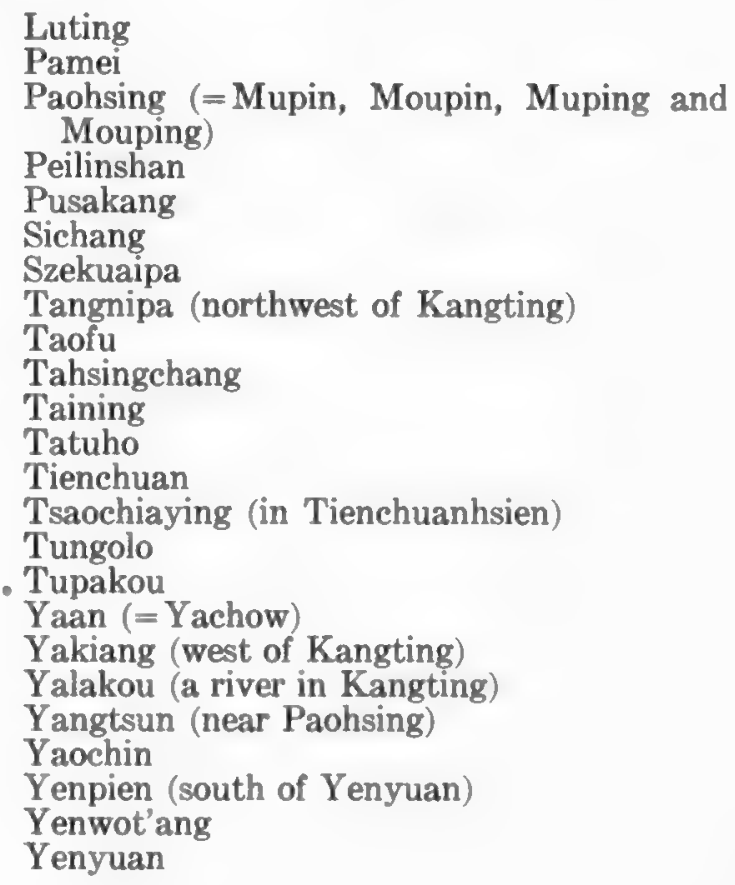




\section{SZECHWAN}

Changchiashan (near Shuimokou)

Chengtu

Chihsinling (near Tachangsze)

Chinkouho

Chungking

Heifengt'ou

Hopachai

Kiating

Kwanhsien

Lifan

Maliuwan

Mapien

Mengtunkou (mountain stream)

Min River

Mount Omei

Nankou (in Lifan City)

Nanyaomiao

Opien
Panch'angkou (on Panlungshan)

Panlungshan

Peip'ei (north of Chungking)

Shaping

Shuimokou

Sungpan

Taliangshan

Tawantou (at Shuimokou)

Tenshitung (on Tsingch'engshan)

Tsakunao

Tsaopo (Wenchwanhsien)

Tsingch'engshan (Kwanhsien)

Tsingshan (near Hopachai)

Washan (Opienhsien)

Weichow

Wenchwan

Yenhsingping (Wenchwanhsien)

Yenmenkwan (near Weichow)

TSINGHAI (=CHINESE TIBET)

Sining

KANSU

Chiuchuan

Lanchow

SHENSI

Nancheng 


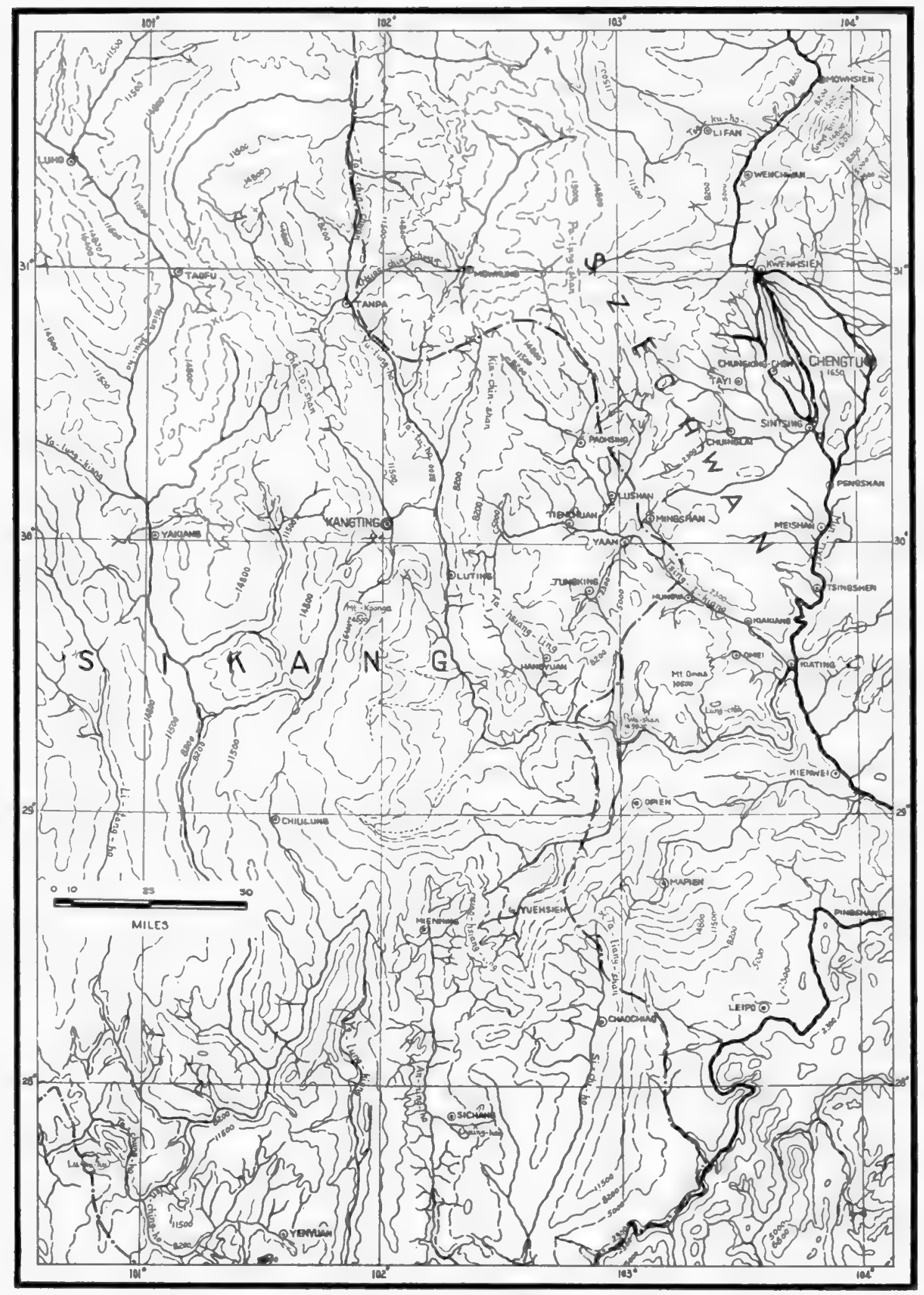

FIG. 3. Map of western Szechwan and eastern Sikang, showing localities, mountain ranges, and altitudes. 


\section{ZOOLOGICAL EXPLORATIONS IN WESTERN CHINA}

\section{$1938-46$}

\section{Emigration of Teachers and Students to Western China; Specimen Case}

Scarcely a month after the first Japanese gun was fired near Peiping on July 7,1937 , every educational institution in northern China was faced with the problem of making decisions regarding its immediate future. Few cities within reach of Japanese planes escaped attack. Educational and cultural institutions seemed to be particularly marked as targets, and nearly every school in northern China was bombed during the first few months of war.

On August 13, 1937, the Japanese army fired its guns at Shanghai and the undeclared Sino-Japanese war flame spread from northern to southeastern China. I was teaching at Soochow University, which is located at Soochow, Kiangsu. I had been driven from Northeastern University at Mukden by the Japanese in 1931, and had lost my first herpetological collection and library at that time. Under the continual bombing and the disturbance of the horrible fighting in the Shanghai zone, Soochow University could not continue its academic work. On October 15, 1937, our institution moved westward to Huchow, where we renewed our school work, although enemy planes dropped their bomb loads in that city and our ears became tuned to the warnings of approaching planes. As day by day the war swept closer to Huchow, the air raids increased in intensity and frequency, and when the Japanese army was only about ten miles away from us, we were forced to close the institution on November 14, 1937. I left the small, beautiful city of Huchow, in company with eighteen of the biology students and four colleagues of the Biology Department. At midnight on November 15, 1937, we started our long unpleasant journey still farther to the west. After all kinds of bitter experiences and using almost every conceivable means of transportation, we arrived safely at Chengtu, the provincial capital of Szechwan, on January 27, 1938. There we went at once to West China Union University.

West China Union University operated a very important service for refugee missionary universities as well as government institutions during wartime, and acted as host to members of these migrant institutions of higher learning. From early morning till late at night its playgrounds, classrooms, laboratories, and libraries were used by students seeking to learn and to prepare themselves for the future New China, of which we never despaired. 
The university is an organization supported by united missionary groups of the United States, Canada, and England. It is located in Chengtu, long one of the most important centers of culture in eastern Asia, and the gateway to Tibet. In addition to the academic program, there are museums of Archaeology and Biology, a West China Border Research Institute and an Agricultural Research Institute, both institutes under the auspices of the university. It was accordingly a favorable headquarters for my explorations and studies in the mountains and high plateaus of Szechwan, Sikang, Shensi, Kansu, and Tsinghai (fig. 1). I was therefore able to carry out the dream of my Cornell days, a study of amphibian life histories, perhaps better under the forced conditions of the Japanese invasion than under the conditions of peace. This was a happy fate, and few of my colleagues were so fortunate.

Western China, and especially the region of the mountain ranges between Szechwan and Sikang, is well known for its rich and characteristic fauna and flora. Naturalists as well as missionaries went to the mountains to try their luck. Many valuable archaeological, zoological, botanical, and geological specimens have been collected and sent to different countries for further detailed studies. The world-famous giant panda was discovered in Paohsing (Muping) in 1876 by Father David, and the type specimen is now in the Paris Museum. Many new species of plants and animals have been discovered in this part of China.

Long before I came to Szechwan, I dreamed many times of going to the mountains and to the high plateau of western China to study the animal life, especially the salamanders and frogs, under their natural conditions. The great distances, the poor means of transportation, and especially the great hazards of the Szechwan Road prevented me from going there by my own efforts. A famous poem, written by Li Po of Tang Dynasty and entitled The Difficulty of the Szechwan Road, contains a faithful description of the landscape of the Chengtu plain and its surrounding high mountain ranges. A part of this poem may serve as a geographical introduction:

$\mathrm{O}$ ! The danger, the steepness!

The Szechwan Road is as difficult as the way to the blue heavens.

Westward, over the snow-capped mountains is a bird-track

By which one can cross and proceed to the Peak of Omei.

It is made of sky-ladders, with hanging paths over the cliffs.

Above, the soaring tips of the mountains hold back the six dragons of the sun;

Below, in the ravines, the flowering waters break into whirlpools and swirl back against the current.

Yellow geese flying towards the peaks cannot pass over them;

The golden-haired monkeys climb and climb, despairingly pulling themselves ever higher and higher, but even their endurance fails.

How the road coils and coils through the Green Mud Pass!

With nine turns to a hundred steps, it winds round the ledges of the mountain crests.

Clutching at Orion, passing the Well Star, I look up and gasp.

I sit alone with my hands pressed to my heart and groan;

It is impossible to climb the terrible road along the edges of the precipices. 
Among the ancient trees, one sees only the cruel and mournful ravens.

Male birds, followed by females, fly to and fro through the woods.

Once in a while, one hears a nightingale in the melancholy moonlight of the lonely mountain.

The Szechwan Road is as difficult as the way to the blue heavens!

The difficulties of the Szechwan Road were experienced by thousands and thousands of Chinese who emigrated to this region of the country during our recent war. For eight years, they escaped from the Japanese in occupied China, and came to Szechwan by every means imaginable - on foot, carrying bundles and babies, in wheelbarrows and sedan chairs, on river junks poled with bamboo poles or pulled upstream by man power. They came in carts, on donkeys or horses, or with the modern speed of steamers, automobiles, and trimotored planes.

Farmers, old people and infants, artisans, professors, industrialists and business men, and seven whole universities were swept back to Chengtu, in ancient times one of the capitals of the Three Kingdoms and a great intellectual center where books were printed long before the time of Gutenberg. The difficulties of the roads to this part of the country afforded a great stronghold, in which China could make her long stand through her most perilous days.

Since I had come to an ideal place for studies in natural history, I utilized all my vacations and every possible opportunity to go to the mountains, near and far, low and high, to hunt for frogs, toads, lizards, and snakes. The variety and strangeness of the amphibians and reptiles caused me to forget dangers and difficulties. In my eight years at Chengtu eleven collecting trips were made, resulting not only in the collecting of many new amphibians and reptiles but in much personal knowledge of the "southwest peoples" such as the Lolo, the Ch'iang, and the Kang or Tibetans, with whom I lived during my explorations.

\section{Herpetological Exploration of Mount Omei}

Mount Omei, the sacred mountain of the west, was chosen as the first locality for field study. This peak (fig. 4), about 11,000 feet high, is the southeastern terminus of the Hungshan range, which begins between northwestern Szechwan and northeastern Sikang. The mountain is 100 miles southwest of Chengtu. From its summit one can see the snow-capped mountains to the west and very high peaks to the northwest and to the south, while to the northeast lies the rich Chengtu plain.

Mount Omei is famous for its lovely landscapes and its numerous and beautiful temples. From spring to autumn, thousands of religious pilgrims toil up the steep slopes of the mountain so that they may worship "nearest Heaven." All the worshipers, regardless of their physical or financial condition, climb the mountain on foot in order to show their religious devotion; when they come down they may take sedan chairs or ride on the backs of other men. The pilgrims have organizations and they form clubs, the members of which keep together and 


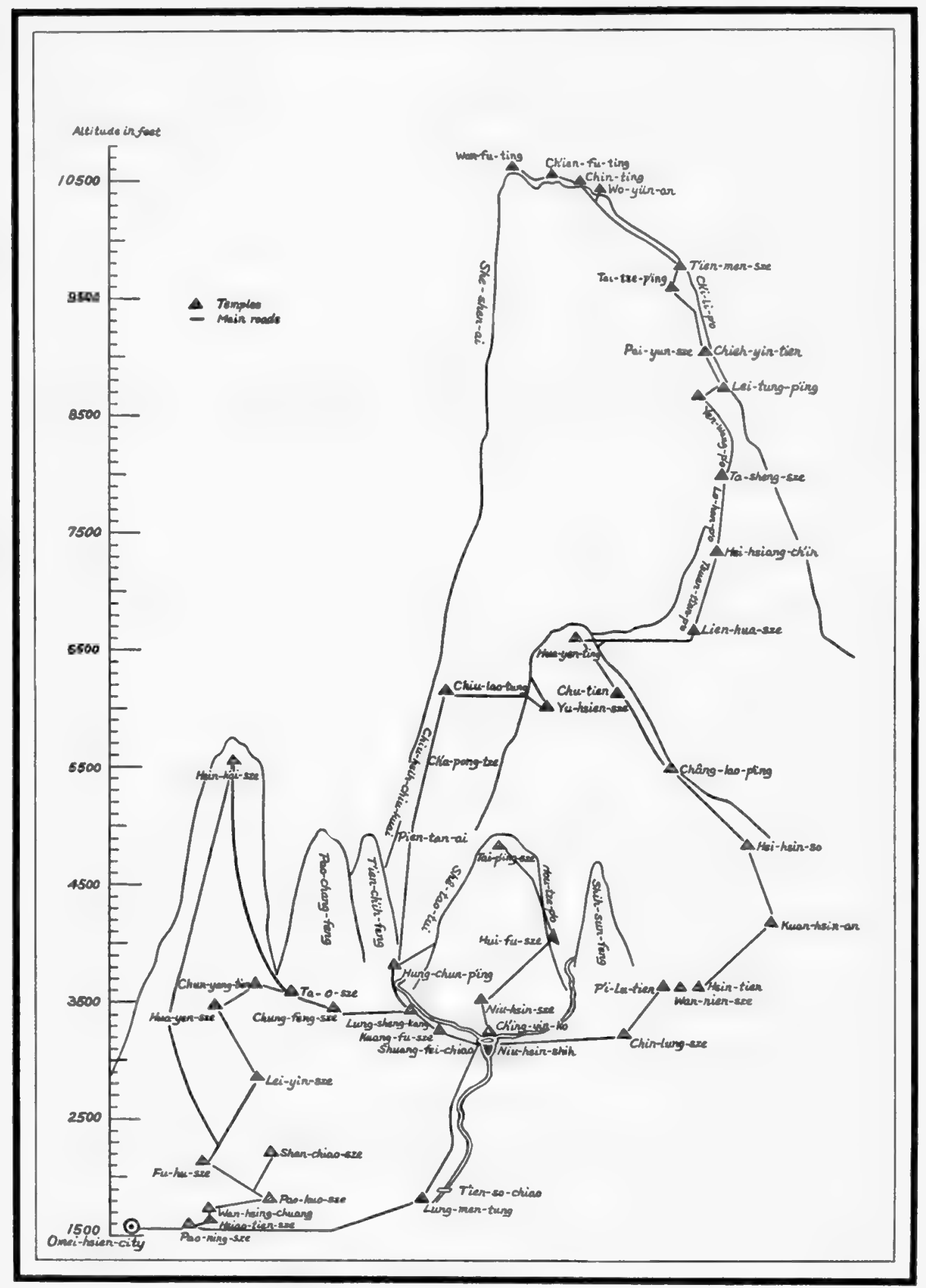

Fig. 4. Map of Mount Omei, showing routes, temples, and altitudes. 
offer precious sacrifices in each temple as they go up the mountain. After they have reached the summit and concluded their worship they descend individually or in groups, paying no more attention to the temples.

Every year the beautiful landscapes of Mount Omei attract many travelers of different nationalities. Visitors of this kind make the ascent in chairs carried on the shoulders of men. They worship no idols, but they usually visit various temples. Nearly every temple is prepared to provide tea, meals, and overnight lodging for both pilgrims and travelers.

The biological interest of the great mountain equals its religious and scenic interest, but only a handful of scientists have visited it. My first field study on Mount Omei was done in 1938, from the end of June to the first part of September. Twenty of us, including the staff members and the students of the Biology Department, went to the mountains. Taosze, a big temple at 3,000 feet altitude, had been chosen as the headquarters for our work. This temple, beautifully located and enclosed by woods and a small mountain stream, is a very convenient place for collecting plants and all kinds of animals--birds, mammals, reptiles and amphibians, and especially insects.

The results of this first trip were most encouraging, for a new genus and two new species of frogs and toads were discovered in our collections. The high altitude, rich vegetation and high humidity of Mount Omei afford varied ecological conditions, with a very rich and characteristic fauna and flora as a result. The animals best known to the pilgrims and travelers are the monkeys at Chiulaotung, "nine old men cave" (6,000 feet altitude), which is one of the finest temples on Mount Omei.

During the summers of 1940 and 1945, we carried out further field studies on Mount Omei, living in the temple of Taosze. Besides making some general collections of plants and insects, we gave special attention to the collecting of amphibians and to the study of their life histories. Four more new species of primitive types of amphibians were discovered, and the life histories of six species of frogs were completed.

\section{Explorations at Muping, Sikang, 1939}

Before the establishment of Sikang as a separate province, in 1939, Muping, now known as Paohsinghsien (fig. 5), was known as a district of Szechwan. It is a mountainous and sparsely populated district, located on the eastern fringe of Old Tibet. In spite of its remoteness, the region is very well known to the naturalists of the world and to big game hunters. During the summer of 1939 , a group of sixteen, including four biology teachers of West China Union University, six students, our artist, and five collectors, went to Muping. We went for a general survey of the flora and fauna, paying special attention to reptiles and amphibians. On July 10, we took a truck from Chengtu to Yaan (Yachow), where we collected specimens for four days and at the same time made preparations for the Muping trip. We took rice, salt, sugar, and even lard with us. 


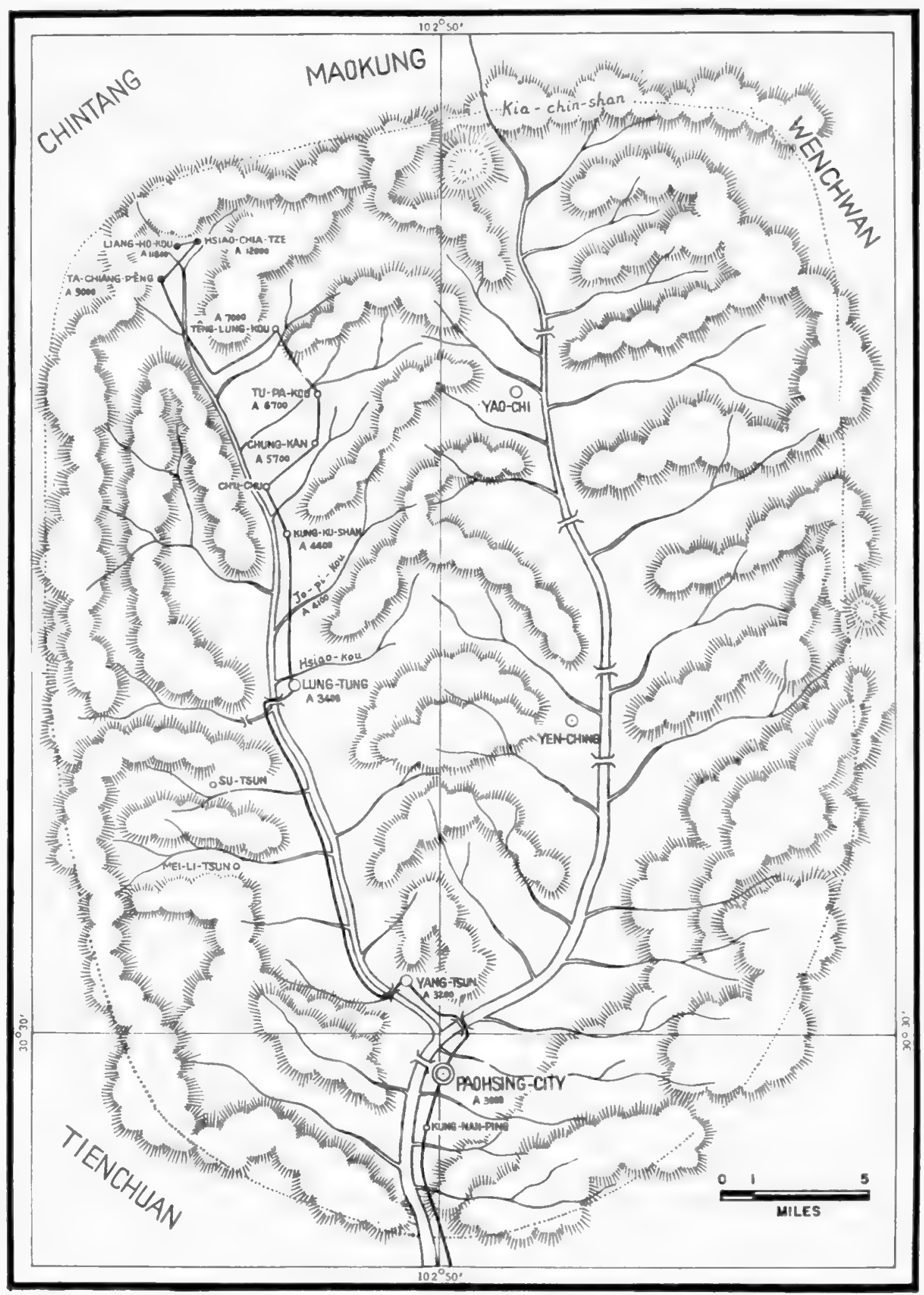

FIG. 5. Map of Paohsinghsien (Muping), Sikang, showing main rivers and mountain ranges, and routes and localities of collecting trip made in 1939. 
After five days on foot we arrived at Muping, where we made our headquarters in the primary school. After four days of collecting around this city, we started for Tupakou.

It was only about fifty miles from the city to Tupakou, but it took us three days to get there. This was partly because we made collections on the way, but more because our path led us across swift mountain streams and deep gorges. Sometimes we had to use a tree trunk bridge to cross a river. Our path sometimes led over the flimsiest of platforms made of branches of trees, skirting a sheer cliff with rapids more than 100 feet below. Tupakou, selected as our headquarters, is a small village at the upper end of a valley (altitude 8,000 feet).

Our collections from Muping are remarkable especially for primitive salamanders of the genus Batrachuperus, frogs of the rare Himalayan genus Scutiger, and the life history of the poisonous snake Trimeresurus jerdonii, remarkable for its brilliant coloration and viviparous reproduction.

\section{Journey to Northwestern Szechwan}

Northwestern Szechwan (fig. 6) is another interesting geographical region, with a very complicated topography. There is a high plateau of grass land cut by mountain ranges that run in a north-south direction and are separated by river valleys. The water for the irrigation of the Chengtu plain comes mainly from the high mountains.

I made five trips for field studies to these mountains, which were accessible from Chengtu. The fauna and flora are rich, and there are characteristic plants and animals. The people in this part of the country are mostly Chinese, with a small area occupied by another non-Chinese tribe known as the Ch'iang people.

\section{The Ch'iang}

Physically, the Ch'iang are of the yellow race, possibly of the Tibeto-Burman group, with dark eyes, black and straight hair, and a brown complexion. The nose is a trifle narrower than that of the Chinese, and the epicanthic fold is often lacking.

These people were originally a nomadic tribe who depended for a livelihood on their flocks of sheep and goats. The Chinese character for Ch'iang consists of the character for sheep or goat and the character for man; this, literally, means "a people who raise sheep and goats."

The Ch'iang figure considerably in early Chinese writings and go back to the Yin Dynasty (1765-1122 B.C.). The oracle bones contain numerous references to them. They lived to the west of the Yin, who made war upon them and took them captive. In the course of Chinese history, they were a constant menace to the northwestern borders of the empire.

Today the Ch'iang inhabit a region along the T'o and the Min rivers, near the Chinese districts of Wenchwanhsien, Weichowhsien, and Lifanhsien. The 


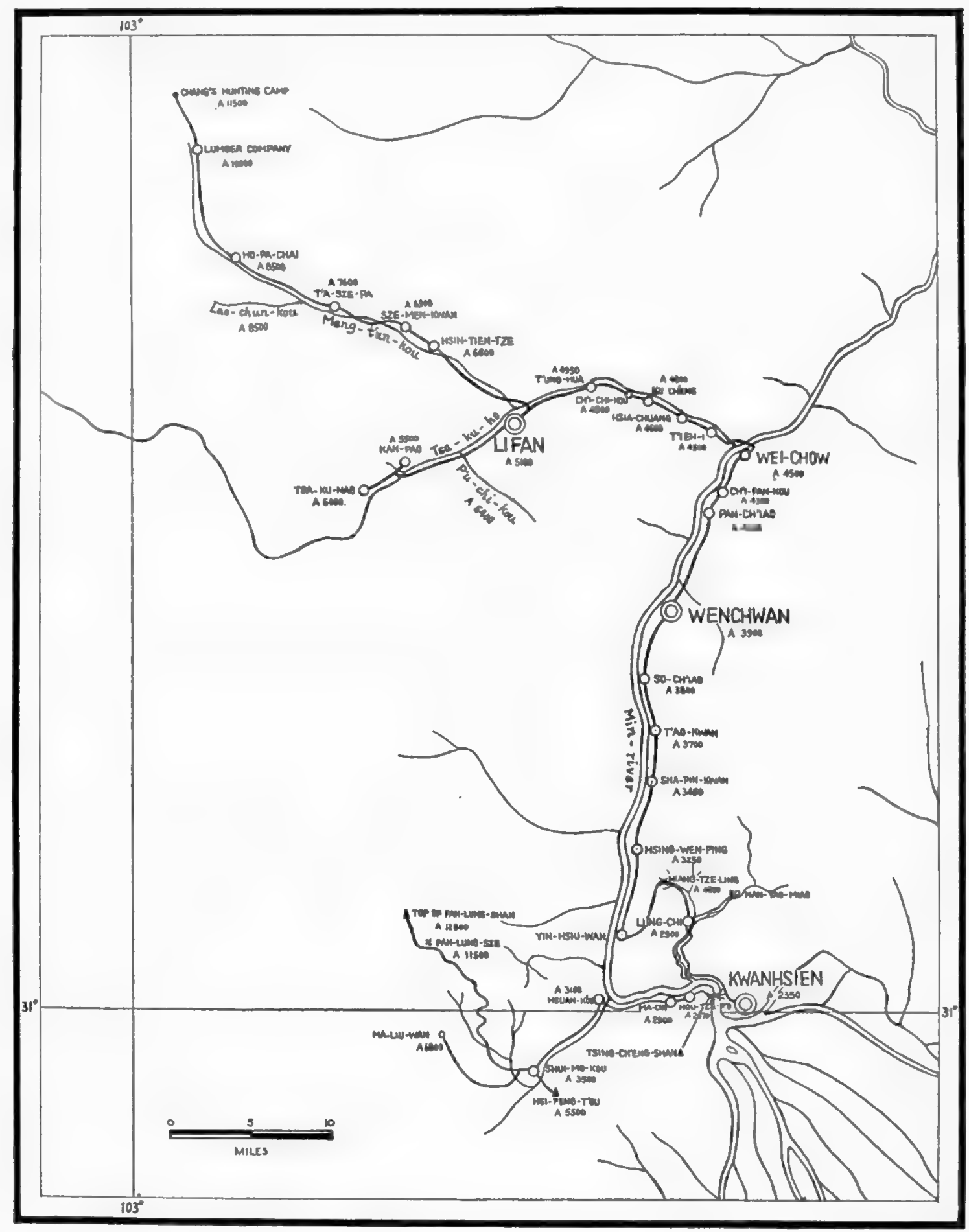

FIG. 6. Map of northwestern Szechwan, showing collecting routes, localities, and altitudes. 
rivers are from four to ten thousand feet above the sea level. The surrounding mountains rise in some places to an altitude of about 15,000 feet. There are extensive loess deposits that make good farm land. Ethnologically, this region is a marginal area of the Tibetan culture, but the people have had constant contacts with the Chinese, who have influenced their lives more than any of the neighboring groups.

Most of the Ch'iang live on farms or in fortified villages. They are all farmers. Houses, usually having two or three stories, are built of stones mortared together with clay; the roofs are flat. The first floor is generally used for raising pigs and sheep, goats and cattle, the second floor is for living quarters, and the top floor is the place for worship. The kitchen on the second floor is used not only for cooking and as the dining room but also as a social room.

There is some buying and selling in the villages, but the principal market places are in the Chinese cities. Here the Ch'iang bring their agricultural products for sale, and purchase salt, cotton cloth, and other commodities.

They lead a very simple life. There are no theatrical performances, few dances, and feasts only during the first moon of the year. Marriage, birth, sickness, death and burial are attended with complicated ceremonies.

There are elaborate rituals with sacrifices for worship in the sacred groves and on the housetops, where a sacred white stone is enthroned. This is a triangular quartz stone, symbolic of the purity of the gods, and near it communion with the gods is natural and easy. It is also believed to possess superhuman potency and is sometimes used as a means of protecting the homes from demons.

The Ch'iang have a supreme god whom they call Mu Bya Sei, or God of the Sky. He resembles closely the Tien or Ti of early Chinese history. However, like the Chinese, they are not monotheists, for they have numerous gods whom they have probably worshipped for many years, in addition to the Chinese, the Buddhist, and the Christian gods, whom they have learned to worship in the sacred groves.

The Ch'iang have no written language, and the chants and rituals have been handed down by word of mouth. Their language, which is dying out, belongs to the broad Tibeto-Burman group, and the preservation of primitive forms, such as case distinction, seems to indicate that the language represents a very old phase of this group.

\section{Journey to Ningshu, Sikang, 1942}

The southeastern corner of Sikang, originally a part of Szechwan, is known as Ningshu (fig. 7) and is a distinct political region. It is inhabited by the Lolo. The topography of the Lolo country is very characteristic, with high mountain ranges running in a north-south direction, cut by deep valleys.

The Lolo permit few strangers to cross their borders, and the flora and fauna are consequently very little known. Through the help of the Minister of Educa- 
tion, and the local government of Sichang, four members of the staff of West China Union University went to the Lolo country, starting in mid-April, 1942.

Sichang, the center for our work, is the largest city in Ningshu, and is the political, economic, and educational center of that part of the country. Through the arrangements made by the local government and the kind assistance of friends in a hospital in Sichang, my assistant and I were able to start from Sichang for Chaochiao, in the heart of the Lolo section, on May 1, 1942. Dr. Yü (a medical doctor) and two nurses from the hospital in Sichang accompanied us. We had horses to carry our supplies of food, baggage, and drugs, together with gifts, such as salt, cloth, needles, and thread, for the Lolo people. The distance from Sichang to Chaochiao is only about 120 miles, but it took us six days to reach the city. On the way, we got a good collection of amphibians.

The third evening we stayed in a headman's house at Lolokou. The old man intended to be very kind to us. He served us a chicken dinner, but we could not appreciate his kindness. The chicken was hammered to death and part of its feathers were removed; it was then drawn, and the intestines were crudely cleaned; thereupon it was chopped into pieces and put in a big cauldron of cold water, which was then brought to a boil. When the chicken was half done, some salt was added and it was ready to be served to the guest. Out of courtesy, we had to eat our dinner with smiling faces, but once is enough in my life. At the same time, we prepared some of our own rice to serve them.

We spent two evenings in Lolo houses. After six days of walking and insufficient food all of us were very anxious to get to the city, where we expected to get a rest and have some good meals. As we approached, we saw the beautiful wall and gates. We hurried forward, but we were greatly disappointed and greatly surprised when we reached the south gate. There were only three houses in the town, one for the magistrate and his family, one for the army, and one for the district National party. The only tree in the city stands in front of the magistrate's house. The magistrate, the only inhabitant of the city, welcomed us, and gave us a dinner of rice, cooked dried meat, and fried soy beans, which seemed extremely good to starving people.

The empty city was the result of fighting between the Chinese and the Lolo in 1936. All of the Chinese in the city were either killed or taken as slaves by the Lolo, and the houses were burned. After that time, the magistrate could not come to Chaochiao, so he kept his office in Sichang, about 120 miles away. The present magistrate had fought his way through with his soldiers the previous winter and the Lolo near the city had run away, leaving empty houses on the hillsides.

The next day, we started our work around the city, and collected specimens of a new species of wood frog. In the afternoon I felt very ill, and had a high temperature. The next day I was unconscious, and my friends decided to take me back to Sichang immediately. Dr. Yü and the magistrate had two poles cut from small trees, and ropes were put between the poles so that two soldiers 


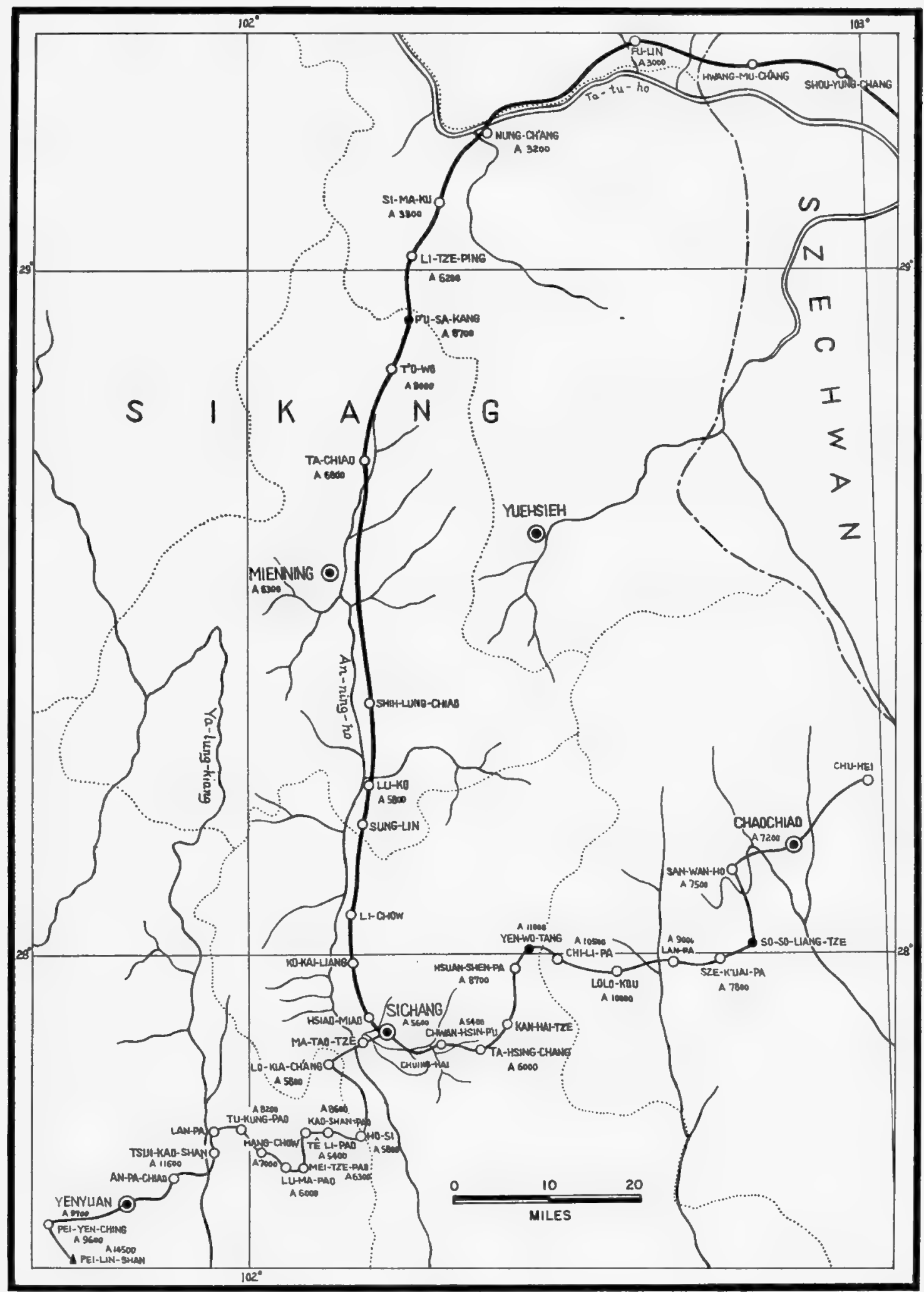

FIG. 7. Map of Ningshu, Sikang, showing collecting routes, localities, and altitudes. 
could carry me back to the hospital in Sichang. It took five days, during which time I was for the most part unconscious. At Sichang Hospital, Dr. Yü found that I had typhus. It took me about fifty days to recover, and I was fortunate that I did not lose my life.

The later investigations in this part of the country were carried out by my assistants, Mr. Chang and Mr. Kao, as I could not go to the field. In their brief collecting, eight new species of amphibians were discovered, and the life histories of two rare frogs were completed. The Lolo country is really virgin territory for the studies on its flora and fauna, but it is still much too dangerous for scientists. The Lolo usually take other people for slaves, and once you have been caught by them there is little chance of escape. I may give a very brief account of this little-known people.

\section{The Lolo}

The Lolo dwell in the mountainous regions of southeastern Sikang and southwestern Szechwan. This section of territory is the Taliangshan, which lies east of the Yalung River and extends south of Tatsienlu (Kangting). The land covers an area of nine or ten thousand square miles, with a population of about 500,000 people.

During the Chou Dynasty (1122-221 B.c.) this people was known as the Lu. According to the Shuching, they helped Emperor Wuwang in his expedition against the Shangs in eastern China. Today the Chinese do use the term "Yichia" but the great majority use the term "Manchia," when referring to the people of this tribe. The name Lolo is most frequently used by foreign investigators, and by a very small minority of Chinese and No Su themselves. When referring to themselves, they generally prefer the terms "No Su," "Ijia" or "Heikut'ou."

In the course of centuries, some Lolo have emigrated to Yunnan and have acquired different names. Along the Red River they are known as the Woli; along the Salween, the Liso; between the Salween and the Mekong, the Lohei; and on the southernmost border of the province, the Ak'a. Linguistically they belong to the Tibeto-Burman family. They have a written language, which is used mainly by the priests or magicians for the purpose of performing rituals and divination.

Villages are perched on the mountain sides in what seem to be precarious positions. The house of a family is always a unit by itself, but sometimes several houses are built side by side to form a hamlet. The house is built of wood, supported by poles, walled with stamped earth or boulders, and roofed with planks or the bark of trees. Stones are placed in rows on the roof so that the structure will not be shaken by the wind. Around the house is a square enclosure surrounded by earthen walls or a bamboo or wood fence. In one corner of the enclosure stands a watch tower of two or three stories, in which are guns and other weapons that are used for the protection of the house from the raids of other families. 
Inside the house the head of the family lives in the left room, which is furnished with a small wooden bed. His wife and children all sleep on the wooden or earth floor. The fireplace is situated in the middle room, where the people gather to have their meals. The room on the right is for animals and for the shelter of the slaves.

The men wear a rather picturesque armor, made of untanned leather decorated with designs in red, black and yellow. The upper half provides protection for chest and back, and to this is attached a skirt made of plaited strips of leather. Worn with the armor there is a large leather gauntlet for the sword arm, and a small leather wristlet that protects the wrist when drawing the bow. The women favor bodices and long, pleated skirts that come to the heels and swing with the rhythm of the wearer as she marches along. Neither men nor women wear shoes or sandals. The men wear long caps, which are referred to as their "heavenly horns," or the hair may be drawn into a forwardly directed "horn." The women wear a cloth on the head.

The Lolo are mainly divided into two classes, the Black Lolo and the White Lolo. The Black Lolo are also called the Black Bones, and rule over the White Bones, who are composed of five classes of slaves. The children of the Black Bones do not learn any occupation except hunting for recreation. Their daughters are often trained to manage the household affairs, and hold a high position in the family. The children of the White Bones are born to be slaves and are the property of their father's overlord. They do all the manual labor and work in the fields. The Lolo grow corn, their staple food, on the mountain slopes. Besides corn, the principal crops are wheat, rice, potatoes, beans, and turnips. Their principal domestic animals are chickens and ducks, and pigs, sheep, cattle, and ponies.

The household unit consists of the overlord's family and his slaves, whom he considers as a form of property to be bought and sold at will. His family is patrilineal and related to other families to form a clan, living in a definite area of the country with one or more headmen.

Marriage is arranged by the parents and the middlemen. The "bridal money," in the form of silver, cattle, weapons, and slaves, is paid in installments. On the wedding day the ceremonies are elaborate. Gifts are exchanged, and there are contests between parties of both families. The marriage system is clan exogamy but class endogamy. Polygamy is known to be practiced. The husband must ask his wife's permission to take concubines. When the husband dies the wife must marry a brother or nephew, or even the father or the uncle, which is a form of levirate. The class system cuts across the organization of the family and the clan.

The relations of one family with another are usually very unfriendly, and feuds are common among them. The No Su are proud of raiding and plundering in their feuds, which are carried on indefinitely. It is these feuds that keep up the warlike spirit among the No Su. 


\section{Explorations in Kangshu, Sikang, 1943}

Kangshu is the vast western section of Sikang Province, originally known as East Tibet. My exploration was limited to the northeastern part of Kangshu, from Kangting, the capital of Sikang, to Kantze (fig. 8). Transportation is difficult, and indeed any collecting trip in Sikang is not without hardship. On my travels in 1943 only a collector and one assistant went with me. Early in the morning of June 27, we started our long journey from Chengtu. For six days we sat on top of a loaded truck, passed the dangerous Erlong Mountain, and, with eight days of additional stopovers at various places, arrived at Kangting on July 8. Kangting, well known as Tatsienlu to the Chinese as well as to foreigners, was the center for our preparations for a trip to the high plateau and high mountain country inhabited by the Tibetans, who are quite different from the Chinese in language and customs.

It took us fifteen days to prepare ourselves for the adventure to a new country. The most essential things to take with us were food, including rice, wheat flour, salt, sugar, smoked meat, and lard; heavy bedding; warm clothes; and heavy shoes. As we could not hire a local interpreter we tried to learn a few necessary phrases and sentences of Tibetan so that we could get along with them. I wrote down the sounds of phrases of the Tibetan language, in place of the actual Tibetan words, in my notebook. With these words and phrases we managed to make our expedition without an interpreter. Another problem we had to solve for our round trip was the means of transportation. Through the help of the local government in Kangting, we got three horses and six yaks for carrying our food stuffs, baggage, and collecting equipment; but we had to change our animals at different stations. We started our journey on the morning of July 23. Four Tibetans looked after the horses and yaks and served as our guides. We traveled very slowly in order to stop at different places to collect specimens and make observations. The round trip from Kangting to Kantze, a distance of about 600 miles, took us 38 days. We stopped overnight in monasteries, the houses of peasants, and the tents of nomads, as well as in the houses of magistrates of districts, and in schoolhouses. In this way we learned much about conditions among the Tibetans in Sikang. As I am not an ethnologist, and our purpose in going there was especially for the study of amphibians, my account of the Tibetans is necessarily very general, and mostly limited to our own experiences.

\section{The Tibetans}

The Tibetans are a mixture of many races, with Mongol stock predominating. Their origin is not known. Their language is classified as of the Tibeto-Burman family. Very little is known about their early history. Originally there were three basic factors in their social organization: the tribe, the kingdom, and the lamasery. Any one of these may form a social unit; the nomads, for example, are organized into tribes; the greater part of the country is divided into 


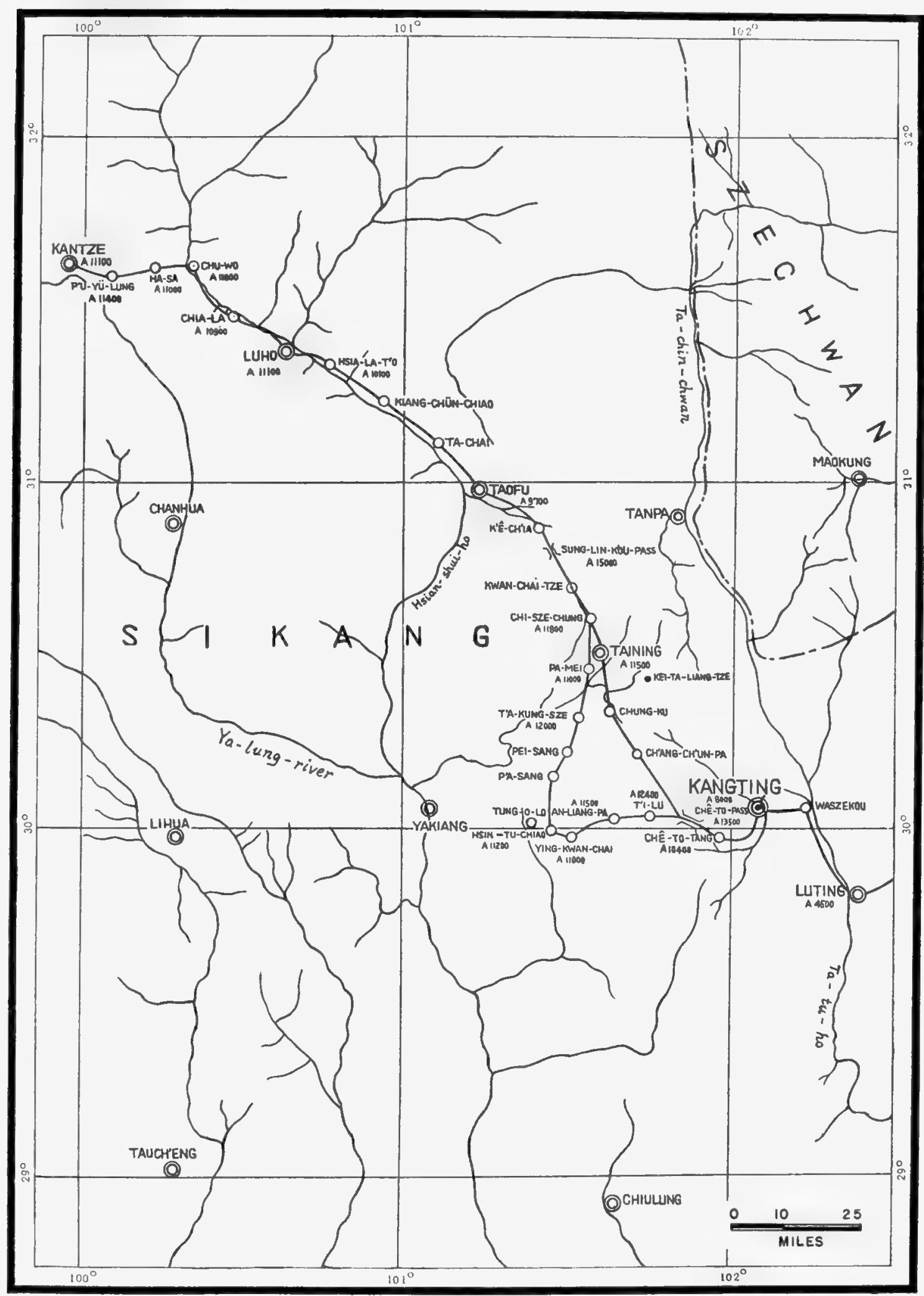

FiG. 8. Map of Kangshu, Sikang, from Kangting to Kangtze, showing collecting routes, localities, and altitudes. 
kingdoms; and the lamasery may, like the western parish, be the dominating factor in a certain area. The lamasery, in fact, plays much the same part in Tibetan life as did the monastery in mediaeval Europe, often forming the chief center of social, economic, religious, and cultural life. It is also a political center. As the Tibetans in Sikang Province are now under the control of the provincial government, the kingdom has been disappearing, but the lamaseries and the tribes remain unchanged. The lamasery retains its social and political influence in Sikang.

In addition to the lamas in the lamaseries of Sikang, the Tibetans or Kang can be classified into three categories: the farmers, the nomads, and the traders.

The great majority of the Tibetans are engaged in farming and in cattle- and sheep-raising, but the herdsmen live a life so different from that of the agricultural peasants that they form a separate group. The Kangshu region of Sikang is one of the poorest countries in the world; the great elevation, the rigorous climate, the brief summer and the lack of men to till the ground make the peasant's life a hard one. The land cannot be plowed till May, when the staple crops of barley and peas are sown. Irish potatoes, turnips and a few other vegetables can be grown at the lower levels in Sikang, at altitudes ranging from nine to ten thousand feet.

On the first day of plowing, a religious service is held to invoke the blessing of the gods and their protection of the land from hail, the farmers' worst enemy. The Tibetans practice crop rotation, according to which the land must lie fallow approximately one year in every three. The harvest is gathered in September, though at the higher altitudes the crops may never ripen because of the early frosts; crops harvested before they ripen can only be used as fodder. Generally the men do the plowing and the women sow the seed, milk the cattle and make butter, while both sexes do the weeding, irrigation, reaping, threshing, and winnowing. During harvest time, the peasants work eighteen hours a day, and the women bring their food to the fields.

Dotted all over the plains or hillsides, wherever there is grazing, may be seen the black hair tents of the nomad herdsmen, who may be considered the original inhabitants of Tibet and are probably the purest specimens of the race. The natural grazing grounds (there are no other), in which the wild pasture is coarse and sparse, is spread over the vast area of Kangshu, and consequently the herds must be continually on the move as the grass is consumed. For this reason, different tribes have their own areas to feed their herds, and may come into conflict. The herds consist mainly of yaks and sheep with a few horses and a few goats. No matter where they go, they always take their dogs to watch the herds, especially during the evening. These dogs are known as "Mango," which means "wild people's dog." They are very large, with especially large heads and big feet. Each dog has the value of several cattle. A nomad values his dog as much as his own life. 
The yak (Poëphagus grunniens) is a heavily built ox with long coarse hair that is usually black, but may be gray or even white; it is hardy and slow, and is the chief means of transportation in Kangshu. Economically it is the nomad's chief asset, for it carries his home on its back, its hair is used to make tents and coarse cloth, its hide is exported for leather, and its meat forms the chief diet of the tribe. The female gives excellent milk, which produces cheese and the white butter that plays such a large part in Tibetan life.

The rectangular tent, which the nomad carries with him in his endless search for fresh pasture, is made of yak hair. When he pitches his tent, he stacks blocks of turf all round the inside, to protect him from the piercing wind and to form a shelf on which to put his meager possessions; these consist of the barest essentials - a churn for making butter and buttered tea, a teapot, a few cooking vessels of iron or clay, and two or three large pans used in boiling milk to make cheese. In the center of the tent is a large stove made of mud and stones; dry yak-dung is the main fuel, as the plateau is treeless. Stacked around the walls are the rugs, saddles and leather bags containing food, so arranged that the family can lie down between them to sleep. The nomads may carry a little "tsamba" (barley powder) with them, but it is an expensive food for them as they grow no crops of their own, and must buy from the agricultural peasants; their diet consists almost entirely of meat, butter, and cheese. Some of the nomads may plunder their fellow tribesmen, or they may prey upon travellers, even attacking large caravans.

The traders form a small middle class that is now increasing greatly in importance, as foreign trade is taking a more important part in Tibetan life. These traders may be independent, or they may be the agents of the big monasteries or of government officials, who do not hesitate to use their official position for trade purposes. The Tibetans are born traders, willing at any time to bargain for their neighbors' possessions in order to sell them again at a profit. Monasteries as well as the city markets are the places for trading. Once a year, the herdsmen come down from their pastures and trade their wool and skins for household articles; they seldom use money, preferring the system of barter. Sometimes the traders may go to the pastures to exchange goods with the nomads.

The main diet of the Tibetans consists of yak meat, mutton, barley flour, butter, cheese, and tea. The wealthy, or those who live at lower altitudes, may supplement this with green vegetables and fruit. The cattle are slaughtered at the end of the summer, after they have had the benefit of the green pasture, and the carcasses are stored, without any curing, throughout the winter. Sometimes the meat is cut into strips and dried. The chief grain used for food is barley. This is eaten usually in the form of "tsamba," which is prepared in the following way: first the grain is washed, then it is roasted in an iron pan, then ground in a water-mill or a small hand mill, to make it into flour. The flour is then mixed with butter and tea, or just water, in a wooden bowl, kneaded into a roll with the fingers, and then eaten. 
The Tibetans drink even more tea than the Chinese or the English. The tea leaves consist of old leaves of various kinds of tea shrubs, together with twigs and dirt. These leaves and twigs are pressed together to form "tea-bricks," which are made solely for the Tibetans. Their way of preparing the tea is unique. They take from the tea-brick a handful of leaves and put them into a cauldron of cold water, adding a small quantity of soda; the mixture is then boiled. When traveling, they drink the tea from a wooden bowl, adding a little butter. In their tents or homes, the boiled tea is poured through a strainer into a wooden churn, in which it is vigorously churned, usually with the addition of butter and a little salt. It is then poured into an earthen-ware or copper teapot, from which it is served. This tea is really more like soup than tea, but it makes a warm and nourishing drink. Huge quantities of it are consumed in the monasteries, especially during festivals. Besides tea, the Tibetans drink milk, barley beer, and spirits.

The uses of butter are manifold; in the household it is used in cooking and is rubbed on the skin of children to keep out the cold; it is mixed with "tsamba" and taken in tea; it is used as hair-dressing by the ladies; and it provides the fuel for lamps. The Tibetans also use butter as money to pay their taxes to the landlords and monasteries. Monasteries consume large amounts of butter for the rows upon rows of little copper lamps that are kept burning constantly on their altars. Butter is also made into images and decorative forms at the time of their festival, which is held at the end of February each year.

Basically, the dress for Tibetan men and women of all classes is the same, consisting of a long, wide gown; there are, however, strict rules governing the material, quality, and color of the robes worn by different classes. The poor people have but one robe, which is made of coarse homespun and is gathered at the waist with a girdle, to give greater freedom of movement. In the pocket formed in front in the fold of the robe, the peasant will store away food, meat, butter, snuff, gunpowder, his wooden bowl, and anything else he may need during the daytime. The herdsmen wear a sheepskin robe all the year round, with the hair on the inside, and a skin or fur cap. The peasant wears rough felt boots with rawhide soles. Only the nobles may wear silk in public. The middle-class Tibetans may wear silk, but are forbidden to appear in public in such dress. The lamas wear red woollen robes.

The women wear a great variety of ornaments - gold and silver rings in the hair, ear-rings of different sorts, and necklaces of beads or even jade. Men always carry a sword in a beautiful scabbard that is given by the father at the time of birth. Both sexes wear a charm-box, a small case of chased gold or silver, often studded with precious stones and varying in shape from a small cylinder to a box about five inches square. The charm-box contains a talisman, usually consisting of an image and an inscription, which must be written by a lama. The image may be the "Lord of Mercy" or more often the "Lady Deliverer," who is believed to cure the sick. The charm-box is worn for protection against accident, various kinds of sickness, and evil spirits. To the Tibetan his charm- 
box is more than an ornament; it is regarded as essential to his safety and health.

"Bon" (commonly known as Buddhism) is the chief religion of the Tibetans, and one third of the men are lamas. The monastic system has attained such huge proportions probably because the monasteries are the centers of culture and upon them has fallen the task of providing for the people's education.

At the present time there are five sections of lamas, each section wearing a different color of robe-yellow, red, white, black and flowered. Yellow Bon is the most influential one.

Tibetans have no less than five different ways to dispose of their dead. The commonest is called "chagoppo" and consists in feeding the corpse to the vultures. At the time of death, a lama magician administers the last rites, which include the reading of passages from the book of the dead, as a kind of guide to the disembodied spirit in its wanderings. When the dying man has ceased to breathe, the lama, sitting at the head of the body, swiftly plucks a few hairs from the scalp, uttering the magic word "Hik" to release the soul from the body through the tiny hole that is believed to have been made in the skull. The corpse is then placed in a sitting position in a corner of the room and the relatives are invited to a feast, at which a good deal of wine is drunk, a little of the food and drink being offered to the corpse. After some days - the time is determined by the sorcerer-the body is carried out to a hillside where, to the sound of the chanting of lamas, it is cut into pieces. The flesh is separated from the bones and is fed to the vultures and magpies that sit patiently waiting a few yards away. 'The bones are crushed with a heavy stone and are also given to the birds. Meanwhile, the service continues at the home of the deceased. If the vultures do not eat the flesh of the corpse, or do not finish it, the dead person is thought to have been in sin, and his soul to be unfit for heaven.

The next most popular form of disposal of the dead is by cremation, but on account of the difficulty of obtaining fuel this method is confined mostly to the religious dignitaries. Water burial is a third method, the corpse being thrown into a river; but this is rarely done, except in the case of convicted criminals. Burial in a grave is limited to those who have died of an infectious disease such as smallpox. A fifth method is reserved for high lamas and living buddhas. The body is placed in a large box in a sitting position, salt is packed around it, and the box is closed and sealed. For three months the box rests in the temple, until the corpse has become completely dehydrated and the skin is hard and shrunken. It is then taken out, built up with clay mixed with wood fibers to represent the features of the lama, and gilded. Then a shrine is built and the mummy takes its place among the sacred relics of the monastery. The salt in which it was preserved is sold as a medicine to the people.

\section{Discoveries in Western China}

The amphibians form a small group of vertebrates. In China, only 88 species were recognized by Pope and Boring in 1939, and they list only 25 species 
for western China. After careful study of my amphibian collections, in addition to six species newly recorded, I found that I had some twenty new species of amphibians, one of which represents a remarkable new genus.

The amphibian fauna of Szechwan and Sikang is decidedly rich in unusual forms. The high plateau of central Sikang and the mountains of eastern Sikang and western Szechwan are the centers of speciation for the primitive pelobatid frogs (Aelurophryne, Scutiger, Megophrys, and Vibrissaphora). The giant salamander, Megalobatrachus, of western China is closely related to the large hellbender, Cryptobranchus, of eastern North America; the fire-bellied toad, Bombina, of Sikang is related to European species; and the tree frog, Rhacophorus leucomystax, is a common tropical form of southeastern Asia. The Siberian toad, Bufo raddei, is a Palearctic species that reaches northern Szechwan and Sikang. Therefore, Szechwan and Sikang are in a transitional zone from the Palearctic in the north to the Oriental in the south; and ecologically their range is from the warm temperate lowland of the east to the high cold plateau of the west. The mountain ranges running in a north-south direction between these two provinces afford the greatest variety of topographic and ecological conditions.

An outstanding element of the amphibian fauna of western China is Aelurophryne, which is found only on the high plateau; originally there was only one species known, $A$. mammata, but now we know no less than five species. Frogs adapted to mountain streams are another special group of western Chinese Amphibia. Tadpoles of the genus Staurois have large ventral suckers by which they adhere to the surface of slippery stones under cascades, and the adults have well-developed digital disks. Tree frogs of the genus Rhacophorus are not uncommon in western China. They live in trees, and their eggs are laid in nests of leaves on trees, not in the water as are those of common frogs. 


\section{DISTRIBUTION AND SPECIATION OF AMPHIBIA OF WESTERN CHINA}

\section{Introduction}

The faunistic distribution of Amphibia is often simpler than that of other vertebrates, because amphibians are bound almost absolutely to the land and to fresh water. The relatively small number of species is another factor simplifying the study of their distribution. The range of morphological specialization is relatively small, for caecilians, salamanders, and frogs form such compact orders that each can be recognized at once, even by the non-specialist. The Amphibia, in the process of evolution from the aquatic to the terrestrial environment, are the smallest and simplest of the classes of higher vertebrates.

The factors influencing amphibian distribution are obvious and great. Common salt, even in weak solution, is an almost insuperable barrier to their distribution, for one per cent salt solution kills the eggs and the larvae of most Amphibia. They are, in general, unable to cross seas, salt lakes, or saline plains. It has been thought that occasionally they might cross bodies of salt water on floating vegetation, but this must be an extremely rare event. Many terrestrial amphibians tolerate relatively high temperatures if moisture is available, but not cold and drought. Permanently frozen regions can have no Amphibia, as is true also of absolutely dry regions, not only because of the low temperature or humidity but also because of the lack of other animals, especially insects, as a food supply. Ranges of mountains are less effective barriers than the oceans, but they are more effective in the distribution of amphibians than in that of birds or mammals. The physical features may limit certain groups, as cascade frogs are limited to mountain streams, and vegetational features may limit other groups to grassy plains or to forests. The great centers of the tree frog evolution are the tropical forests of Malaysia, Africa, and tropical America.

The geographic location and the physical features of Szechwan and Sikang are favorable to differentiation of amphibians and to certain types of adaptation. The forms found on the high plateau are adapted to cold; the inhabitants of the high mountains may be torrent breeders, and tree frogs (not necessarily found in forests), burrowing forms, and dry land and swamp types are represented. The geographic location of Szechwan and Sikang places them mostly in the Palearctic region, but at the south they exhibit a few relations with tropical southeastern Asia, that is, with the Oriental region. The physical features of 
these two provinces, especially on the boundary between Szechwan and Sikang, are very remarkable. The great amount of topographic differentiation affords the greatest diversity of ecological conditions and thus favors speciation. This seems to be the chief factor producing the richness of the amphibian fauna of western China.

\section{General Relations between Amphibia of Western China and Other Parts of the World}

There is a definite pattern of distribution of world Amphibia. Species of Cryptobranchidae are found only in the Eastern Palearctic and Southeastern Nearctic; those of the Discoglossidae are limited to the Palearctic and are absent in the Nearctic. Various species of true toads (Bufo) are widely distributed over the world, being absent only in Malaysia, Australia, and New Zealand. The amphibian fauna of western China is very characteristic, with numerous genera developed chiefly on the border of the Tibetan Plateau, but with other species, genera, or families exhibiting varied relations with amphibian faunas of the other parts of the world.

The broadest geographic relations of the Amphibia of western China are demonstrated at the generic level by Bufo and Rana. Toads of the genus Bufo in Szechwan and Sikang include four species. There are sixteen species of the frogs of the genus Rana in western China. Rhacophorus, with five species, represents a tropical element in the fauna, the genus being very widespread in the East Indies and southeastern Asia.

Bombina is a Eurasian genus with two species in Europe and two in eastern Asia. These fire-bellied toads are forms having a red belly variegated with black and yellow or orange. The distribution of the species of this genus is curious; orientalis is found only in Shantung and Manchuria and certain adjacent areas, while the West Chinese species, maxima, is found only in southeastern Sikang, the southwest corner of Szechwan, Yunnan, and adjacent Tongking. Stejneger, in 1905, before Bombina maxima was discovered, suspected that Bombina arose in southeastern Asia and emigrated to the north and west, that is, to northeastern Asia and to Europe. The dispersal of Bombina throughout northern Asia offers no great difficulty, there being no significant barriers. The present restriction of the ranges of the several species appears to indicate relict distribution of a primitive type.

Megalobatrachus davidianus of the family Cryptobranchidae is widely distributed in southwestern China, ranging as far north as the middle region of Shensi. Another more primitive member of the family, Cryptobranchus, is found in eastern North America. The original headquarters of Cryptobranchidae was presumably in Asia. It must be assumed that the North American stock came from Asia by crossing the land bridge that once connected Asia and North America via Alaska. All of the living members of the family are aquatic forms living in rivers or small streams. During the latter part of the Tertiary, they were widely distributed. Fossil cryptobranchids are known from the Miocene 
of Europe and the lower Pliocene of Nebraska, where today the family is extinct. There are numerous other east Asiatic-southeast North American faunal relations, presumably of age equivalent with that of the Cryptobranchidae, for example, the Microhylidae and Pelobatidae.

The amphibian fauna of Szechwan and Sikang, especially in the south of these provinces, exhibits certain close relations with the amphibian fauna of tropical Asia. The best examples are the various species of Megophrys of the otherwise Holarctic family Pelobatidae. The pelobatids appear to be Holarctic in origin, but they invaded the Oriental region in giving rise to the genus Megophrys, which is extremely characteristic of the East Indies. The presence of this genus in temperate western China thus seems to be a secondary northward dispersal of the genus. Megophrys boettgeri, found in Shansi and Kansu, is the northernmost species of the genus.

\section{General Relations between Amphibia of Western China and Other Parts of China}

The mountain ranges between Szechwan and Sikang, especially toward the southern parts of these two provinces, afford favorable topographic and geographic conditions for the differentiation of the amphibian fauna. The transition from the Palearctic to the Oriental region gives this area a mixed amphibian fauna, with Palearctic forms at the north and Oriental species in the south, somewhat confusing the evident endemic and more characteristic special West Chinese fauna. The distribution of the Oriental and Palearctic forms overlaps to a certain extent, but each fauna still has its own distribution pattern.

The following lists show the distribution and relations of the Amphibia of western China.

I. Szechwan and Sikang species extending into other parts of China.

1. Batrachuperus pinchonii

2. Batrachuperus tibetanus
3. Bufo bufo wrighti

4. Bufo bufo minshanicus
5. Bufo tibetanus

6. Rana boulengeri

Bufo bufo minshanicus was first known from Kansu, but the center of its range is evidently northwestern Szechwan.

II. Northern and northeastern species found in Szechwan or Sikang.
1. Bufo bufo gargarizans
2. Rana nigromaculata
3. Rana temporaria chensin-

Rana temporaria chensinensis is a northern species widely distributed in Siberia and northern China. Rana nigromaculata and Bufo bufo gargarizans, representative of the European Rana esculenta and Bufo bufo bufo, are essentially northern types, but with a wide range in western China.

III. Southern and southeastern species found in Szechwan or Sikang.

1. Megalobatrachus davidianus

2. Bombina maxima

3. Hyla chinensis (Nomaterial collected)
4. Hyla annectans

5. Staurois chunganensis

6. Rana phrynoides

7. Rana pleuraden
8. Rana japonica

9. Rana adenopleura

10. Rana guentheri

11. Rana andersonii 
This list includes forms that are well represented in Fukien, and some, like Megalobatrachus davidianus and Bombina maxima, with their centers of dispersal only little to the south and east of Szechwan.

IV. Tropical forms extending into Szechwan and Sikang.
1. Microhyla ornata
3. Rana limnocharis
2. Microhyla butleri
4. Rhacophorus leucomystax

V. Endemic species of Szechwan and Sikang.

A. Endemic Species of Szechwan

1. Megophrys minor

2. Megophrys omeimontis

3. Megophrys shapingensis

4. Scutiger schmidti
5. Scutiger sp. (Mount Omei)

6. Scutiger sp. (Panlungshan)

7. Vibrissaphora boringii
8. Aelurophryne glandulata

9. Kaloula rugifera

10. Staurois lifanensis

11. Staurois ricketti minor

12. Rhacophorus chenfui

B. ENDEMuc Species of SikANG

1. Batrachuperus yenmaanensis

2. Batrachuperus cochranae

3. Tylototriton taliangensis

4. Scutiger pingii

5. Scutiger rugosa
6. Scutiger sp. (Lungtung, Paohsing)

7. Aelurophryne mammata

8. Aelurophryne brevipes

9. Aelurophryne maculata

10. Kaloula macroptica
11. Calluella ocellata

12. Staurois mantrorum

13. Staurois kangtingensis

14. Staurois loloensis

15. Rana chaochiaoensis

16. Rana shuchinae

C. Species Found in Both Stechwan and Sikang, and Confined to Those Two Provinces
1. Batrachuperus karl-
3. Scutiger popei
6. Staurois mantzorum schmidti
4. Aelurophryne tainingensis
7. Rhacophorus omeimontis
2. Megophrys boulengeri
5. Nanorana pleskei
8. Rhacophorus dugritei

The first two lists (A and B) may be expected to yield various species to the third $(\mathrm{C})$ when their ranges become better known. Many forms appear to have a very sharply localized range, which contributes to the richness of the fauna of western China.

\section{DISTRIBUTION OF THE AMPHIBIA OF WESTERN CHINA}

The amphibian fauna of Szechwan and Sikang is decidedly rich in distinctive forms. The high plateau of Sikang and the mountains of eastern Sikang and western Szechwan are the centers of dispersal and probably of the origin of the genera Batrachuperus, Scutiger, Vibrissaphora, and Aelurophryne; of a series of species of Megophrys, and of the ranids Altirana and Nanorana; and of Bufo bufo minshanicus and Bufo bufo wrighti.

The amphibian fauna of Szechwan and Sikang is much more closely related to that of the southern and southeastern parts of China than to that of northern and northeastern China. The ecological conditions in northern China are not favorable for Amphibia, so that only a few species that are adjusted to low temperatures and low humidity exist there, and most Palearctic forms are absent. 
There are only six species of amphibians, with no salamander, in the Province of Hopei. Although the number of northern species found in Szechwan and Sikang is apparently small, no less than four of these six species are found in western China; but this is associated with very wide range of these forms. The amphibian fauna of southern and southeastern China is much richer than that of northern China, and various species and genera are common to southeastern China and western China. The forms of northern China are found in northern Szechwan and Sikang, and the southern and southeastern forms are scattered in southern Szechwan and the southeast corner of Sikang. Overlapping of the distribution of the northern and southern species occurs, especially for the northern Bufo bufo gargarizans and Rana nigromaculata and the southern Megalobatrachus davidianus and Microhyla ornata.

According to zoogeographical relations, Szechwan and Sikang are in a transitional zone from the Palearctic in the north to the Oriental in the south; ecologically they range from the lowlands of the east to the high plateau of the west. The mountain ranges running in a north-south direction between these two provinces afford great variety of topographic and ecological conditions in which the habitat niches have been filled by various adaptive groups. Mount Omei presents the most varied and interesting amphibian fauna of any of the collecting stations.

This mountain is the southeastern end of the Hungshan range with the Tatuho at the west and south. The amphibian fauna of Mount Omei consists mainly of forms found in the northern parts of the Hungshan, whereas the amphibians of the Taliangshan south of the lower arm of the Tatuho are mostly quite distinct species. The high plateau of Sikang and northwestern Szechwan, separated from Mount Omei by the Tatuho, has a different amphibian fauna. For the present discussion, western Szechwan and Sikang are arbitrarily divided into five zones: Mount Omei; Taliang Mountains and Ningshu in Sikang; the Kangshu region in Sikang from Kangting to Kantze; northwestern Szechwan and the adjacent region in Sikang; and the Chengtu plain.

The amphibian fauna of Mount Omei is characteristic in having more species of Scutiger, Megophrys, and Rhacophorus. The following lists of species found in each region indicate the similarities and the differences between the amphibian fauna of those regions.

\section{Mount Omei.}

1. Megalobatrachus davidi-

2. Batrachuperus pinchonii

3. Megophrys minor

4. Megophrys omeimontis

5. Megophrys boulengeri

6. Megophrys oshanensis

7. Scutiger popei

8. Scutiger schmidti

9. Scutiger sp.
10. Vibrissaphora boringii

11. Bufo bufo gargarizans

12. Hyla annectans

13. Kaloula rugifera

14. Microhyla ornata

15. Staurois chunganensis

16. Rana margaretae

17. Rana boulengeri

18. Rana adenopleura

19. Rana japonica
20. Rana limnocharis

21. Rana nigromaculata

22. Rana guentheri

23. Rhacophorus leucomystax

24. Rhacophorus omeimontis

25. Rhacophorus chenfui

26. Rhacophorus bambusi- 
II. Taliang Mountains and Ningshu, Sikang.
1. Megalobatrachus davidi- anus
7. Hyla annectans
8. Kaloula macroptica
2. Batrachuperus yenyuan-
9. Calluella ocellata ensis
3. Tylototriton taliangensis
10. Staurois loloensis
11. Staurois ricketti minor
12. Rana chaochiaoensis
13. Rana shuchinae
14. Rana andersonii
15. Rana phrymoides
16. Rana pleuraden
17. Rana adenopleura
18. Rhacophorusbambusicola
4. Bombina maxima
5. Scutiger pingii
6. Scutiger rugosa
19. Rhacophorus omeimontis
20. Rhacophorus dugritei

III. Kangshu, Kangting to Kantze, Sikang.
1. Batrachuperus karl- schmidti
4. Aelurophryne taining-
8. Altirana parkeri
9. Nanorana pleskei
2. Aelurophryne mammata ensis
3. Aelurophryne brevipes
5. Aelurophryne maculata
10. Staurois kangtingensis
6. Bufo tibetanus
7. Bufo bufo wrighti
11. Rana temporaria chensin- ensis

\section{Northwestern Szechwan and adjacent Sikang.}

1. Megalobatrachus davidianus

2. Batrachuperus pinchonii

3. Batrachuperus karlschmidti

4. Batrachuperus cochranae

5. Batrachuperus tibetanus

6. Megophrys minor

7. Scutiger popei

8. Scutiger schmidti

9. Scutiger sp. (Lungtung, Paohsing)
10. Scutiger sp.

(Panlungshan, Kwanhsien)

11. Aelurophryne glandulata

12. Aelurophryme tainingensis

13. Bufo bufo wrighti

14. Bufo bufo gargarizans

15. Hyla annectans

16. Kaloula rugifera

17. Microhyla ornata

18. Nanorana pleskei

19. Staurois mantzorum
20. Staurois lifanensis

21. Staurois loloensis

22. Staurois chunganensis

23. Rana margaretae

24. Rana boulengeri

25. Rana japonica

26. Rana temporaria chensinensis

27. Rana limnocharis

28. Rana nigromaculata

29. Rhacophorus leucomystax

30. Rhacophorus omeimontis

31. Rhacophorus dugritei

V. Chengtu Plain.

1. Bufo bufo gargarizans

2. Kaloula rugifera
3. Microhyla ornata

4. Rana limnocharis
5. Rana nigromaculata

6. Rana guentheri

The vertical distributions of the Amphibia of western China are discussed under the species headings.

\section{Discussion of Endemic Genera}

The factors involved in the rise of a new species are numerous and varied. The interaction of the various types of isolation-topographic, geographical or spatial, chronological or seasonal, ecological or physiological-in combination with genetic change of the populations and natural selection, produces speciation. The amphibian fauna of western China affords an interesting example of speciation, with numerous closely related species of endemic generic groups. Topographic isolation, favored by the rugged mountainous terrain with deep permanent streams and their valleys, ecological and physiological isolations, favored by varied climatic and vegetational environmental niches, and the pressure of 
natural selection have been the chief factors in the evolutionary specialization of the amphibians of Szechwan and Sikang.

The topography of western China is determined by the relation of the region to the Tibetan Plateau and by the north-south mountain ranges between Szechwan and Sikang. Altitudes in western China range from 1,750 feet at Chengtu to 25,000 feet on Koonga Mountain in Sikang. The low and mild temperate Chengtu Plain passes into high, cold plateaus at 14,000 feet. The mingling of the northern and southern faunal elements in a zone transitional between the Palearctic and the Oriental clearly has been favorable to species formation.

The pelobatid genus Aelurophryne and the ranid Nanorana (with its close relative Altirana) flourish only on the high plateau of Sikang and in the northwestern corner of Szechwan, and are completely absent from the warmer lowlands. These two genera, both adapted to cold, are found under different ecological conditions. The various species of Aelurophryne always inhabit stony mountain streams, especially near their upper reaches, where the water is shallow and very cold. Nanorana pleskei is found only in the quiet water of the marshes on the high plateaus, where there is usually a rich vegetation. A third high plateau species, Bufo tibetanus, endemic in western China, ranges north to Tsinghai. This toad is found only under stones or in holes on hillsides. None of these three quite differently adapted Salientia of the high plateau range into the equally cold lowlands of the Palearctic region, and they are found nowhere else in the world.

The salamander genus Batrachuperus of western China also illustrates topographic as well as physiological and geological isolation in relation to speciation. There is no doubt that the center of differentiation of Batrachuperus is in northwestern Szechwan and the northeastern corner of Sikang, where four of the five species are found. B. pinchonii is found together with Aelurophryne brevipes on the high plateau of Sikang, and with $A$. glandulata in northwestern Szechwan. It occurs with Megophrys boulengeri on the top of Mount Omei. Curiously enough, it is never found in association with frogs of the genus Scutiger, or indeed with any other amphibian. Batrachuperus and Aelurophryne thus characterize an ecological group, the former being somewhat more a mountain form, and the latter more an inhabitant of the high plateau.

The Himalayan pelobatids of the genus Scutiger have long been rarities in museum collections. They are really not rare, but because of their characteristic isolation in very small and inaccessible streams at high altitudes, they have not often been collected. Scutiger sikkimensis is recorded from the Burmo-Sikang border, and $S$. alticola was discovered in the southern part of Tibet. As a result of my collecting trips in western China, I can record four new species of Scutigerpingii, rugosa, schmidti and popei-and it appears that there are three more undescribed species in western China, known only from tadpoles and specimens just metamorphosed. It now appears that the center of differentiation of Scutiger is unquestionably in the mountains of the western border of Szechwan 
and in the eastern and the southeastern parts of Sikang. The species of Scutiger are all cold-adapted animals found in upper reaches of mountain streams; but they are not adapted to the extremes of the high plateau or high mountain zones like Aelurophryne and Batrachuperus. All the species of Scutiger are definitely limited to a topographic zone and a special habitat-small mountain streams from 3,000 to 8,000 feet altitude. Aelurophryne, closely related to Scutiger, is sharply limited to the high plateau and mountain slopes from 8,000 to 12,000 feet altitude.

Geographic isolation is also well illustrated by various species of the amphibian fauna of western China. Bufo raddei and Rana temporaria chensinensis, which are northern Chinese forms, are limited to the northern part of Szechwan and Sikang. The high plateau species of Aelurophryne, Bufo tibetanus, and Nanorana pleskei never extend southeastward to the high mountains south of Wenchwanhsien in Szechwan. The western Chinese species of Megophrys are found mainly south of Lat. $30^{\circ} \mathrm{N}$., and especially in the Mount Omei region.

The results of my investigations in western China indicate that the amphibian fauna of Mount Omei is more closely related to the amphibians of the mountains north of Mount Omei than to those of the Taliang Mountains to the south. This is especially clear in the genus Scutiger. Scutiger schmidti and S. popei are found on Mount Omei and also in the mountain streams of Panlungshan, west of Kwanhsien and in the vicinity of Paohsinghsien (Muping); but not one specimen of these two forms has been taken on the Taliang Mountains. In the streams on the west side of the Taliang Mountains there are two other quite different species, Scutiger pingii and S. rugosa, which are not found on Mount Omei or anywhere else. The Tatu River, south of Mount Omei and north of the Taliang Mountains, marks the boundary of two different faunal areas that are characterized by distinct species but related by their genera.

Mount Omei, at the south end of Hungshan range, has an altitude of 11,000 feet, much higher than the mountains just to the west and northwest. Above the level of 5,000 feet it is really an ecological island, isolated like the islands in the sea. This may be the chief factor in its amphibian speciation. The extent of this speciation is well illustrated by the distinctness of the genus Vibrissaphora, which I discovered on the mountain in the zone between 3,000 and 4,000 feet, and which is now known to have a representative also in the mountains of Fukien. Megophrys presents other good examples of Mount Omei speciation, $M$. boulengeri being found only at the top of the peak. Another endemic species, $M$. omeimontis, is found at about 3,000 feet altitude.

\section{Habitat Isolation}

Certain closely related species of the amphibian fauna of western China are found breeding in the same place. The northern Chinese woodfrogs, Rana temporaria chensinensis, and the southern Chinese woodfrogs, $R$. japonica, lay their egg-masses in side pools of Kialing River near Peip'ei, north of Chungking. 
Although they are closely related species and have the same breeding site, they are still easily distinguished; their breeding seasons at Chungking are also different. According to $\mathrm{H}$. W. Chang, $R$. japonica lays its eggs from the end of November to the end of December, whereas, for the closely related species $R$. temporaria chensinensis, the breeding season is as late as January.

There are very good illustrations to show the physiological isolation of the amphibian fauna of Mount Omei. Four species of Rhacophorus found on Mount Omei differ from each other morphologically as well as physiologically. The common tree frogs of the tropical species $R$. leucomystax have a different voice from that of three Rhacophorus of western China. $R$. chenfui is an endemic form of Mount Omei; $R$. omeimontis and $R$. bambusicola are endemic to Szechwan and Sikang and are found with chenfui on Mount Omei. In their habits, and thus in their physiological reactions, these three species are more closely related to each other than to $R$. leucomystax. The females of leucomystax lay their eggfoam masses on the walls of small pools or ponds or on vegetation in flooded rice fields. The other three species never choose this kind of site for egg-laying. This is one of the factors that separates them from the widespread leucomystax. The breeding season of leucomystax is also later than that of the other three tree frogs. The habitat of leucomystax is characteristic. I rarely found it on trees or bushes; it is a terrestrial form. The vertical distribution of this species is from 1,000 to 4,000 feet altitude. In other words, in western China it is a characteristic lowland frog, though absent from the Chengtu plain.

The other three closely related species found on Mount Omei are distinctly different species, rather than subspecies. The development of three species of tree frogs in one region has been effected by adjustment both to specific habitat and to physiological requirements of the habitat zones. $R$. bambusicola is found from 8,000 feet upward to the very top of the mountain. Frogs of this species are physiologically adjusted to cold temperatures. In connection with adaptation to cold they are more terrestrial than arboreal, with stouter bodies, smaller adhesive disks, shorter legs, and much better developed inner metatarsal tubercles. They lay their egg-foam masses under the roots of vegetation, under stones near pools, ponds, or ditches, or even in holes in the ground. They never lay eggs on trees as does $R$. omeimontis. This terrestrial breeding habit has a positive correlation with the zonal vegetation, as there are no broad-leaved trees above 8,000 feet altitude, but only pine trees, dwarf bamboos, and numerous low bushes.

$R$. omeimontis is found from 3,000 to 5,000 feet altitude, but never associated with bambusicola. This species is the most typical tree frog, and its habitat is presumably that of the ancestral type. $R$. omeimontis has the longest legs and the largest adhesive disks of the three endemic forms, and it lays its eggs in nests made by pulling together the leaves of broad-leaved trees or other vegetation near the water. This species is found at lower altitudes, with the trees appropriate for its breeding habit.

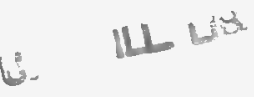


$R$. chenfui is found on Mount Omei together with omeimontis. $R$. chenfui is limited to two places on the mountain and is certainly not widely distributed like omeimontis, bambusicola, or leucomystax. This species still has arboreal adaptations, but has shorter legs and smaller adhesive disks than omeimontis. Unfortunately, the breeding habits of chenfui are still unknown, although my assistants and I tried very hard throughout three summers to learn more about them, after finding the tadpoles during our first season.

The adaptive complex of bambusicola, omeimontis, and chenfui is distinct in each species, but they are nevertheless closely allied forms. Their croaking is very similar; an inexperienced person never recognizes the differences between their voices. The morphological characters of their tadpoles are similar. I failed to distinguish them during my first investigations; but once one knows the differences between them, one never fails to recognize them in the field. Physiological isolation (including behavior characters) as well as habitat isolation, are the factors that make possible the presence of three closely related species of frogs on the same mountain.

Rana adenopleura, also found on Mount Omei, is another good example of speciation through habitat and behavioral isolation. The breeding habits of this frog are absolutely different from those of other Chinese species of Rana. Eggs are laid in nests near the margin of the water of small pools but never in the water. (Pope [1931] stated that this frog lays its eggs in flooded rice fields.) Through this habit, Rana adenopleura is excluded from any possibility of inbreeding with other species. Again, this frog can only perpetuate its race in places where rains are frequent, so that the hatched tadpoles are washed into the pool for further development.

The vertical distribution of the vegetation of the Mount Omei region exhibits four zones. These are the warm-temperate, up to 2,000 feet altitude; the temperate, from 2,000 to 5,000 feet; the cool-temperate, from 5,000 to 10,000 feet; and the sub-Alpine, from 10,000 feet upward. In the lowest zone, at the foot of Mount Omei, there are seven species of frogs and toads but only Rana guentheri is limited to this area, the remaining six extending into the next zone. The temperate zone has the richest amphibian fauna, consisting of nineteen species. Six of these are more commonly found in the warm-temperate zone below and three range upward to the cool-temperate, leaving ten species confined to the 2,000 to 5,000 foot zone. In the cool-temperate zone, there are eight species of frogs and toads but only three of these are limited to this area. The pelobatid frogs of the genus Scutiger are characteristically cool-temperate.

The ecological conditions on the top of Mount Omei are absolutely different from those in the zones below and only a few species of cold-adapted Amphibia exist there. Batrachuperus pinchonii and Megophrys boulengeri occur only in this zone and breed there freely. They are not found below 10,000 feet altitude. The third species found in the uppermost zone is Rhacophorus bambusicola, which ranges downward into the cool-temperate, to about 8,000 feet. 


\section{PROVINCIAL LISTS OF THE SPECIES OF AMPHIBIA OF WESTERN CHINA}

\section{SZECHWAN}

Megalobatrachus davidianus

Batrachuperus pinchonii

Batrachuperus tibetanus

Batrachuperus karlschmidti

Hynobius shihi

Megophrys oshanensis

Megophrys minor

Megophrys boulengeri

Megophrys omeimontis

Megophrys shapingensis

Scutiger popei

Scutiger sp.

(Mount Omei)

Scutiger sp.

(Panlungshan)

Megalobatrachus davidianus

Batrachuperus pinchonii

Batrachuperus tibetanus

Batrachuperus karlschmidti

Batrachuperus yenyuanensis

Batrachuperus cochranae

Tylototriton taliangensis

Bombina maxima

Megophrys boulengeri

Megophrys omeimontis

Scutiger popei

Scutiger pingii

Scutiger rugosa

Scutiger sp.

(Lungtung)

Tylototriton verrucosus

Triturus wolterstorffi

Bombina maxima

Megophrys lateralis

Megophrys carinensis

Bufo bufo wrighti

Bufo melanostictus

Hyla annectans
Scutiger schmidti

Vibrissaphora boringii

Aelurophryne glandulata

Aelurophryne tainingensis

Bufo bufo gargarizans

Bufo bufo wrighti

Bufo bufo minshanicus

Hyla annectans

Microhyla ornata

Microhyla butleri

Kaloula rugifera

Nanorana pleskei

Staurois chunganensis

Staurois lifanensis

Staurois ricketti minor

\section{SIKANG}

Aelurophryne mammata

Aelurophryne brevipes

Aelurophryne tainingensis

Aelurophryne maculata

Bufo bufo gargarizans

Bufo bufo wrighti

Bufo tibetanus

Hyla annectans

Microhyla ornata

Kaloula macroptica

Calluella ocellata

Altirana parkeri

Nanorana pleskei

Staurois mantzorum

\section{YunNaN}

Microhyla ornata

Kaloula verrucosa

Calluella yunnanensis

Kalophrynus pleurostigma interlineatus

Staurois afghanus

Rana limnocharis

Rana tigerina rugulosa

\section{TsINGHAI}

Bufo tibetanus
Rana limnocharis

Rana nigromaculata

Rana guentheri

Rana boulengeri

Rana adenopleura

Rana margaretae

Rana andersonii

Rana temporaria chensinensis

Rana japonica

Rhacophorus dugritei

Rhacophorus omeimontis

Rhacophorus bambusicola

Rhacophorus leucomystax

Rhacophorus chenfui

Staurois chunganensis

Staurois kangtingensis

Staurois loloensis

Rana limnocharis

Rana nigromaculata

Rana boulengeri

Rana phrynoides

Rana pleuraden

Rana andersonii

Rana temporaria chensinensis

Rana japonica

Rana chaochiaoensis

Rana shuchinae

Rhacophorus bambusicola

Rana kuhlii

Rana guentheri

Rana phrynoides

Rana feae

Rana pleuraden

Rana andersonii

Rana chaochiooensis

Rhacophorus leucomystax

Rana temporaria chensinensis 


\author{
Batrachuperus tibetanus \\ Megophrys boettgeri \\ Bufo bufo gargarizans
}

\section{KANSU}

Bufo bufo minshanicus

Bufo raddei

Rana nigromaculata
Rana boulengeri

Rana temporaria chensinensis

\section{ADAPTATIONS OF THE AMPHIBIA OF WESTERN CHINA}

Adaptive radiation in the Amphibia is limited in comparison with this mode of evolution in other groups of vertebrates. The external modifications for protection and adjustment to new ecological conditions are poorly developed or lacking in the adult form of modern amphibians. They are accordingly very easily controlled and influenced by environmental factors, especially temperature and moisture. Although various ways of protecting the eggs and the tadpoles have been developed among the Amphibia, most amphibians in these stages are exposed to biological, physical, and chemical hazards. Furthermore, the eggs and the tadpoles themselves have a narrow range of adaptive structure and are very poorly equipped for protection against the environment. This limited adaptability helps to account for the small amphibian fauna in the world in general.

The Chinese fauna and flora are by no means well studied, and this is true for the Amphibia. Little has been written on the habits and habitats of Chinese salamanders, or on the toads and frogs, except for the paper by Pope (1931), who made intensive field studies of the amphibians of Fukien and Hainan, and for my own series of papers (1930-31), examining the habits and life histories of the Amphibia of northern China. Although many people have collected in western China, no studies in nature have been made. The following account of the adaptation of amphibians of western China is mainly the result of my own observations.

Discussion of the habitat preferences of the Amphibia requires great caution, as it is difficult to draw a definite line between the different kinds of habitats and the various species may overlap to some extent from one habitat to another. When I record a frog from a certain habitat, I mean that it was found there by me, but this does not mean that this species is invariably to be found only in such an environment. This is well illustrated by Rana adenopleura, which Pope found in flooded fields on mountains in Fukien, whereas I invariably found it in pools, and very rarely in ponds, on Mount Omei. Amphibians, like other animals, may make short distinct migrations at the breeding season and in pursuit of food. The same species of frog may be found in different ecological niches during different seasons of the year and different stages of its life history. A good example of this is Staurois chunganensis, found only in large mountain streams during its breeding activities. Before and after the breeding season these frogs are rarely seen, and it is probable that they live in the vegetation on hillsides. I obtained two specimens in such a habitat at the time of rain. Finally, the vertical distribution of amphibians varies from species to species, in correla- 
tion with differences of habitat, but often with large overlap. Bufo bufo wrighti has a vertical range extending from 3,000 to 10,000 feet. This toad may breed in pools and ponds, in stationary bodies of water along mountain streams or in mountain streams themselves. The tadpoles of a given species may be found in different types of water; they are subject to conditions of current and may be washed down from pond to stream or from running water to swift water. Such displacement is well illustrated by the tadpoles of Scutiger popei.

It is difficult to draw sharp lines between different types of water habitats, as explained below, and it may therefore be difficult to distinguish the frog types from one habitat to the next. Examples of this difficulty are the indefinite boundaries between swift and running water; or between ponds and pools. After a heavy rain, the water in a small mountain stream, normally with "running water," changes into "swift water"; and a pool may temporarily become a pond. It is also true that after a heavy rain the quiet water of a ditch, pond, or pool may become "slow-running water." Thus, bodies of water may change from one current condition to another during the year. When we say "swift water" we mean that of permanent streams with cascades.

\section{Adaptation in Adults and Tadpoles}

The high mountains of western China afford various kinds of interesting environments that are good laboratories for studies of the fauna and flora in nature and excellent experimental ground for ecological and taxonomic studies. The amphibian fauna in western China is rich and characteristic, especially in montane forms such as the different species of the family Pelobatidae, the cascade frogs of the genus Staurois, and the different tree frogs of the genus Rhacophorus. The habitats of the adult amphibians fall naturally into three categories, the aquatic, the terrestrial, and the arboreal.

Aquatic AdAPTATION.-The aquatic forms of amphibians can be divided into three subordinate categories, the swift-water or cascade group, the runningwater group, and the quiet-water group.

In the cascade group, we shall take up only two examples, Rana margaretae and Staurois lifanensis. Rana margaretae is commonly seen adhering closely to the surface of the rocks that form the steep banks of swift mountain streams, or sitting on mats of green vegetation on such rocks. This frog usually directs its head toward the current, into which it dives at the slightest disturbance. These frogs usually sit from one to four feet above the water level. They are green in color, matching the vegetation. Staurois lifanensis, as well as all the other species of Staurois except chunganensis, is a true cascade frog, usually seen adhering closely to the surface of a rock by the side of a shaded cascade, either on bare rock or on matted vegetation reached by the spray. The body of this frog is slender and dorso-ventrally depressed, the legs are long, and the toes are fully webbed and provided with adhesive disks at the digital extremities. The depressed body and the adhesive disks enable the animal to maintain its hold 
on the slippery stones within the spray zone. The webs and the long legs enable it to swim vigorously in the swift water. The coloration, varying greatly and changing under different conditions, is of great survival value in the effective protection of the species. Only a trained eye can detect one of these frogs before it moves.

The running-water habitat, in about the same altitude zone as the cascading larger streams, consists mainly of the smaller headwater brooks. There are only a few species of salamanders and frogs in western China that inhabit this niche. Rana boulengeri, the large mountain frog, and the allied species, $R$. phrynoides, are adapted to mountain streams. The body is stout and heavy but the legs are long and provided with very strong muscles and fully developed webs. These frogs are good swimmers in running water. Their coloration is very similar to that of the stones in the water or near the margin of the mountain streams, where they usually sit. The primitive pelobatid frogs, like Aelurophryne glandulata and Scutiger popei, may be found under stones in the water of mountain streams. However, they are not truly aquatic forms and they hide normally in crevices between stones and in similar situations on hillsides along or near the mountain streams. The high mountain salamanders of the species Batrachuperus pinchonii hide themselves under stones in small mountain brooks from 6,000 feet upward, but are never found in larger and swifter streams. They are occasionally seen under decayed logs of pine on hillsides. The strong tail of this species and the undulating movements of the body form the powerful means needed for locomotion in its brook habitat.

The quiet-water group of Amphibia exhibits great variety of size and form. It is more heterogeneous than any of the other ecological groups of amphibians and its species are widely distributed vertically and horizontally. Mountain forms and plains types can be recognized. Nanorana pleskei is a swamp-dweller in grassland on high plateaus and mountains; it is found under stones or roots of vegetation in quiet water from 9,000 to 14,000 feet altitude. The depressed body resembles that of the cascade frogs; this type of body is not found in other frogs living in quiet water. Body form in Nanorana pleskei seems to be associated with the habits of the species. These frogs hide themselves under flat stones in the water during the summer and at the time of hibernation they may go deep in the ground in the crevices between stones. Their legs are weak and short, but their feet are provided with well-developed webs for swimming in the temporary pools and ponds and open water of the high mountain marshes. Bombina maxima, the most primitive salientian in China, is more aquatic than terrestrial. This frog is generally found under stones in or at the edge of the water of small ponds or pools of high mountains. The legs are moderately developed and the toes are fully webbed, especially in the males. The beautiful musical frog, Rana adenopleura, especially famous on Mount Omei, is another good example of adaptation to quiet water. It inhabits pools and is occasionally found in ponds and marshes. This species is a typical mountain quiet-water form with much stouter body, rather short and weak legs, and 
moderately developed webs between the toes. There are only a few species of frogs inhabiting the quiet water of the lower plains. The common Chinese pond frogs, Rana nigromaculata and $R$. guentheri, are the best illustrations of the quiet-water type of low altitudes (from 1,000 feet above sea level at Chungking to 1,750 feet at Chengtu). These frogs are well equipped for a pond life and at the same time are good swimmers, with well-developed legs and webs. R. nigromaculata may be found in ponds on the lower slopes of the mountains up to about 3,000 feet altitude.

TERRESTRIAL ADAPTATION.-Many species of various genera of salamanders and frogs visit the water only during their breeding season, and live on land, often far from water, at other seasons. Such forms should be classified as terrestrial, and they may be distinguished as a special ecological group. Terrestrial amphibians may have different habitats from time to time and under different conditions. The burrowing, narrow-mouthed toads (Kaloula rugifera) remain in their hiding places during the daytime, but during or after a heavy rain they may come out onto open ground, or hide themselves among vegetation. They feed at twilight. This case clearly illustrates the difficulties of classifying the amphibians into definite groups, according to habitat. However, in general, they can be divided into two adaptive groups: the grassland inhabitants and the burrowing forms.

The grassland group includes quite a few species of Amphibia, both montane and plains forms. The common members of this group are the wood frogs, Rana japonica and $R$. temporaria chensinensis; the rice-field frog, $R$. limnocharis; the pond frog, $R$. nigromaculata; the small narrow-mouthed frog, Microhyla ornata; and the pelobatid frog, Megophrys minor. M. minor is the only species found in grass or among bushes of mountain sides; all the rest inhabit the hills as well as the Chengtu Plain. Sometimes one may find Rana limnocharis and Microhyla ornata in cracks of the earth or in crevices in stones. There is no definite structural differentiation for such habits.

Some of the terrestrial forms of amphibians hide during the daytime in cracks of stones and earth or in holes, dug by themselves. They are burrowers in varying degree, and are usually provided with shorter legs and strong inner metatarsal tubercles for digging. They are protected from desiccation by the thicker skin with its large number of mucous glands, as in Kaloula rugifera and K. macroptica. The toads of the genera Kaloula and Bufo have sometimes been regarded as forming, ecologically, a stone pile and old-building group, because they are so generally found near old houses. These species obviously meet more enemies than do other terrestrial forms, and are much more exposed to predation than the cascade and running-water species.

In amphibians there are no structures for active offense, the defensive weapons of toads and frogs being mainly chemical in nature. Little is known of the biochemistry of their glandular secretions. Bufo bufo gargarizans has an ugly appearance with large numbers of warts of varying size; there is a super- 
stition that by touching them one may acquire warts. That the chemical secretions of the skin of toads provide an effective defense is shown by the fact that cats and dogs, especially the former, will eat frogs but not toads. It is likely that these animals learn by experience in each generation to avoid toads; one experience, perhaps, will be remembered for life. Histological study demonstrates the many poison glands found in the skin of Bufo bufo gargarizans and Kaloula rugifera. Other toads, Bufo raddei, B. tibetanus, and B. bufo wrighti, are protected in the same way. The pelobatid frogs of the genera Scutiger and Aelurophryne also belong to the digging and burrowing group, hiding in holes in the earth or in crevices in stones on hillsides except at the breeding season. After this season one may find some Aelurophryme glandulata under stones in the water, but only rarely can specimens of the species of Scutiger be found in this habitat. The dull coloration in these amphibians, very much like that of the earth and stones under which they hide themselves during the day, seems to be correlated with their habitat. When they come out at twilight to search for food, their coloration may be protective to a degree.

Tree frogs of the Rhacophorus group (Rhacophoridae) and the tree toad Hyla annectans (Hylidae) are mostly arboreal in habits and sometimes have terrestrial adaptations. They are never truly aquatic. The chief structural specializations for arboreal habits are the large adhesive disks at the tips of the fingers and toes, the long limbs and the dorso-ventrally depressed body. Rhacophorus omeimontis is the best example of arboreal adaptation among West Chinese frogs, with the most highly developed adhesive disks and the most striking resemblance to its environment in coloration. This tree frog is usually found on trees or on the roofs or walls of houses, only rarely on bushes. The color of the back of $R$. omeimontis is very similar to that of the lichens of its usual habitat. Without learning how to look for it, and without keen eyes, very few people will be able to find this frog. $R$. bambusicola is generally found among bushes or in grass, and its adhesive disks are much smaller than those of $R$. omeimontis. Disk size is also correlated with breeding habits, as the females of bambusicola lay their eggs in holes in the ground or under stones out of water, and omeimontis lay theirs in leaves at the tips of the branches of trees overhanging water. The small green tree toad, Hyla annectans, may be found on bushes or in grass by the side of streams or in marshes; the legs and adhesive disks are only moderately developed. In this species there is very good color protection.

BREEDING ADAPTATION.--Most of the frogs breeding in swift mountain streams of western China belong to the genus Staurois; only one species of Rana breeds in such streams. In the genus Staurois, sex dimorphism is distinctly marked. Males are much smaller in size than the females; for example, the average body length of fifty males of Staurois chunganensis is $36.5 \mathrm{~mm}$., and of fifty females $49.8 \mathrm{~mm}$. This proportion of male to female size holds roughly for all other species of Staurois studied, and for Rana margaretae as well. Means of clasping and holding fast to the female are moderately developed. Nuptial 
pads of dark or creamy color are moderately developed on the inner dorsal side of the first finger of the males of the several species. The arms in the males of Staurois are moderately enlarged as compared with the arms of the females, except in $S$. chunganensis, in which the males have only slightly enlarged arms. Enlargement of the arms of the male is also to be seen in Rana margaretae, which probably belongs to the cascade-frog group, for both adults and tadpoles are found with the species of Staurois, along large mountain streams. Dimorphism in size of the sexes is distinctly an adult adaptation to breeding in swift water. The smaller size of the male is correlated with comparatively slender and dorso-ventrally depressed body; this is interpreted as facilitating breeding activities by decreasing the total area of the breeding pair exposed to the swift current in the mountain torrents.

The method of egg-laying, the nature of the egg-mass, and the type of egg are especially adapted to breeding in swift water. The process of egg-laying was observed only in Staurois chunganensis. The attachment of the eggs to the under side of the stones in the water is functional in keeping the eggs from being washed downstream. The small amount of jelly also reduces the resistance to the current. The white color of the eggs of $S$. chunganensis is not clearly adaptive; the egg color is unknown for other species of Staurois.

Tadpoles inhabiting the swift water of mountain streams of western China belong chiefly to the genus Staurois, but some tadpoles of various species of Rana are also found in relatively quiet pools back of the large stones of such mountain streams. Staurois tadpoles adhere tightly to the surface of slippery rock in the water by means of a ventral sucker formed by the mouth and the adjacent region of the body. The flat body of the tadpole decreases the likelihood of its being washed down from the stone to which it adheres, and also diminishes the effect of the swift current. The strong tail muscle and the low thick crest of the tail enable the tadpole to swim even against a swift current. Tadpoles of Rana margaretae are not equipped to live in such swift water, but are found in rather quiet pools behind large stones in swift mountain streams. Sometimes the tadpoles of Scutiger popei, Aelurophryne glandulata, Megophrys minor, and Rana boulengeri may also be found in such mountain streams. These tadpoles are much more abundant in the smaller streams where the adults as well as eggs and young tadpoles of those species are found. Floods and mere accident account for the carrying down of some of the tadpoles to larger, swifter parts of the stream below.

Among the Amphibia of western China most of the frogs of the family Pelobatidae breed in small mountain streams, especially in their upper reaches. A very few species of Rana also lay their eggs in this type of stream. The frogs of the genus Scutiger afford the best examples of breeding adaptations to this habitat. The adults of various species of Scutiger, Aelurophryne, and Megophrys inhabit running water only in the breeding season, when they repair to the smaller mountain streams. Sex dimorphism in size in these forms is slight, and the males are in fact found to be smaller only in Scutiger schmidti. 
All the males of the species of Scutiger have two patches of fine spines on the chest and nuptial spines on the inner dorsal sides of the first and second fingers. The arms of the males are much stronger than those of the females. Field observation proves that the spines on the chest of the male have nothing to do with maintaining the firm grip of the male, the amplexus being inguinal. The mating occurs in small mountain streams, under stones or among roots, and there is little evident need for difference in size between the sexes. The secondary sex characters correlated with amplexus are nevertheless moderately developed. The frogs of the genus Megophrys also lay their eggs under stones in small mountain streams. The secondary sex characters in this genus are poorly developed, the males being generally a little smaller than the females. The males do not have strongly developed arms, and have only a very moderate gray nuptial pad developed on the inner dorsal side of the first finger, instead of spines, as in Megophrys minor. Rana boulengeri, also characteristically a runningwater form, is an example of very different adaptations in its secondary sex characters. Males of $R$. boulengeri are distinctly larger than the females, and are equipped with strong spines on the throat, the chest, the belly, and the inner dorsal side of the first, the second and sometimes the third fingers. The arm of the male is enormously enlarged, and with the spines this assures a very strong hold on the female. In sex dimorphism another pelobatid frog, Aelurophryne mammata, resembles Rana boulengeri rather than Megophrys.

It is obvious that frogs breeding in the running water of small mountain streams differ ecologically, as a group, from those that breed in swift water. Frogs of running water have much less sex dimorphism in size, and may have little development of nuptial spines. However, when the males are distinctly larger than the females, the other secondary sex characters, especially the nuptial spines and the enlargement of the arm, are very strongly developed.

In the running-water forms the mode of egg-laying among the frogs of the genus Scutiger has been observed only for $S$. schmidti. It may be presumed to be similar in other frogs of this habitat, since the egg-masses of other species of Scutiger are likewise known to be attached to the under side of rocks or roots. This mode of egg-laying is similar to that of Staurois chunganensis.

As far as is known, the color of the egg is white in all of the frogs breeding in running water, except in Rana boulengeri, in which the egg is gray at the animal pole and yellowish white at the vegetal pole. Thus the mode of egglaying, the color of the eggs, their attachment, and the amount of jelly are very similar in the running-water and the swift-water species. Rana boulengeri affords a variety of exceptions (see p. 267).

Tadpoles inhabiting running water of mountain streams illustrate two types of adaptation, one for surface feeding and the other for bottom feeding. Tadpoles of Megophrys minor swim at the surface of water when feeding, in quieter places back of large stones, with their funnel-like mouth parts expanded at the surface film. In such clear waters even the surface plankton must have 
an impoverished micro-fauna and micro-flora. The bottom-feeding forms have very strong mandibles and labial teeth, as in the tadpoles of different species of Scutiger, Aelurophryne, Megophrys pelodytoides, and Rana boulengeri. Both surface and bottom feeders are good swimmers in the running water of their habitat. Their bodies are elongated and cylindrical, with strong, long tails provided with low thick crests.

It is difficult to find a clear demarcation between "running water" and "slowrunning water." In slow-running water, distinguished as a breeding habitat of frogs, the flow of the water is so much reduced that it does not carry away the unattached eggs laid there by certain species of frogs. As set forth above, all the eggs laid in running water are of the attached type, and no free-floating or submerged eggs are to be found. It is difficult to find a species that lays its eggs in slow-running water and not in completely quiet water, because there is no effective difference between these two habitats. Comparatively speaking, however, there are certain species that generally lay their eggs more commonly in slow-running water than in quiet pools or ponds. The West Chinese mountain toad, Bufo bufo wrighti, is often found laying its egg-strings in slow-running water in mountain streams, and this is true also for some Chinese wood frogs, such as Rana chaochiaoensis. In the frogs with this breeding habit, the female is a little larger than the male and other secondary sex characters associated with breeding habits are only moderately developed and never as strongly so as in the running-water frogs, which include striking forms like Rana boulengeri and Aelurophryne mammata.

The eggs are laid in masses in Rana chaochiaoensis and in strings in Bufo bufo wrighti but always with an amount of jelly much greater in quantity than the jelly of the eggs of the swift-water and running-water frogs. The eggs of Rana boulengeri are exceptional (see p. 267). The eggs of the frogs of slowrunning water are strongly pigmented and black or dark gray in color; the size of these eggs is generally less than that of the eggs found in the cascade and running-water habitats.

Tadpoles of Bufo bufo wrighti are of the slow-running-water type, differing from the tadpoles of the very nearly allied species, $B$. $b$. gargarizans, in having a rather depressed body and a stronger tail with low thick tail crest. They are only rarely found in quiet water. There are two small depressions on the throat, which is flattened in the tadpole of wrighti. This specialization is closely associated with the adaptation of this tadpole, since it can be used to adhere to the substratum in slow-running water. The tadpoles of Chinese wood frogs can adjust themselves to slow-running as well as to quiet water. The form of the body and the shape of the tail are really intermediate between those of the tadpoles of running water and those of the tadpoles of quiet water. Other quiet-water tadpoles may be found in slow-running water when their normal pools are invaded after rains by flood water that drives the tadpoles into the nearest stream. 
Numerous species of frogs and toads lay their eggs in pools, ponds, ditches, or flooded rice fields. In the frogs breeding in this habitat the males are usually smaller than the females, and the other secondary sex characters are moderately developed. However, sex dimorphism in size is not as great as in the swiftwater group. The secondary sex characters correlated with amplexus are less strongly developed than in frogs of the running-water group. The general phenomena connected with breeding adaptations are similar to those found in the slow-running-water group. Males are provided with nuptial asperities, as in Bufo bufo gargarizans, or nuptial pads, as in Rana nigromaculata, and usually the arms of the males are enlarged for amplexus in most species of this group of frogs.

The egg-laying adaptations of the different species of the quiet-water frog vary greatly, but the general principle is the same for all, with adjustments essential for the preservation of the race. Species of Kaloula lay their eggs in temporary pools, usually near old houses or in roadside ditches. The eggs float singly on the surface of the water like drops of oil, and are very easily overlooked. The external layer of jelly has a winglike projection near the animal pole. This functions as a floating apparatus. In this surface situation the eggs get the optimum amount of light (or heat) and oxygen for rapid development, which is of great importance in shallow pools that are easily dried up in a short time. The eggs are small and dark in color, and thus have high capacity for absorption of heat. The early developmental stages - cleavage, blastulation, and gastrulation-are much more rapid than in any other amphibians.

The species of Microhyla seem to form another ecological group adapted to breeding in quiet water. $M$. ornata lays its eggs in rice fields, and more rarely in small ponds or pools. The jelly surrounding the small, light brown eggs forms a film floating on the surface of the water. Without special attention, one usually fails to see the egg-film. The process of development is much more rapid than in other pond frogs or toads. This is presumably because the water bodies, in which the eggs are laid, are not permanent. The pool may dry up, or the farmer may drain the rice field for a season. The process of development, under such hazards, must be rapid in order to perpetuate the species. This condition is similar to that found in Kaloula.

Many species of Rana lay their eggs in the various types of quiet water. $R$. nigromaculata generally goes to ponds to breed, and limnocharis and guentheri lay their eggs mostly in flooded rice fields. The eggs of the various species of Rana are mostly medium in size and dark brown or nearly black at the animal pole, with a large amount of jelly surrounding and connecting the egg envelopes to form the egg-mass. Toads, such as Bufo bufo gargarizans, lay their eggs in strings entangled with aquatic plants in ponds and ditches. The eggs are black and are protected by their jelly strings, within which each egg is enclosed by a thin layer of jelly.

The species of tadpoles inhabiting the quiet water form a heterogeneous group, both in phylogenetic and in morphological features. These tadpoles vary 
greatly as to the form of the body, the type of the mouth parts, and the nature of the tail, being derived from different families of Salientia. The convergent characters that adapt them specifically to the ecological environment of quiet water will be described below.

Arbitrarily, the quiet-water tadpoles could be divided into three categories, the pond group, the pool group, and the flooded rice-field group. But the tadpoles of a single species may be found in all of these habitats. Presence in the several types of quiet water is best illustrated by the tadpoles of Rana nigromaculata; Bombina maxima inhabits ponds and pools in the tadpole stage; and the tadpoles of Kaloula rugifera are found only in pools, as distinguished from the more permanent ponds. The typical tadpole inhabiting quiet water is not exposed to strong currents and does not require a capacity for powerful swimming. These tadpoles have a stout body, moderately developed mouth parts, and a weak tail of characteristic form, provided with a high delicate crest and with a pointed or attenuate and delicate tip. The best examples of this type are the tadpoles of Microhyla ornata, Rana nigromaculata, and Rhacophorus leucomystax. Some of these tadpoles may have their body form approaching the condition suitable for running water, as in the tadpoles of Bufo bufo gargarizans in the lowland, and Rhacophorus bambusicola at higher altitudes. The mouth parts of the quiet-water tadpoles in general are provided with moderately developed mandibles and labial teeth, but never have such strong mouth parts as those of Scutiger or Aelurophryne. The quiet-water tadpoles of Kaloula and Microhyla have no mandibles and no labial teeth in adjustment to their openwater feeding habits.

Most amphibians lay their eggs in water, and this element is necessary for their development, unless they have evolved specialized protection against drying. There are, however, many salamanders and frogs that lay their eggs on the ground, in hollows in the ground, or on vegetation. The eggs of frogs in this ecological group do not develop into normal living tadpoles if they are placed in water, as I have shown by some simple experiments with the eggs of Rhacophorus omeimontis. In western China there are five such species, one of Rana and four of Rhacophorus, that belong to this ecological group.

Rana adenopleura, the famous musical frog of Mount Omei, lays its eggs in small nests excavated in the banks of small pools from six to twelve inches above the water's edge. In this species the males make the nest; two males found in new nests had bleeding snouts when they were collected. The nests are rounded or oval with a smooth inner surface and a comparatively narrow opening. The eggs, which are always laid in the nests, are small and are scattered in a large amount of jelly that is much more watery than the jelly of other amphibians of western China. The function of the enormous amount of jelly for this breeding habit is obvious. If there is no rain to moisten the eggs in the nests, or to wash the newly hatched tadpoles from the nests to the pool, then the jelly, which soon becomes liquefied, is the medium in which development takes place. This type of jelly seems to protect the embryos and young tadpoles while waiting 
for the rain to wash them into the pool nearby. Rana adenopleura is found only in regions where rains are usually frequent, as on Mount Omei, where this frog is abundant. Its breeding season is from June to September, which is the rainy season of this sacred mountain. The breeding adaptations seem to be the chief factors in the distribution of this species. The secondary sex characters (including dimorphism in size) are poorly developed in association with the habit of laying eggs in nests. The longer snout of the male may have something to do with the construction of the nest. This character recalls the sharp spadelike snouts of males of various species of the American Leptodactylus.

The tree frogs of the genus Rhacophorus present further interesting developments of terrestrial breeding habits. Some species, among them bambusicola, lay their eggs in holes under stones or roots of vegetation; some lay on walls of pools (such as those of unused manure pools) or on vegetation in flooded rice fields, as does leucomystax; and others place their eggs on the leaves of low plants, or most strikingly in leaf-nests made in trees overhanging pools or ponds, as does omeimontis.

Rhacophorus bambusicola, a tree frog discovered in the Lolo country of Chaochiaohsien, Sikang, June, 1942, is characterized by short legs. Males are much smaller than females, and have other secondary sex characters poorly developed. The disks are much smaller than in other species of the same genus found in western China. The body is stout for a tree frog. All these characters have something to do with the breeding habits. The eggs are laid in holes near pools or ditches or sometimes just under wood, stones, or even among the roots of plants, wherever a space can be found, the egg jelly being whipped up into foam by the female. Since bambusicola is a ground breeder, it is not necessary for the frogs of this species to have the long legs, the large disks, or the somewhat flattened bodies adapted to the arboreal breeding habit, the extreme of which is illustrated by omeimontis. The eggs of bambusicola are rather small $(2.1 \mathrm{~mm}$.) and white in color; they are buried in a foam mass, the fluid secreted with the eggs being beaten by the legs of the female into foam, a little of this fluid being secreted before the eggs are laid. Eggs are scattered singly or in groups in the foam and each egg is enclosed by a thin capsule. The foam protects the eggs from drying and the liquefaction of the foam on the inside corresponds functionally more or less to a small pool of water. This serves to protect the embryos or newly hatched tadpoles when there is no rain to wash them into the adjacent pond or ditch, where they can metamorphose.

Rhacophorus leucomystax, which has a wide distribution in southeastern Asia, is another interesting tree frog that enters western China. It could be considered as a form intermediate in the evolution of breeding habit between the shortlegged bambusicola, which is a ground breeder, and the arboreal breeder, omeimontis. Males of leucomystax are smaller than females. The average diameter of the disks of males and females is 4.2 per cent of the body length. The male has a nuptial pad developed on the first and second fingers as in bambusicola. The eggs are laid in foam masses, which may be hung on vegetation in flooded 
rice fields, or, commonly, are attached to the walls of vertical-sided pools. If there is no chance to reach such a site for egg-laying, the egg foam may be placed on the ground anywhere near a pool. The eggs are small (1.8-2 mm.) and white in color, scattered singly or in groups inside of the foam. Each egg is enclosed by a capsule firmly connected with the foam substance. At a later stage, a yellowish layer of liquid forms the egg capsule. This is the beginning of liquefaction. The foam is essential for the development of the embryos. It also protects the young tadpoles from drying up when there is no rain. At a certain stage of development the whole foam mass may drop into the water because of liquefaction of the foam by which it is attached; or the young tadpoles may drop into the water through an opening in the foam mass. When the foam drops into the water, it spreads out on the surface as a mass of small bubbles and the tadpoles free themselves from it and swim vigorously.

Arboreal breeding habits are the most extraordinarily interesting phenomena in Amphibia of western China. The beautiful tree frog, Rhacophorus omeimontis, has a bird-like voice and whistles on trees at twilight during the breeding season (April-June) to attract the females. With a flashlight one may see him standing on the small branches of trees just above a pool, and singing without distended throat. Males are much smaller than females, and both have a dorso-ventrally depressed body. The legs are long and have very large disks at the tips of the digits; the average diameter of the disks in this species is $3.2 \mathrm{~mm}$., 5.4 per cent of the body length. Nuptial pads are developed on the inner dorsal sides of the first two fingers of the male. According to my observations, these frogs usually lay their eggs on leaves of trees that hang over a body of water. If there are no trees on the edge of the ponds, the frogs lay their eggs on low vegetation on sloping banks of small stationary bodies of water. The nests exhibit much variation, being formed by a varying number of leaves. The eggs are partly exposed and partly concealed by the leaves. There is no foam mass. The exposed portion of the egg mass is covered by a sticky secretion, by which the leaves of the nest are glued together. The eggs are large $(3.5 \mathrm{~mm}$.) and light green in color, lighter than the leaves of the nest; such a color may offer some protection for the eggs. The eggs are well protected by their three capsules, with two layers of liquid, the first between the egg and the inner capsule, the second between the first and second capsules. The outer layer is a white opaque elastic membrane. This is a porous egg coat that connects egg to egg and attaches the egg mass to the leaves. Although the jelly is not so abundant as in Rhacophorus bambusicola and leucomystax, the eggs of omeimontis are better protected by leaves, by the sticky secretion just inside of the leaves, and by the elastic outer coat of each egg. Furthermore, inside of the outer coat there are two capsules and two layers of liquid (see pl. 9).

Tadpoles of different species of Rhacophorus in western China and of Rana adenopleura are found in pools and ponds on the hillsides, between 1,500 and 11,000 feet above sea level. According to the form of the body and the shape of the tail, the tadpoles of Rhacophorus leucomystax and Rana adenopleura are 
interpreted as typical quiet-water forms. Their bodies are stout, with high delicate tail crests. The tadpoles of other species of Rhacophorus tend toward the running-water type, as they are very much like the tadpoles of wood frogs and toads. However, they are still found mostly in pools and ponds, rarely in ditches.

On the basis of structural adaptations for breeding, Amphibia of western China might be classified into three categories. The cascade forms, Staurois, and the tree frogs, Rhacophorus, constitute the first category, with certain external similarities, especially in breeding adaptations. These adjust them on one hand for cascade life, or on the other for arboreal life. The general body form is somewhat dorso-ventrally depressed in both Staurois and Rhacophorus. It is unquestionably true that the depressed body of Staurois is associated with its life in the crevices of rocks by the sides of the mountain streams, and the depressed body may assist it in getting beneath stones for egg-laying. The flattened body of Rhacophorus omeimontis is evidently associated with arboreal life, but it also bears some relation to the arboreal breeding habits.

The males of Staurois and Rhacophorus are much smaller than the females, in correlation with breeding behavior. A big male on the back of a female must offer much resistance in swift water and in getting beneath stones for egg-laying. It may be even harder for a female Rhacophorus to bear a large male at the breeding site on the tree or on the walls of pools. Furthermore, if the male of a Rhacophorus is larger than the female it is difficult or even impossible for the female to move her legs freely to beat the secretion into foam.

The disks at the tips of the digits are characteristic specializations for Staurois and Rhacophorus. They are an essential adaptation for cascade and arboreal life, but they also aid the female to maintain herself while laying her eggs in swift water and on trees. The disks on the digits of bambusicola are much smaller than those of other species of Rhacophorus, possibly because they are less needed in the egg-laying process in or on the ground. In leucomystax the disks are much larger than in bambusicola but smaller than in omeimontis: these disks come into use in climbing on stone walls or among vegetation. $R$. omeimontis is best adapted to arboreal life, and lays its eggs on leaves of trees. The disks in this species are better developed than those of any other tree frog of western China.

The second category consists of the frogs that breed in running water. According to the relative size of the male and female, this category may be subdivided into two groups, in one of which the males are slightly smaller than the females, while in the other the males are distinctly larger. If the male is somewhat smaller than the female, the secondary sex characters may be well developed, as in Scutiger schmidti, or may be poorly developed, as in Megophrys minor. The more interesting condition is found in the second group, in which the males are larger than females, as is the case with Rana boulengeri and Aelurophryne mammata. Secondary sex characters correlated with breeding adaptations are extraordinarily developed, as may be seen in the greatly enlarged arm, the strong 
spines on the fingers, the spines over the entire belly of Rana boulengeri, and the two patches of spines on the chest of Aelurophryne mammata. It is not easy to explain these relations, or to see what adaptive advantage the remarkable sex differences in the above two species of Amphibia of western China may have.

It is often difficult to distinguish slow-running water from quiet water. Moreover, a quiet body of water after a heavy rain may become slow-running water. In any case, the frogs of the quiet-water category have stout bodies and moderate secondary sex characters, quiet water affording suitable sites for them to breed and lay their eggs.

Eggs of frogs in all the categories vary greatly in color, size, and amount of jelly. It is hard to draw any conclusion about the significance of such variation. It is true, however, that eggs attached to the under sides of stones, protected by foam or covered by leaves of vegetation, are white in color. The exposed floating eggs and the eggs in unconcealed submerged egg masses are more or less pigmented; furthermore, eggs of these types laid in early spring are noticeably pigmented and even black; and those eggs laid later in the season are usually much lighter in color.

There is no positive correlation between the size of the eggs and the size of the adults. It is true that the size of the egg has a positive correlation with the nature of the body of water in which the eggs are laid. The narrow-mouthed toads lay their small eggs in temporary pools. The developmental process of these eggs is so extraordinarily rapid that they can complete their metamorphosis before the pools dry up. This is an ecological adaptation.

The jelly of the eggs of Amphibia provides both biological and physical protection. From the study of Amphibia of western China, it is evident that jelly is much more important for protection against the physical environment than for protection against biotic elements of the environment as a whole. The eggs of the cascade and running-water forms have very little jelly, as they are not in danger of evaporation and their smaller amount of jelly may be thought to offer an advantage in lessened resistance to current. Although the eggs of Rana boulengeri are an attached running-water type, each egg appears to hang down individually. These eggs are protected by a large amount of jelly. This is easily explained, as part of the jelly is used for attachment and for the jelly cables that suspend the eggs. Again, as these eggs are laid in small mountain streams, usually just after rains, the water level may go down quickly and leave the eggs exposed and in need of greater protection from the jelly. The large amount of jelly in the eggs of the nest-breeding frog, Rana adenopleura, is more obviously and definitely for the physical protection of the eggs, as there is no water in the nests. In the foam masses of tree frogs the liquefying foam takes on the function of the water and jelly of the aquatic breeding forms. The foam protects the eggs, which are only enclosed by a thin capsule. The jelly may be specialized for the formation of a floating apparatus composed of cap-like projections, as in Kaloula. 
The most remarkable specialization in the tadpoles of western Chinese Amphibia is the large ventral adhesive suction disk of the cascade species of Staurois. It is used as a vacuum adhesive apparatus to attach to and move back and forth on stones under cascades. The tadpoles inhabiting running water always have a cylindrical body, a strong tail, and a low and thick tail crest. All these structures are necessary for effective swimming. On the other hand, tadpoles found in quiet water mostly have a stout body and a weak tail, with a high and delicate crest drawn out to a narrow pointed tip. Feeding adaptations afford other interesting problems in the natural history of amphibian tadpoles. The surfacefeeding form has its lips expanded into a funnel to collect its plankton food; the bottom-feeding forms naturally require strong mouth parts in order to scrape off the food stuffs from the surfaces of stones, or to eat other organisms. The mouth parts of quiet-water tadpoles are moderately developed and without strong specialization. 


\section{LIST OF SPECIES}

\section{CAUDATA}

\section{Megalobatrachus davidianus ${ }^{1}$ Blanchard}

Sieboldia davidiana Blanchard, 1871, Compt. Rend. Acad. Sci., Paris, 73: 79-Thebet oriental; idem, 1871, Ann. Mag. Nat. Hist., (4), 8: 212; David, 1871, Nouv. Arch. Mus. Hist. Nat. Paris, 7, Bull.: 95-Tchongpa [Chungpa], Szechwan; Gray, 1873, Ann. Mag. Nat. Hist., (4), 12: 188.

Sieboldia davidi David, 1875, Jour. Trois. Voy. Chinois, 1: 326; idem, 2: 20-22, 216Ouang-Kia-Ouan [Huang-kia-wan], southwestern Shensi.

Hoplobatrachus davidi Möllendorff, 1877, Jour. N. China Asiat. Soc., 11: 105.

Megalobatrachus maximus Boulenger, 1882, Cat. Batr. Grad., Brit. Mus., p. 80 (part, China; not of Schlegel 1837); Boettger, 1885, Offenb. Ver. Naturk., 24-25: 166.

Megalobatrachus japonicus Barbour, 1912, Mem. Mus. Comp. Zool., 40: 125; Stejneger, 1925, Proc. U. S. Nat. Mus., 66, Art. 25: 3.

Megalobatrachus sp. Despax, 1913, Bull. Soc. Zool. France, 38: 134.

Cryptobatrachus maximus Stanley, 1915, Jour. N. China Asiat. Soc., $44: 14$.

Megalobatrachus sligoi Boulenger, 1924, Proc. Zool. Soc. London, 1924 : 173-Hongkong.

Megalobatrachus japonicus davidi Chang, 1935, Bull. Soc. Zool. France, 60 : 347; Chang, 1936, Contr. Etude Morph. Biol. Syst. Amph. Urodèles Chine, p. 82.

Megalobatrachus japonicus davidianus Pope and Boring, 1940, Peking Nat. Hist. Bull., 15, pt. 1: 18; Freytag, 1943, Wochenschr. Aquar.-Terrarienk., 4: 88, figs.

History of species.-Megalobatrachus davidianus was regarded as a lizard in the books of the pupils of Confucius. In these books, "salamander," "lizard," "skink" and "gekko" are regarded as four names for the same kind of animal, and applicable reciprocally to one another. One can also find there the word "Nei-yu," the Chinese name still used to designate this giant salamander. It is described as follows: "In the streams of Ille-tzu, Shansi Province, there are found numerous Nei-yu; their form is similar to that of a serpent; the largest one is called Sha-yu." This passage is repeated in Shan-hai-ching ("Documents of the sea and mountains"), which was written by an anonymous author about 600 B.c. About 100 B.c., Tze Ma-chien, the most celebrated author of the Han Dynasty, remarked that the giant salamander also existed in the province of Shensi, where it was called Jen-yu ("man-fish" or "a fish like a man"). Koo Po (A.D. 300) illustrated the salamander in Er-ya, and described it in the follow-

${ }^{1}$ For further references, see Chang, 1936, p. 82. Throughout the paper, synonymies are in abbreviated form, giving only the essential references. 
ing words: "Nei-yu shows nearly the form of the catfish with four feet. The anterior feet resemble those of the monkey, the posterior ones those of the dog. It emits cries similar to those of a small infant; the ones a size of 8-9 feet are called Sha-yu."

About A.D. 840 Tau-haun-tsin, a naturalist, noted the presence of this salamander in the provinces of Hunan, Hupei, and Anhwei. Five hundred years later, Yan-fu noted it from Kwangtung Province in his Documents on rare objects, from which Li-fang and his collaborators cited the following passage in compiling their encyclopedia of the Sung Dynasty, "Tai-ping-yu-lan: Nei-yu has four feet, the form of a fish, walks slowly by means of its feet, approaches the catfish in size, lives and grows in the mountain streams." About A.D. 1120 Koen-tzeun-pi dissected this creature for the first time. He describes it as follows: "Nei-yu, the giant salamander, has a form similar to that of the otter, four feet, a belly hanging like a heavy sack, without scales like the catfish; its body has a purple color; the stomach contains small fishes, small crabs and small stones. I have opened it and determined the food." But he placed it in the same class as the fishes, and he did not distinguish it from the lizard. Tsai-yuen-dou (1070) described it more correctly. In Mau-tze-mine-fu-chia ("Interpretation of the objects mentioned in Shih-ching") he writes: "The salamander, although it closely resembles the lizard in its general form, may be distinguished from the latter by its habitat. Those that live on land are lizards; those that live in the water are salamanders, belonging to the Pisces." In 1569, Li Chi-chen mentioned the existence of the giant salamander in the provinces of Szechwan, Honan and Shensi.

It was not until 1837 that Europeans suspected that the giant salamander might be found in China. In the Fauna Japonica, Temminck and Schlegel (p. 135) state that de Guignes (1813) mentions the "Nei-yu" in his Chinese Dictionary, page 895 . This supposition was confirmed when Abbé Armand David discovered this animal in western China in 1869.

The exact type locality of Megalobatrachus davidianus has never been definitely recorded. In Emile Blanchard's original description of the species, which, by the way, properly lists the difference in the tuberculation of the head and the length of the digits among the specific characters, the type locality is given only as western China, qualified as follows: "La gigantesque Salamandre vit sur les frontiers du Celeste-Empire dans des eaux claires et limpides qui descendent des montagnes du Khou-khou-noor." It may, however, be possible to ascertain more exactly the place where Abbé David obtained his specimens.

The giant salamander was collected during David's second voyage, which lasted from May, 1868, to June, 1870. His epochal stay at the Catholic missionary station in the then independent principality of Muping occupied most of the year 1869. He left Chengtu on February 22 and arrived at the station, now referred to as Paohsing, six days later. With the exception of a period from August 30 to September 27, when he was obliged to go to Chengtu on account 
of ill health, the rest of the year was spent at Muping, where he made the famous collections that startled the scientific world. By the end of November, 1869, he was back in Chengtu. He has recorded in considerable detail his doings from day to day while at Muping (Nouv. Arch. Mus. Hist. Nat. Paris, 10), but, although he mentions the various novelties as they were collected, nowhere is there any mention of the giant salamander. It may therefore be safely concluded that it was not obtained at Muping, for he would certainly not have failed to record such a startling find. Moreover, we have his positive statement (Nouv. Arch. Mus. Hist. Nat. Paris, 7, Bull.: 97) that it was obtained during his trip to eastern Kokonor (Tsinghai). He says: "Mon excursion du Kokonoor oriental m'a fourni quelques nouveautés. J'en ai rapporté la grande salamandre (laquelle vit aussi au Setchuan, au Tibet et au Yunnan, d'aprés mes informations)." Of this excursion to eastern Kokonor I have been unable to find any detailed account, although he promised to publish one. We only know that after a short rest at Chengtu he left on a trip to the northern mountains on December 26, 1869, arriving at the "eastern corner of Kokonor" on January 7, 1870.

Shortly after his arrival he was taken ill with the cholera, which stopped his further progress. He returned by way of Lunganfu to Chengtu, where he arrived at the end of March, 1870. He must have obtained the giant salamander during this return voyage. During his third voyage to China he again obtained specimens, this time in the province of Shensi. In relating this fact (Jour. Trois. Voy. Chinois, 2, 1875, p. 20) he says that they were "bien les mêmes que le Sieboldia Davidi, de Tchong-pa." This is the first and only reference known to the type locality of $M$. davidianus. On the road travelled by David from Lunganfu, halfway between that city and Chengtu, the maps show a district city, Chungpa, on the river known as Fowho, and there can be little doubt that this is David's Tchong-pa and the specific type locality of the Chinese giant salamander.

Various authors have concluded that the Chinese and Japanese giant salamanders are identical, while others have considered the Chinese form to be a subspecies of the Japanese Megalobatrachus japonicus. I have studied living specimens of the Chinese form in their natural condition near Yaan, in Sikang Province, and preserved specimens of both Chinese and Japanese giant salamanders in Chicago Natural History Museum and the United States National Museum. The manuscript notes of Stejneger have been available to me, thanks to Dr. Doris M. Cochran, and Mr. Clifford H. Pope has turned over to me his own notes as well. His comparative study indicates that the Chinese and Japanese forms are specifically distinct. The tail of $M$. davidianus is proportionately longer than the tail of $M$. japonicus. But the most distinct character that separates the two species of Asiatic giant salamanders is the nature of the tubercles on the head. The tubercles of $M$. davidianus (fig. 9) are mostly in pairs, and are much smaller and fewer than those of $M$. japonicus (fig. 10). The tubercles on the throat differ even more and are characteristic for each species. In $M$. davidianus, the very small paired tubercles are arranged in rows parallel with 
the lower jaw; in $M$. japonicus they are mostly single and large and irregularly scattered. The central position of the throat is free from tubercles in both species. Although Chang (1935) mentioned these differences, he intended to keep the Chinese form as a subspecies Megalobatrachus japonicus davidi.

All the Japanese specimens have the top of the head densely tuberculated, especially around the eyes; only a narrow space down the middle of the interorbital region is smooth. Even in the youngest specimen (No. 6163), in spite of its soft condition, the tubercles are quite perceptible. In the largest Chinese specimen (No. 69456) the whole median part is smooth, as is also a considerable space around the eyes; Nos. 52409 and 16801 from Yaan are smaller, but the tubercles are similar. In No. 69347, which is only slightly smaller than the largest, the whole top of the head in front of the eyes is perfectly smooth and there are only a few scattered tubercles on the sides of the postorbital region. ${ }^{1}$ Finally, in No. 65454, also from Yaan, a somewhat younger individual than the smallest Japanese specimen, but in an excellent state of preservation, the skin of the head is absolutely smooth, without trace of tubercles. The most conspicuous differences between the two forms are well shown in figures 9 and 10.

Mr. E. G. Boulenger (Proc. Zool. Soc. Lond., 1924, pt. 1, p. 173) has described a living specimen of uncertain type locality, probably Chinese and possibly from the mountain regions of northern Kwangtung or Kwansi, as Megalobatrachus sligoi. It has the characters that distinguish $M$. davidianus from $M$. japonicus and is evidently related to the former, not to the latter. Boulenger differentiates $M$. sligoi from maximus (under which he includes both japonicus and davidianus) by its longer, flatter, and smoother head, and by the supposed lesser distance between eye and labial border.

Neither the length of the head (which is difficult to define, and which was not defined by Boulenger) nor the relative distance of the eye from the labial border are valid characters. Boulenger's type specimen, however, agrees in every essential, especially in the nature of the tubercles, with specimens from the upper Yangtze Valley. I regard the Hongkong locality as certainly representing a transported specimen. This animal is eaten, particularly by the Cantonese, and is known to be transported for this purpose.

Stejneger's manuscript notes show that he had reversed his decision of 1925 and reached the conclusion that the two giant salamanders are distinct species. He wished to retain $M$. sligoi as possibly representing a third form with a more eastern range in China than that of davidianus. Pope and Boring, following Chang, have placed sligoi definitely in the synonymy of davidianus. They have used the trinomial forms $M . j$. davidianus and $M . j$. japonicus, because the two forms can be regarded as geographically representative. There is of course no possibility of intergradation between forms separated by more than a thousand

${ }^{1}$ In No. 15098, from Yaan, there are only a few large paired tubercles on the posterodorsal side of the head, a few very small ones on the snout, and a large smooth area on top of the head. 

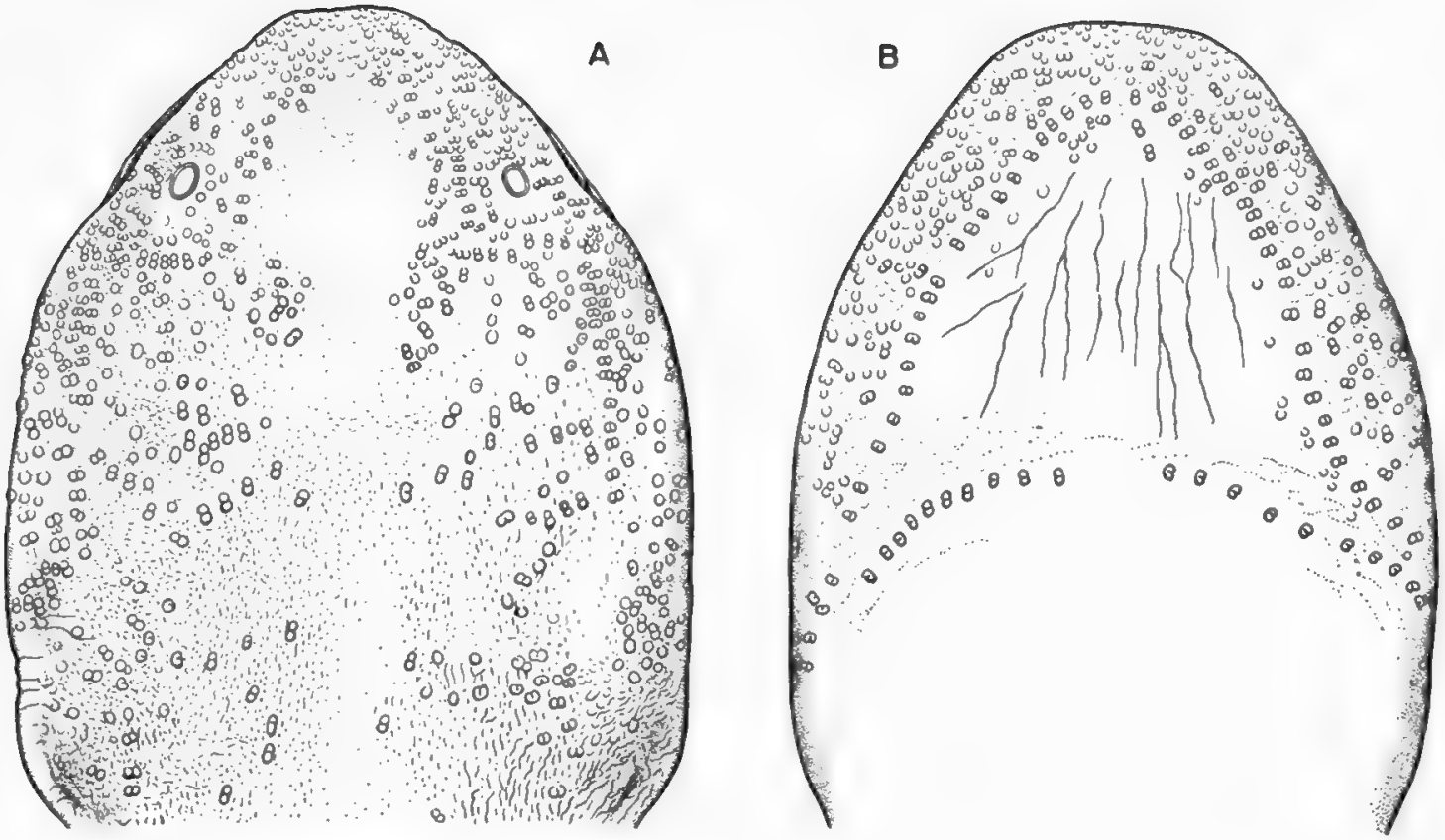

FIG. 9. Megalobatrachus davidianus ( $\times 3 / 4)$ view of head.

A. Dorsal view of head. B. Ventral
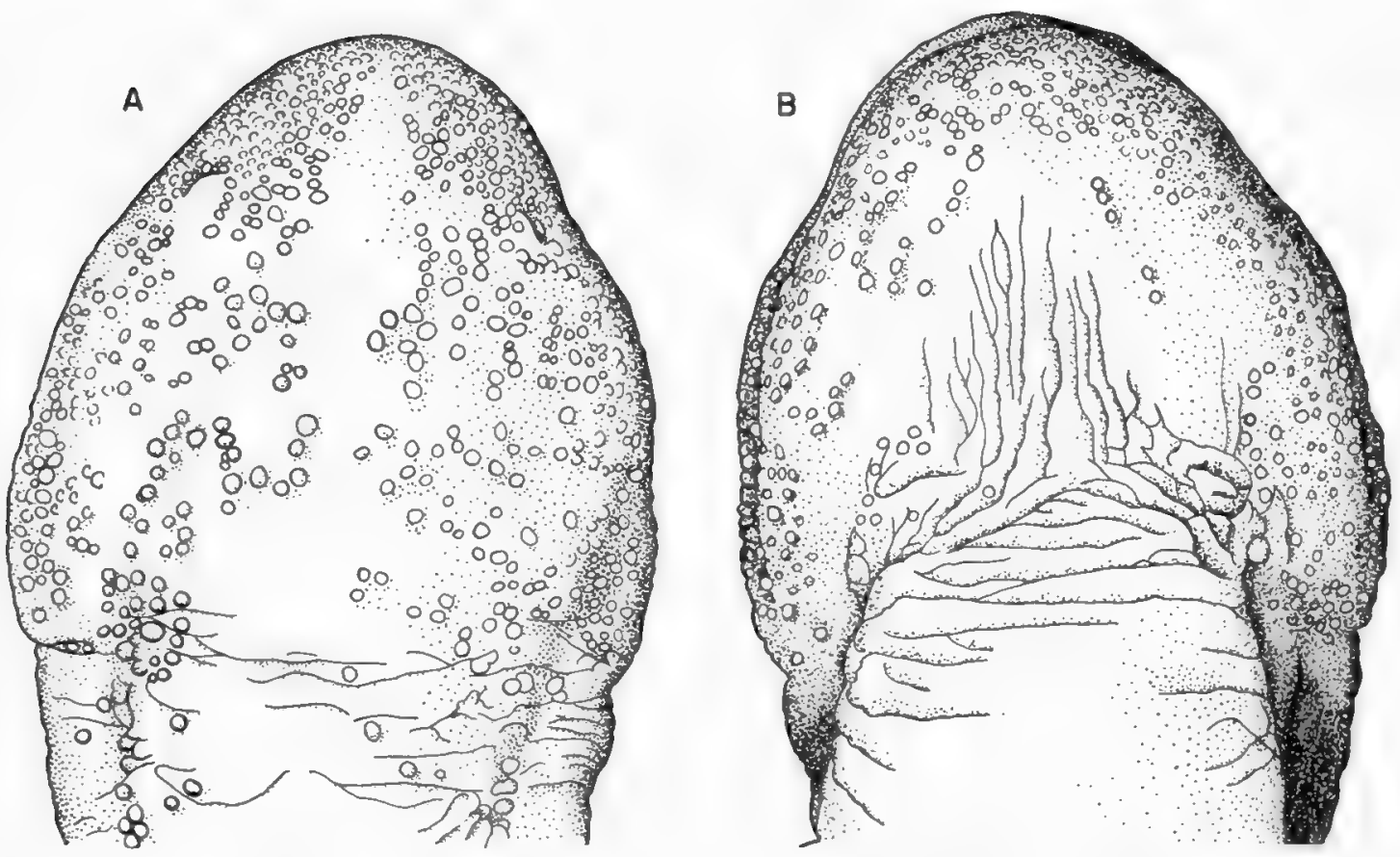

Fig. 10. Megalobatrachus japonicus $\left(x^{3} / 4\right)$. A. Dorsal view of head. B. Ventral view of head. Drawn by Margaret Bradbury. 
miles. It seems preferable to me to recognize their long separation in both time and space by referring the two forms to distinct species.

Original description.- "Among the objects collected by David after his departure from eastern Tibet we had the skin of the great batrachian. It was important to compare the salamander from China with that from Japan and to ascertain whether the two animals were the same species or different species. Comparison leaves no doubt: The salamander reported by David, very close to the salamander discovered by Siebold, is distinguished by several very apparent characters. It has, on the head and anterior part of the body, tubercles less confluent and regularly arranged so as to form lines and very definite patterns. In this way, the eye is as if enclosed by a double row of tubercles which, on the internal side, become angular like a widely open $\mathrm{V}$. In the Japanese species the tubercles present, on the contrary, only a confused arrangement. The Chinese species also appears to us to have the digits and the four limbs a little longer, and we believe that the general color of the body is more black, but the imperfect state of preservation of our single specimen prevents us from insisting on several details. We give to the great salamander of western China the name of Sieboldia Davidiana, which will recall once again the memory of the admirable explorer of China, Mongolia, and Tibet. The gigantic salamander lives on the frontiers of the Celestial Empire in the clear and limpid waters that descend from the mountains of Khou-Kou-Noor. It appears that it reaches an enormous size; David reports that he took specimens of which the weight is 25 to 30 kilograms. One understands that such animals are a valuable food resource for the inhabitants of the country."

Description.--A specimen collected at Fuhsienkwan, Yaan, Sikang, by Floyd Tangier Smith, Chicago Natural History Museum No. 16801, serves well for redescription.

Form very robust; head strongly depressed, snout obtusely truncate; nostrils small, rounded, close to the edge of the upper lip and at the corners of the truncated snout, the internasal space less than half of the interorbital space; eye small, rounded, dorso-lateral in position, and without eyelid; top of head from interorbital region to snout more or less flat, with a rounded temporal protuberance above and behind each eye; angles of the mouth about at the level of the middle of the temporal protuberance; vomerine teeth in an arched series starting between the choanae, parallel to the maxillary and premaxillary series; a thin lower labial fold starting about midway between nostril and eye to the angle of the mouth.

Trunk less depressed than head, with about fifteen costal grooves (in most cases not very distinct), a strong vertebral groove, and strong lateral dermal folds.

Foreleg short, dorso-ventrally flattened, with dermal fold at the posterior side, fingers four, 3-2-4-1 in order of length, the outer one flattened and widened with a dermal fold continuous with the dermal fold of the arm, the other three 
Megalobatrachus davidianus: Measurements

\begin{tabular}{|c|c|c|c|c|}
\hline $\begin{array}{l}\text { U.S.N.M. } \\
\text { No. } 69456\end{array}$ & $\begin{array}{l}\text { U.S.N.M. } \\
\text { No. } 52409\end{array}$ & $\begin{array}{l}\text { C.N.H.M. } \\
\text { No. } 15098\end{array}$ & $\begin{array}{l}\text { C.N.H.M. } \\
\text { No. } 16801\end{array}$ & $\begin{array}{l}\text { U.S.N.M. } \\
\text { No. } 65454\end{array}$ \\
\hline Total length..............1056 & 725 & 695 & 660 & 240 \\
\hline Body length............ 621 & 436 & 385 & 415 & 150 \\
\hline $\begin{array}{l}\text { Head width at angle of jaw... } 115 \\
\text { Ratio to body length }(\%) \ldots . .10 .8\end{array}$ & $\begin{array}{l}95 \\
10.8\end{array}$ & $\begin{array}{l}96 \\
13.8\end{array}$ & $\begin{array}{l}84 \\
18.7\end{array}$ & $\begin{array}{l}30 \\
12.5\end{array}$ \\
\hline $\begin{array}{l}\text { Internasal space } \\
\text { Ratio to head widh }(\%) \ldots . . .\end{array}$ & $\begin{array}{l}20 \\
21.0\end{array}$ & $\begin{array}{l}18 \\
18.7\end{array}$ & $\begin{array}{l}19 \\
22.6\end{array}$ & $\begin{array}{r}7.5 \\
25.0\end{array}$ \\
\hline $\begin{array}{l}\text { Nostril to edge of lip } \\
\text { Ratio to head width }(\%) . . . .\end{array}$ & $\begin{array}{l}4.5 \\
4.8\end{array}$ & $\begin{array}{l}5 \\
5.2\end{array}$ & $\begin{array}{l}4.5 \\
5.3\end{array}$ & $\begin{array}{l}2.5 \\
8.3\end{array}$ \\
\hline $\begin{array}{l}\text { Interorbital space } \ldots \ldots \ldots . . . \\
\text { Ratio to head width }(\%) \ldots . .66\end{array}$ & $\begin{array}{l}51 \\
52.6\end{array}$ & $\begin{array}{l}46 \\
47.5\end{array}$ & $\begin{array}{l}44 \\
52.3\end{array}$ & $\begin{array}{l}16 \\
53.3\end{array}$ \\
\hline $\begin{array}{l}\text { Eye to edge of lip.......... } \\
\text { Ratio to head width }(\%) \ldots \ldots \\
15.6\end{array}$ & $\begin{array}{l}10.5 \\
11.0\end{array}$ & $\begin{array}{l}13 \\
13.5\end{array}$ & $\begin{array}{l}10 \\
11.9\end{array}$ & $\begin{array}{c}5 \\
16.6\end{array}$ \\
\hline $\begin{array}{l}\text { Tip of snout to eye } \\
\text { Ratio to head width }(\%) \ldots \ldots\end{array}$ & $\begin{array}{l}38 \\
40.0\end{array}$ & $\begin{array}{l}37 \\
38.5\end{array}$ & $\begin{array}{l}35 \\
41.6\end{array}$ & $\begin{array}{l}13 \\
43.3\end{array}$ \\
\hline $\begin{array}{l}\text { Length of foreleg. . . } \% \ldots . . .102 \\
\text { Ratio to body length }(\%) \ldots .16 .4\end{array}$ & $\begin{array}{l}74 \\
17.0\end{array}$ & $\begin{array}{l}75 \\
19.4\end{array}$ & $\begin{array}{l}64 \\
15.4\end{array}$ & $\begin{array}{l}29 \\
19.3\end{array}$ \\
\hline $\begin{array}{l}\text { Length of longest finger....... } 31 \\
\text { Ratio to body length }(\%) \ldots . .4\end{array}$ & 22 & $\frac{21}{5.4}$ & $\begin{array}{l}15 \\
3.6\end{array}$ & $\begin{array}{l}8 \\
5.3\end{array}$ \\
\hline $\begin{array}{l}\text { Length of hind leg. . }(\% \ldots . .140 \\
\text { Ratio to body length }(\%) \ldots .22 .5\end{array}$ & $\begin{array}{l}93 \\
21.3\end{array}$ & $\begin{array}{l}88 \\
22.8\end{array}$ & $\begin{array}{l}84 \\
20.2\end{array}$ & $\begin{array}{l}33 \\
22.2\end{array}$ \\
\hline $\begin{array}{l}\text { Length of longest toe ......... } \\
\text { Ratio to body length }(\%) \ldots . .5 \\
\end{array}$ & $\begin{array}{l}29 \\
6.6\end{array}$ & 21 & 21 & $\begin{array}{l}8 \\
5.3\end{array}$ \\
\hline $\begin{array}{l}\text { Length from axilla to groin. . . } 300 \\
\text { Ratio to body length }(\%) \ldots 38.0\end{array}$ & $\begin{array}{r}205 \\
47.1\end{array}$ & $\begin{array}{r}235 \\
60.0\end{array}$ & $\begin{array}{r}230 \\
55.4\end{array}$ & $\begin{array}{l}73 \\
48.6\end{array}$ \\
\hline $\begin{array}{l}\text { Length of tail ............. } 435 \\
\text { Ratio to body length }(\%) \ldots . \\
70.4\end{array}$ & $\begin{array}{r}290 \\
66.6\end{array}$ & $\begin{array}{l}310 \\
80.0\end{array}$ & $\begin{array}{r}245 \\
59.2\end{array}$ & $\begin{array}{l}90 \\
60.0\end{array}$ \\
\hline
\end{tabular}

fingers less flattened and with rounded tips; no webs between fingers; tips of fingers light brown, cornified; and a large rounded cornified pad at the bases of the first and second fingers.

Hind leg short and flattened, with a strong dermal fold at the back and very loose skin folded on the ventral side except for the distal part of the leg; toes flattened with rudimentary webs, 3-4-2-5-1 in order of length, the outer toe with the strongest dermal fold continuous with the dermal fold of the leg; the second and third toes fringed on their outer edges, the fourth toe more strongly fringed; fringes developed on the inner sides of the two outer toes; tips of toes rounded, with light brown cornified epidermis; a round, brown cornified pad at the base of the first and the second toes.

Tail short, 59 per cent of the body length, compressed, nearly rounded at the base and thin on last one-fourth; dorsal tail fin extending to the trunk, the first half thick with a dull edge and the distal half thin and sharp-edged; vent slit-like, just posterior to the base of the leg.

Skin rough and porous, with numerous wrinkles, folds, and tubercles. The largest and most prominent tubercles with characteristic arrangement in the 


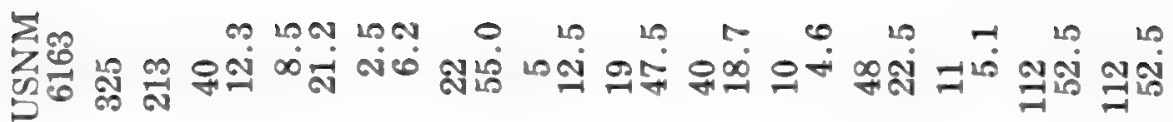

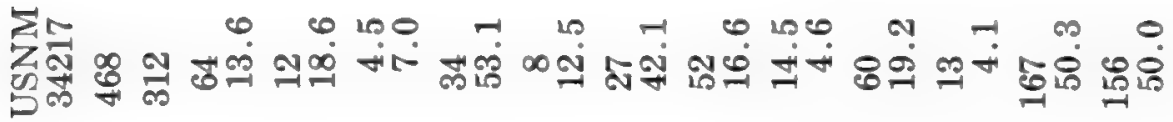

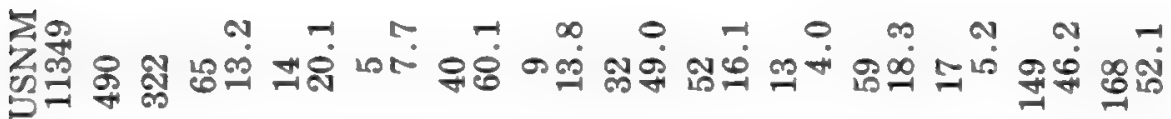

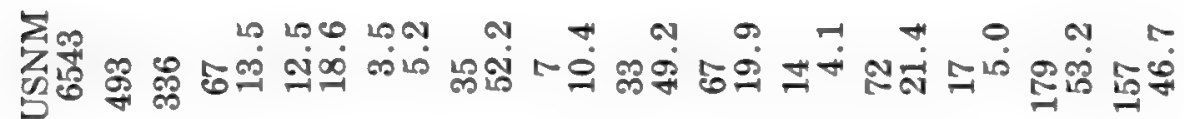

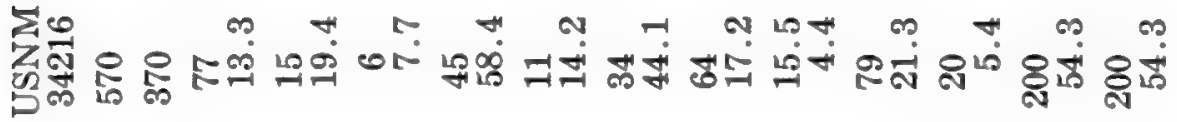

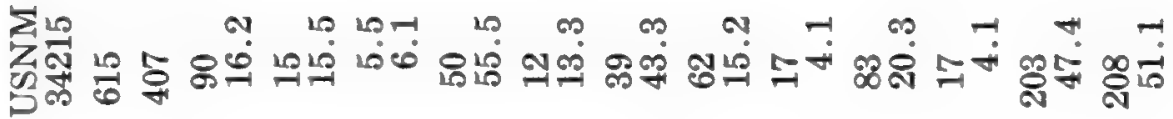

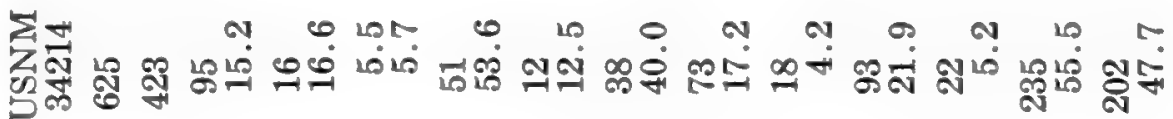

商量

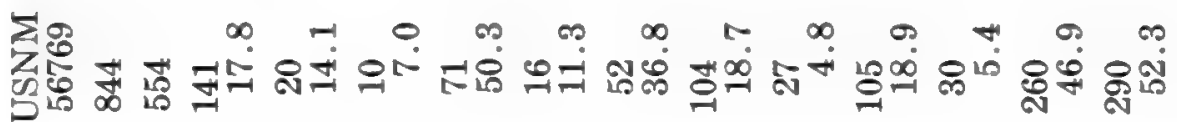

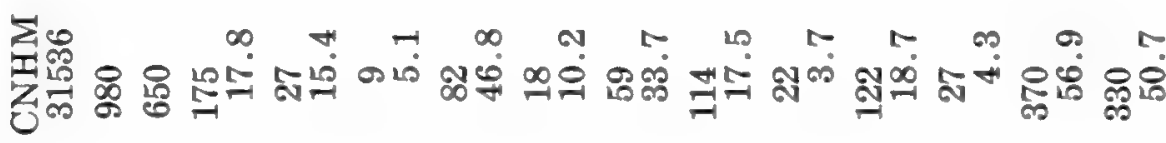

要密

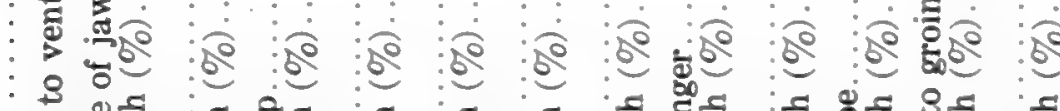

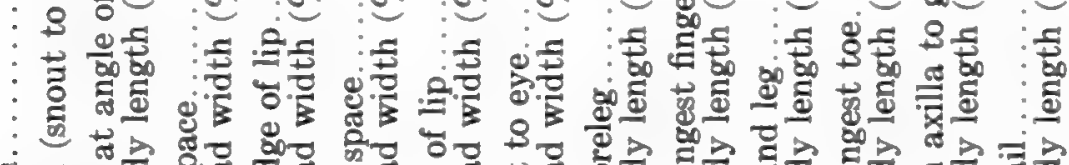

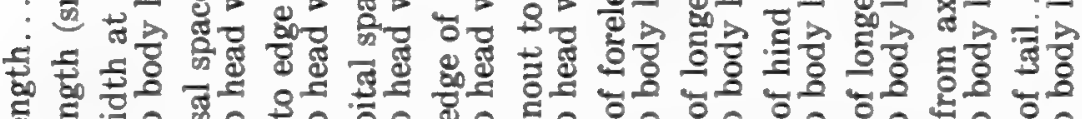

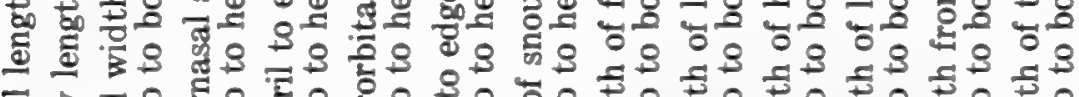

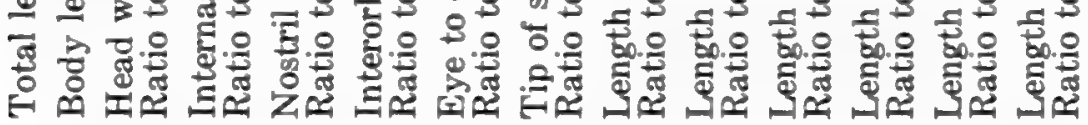


head; large tubercles scattered mostly in pairs on the postero-dorsal side of the head, with a central median long smooth area from the top of the snout to the neck region; smaller tubercles arranged more or less distinctly in rows and in pairs on the dorso-lateral sides of the head, the smallest tubercles near the margin of the upper jaw. Throat provided with even smaller tubercles, arranged in regular pairs and in rows parallel to the lower jaw, and a very regular row of small paired tubercles near the edge of the lower jaw from one corner of the mouth to the other; the central large portion of the throat free from tubercles. Paired tubercles scattered on the body, especially along the lateral dermal fold, but not on the limbs and the belly; a few paired tubercles scattered on the sides of the tail, with a row of paired tubercles in the lateral groove of the tail. The prominent lateral dermal folds originate at the side of and below the temporal protuberances, continuous with the lateral parts of the upper jaw, and extend caudally, ending on the postero-dorsal sides of the hind legs.

Color (in alcohol) Saccardo Umber, irregularly blotched and marbled with dusky spots, limbs similarly spotted, tips of digits light brown.

\section{Hynobius shihi sp. nov.}

Type.-No. 49384 Chicago Natural History Museum, from Chihsinling, Tachangsze, eastern Szechwan, China. Adult female, collected July, 1938, by Pei-nan Shih.

Diagnosis.-A distinct Hynobius with vomerine teeth in two arched series convex antero-laterally and not meeting; black cornified claw-like digital tips with sharp edges curved downward; tail with thin dorsal and ventral tail fins, thin and very pointed at tip; light brown cornified epidermis on palms and soles. Apparently reaches a large size before transforming (fig. 11). Geographically nearest Hynobius chinensis, from which it is sharply distinguished by the characters above.

Description of type.-Body rather stout, somewhat depressed, with ten costal grooves. Head length 27.5 per cent of the length of the body from snout to vent, its width 19 per cent of the body length, and its height 10 per cent of the body length; snout very much depressed and somewhat squarish, with nostrils near the antero-lateral corners; internasal space greater than the length of the eye and about twice as wide as the interorbital space; angle of the mouth just back of the posterior corner of the eye; eyes dorso-lateral in position; sides of jaws flattened out laterally, with poorly developed dorsal and ventral labial folds; skin on the throat very thin and colorless with many longitudinal folds, gular fold distinguishable; small black gill stumps forming a knob covered with skin just back of the sides of the head. Limbs well developed, the digits overlapping when the arms and legs are appressed, fingers 3-2-4-1 and toes 3-4-2-5-1 in order of length; palms and soles covered with light brown cornified epidermis; digital tips covered with black cornified claw-like epidermal structures with sharp edges curved ventrally, fingers and toes flattened, with thick lateral fringes. Tail 
shorter than the body, posterior half laterally flattened and distally with very thin dorsal and ventral fins, and with a very thin pointed tip. Vent a longitudinal slit with swollen lips, much pigmented at the antero-lateral margin. Vomerine teeth in two arched series convex forward and outward, eight teeth in the left series and seven teeth in the right, beginning just inside the choanae, curving forward and then toward the mid-line, but not meeting. Premaxillary teeth and the teeth at the anterior region of the maxillae much
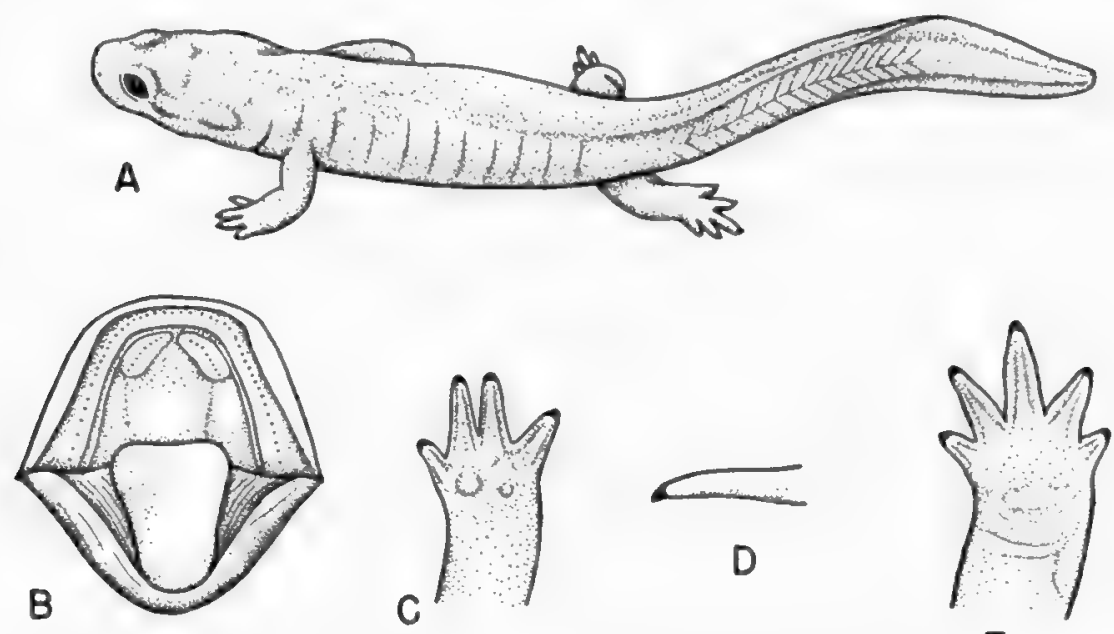

E

FIG. 11. Hynobius shihi. A. Adult $(\times 1)$. B. Oral cavity $(\times 3)$. C. Ventral view of hand $(\times 4)$. D. Finger, showing cornified tip. E. Ventral view of foot $(\times 4)$.

larger than the post-maxillary teeth. Color on the back gray, densely and unevenly stippled with dark brown, belly lighter, throat colorless.

Paratypes.-Three males, two females, and three larvae (Liu coll.) were collected at the same time and place by Mr. Shih. No. 371, a female, resembles the type except in having a tubercle at the base of the fourth finger, a large pad at the base of the first toe, and a small tubercle at the base of the fifth toe; the vomerine teeth are like those of the type except that the number in each series is nine. No. 397, adult female, has light brown cornified claw-like digital tips, seven with the black cornified part lost; two tubercles on the left palm, one at the base of the first and the other at the base of the fourth finger; tubercle at the base of the fifth toe distinct; vomerine tooth series as in type but with teeth 8-10. In No. 382, adult female, the tubercles and cornified condition on the palms and soles are as in No. 371; vomerine tooth series shorter, more widely separated, teeth 6-7. In two adult males collected from the same locality the tubercles and cornification of the palms and digits are as in No. 371 ; in No. 387 the two vomerine tooth series are narrowly separated, teeth 9-9; in No. 383, light brown cornified epidermis covers the palms and soles, all the digital tips are capped by the black claw-like structure of the type, and each palm and sole is provided with two distinct tubercles; vomerine teeth 10-10. 
Larvae.-Three larvae, Nos. 344,377 , and 380 , ready to transform, range in length from 81 to $82 \mathrm{~mm}$. The description of the larva is based upon specimen No. 344. Most of the external characters are similar to those of the adults, except as to size, presence of gills, and condition of eye and mouth. The proportionate length of the tail of the young is much less than in adults, about 78 per cent of the body length, whereas in the adult it is about 88 per cent. The eye of the larva is covered by a transparent membrane connecting with the developed eyelids. The angle of the mouth reaches a point opposite the middle of the eye in the larva and to a line at the posterior corner of the eye in adults. There are three pairs of external gills developed on the sides of the neck. The gill filaments are in a stage of absorption, being black and shrivelled and more or less entangled on their thin low rami. There are four gill slits: the first is the largest, with the antero-median edge of the slit at the level of the angle of the jaw, covered externally by the gular fold; and the last is the smallest, with a slightly developed transparent membrane at its caudal edge. The size of the second and the third gill slits is about two-thirds of the first, and each is protected by a colorless membrane on the latero-ventral side of the second and third gill arches. On the postero-inner margin of the first gill arch there is a row of five gill filaments; the second gill arch has two rows of filaments, five in each row; the third gill arch has two rows, four in each row; and the fourth gill arch has four filaments in a single row on the antero-inner margin.

Discussion.--Hynobius is the most generalized genus of salamanders and is widely distributed in Asia, especially in the northeastern region. The four species in China are Hynobius leachii, in southern Manchuria and Korea; H. keyserlingii, in Outer Mongolia and northern Manchuria; H. sonani in Formosa; and $H$. chinensis in southeastern China, in Hupeh, Chekiang, and Fukien. The type locality of chinensis is Ichang, Hupeh. Mell (1929) states that Pratt, who sent specimens labeled Ichang to the British Museum, collected his material in the mountains south of the Yangtze River near Changyang. The type locality of the new species in eastern Szechwan is not very far from the type locality of chinensis, but the new species does not appear to be directly related to chinensis.

Hynobius shihi can be distinguished from all other species of the genus in China by the characters named in the diagnosis. The claw-like digital tips are very similar to those of Onychodactylus, but shihi differs in having well-developed lungs and a short compressed tail with delicate tail fins and slender tip. The larva of Hynobius shihi has a maximum size of $82 \mathrm{~mm}$., while in $H$. chinensis the maximum size is $62 \mathrm{~mm}$. (Pope, 1931). The larva of chinensis has a very large head, short body, and high tail, while in the larva of the new species the head is not so conspicuously large, the body is long, and the tail is low. There is a black, fine, horny line on the inner margin of the lower jaw in larval chinensis but not in shihi. The general form of the larva of shihi is very much like the larva of Batrachuperus pinchonii or B. karlschmidti.

This new species of Hynobius is an interesting addition to the amphibian fauna of Asia, especially on account of its morphological retardation. Dunn 
(1923) described Hynobius retardatus, in which some specimens have the vomerine tooth series not meeting in the median line, which he regards as a larval condition. In $H$. shihi, all the adults in hand have separated vomerine tooth series. Still more interesting is the fact that the gill stumps are still found in the adults, covered by skin. In order to check sexual maturity, two females were opened and both were found to have matured ova. Besides the matured ova as the check of sexual maturity, the four female specimens have the antero-lateral lips of the vent greatly pigmented and swollen, while the female larvae have slit-like vents without pigmentation. $H$. shihi represents a further change in the direction of neoteny and eventually may prove to be truly neotenic, producing eggs in the larval stage.

Hymobius shihi: Measurements of Type and Paratypes

\begin{tabular}{|c|c|c|c|c|c|c|c|c|}
\hline \multirow[b]{2}{*}{ Measurements } & \multicolumn{2}{|c|}{ No. 49384 (type) } & \multicolumn{2}{|c|}{ No. 371} & \multicolumn{2}{|c|}{ No. 383} & \multicolumn{2}{|c|}{ No. 387} \\
\hline & $\mathrm{mm}$. & $\begin{array}{l}\text { Ratio } \\
\text { to body } \\
\text { length } \\
(\%)\end{array}$ & $\mathbf{m m}$. & $\begin{array}{c}\text { Ratio } \\
\text { to body } \\
\text { length } \\
\text { (\%) }\end{array}$ & mm. & $\begin{array}{l}\text { Ratio } \\
\text { to body } \\
\text { length } \\
(\%)\end{array}$ & $\mathbf{m m}$. & $\begin{array}{l}\text { Ratio } \\
\text { to body } \\
\text { length } \\
\text { (\%) }\end{array}$ \\
\hline$d$ & 69 & & 74 & & 56 & & & \\
\hline & 1 & 27.5 & 2 & 27.0 & 17 & 29.3 & & 29.2 \\
\hline & 1 & 18 & 15 & 20 & 18 & 20 & 13 & 20.0 \\
\hline 150 & 31 & 44. & 38 & 50 & 29 & 50 & 27 & 41.5 \\
\hline & 17.5 & & 18 & & 16 & & 17 & 26.1 \\
\hline & 22 & 31.8 & 22 & 30 & 20 & 34 & 21 & 32.3 \\
\hline & 62 & 89 & 65 & 87 & 52 & & 57 & 87.8 \\
\hline & 7.5 & 10. & 7.5 & 10 & 6.5 & 11 & 7.5 & 11.5 \\
\hline theight & 8.0 & 11.5 & 7.5 & 10.1 & 8.0 & 13.7 & 9.0 & 13.8 \\
\hline
\end{tabular}

\section{Genus BATRACHUPERUS Boulenger}

Batrachuperus Boulenger, 1878, Bull. Soc. Zool. France, 3: 71 (monotype, Salamandrella sinensis Sauvage); Barbour, 1912, Mem. Mus. Comp. Zool., 40: 126.

Batrachyperus Boulenger, 1882, Cat. Batr. Grad., Brit. Mus., p. 37.

\section{KEY FOR IDENTIFICATION OF SPECIES OF BATRACHUPERUS}

I. Well-defined tubercles on palms and soles.

A. Tail longer than body, without brown horny epidermis covering its tip; palms and soles without cornification........................... yenyanensis.

AA. Tail equal to or shorter than body, with brown horny epidermis covering its tip;

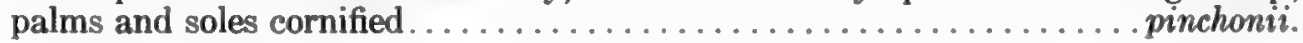

II. No distinct tubercles on palms or soles.

A. No labial fold, skin of the throat pitted cochranae.

AA. Labial fold present, skin of throat not pitted.

B. Coloration uniform, without distinct spots or marbling; size large.

BB. Body finely mottled or with distinct dark spots..............tibetanus.

General Account of Batrachuperus

Several species of Batrachuperus, found in the high mountains of Szechwan, Sikang, Tsinghai, Kweichow, and Kansu, can be demonstrated as a result of 
my collections and studies. The first species of the genus was described as Dermodactylus pinchonii by David in 1871 from specimens collected by himself in 1870 at Muping, Sikang. In 1878 Boulenger studied the same material and named the genus Batrachuperus, using the name sinensis, of Sauvage, who had renamed the same Muping specimens as Salamandrella sinensis in 1877 (Dermodactylus, type scutatum, is a synonym of Hemidactylium). In 1925 Schmidt described Batrachuperus tibetanus from the "Tibetan border of Kansu, at about $33^{\circ}$ N. Lat." Chang (1936) and Pope and Boring (1940) placed B. tibetanus in the synonymy of $B$. pinchonii, which name had been shown by Stejneger (1925) to be earlier than sinensis. In 1945 I published the life history of $B$. pinchonii, as the result of my field studies during eleven collecting trips in the mountains and high plateaus of western China, including Szechwan, Sikang, Kansu, Tsinghai, and Shensi. In this paper I suggested that there are at least two more species besides $B$. pinchonii, one the form collected from Yenyuanhsien, Sikang, and the other the smaller spotted one from Lifanhsien, Szechwan, and from Muping, Sikang.

Since studying my collections with the library facilities of Chicago Natural History Museum, and discussing them with Dunn, Schmidt, Pope, and Netting, and after examining the additional material in Chicago, Washington, New York, Cambridge, and Pittsburgh, I find that there are no less than five species of Batrachuperus. The smaller spotted form from Lifan, Muping, and Mount Omei fits the original description and in fact all of the descriptions of the types of B. pinchonii. Boulenger (1882) figured the type. The larger and uniformly colored form that I had identified as $B$. pinchonii in 1945 differs from pinchonii in lacking (1) conspicuous spots or marblings; (2) light brown horny epidermis covering the palms, soles, digits, and ventral lower parts of the arms and legs; and (3) tubercles on palms and soles. Also, it has shorter legs. This new species I name B. karlschmidti after Mr. Karl P. Schmidt. The long and weak-tailed form taken in Yenyuanhsien is a distinct species, as I suspected, and is here named B. yenyuanensis; a specimen collected from Muping, together with pinchonii and karlschmidti, lacks the labial fold, has much stronger jaws and stronger vomerine teeth, and is named $B$. cochranae after Dr. Doris M. Cochran. $B$. tibetanus is different from the other species, and may be regarded as a further distinct form, known only from the types.

The West China amphibian fauna is complicated by the complexity of the ecological and topographic conditions. It seems at first unbelievable that five species of salamanders of the genus Batrachuperus should occur in the mountains and the plateaus of western China. This wealth of species is similar to that of the amphibian fauna of the Appalachian Mountains of the eastern United States. In the Appalachians one may find two or three species of Desmognathus in the same mountain stream. In our experience it is difficult to distinguish these species, especially from a few preserved specimens. Much more material of Batrachuperus from western China is desirable, and further studies in the field are required to clarify the systematics and ecology of these closely related forms. 
Complicated speciation may be discerned in five groups of amphibians in western China: the aquatic salamanders of the genus Batrachuperus (Hynobiidae); the cascade frogs of the genus Staurois (Ranidae); the high plateau frogs of the genus Aelurophryne (Pelobatidae); the montane Scutiger (Pelobatidae); and the tree frogs of the genus Rhacophorus (Rhacophoridae). Among these five groups it is easier to distinguish the species of the arboreal or more terrestrial types than those of the aquatic forms. Thus, it is difficult to identify the species of Batrachuperus and Staurois, easier to separate the forms of Aelurophryne, and easiest of all to distinguish the species of Scutiger and Rhacophorus.

The center of speciation of Batrachuperus is in the mountains around Muping, Sikang, and around Wenchwan, Weichow, and Lifan of western Szechwan. This is also the center for the species of Staurois. Batrachuperus pinchonii and $B$. karlschmidti are widely distributed and more abundant than other species of the same genus. Batrachuperus cochranae is a more specialized form, with much better developed vomerine and maxillary teeth and also with stronger mandibles. In Batrachuperus cochranae the labial folds are lacking in old adults but are indicated in somewhat younger specimens. This fact clearly indicates that $B$. cochranae is the most specialized form in the genus. The long tail and very thin and high tail fin of $B$. yenyuanensis represent a special direction of evolution, with adaptation to quiet water. The other species of the genus are found in mountain streams. The rich ecological and complex topographic conditions are the chief factors influencing the speciation of such a group of cold-adapted salamanders. Further investigation may reveal still more forms, or may indicate that one or more of the forms here described do not warrant recognition.

The specimens of Batrachuperus in Fan Memorial Institute of Biology, Peiping, collected from Maha, Kweichow, and referred to pinchonii by Pope and Boring, may be supposed to represent still another undescribed species.

\section{Batrachuperus pinchonii David}

Dermodactylus pinchonii David, 1871, Nouv. Arch. Mus. Hist. Nat. Paris, 7: 95Muping.

Salamandrella sinensis Sauvage, 1877, Bull. Soc. Philom. Paris, (7), 1: 117-Muping (same types).

Batrachuperus sinensis Boulenger, 1878, Bull. Soc. Zool. France, 3: 72; Dunn, 1923, Proc. Amer. Acad. Arts Sci., 58: 520.

Salamandrella keyserlingii Bedriaga, 1898, Wiss. Res. Przewalski Central Asien Reisen, Zool., 3, (1): 3 .

Batrachuperus pinchonii Stejneger, 1925, Proc. U. S. Nat. Mus., 66: 5; Chang, 1932, Contr. Biol. Lab. Sci. Soc. China, Zool. Ser., 8: 142, figs. 3-4; Chang, 1936, Contr. Etude Morph. Biol. Syst. Amph. Chine, Paris, p. 77; Pope and Boring, 1940, Peking Nat. Hist. Bull., 15, pt. 1: 17; Liu, 1945, Jour. West China Border Res. Soc., 15, (B): 44, figs. 1-11.

History of species. - Batrachuperus pinchonii was long a poorly defined species because it was known only from the types and only from preserved material. The complicated history of its synonymy has been set forth above. 
David (1871) described the color of Batrachuperus pinchonii as "ranging from mottled brown to gray-yellow mottled with brown, with numerous blackish spots. Belly lighter." Sauvage (1877) stated that the body is gray, slightly pinkish, with brown spots more or less in rows, varying from specimen to specimen. Boulenger (1882a) gave a much better description of the types as follows: "greyish brown above, more or less variegated with blackish; lower surface lighter, mottled with brown; the limbs being adpressed along the body, the median fingers and toes meet." He did not mention the light brown horny epidermis that covers the tips of the fingers and toes and extends on the ventral surfaces of the digits and on the palms and soles to the base of the arm and leg. His figures, however, show this character very clearly. Pope noted this light brown horny epidermis when he examined the cotypes in London. Chang (1936) states that the color of the types in alcohol is generally grayish or olive brown, mottled above with blackish spots and marked with denser specks below; the horny palms and soles are intense brown, deeper at the tips of the digits; and the crest of the terminal quarter of the tail is brown. In 1945, in my paper on the life history of Batrachuperus pinchonii, I suspected the existence of additional species, but had not reached definite conclusions.

Distribution and collection data.-Batrachuperus pinchonii is a widely distributed species in streams of the mountain ranges along the boundary between Szechwan and Sikang. Its northern limits of distribution may be at Sungpan, Szechwan, and its southern limits in the northern Taliangshan at the southwestern corner of Szechwan and the southeastern corner of Sikang. The known vertical distribution is from 5,000 to 13,000 feet. I collected this species from the top of Mount Omei during the summers of 1938, 1940, and 1945; from Lianghokou of Paohsinghsien during August, 1939; and from Tsakunao and Tsingshan of Lifanhsien during the summer of 1941. Thirty-one specimens were collected from Yenmenkwan, near Weichow, Szechwan, at about 5,000 feet altitude, September 16, 1934, by F. T. Smith.

Comparison with allied species.-Batrachuperus pinchonii (pl. 1, figs. 4 and 5; pl. 3, fig. 1) can be distinguished from all the other species of the genus by the light brown epidermis covering its palms and soles and extending to the lower parts of the arms and legs, covering the ventral sides of all digits and even extending to the dorsal sides of the first or second segments of the fingers and toes. The "brown crest" of the tip of the tail mentioned by Chang is a cornified covering like that of the feet; it is present in all of the specimens referred to pinchonii. There are usually two small tubercles on each palm and sole in pinchonii and in yenyuanensis, but such tubercles are not present in the other species of the genus. $B$. pinchonii and $B$. yenyuanensis are easily distinguished: the former has a shorter and stronger tail, longer and stronger limbs, and large dark spots on the back; yenyuanensis has a much weaker and longer tail, more slender and shorter limbs, and a finely marbled dorsal coloration.

Original description.--The original description, in French, is very brief. It may be translated as follows: "Another salamander, of small size, is of special 
interest in that it is not related to any known European genus, but to the American genus Dermodactylus. It is described as follows: Size like that of our common [European] salamander. Color ranging from mottled brown to grayyellow mottled with brown, with numerous blackish spots. Belly lighter. Iris golden gray. Lives in the cold streams of the high forest-covered mountains, and often retires into holes in pine trees called 'Chamou'; whence it is called 'Chamouyre' (fish of the pines). I have dedicated this remarkable amphibian to Monseigneur Pinchon, apostolic vicar of upper Szechwan, under the name Dermodactylus pinchonii, in memory of the service he has rendered to my expedition, and because he gave me the first information about this species."

Chang's amplification of this inadequate description, based on the four cotypes in the Paris Museum, is as follows (translation): "Head depressed, longer than wide. Snout very short, rounded, somewhat elevated. Loreal region oblique; canthus rostralis indistinct. Naris very small, closer to eye than to that of opposite side; internasal space greater than interorbital space, which is somewhat depressed. Eye large, rather prominent, projecting laterally, larger than the distance that separates it from the end of the snout. Eyelids well developed, upper a little less than the interorbital space, joined to the lower by a dermal fold behind the eye. Mouth wide, buccal angle situated below eye; labial fold well developed partly covering lower jaw, which also has a fold but less well developed. Vomerine-palatine teeth in two small transverse rows, situated at the middle and on the line of the choanae, separated from each other by a distance equaling half of the length of each row. Neck rather long, provided with a fold curved anteriorly. Body cylindrical, of medium length, measuring three times length of head, with twelve costal grooves. Tail long, shorter than head and body combined, cylindrical at base and gradually diminishing toward the end, where it is very compressed, especially the last quarter. It shows a straight superior keel that becomes a low crest terminating in a rather obtuse point. Feet well developed, flattened as far as the ends of the digits, overlapping or meeting if placed along the body. Four fingers, in order of length: 2-3-4-1; four toes: 3-2-4-1. A soft, rather indistinct cornified sheath under the carpus and tarsus, extending to beyond the phalanges like a nail. Anus a cruciform slit, the short transverse slit situated at the anterior part of the longitudinal slit; edge in front of anus slightly elevated.

"Skin fairly smooth, with minute pores everywhere except on the throat and under the palms and soles. A vertebral groove; another groove extending from eye to gular fold marks the parotoid; throat provided with very distinct longitudinal folds in front of gular fold.

"Color in alcohol: generally grayish or olive brown, mottled with blackish spots above and marked with denser specks below. Cornified skin intense brown, deeper at tips of fingers. Crest of terminal quarter of tail brown."

Measurements of types (from Chang).--Total lengths of types 143, 137.5, 152.7 , and $137 \mathrm{~mm}$., tail lengths $64,64,71.6$, and $61.4 \mathrm{~mm}$., respectively. 
Variation.-On September 16, 1934, thirty-one specimens were collected by F. T. Smith from Yenmenkwan, near Weichow, Min Valley, Szechwan, at about 5,000 feet altitude. Of the twenty-eight specimens of this Batrachuperus in Chicago Museum, fifteen are adult males and thirteen adult females. Variation is not great. All the specimens have more or less cornification of the digits, palms, and soles, the lower parts of the lower limbs, and the tip of the tail. Thirteen males have two tubercles on each palm or sole and two males have no tubercles on the feet; ten females have the two tubercles on both palm and sole, one specimen has them only on the hands, one has them only on the feet, and they are indistinct in one. The coloration is rather uniform, with light brown background color on the back and dorsal sides of the limbs and on the dorsal and dorso-lateral aspects of the tail; all have irregularly scattered dark spots and markings on the sides of the tail, especially near its tip. Some specimens have the dark spots more crowded, and arranged more or less in dorso-lateral rows.

I collected many specimens of $B$. pinchonii at Mengtunkou, Lifanhsien, 50 miles from Weichow, where the Chicago Museum specimens were obtained. Both series agree closely and also agree with the characters of the types. Two specimens in the Museum of Comparative Zoology (Nos. 17427 and 17428) from Ulongkong, in western Szechwan, are in close agreement with other pinchonii examined.

Twenty specimens, five of each sex from two localities, were measured to examine relative proportions (see table). Sexual dimorphism is shown in this species. Males are smaller than females and the length of the trunk is slightly longer in the female than in the male. The number of costal grooves is normally twelve, but this character is of little systematic importance in Batrachuperus.

The vomerine tooth patches vary in shape, in position and in number of teeth. Among seven specimens from Weichow, chosen at random, one has two oblique patches of vomerine teeth between the choanae with postero-lateral extensions slightly posterior to the choanae, and seven teeth in each patch. These tooth patches are narrowly separated by a space about one-fourth the length of each patch. Another specimen has slightly oblique vomerine tooth patches between the choanae, with six teeth in each patch, the space between the patches being about one-fifth of the length of each patch. Five specimens have two more or less straight tooth patches, with teeth $4-4,4-5,5-4,4-5$, and $5-6$, between the choanae, separated by a space equal to about one-half the length of one of the patches. It is clear that the vomerine teeth are not good taxonomic characters.

In the male, the vent is a transverse crescentic opening, convex anteriorly, with a light-colored papilla in the middle of the anterior lip. A shallow longitudinal groove extends backward from the middle of the transverse opening. The vent of the female is a longitudinal opening, with or without lateral grooves. The vent is more prominently swollen in the female than in the male. Differences in preservation produce variation in the appearance of the vent in the female, but the sexes are nevertheless readily distinguishable. 
Batrachuperus pinchonii: Measurements of Adult

\begin{tabular}{|c|c|c|c|c|}
\hline \multirow[b]{2}{*}{ Measurements } & \multicolumn{2}{|c|}{ Yenmenkwan, Weichow } & \multicolumn{2}{|c|}{ Mengtunkou, Lifan } \\
\hline & Five Males & Five Females & Five Males & Pive Females \\
\hline 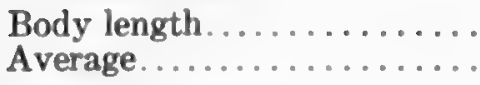 & $\begin{array}{l}65-75 \\
(69.6)\end{array}$ & $\begin{array}{l}71-77 \\
(74.6)\end{array}$ & $\begin{array}{l}60-75 \\
(67.4)\end{array}$ & $\begin{array}{l}66-76 \\
(72.2)\end{array}$ \\
\hline $\begin{array}{l}\text { Head width . ..................... } \\
\text { Average } \\
\text { Ratio to body length }(\%) . .\end{array}$ & $\begin{array}{l}13-16 \\
(15.1) \\
21.6\end{array}$ & $\begin{array}{c}13.5-14.5 \\
(14.1) \\
18.9\end{array}$ & $\begin{array}{c}12.5-13.5 \\
(12.9) \\
19.1\end{array}$ & $\begin{array}{c}12-14 \\
(13) \\
18.0\end{array}$ \\
\hline $\begin{array}{l}\text { Head length .................... } \\
\text { Average } \\
\text { Ratio to body length }(\%)\end{array}$ & $\begin{array}{r}17-19 \\
(17.9) \\
25.7\end{array}$ & $\begin{array}{r}17.5-19 \\
(17.8) \\
23.8\end{array}$ & $\begin{array}{r}16.5-18 \\
(17.3) \\
25.7\end{array}$ & $\begin{array}{c}17-19 \\
(18.4) \\
25.5\end{array}$ \\
\hline 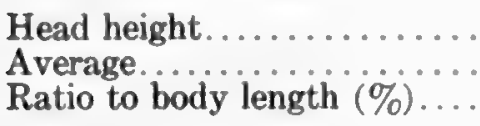 & $\begin{array}{r}9-11 \\
(10.4) \\
14.9\end{array}$ & $\begin{array}{c}8.5-10 \\
(9.1) \\
12.1\end{array}$ & $\begin{array}{r}6.5-9 \\
(7.7) \\
11.4\end{array}$ & $\begin{array}{l}7-8 \\
(7.6) \\
10.5\end{array}$ \\
\hline 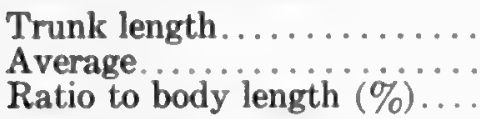 & $\begin{array}{c}30-36 \\
(33.0) \\
47.4\end{array}$ & $\begin{array}{c}33-39 \\
(37.4) \\
50.1\end{array}$ & $\begin{array}{c}29-39 \\
(32.7) \\
48.5\end{array}$ & $\begin{array}{c}33-39 \\
(35.6) \\
49.3\end{array}$ \\
\hline $\begin{array}{l}\text { Length of foreleg............ } \\
\text { Average } \\
\text { Ratio to body length }(\%) \ldots\end{array}$ & $\begin{array}{c}20.5-22 \\
(21.1) \\
30.3\end{array}$ & $\begin{array}{c}19-21 \\
(20.1) \\
26.9\end{array}$ & $\begin{array}{r}17.5-20 \\
(19.1) \\
28.3\end{array}$ & $\begin{array}{l}19-21 \\
(20) \\
27.7\end{array}$ \\
\hline $\begin{array}{l}\text { Length of hind leg............ } \\
\text { Average } \\
\text { Ratio to body length }(\%) . .\end{array}$ & $\begin{array}{c}20.5-23 \\
(21.9) \\
31.4\end{array}$ & $\begin{array}{l}22-25 \\
(23.2) \\
31.0\end{array}$ & $\begin{array}{c}21-24 \\
(22.7) \\
33.7\end{array}$ & $\begin{array}{l}22-25 \\
(24.1) \\
33.4\end{array}$ \\
\hline $\begin{array}{l}\text { Tail length ......................... } \\
\text { Average } \\
\text { Ratio to body length }(\%) . . .\end{array}$ & $\begin{array}{l}66-75 \\
(70.1) \\
100.7\end{array}$ & $\begin{array}{c}59-71 \\
(67.2) \\
90\end{array}$ & $\begin{array}{l}59-68 \\
(64) \\
95.0\end{array}$ & $\begin{array}{l}70-81 \\
(74.8) \\
103.6\end{array}$ \\
\hline 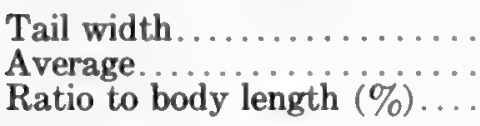 & $\begin{array}{l}9-10 \\
(9.4) \\
13.5\end{array}$ & $\begin{array}{l}7.5-8.5 \\
(7.9) \\
10.6\end{array}$ & $\begin{array}{c}6-7 \\
(6.05) \\
9\end{array}$ & $\begin{array}{l}7-8 \\
(7.7) \\
10.7\end{array}$ \\
\hline 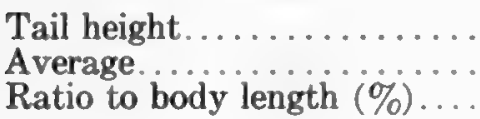 & $\begin{array}{c}9-10.5 \\
(9.7) \\
13.9\end{array}$ & $\begin{array}{l}9-11 \\
(9.9) \\
13.2\end{array}$ & $\begin{array}{l}8-9.5 \\
(8.4) \\
12.5\end{array}$ & $\begin{array}{l}7-8 \\
(7.6) \\
10.5\end{array}$ \\
\hline
\end{tabular}

Habitat and habits.-Batrachuperus pinchonii is an aquatic salamander adapted to cold mountain streams from 5,000 to 13,000 feet in altitude. Specimens are found in the water or under stones near the margins of streams. This species may occur together with others of the same genus, especially with karlschmidti, and is occasionally associated with Aelurophryne glandulata in larger mountain streams. B. pinchonii is most abundant in smaller mountain streams. Larvae and the recently metamorphosed young are commonly found near the upper reaches of the streams, especially where springs emerge from beneath stones.

Breeding behavior.-The breeding habits of this species are not well known.

Eggs.-A number of egg-cases were collected in July, 1948, in association with many adults, on Nine Peaks Mountain, Szechwan. These egg-cases are very similar to those of karlschmidti, described below (p. 92).

Larvae.-Batrachuperus larvae of different stages, which were collected from small mountain streams along Mengtunkou, especially around 9,000 feet altitude, 


\section{Batrachuperus pinchonii: Measurements ${ }^{1}$ of Larvae}

Measurements $\begin{gathered}\text { Ten fully } \\ \text { developed specimens }\end{gathered}$

Body length

Head width

Ratio to body length $(\%)$.

Head length

Ratio to body

Head height.

Ratio to body length $(\%) \ldots \ldots . . . . . . . . . . .$.

Trunk length

Ratio to body length $(\%) \ldots \ldots \ldots \ldots \ldots . . .$.

Length of foreleg.

Ratio to body length (\%)

Length of hind leg.

Ratio to body length $(\%) \ldots \ldots \ldots \ldots \ldots . . . . . . . . .$.

Tail length

Ratio to body length $(\%)$.

Tail width

Ratio to body length $(\%) \cdot \ldots . . . . . . . .$.

Tail height

Ratio to body length $(\%) \ldots . . . . . . . . . . . . . .$.

${ }^{1}$ Average in parentheses.
$1.8-2.2(2.0)$

$3.8-5.2(4.63)$
Four specimens with gill stumps $27.4-30.0(28.2)$ $6.2-7.0(6.7)$ 23.7

$6.8-8.5(7.4)$ 26.2

$3.4-4.0 \quad(3.7)$ 14.1

$11.3-13.3(12.2)$ 43.2

-...

$6.6-8.0(7.7)$

27.3

20.4-24.7 (21.9)

77.6

$1.8-2.5$
7.8

$3.8-4.4(4.2)$ 14.8

differ from those of $B$. karlschmidti in smaller size and the condition of the gills. Ten fully developed larvae of pinchonii have been carefully studied and measured. In most dimensions they are much smaller than karlschmidti. The most conspicuous difference between pinchonii and karlschmidti larvae lies in the gills: pinchonii has fewer filaments, and these are arranged in one row only, except on the third gill (number of gills and gill filaments on both sides I:8-8, II:11-11, III:12-10), while, for the fully developed larvae of karlschmidti, the gill filaments are in two rows on each gill; for Paohsinghsien specimens the gill formula is I:9-9, II:14-12, III:18-16; for Lifanhsien material the gill formula is I:16-14, II :22-22, III:17-21; and for Luho specimens the gill formula is I:21-20, II:34-36, III:37-36. The fleshy bases of the gills are well developed in karlschmidti and only poorly in pinchonii. The length of the filaments is also different in these two species. In pinchonii, the longest filaments reach not more than half way to the forelimb in the neck region, whereas in karlschmidti they reach the middle upper arm region. The larvae of pinchonii, with only stumps of the gills left, are much smaller than karlschmidti larvae of the same stage; the body length of pinchonii ranges from 27.4 to $30.0 \mathrm{~mm}$., mean $28.2 \mathrm{~mm}$.; in karlschmidti the range is from 39.0 to $50.3 \mathrm{~mm}$., and the average $43.6 \mathrm{~mm}$.

\section{Batrachuperus karlschmidti sp. nov.}

Type.-No. 49379 Chicago Natural History Museum, from Chiala (11,000 feet altitude), Luhohsien, Sikang. Adult female, collected August 10, 1943, by Ch'eng-chao Liu. 
Diagnosis.-A distinct species of Batrachuperus, differing from cochranae by having labial folds, and from all other species of the genus in the total lack of spots and marblings (fig. 12), and in the wide separation of the vomerine tooth patches, the space varying from two-thirds of the length to the full length of one of the tooth patches.

Description of type.-Body cylindrical and rather stout, with thirteen costal grooves. Snout squarish rather than rounded, head length 23.8 per cent of the body length, its width 16.6 per cent and its height 10.7 per cent of the same

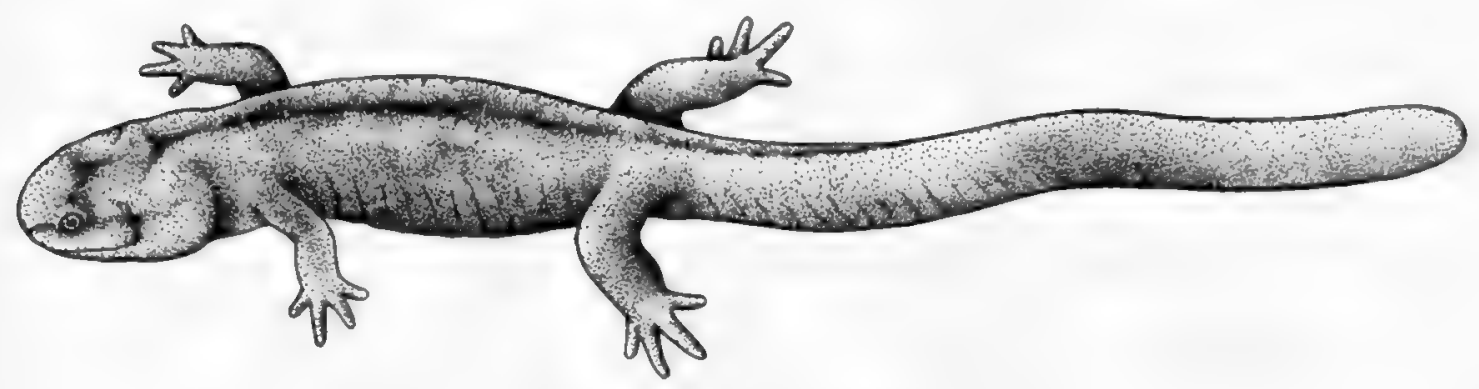

FIG. 12. Batrachuperus karlschmidti; adult $(\times 1)$.

measurement; labial folds well developed; length of eye greater than the distance from the anterior corner of the eye to the nostril; interorbital space flat; angle of the mouth reaching a point below the posterior corner of the eye; distance from the angle of the mouth to the postrictal vertical groove about equal to the length of the eye; gular fold extending to the dorso-lateral sides of the neck, visible from above; tongue small and elongate, with sides free; vomerine teeth 4-5, in two small patches between the choanae and separated by a space about equal to the length of one vomerine tooth patch.

Limbs short; when appressed, the tips of the longest digits separated by more than two costal spaces; fingers 2-3-4-1 and toes 3-2-4-1 in order of length; a large pad between the bases of the first and second fingers and another between the bases of the first and second toes; tips of digits covered with dark brown horny epidermis; no horny epidermis on the palms and soles. Tail strong, little shorter than the body, cylindrical at the base, flattened gradually toward the tip; only the posterior part of the dorsal side of the tail fin thin, as is the extreme tip of the tail; the ventral side of the tail thick and rounded. Vent quadrangular with a groove behind.

Chaetura black on the back and much lighter below, all stippled with dark color.

Measurements of type (percentage of body length in parentheses).-Body length $84 \mathrm{~mm}$.; head width $14 \mathrm{~mm}$. (16.6); head length $20 \mathrm{~mm}$. (23.8); head height $9 \mathrm{~mm}$. (10.7); length of eye $5 \mathrm{~mm}$. (5.9); trunk length $45 \mathrm{~mm}$. (53.5); length of foreleg $18.5 \mathrm{~mm}$. (22.0); length of hind leg $24 \mathrm{~mm}$. (28.5); tail length $82 \mathrm{~mm}$. (97.6); tail width $9 \mathrm{~mm}$. (10.7); tail height $8.5 \mathrm{~mm}$. (10.1). 
History of species.-In 1945 I published the information gained on various collecting trips under the title of Life History of Batrachuperus pinchonii. In this paper, I mentioned two more possible subspecies besides the large common form that was identified as $B$. pinchonii. These were a smaller spotted form from Lifanhsien and a long weak-tailed and marbled species from Yenyuanhsien, Sikang. Study of the literature and conferences with Schmidt, Pope, Dunn, and Netting have convinced me that the large form is a distinct new species, that the smaller spotted one is $B$. pinchonii, and that the form collected from Yenyuanhsien is another new species. The large, uniformly colored salamander is named after my friend and colleague Mr. Karl P. Schmidt, Chief Curator of the Department of Zoology at Chicago Natural History Museum.

Distribution and collection data.-B. karlschmidti is a common salamander in small mountain streams ranging from 6,000 to 13,000 feet altitude in the mountains of the Szechwan-Sikang boundary and on the plateau of Kangshu, Sikang. In 1938, 1940, and 1945, adults as well as young ones were collected from the White Dragon Pool on the top of Mount Omei. From August 11 to 15, 1939, egg-cases, young, and adults were obtained in small mountain streams at Lianghokou (12,500 feet altitude) of Paohsinghsien, Sikang. During the summer of 1941, large numbers of young and adults were collected from Tsakunao, Mengtunkou, and Tsingshan of Lifanhsien, Szechwan. From July 8 to September 5, 1943, many egg-cases, young of different stages, and adults were collected from Kangting, Taining, Taofu, Luho and Kantze of Kangshu, Sikang Province. No. 92318 in the Museum of Zoology, University of Michigan, collected by D. C. Graham from Jedo, Sikang, is a specimen of this new Batrachuperus.

B. karlschmidti is generally found together with $B$. pinchonii on Mount Omei and in the mountain streams between northern Szechwan and northeastern Sikang. In a stream at Lianghokou, pinchonii, karlschmidti and cochranae were collected on the same day. Only karlschmidti was obtained on the high plateau of Kangshu.

Variation.-The natural coloration of karlschmidti is nearly uniform, varying slightly in intensity, and without spots or marbling. Most individuals are Chaetura Black or dark neutral gray above and lighter below; many have dark olive or olive green on the back, and in a few cases the back is yellowish olive. After preservation in formalin, they are usually Chaetura Black or dark gray.

The dimensions of the different parts of the body in proportion to its length have no positive or negative correlation with size. Measurements of ten specimens of each sex from three localities are given (see table). The tail is relatively longer and the body shorter in the male than in the female. The longer body of the female may be related to the requirements of reproduction, by providing space for developing eggs. The number of costal grooves varies from eleven to thirteen, the usual number being twelve. The shape and the number of the vomerine teeth vary greatly. Nine specimens from Luho, chosen at random, have been studied. One has two round patches between the choanae, with four 
Batrachuperus karlschmidti: Measurements

\begin{tabular}{|c|c|c|c|c|c|c|}
\hline \multirow[b]{2}{*}{ rements } & \multicolumn{2}{|c|}{ Paohsing (Muping) } & \multicolumn{2}{|c|}{ Luho } & \multicolumn{2}{|c|}{ Lifan } \\
\hline & Ten males & Ten females & Ten males & Ten females & Ten males & Ten females \\
\hline $\begin{array}{l}\text { ody length.... } \\
\text { verage....... }\end{array}$ & $\begin{array}{c}88.3-96 \\
91.0\end{array}$ & $\begin{array}{c}82.5-96 \\
91.0\end{array}$ & $\begin{array}{c}74.0-88 \\
80.8\end{array}$ & $\begin{array}{c}78.0-90 \\
84.8\end{array}$ & $\begin{array}{c}30.0-98 \\
86.1\end{array}$ & $\begin{array}{c}75.0-89.8 \\
83.2\end{array}$ \\
\hline $\begin{array}{l}\text { Iead width } . . . \\
\text { verage........ } \\
\text { latio }{ }^{1} \ldots . . .\end{array}$ & $\begin{array}{c}11.5-18.9 \\
16.7 \\
18.4\end{array}$ & $\begin{array}{r}14.6 \\
15 \\
17\end{array}$ & $\begin{array}{r}13.3 \\
14 \\
17\end{array}$ & $\begin{array}{r}14.0 \\
15 \\
17\end{array}$ & $\begin{array}{c}5.0-19 \\
17.0 \\
19.8\end{array}$ & $\begin{array}{c}13.4-16.0 \\
14.8 \\
17.8\end{array}$ \\
\hline $\begin{array}{l}\text { lead length.... } \\
\text { verage.......... } \\
\text { atio......... }\end{array}$ & $\begin{array}{c}19.5-23.6 \\
21.3 \\
23.3\end{array}$ & $\begin{array}{c}17.4-21.5 \\
19.7 \\
21.6\end{array}$ & $\begin{array}{r}16.0-20 \\
18.7 \\
23.2\end{array}$ & $\begin{array}{c}17.8-21.5 \\
19.3 \\
23.6\end{array}$ & $\begin{array}{c}20.0-24.5 \\
22.0 \\
25.6\end{array}$ & $\begin{array}{c}17.2-21.5 \\
19.3 \\
23.2\end{array}$ \\
\hline $\begin{array}{l}\text { lead height.... } \\
\text { verage............. } \\
\text { atio......... }\end{array}$ & $\begin{array}{c}7.5-9.6 \\
8.7 \\
9.6\end{array}$ & $\begin{array}{c}7.0-8.7 \\
8.1 \\
8.9\end{array}$ & $\begin{array}{c}7.0-9.0 \\
7.8 \\
9.6\end{array}$ & $\begin{array}{c}7.4-9.3 \\
8.2 \\
10.0\end{array}$ & $\begin{array}{r}8.0-13 \\
9.8 \\
11.5\end{array}$ & $\begin{array}{c}7.5-10.5 \\
8.8 \\
10.5\end{array}$ \\
\hline $\begin{array}{l}\text { of eye. } \\
\text { e.......... }\end{array}$ & $\begin{array}{l}4.8-5.5 \\
5.2 \\
5.7\end{array}$ & $\begin{array}{l}4.8-5.5 \\
5.0 \\
5.5\end{array}$ & $\begin{array}{l}4.2-5.0 \\
4.6 \\
5.8\end{array}$ & $\begin{array}{c}4.2-5.3 \\
4.8 \\
5.7\end{array}$ & $\begin{array}{c}4.0-5.2 \\
4.4 \\
5.1\end{array}$ & $\begin{array}{c}4.0-4.8 \\
4.4 \\
5.3\end{array}$ \\
\hline $\begin{array}{l}\text { length... } \\
\text { e.......... }\end{array}$ & $\begin{array}{r}41.4-4 \\
44 . \\
49 .\end{array}$ & $\begin{array}{r}43.0 \\
47 . \\
52 .\end{array}$ & $\begin{array}{r}36.4 \\
41 \\
51\end{array}$ & $\begin{array}{r}37.6 \\
44 \\
52\end{array}$ & $\begin{array}{r}36.0 \\
42 \\
49\end{array}$ & $\begin{array}{c}38.0-47.5 \\
43.4 \\
52.2\end{array}$ \\
\hline $\begin{array}{l}\text { eng } \\
\text { fo }\end{array}$ & $\begin{array}{c}24.3-27.3 \\
25.6 \\
28.1\end{array}$ & $\begin{array}{r}21.0-26 \\
23.8 \\
25.6\end{array}$ & $\begin{array}{c}18.0-24.0 \\
20.6 \\
25.5\end{array}$ & $\begin{array}{r}18.5 \\
20 \\
24\end{array}$ & $\begin{array}{r}20.0-26 \\
23.3 \\
27.0\end{array}$ & $\begin{array}{c}18.0-22.2 \\
20.2 \\
24.3\end{array}$ \\
\hline f & $\begin{array}{c}27.0-30.6 \\
28.6 \\
31.4\end{array}$ & $\begin{array}{c}25.0-28.6 \\
26.5 \\
29.2\end{array}$ & $\begin{array}{c}20.7-27.5 \\
23.9 \\
29.6\end{array}$ & $\begin{array}{r}23.0-27 \\
25.7 \\
30.0\end{array}$ & $\begin{array}{r}25.0-29 \\
24.5 \\
28.4\end{array}$ & $\begin{array}{r}23.7-27 \\
26.1 \\
31.4\end{array}$ \\
\hline $\begin{array}{l}\text { Tail length..... } \\
\text { Average....... } \\
\text { Ratio......... }\end{array}$ & $\begin{array}{c}93.0-108 \\
99.7 \\
109.5\end{array}$ & $\begin{array}{c}77.5-95 \\
79.3 \\
87.1\end{array}$ & $\begin{array}{c}77.0-102 \\
84.7 \\
104.8\end{array}$ & $\begin{array}{r}79.0-99 \\
84.6 \\
98.5\end{array}$ & $\begin{array}{c}88.0-122 \\
98.7 \\
114.5\end{array}$ & $\begin{array}{c}70.5-93.4 \\
82.4 \\
98.9\end{array}$ \\
\hline $\begin{array}{l}\text { Tail width.... } \\
\text { Average....... }\end{array}$ & $\begin{array}{l}8.6-11 \\
10.0 \\
11.0\end{array}$ & $\begin{array}{c}6.4-9.8 \\
8.0 \\
8.8\end{array}$ & $\begin{array}{r}7.3-10 \\
8.6 \\
10.5\end{array}$ & $\begin{array}{c}8.0-10.5 \\
8.8 \\
10.7\end{array}$ & $\begin{array}{r}9.0-13 \\
10.3 \\
12.0\end{array}$ & $\begin{array}{c}6.6-9.6 \\
8.4 \\
10.0\end{array}$ \\
\hline $\begin{array}{l}\text { Tail height..... } \\
\text { Average....... } \\
\text { Ratio......... }\end{array}$ & $\begin{array}{c}9.2-11.5 \\
10.3 \\
11.3\end{array}$ & $\begin{array}{c}8.0-10.3 \\
9.1 \\
10.0\end{array}$ & $\begin{array}{r}9.4-11 \\
9.9 \\
12.2\end{array}$ & $\begin{array}{c}8.0-11.0 \\
9.6 \\
11.7\end{array}$ & $\begin{array}{r}10.0-15 \\
11.7 \\
13.6\end{array}$ & $\begin{array}{c}8.0-11.4 \\
9.9 \\
11.7\end{array}$ \\
\hline
\end{tabular}

${ }^{1}$ Percentage of body length.

teeth in the left patch and five in the right one. Five specimens have two oblique rows anterior to the choanae with the posterior edge near the choanae, teeth $3-3,3-4,4-3,4-4$, and $6-6$; one specimen has two curved patches, teeth $5-5$, median to the choanae; two have a rounded patch on one side and an oblique patch on the other, teeth $2-3$ and 3-3, all anterior to the choanae. The shape and position of the patches and the number of the teeth are not reliable as taxonomic characters.

In the male, the vent is a transverse crescentic opening with a large lightcolored papilla in the middle, with a longitudinal groove posterior to it. The vent of the female varies greatly with preservation; in this sex there is never a transverse crescentic opening with a large papilla. With experience, one can tell the sex in spite of differences of preservation, the vent being a longitudinal 
slit (as is normal in salamanders) sometimes contracted so as to appear quadrangular or puckered, with a short slit anterior to the opening and a long one behind. The vent is more prominently swollen in the female, the opposite of the normal salamander sex difference.

Habitat and habits.-Batrachuperus karlschmidti is a salamander adapted to cold water and found under stones of small mountain streams from 6,000 feet to 13,000 feet above sea level. Specimens are more abundant under somewhat flat stones than under pebbles or small boulders, and they are most often found under stones near the margins of streams. I occasionally found specimens hiding under decayed logs or under roots of vegetation on the banks. The larvae and small metamorphosed individuals are generally found under stones in the upper reaches of small streams, especially in springs, which are the principal breeding sites. The cold-adaptation of this salamander is well known to the monks of Mount Omei, but they interpret it in a different way. The monks told me that one cannot bring such a salamander down the mountain for if one tries to do so, the animal either mysteriously disappears on the way or dies. My experience indicates that these salamanders die from an abrupt rise in temperature.

Analysis by number of items of stomach contents of six specimens collected September 17, follow: 61.2 per cent gammarids; 24.3 per cent stone fly larvae; 11.3 per cent caddis fly larvae; 1.6 per cent fly larvae; and 1.6 per cent muscoid fly. A piece of moss was found in one of the stomachs. It is evident that this salamander eats aquatic animals.

Superstitions and economic value.-Near the White Dragon Pool on the top of Mount Omei there is a small temple consecrated to the worship of this salamander. The pool is so named because the monks and the people of that mountain call the salamander the "white dragon" and believe that the White Dragon King is in the pool. They say that if one captures and kills one of these salamanders a storm will follow.

The people of the high mountains of Sikang and western Szechwan believe in the use of this salamander for the cure of stomach trouble. The herb collectors usually collect the various species of Batrachuperus and dry them. They sell the dry salamanders to drug stores, or may keep them. I was told that when one has a stomach ache one should grind the dry animal into powder and drink it in boiling water.

Breeding.-The breeding season probably lasts from May to the first part of August. Young with external gills were collected on Mount Omei on July 25, 1938; young animals of different stages and three egg-cases with fully developed embryos were collected at Lianghokou on July 21, 1939; many young individuals at different stages and some empty egg-cases were obtained from Tsingshan, Lifanhsien, on August 12, 1941. On August 10, 1943, many larvae just hatched and others at different stages of metamorphosis, as well as many egg-cases containing embryos of various stages, were secured in a very small mountain stream near Chiala and Chuwo of Luhohsien, Sikáng. 
Egg-cases (fig. 13, A) are attached to the under surfaces of large stones, or to the stream-bed under or by the sides of large stones, where the water flows through. They are found mostly in very small brooks, especially near their sources where spring water seeps out of the ground or from under stones. The end of the egg-case attached to the stone is flattened and sticky; the body is a cylindrical tube, largest in the middle and becoming smaller toward the free end, which is smooth and transparent. Longitudinal striations are found on the transparent wall of the body, which has some traces of a creamy yellow color in the fresh condition. The smooth, cup-like cap at the free end is even more delicate than the rest of the egg-case. Young animals free themselves through a hole at the tip, where the cap is forced off by the movement of the fully developed embryos and the weight of the liquefied jelly inside.

In five egg-cases collected from Luho, the average length was $91.6 \mathrm{~mm}$., the range from 75 to $96 \mathrm{~mm}$. The average greatest diameter was $16.6 \mathrm{~mm}$., with a range from 14 to $19 \mathrm{~mm}$. The number of the embryos in each egg-case varied from seven to twelve. The embryos lie at right angles to the long axis of the eggcase. Eggs dissected out from the female are yellowish in color, and the average diameter is $3.7 \mathrm{~mm}$. Eggs laid under natural conditions must be larger than this. How many eggs and egg-cases are laid by a single female is unknown; more than forty-five eggs at the same stage of development have been dissected out from a single specimen.

Larvae.-Young specimens collected at the time of hatching (fig. 13, B) are different from adults. The color is light gray on the back, yellowish on the belly. Labial folds are discernible, but there is no indication of a movable eyelid. The top of the head is smooth and the parotoid glands are indistinct. A light mid-dorsal line is present on the head. Pores of the lateral line organ are clearly to be seen on the head. External gills are well developed. There are four gill slits on each side of the neck, the first the largest, the last the smallest. Three gill arches are developed, with short rod-like gill filaments on the internal lateral surface of each arch, the outer lateral side of which bears a fleshy base on which two rows of gill filaments are developed; the filaments of the external row are regularly arranged and with pigmented cords, whereas those of the inner row are fewer in number, irregularly arranged and colorless. The filaments of the outer row are antero-posteriorly flattened, those of the inner row laterally flattened, so that they occupy less space when they fold like a fan. A thin colorless membrane is developed on the ventro-median side of each arch. A similar membrane, continuous with the side of the throat, covers the first gill slit, and the last gill slit has such a membrane at its posterior margin. The most anterior gill, near the throat, has an outer regular row of eleven or more long filaments, and from three to five short filaments median to the outer row. The second gill is dorso-posterior to the first, with thirteen or fourteen filaments in the outer row, and eight or nine in the inner. The third gill is dorso-posterior to the second, the outer row of filaments containing from eight to twelve, the inner row from nine to eleven, all about equal in length with those of the outer 
row. The vertebral groove is distinct but limited to the anterior region of the trunk. The anterior limbs have three fingers well developed, with an indication of the fourth. On the hind limb only the third toe is indicated. The tail is much deeper than that of an adult. The dorsal fin, more pigmented than the ventral, reaches nearly to the shoulder region.

The measurements of ten hatchlings are tabulated. The body length (from the tip of the snout to the vent) ranges from 15 to $16 \mathrm{~mm}$. (average 15.3).

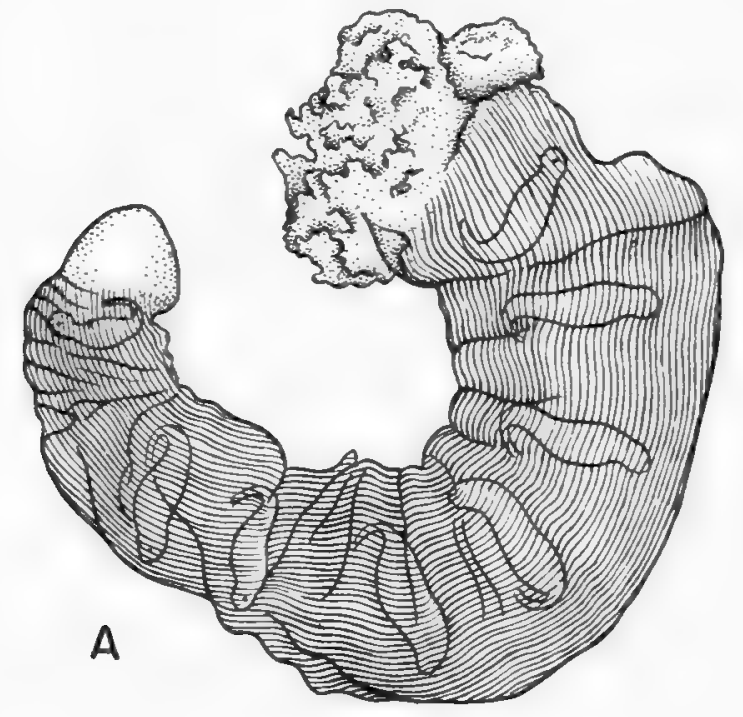

B
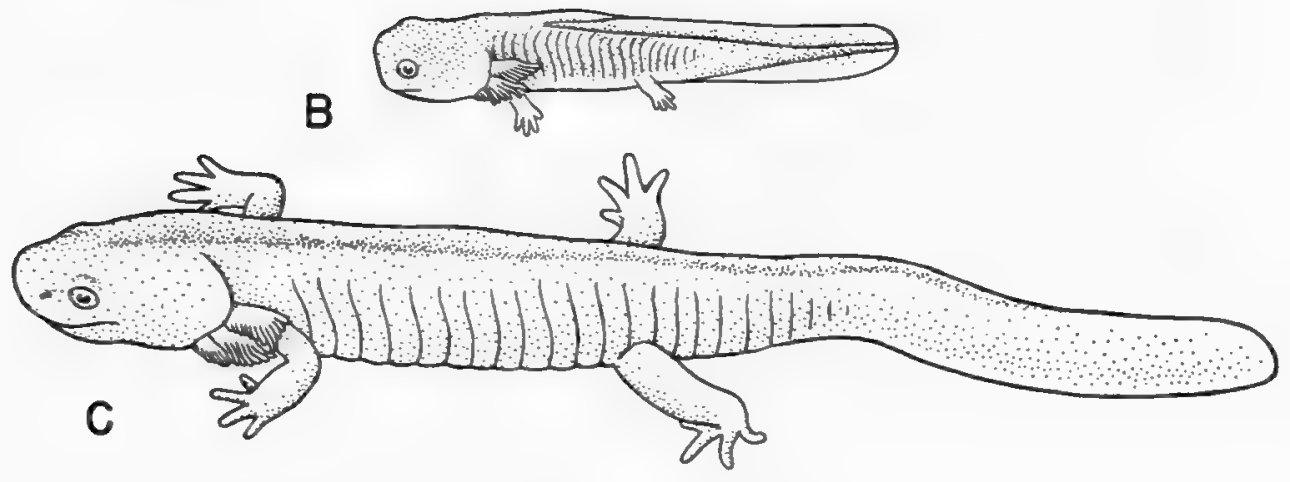

Fig. 13. Batrachuperus karlschmidti. A. Egg-case $(\times 11 / 2)$. B. Larva just after hatching $(\times 2)$. C. Fully developed larva $(\times 13 / 5)$.

The head length of the larva is proportionately larger than that of the adult, 35.8 per cent of the body length as compared with 23.4 per cent for the adult. The height of the head is 18 per cent of the body length in the larva and only 9.8 per cent in the adult; its width is 23.7 per cent in the larva and about 18 per cent in the adult. The hind limb is shorter than the fore limb in the larva, and the reverse is true in the adult. The tail of the larva, with a much higher tail fin, is much shorter than that of the adult. Its length is 80 per cent of the 


\section{Batrachuperus karlschmidti: Measurements of Larvae and Young}

\begin{tabular}{|c|c|c|c|c|}
\hline Measurements & $\begin{array}{l}\text { Ten specimens } \\
\text { at time of } \\
\text { hatching }\end{array}$ & $\begin{array}{l}\text { Ten fully } \\
\text { developed } \\
\text { larvae }\end{array}$ & $\begin{array}{l}\text { Ten specimens } \\
\text { with gill stumps }\end{array}$ & $\begin{array}{l}\text { Ten specimens } \\
\text { just after } \\
\text { metamorphosis }\end{array}$ \\
\hline $\begin{array}{l}\text { Body length ............ } \\
\text { Average ................ }\end{array}$ & $\begin{array}{l}15-16 \\
15.33\end{array}$ & $\begin{array}{l}36-43 \\
39.59\end{array}$ & $\begin{array}{l}39-50.3 \\
43.57\end{array}$ & $\begin{array}{l}34.8-47.5 \\
42.6\end{array}$ \\
\hline 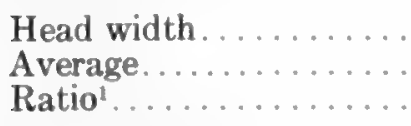 & $\begin{array}{l}3.5-4.0 \\
\cdot \quad 3.64 \\
\quad 23.7\end{array}$ & $\begin{array}{l}7.8-8.5 \\
8.13 \\
20.5\end{array}$ & $\begin{array}{l}8.0-9.4 \\
8.65 \\
19.9\end{array}$ & $\begin{array}{l}7.3-9.9 \\
8.31 \\
19.5\end{array}$ \\
\hline 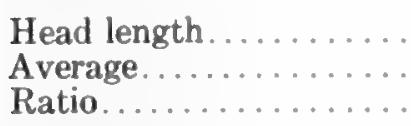 & $\begin{array}{c}4.7-6.0 \\
5.49 \\
35.8\end{array}$ & $\begin{array}{l}10.0-11.4 \\
10.63 \\
26.8\end{array}$ & $\begin{array}{l}10.3-13.6 \\
11.61 \\
26.7\end{array}$ & $\begin{array}{l}9.3-12.2 \\
10.88 \\
25.5\end{array}$ \\
\hline 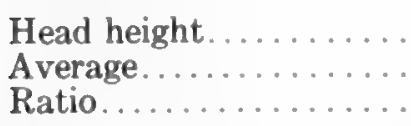 & $\begin{array}{c}2.7-3.0 \\
2.79 \\
18.0\end{array}$ & $\begin{array}{c}4.3-5.0 \\
4.71 \\
11.8\end{array}$ & $\begin{array}{l}3.5-4.5 \\
4.21 \\
9.7\end{array}$ & $\begin{array}{c}3.4-4.8 \\
4.32 \\
10.1\end{array}$ \\
\hline $\begin{array}{l}\text { Length of eye } \ldots \ldots \ldots \ldots \\
\text { Average } \ldots \ldots \ldots \ldots \ldots \\
\text { Ratio.............. }\end{array}$ & $\begin{array}{l}\cdots \cdots \\
\cdots \cdots \\
\cdots \cdots\end{array}$ & $\begin{array}{l}2.3-2.8 \\
2.54 \\
6.4\end{array}$ & $\begin{array}{l}2.5-3.4 \\
2.79 \\
6.4\end{array}$ & $\begin{array}{l}2.5-3.7 \\
2.9 \\
6.8\end{array}$ \\
\hline 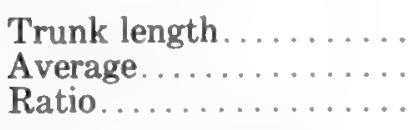 & $\begin{array}{l}\cdots \cdots \\
\cdots \cdots \\
\cdots \cdots\end{array}$ & $\begin{array}{c}16.0-23.5 \\
19.47 \\
49.1\end{array}$ & $\begin{array}{l}19.8-23.0 \\
21.97 \\
50.4\end{array}$ & $\begin{array}{l}17.0-23.4 \\
20.67 \\
48.5\end{array}$ \\
\hline $\begin{array}{l}\text { Length of foreleg....... } \\
\text { Average } \ldots \ldots \ldots \ldots \ldots \\
\text { Ratio.............. }\end{array}$ & $\begin{array}{l}2.7-3.7 \\
3.15 \\
\cdot \quad 20.5\end{array}$ & $\begin{array}{l}10.5-13.5 \\
12.13 \\
30.6\end{array}$ & $\begin{array}{l}11.3-13.8 \\
12.55 \\
28.8\end{array}$ & $\begin{array}{l}10.6-14.9 \\
12.54 \\
29.4\end{array}$ \\
\hline 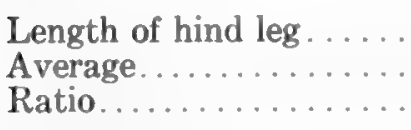 & $\begin{array}{l}2-3 \\
2.55 \\
16.7\end{array}$ & $\begin{array}{l}11.0-13.6 \\
12.84 \\
32.1\end{array}$ & $\begin{array}{c}13.2-16.7 \\
14.43 \\
33.1\end{array}$ & $\begin{array}{l}10.0-16.5 \\
13.27 \\
31.1\end{array}$ \\
\hline 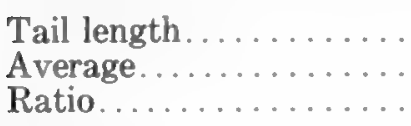 & $\begin{array}{c}12.0-12.8 \\
12.27 \\
80.0\end{array}$ & $\begin{array}{l}31.0-44.5 \\
36.41 \\
91.9\end{array}$ & $\begin{array}{c}33.7-48.7 \\
40.83 \\
93.7\end{array}$ & $\begin{array}{l}28.2-42.0 \\
34.4 \\
98.7\end{array}$ \\
\hline 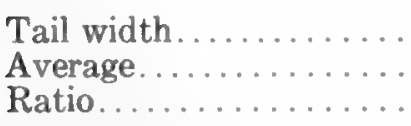 & $\begin{array}{l}\ldots \cdots \\
\cdots \cdots \\
\cdots \cdots\end{array}$ & $\begin{array}{l}3.3-4.4 \\
3.65 \\
9.2\end{array}$ & $\begin{array}{l}3.5-5.0 \\
4.07 \\
9.3\end{array}$ & $\begin{array}{l}2.6-4.3 \\
3.36 \\
7.8\end{array}$ \\
\hline 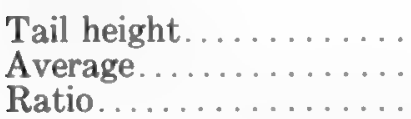 & $\begin{array}{l}\quad 3.5-4.0 \\
\quad 3.75 \\
\quad 24.5\end{array}$ & $\begin{array}{l}5.8-7.0 \\
6.4 \\
16.4\end{array}$ & $\begin{array}{l}4.3-6.5 \\
5.37 \\
12.3\end{array}$ & $\begin{array}{l}3.3-5.0 \\
4.21 \\
9.8\end{array}$ \\
\hline
\end{tabular}

${ }^{1}$ Percentage of body length.

body length in the larva and its height 24.5 per cent; in the adult, its length is 104 per cent and its height only 12 per cent.

In ten fully developed larvae from the same locality (see table), the average body length from tip of snout to vent is $39.6 \mathrm{~mm}$., ranging from 36 to $43 \mathrm{~mm}$.

At this stage the animal (fig. 13, C) is nearly black above, with a lighter bluish-black belly. Pores of the lateral line organ are even more conspicuous than in earlier stages, as the ground color is much darker, especially on the head. The median dorsal interparotoidal groove, parotoids, and other prominences are still inconspicuous. The eyelids are well developed, but the membrane covering the eyeball is still connected with the margins of the upper and lower eyelids. Gill filaments and their arrangement are as before, except that the color is lighter than the surrounding tissue. 
The number of gill filaments varies greatly, but the first gill always has fewest filaments and the third gill the greatest number; for example, in one specimen the first gill has two rows of filaments, the exposed row having twelve filaments, the inner row only one; the second gill has seventeen filaments, fourteen in the outer row and three in the inner, whereas, in the third gill, the outer row consists of thirteen filaments and the inner of ten. In another specimen, the number of gill filaments is much greater, twenty-one on the first gill, with fourteen in the outer row and seven in the inner; thirty-four on the second gill, with twentyone in the outer row and thirteen in the inner; on the third gill there are thirtysix filaments, the separation into two rows being indistinct. Furthermore, the number of filaments is different on the two sides of the same animal. The filaments are flattened obliquely, in correlation with the axis of the fleshy base of the gill, and the inner gill filaments are flattened at right angles to the outer row. They may also overlap each other, so that the filaments of the outer row and the inner accessory filaments fold down like a fan on the sides of the neck region. When they fold down, the tips of some filaments of the first gill reach to just anterior to the base of the arm, those of the second gill to the middle region of the upper arm, and those of the third gill to the dorsal side of the elbow, or in some specimens even to the third costal groove.

The fingers as well as the toes are fully developed in the metamorphosing individual, but the arms and legs are longer in proportion to the body than those of the adults. It is difficult to correlate this difference with adaptation. Costal grooves are well formed. The vertebral groove is evident only anteriorly, as the dorsal tail fin reaches the middle of the body. The head is still larger in proportion to the body than in the adult but much smaller than that in the young at the time of hatching. The tail differs from that of the adult, its length being 91.1 per cent of the body length and its height 16.4 per cent, whereas in the young at the time of hatching, the tail is shorter and higher, and in the adult it is longer and lower.

During metamorphosis, the gill filaments become black and shrivelled. Ten specimens at this stage were measured (see table). The body length ranges from 39 to $50.3 \mathrm{~mm}$., averaging $43.6 \mathrm{~mm}$. In young specimens nearing the completion of metamorphosis, body proportions approach those of the adult. The coloration at this stage varies greatly; usually there are indistinct marblings or spots on a dark bluish black or dark brownish black ground color. The belly is much lighter. The pores of the lateral line organ have disappeared. The median dorsal interparotoidal grooves, parotoids, and other prominences are clearly evident. The vertebral groove reaches the level of the posterior aspect of the hind limbs, and in some specimens a lighter line is indicated along the groove, this being much deeper and wider on the back, above the hind limbs. The length of the head in proportion to that of the body is less than in the early stages but still larger than the head of the adults. The limbs of the young at this stage are proportionately the same as those of adults. The most conspicuous change occurs in the gills. Not only the filaments, but also the fleshy bases of 
the gills are blackened and shrunk in the advanced larvae, and the fleshy bases are covered by a fold growing posteriorly from the sides of the neck. The gill filaments are not only shrivelled but have also lost their regular arrangement and are curved and more or less entangled. The tail is still shorter and weaker than that of the adult. The animals of this stage are generally found with the adults in the larger mountain streams.

Near or just after the completion of metamorphosis, the adult form has been attained except that the head is still larger and the tail still shorter. Gills have either completely disappeared or there may be an indication of a small, dark, depressed spot on each side of the neck. The animals of this stage are found together with the adults in the larger mountain streams.

\section{Batrachuperus tibetanus Schmidt}

Batrachuperus tibetanus Schmidt, 1925, Amer. Mus. Nov., No. 175: 5-Tibetan border of Kansu, at about Lat. 33 N., southwest of Titao, 9,000 feet altitude, type in Chicago Natural History Museum; idem, 1927, Bull. Amer. Mus. Nat. Hist., 54: 554 .

History of species.-Two female paratypes collected by Robert B. Ekvall, with the same data, agree with the type (an adult female) in all essential characters. Eleven specimens (five adult females, one adult male, two young, and three metamorphosing individuals) of $B$. tibetanus are in the United States National Museum, also collected by Mr. Ekvall at the type locality in 1924 . One of this series was exchanged to the Museum of Zoology of the University of Michigan. These eleven specimens agree in all essential characters with the type.

Schmidt (1927) suggested that a male, M.C.Z. No. 2848, from "Lianghokou (12,000 feet altitude), western Szechwan," collected by Zappey and recorded by Barbour (1912) and described in detail by Dunn (1923), belongs to the species tibetanus. This locality is undoubtedly the Lianghokou of Paohsinghsien (Muping) in Sikang. Examination of this specimen convinces me that this is its correct allocation. Chang (1936) put tibetanus ("thibetina") in the synonymy of pinchonii, as he found some young specimens in the Paris Museum collected from the type locality of pinchonii and also without horny palms and soles. Boring (1936) examined the specimens in the Hoangho Paiho Museum in Tientsin from Hweihsien, Kansu, and could not find any characters to distinguish them from pinchonii, thus extending the range of that species to include the region of the type locality of tibetanus. Pope and Boring (1940) remarked that none of the characters listed by Schmidt is easy to use for diagnosis, and they concluded that tibetanus should be placed in the synonymy of pinchonii. From my field studies in the mountains and plateaus of western China, it is clear that the amphibian fauna of that region is extremely complex and rich in distinct species. Study of the types and topotypes of tibetanus proves that, though it is difficult to distinguish from pinchonii, it is in fact a valid species. 
Distribution and collection data.-Batrachuperus tibetanus is known only from the type locality, which lies well north of the known range of pinchonii.

Comparison with related species.-Batrachuperus tibetanus (pl. 1, figs. 1, 2, 3) can be distinguished from all other species of the genus by its thirteen costal grooves and more posteriorly located vomerine teeth. The absence of palmar and solar tubercles separates tibetanus from pinchonii and yenyuanensis; the presence of a labial fold distinguishes it from cochranae; the spotted back and tail differ from those of the more or less uniformly colored karlschmidti.

Original description. - "Costal grooves, 14; the adpressed toes overlap; head width 6 times, and head length $4 \frac{1}{2}$ times in length from snout to vent; eye as long as its distance from tip of snout; a prominent labial fold on the upper jaw; a slight fold on the lower jaw; a shallow groove back of the eye; a well-marked groove from eye to gular fold; no groove to angle of jaw; gular fold extends on sides of neck to dorsal surface; limbs well developed, overlapping when adpressed; fingers 2-3-4-1 and toes 3-2-4-1 in order of length; tips of digits covered with a thick horny epidermis, which is absent from the palms and soles; tail cylindrical at the base, flattened gradually to the tip, only the last one-fourth very flat; vent formed by the confluence of five grooves; much swollen; vomerine teeth $5-5$, in slightly arched series beginning well within and slightly behind the internal nares and extending diagonally forward to the level of their anterior border; distance between the vomerine series about equal to the length of one of them; olive-gray above with indistinct black marbling.

"Measurements.-Body $85 \mathrm{~mm}$.; tail $80 \mathrm{~mm}$.; length of head $18 \mathrm{~mm}$.; breadth of head $14 \mathrm{~mm}$.; arm $23 \mathrm{~mm}$.; leg $27 \mathrm{~mm}$."

Diagnosis.-Closely allied to Batrachuperus pinchonii, from which it is distinguished by the absence of tubercles and horny covering of the palms and soles, the weak and low tail, smaller head, longer trunk, and more posteriorly situated vomerine teeth.

Description of type.-Body cylindrical and moderately stout, with thirteen costal grooves and a narrow vertebral groove from the postero-dorsal side of the head to the base of the tail. Snout round from above and below, head length 22.0 per cent, head width 16.2 per cent of the body length; labial fold well developed; angle of the jaw on level with the posterior corner of the eye; distance of the postrictal vertical groove from the angle of the jaw slightly less than the length of the eye; gular fold extending on the sides of the neck; tongue large, oval, extensively free on the sides; vomerine teeth $5-5$, in slightly arched series beginning well within and slightly behind the choanae and extending diagonally forward to the level of their anterior border; distance between the vomerine tooth patches less than half of the length of one series. Limbs slender, the tips of the longest digits not meeting when limbs are appressed; fingers 2-3-4-1 and toes 3-2-4-1 in order of length; tips of digits covered with thick horny epidermis, which is lacking on palms and soles; no tubercles on palms and soles. Tail shorter than body, with weaker tail muscle, the width near its base only 
9.8 per cent of the body length, whereas in pinchonii it is 13.5 per cent in the male and 10.6 per cent in the female; the height of the tail only 9.8 per cent of the body length, while for pinchonii the tail height is 13.9 per cent for the males and 13.2 per cent for the females.

Light olive grayish brown above with black marbling, ventral side light in color with indistinct black marbling.

Measurements of type (percentage of body length in parentheses).-Body length $86 \mathrm{~mm}$.; head width $14 \mathrm{~mm}$. (16.2); head length $19 \mathrm{~mm}$. (22.0); head height $7 \mathrm{~mm}$. (8.1); length of eye $4 \mathrm{~mm}$. (4.6); trunk length $44 \mathrm{~mm}$. (51.1); length of foreleg $21 \mathrm{~mm}$. (24.4); length of hind leg $25 \mathrm{~mm}$. (29.0); tail length $79 \mathrm{~mm}$. (91.8); tail width $8.5 \mathrm{~mm}$. (9.8); tail height $8.5 \mathrm{~mm}$. (9.8).

Variation.-Five adult females and one adult male collected by Robert B. Ekvall from the type locality, Titao, Kansu, in 1924, closely resemble the type. All have thirteen costal grooves. The condition of the vomerine tooth patches varies from specimen to specimen but in most cases the patches are widely separated and posterior to the choanae. The vomerine tooth patches in No. 69093 are curved, separated by a space about equal to the length of one patch, nearly posterior to the choanae and with teeth 5-6; in No. 69094 the vomerine teeth are similar, 4-4; in No. 69095 the patches are between the choanae, teeth 3-3; in No. 69096 the patches are separated by a space about three-fourths of the length of one patch, and the teeth are 4-5; in No. 69097 the tooth patches are as in the last, with teeth 6-7. Abnormality of the digits is uncommon in any species of Batrachuperus except yenyuanensis and tibetanus. There are only three fingers on the right hand of No. 69094; in No. 69095 the first and second fingers of the right hand are rudimentary, and on the left hand the second finger is very long, the first very small, and the third rudimentary and fused with the fourth; in No. 69096 the fingers and toes are normal but rather long; and in No. 69097 the third finger of the right hand is short, and the first and second toes of the left foot are abnormal and very short.

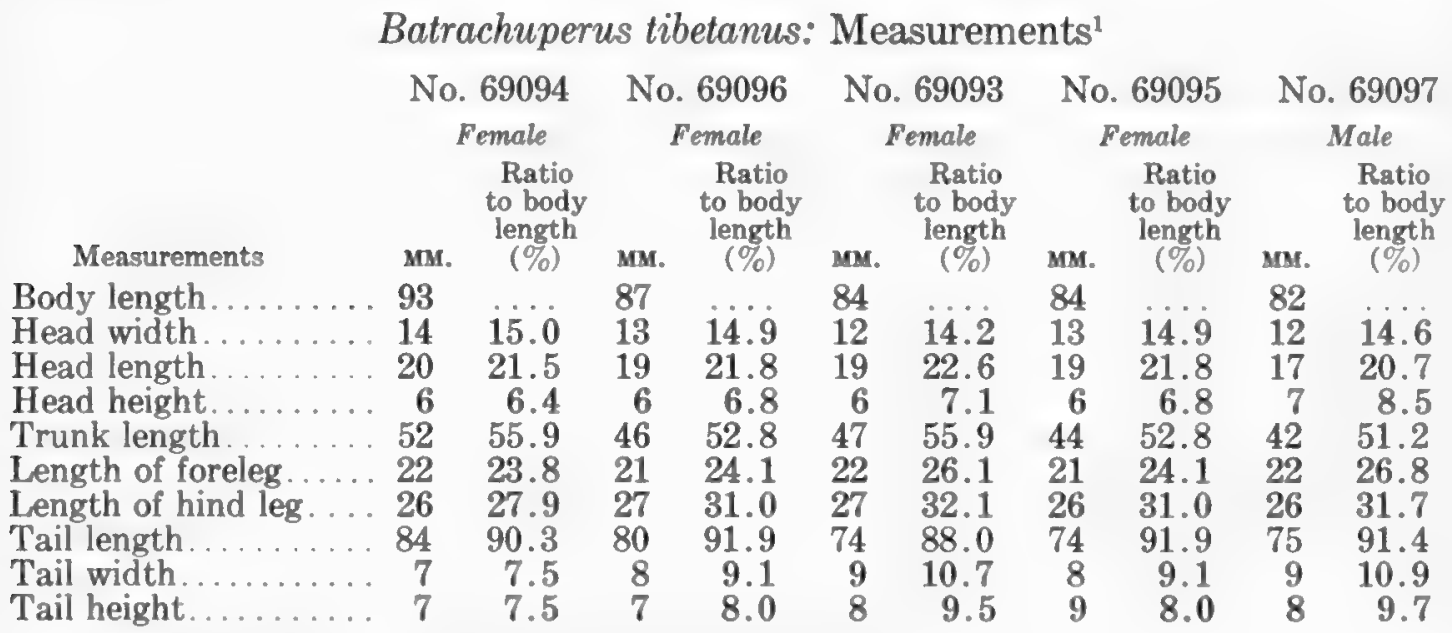

${ }^{1}$ All specimens in United States National Museum. 
A juvenile specimen with shrivelled gills is $65 \mathrm{~mm}$. long, with body length $35 \mathrm{~mm}$. and tail $30 \mathrm{~mm}$. It has all the adult characters and has a very distinct light-colored vertebral groove running from the postero-dorsal side of the head to the base of the tail.

\section{Batrachuperus yenyuanensis sp. nov.}

Type.-No. 49370 Chicago Natural History Museum from Peilinshan, Yenyuanhsien, Sikang, China, 14,500 feet altitude. Adult male, collected July 4, 1942, by H. W. Chang and Y. W. Kao.

Diagnosis.-Batrachuperus yenyuanensis (fig. 14) is a distinct species, distinguished from all others by its long and weak tail, and especially by the dorsal
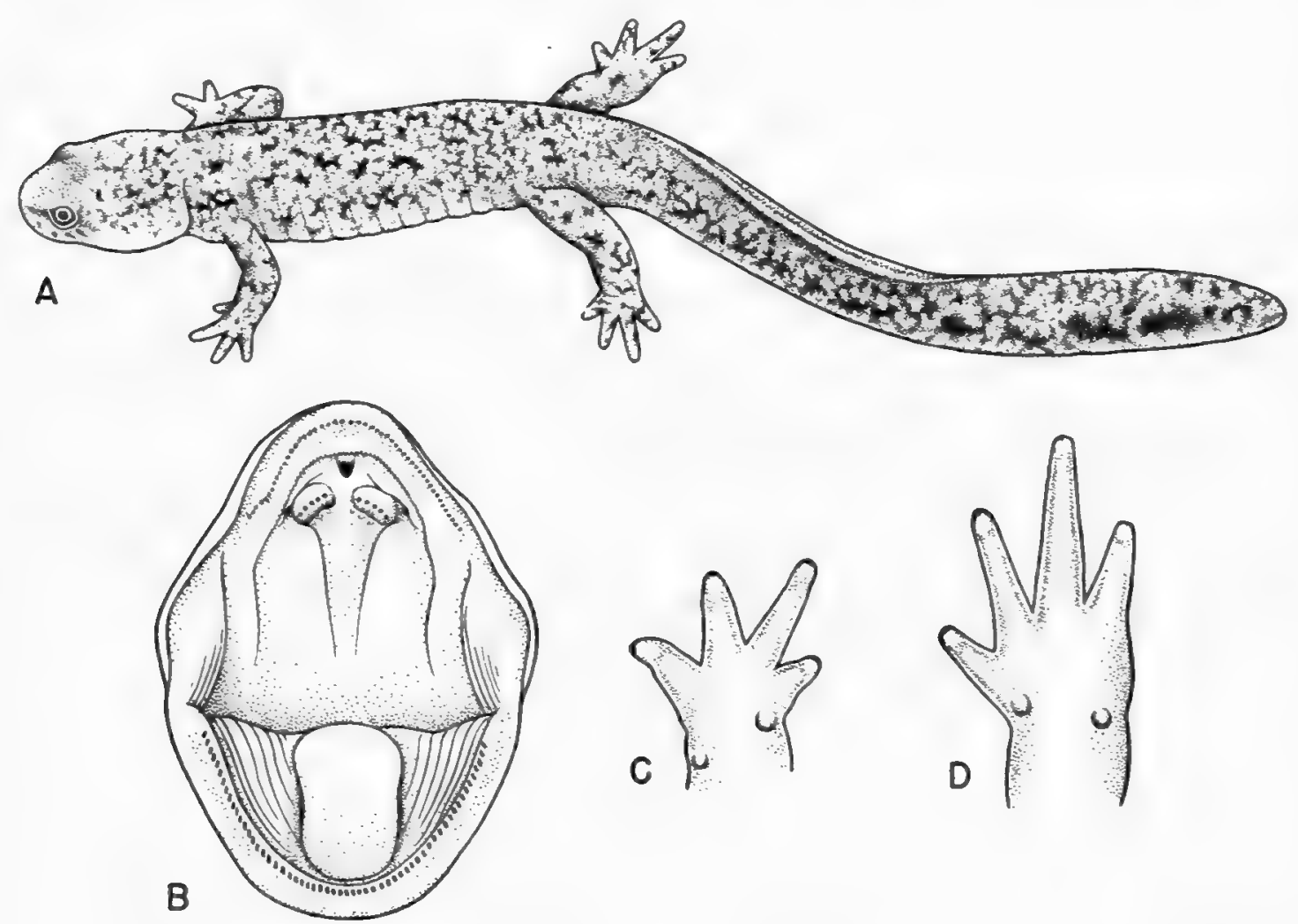

FIG. 14. Batrachuperus yenyuanensis. A. Adult female $(X 1)$. B. Oral cavity $(\times 21 / 2)$. C. Ventral view of hand $\left(\times 2 \frac{1}{2}\right)$. D. Ventral view of foot $\left(\times 2 \frac{1}{2}\right)$.

tail fin, which reaches the base of the tail. The posterior two-thirds of the tail is thin, and the last quarter is a knife-like fin. The two tubercles on the palms and soles distinguish this new form from all other species of the genus except pinchonii. The depressed head distinguishes it from all except tibetanus.

Description of type.-Body slender, dorso-ventrally depressed, with twelve costal grooves. Head greatly depressed; snout rounded; labial folds strongly developed; skin on the throat very loose, with many longitudinal folds; tongue 
small, elongated, with narrow free edges; two short, slightly curved patches of vomerine teeth, four teeth in the right patch and five in the left; head length four times in body length; head height about ten times, and head width about six times in body length; angle of the mouth reaching beyond the posterior corner of the eye, postorbital horizontal groove indistinct, postrictal vertical groove not visible, gular fold extending to the sides of the neck; eye as long as its distance from the nostril. Limbs well developed; longest digits meet when appressed; fingers 3-2-4-1, toes 3-2-4-1 in order of length; tips of fingers and toes covered with dark thickened horny epidermis; two darker cornified tubercles on the palm, one between the first and second fingers and one at the base of the fourth finger; two darker cornified tubercles on the sole, one between the first and second toes and the other at the base of the fourth toe. Tail longer than body, 112.6 per cent of the body length, cylindrical at the base, flattened toward the tip, last two-thirds very flat, tail fin thin and high and with last one-fourth knife-like, the edge of the dorsal tail fin especially thin. Vent crescentic, transverse, with a papilla-like swelling at the middle of the anterior edge, and with a shallow posterior longitudinal groove.

Dark brown above, indistinctly stippled with black, light gray below, distinctly stippled with black.

Measurements of type (percentage of body length in parentheses).-Body length $79 \mathrm{~mm}$.; head width $14.4 \mathrm{~mm}$. (18.2); head length $19 \mathrm{~mm}$. (24.5); head height $7.3 \mathrm{~mm}$. (9.2); length of eye $4.5 \mathrm{~mm}$. (5.6); trunk length $39.5 \mathrm{~mm}$. (50.0); length of foreleg $23 \mathrm{~mm}$. (29.1); length of hind leg $24 \mathrm{~mm}$. (30.3); tail length $89 \mathrm{~mm}$. (112.6); tail width $7 \mathrm{~mm}$. (8.8); tail height $12.4 \mathrm{~mm}$. (15.6).

Discussion of paratypes.-Fifty-nine specimens of yenyuanensis were collected from a large pond on Peilinshan at an altitude of 15,000 feet between Yenyuanhsien and Yenpienhsien, Sikang, on July 6, 1942, by H. W. Chang and Y.W. Kao. The series is uniform in coloration, body form, and shape of tail. The coloration exhibits indistinct marbling on the back, belly, and tail. The head is depressed, as is the body. The tail is weak, with a thin, high fin reaching the base of the tail dorsally, and with a knife-like tip. There are eleven or twelve costal grooves. The vomerine teeth are in two oblique patches on a line between the choanae, the number in each patch varying in the ten specimens studied as follows: $3-4$ in one, $4-4$ in two, 4-5 in three, 5-5 in two, 5-6 in one, and 6-6 in one. The digits are much more flattened and pointed than in any other species of Batrachuperus. They exhibit abnormalities in number, shape, and size, fifty-one out of fifty-nine specimens showing some combination of abnormalities. The tubercles on palms and soles are very distinct.

The average body length of ten males is $82.9 \mathrm{~mm}$., and of ten females 74.8 $\mathrm{mm}$. The trunk of the female is proportionately longer than that of the male. The male has a transverse crescentic vent, with a lighter-colored papilla in the middle of the anterior lip; in the female the vent is a longitudinal slit with swollen lips. 
Batrachuperus yenyuanensis: Measurements of Ten Male and Ten Female Paratypes

\begin{tabular}{|c|c|c|c|c|}
\hline Measurements & Sex & Range & Average & $\begin{array}{c}\text { Ratio to } \\
\text { body length }(\%)\end{array}$ \\
\hline Body length...... & $\begin{array}{l}07 \\
9\end{array}$ & $\begin{array}{l}75.6-91.5 \\
68.2-82.2\end{array}$ & $\begin{array}{l}82.8 \\
74.8\end{array}$ & $\ldots$ \\
\hline Head width. . & $\begin{array}{l}7 \\
\wp\end{array}$ & $\begin{array}{l}14.0-16.7 \\
11.6-13.5\end{array}$ & $\begin{array}{l}15.0 \\
12.9\end{array}$ & $\begin{array}{l}18.0 \\
17.2\end{array}$ \\
\hline Head length. & $\begin{array}{l}\sigma^{7} \\
9\end{array}$ & $\begin{array}{l}17.8-23.0 \\
16.2-19.0\end{array}$ & $\begin{array}{l}20.3 \\
17.7\end{array}$ & $\begin{array}{l}24.4 \\
23.6\end{array}$ \\
\hline Head height. . & $\begin{array}{l}0^{7} \\
9\end{array}$ & $\begin{array}{l}6.6-8.3 \\
6.2-7.8\end{array}$ & $\begin{array}{l}7.4 \\
7.0\end{array}$ & $\begin{array}{l}8.9 \\
9.3\end{array}$ \\
\hline Length of eye. . & $\begin{array}{l}0^{7} \\
q\end{array}$ & $\begin{array}{l}4.2-5.2 \\
3.9-5.0\end{array}$ & $\begin{array}{l}4.6 \\
4.3\end{array}$ & $\begin{array}{l}5.7 \\
5.6\end{array}$ \\
\hline Trunk length..... & $\begin{array}{l}0^{7} \\
9\end{array}$ & $\begin{array}{l}34.7-45.6 \\
34.5-48.0\end{array}$ & $\begin{array}{l}40.4 \\
40.0\end{array}$ & $\begin{array}{l}48.8 \\
52.0\end{array}$ \\
\hline Length of foreleg. . & $\begin{array}{l}0^{7} \\
9\end{array}$ & $\begin{array}{l}23.0-26.9 \\
20.5-24.0\end{array}$ & $\begin{array}{l}25.0 \\
22.0\end{array}$ & $\begin{array}{l}30.1 \\
29.5\end{array}$ \\
\hline Length of hind leg. & $\begin{array}{l}0^{7} \\
0\end{array}$ & $\begin{array}{l}24.0-28.4 \\
21.8-27.4\end{array}$ & $\begin{array}{l}26.4 \\
24.0\end{array}$ & $\begin{array}{l}31.7 \\
32.0\end{array}$ \\
\hline Tail length. . & $\begin{array}{l}0^{7} \\
q\end{array}$ & $\begin{array}{l}89-120 \\
67-95\end{array}$ & $\begin{array}{l}98.6 \\
79.9\end{array}$ & $\begin{array}{l}118.9 \\
106.6\end{array}$ \\
\hline Tail width... & $\begin{array}{l}0^{7} \\
\%\end{array}$ & $\begin{array}{l}5.7-8.4 \\
4.6-6.3\end{array}$ & $\begin{array}{l}6.6 \\
5.4\end{array}$ & $\begin{array}{l}7.9 \\
7.2\end{array}$ \\
\hline Tail height. & $\begin{array}{l}0^{7} \\
\text { + }\end{array}$ & $\begin{array}{r}10.4-13.5 \\
8.3-10.8\end{array}$ & $\begin{array}{r}11.3 \\
9.4\end{array}$ & $\begin{array}{l}13.6 \\
12.5\end{array}$ \\
\hline
\end{tabular}

Batrachuperus cochranae sp. nov.

Type.-No. 49378 Chicago Natural History Museum, from Lianghokou, Paohsinghsien (Muping), Sikang, China, 12,500 feet altitude. Adult male, collected August 9, 1939, by Ch'eng-chao Liu.

Diagnosis.-A smaller Batrachuperus, distinguished from all other species by the lack of labial folds and the presence of pitted and thickened skin on the throat; mouth large, with the rictus as far back of the posterior corner of the eye as the distance from the nostril to the anterior corner of the eye; maxilla much better developed than that of other species of Batrachuperus; without cornified epidermis on the palm or sole; the tips of the digits slightly cornified, palmar and plantar tubercles lacking; vomerine teeth seven to nine; the vomerine tooth patches curved and nearly meeting each other.

Description of type.-Body cylindrical and moderately stout, with eleven costal grooves. Head long, snout oval as seen from above and below; head length 25 per cent, head width 17.1 per cent, and head height 10 per cent of the body length; eye longer than the distance from the nostril to its anterior corner; no labial folds; maxillary and mandible well developed, with rictus as far behind the posterior corner of the eye as the distance from the nostril to the anterior corner of the eye; top of the head flat; postorbital horizontal grooves, and postrictal grooves very strongly developed, with a distinct depression where they meet; gular fold extending on to the sides of the neck; skin on the throat thick, without the folds of other species of the genus; mouth large, tongue large, 
rounded, with free edge; vomerine teeth well developed, 9-7, the tooth patches curved and nearly meeting each other; maxillary teeth well developed; when appressed the tips of the longest digits do not meet by a distance less than a costal space; fingers 2-3-4-1 and toes 2-3-4-1 in order of length; no dark, thickened horny epidermis on palms and soles or at the tips of digits; tubercles on palms and soles wanting. Tail as long as body, cylindrical at the base, flattened gradually toward the tip; tail fin very thick, only the dorso-posterior portion thin. Vent T-shaped externally; the opening proper crescentic, with a small papilla at the middle of the anterior lip, and posteriorly with a shallow longitudinal groove. Skin thick and smooth but with conspicuous pits, especially on the head; skin of throat and belly also greatly pitted.

Back dark brown, with three ill-defined, black, marbled lines; throat, belly and the ventral sides of the tail and limbs lighter in color and uniform.

Measurements of type (percentage of body length in parentheses).-Body length $70 \mathrm{~mm}$; head width $12 \mathrm{~mm}$. (17.1); head length $17.5 \mathrm{~mm}$. (25.0); head height $7 \mathrm{~mm}$. (10.0); length of eye $4 \mathrm{~mm}$. (5.7); trunk length $32 \mathrm{~mm}$. (45.7); length of foreleg $18 \mathrm{~mm}$. (25.7); length of hind leg $20.5 \mathrm{~mm}$. (29.2); tail length $70 \mathrm{~mm}$. (100.0); tail width $9 \mathrm{~mm}$. (12.8); tail height $9 \mathrm{~mm} .(12.8)$.

Discussion of paratype.-The single paratype, a smaller specimen, was collected with the type. It has a very poorly developed labial fold, and fewer vomerine teeth $(6-7)$. In all other characters it is similar to the type.

\section{Genus TYLOTOTRITON Anderson}

Key FOR IDENTIFICATION OF SPECIES OF TYLOTOTRITON

I. Costal tubercles indistinct and squarish.

A. Three or more wide clay-colored bands on the body and a clay-colored tail. kweichorvensis.

AA. No clay-colored bands on the body, which is uniformly black; tail black with a scarlet-edged ventral tail fin.....................................

II. Costal tubercles very distinct and rounded.................. verrucosus.

\section{Tylototriton kweichowensis Fang and Chang}

Tylototriton kweichowensis Fang and Chang, 1932, Sinensia, 2, (9): 112-Kungchishan, Tatinghsien, western Kweichow.

History of species.-The type and seven paratypes were collected on September 8, 1930, from Kungchishan (about 2,000 meters altitude) of Tatinghsien by Mr. Y. S. Ling and described (1932) as Tylototriton kweichowensis.

Distribution and collection data.-Besides the type series, ten specimens were collected from Shihfangin, Kweichow, July, 1934, by D. C. Graham, and in the same year he collected four specimens from Shihmenkan, in the same province. All these specimens are in the United States National Museum. Tylototriton kweichowensis is endemic in Kweichow, from about 6,000 feet altitude.

Comparison with related species. - Tylototriton kweichowensis can easily be distinguished from andersonii, verrucosus, and asperrimus by its costal tubercles, 
which are indistinct and squarish, whereas in the three other species the costal tubercles are rounded and distinct. The coloration sharply distinguishes kweichowensis from taliangensis. Preserved specimens of kweichowensis (pl. 2) have three wide clay-colored bands on the back, and a clay-colored tail, and in some cases two clay-colored bands on the sides of the body.

Original description (type No. 4664 Academia Sinica, adult male).- "Habit rather stout; head flat, depressed broader than long; snout short, obtusely rounded; lateral cranial porous ridge subtriangular, prominent, very slightly depressed at anterior connection on the tip of the snout, posterior end curved inward, like a scroll, in front of the parotoid; a faintly marked median ridge beginning from a little behind the apex inside the triangle, running posteriorly to end at a point $3 \mathrm{~mm}$. anterior to vertebral porous ridge in a prominent knob with a depression before it; parotoids also prominent, auricular, slightly concave above, as long as the distance between two scrolls of lateral cranial ridges; eye lateral and moderate, orbit diameter about equal to its distance from the nostril or to the internasal space; upper eyelid granular and rather broad, about onethird of interorbital and visible from above; lower eyelid smooth, semitransparent and narrower than the upper one; nostril oval, rather small, with a small valvular flap in it, close to the anterior extremity of the lateral cranial ridge and half way between the top of the snout and the labial edge, separated from its fellow of the opposite side by a wide internasal space which is about half the width of the interorbital; vomero-palatine teeth in two oblique longitudinal series, meeting anteriorly and commencing in front of (or on a line with), and between the anterior borders of choanae, nearly parallel to each other at first, then diverging latero-posteriorly, and sometimes sharply diverging behind and along the inner elevation of the eyeball, ending at a point slightly before a line between the mouth corners; tongue nearly circular, moderate, its diameter slightly less than half the width of the mouth, slightly free at lateral sides; a gular fold from parotoid to parotoid transversely across the under side of the nape; a series along each side of the body of somewhat squarish knob-like porous glands separated from each other by narrow grooves, about eighteen in number, comparatively prominent and distinct anteriorly, evanescent and confluent to each other posteriorly, the first starting a little behind and quite above the axilla on a level with the parotoid, the last terminating at the root of the tail just on the level of the posterior border of the vent; a flattened vertebral porous ridge nearly as wide as the lateral series beginning on a line with the scrolls of the lateral cranial ridges and terminating at the same level as that of the lateral series; glandular pores on the anterior cranial ridges readily seen externally; distance from the tip of the snout to the gular fold more than one-third of the distance from the gular fold to the anterior border of the vent; tail long, slightly shorter than head and body together, laterally compressed, with a sharp dorsal edge commencing just behind the vent, tapering from the base and ending in a blunt point, but curved up or more vertically expanded at its mid portion, slightly higher than the base; limbs rather stout, moderately long, the tips of 
the fingers reaching much beyond the nostril to the tip of the snout, those of the toes much beyond the middle of the distance between the axilla and the groin when both fore and hind limbs are stretched forward, and interpalmating when both are appressed against the flank; phalanges rather short, with blunt tips and without webs; fingers four, the third one longest, the fourth subequal to the first; toes five, the third one the longest, the fourth very slightly shorter than the third, the first and fifth the shortest; no metacarpal or metatarsal tubercles; vent a short longitudinal slit with transverse folds or papillae along the edges, which are slightly swollen up. Top of head, dorsal and lateral sides of body and tail covered with glandular porous tubercles of various sizes, irregularly distributed; ventral surface of body transversely wrinkled and also with glandular tubercles which are much smoother than those of other parts of the body; tail with its dorsal and ventral margins vertically wrinkled, the dorsal margin more or less with discriminable minute tubercles, the ventral margin rather smooth, without tubercles; snout, lips, digits, palms and soles as well as lower eyelids free from tubercles.

"Ribs sixteen in number, one stout sacral, fifteen dorsal, the first two under the scapula, the third to the sixth each bearing a small latero-posterior process, each process ending in one of a knob-like lateral series of glands that begin on the end of the process of the third rib; the extremities of the remaining ribs not associated with, but beneath these glands and terminating in the pleuromuscles; first four (or more or less) caudal vertebrae with their transverse processes projected, also terminating in the knob-like glands."

Measurements of type (after Chang; percentage of body length in parentheses).-Total length $155.8 \mathrm{~mm}$.; body length $82.0 \mathrm{~mm}$.; head length $18.6 \mathrm{~mm}$. (22.6); head width $18.3 \mathrm{~mm}$. (22.3); length of foreleg $27.5 \mathrm{~mm}$. (33.5); length of hind leg $31.5 \mathrm{~mm}$. (37.8); tail length $73.8 \mathrm{~mm}$. (90.0).

Variation.-Variation in Tylototriton kweichowensis is great. In preserved specimens there are two groups: one is blackish brown on the head, the body, the limbs, and a small part of the sides of the base of the tail; the other has three or five wide clay-colored bands on the body, this color covering nearly the whole tail, and present on the lower eyelids, the corners of the mouth, the posterior ends of the cranial ridges, most of the parotoids, the sides of the neck, the anterior aspects of the bases of the arms and legs, all the fingers and toes, and the region around the vent. The three dorsal bands, and the color of the tail and the parotoids are constant, the coloration being otherwise variable. Of eleven specimens, five had three clay-colored bands on the back, with scattered spots of the same color near the groin region, and the basal region of the vent blackish brown; four individuals had five clay-colored bands, three on the back and two wide ones on the sides of the body, with the vent region entirely claycolored; two had three bands on the back and two narrow interrupted ones on the sides.

The vomerine teeth of five specimens do not meet at their anterior ends between the choanae, and their anterior portions are parallel; they are angularly 
bent laterad opposite the middle or posterior parts of the ocular prominences. The anterior ends of the vomerine tooth rows meet anteriorly between the choanae in three specimens and diverge posteriorly along the curves of the ocular prominences. In one specimen the anterior ends of the two vomerine tooth rows are fused into a single row for a short distance posterior to the choanae, after which the two rows are divided, diverging along the curves of the ocular prominences.

I took X-ray pictures of five specimens, and four were dissected and carefully studied with the binocular microscope. The X-ray pictures show very definitely that all the specimens have fifteen ribs instead of sixteen, as stated by Chang, and this is substantiated by the dissections.

\section{CONDITION OF RIBS}

$\begin{array}{ll}\text { Rib } & \text { U.S.N.M. } \\ \text { No. } & \text { No. } 95523\end{array}$

1 No spine and under scapula

2 Small spine near apical end of rib, partly under scapula

3 Small spine more apical

4 Large spine near apical

5 Small spine more apical

6 With apical dorsal ridge

7 With apical dorsal ridge

8 With apical dorsal ridge

9 With apical dorsal ridge

10

Normal

11

Normal

12 Free end curved upward

13 Free end curved upward

14 Free end curved upward

\section{U.S.N.M.} No. 95525

No spine and under scapula

No spine and partly under scapula

Large spine at middle

Large spine near distal

Small spine more distal

$$
\text { Normal }
$$

Normal

Normal

Normal

Normal

Normal

Free end curved upward

Free end curved upward

Free end curved upward

Sacral rib
U.S.N.M. No. 95560

No spine and under scapula

No spine and partly under scapula $\underset{\text { apical }}{\text { Small spine more }}$

Large spine near apical

Normal

Normal

Normal

Normal

Normal

Slightly broad and flattened

Slightly flattened and forked at free end

Broad, flattened and forked at free end

Broad, flattened and forked at free end

Very broad, flattened and forked at free end

Sacral rib
U.S.N.M.

No. 95562

No spine and under scapula

Spine near apical end of rib, under scapula

Small spine more apical

Large spine near apical

Small spine more distal

Normal

Normal

With apical dorsal ridge

With apical dorsal ridge

With apical dorsal ridge

Forked at free end

Forked at free end

Forked at free end

Greatly flattened, not forked

Sacral rib 
Although all have fifteen ribs, no two specimens have the same modifications in all of the ribs (table, p. 105). Nos. 95560 and 95562, collected from Shimenkan, have most of the posterior ribs forked. This condition is not found in Nos. 95523 and 95525 , collected from Shihfangin.

Tylototriton kweichowensis: Measurements of Ten Specimens

\begin{tabular}{|c|c|c|c|}
\hline Measurements & Range & Average & $\begin{array}{c}\text { Ratio to } \\
\text { body length (\%) }\end{array}$ \\
\hline Total length....... & $.158-174$ & 163.4 & $\ldots$ \\
\hline Body length. & $82-94$ & 86.9 & $\cdots$ \\
\hline Head length. & $19-22$ & 20.2 & 23.2 \\
\hline Head width. & $18-20$ & 18.8 & 21.6 \\
\hline Head height. & $9-14$ & 11.5 & 13.2 \\
\hline Tail length. & $65-88$ & 76.5 & 88.1 \\
\hline Tail width. & $7-10$ & 8.6 & 9.8 \\
\hline Tail height. & $10-16$ & 13.1 & 15.0 \\
\hline
\end{tabular}

The proportions and dimensions vary greatly. The length of the tail of No. 95522 is only 84.0 per cent of its body length, whereas it is 103.5 per cent in No. 95560. The tail height of No. 95560 is 8.2 per cent of its body length and 10.7 per cent in No. 95522. The preservation has something to do with the height of the head and the diameter of the tail muscle but does not greatly affect the length of the body and the tail. Four specimens out of nine have abnormal digits: in No. 95521 the two outer fingers of the right hand are fused together, and the outer finger of the left hand is very small; No. 95523 has six toes on the left foot; No. 95560 has four very short flattened fingers on each hand; and No. 95562 has four toes on the right foot, and the fourth toe on the left foot as long as the third, both flattened.

\section{Tylototriton taliangensis sp. nov.}

Type.-No. 49388 Chicago Natural History Museum, from Pusakang, Fulinhsien, Sikang, 8,700 feet altitude. Adult male, collected July 25, 1942, by $\mathrm{H}$. W. Chang.

Diagnosis.-A Tylototriton differing from verrucosus and asperrimus in having the costal glands very indistinct and squarish. T. verrucosus has fourteen ribs, the last one the sacral, and has fifteen or sixteen large, distinct, rounded and light-colored costal glands. T. asperrimus has fifteen ribs, the last two being sacrals, and has fifteen or sixteen small, rounded costal glands, of the same coloration as the body. T. taliangensis (pl. 3, fig. 3) can easily be distinguished from kweichowensis by its uniformly black body and long black tail, whereas kweichowensis has light-colored longitudinal bands on the back, and a relatively short, light-colored tail.

Description of type.-Body moderately stout. Head depressed, longer than broad, its height about half of its width; snout squarish and projecting beyond the mouth; cranial ridges prominent, with a broad, somewhat convex space on top of the head; nostrils at the corners of the squarish snout; length of eye equal 
to the distance from the nostril to the anterior corner of the eye; upper eyelid with small warts, the lower free from warts; an elongated oval elevation on the top of the head with a free posterior edge in a line with the posterior ends of the cranial ridges; light-colored parotoid glands well developed, their caudal ends curved mesad in the neck region; mouth large, rictus in line with the posterior ends of the cranial ridges; tongue small and rounded; vomero-palatine teeth in two long oblique longitudinal series, near each other between the choanae, diverging posteriorly, and ending in a line at the middle of the quadratojugal bone; gular fold distinct and limited to the ventral side. Body cylindrical with very indistinct squarish costal grooves; ribs sixteen, the first two under the scapula and the last one modified as a sacral. Arm long, the tip of the longest finger reaching beyond the snout; fingers flattened, 2-3-4-1 in order of length; no subarticular or palmar tubercles; when the arm and leg are appressed, the fingers and toes overlap. Legs well developed, with five well-developed toes; toes flat and long, 3-4-2-5-1 in order of length, the third only slightly longer than the fourth; no subarticular or metatarsal tubercles. Tail weak, thin and long, $\mathbf{1 1 7 . 2}$ per cent of the body length, low, at the highest place only 11.7 per cent of the body length; the thin, sharp-edged dorsal tail fin reaching farther forward than the anterior margin of the vent; the ventral tail fin rounded and thick, reaching the posterior edge of the vent; the tail tip rounded, but very thin and narrow.

The skin very rough, with numerous small and large warts scattered over the body, except on the very margin of the jaws, around the nostrils, the lower eyelids, the ventral and dorsal surfaces of the digits, and the ventral edge of the tail; besides warts, the muscular portion of the tail has many vertical folds, and the belly many transverse folds. Vent a long slit, its length 9.8 per cent of the body length, surrounded by numerous folds.

Color in life.-Uniformly black, the dorsal side darker, in ground color; scarlet on the parotoid and the posterior ends of the cranial ridges, around the vent, on the ventral margin of the ventral tail fin, from the vent to the ventral side of the tip of the tail, and on the dorsal and ventral sides of the distal parts of all the digits, except that the tips of the digits are black. After preservation in formalin there is no change in the dark color, but the scarlet parts all become old ivory.

Measurements of type (percentage of body length in parentheses).-Total length $178 \mathrm{~mm}$.; body length $81 \mathrm{~mm}$.; head length $17 \mathrm{~mm}$. (20.9); head width $15.5 \mathrm{~mm}$. (19.1); head height $8 \mathrm{~mm}$. (9.8); length of foreleg $27 \mathrm{~mm}$. (33.3); length of hind leg $29 \mathrm{~mm}$. (35.8); tail length $95 \mathrm{~mm}$. (117.2); tail width $6 \mathrm{~mm}$. (7.4); tail height $9.5 \mathrm{~mm}$. (11.7); length of vent $8 \mathrm{~mm}$. (9.8).

Remarks.-Only three specimens of this exceedingly rare species are known, all of these collected from two localities during the summer of 1942. One specimen was obtained near Lolokou, Chaochiaohsien, and two were collected in the vicinity of Pusakang, Fulinhsien, Sikang Province. All these specimens were found on land. 


\section{Tylototriton verrucosus Anderson}

Tylototriton verrucosus Anderson, 1871, Proc. Zool. Soc. Lond., 1871: 423, pl. 76, fig. 6, and pl. 77-West Yunnan; Boulenger, 1882, Cat. Batr. Grad. Brit. Mus., p. 29; Brown, 1910, Rec. Ind. Mus., 5: 193; Annandale, 1911, op. cit., 6: 215; Boulenger, 1920, Bull. Soc. Zool. France, 45: 98; Schmidt, 1927, Bull. Amer. Mus. Nat. Hist., 54: 555; Pope, 1931, op. cit., 61 : 430.

Tylototriton verrocosa Fang and Chang, 1932, Contr. Metro. Mus. Nat. Hist. Acad. Sinica, 2: 121.

Tylototriton verrucosa Pope and Boring, 1940, Peking Nat. Hist. Bull., 15, pt. 1: 20.

History of species.-Anderson (1871) described the new genus and species from the Nantin, Momien (Tengyueh), and Hotha valleys of western Yunnan. In 1882, Boulenger reported another specimen from Yunnan; Brown (1910) stated that verrucosus is common around Tengyueh; Annandale (1911) reported this species from Yangpi about ten miles west of Talifu at an altitude of 5,200 feet, and from Tengyueh; Schmidt (1927) reported two specimens from Tengyueh and one from Chenkang, a town in Yunnan southwest of Shunning; and Pope (1931) reported another specimen from Yunnan.

Distribution and collection data.-This species is limited to the western part of Yunnan in China and ranges to the Kakhien Hills of Upper Burma, to Darjiling, Sikkim, and to Chieng Dao, northern Siam. The vertical distribution is from 4,500 to 6,000 feet altitude. I have collected no material.

Comparison with related species.-Tylototriton verrucosus can be distinguished from kweichowensis and taliangensis by its distinct rounded costal tubercles, these tubercles being indistinct and squarish in kweichowensis and taliangensis.

Original description.- "The lateral cranial ridge subtriangular; the median ridge running backwards from the inside of the apex of the triangle, but not reaching so far posteriorly as the lateral ridge, the extremities of which curve inwards like a scroll in front of the parotoids. The parotoids slightly concave above, and somewhat resembling the outline of an upturned human ear. The nostrils close to the extremity of the rounded snout, but with a considerable interval between them, semicircular, closed by a small valvular flap of skin. Eye of moderate size; upper eyelid large, granular. Fifteen knob-like glands along the side of the body; the first a short distance behind and about the axilla and on a level with the parotoids; the last three behind the leg when it is extended at right angles to the body. The vertebral glandular ridges begin on a line with the scroll-like extremities of the cranial crest, and terminate at the root of the tail. An obscure line of pores, larger than those of the rest of the body, from below the arm to the groin, rather toward the under surface of the side. A series of pores behind the angle of the mouth along the lateral cranial ridge to the top of the snout, on the loreal region behind the eye, and along the mandible and internal to it. The chin and throat thickly covered with small, smooth, porous glandular tubercles of nearly uniform size. The sides and upper parts of the body and of the tail are densely covered with glandular tubercles (porous) of various sizes and irregularly distributed. The ventral surface transversely 
wrinkled and covered with very minute porous glands, which scarcely project above the level of the skin. The upper margin of the tail sharp, and commencing with the last lateral knob. Under surface rather rounded. Numerous folds on the inner margin of the vent. Forearms extend the length of the fingers beyond the snout; the legs reach halfway to the axilla.

"Uniform blackish brown, paler on lips, snout, chin, throat, and undersurface of the limbs, all of which are of a brownish-olive tinge. Under-surface of the tail dull orange-yellow, fading to lightish brown on the sides.

"Length from tip of snout to vent 3 to 4 inches; vent to tip of tail 3 to $33 / 4$ inches.

"Hab. Nantin, Momien, and Hotha valleys, Western Yunnan, China.

"I first met with this remarkable newt in the flooded rice fields about the little Chinese town of Nantin, where, however, it was not very common. In the more elevated and subtemperate valley of Momien, at about a height of nearly 5,000 feet above the sea, and in the high sequestered valley of Hotha (5,000 feet) it was far from uncommon."

\section{Triturus wolterstorffi Boulenger ${ }^{1}$}

Molge wolterstorffi Boulenger, 1905, Proc. Zool. Soc. Lond., 1905, pt. 1: 277, pl. 17Yunnanfu.

Triturus wolterstorffi Dunn, 1918, Bull. Mus. Comp. Zool., 62: 451.

Hypselotriton wolterstorff Herre, 1934, Verh. Deutsch. Zool. Ges., 1934: 158; Wolterstorff, 1934, Zool. Anz., 108: 257; Pope and Boring, 1940, Peking Nat. Hist. Bull., 15, pt. 1: 23.

Cynops wolterstorff Chang, 1935, Bull. Soc. Zool. France, 60: 426; idem, 1936, Contr. Etude Morph. Biol. Syst. Amph. Urodéles Chine (Paris), p. 110.

History of species. - The above synonymy accounts for the history of the species, which has not been adequately studied. I got four living specimens from Professor Tieng, who studied the embryology of this species in Peip'ei, Szechwan, by means of living specimens transported from Yunnanfu.

Distribution and collection data.-Triturus wolterstorff (pl. 3, fig. 2) is an endemic form in Yunnan, inhabiting the lake outside of Yunnanfu. I have not collected specimens.

Comparison with related species.-The species wolterstorff has been referred to the distinct genus Hypselotriton because its quadrate is directed anterolaterally instead of postero-laterally, as in Triturus sensu str. Triturus wolterstorffi is larger and has a somewhat more laterally compressed body than is usual in related forms. I have followed Dunn and others in the use of Triturus in a broad sense.

Original description.- "Fronto-squamosal arch bony, thick. A chevronshaped series of palatine teeth, the apex on a line with the choanae. Tongue

${ }^{1}$ For detailed synonymy, see Chang, 1936, p. 110. 
small, subelliptical, the sides slightly free. Head without grooves, once and onefourth to once and one-third as long as broad, its length to base of tail; the greatest width of the head behind the eyes, which are rather small and feebly prominent; snout broadly rounded; labial lobes much developed. Body rounded in both sexes; no dorsal crest, no vertebral ridge. Limbs moderate; fingers and toes depressed, free; outer carpel and tarsal tubercles small but distinct, the latter sometimes very prominent. Tail strongly compressed, blade-like, with upper and lower crest, obtusely pointed, its length about that of head and body. Cloacal lips as in $M$. vulgaris. Skin perfectly smooth and shiny; a strong gular fold. Blackish olive above, with an orange or orange-vermilion vertebral stripe, with or without round or roundish spots or dots of the same color; orangevermilion beneath, with black spots or marblings, which may be confluent into longitudinal bands; lower edge of tail vermilion-orange.

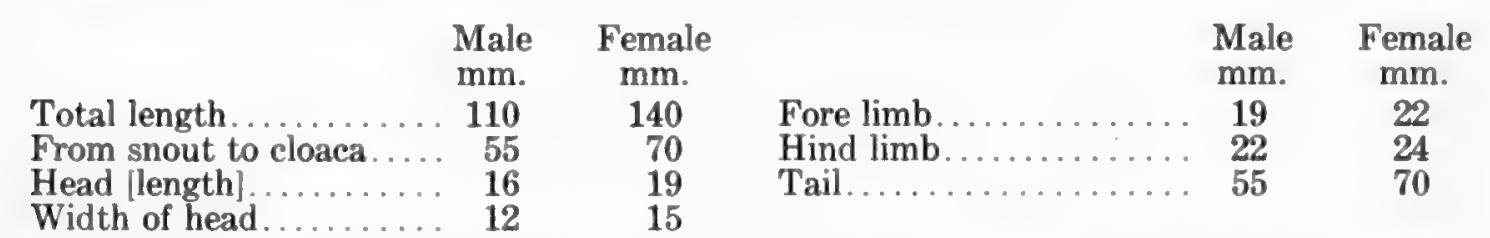

"Of the six specimens sent by Mr. Graham, all except the male, of which measurements are here given, have preserved the external gills - another instance of the neoteny already observed in tailed Batrachians living at great altitudes. The altitude of Yunnanfu, where the specimen was obtained, is about 6,000 feet. The skull in these branchiferous specimens is fully ossified and has all the features of the mature state. The female is full of ripe spawn.

"In the structure of the skull and the absence of crest or digital web in the male this new species approaches the Spanish-Portuguese $M$. boscae Lat., and the Chinese-Japanese M. pyrrhogaster Boie, the affinity of which I pointed out many years ago."

\section{SALIENTIA}

\section{Bombina maxima Boulenger}

Bombinator maximus Boulenger, 1905, Ann. Mag. Nat. Hist., (7), 15: 188, pl. 13, text fig. 2-Tungchuan, Yunnan.

Bombina maxima Schmidt, 1927, Bull. Amer. Mus. Nat. Hist., 54: 556; Liu, 1945, Jour. W. China Border Res. Soc., 15, (B) : 56, figs. 1-5.

Distribution.-Bombina is Eurasian, with two species in Asia and two in Europe. This genus has a curious discontinuous distribution. Bombina maxima is the species common in western and southwestern China, characteristic of the mountain regions of Yunnan, of southwestern Szechwan, southeastern Sikang, the western part of Kweichow and Kwangsi and northern Tonking. Bombina orientalis is a northern species of fire-bellied toad and is a low mountain form. It is found in very small mountain streams along the seacoast of northeastern Shantung, and in Manchuria, Korea, and adjacent areas. 
Comparison with related forms.-The various species of Bombina can easily be distinguished from all other Salientia of China by the red or orange yellow and black patches on the belly. The common name "fire-bellied toad" refers to these colored patches.

Bombina maxima (fig. 15) can be easily separated from Bombina orientalis by the body length, the size of the warts, and the colored patches on the belly. Bombina maxima is much larger in size than orientalis, with an average body length from snout to vent of about $60 \mathrm{~mm}$., while in orientalis it is only about

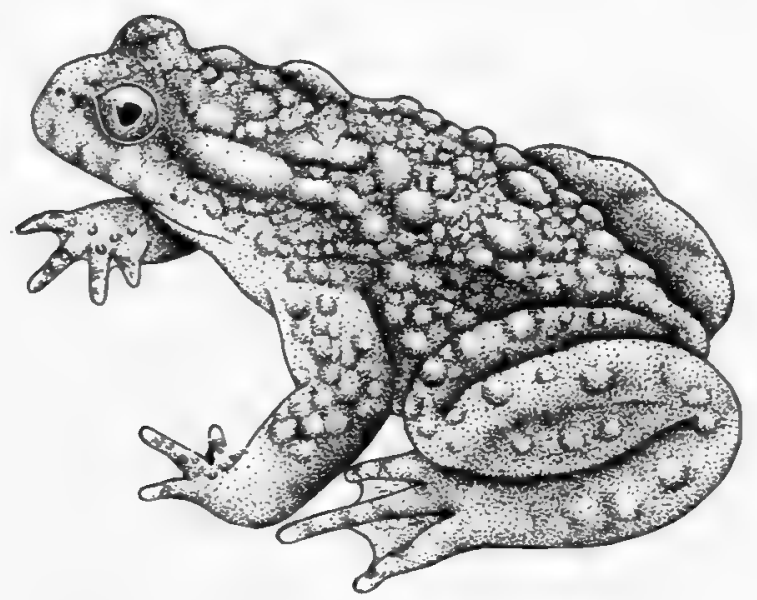

FIG. 15. Bombina maxima; male ( $\times 1)$.

$45 \mathrm{~mm}$. The body of maxima is rather stout and heavily built; in the northeastern form, the body is rather slender and more or less dorso-ventrally depressed. This difference may be related to their different breeding habitats, since maxima lays its egg-masses in open water, while orientalis attaches its eggs to the under surface of stones in small mountain streams. The warts of maxima are much larger and less uniform in size than those of orientalis. In maxima the colored patches of the belly are very large, while in orientalis the patches are smaller and much more numerous, so that its belly seems much more marbled.

It is especially noteworthy that the warning behavior of the fire-bellied toad is a generic character as well fixed as are skeletal or other structural features.

Collection data.-For the study of the life history of this toad I made a collecting trip to Sichang, Chaochiao, and Yenyuan in Sikang from March to August of 1942. The altitude of the city region of Sichang is 5,700 feet, and the maximum temperature is about $92^{\circ} \mathrm{F}$. from the end of April to the end of July. The city of Chaochiao is about 150 miles northeast of Sichang. The highest mountain between these two cities reaches an altitude of 11,000 feet, but the altitude of the city of Chaochiao is not more than 7,200 feet, and the temperature range was about $60^{\circ}-78^{\circ} \mathrm{F}$. from May 7 to 15 . The best place for collecting is on the high mountain between Hsuanshenpa (8,700 feet) and Lolokou 
$(10,000$ feet). Bombina maxima is found midway between these two villages, and also on the way to the city of Chaochiao. Its vertical distribution in this region is from 7,800 to 10,000 feet. The city of Yenyuan is about 120 miles southwest of Sichang, and has an altitude of 9,600 feet; from June 22 to July 9 , 1942 , a collecting trip was made to study the Amphibia of that locality. Bombina maxima is very abundant from 9,000 feet upward in Yenyuanhsien.

Original description.- "Vomerine teeth in two small groups or short transverse series close together behind the level of the choanae. Tongue large, circular, scarcely free at the sides and behind. Head broader than long; snout rounded, not quite as long as the diameter of the orbit; no canthus rostralis; nostril equally distant from the eye and the tip of the snout; interorbital space narrower than the upper eyelid, nearly equal to the distance between the nostrils. Fingers short, obtusely pointed, first shortest, third longest, fourth a little longer than second; no subarticular tubercles; two round palmar tubercles, inner larger and more prominent. Tibio-tarsal articulation reaching the shoulder, tarso-metatarsal articulation reaching the eye; tibia as long as the femur, the heels meeting when the legs are folded at right angles to the rhachis; foot as long as the tibia; toes short, obtuse, flattened, only half-webbed; no subarticular tubercles; a small, rounded inner metatarsal tubercle. Upper parts covered with small warts intermixed with very large glands studded with pores, similar to the parotoids of toads; the largest are situated behind the eyes (true parotoids), on the tibia, on the tarsus, and on the back, where they form a pair of curved or angular chains behind the head, with the convexity turned inwards. Lower parts nearly smooth; a more or less distinct gular fold. No horny spines on any part of the body. Blackish olive above, with rather ill-defined black markings forming vertical bars on the upper lip and cross-bars on the limbs; only the inner finger and toe with a light tip; a more or less distinct light transverse spot on the back, just behind the head. Lower parts marbled bright orange and black, in about equal proportions, or the black predominating; greater part of palm and sole orange, this colour involving the inner digit; the orange of the lower surface of the arm either extending across the breast, or widely separated from a pair of pectoral spots; plantar, tarsal, and tibial orange spots continuous or interrupted; the orange not extending on the back of the thighs.

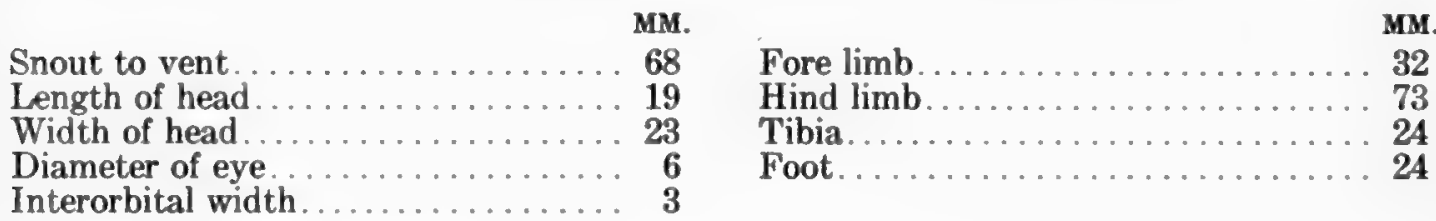

"The three specimens here described are females."

Coloration.--The variation in coloration has no connection with sex. The adult toad is stippled with silver gray or silver tinged with golden on the cinnamon brown ground color of the head, back of the body, and dorsal sides of the limbs, and mostly has a green area on the dorso-median part of the shoulder region. 
Each wart on the back bears numerous fine black spines, and these spines are more numerous in males than in females. This coloration varies slightly according to the nature of the surroundings. Under bright light it is lighter, but in the dark the silver appearance may be lost, and the animal may become a golden cinnamon brown. Dark olive or black bars are developed on the limbs, but those on the upper arms and legs are not constantly present and are rather inconspicuous, while those on the lower arms, fingers, tarsus, foot and toes are much better developed, especially those on the digits. The pupil is triangular in shape, with a single angle pointed ventrad, amber in color. A bright golden ring encloses the pupil and the rest of the iris is golden, stippled with black. The throat, the belly and the ventral sides of the limbs are black or dark gray variegated with scarlet, orange, or orange yellow. There is always a patch of scarlet or orange color on the palms and soles, and a transverse patch of the same color extends on the ventral side of the thighs.

All this makes the several species of fire-bellied toads unlike any other salientians. The brilliant colors are unquestionably effective in warning off predators, as is known to be the case with the European species of Bombina.

\begin{tabular}{|c|c|c|c|c|}
\hline Measurements & Sex & Range & Average & $\begin{array}{l}\text { Ratio to } \\
\text { body length (\%) }\end{array}$ \\
\hline $\begin{array}{l}\text { ody length...... } \\
\text { (snout to vent) }\end{array}$ & $\begin{array}{l}\sigma^{7} \\
q\end{array}$ & $\begin{array}{l}53-69 \\
54-73\end{array}$ & $\begin{array}{l}62.2 \\
61.8\end{array}$ & $\cdots$ \\
\hline $\begin{array}{l}\text { Head length...................... } \\
\text { (angle of jaws to tip of snout) }\end{array}$ & $\begin{array}{l}\sigma^{\top} \\
\text { Q }\end{array}$ & $\begin{array}{l}17-22 \\
18-22\end{array}$ & $\begin{array}{l}19.9 \\
19.7\end{array}$ & $\begin{array}{l}32.0 \\
31.9\end{array}$ \\
\hline Head width $\ldots . . . . \cdots \ldots \ldots \ldots$ & $\begin{array}{l}0^{\pi} \\
q\end{array}$ & $\begin{array}{l}17-25 \\
20-23\end{array}$ & $\begin{array}{l}20.7 \\
21.1\end{array}$ & $\begin{array}{l}33.3 \\
34.2\end{array}$ \\
\hline $\begin{array}{l}\text { ower arm length } \\
\text { (elbow to tip of third finger) }\end{array}$ & $\begin{array}{l}\sigma^{7} \\
\varnothing\end{array}$ & $\begin{array}{l}20-29 \\
23-29\end{array}$ & $\begin{array}{l}23.8 \\
24.4\end{array}$ & $\begin{array}{l}38.2 \\
39.5\end{array}$ \\
\hline $\begin{array}{l}\text { Diameter of lower arm } \ldots \ldots \ldots \ldots \ldots \\
\text { (greatest diameter) }\end{array}$ & $\begin{array}{l}\sigma^{7} \\
8\end{array}$ & $\begin{array}{l}7-12 \\
6.0-8.5\end{array}$ & $\begin{array}{l}9.6 \\
7.1\end{array}$ & $\begin{array}{l}15.5 \\
11.4\end{array}$ \\
\hline $\begin{array}{l}\text { (base of palm to tip of third finger) } \\
\text { (bal hand }\end{array}$ & $\begin{array}{l}0^{7} \\
q\end{array}$ & $\begin{array}{l}11-15 \\
12-15\end{array}$ & $\begin{array}{l}13.1 \\
12.8\end{array}$ & $\begin{array}{l}21.0 \\
20.7\end{array}$ \\
\hline 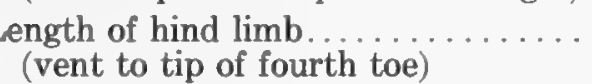 & $\begin{array}{l}0^{7} \\
9\end{array}$ & $\begin{array}{l}76-107 \\
70-90\end{array}$ & $\begin{array}{l}82.6 \\
75.7\end{array}$ & $\begin{array}{l}132.8 \\
122.5\end{array}$ \\
\hline 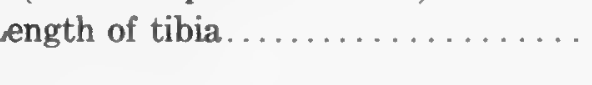 & $\begin{array}{l}\sigma^{7} \\
\wp\end{array}$ & $\begin{array}{l}22-33 \\
21-27\end{array}$ & $\begin{array}{l}26.1 \\
22.9\end{array}$ & $\begin{array}{l}42.0 \\
37.1\end{array}$ \\
\hline ength of foot and tarsus. & $\begin{array}{l}0^{7} \\
9\end{array}$ & $\begin{array}{l}32-49 \\
32-44\end{array}$ & $\begin{array}{l}37.1 \\
35.8\end{array}$ & $\begin{array}{l}59.6 \\
57.9\end{array}$ \\
\hline (base of inner metatarsal tubercle to & $\begin{array}{l}\sigma^{7} \\
\text { q }\end{array}$ & $\begin{array}{l}19-31 \\
17-25\end{array}$ & $\begin{array}{l}23.3 \\
20.6\end{array}$ & $\begin{array}{l}37.2 \\
33.3\end{array}$ \\
\hline
\end{tabular}

Secondary sex characters.-The average body length of females is $62 \mathrm{~mm}$., while in males it is the same. In males, a large diffuse nuptial pad covers the inner side of the arm, extending from the distal portion of the upper arm, covering the inner face of the forearm, and two-thirds of the inner metacarpal tubercle (fig. $16, \mathrm{~B})$. The inner dorsal aspects of the first, second, and third fingers are provided 
with similar horny nuptial pads. There are also two patches of nuptial pads on the thorax near the base of each arm (fig. 16, A). The arm of the male is distinctly larger than that of the female, with the hand strongly bent inward. The fingers are much shorter in the males, especially the first, which is angularly bent. The fingers of the male are fringed with a skin fold, rather wide at the base, diminishing towards the tip. The metacarpal tubercle is larger in the males.

The skin of the male is more rugose, with minute spines on the back, the sides, and the limbs. The number of warts is much greater in the male. Thus
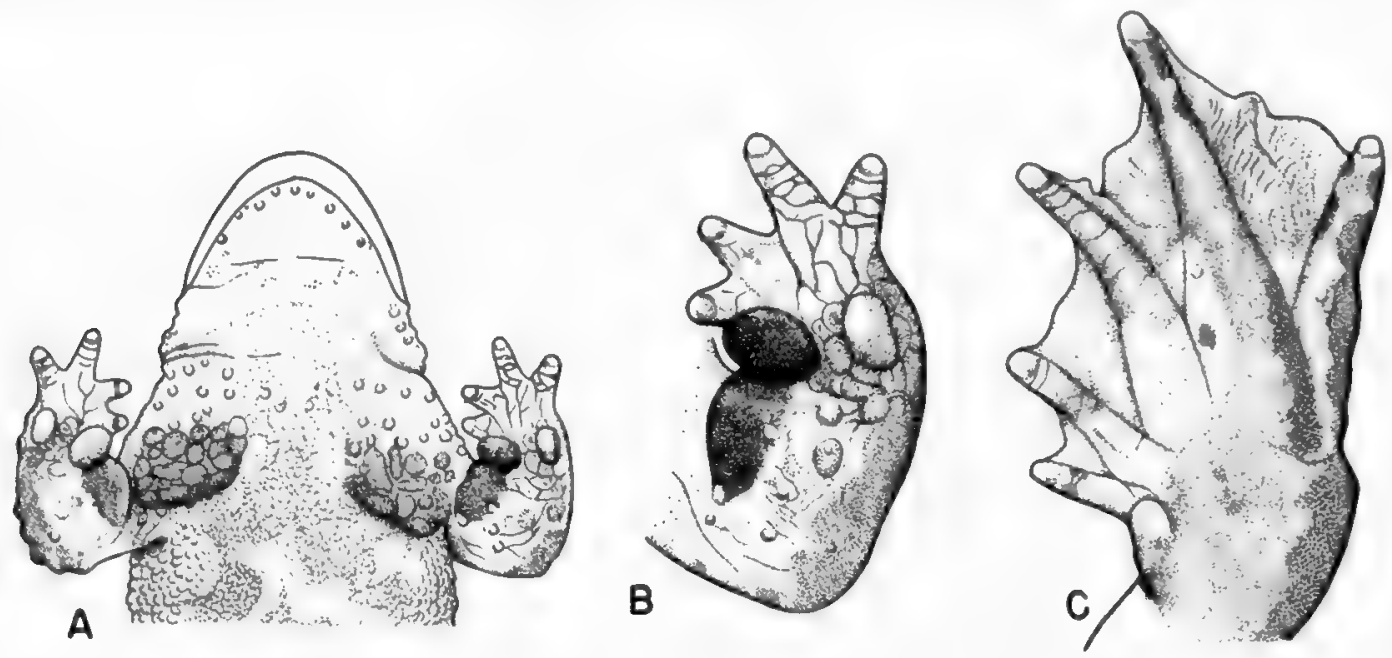

Fig. 16. Bombina maxima; male. A. Ventral view of head and thoracic region $(\times 1)$. B. Ventral view of hand $(\times 2)$. C. Ventral view of foot $(\times 2)$.

the females have a generally smoother appearance, though covered with large warts. The hind limb is distinctly longer in the males, and the glands on the tarsus and the toes are much better developed. The toes are nearly fully webbed in the male (fig. 16, C), and slightly more than half in the female.

Habitat and habits.- The adults of this fire-bellied toad are found in small pools and ponds, especially those with dead vegetation, and also less commonly in small mountain streams of running water. Both adults and young are found under stones at the edges of very small mountain streams, and of pools or ponds formed in connection with the streams. Just by turning a stone, very often one or more individuals are obtained. Some specimens were even found in a well by Mr. Kao at Lolokou. Fire-bellied toads are very inactive, and it is easy to catch them by hand.

This animal has a distinctively warning coloration, for the black and red, orange-red, or orange-yellow patches on the lower side and on the palms and soles are very conspicuous. When disturbed it does not attempt to escape, but remains in place and turns its limbs over its back, with the head and posterior extremity of the body bent upward, so as to show as much as possible of the bright colors on the lower surface. The palms and soles of the hands and feet are turned outward and upward, so that four red spots are shown conspicuously. 
Breeding behavior.-The breeding season is rather short. I found many paired individuals in pools near the top of the mountain of Yenwot'ang on May 4, 1942, on the way to the city of Chaochiao, but when I came back, on May 12, only eggs and embryos at different stages of development were collected from those pools. Eggs and tadpoles at different stages were collected near the city of Yenyuan on June 29 by H. W. Chang and Y. W. Kao. Although there is no vocal sac in the male, yet a weak croak like the sound of a very young chicken or the cry of a newly born puppy was produced at twilight, near the breeding ground, or when they were carried around in the collecting bags. The male grasps the female just in front of the base of the thigh, as she is floating on the water.

Eggs.--Eggs are laid in masses, which mostly sink to the bottom of the pools, where they are covered by a thin layer of mud from the red soil. If there is any vegetation floating on the surface of the water, the egg-mass is attached to it and suspended from it. The eggs are coated with three layers of jelly, the middle layer being the thickest and the inner layer the thinnest. In the living condition the jelly is usually in masses, closely connected with the corresponding layer of the other eggs, but sometimes there are isolated eggs. The animal pole of the egg is brownish gray, with a creamy yellow color on the vegetal pole. The eggs are rather large. Ten eggs were measured, the average diameter being $3.18 \mathrm{~mm}$., with a range from 3.0 to $3.4 \mathrm{~mm}$.

Tadpoles and development.--A newly hatched individual is rather large and greatly flattened, as it is $9.8 \mathrm{~mm}$. long from the snout to the tip of the tail and $3.7 \mathrm{~mm}$. high in the middle region of the body; but it is only $1.5 \mathrm{~mm}$. in diameter in the thickest region of the body. That is why the animal at this stage always lies on its side. The color in this stage is uniformly grayish brown, with evenly distributed, light-colored granules. Nasal pits and proctodeum are clearly shown, with two dark-colored ventral suckers on the ventral side of the head region. Six short gill-filaments are developed on a single large fleshy base. The tail crest is strongly developed, reaching the nuchal region.

When the tadpole reaches $12 \mathrm{~mm}$. in length, the color of the body is darker and the tail crest is much lighter. The eyes are seen externally as black spots, the mouth is well developed, and the ventral suckers are clearly shown. The number of external gill-filaments is generally twelve. They are without fleshy bases, and are located near the ventral side of the neck region. The abdomen, which is larger than before, becomes much more rounded and the center of gravity is established in the mid-ventral region. Thus at this stage the body assumes a normal position. The tail crest is tremendously developed, reaching the dorso-posterior region of the head.

The external gills are covered up by a skin fold when the tadpole reaches $14 \mathrm{~mm}$. in length. Vestiges of the ventral suckers are still visible. Black lines that form a network by crossing each other are developed all over the body and at the tail crest, but the black granules are limited to the body and the muscular 
axis of the tail. The tail crest is still very high and reaches to the middle part of the trunk. A median ventral spiracle is formed posterior to the thoracic region.

At the morphologically defined stage, when the tadpole has developed a hind limb-bud (pl. 10, fig. 8), it is a pale creamy color on the head, the gill region, and the tail. The length at this stage varies according to environmental conditions. The body is a dark brownish gray, stippled with yellow. Most characteristic of the tadpole of this species are the sharp black lines crossing each other in a definite fashion on the body, especially conspicuous on the tail crest, where there are no other pigment granules. The whole animal is semi-transparent, so that the different parts of the brain, the circulation of the internal gills, and the viscera can be seen through the body wall. For this reason, the tadpole seems very delicate and very much like a mass of jelly. The pupil is round and surrounded by a wide black iris stippled with gold. The fully developed tadpoles are darker than the young ones.

Ten tadpoles with hind legs fully developed were measured. The average body length from snout to vent was $16.9 \mathrm{~mm}$., ranging from 16 to $18 \mathrm{~mm}$. As this tadpole is a quiet-water form, the body is stout and the tail is short, with a delicate tail crest. The width of the head is very nearly equal to the height of the body, and nearly equal to the height of the tail. The eyes are dorsolaterally located and quite close together, the space between them being only 25 per cent of the body length. The tail is very weak, delicate, and short, resembling that of Nanorana pleskei. It is interesting that this body feature is common to these two unrelated forms, both living in similar bodies of water in high mountains. Obviously this is a body form adapted to quiet water. The length of the tail, with its rounded tip, is 122.6 per cent of the body length, though the diameter of its muscular part is only 16.1 per cent of the body length. The weakness of the tail muscle is regarded as an adjustment to quiet water. The spiraculum is median ventral in position, with a transverse slit-like opening a little bit anterior to the central coil of the intestine. The anal opening is rather small, median ventral in position, at the base of the ventral tail crest.

\section{Bombina maxima: Measurements of Ten Tadpoles}

\begin{tabular}{|c|c|c|c|}
\hline Measurements & Range & Average & $\begin{array}{l}\text { Ratio to } \\
\text { body length }(\%)\end{array}$ \\
\hline Body length (snout to vent). & $16-18$ & 16.9 & \\
\hline Body height (at highest place) & $8.2-9.2$ & 8.5 & 50.5 \\
\hline Body width (greatest diameter). & $9.6-10.8$ & 10.4 & 61.2 \\
\hline Head height (at orbital region). & $5.8-7.2$ & 6.3 & 37.1 \\
\hline Head width (at orbital region). & $7.2-8.8$ & 8.1 & 47.9 \\
\hline Mouth width (including lips). & $3.9-4.2$ & 4.0 & 23.7 \\
\hline Space between eyes......... & $4.0-4.5$ & 4.3 & 25.0 \\
\hline Snout to spiraculum. & $9.0-9.8$ & 9.4 & 55.1 \\
\hline Tail length (vent to tip) & $19-23$ & 20.8 & 122.6 \\
\hline Tail height (at highest place). & 7.89 .0 & 8.1 & 47.5 \\
\hline Thickness of tail muscle (near tail base) & $2.5-3.0$ & 2.7 & 16.1 \\
\hline
\end{tabular}

The mouth is small and ventral in position. Its average width is $4.04 \mathrm{~mm}$., ranging from 3.9 to $4.2 \mathrm{~mm}$. A single row of small papillae are found around 
the mouth. The labial teeth of the tadpole are the type characteristic of Bombina. Each row generally consists of two sub-rows of short pointed teeth. In some specimens extra teeth may be present between the two sub-rows, making the arrangement of the teeth more or less irregular. Ten tadpoles with well-developed hind limbs were selected at random, and were carefully studied as to their tooth characters. Six individuals had two continuous rows on the upper lip and three rows on the lower lip but the innermost row was very narrowly interrupted; and four tadpoles had two continuous rows on the upper lip and three continuous rows on the lower lip. Under normal conditions the inner row of the upper lip and the middle row of the lower lip are the longest for the upper and the lower lips, respectively. The mandibles are rather weak, with fine teeth on their margins.

Metamorphosis.-As soon as the hind limbs become fully developed, the fore limbs come out through the skin, and dark marks on the limbs and the warts on the body and limbs are conspicuously developed. In the centers of the palms and soles a patch of light orange-yellow color is developed. As soon as half of the tail has been resorbed, the light orange-yellow patches become much more conspicuous. The ventral side of the limbs and the belly also develop dark and yellowish-orange patterns. The body is $14 \mathrm{~mm}$. long from snout to vent, immediately after the completion of metamorphosis.

\section{Genus AELUROPHRYNE Boulenger}

The first species of Aelurophryne was described by Günther in 1896 as Bufo mammatus, from specimens collected by the Russian explorer Potanin in the mountains and on the Kham Plateau (Tungsolo) on May 16 and July 3, 1894. Günther's specimens were in a poor state of preservation, and he could not recognize the shape of the pupil.

Boulenger (1919) received a single young specimen, still with a vestige of the tail, collected by his son Captain C. L. Boulenger in Ladakh Valley, Kashmir, at an altitude of 12,000 feet, in August, 1919. The combination of a vertical pupil with the absence of teeth in this $25 \mathrm{~mm}$. specimen suggested to Boulenger the examination of the vertebral column and the pectoral girdle of one of the type specimens of Bufo mammatus in the British Museum. He found that the sacral vertebra, with unusually widely dilated transverse processes, articulated with the coccyx by a single condyle, as in Pelobates and Megophrys, with which it agreed also in the structure of the pectoral girdle. Boulenger accordingly proposed the generic name Aelurophryne for Bufo mammatus, in allusion to the cat-like pupil. Aelurophryne is closely allied to Scutiger, differing from it in the absence of a notch in the posterior border of the tongue, which is oval, and in having the tympanum present, though hidden under the skin, and the eustachian tube moderately large. In 1917 Annandale described a tadpole from Lake Kreshen, Kashmir, as that of Rana pleskei, and in 1919 Boulenger suggested that this must be the tadpole of Aelurophryne mammata. Zarevsky (1925) 
recorded Bufo mammatus from western China, describing his specimens as similar to those of Guinther's original series.

Aelurophryne gigas was described by Zarevsky in 1925, based on a breeding male and female collected in September, 1900, from the Chamchu River, Kham Plateau, Tibet. His new frog is markedly distinguished from Aelurophryne mammata by its much greater size and by absence of glands on the chest.

Six specimens identified by Stejneger as Aelurophryne mammata included three collected from Sungpan by D. C. Graham, July, 1924, and three from Gieolonghsien (=Chiulung), Sikang, also collected by Graham, August 1-5, 1930.

Careful examination of my own collection, of the collections of Chicago Natural History Museum, and of the six specimens in the United States National Museum, discloses a considerable amount of taxonomic confusion. The tadpole described by Annandale as Rana pleskei (1917) and regarded as a specimen of Aelurophryne mammata by Boulenger (1919), must be quite another species of Aelurophryne, for the labial tooth formula described is entirely different from that of tadpoles from Sikang, which I regard as certainly true mammata. The Kashmir tadpole has the labial tooth formula I:4-4/I:3-3 and most of the mammata tadpoles have the formula I:5-5/I:5-5. I have now carefully studied three species of Aelurophryne tadpoles, and none have three interrupted rows of teeth on the lower lip, as described by Günther. Therefore, I consider Günther's tadpole to represent still another species of Aelurophryne. Boulenger's young specimen from Kashmir may represent the adult of the Kashmir tadpole, and in any case is not likely to belong to the species mammata.

A young adult specimen in the United States National Museum is not mammata but belongs to my species tainingensis, as shown by the rounded glands on the posterior median region of the belly, the longer slender arms, and the elongated depressed body. Another adult male in the same museum is not a mammata and is clearly a distinct new species characterized by the shape and location of the chest glands and the number and arrangement of their spines. Two further new forms, glandulata and brevipes, without spines on the chest glands, are represented in my own collection. According to the nature of the chest-gland spines the three large species of Aelurophryne of western China can be assorted into two groups; mammata has strong spines, and this form has a geographical distribution limited to the western and southern parts of the Kham Plateau, whereas glandulata and brevipes, without spines on the glands, are limited to the northeastern corner of Sikang and the northwestern part of Szechwan.

It has been suspected that the spines on the chest glands of the males may be present only during the breeding season. The present study does not support this hypothesis, as males of Aelurophryne brevipes, collected July 29, have on the thorax very finely granulated chest glands without spines or the scars of spines; whereas true Aelurophryne mammata, collected July 21, have very strong black spines on the chest glands. Furthermore, the eggs of brevipes were col- 
lected with the adult in the same locality and at the same time; July must accordingly be the breeding season of this species of Aelurophryne. All the males of brevipes have spines on their first and second fingers, like those of mammata, but have neither spines nor the traces of spines on the chest glands. The shape of the chest glands and the space between the chest glands in the males of brevipes are quite different from those of mammata; it is evident that they are distinct species with well-defined specific characters. It now appears that the presence or absence of spines on the chest is not the result of seasonal change.

Aelurophryne glandulata from Hopachai, Lifan, Szechwan, is closely related to brevipes.

Aelurophryne tainingensis is an independent and distinct species not closely related to the four species discussed above. Its smaller size, slender depressed body, absence of spines on the chest glands and on the fingers, and rounded glands on the belly distinguish it fully.

The types of Aelurophryne mammata were not sexed. Günther described only the gland near the axilla, as "an oval white or pink gland on each side of the chest, immediately behind the shoulder-joint." This is not the chest gland of the male, but the axillary gland of the female. The axillary gland is distinct in the female specimens collected by Herbert Stevens and indistinct in his male specimens. The chest glands, either with or without spines, are always present and prominent in the males of the various species of Aelurophryne, and it would be impossible to overlook such a conspicuous structure. Günther's specimens thus appear to be females.

Zarevsky's Aelurophryne gigas was distinguished from mammata by its much greater size and by absence of glands on the chest. Size alone is quite unreliable as a character to distinguish closely allied species when only one specimen of each species has been measured, especially when the difference amounts only to $10 \mathrm{~mm}$., Günther's type measuring $60 \mathrm{~mm}$., and Zarevsky's specimen $70 \mathrm{~mm}$. Zarevsky reports the "breeding male with callosities forming brushes of black prickles on the upper parts of first and second finger and with two asperities on each side of the chest." The axillary glands are indistinct in male specimens of Aelurophryne mammata in the large series collected by Stevens, and the absence or presence of axillary glands, unless the sex of the specimen is specified, does not distinguish allied species. It appears to me that Günther described the female of mammata and Zarevsky gave a description of a male of the same species. The difference in relative leg-length stated in the descriptions of Günther and Zarevsky appears to be explainable by differences of preservation of the material and a different terminology (see description of Aelurophryne mammata below).

Within the relatively primitive family Pelobatidae the species of Aelurophryne form a specialized group in which the maxillary teeth are entirely lost and the jaws are feeble. The ecological valence of Aelurophryne is much limited, as the several species live only on the high plateau or high mountains and are 
evidently adjusted to low temperatures. The wealth of species of Aelurophryne in western China appears to represent a rejuvenation of the genus after its establishment as a relict in the unfavorable plateau environment.

\section{Key For IDENTIFICATION OF AdULTS OF AELUROPHRYNe}

I. Size large, with warts on the soles and with nuptial spines on the first and second fingers of the male.

A. Strong spines on chest glands, no pre-humeral glandular areas...... mammata.

AA. Chest glands without strong spines, with pre-humeral glandular area.

B. Fourth toe long, two inner toes two-thirds webbed, inter-glandular space on chest small, about 1.2 per cent of body length.............. glandulata.

BB. Fourth toe short, two inner toes one-third webbed, inter-glandular space on chest wider, about 3 per cent of body length............... brevipes.

II. Size small, without warts on the sole and with nuptial pads on the first and second fingers of the male.

A. Warts on belly, two inner toes one-third webbed.............tainingensis.

AA. Belly without warts, two inner toes one-half webbed........... maculata.

\section{KEY FOR IDENTIFICATION OF TADPOLES OF AELUROPHRYNE}

I. Upper labial teeth six rows.

A. Labial tooth formula mostly $I: 5-5 / I: 5-5 \ldots \ldots \ldots \ldots \ldots$ mammata.

II. Upper labial teeth less than six rows.

A. Labial tooth formula mostly $I: 3-3 / I: 4-4 \ldots \ldots \ldots \ldots$ glandulata.

AA. Labial tooth formula mostly $I: 4-4 / I: 5-5 \ldots \ldots \ldots \ldots \ldots$ brevipes.

\section{Aelurophryne mammata Günther}

Bufo mammatus Günther, 1896, Ann. Mus. Zool. Acad. Sci. St. Petersbourg, 1: 208Tungsolo [Tungolo], Kham Plateau, Sikang, China.

Aelurophryne gigas Zarevsky, 1925, Ann. Mus. Zool. Acad. Sci. USSR, 26: 77-Chamchu River, Kham Plateau.

History of species in China.-The type locality of Aelurophryne mammata formerly was in western Szechwan, near Tibet. It is now in central Sikang. Specimens collected from the Kham Plateau have sometimes been recorded as from Szechwan and sometimes as from Tibet. Chicago Museum has 52 specimens of mammata, including adult males and adult females, collected by Herbert Stevens from Hlagong, near Yakiang, west of Kangting, July 21, 1929. Hlagong is on the Kham Plateau and it seems clear that this series may be regarded as essentially topotypic. These specimens afford the opportunity for a more detailed description of the species than has hitherto been possible.

Comparison with allied species.-Aelurophryne mammata (fig. 17) differs from Aelurophryne glandulata, brevipes, and tainingensis in having strong spines on the chest glands, which are only granulated or may have some fine black pigment in the three latter species; axillary glands are indistinct in the males of mammata and well developed in the males of glandulata, brevipes, and tainingensis. The warts on the soles of the feet of mammata distinguish this frog from maculata and tainingensis. 
Distribution.-The range of Aelurophryne mammata is the Kham Plateau, Kangshu, Sikang. Tadpoles of various stages were collected in a small stream near Hsintuchiao, which is close to the type locality, Tungsolo (Tungolo).

Original description.- "Crown without bony ridges. Head broad, snout obtuse, with the bones of the jaws remarkably feeble. Inter-orbital space as broad as the eye-lid. Tympanum small, entirely hidden under the skin. Fingers rather slender, the first and the second subequal in length; legs thin; the hind-

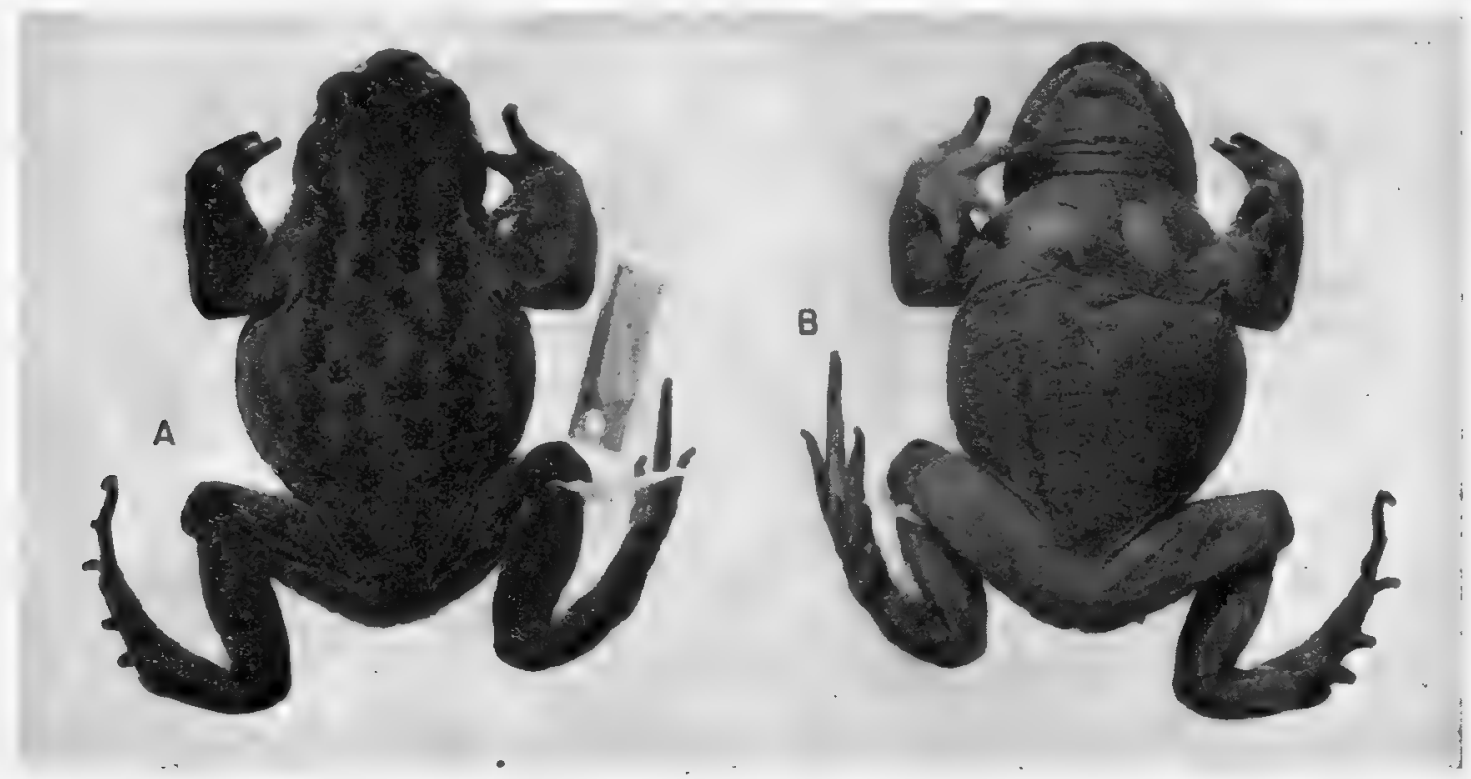

FIG. 17. Aelurophryne mammata; male (× 1). A. Dorsal view. B. Ventral view.

limb being carried forwards, the tibiotarsal articulation reaches the eye; metatarsus with an elliptical, flat tubercle; subarticular tubercles very indistinct. The three outer toes not half webbed, but the web between the three inner ones is as broad as that between the three outer ones. Upper surfaces with very flat, glandular patches, that representing the parotoids not more prominent than the others. Lower parts smooth, but there is an oval white or pink gland on each side of the chest, immediately behind the shoulder joint. Legs smooth, with small simple glands disseminated over the hinder part of the thighs. Uniform black, or dark brown with the glandular patches on the back of a darker shade. Length of body $60 \mathrm{~mm}$., length of third finger $12 \mathrm{~mm}$., length of hindlimb $84 \mathrm{~mm}$., length of fourth toe with metatarsal $27 \mathrm{~mm}$."

Description.-Adult male, C.N.H.M. No. 15199, Hlagong, near Yakiang, west of Kangting, Sikang, collected July 21, 1929, by Herbert Stevens. Body stout (fig. 17), head depressed, broader than long; snout round, depressed, and slightly projecting beyond the mouth, as long as the length of the eye; canthus rostralis very obtuse; loreal region oblique and slightly concave; nostrils about halfway between the eyes and the tip of the snout; interorbital space 
flat, about equal to the width of the upper eyelid; tympanum hidden; parotoid glands flat, with indistinct mesial and posterior boundaries, with a latero-ventral fold running obliquely to the arm; jaws weak, without teeth; tongue thick, oval, with very slight indentation behind; no vomerine teeth.

Arm very strong, fingers slender, tips rounded, the first and second fingers equal in length, much stronger and broader than the third and fourth fingers and with strong black sharp spines on the dorsal aspect of their basal segments; third and fourth fingers slender, the third one longest and the fourth much longer than the first two fingers; no subarticular tubercles; two large palmar tubercles of which the inner is larger than the outer.

Legs short, tibio-tarsal articulation reaching the posterior part of the parotoid gland, heels not meeting when hind limbs are placed at right angles to the body; toes fringed, with very small rounded tips except the first; first and second toes about one-half webbed, and the third and the fourth toes about one-third webbed; subarticular tubercles wanting; inner metatarsal tubercle oval, flat and without free edge; no outer metatarsal tubercle.

The skin extremely loose with numerous wrinkles or folds, and a large quantity of white spongy connective tissue between the skin and the muscle, especially prominent on the back of the body; warts extremely flat so that the skin is quite smooth; warts dark in color on account of their dark-colored pits; small rounded warts at postero-ventral sides of the thighs just below the anus; small black spines on the sides of the head, especially near the tympanic region; black pigmented areas on the ventral margin of the jaws; some small rounded warts developed behind the angles of the jaws. Throat skin smooth with fine wrinkles; the skin of the belly and the ventral sides of the thighs smooth, with loose, wrinkled, and folded skin; chest glands with strong black spines forming two elongated patches on the chest (fig. 17, B) similar to the strong black spines on the inner dorsal sides of the first and second fingers.

Color (in alcohol) on the upper side of the body nearly uniform deep mouse gray; when the specimen is submerged in water, a darker mark with a lighter margin may be seen extending from the middle part of the interorbital space backward to the shoulder region, where it becomes inconspicuous; flattened warts covered with black pits, the top of the snout much lighter in color than the region below the canthus rostralis; pale mouse gray on the throat, the belly and the ventral sides of the limbs; black pigmented areas on the margin of the jaws; spines of chest glands and of the first and second fingers coal black; tips of digits lighter in color.

The skin, the warts, and the coloration vary very slightly among the male specimens. The most noticeable variation is in the length of the hind limb; the tibio-tarsal articulation may extend to the angle of the mouth or only to the shoulder region. The fringing and webbing of the toes, though usually as described above, is subject to some variation; in one, the toes are more extensively fringed, and the two inner toes are about two-thirds webbed instead of one-half. 
The tips of the fingers and toes may be covered by black cornification but usually are lighter in color.

The secondary sex characters of Aelurophryne mammata are remarkably developed. Sex dimorphism in size is slight. In ten of the largest specimens of each sex, the average body length of the males is $72.0 \mathrm{~mm}$., while for the females it is $67.1 \mathrm{~mm}$. The skin of the males is extremely loose, with numerous wrinkles and folds, whereas in the females the skin is not loose and is more rugose on the dorsum, with various-sized warts, very numerous small warts on the sides, and only the throat and belly smooth. A large quantity of white spongy connective tissue is present between the skin and the muscles in the males; in the females this is not conspicuous. There is no conspicuous color dimorphism in alcoholic specimens except that the throat of the female is greatly marbled by deep mouse gray on a much lighter background.

In males, there are two well-developed chest glands covered by strong spines. The axillary glands present in the arm pits of the females are not developed in the males. In the males, very strong black spines are present on the inner dorsal sides of the first and second fingers, which are much stronger and broader than the corresponding fingers of the female.

Aelurophryne mammata: Measurements of Ten Male and Ten Female Adults

\begin{tabular}{|c|c|c|c|c|}
\hline Measurements & Sex & Extremes & Average & $\begin{array}{c}\text { Ratio to } \\
\text { body length }(\%)\end{array}$ \\
\hline Body length. & $\begin{array}{l}\sigma^{x} \\
0\end{array}$ & $\begin{array}{l}63-75 \\
62-75\end{array}$ & $\begin{array}{l}72.0 \\
67.1\end{array}$ & $\begin{array}{l}\ldots \\
\ldots\end{array}$ \\
\hline Head length.......... & $\begin{array}{l}\sigma^{7} \\
\wp\end{array}$ & $\begin{array}{l}19.5-24.0 \\
20.0-23.0\end{array}$ & $\begin{array}{l}22.5 \\
21.2\end{array}$ & $\begin{array}{l}31.2 \\
31.5\end{array}$ \\
\hline Head width. & $\begin{array}{l}0^{7} \\
9\end{array}$ & $\begin{array}{c}22-27 \\
21.0-23.5\end{array}$ & $\begin{array}{l}24.5 \\
21.8\end{array}$ & $\begin{array}{l}34.0 \\
32.4\end{array}$ \\
\hline Interorbital width. & $\begin{array}{l}7 \\
0\end{array}$ & $\begin{array}{l}5.0-6.5 \\
4.5-5.5\end{array}$ & $\begin{array}{l}5.7 \\
5.2\end{array}$ & $\begin{array}{l}7.9 \\
7.7\end{array}$ \\
\hline Length of chest gland. & $\begin{array}{l}7 \\
0\end{array}$ & $7.5-12.0$ & 9.4 & 13.0 \\
\hline Width of chest gland. & $\begin{array}{l}0^{7} \\
\wp\end{array}$ & $2.5-6.5$ & 4.8 & 6.6 \\
\hline Length of lower arm.... & $\begin{array}{l}0^{x} \\
9\end{array}$ & $\begin{array}{c}28-37 \\
27.5-35.0\end{array}$ & $\begin{array}{l}33.4 \\
30.2\end{array}$ & $\begin{array}{l}46.3 \\
44.9\end{array}$ \\
\hline Diameter of lower arm. & $\begin{array}{l}0^{\pi} \\
q\end{array}$ & $\begin{array}{c}10.5-17.0 \\
6-8\end{array}$ & $\begin{array}{r}13.3 \\
6.7\end{array}$ & $\begin{array}{r}18.4 \\
9.9\end{array}$ \\
\hline Length of hand. & $\begin{array}{l}0 \\
0 \\
0\end{array}$ & $\begin{array}{c}16.0-20.5 \\
15-19\end{array}$ & $\begin{array}{l}17.9 \\
15.9\end{array}$ & $\begin{array}{l}24.8 \\
23.6\end{array}$ \\
\hline Length of leg. & $\begin{array}{l}0^{7} \\
\wp\end{array}$ & $\begin{array}{l}82-104 \\
72-89\end{array}$ & $\begin{array}{l}91.4 \\
81.8\end{array}$ & $\begin{array}{l}126.9 \\
121.9\end{array}$ \\
\hline Length of tibia. & $\begin{array}{l}9 \\
0 \\
0\end{array}$ & $\begin{array}{c}25-31 \\
22.0-23.3\end{array}$ & $\begin{array}{l}27.8 \\
22.5\end{array}$ & $\begin{array}{l}38.5 \\
33.7\end{array}$ \\
\hline Length of foot and tarsus. & $\begin{array}{l}0 \\
0 \\
1\end{array}$ & $\begin{array}{l}41-49 \\
35-45\end{array}$ & $\begin{array}{l}44.6 \\
38.8\end{array}$ & $\begin{array}{l}61.9 \\
57.9\end{array}$ \\
\hline Length of foot. & $\begin{array}{l}\sigma^{7} \\
9\end{array}$ & $\begin{array}{l}29-37 \\
25-32\end{array}$ & $\begin{array}{l}31.5 \\
26.9\end{array}$ & $\begin{array}{l}43.6 \\
40.0\end{array}$ \\
\hline Length of inner metatarsal tubercle. . & $\begin{array}{l}0 \\
0 \\
0\end{array}$ & $\begin{array}{l}4.0-5.5 \\
3.5-5.0\end{array}$ & $\begin{array}{l}4.7 \\
4.0\end{array}$ & $\begin{array}{l}6.5 \\
5.9\end{array}$ \\
\hline
\end{tabular}


The arm is distinctly stronger and bent inward in the males. The ratio of the diameter of the lower arm to the body length is 18.4 per cent in ten males; this ratio is only 9.9 per cent in ten females. The hind limb of the male is longer and stronger than that of the female, especially in the tibial region. The toes are much more webbed and strongly fringed in the males than in the females. Lineae masculinae and vocal sacs are wanting.

Measurements (adult male; percentage of body length in parentheses).Body length $76.0 \mathrm{~mm}$.; head length $25.0 \mathrm{~mm}$. (32.8); head width $27.0 \mathrm{~mm}$. (35.5); interorbital space $6.0 \mathrm{~mm}$. (7.8); length of chest gland $10.0 \mathrm{~mm}$. (13.1); width of chest gland $5.0 \mathrm{~mm}$. (6.5); space between two chest glands $3.5 \mathrm{~mm}$. (4.6); lower arm length $37.0 \mathrm{~mm}$. (48.6); diameter of lower arm $16.0 \mathrm{~mm}$. (21.0); length of hand $20.5 \mathrm{~mm}$. (26.9); length of leg $101.0 \mathrm{~mm}$. (132.8); length of tibia 32.5 $\mathrm{mm}$. (42.7); length of foot and tarsus $50.0 \mathrm{~mm}$. (65.7); length of fourth toe and sole $34.0 \mathrm{~mm}$. (44.7); length of inner metatarsal tubercle $4.2 \mathrm{~mm}$. (5.5).

Tadpoles.-Five tadpoles of Aelurophryne mammata were collected by Stevens at Hlagong. One of these five tadpoles is fully developed, with hind limbs measuring $10 \mathrm{~mm}$. Ten tadpoles from Hsintuchiao were measured and studied.

The coloration of the alcohol-preserved tadpole is uniformly dark gray on the back and sides and the muscular portion of the tail; the belly and the crests of the tail are cream. This coloration is similar to that of preserved tadpoles of glandulata and brevipes.

The tadpole of $A$. mammata is a typical running-water form, the body being elongated and dorso-ventrally depressed, with a long tail, strong tail muscle, and low thick tail crest with a blunted tip; the head is depressed, with a rounded snout.

The mouth is ventral, with strong mandibles. There is a single row of papillae on the margin of the lips, with additional papillae, some with teeth, at the corners of the mouth. The number of rows of labial teeth varies, but all are supported by thick fleshy ridges. Three of the tadpoles from Hlagong have

Aelurophryne mammata: Measurements of Ten Tadpoles from Hsintuchiao

\begin{tabular}{|c|c|c|c|}
\hline Measurements & Extremes & Average & $\begin{array}{c}\text { Ratio to } \\
\text { body length (\%) }\end{array}$ \\
\hline Body length. & $25-28$ & 26.5 & \\
\hline Body height. & $11-12$ & 11.2 & 42.2 \\
\hline Body width. & $11-16$ & 14.9 & 56.3 \\
\hline Head height. & $7.5-9.0$ & 7.9 & 29.7 \\
\hline Head width. & $\therefore 11-12$ & 11.7 & 44.0 \\
\hline Mouth width. & $7-8$ & 7.7 & 28.9 \\
\hline Space from eye to eye. & $7-8$ & 7.2 & 27.2 \\
\hline Space from nostril to nostril. & $.4 .5-5.0$ & 4.9 & 18.7 \\
\hline Tip of snout to spiraculum.. & $.15-18$ & 16.9 & 64.0 \\
\hline Tail length............ & 41-52 & 46.1 & 174.3 \\
\hline Tail height. & $11-14$ & 12.0 & 45.6 \\
\hline Diameter of tail muscle. & $6-7$ & 6.7 & 25.3 \\
\hline Length of hind $\operatorname{limb}$... & $7-12$ & 8.6 & 32.4 \\
\hline
\end{tabular}


the labial tooth formula I:5-5/I:5-5; one has teeth I:5-6/I:5-6; and one $\mathrm{I}: 4-4 / \mathrm{I}: 5-5$. On the upper lip, the outermost row is very short and continuous, partly filling the gap on the mid-dorsal part of the lip where no papillae are developed. The remaining rows on the upper lip are all interrupted, the outermost row the longest, and the innermost the shortest. On the lower lip there are usually six rows of teeth, the outermost the shortest and continuous, and the inner five all interrupted, the innermost the shortest. In the Hsintuchiao tadpoles, five have the formula I:5-5/I:5-5; two have the formula I:4-4/I:5-5; one has I:4-4/I:5-4; one has I:6-6/I:5-5; and one has I:6-6/I:6-6.

\section{Aelurophryne brevipes sp. nov.}

Type.-No. 49393 Chicago Natural History Museum, from Taining, 11,500 feet altitude, Sikang, China. Adult male, collected in July, 1943, by Ch'eng-chao Liu.

Diagnosis.-Closely related to Aelurophryne glandulata, but with shorter feet, about 41 per cent of the body length; chest glands large and oval, the
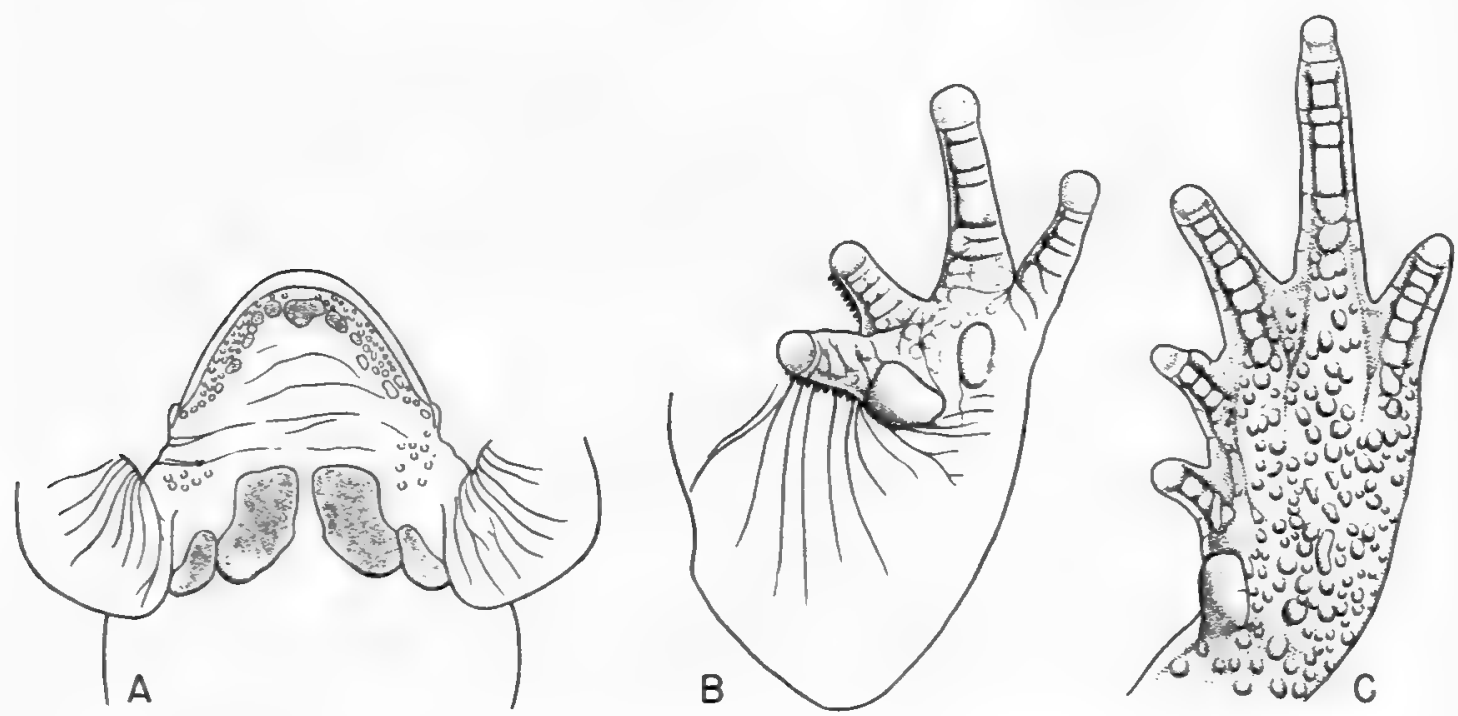

Fig. 18. Aelurophryne brevipes; male. A. Ventral view of head and thoracic region $(\times 1)$. B. Ventral view of hand $(\times 2)$. C. Ventral view of foot $(\times 2)$.

anterior half of their inner margins parallel, and posteriorly diverging; axillary glands with two-thirds of their anterior inner margins in contact with the chest glands; the inner two toes about one-third webbed, and the third, fourth and fifth toes with webs only at the base; prehumeral glandular area developed.

Description of type.-Body stout, somewhat depressed; head depressed, slightly broader than long, snout rounded, depressed, slightly projecting beyond the mouth, and much longer than the length of the eye (fig. 18, A); canthus rostralis obtuse; loreal region very oblique and slightly concave; nostrils about mid-way between the tip of the snout and the anterior corner of the eye; inter- 
orbital space about equal to the width of internasal space or upper eyelid; tympanum hidden; jaws feeble, without maxillary teeth; no vomerine teeth; tongue large, oval, and slightly notched behind; no vocal sac.

Arm strong; fingers moderately long, the first and second fingers equal in length but thicker and shorter than the fourth finger, and the third finger the longest; tips of the fingers lighter in color; nuptial spines developed on the inner dorsal sides of the first and second fingers; subarticular tubercles indistinct,

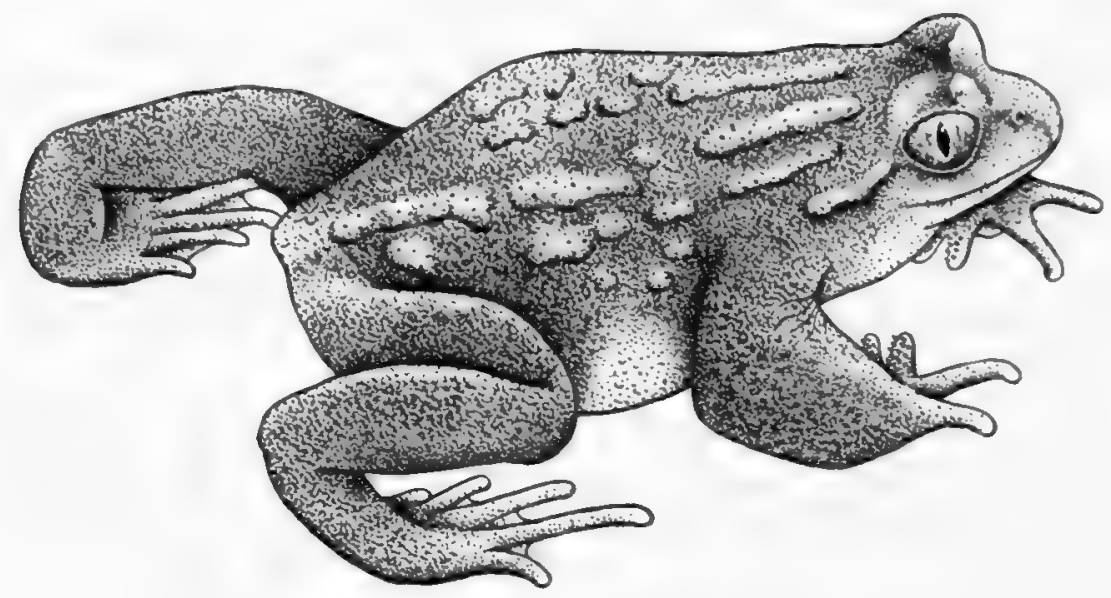

FIG. 19. Aelurophryne brevipes; male $(\times 1)$.

palmar tubercles prominent, a larger rounded inner one and an outer slightly smaller one; palm not rugose, with a few inconspicuous small warts (fig. 18, B).

Hind limb short and weak, the length of the hind limb only 127.7 per cent of the body length, the tibio-tarsal articulation reaching the shoulder region, the tibia only 31 per cent of the body length, the foot shorter than those of other species of Aelurophryne; toes fringed, with tips dilated and light in color; the two inner toes about one-third webbed, and the other toes webbed only at the base; the subarticular tubercles indistinct and easily confused with warts on the toes; the inner metatarsal tubercle well developed, elongated oval, with a free edge (fig. 18, C).

Skin rough, with large flattened warts more or less in rows on the dorsolateral sides of the back (fig. 19); many small warts on the sides of the body and on the dorsal sides of the limbs; larger warts pitted, especially on the back; parotoids large, distinct, flat, and with a strong ridge running from the posterior corner of the upper eyelid toward the base of the arm; many rounded and lightcolored warts on the median postero-ventral aspects of the thighs. Skin of the throat, chest, belly, and the ventral sides of limbs smooth, except for the development of glandular areas on the margins of the jaws; two pairs of flattened glands developed on the thoracic region-chest glands-large, oval and flat, with the anterior half of their inner margins parallel and the posterior half diverging; the axillary glands small, with two-thirds of their anterior inner margins in 
contact with the postero-lateral edges of the chest glands; a definite glandular area with scattered small rounded warts antero-laterad from each chest gland (fig. 18, A); skin of belly wrinkled in preserved specimens.

Measurements of type (percentage of body length in parentheses).-Body length $72.0 \mathrm{~mm}$.; head length $23.0 \mathrm{~mm}$. (31.9); head width $24.0 \mathrm{~mm}$. (33.3); interorbital space $5.0 \mathrm{~mm}$. (6.9); length of chest gland $13.0 \mathrm{~mm}$. (18.0); width of chest gland $7.0 \mathrm{~mm}$. (9.7); space between two chest glands $2.0 \mathrm{~mm}$. (2.7); length of axillary gland $7.0 \mathrm{~mm}$. (9.7); width of axillary gland $2.5 \mathrm{~mm}$. (3.4); length of lower arm $32.0 \mathrm{~mm}$. (44.4); diameter of lower arm $12.0 \mathrm{~mm}$. (16.6); hand length $17.5 \mathrm{~mm}$. (24.3); leg length $92.0 \mathrm{~mm}$. (127.7); length of tibia 22.5 $\mathrm{mm}$. (31.2); length of foot and tarsus $42.0 \mathrm{~mm}$. (57.5); length of foot $29.5 \mathrm{~mm}$. (40.8); length of inner metatarsal tubercle $4.6 \mathrm{~mm}$. (6.3).

Coloration in life.-Yellowish olive stippled with gold on the back and the upper sides of the limbs; much lighter on the anterior region of the top and the sides of the head and on the large, pitted, flattened glands; sides of the body greenish yellow, with lighter-colored small warts; yellowish gray on the throat, chest, and anterior region of the belly; more yellowish on the hip region, the posterior part of the belly, and the under sides of the limbs; dorsal sides of the inner fingers and toes greenish yellow; chest gland pinkish gray; axillary glands yellowish, stippled with gold; the color of the eye similar to that of Aelurophryne glandulata. After preservation, the back and dorsal sides of the limbs are dark, the snout being lighter in color.

The coloration of living tadpoles of Aelurophryne brevipes is usually Chaetura Black on the body, with the muscular portion of the tail stippled with gold. The snout and the sides of the body are Benzo Brown, stippled with gold. The tail crest is much lighter in color, near Ecru Drab, with scattered black stippling. The belly is light pinkish gray. The pupil is round and black enclosed by a golden ring, and the iris is golden stippled with black. The preserved tadpole of brevipes is black, with the belly light gray and the tail crest colorless.

Collection data.-Kangting, also known as Tatsienlu, the capital of Sikang Province, has an altitude of about 8,000 feet. The temperature was $52^{\circ}$ to $60^{\circ} \mathrm{F}$. on July 9, 1943. Tadpoles of a species of Aelurophryne were collected from a river in the city. In one of these tadpoles nearly through metamorphosis, the coloration of the back was dark gray stippled with gold and four ill-defined rows of elongated warts with lighter centers were developed on the back. This character is very much like that of adult Aelurophryne brevipes collected from Taining on July 29 of the same year. Tadpoles of different stages collected from small mountain streams of Tangnipa (12,600 feet altitude), northwest of Kangting, on the way to Taining, July 25, probably belong to this species.

On July 29 many fully developed tadpoles of $A$. brevipes were collected from mountain streams east of the city of Taining at 11,500 feet altitude. Many adults were found under stones along the same mountain streams. In such mountain streams Batrachuperus pinchonii is also common, but no other salien- 
tians appear to be present. Aelurophryne brevipes is an inactive frog. Individuals of this species hide under stones at the sides of mountain streams or in the water. Turning such a stone discloses the frog, and one can scarcely miss catching it. Egg-masses were obtained in the upper reaches of the same stream where adults and tadpoles were found.

On the way from Taining to the city of Luho (11,100 feet) tadpoles of this new Aelurophryne at different stages were collected but no adults were seen. On August 8, 1943, adult males and females were collected from a mountain stream west of the city of Luho together with tadpoles of various stages and some specimens of Batrachuperus pinchonii. From August 12 to 14 more specimens of adults and tadpoles of Aelurophryne brevipes were obtained from a small mountain stream at Chuwo, the largest village in the west border of Luhohsien, at the same altitude as the city of Luho. In the stream at Chuwo we collected, besides Aelurophryne brevipes, Batrachuperus pinchonii of various stages and some cascade frogs (Staurois). This was one of the few places where I found true cascade forms inhabiting the same mountain stream as running-water types.

The dark brown mask between the eyes extending to the back of the shoulder region is generally very distinct in young specimens and indistinct or entirely lost in large adults. The background coloration on the back varies from yellowish olive to golden. Two large males collected by the author are uniform muddy golden in color without any markings or pattern on their backs.

Sex dimorphism.- Sex dimorphism in size is very marked. Ten large males and nine large females were measured. The average body length of the males is $71.4 \mathrm{~mm}$., ranging from 68 to $80 \mathrm{~mm}$., while in females it is $64.6 \mathrm{~mm}$., with a range from 58 to $68 \mathrm{~mm}$. The skin of living males is looser than that of females, but after preservation this condition is much less evident than in A. mammata.

The chest glands of the thoracic region of the male are without spines or pigmented granules, in contrast with Aelurophryne mammata and glandulata. Axillary glands are found in both sexes but are larger in males. A well-defined area, covered with thinner skin and with scattered small warts antero-ventral to the base of the arm and antero-lateral to the chest gland, is found only in males. Such an area is present in males of all species of Scutiger and in the males of Aelurophryne glandulata and tainingensis, but not in the male of mammata. A conspicuous male character is the development of strong black spines on the inner dorsal sides of the inner two fingers. These two fingers, especially the first, much stronger than the third and fourth fingers, are flattened and curved toward the palm.

The arm of the male is distinctly stronger than that of the female, and bent inward. The average diameter of the lower arm of the male is $13.6 \mathrm{~mm}$. with a ratio to the body length of 19 per cent, while in the female this ratio is only 10 per cent. The hind limb of the male is longer and stronger than that of the female, and the toes are much more webbed and more strongly fringed. 
Aelurophryne brevipes: Measurements of Ten Male and Nine Female Paratypes

\begin{tabular}{|c|c|c|c|c|}
\hline Measurements & Sex & Extremes & Average & $\begin{array}{c}\text { Ratio to } \\
\text { body length (\%) }\end{array}$ \\
\hline Body length....... & $\begin{array}{l}0^{7} \\
9\end{array}$ & $\begin{array}{l}68-80 \\
58-68\end{array}$ & $\begin{array}{l}71.4 \\
64.6\end{array}$ & ... \\
\hline Head length. & $\begin{array}{l}0 \\
9\end{array}$ & $\begin{array}{l}21-27 \\
19-23\end{array}$ & $\begin{array}{l}23.3 \\
21.4\end{array}$ & $\begin{array}{l}32.7 \\
33.1\end{array}$ \\
\hline Head width. & $\begin{array}{l}07 \\
9\end{array}$ & $\begin{array}{l}23-27 \\
20-23\end{array}$ & $\begin{array}{l}24.7 \\
22.3\end{array}$ & $\begin{array}{l}34.6 \\
34.5\end{array}$ \\
\hline Interorbital space. . & $\begin{array}{l}\sigma^{x} \\
9\end{array}$ & $\begin{array}{l}5-6 \\
5-6\end{array}$ & $\begin{array}{l}5.6 \\
5.4\end{array}$ & $\begin{array}{l}7.8 \\
8.4\end{array}$ \\
\hline Length of lower arm. & $\begin{array}{l}0^{7} \\
0\end{array}$ & $\begin{array}{l}32-36 \\
28-32\end{array}$ & $\begin{array}{l}33.5 \\
30.6\end{array}$ & $\begin{array}{l}46.8 \\
47.4\end{array}$ \\
\hline Diameter of lower arm. . & $\begin{array}{l}\sigma^{7} \\
\text { + }\end{array}$ & $\begin{array}{c}10-16 \\
6-7\end{array}$ & $\begin{array}{r}13.6 \\
6.5\end{array}$ & $\begin{array}{l}18.9 \\
10.1\end{array}$ \\
\hline Length of hand. . & $\begin{array}{l}\sigma^{7} \\
q\end{array}$ & $\begin{array}{c}16-20 \\
15.5-17.0\end{array}$ & $\begin{array}{l}18.6 \\
16.6\end{array}$ & $\begin{array}{l}26.1 \\
25.7\end{array}$ \\
\hline Length of leg. & $\begin{array}{l}0^{7} \\
9\end{array}$ & $\begin{array}{l}90-105 \\
77-88\end{array}$ & $\begin{array}{l}95.6 \\
82.2\end{array}$ & $\begin{array}{l}132.9 \\
127.3\end{array}$ \\
\hline Length of tibia. & $\begin{array}{l}\sigma^{7} \\
0\end{array}$ & $\begin{array}{l}27-32 \\
23-25\end{array}$ & $\begin{array}{l}29.1 \\
24.0\end{array}$ & $\begin{array}{l}40.8 \\
37.1\end{array}$ \\
\hline Length of foot and tarsus......... & $\begin{array}{l}\sigma^{7} \\
0\end{array}$ & $\begin{array}{l}43-50 \\
37-41\end{array}$ & $\begin{array}{l}46.7 \\
39.1\end{array}$ & $\begin{array}{l}65.4 \\
60.5\end{array}$ \\
\hline Length of foot. . & $\begin{array}{l}97 \\
0 \\
0\end{array}$ & $\begin{array}{l}31-37 \\
26-30\end{array}$ & $\begin{array}{l}33.2 \\
28.5\end{array}$ & $\begin{array}{l}46.5 \\
44.1\end{array}$ \\
\hline Length of inner metatarsal tubercle. . & 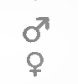 & $\begin{array}{l}5-7 \\
4-5\end{array}$ & $\begin{array}{l}5.9 \\
4.6\end{array}$ & $\begin{array}{l}8.3 \\
7.1\end{array}$ \\
\hline
\end{tabular}

Habitat and habit.-Aelurophryne brevipes is a high mountain form. Frogs of this species are found under stones at the edge of the water in small or mediumsized mountain streams from 9,000 to 13,000 feet altitude. Tadpoles were very abundant in mountain streams from Kangting to Kantze, but not many adults were found in or near the same streams. This fact indicates that Aelurophryne brevipes is not essentially an aquatic running-water form. Before and after the breeding season, these frogs appear to live in the crevices of stones on hillsides and only come out at twilight to feed. In a dry season the individuals near a stream may enter the water and hide themselves under stones. The short and weak hind limbs and the poorly developed webs, the well-developed palmar tubercles, much like those of the common toad, and the rareness of the adults in the mountain streams where their tadpoles are so abundant, all indicate that this species must be a terrestrial form.

Breeding behavior.-From my data, it appears that the breeding season of this species is rather long. Fully developed tadpoles were found in mountain streams in the middle of July. On July 29, 1943, two egg-masses and newly hatched tadpoles were collected from the upper reaches of a mountain stream. I conclude that the breeding season of this new frog may extend from the middle of May to the middle of July. The breeding season may of course vary from year to year according to temperature and the rainy season. The upper reaches of mountain streams, where large and small stones are numerous, with little vegetation, and only a small amount of water, are the site for egg-laying. 
Eggs are laid in masses and attached to the under surface of the larger stones. The eggs are large $(3.5 \mathrm{~mm}$.) and white, with their outer jelly layers connected with those of other eggs. In my limited material, the eggs at the center of the egg-masses were mostly spoiled and only the outer eggs developed into tadpoles and hatched.

Tadpoles.-Newly hatched tadpoles stay with the jelly mass from which they hatched. At this stage they attach themselves to the jelly or swim in the

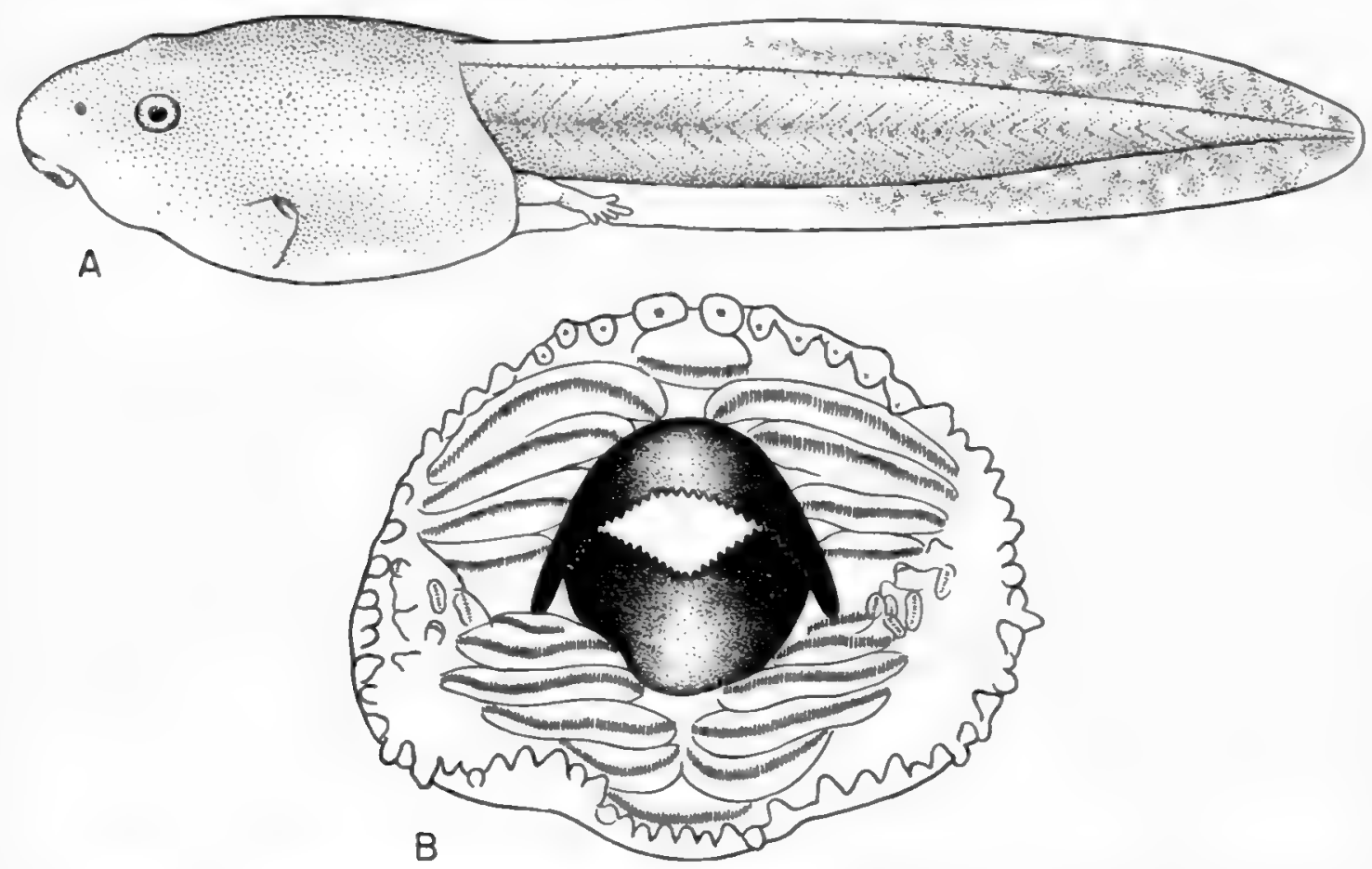

Fig. 20. Aelurophryne brevipes; tadpole. A. Lateral view $(\times 2)$. B. Mouth $(\times 101 / 2)$.

shallow water. The body of the newly hatched tadpole is gray, the tail crest is much lighter, and the belly is nearly colorless.

Large tadpoles are not found in the places where the eggs are laid. They inhabit the larger mountain streams and the quieter waters at the sides of mountain rivers. They generally hide themselves under stones and one rarely sees them swimming in open water. They are good swimmers and very sensitive to any disturbance.

Ten tadpoles from Taining and ten from Pamei, selected at random, were measured and carefully studied. The general body form, the size of the different parts of the body and the mouth parts are relatively constant (see table). The detailed description is based on tadpoles from Taining, where most of the adults were obtained, tadpoles from other localities being mentioned only for comparison.

The tadpole of Aelurophryne brevipes (fig. 20, A) is rather large in size and is a typical running-water form. The average body length of ten tadpoles of 
Taining is $24.3 \mathrm{~mm}$., ranging from 23 to $26 \mathrm{~mm}$. The body is somewhat depressed dorso-ventrally, the average body height being $10.6 \mathrm{~mm}$. and the width $13.7 \mathrm{~mm}$. The length of the tail is 168 per cent of the body length, with rather low tail crest and strong tail muscle.

The head is depressed, its average height about 28 per cent of the body length, and its width 43 per cent. The snout is rounded; the nostril, enclosed by a light-colored ring, is about mid-way between the tip of the snout and the anterior corner of the eye. The eyes are dorso-lateral in position, and the space between them is greater than that between the nostrils. The spiraculum is sinistral, ending in an attached tube, directed upward and backward, scarcely visible from above and below. It is nearer to the vent than to the tip of the snout. The vent is dextral, with a large oblique opening under a skin fold that overlies it and is continuous with the ventral tail crest. The tail is long and strong, with its muscular part strongly developed. The tip of the tail is blunt, with the tail crest about equally developed dorsally and ventrally. The dorsal tail crest is thickened at its anterior end and only indicated by a very low ridge near the base of the tail.

The ventrally placed mouth is large and strong (fig. 20, B). A single row of papillae, variable in size, is developed on the margin of the lips, except for a

Aelurophryne brevipes: Measurements of Tadpoles

\begin{tabular}{|c|c|c|c|c|}
\hline Measurements & Localities & Range & Average & $\begin{array}{c}\text { Ratio to } \\
\text { body length (\%) }\end{array}$ \\
\hline Body length (snout to vent). & $\begin{array}{l}\text { Pamei } \\
\text { Taining }\end{array}$ & $\begin{array}{l}24-26 \\
23-26\end{array}$ & $\begin{array}{l}25.4 \\
24.3\end{array}$ & $\cdots$ \\
\hline Body height (highest region). & $\begin{array}{l}\text { Pamei } \\
\text { Taining }\end{array}$ & $\begin{array}{l}10-12 \\
10-12\end{array}$ & $\begin{array}{l}10.7 \\
10.6\end{array}$ & $\begin{array}{l}42.3 \\
43.6\end{array}$ \\
\hline Body width (greatest diameter). & $\begin{array}{l}\text { Pamei } \\
\text { Taining }\end{array}$ & $\begin{array}{l}13-16 \\
12.5-15.0\end{array}$ & $\begin{array}{l}14.4 \\
13.7\end{array}$ & $\begin{array}{l}56.5 \\
56.4\end{array}$ \\
\hline Head height (at eye region). . & $\begin{array}{l}\text { Pamei } \\
\text { Taining }\end{array}$ & $\begin{array}{l}6.0-8.1 \\
6.0-7.0\end{array}$ & $\begin{array}{l}7.3 \\
6.9\end{array}$ & $\begin{array}{l}28.5 \\
28.4\end{array}$ \\
\hline Head width. & $\begin{array}{l}\text { Pamei } \\
\text { Taining }\end{array}$ & $\begin{array}{r}10.5-13.0 \\
9.0-11.5\end{array}$ & $\begin{array}{l}11.4 \\
10.4\end{array}$ & $\begin{array}{l}44.9 \\
42.8\end{array}$ \\
\hline Mouth width (including lips). & $\begin{array}{l}\text { Pamei } \\
\text { Taining }\end{array}$ & $\begin{array}{l}6-7 \\
6-7\end{array}$ & $\begin{array}{l}6.8 \\
6.2\end{array}$ & $\begin{array}{l}26.8 \\
25.5\end{array}$ \\
\hline Space between eyes. & $\begin{array}{l}\text { Pamei } \\
\text { Taining }\end{array}$ & $\begin{array}{l}6-7 \\
6-7\end{array}$ & $\begin{array}{l}6.4 \\
6.6\end{array}$ & $\begin{array}{l}25.0 \\
27.0\end{array}$ \\
\hline Space between nostrils. & $\begin{array}{l}\text { Pamei } \\
\text { Taining }\end{array}$ & $\begin{array}{l}4-5 \\
4-5\end{array}$ & $\begin{array}{l}4.3 \\
4.3\end{array}$ & $\begin{array}{l}16.7 \\
17.4\end{array}$ \\
\hline Tip of snout to spiraculum & $\begin{array}{l}\text { Pamei } \\
\text { Taining }\end{array}$ & $\begin{array}{l}14.5-17.0 \\
14.0-15.5\end{array}$ & $\begin{array}{l}15.8 \\
14.6\end{array}$ & $\begin{array}{l}62.2 \\
60.0\end{array}$ \\
\hline Length of tail (vent to tip). & $\begin{array}{l}\text { Pamei } \\
\text { Taining }\end{array}$ & $\begin{array}{l}40-46 \\
37-46\end{array}$ & $\begin{array}{l}43.8 \\
40.8\end{array}$ & $\begin{array}{l}172.4 \\
168.0\end{array}$ \\
\hline Height of tail (highest part) & $\begin{array}{l}\text { Pamei } \\
\text { Taining }\end{array}$ & $\begin{array}{r}10-12 \\
9-11\end{array}$ & $\begin{array}{l}10.9 \\
10.1\end{array}$ & $\begin{array}{l}43.1 \\
41.6\end{array}$ \\
\hline $\begin{array}{c}\text { Diameter of tail muscle. } \\
\text { (near tail base) }\end{array}$ & $\begin{array}{l}\text { Pamei } \\
\text { Taining }\end{array}$ & $\begin{array}{l}6.0-7.0 \\
5.5-7.0\end{array}$ & $\begin{array}{l}6.4 \\
6.0\end{array}$ & $\begin{array}{l}25.2 \\
24.7\end{array}$ \\
\hline Length of hind limb. & $\begin{array}{l}\text { Pamei } \\
\text { Taining }\end{array}$ & $\begin{array}{l}6-14 \\
5-9\end{array}$ & $\begin{array}{l}9.1 \\
6.6\end{array}$ & $\begin{array}{l}\cdots \\
\cdots\end{array}$ \\
\hline
\end{tabular}

Number of specimens measured: 10 from Pamei, 10 from Taining 
median gap above. Papillae on the mid-dorsal margin of the upper lip usually have pigmented centers and the last two papillae near the mid-dorsal notch are usually largest. Additional papillae, mostly with teeth, are found at the corners of the mouth. The number of rows of labial teeth varies greatly, but there are usually five rows on the upper lip and six on the lower. All the labial teeth are supported by thick fleshy ridges. The uppermost row is very short and continuous, and partly fills up the gap where no papillae are developed. The remaining four rows on the upper lip are all interrupted, the innermost row the shortest. On the lower lip, with six rows of labial teeth, the outermost row is continuous and longer than the outermost row of the upper lip. The other five rows on the lower lip are all interrupted, the innermost row being the shortest. The mandibles are thick and strong, with large sharp denticulation of their edges. The number of rows of labial teeth varies greatly in the tadpoles of this species, especially in those collected from different localities. Ten tadpoles selected at random from each of three different localities were examined. In the Taining group, the tooth formula is as follows: eight have $I: 4-4 / 1: 5-5$; one has $I: 5-5 / I: 5-5$; one has $I: 5-5 / I: 6-6$. In the Pamei group, four have $\mathrm{I}: 4-4 / \mathrm{I}: 5-5$; four have $\mathrm{I}: 5-5 / \mathrm{I}: 5-5$; two have $\mathrm{I}: 6-6 / \mathrm{I}: 6-6$.

\section{Aelurophryne tainingensis sp. nov.}

Type.-No. 49395 Chicago Natural History Museum, from Taining, 11,500 feet altitude, Sikang, China. Adult male, collected July 29, 1943, by Ch'engchao Liu.

Diagnosis.-A very distinct Aelurophryne (pl. 4, fig. 4) with many rounded light-colored warts on the back, marbled with many smaller ones scattered among them; crowded rounded warts on the belly of the male, confined to the posterior belly region in the female; size small, body slender and depressed; a pair of squarish flattened chest glands narrowly separated from each other, and a pair of oval axillary glands with two-thirds of their inner margins in contact with the lateral margins of the chest glands in the male; the inner two fingers of the male with nuptial pads, without strong black asperities; tongue notched behind, no vomerine or maxillary teeth; no prehumeral glandular area; no warts on the soles of the feet.

Description of type.-Body slender and dorso-ventrally depressed; head scarcely longer than broad, depressed; snout rounded, slightly projecting beyond the mouth, and longer than the length of the eye; canthus rostralis obtuse; loreal region oblique, concave; nostril nearer to the tip of the snout than to the anterior border of the eye; interorbital space as broad as the space between the nostrils and greater than the width of the upper eyelid; tympanum hidden; jaws rather weak; no vomerine teeth; no vocal sacs in the male.

Fingers long and rather slender (fig. 21, B), the first as long as the second, with light-colored nuptial pads on the inner dorsal sides; the fourth finger longer than the first and second but much more slender; the third the longest and also 
slender; subarticular tubercles indistinct; palmar tubercles developed but very flat; tips of fingers lighter in color.

Hind limb short and weak, its length 125 per cent of the body length, the tibio-tarsal articulation reaching the base of the arm, the heels not meeting when placed at right angles to the body; tibia 38 per cent of the body length; toes (fig. 21, C) slightly fringed, their tips rounded and slightly dilated, the two inner toes about one-third webbed at base; subarticular tubercles present but
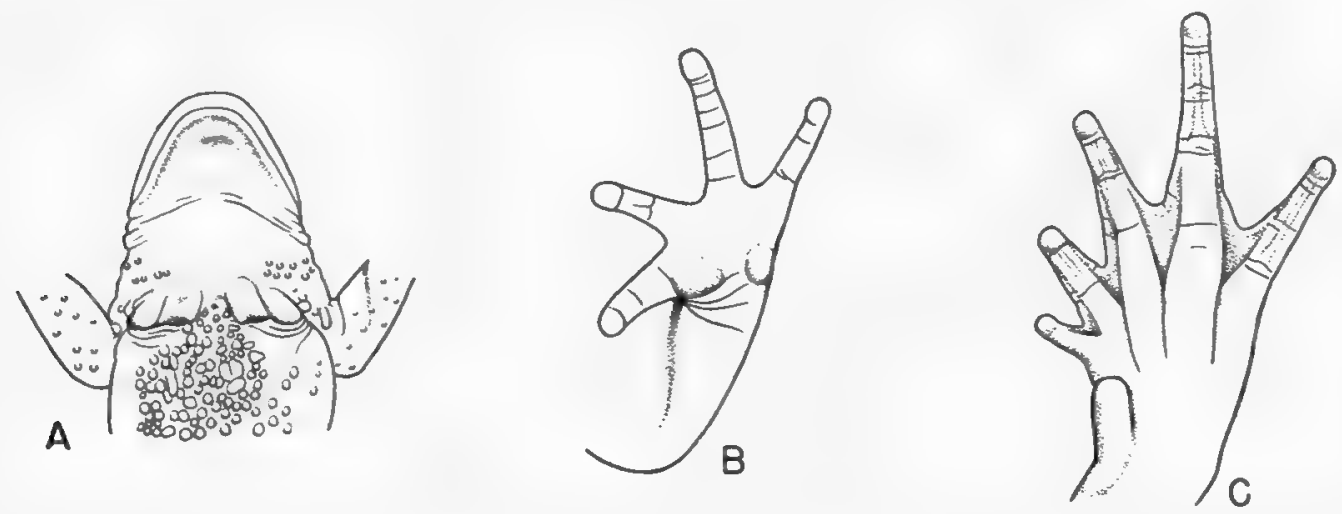

FIG. 21. Aelurophryne tainingensis; male. A. Ventral view of head and thoracic region $(x 1)$. B. Ventral view of hand $(\times 2)$. C. Ventral view of foot $(\times 2)$.

indistinct; inner metatarsal tubercle elongated, with a free edge, outer metatarsal tubercle wanting.

Skin rough, with many large and small pitted warts, more or less evenly distributed on the back; smaller warts on the exposed parts of the limbs; a strong glandular fold from the posterior corner of each upper eyelid, descending obliquely to the forelimb; large warts near the anal region; numerous warts varying in size on the posterior aspect of the thighs, extending distad to a large light-colored wart at about the middle of the thigh. Belly with numerous smooth warts, with smaller ones scattered on the inner and ventral sides of the arms. Two pairs of large glands on the thoracic region (fig. 21, A); the chest glands, the inner pair, slightly longer than broad, rounded anteriorly, the posterior margin squarish, with indentations; the outer pair, the axillary glands, oval, the anterior two-thirds of the inner margin in contact with the posterior lateral margin of the chest gland; both pairs smooth and without black asperities or spines; light-colored nuptial pads developed on the inner dorsal sides of the first two fingers.

Measurements of type (percentage of body length in parentheses).-Body length $51.0 \mathrm{~mm}$.; head length $16.0 \mathrm{~mm}$. (31.3); head width $16.0 \mathrm{~mm}$. (31.3); interorbital space $4.4 \mathrm{~mm}$. (8.6); length of chest gland $5.0 \mathrm{~mm}$. (9.8); width of chest gland $5.5 \mathrm{~mm}$. (10.7); space between chest glands $0.33 \mathrm{~mm}$.; length of axillary gland $4.5 \mathrm{~mm}$. (8.8); width of axillary gland $2.5 \mathrm{~mm}$. (4.9); length of lower arm $25.0 \mathrm{~mm}$. (49.0); diameter of lower arm $6.0 \mathrm{~mm}$. (11.7); length of 
hand $13.5 \mathrm{~mm}$. (26.4); length of leg $63.5 \mathrm{~mm}$. (124.5); length of tibia $19.5 \mathrm{~mm}$. (38.2); length of foot and tarsus $33.0 \mathrm{~mm}$. (64.7); length of foot $23.0 \mathrm{~mm}$. (45.0); length of inner metatarsal tubercle $4.0 \mathrm{~mm}$. (7.8).

Aelurophryne tainingensis: Measurements of Five Male and Two Female Adult Paratypes

\begin{tabular}{|c|c|c|c|c|}
\hline Measurements & Sex & Range & Average & $\begin{array}{c}\text { Ratio to } \\
\text { body length (\%) }\end{array}$ \\
\hline Body length...... & $\begin{array}{l}0^{x} \\
\wp\end{array}$ & $\begin{array}{l}47-52 \\
56-57\end{array}$ & $\begin{array}{l}48.8 \\
56.5\end{array}$ & $\cdots$ \\
\hline Head length. & $\begin{array}{l}0^{x} \\
q\end{array}$ & $\begin{array}{c}15-17 \\
16.5-17.0\end{array}$ & $\begin{array}{l}16.0 \\
16.7\end{array}$ & $\begin{array}{l}32.9 \\
29.6\end{array}$ \\
\hline Head width. & $\begin{array}{l}\sigma^{x} \\
\%\end{array}$ & $\begin{array}{l}15.6-17.0 \\
17.5-18.0\end{array}$ & $\begin{array}{l}16.2 \\
17.7\end{array}$ & $\begin{array}{l}33.2 \\
31.6\end{array}$ \\
\hline Interorbital space. & $\begin{array}{l}0^{7} \\
q\end{array}$ & $\begin{array}{c}3.8-4.0 \\
4.5\end{array}$ & $\begin{array}{l}4.0 \\
4.5\end{array}$ & $\begin{array}{l}8.1 \\
7.9\end{array}$ \\
\hline Length of lower arm... & $\begin{array}{l}0^{7} \\
\wp\end{array}$ & $\begin{array}{c}22.5-24.5 \\
26\end{array}$ & $\begin{array}{l}23.9 \\
26\end{array}$ & $\begin{array}{l}48.9 \\
46.0\end{array}$ \\
\hline Diameter of lower arm. . & $\begin{array}{l}\sigma^{7} \\
9\end{array}$ & $\begin{array}{c}5.4-6.0 \\
4.5\end{array}$ & $\begin{array}{l}5.8 \\
4.5\end{array}$ & $\begin{array}{r}11.8 \\
7.9\end{array}$ \\
\hline Length of hand. & $\begin{array}{l}0^{x} \\
0\end{array}$ & $\begin{array}{l}12.0-13.5 \\
14.5-15.0\end{array}$ & $\begin{array}{l}12.9 \\
14.7\end{array}$ & $\begin{array}{l}26.4 \\
26.1\end{array}$ \\
\hline Length of leg. & $\begin{array}{l}0^{7} \\
9\end{array}$ & $\begin{array}{l}63.0-64.5 \\
62-67\end{array}$ & $\begin{array}{l}63.7 \\
64.5\end{array}$ & $\begin{array}{l}130.5 \\
114.3\end{array}$ \\
\hline Length of tibia. . & $\begin{array}{l}0 \\
9\end{array}$ & $\begin{array}{l}17.0-19.5 \\
18.5-19.0\end{array}$ & $\begin{array}{l}18.6 \\
18.7\end{array}$ & $\begin{array}{l}38.1 \\
33.1\end{array}$ \\
\hline Length of tarsus and foot. . & $\begin{array}{l}0^{7} \\
9\end{array}$ & $\begin{array}{c}28-32 \\
32\end{array}$ & $\begin{array}{l}30.1 \\
32\end{array}$ & $\begin{array}{l}61.7 \\
56.6\end{array}$ \\
\hline Length of foot. . & $\begin{array}{l}9 \\
9\end{array}$ & $\begin{array}{c}21.0-22.5 \\
22\end{array}$ & $\begin{array}{l}22 \\
22\end{array}$ & $\begin{array}{l}45.1 \\
38.9\end{array}$ \\
\hline Length of inner metatarsal tubercle. . & $\begin{array}{l}0^{x} \\
0\end{array}$ & $\begin{array}{l}3.2-4.0 \\
3.5-4.0\end{array}$ & $\begin{array}{l}3.6 \\
3.7\end{array}$ & $\begin{array}{l}7.5 \\
6.6\end{array}$ \\
\hline
\end{tabular}

Coloration in life.-Light brownish golden anteriorly and on the sides of the head, yellowish olive green on the back and dorsal sides of the limbs, with a dark brown mark from between the eyes extending posteriorly and becoming indistinct in the shoulder region; a dark brown band from the tip of the snout through the nostrils to the anterior corner of the eye, and descending from the posterior corner of the eye below the light-colored glandular fold to the shoulder. Below this dark brown band, on the sides of the jaws, light brownish golden color; some brownish marblings on the limbs. Warts lighter in color than their surroundings and mostly greenish yellow. Yellowish creamy on the throat and chest and yellowish on the belly, with many yellowish warts; ventral sides of limbs also yellowish. The axillary glands yellowish creamy, and the chest glands dark gray. The pupil black, vertically oval, enclosed by a golden ring; the dorsal part of the iris lighter in color, the ventral part darker, stippled with gold. After preservation, dark gray on the back with a distinct dark brown pattern between the eyes extending backward and becoming indistinct in the shoulder region; warts light gray; light dirty gray on the throat and chest, and gray on the belly, with many lighter-colored warts. 
This new frog is not a common form. In July, 1938, M. C. Chang of West China Union University got one specimen from Taining. Description was reserved for additional information and material. From the end of June to the middle of September, 1943, I had the opportunity to go to Sikang for field studies, and on July 29, 1943, I collected three adult males, two females, and eleven young specimens from a small mountain stream east of the city of Taining. On August 24, 1943, I collected two adult males and one female from the upper reaches of a small mountain stream east of "Eight Beauties Village," Pamei. The altitude of this locality is 11,000 feet, with a temperature of $42^{\circ}$ to $60^{\circ} \mathrm{F}$. on that date. Pamei is about fifteen miles southwest of the city of Taining.

Description of paratypes.-Variation in structure and coloration is very slight in five adult males and two females. Sex dimorphism in size is marked, the average body length of the males being $48.8 \mathrm{~mm}$. $(47-52 \mathrm{~mm}$.) and that of the females $56.5 \mathrm{~mm}$. $(56-57 \mathrm{~mm}$.). The female is darker than the male. The male is much more rugose than the female. The warts on the back of the female are fewer in number, much larger, and mostly more elongated than in the male. In the female there are two lateral rows of large rounded warts extending from the shoulder region above the base of each arm posteriorly to the groin, and lateral to this there are many light-colored and rounded warts. At the midposterior aspect of each thigh of the male there is a very light-colored gland, not found in the female. Enclosing the latero-ventral sides of the anus in both sexes there are elevated glands not found in other species of Aelurophryne. Chest glands are found only in males, axillary glands in both males and females. The whole belly is covered by large rounded warts in the male, whereas in the female such warts are confined to the posterior and middle of the belly. In the male, the margins of the jaws bear glandular areas.

The arm is distinctly stronger, longer and inwardly bent in the male. The ratio of the diameter of the lower arm to the body length is 12 per cent in the male and only 8 per cent in the female. The hind limb of the male is distinctly longer than that of the female. The webbing between the toes is similar in both sexes. No vocal sac or linea masculina is developed in the male.

Habitat and habits.-Aelurophryne tainingensis is a high mountain form. According to our present knowledge it is an endemic species of the high plateau of Sikang, found around Taining (11,500 feet). The habitat of this species is in the upper reaches of very small mountain streams where the water trickles through beneath the stones. There is no vegetation where I found my specimens, otherwise the habitat would be very much like that of Scutiger schmidti. Aelurophryne tainingensis is not a good swimmer, as its legs are short and weak and its webs poorly developed. It may be a more terrestrial frog, hiding itself under stones for moisture. The depressed body, short legs and rather well-developed inner metatarsal tubercle are fitted for terrestrial life under stones or in crevices of stones on hillsides.

The time and site for breeding of this new frog are still unknown. The breeding season of tainingensis may be earlier than that of Aelurophryne brevipes, 
as egg-masses of brevipes were collected on July 29, 1943, when no eggs that could be those of tainingensis had been seen.

Aelurophryne maculata sp. nov.

Type.-No. 55869 Chicago Natural History Museum, from Hasa, 11,000 feet altitude, Kantze, Sikang, China. Juvenile male, collected August 19, 1943, by Ch'eng-chao Liu.

Diagnosis.-A small species of Aelurophryme (fig. 22) closely related to $A$. tainingensis, differing in being without warts on the belly; in having the warts

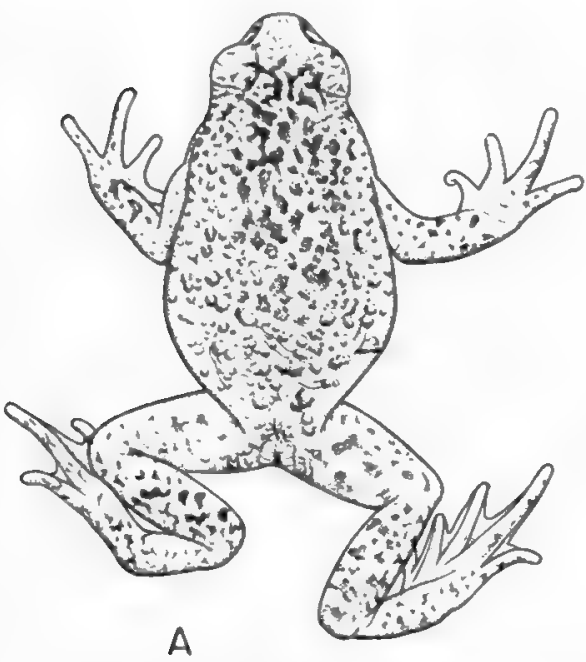

Fig. 22. Aelurophryne maculata. A. Dorsal view $(\times 1)$.

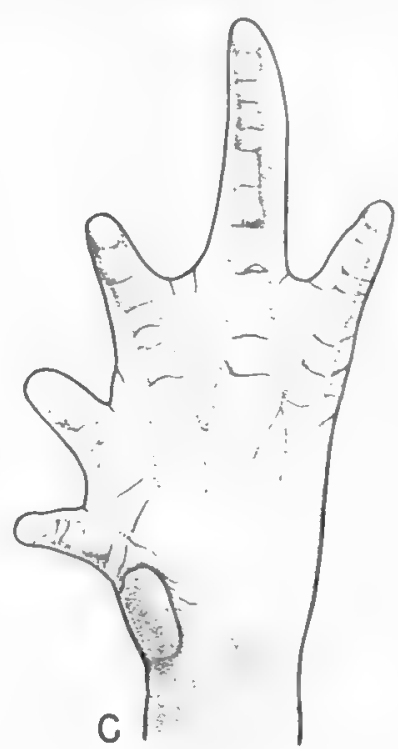

B. Ventral view of hand $(\times 4)$. C. Ventral view of foot $(\times 4)$.

on the back very small and dark; toes about two-thirds webbed; no solid dark brown triangular mark between the eyes and on the anterior part of the back; no large light-colored flat wart at the mid-posterior aspect of each thigh; subarticular tubercles on fingers and toes well developed; fringes on toes very strongly developed; no warts on soles of feet.

Description of type.-Tongue slightly notched; no vomerine teeth; jaws weak and without maxillary teeth.

Body moderately stout; head scarcely broader than long, depressed; snout rounded, slightly projecting beyond the mouth, about as long as the eye; canthus rostralis obtuse, with loreal region oblique and concave; nostril nearer to the tip of the snout than to the anterior corner of the eye; internasal space narrower than the interorbital space, which is wider than the upper eyelid; tympanum hidden.

Arm moderately long, fingers (fig. 22, B) slender and long, the first slightly shorter than the second, the fourth longer than the second and the third the 
longest; palmar tubercles prominent, the inner larger and flat, the outer small but with elevated center; subarticular tubercles well developed; finger tips much lighter in color.

Hind limb short and weak, the length of the hind limb 128 per cent of the body length; tibio-tarsal articulation reaching the base of the arm, heels not meeting when placed at right angles to the body; tibia 39 per cent of the body length; toes (fig. 22, C) greatly flattened, with wide fringes, tips with very small dilations, about two-thirds webbed; subarticular tubercles well developed; inner metatarsal tubercle flattened, elongated oval, with a free edge; no outer metatarsal tubercle.

Skin moderately rugose, with very small warts on the anterior part of the back, with much larger ones on the sides and posteriorly and with some small warts on the upper sides of the limbs; medium-sized warts developed around the anal region; skin smooth on the throat, the belly, and the ventral sides of the limbs. A thick glandular fold from the posterior angle of the upper eyelid extending posteriorly and obliquely to the shoulder.

Measurements of type (percentage of body length in parentheses).-Body length $49 \mathrm{~mm}$; head length $16 \mathrm{~mm}$. (32.6); head width $17 \mathrm{~mm}$. (34.6); interorbital space $4 \mathrm{~mm}$. (8.3); length of lower arm $24 \mathrm{~mm}$. (48.9); diameter of lower arm $4 \mathrm{~mm}$. (8.3); length of hand $13 \mathrm{~mm}$. (26.5); length of leg $63 \mathrm{~mm}$. (128.5); length of tibia $19 \mathrm{~mm}$. (38.6); length of foot and tarsus $32 \mathrm{~mm}$. (65.3); length of foot $22 \mathrm{~mm}$. (44.8); length of inner metatarsal tubercle $3.7 \mathrm{~mm}$. (7.5).

Coloration in life.-Olive green on the back and greatly marbled with dark brown, which usually encloses the olive green warts; limbs similar but the concealed parts of the hind limbs lighter and more pinkish; the throat, the belly, the ventral sides of the limbs and the inner dorsal sides of the hands and the feet pinkish cream. After preservation, gray is the ground color on the back and on the upper sides of the limbs, marbled with darker; colorless on the throat, the belly and the ventral sides of the limbs and the inner dorsal sides of the hands and feet.

Distribution.-This new frog was found under a stone at the edge of a small mountain stream close to Hasa, about 11,000 feet altitude. Many tadpoles and a few adults of Aelurophryne brevipes and adults of Rana temporaria chensinensis were collected along the same stream. After I discovered the new frog, we worked long and hard, but we failed to find another specimen. The new Aelurophryne is notably distinct in the field in its remarkable coloration.

Aelurophryne glandulata sp. nov.

Type.-No. 49392 Chicago Natural History Museum, from Hopachai, Lifanhsien, Szechwan, China, altitude 8,500 feet. Adult male, collected August 9, 1941, by H. C. Chang.

Diagnosis.-An Aelurophryne (pl. 4, fig. 6) with a long foot, nearly 51 per cent of the body length; foot rugose beneath; tibio-tarsal articulation reach- 
ing the shoulder region; the inner two toes more than two-thirds webbed, the third and fifth toes about one-half webbed; chest glands without strong spines, large, elongate oval, diverging posteriorly; axillary glands long and prominent, the anterior third of their inner borders in contact with the chest glands; prehumeral glandular area distinctly developed.

Description of type.-Body stout; head depressed, slightly broader than long; snout rounded, slightly projecting beyond the mouth and much longer
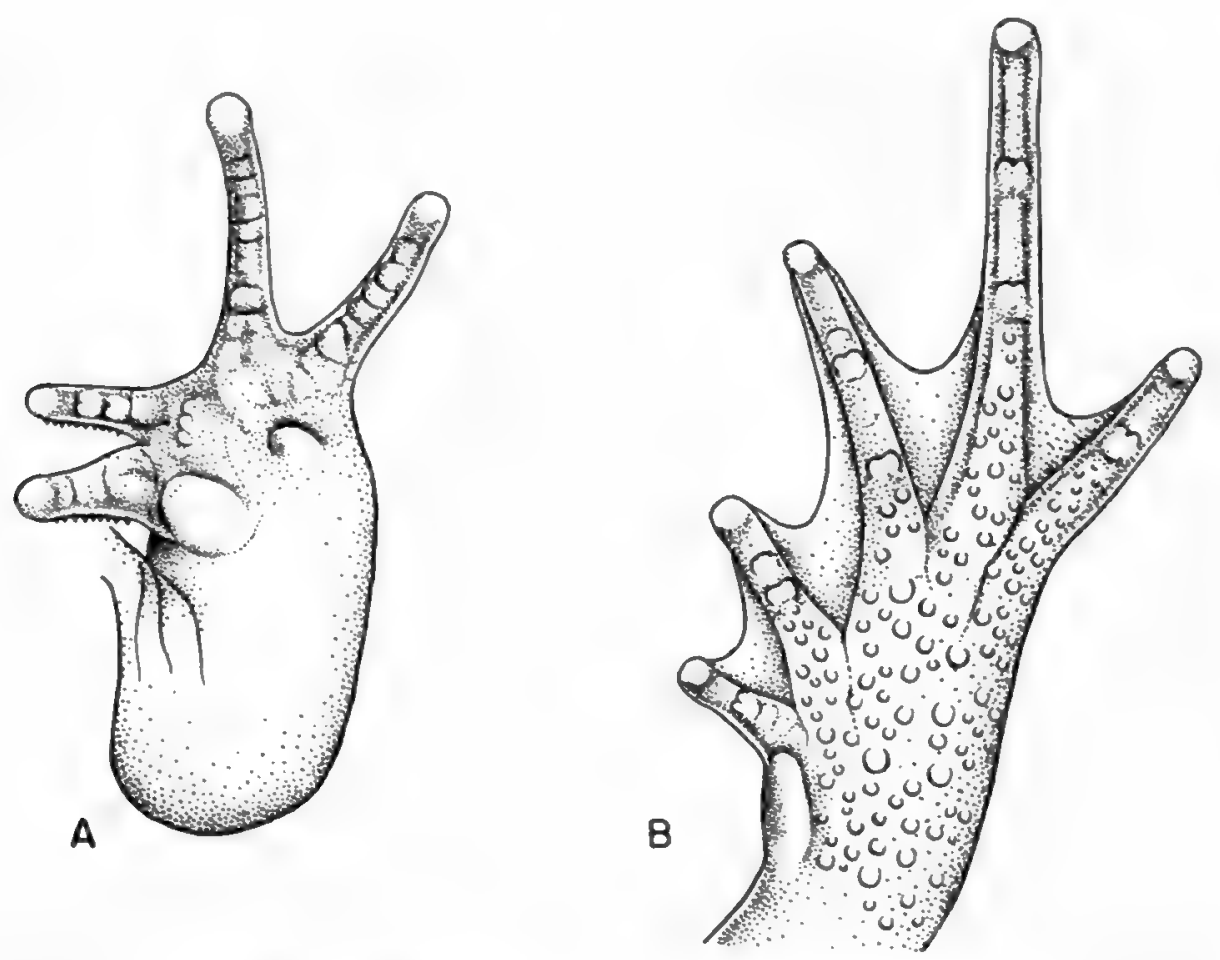

Fig. 23. Aelurophryne glandulata; male. A. Ventral view of hand $(\times 2)$. B. Ventral view of foot $(\times 2)$.

than the length of the eye; canthus rostralis obtuse; loreal region very oblique, only slightly concave; nostrils about mid-way between the tip of the snout and the anterior corner of the eye; interorbital space wider than the distance between the nostrils, and broader than the width of the upper eyelid; tympanum hidden; jaws weak, without teeth; tongue oval, slightly emarginate behind; no vomerine teeth; no vocal sac.

Arm strong; fingers (fig. 23, A) slender and long, first and second equal, thicker, and shorter than third and fourth, the third finger the longest; nuptial spines developed on inner dorsal sides of the first and second fingers; tips of fingers lighter in color; subarticular tubercles present but not differentiated from other tubercles on the fingers, much as in the Chinese common toad; palmar tubercles large and prominent, the inner larger and flat, the outer much smaller; palm rugose with small warts. 
Hind limb short and weak, its length about 142 per cent of the body length; tibio-tarsal articulation reaching the shoulder region; tibia 42 per cent of the body length; foot (fig. 23, B) longer than those of other species of Aelurophryne, about 51 per cent of the body length; toes prominently fringed; the two inner toes about two-thirds webbed and the third and fifth toes about half webbed; tips of toes rounded, slightly dilated, lighter in color; subarticular tubercles present, but not distinct, like those of the fingers; inner metatarsal tubercle well developed, elongated oval, with a free edge.

Skin rough, with flat, irregularly shaped and pitted warts on the back and rounded pitted ones on the sides of the body; numerous small warts without pits

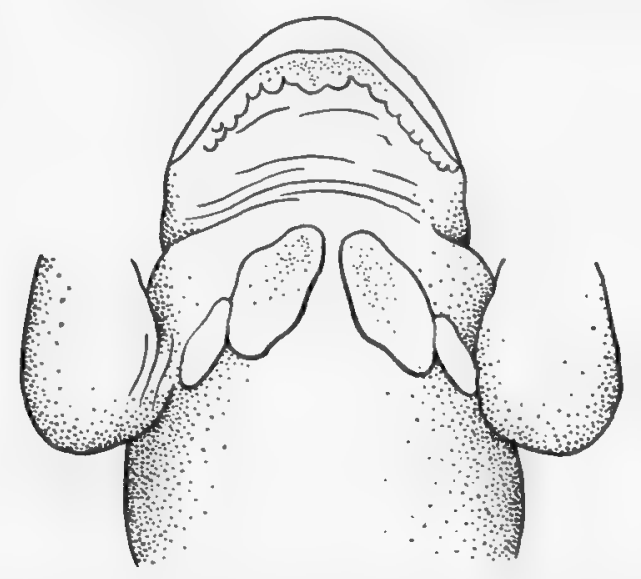

FIG. 24. Aelurophryne glandulata; male. Ventral view of head and thoracic region $(\times 1)$.

scattered among the rounded warts, fewest on the back; the pitted warts dark brown in color; small warts on upper sides of limbs; a large, ill-defined, flattened parotoid gland behind the eye; a strong glandular fold at latero-ventral margin of each parotoid, extending obliquely to the base of the arm; many rounded lightcolored warts behind and at the base of the thighs; skin of the throat, chest, belly and the ventral sides of the limbs smooth, except for glandular areas on the margin of the jaw (fig. 24); two pairs of flattened glands on the chest, the inner pair oval, large, and flat, with fine black spines on some of the granules of the gland, $16 \mathrm{~mm}$. long, about 20 per cent of the body length; the lateral pair (the axillary glands) smaller, elongate oval and much more elevated than the chest glands; latero-dorsal to the chest gland and ventro-anterior to the base of the arm, a definite area covered by thinner skin with scattered small warts; belly much wrinkled in the preserved specimen.

Coloration in life.-The ground color of the head, the back and the sides of the body and the dorsal sides of the limbs is olive. A dark brown bar crosses the posterior interorbital space. The top of the snout is much lighter than the other parts of the body. The anterior region of the upper eyelid and its margin are golden stippled, more so than other parts of the body. The snout has dark brown marblings and a brown band extends from the snout through the nostril 
and the edge of the upper eyelid to the latero-ventral side of the glandular folds, ending at the base of the arm. Irregular dark brown spots are scattered on the back and sides of the body and the dorsal sides of the limbs and digits. The exposed parts of the lower arm and leg have more golden stipples and the digits are lighter in color, especially the two inner fingers and toes. Webs are colored like the corresponding digits, stippled with dark brown. Pupils vary in shape with the intensity of light, but are always vertically elongated; the lower part of the iris is darker than the upper, depending on the amount of golden stippling. A bluish membrane is sometimes visible on the ventral inner margin of the upper eyelid. The throat is gray, with some indication of purple, and lightly marbled with ochraceous buff. The large anterior median glands of the chest are purplegray, stippled with bluish black, and the lateral pair is cream-buff stippled with gold. Belly is brownish ashy. There are round greenish-yellow warts on the ventral side of the base of the thigh and the vent. The coloration of the ventral sides of the arms and legs is like that of the belly, but the palms and soles correspond in color with the upper sides of the hands and feet. The coloration varies slightly among the five specimens available. The sides of the body, especially the groin region and the latero-ventral sides of the limbs may be greenish yellow or light olive green. After preservation, the back is dark gray, with scattered dark brown patches, and the dorsal sides of the limbs have small whitish warts. Throat, belly, and under sides of limbs are light grayish cream.

Distribution.-This new frog was discovered at Hopachai, about 45 miles from the city of Lifan. The altitude of Hopachai is 8,500 feet, and the temperature was only $35^{\circ}$ F. at 6:00 A.M., August 9, 1941. On this morning Mr. H. C. Chang found the first specimen under a stone in a small mountain stream by the side of a larger stream. We turned over nearly all the stones of that small stream, and an additional adult male, an adult female, two young specimens, and tadpoles, were obtained. On August 10, while we were on the way to the top of Tsingshan, we collected another female from a side branch of a mountain stream at an altitude of about 9,500 feet. No specimens were found during four days spent in a lumber company house near the top of Tsingshan, at 11,000 feet. On August 15, when we came back to Hopachai, we collected an egg-mass and tadpoles at various stages from another very small mountain stream.

Comparison with related species.-Aelurophryne glandulata can easily be distinguished from mammata and other species by the chest glands, as in glandulata these glands are very large and without the spines of the other species. It differs from $A$. tainingensis and $A$. maculata in size, the length of the body being about $80 \mathrm{~mm}$., while in tainingensis and maculata it is never over $60 \mathrm{~mm}$. In tainingensis there are rounded warts on nearly the whole belly in the male, and on the posterior central region of the belly in the female, whereas in glandulata the belly in both sexes is smooth. The foot is rugose beneath in glandulata and smooth in tainingensis and maculata. A. glandulata is more closely related to $A$. brevipes than to other species of the same genus, but in glandulata the two chest glands are separated by a space 1.2 per cent of the body 
length, and in brevipes this space amounts to 3 per cent; the axillary glands are longer and wider in glandulata than in brevipes; and the anterior third of the axillary gland is in contact with the postero-lateral side of the chest gland in glandulata, this contact being about two-thirds in brevipes. The hands and feet are much longer in glandulata than in brevipes, the length of the hand being about 30 per cent of the body length in the former while it is only about 25 per cent in the latter. The length of the foot is about 51 per cent of the length of the body in glandulata, while in brevipes it is 41 per cent. There are more spines on the first and second fingers (27-37) in glandulata and fewer (17-24) in brevipes.

Aelurophryne glandulata: Measurements of Adults

\begin{tabular}{|c|c|c|c|c|c|c|c|c|}
\hline \multirow[b]{2}{*}{ Measurements } & \multicolumn{2}{|c|}{ Male (type) } & \multicolumn{2}{|c|}{ Male } & \multicolumn{2}{|c|}{ Female } & \multicolumn{2}{|c|}{ Female } \\
\hline & MM. & $\begin{array}{c}\text { Ratio } \\
\text { to body } \\
\text { length } \\
(\%)\end{array}$ & мм. & $\begin{array}{c}\text { Ratio } \\
\text { to body } \\
\text { length } \\
\text { (\%) }\end{array}$ & MM. & $\begin{array}{c}\text { Ratio } \\
\text { to body } \\
\text { length } \\
(\%)\end{array}$ & MM. & $\begin{array}{c}\text { Ratio } \\
\text { to body } \\
\text { length } \\
\text { (\%) }\end{array}$ \\
\hline Body length. & 81.0 & & 67.0 & & 81.0 & & 77.0 & \\
\hline Head length. & 28.0 & 34.5 & 22.0 & 32.8 & 26. & 32.1 & 24.6 & 31.9 \\
\hline Head width. & 28.5 & 35.1 & 23.7 & 35.2 & 28.0 & 34.5 & 27.0 & 35.0 \\
\hline Interorbital space. & 7.0 & 8.6 & 5.0 & 7.4 & 7.0 & 8.6 & 5.5 & 7.1 \\
\hline Length of lower arm & 42.5 & 52.4 & 35.0 & 52.2 & 41.0 & 50.6 & 40.0 & 51.9 \\
\hline Diameter of lower arm. & 14.0 & 17.2 & 8.5 & 12.6 & 8.4 & 10.3 & 8.0 & 10.3 \\
\hline Length of leg. & 115.0 & 141.9 & 88.0 & 131.3 & 110.0 & 135.8 & 102.0 & 132.4 \\
\hline Length of tibia. & 34.5 & 42.5 & 27.5 & 41.0 & 31.0 & 38.2 & 29.5 & 38.3 \\
\hline Length of foot and tarsus. & 60.0 & 74.0 & 46.0 & 68.6 & 55.0 & 67.9 & 52.0 & .67 .5 \\
\hline Length of foot.... & 41.5 & 51.2 & 32.0 & 47.7 & 37.0 & 45.6 & 36.5 & 47.4 \\
\hline $\begin{array}{l}\text { Length of inner metatarsal } \\
\text { tubercle.................. }\end{array}$ & 6.3 & 7.7 & 4.4 & 6.5 & 7.0 & 8.6 & 4.5 & 5.8 \\
\hline
\end{tabular}

Sex dimorphism.- Sexes do not differ in size; body length of males is from 67 to $81 \mathrm{~mm}$., while that of females is from 77 to $81 \mathrm{~mm}$. The arm of the male is much stronger than that of the female. On the ventral region of the lower jaw of the male specimens there are many glandular areas (fig. 24), the median ones well developed and tending to be fused. Black pigment is irregularly scattered on the purplish glandular areas. In the males there are two pairs of flattened glands, one pair on the chest (the chest glands), and the other near the axilla (the axillary glands). In the female, only axillary glands are present. The first and second fingers are provided with spines in the male (fig. 23, A) but not in the female, and these two fingers are obviously stronger in the male than in the female.

Habitat and habits.--The adults of Aelurophryne glandulata are found under stones of the side branches of mountain streams from 7,500 to about 9,000 feet altitude. Their behavior - their slow awkward movements and their way of walking and jumping - is like that of the common toad. When it is found under a stone, the frog does not jump or move away. We turned over hundreds of stones along the river from 7,500 to 11,500 feet altitude, and also stones on the bank of the river, but only five animals were found. The real home of this frog may be on the hillsides in holes under stones near streams. 
Breeding.--The breeding season may be from July to August, as we collected tadpoles of different stages, including newly hatched individuals and tadpoles with four limbs well developed. Spoiled egg-masses were also obtained. On August 10, 1941, one large and three small egg-masses were found under boulders in a very small slow-running stream near Hopachai. The eggs were not measured,

A

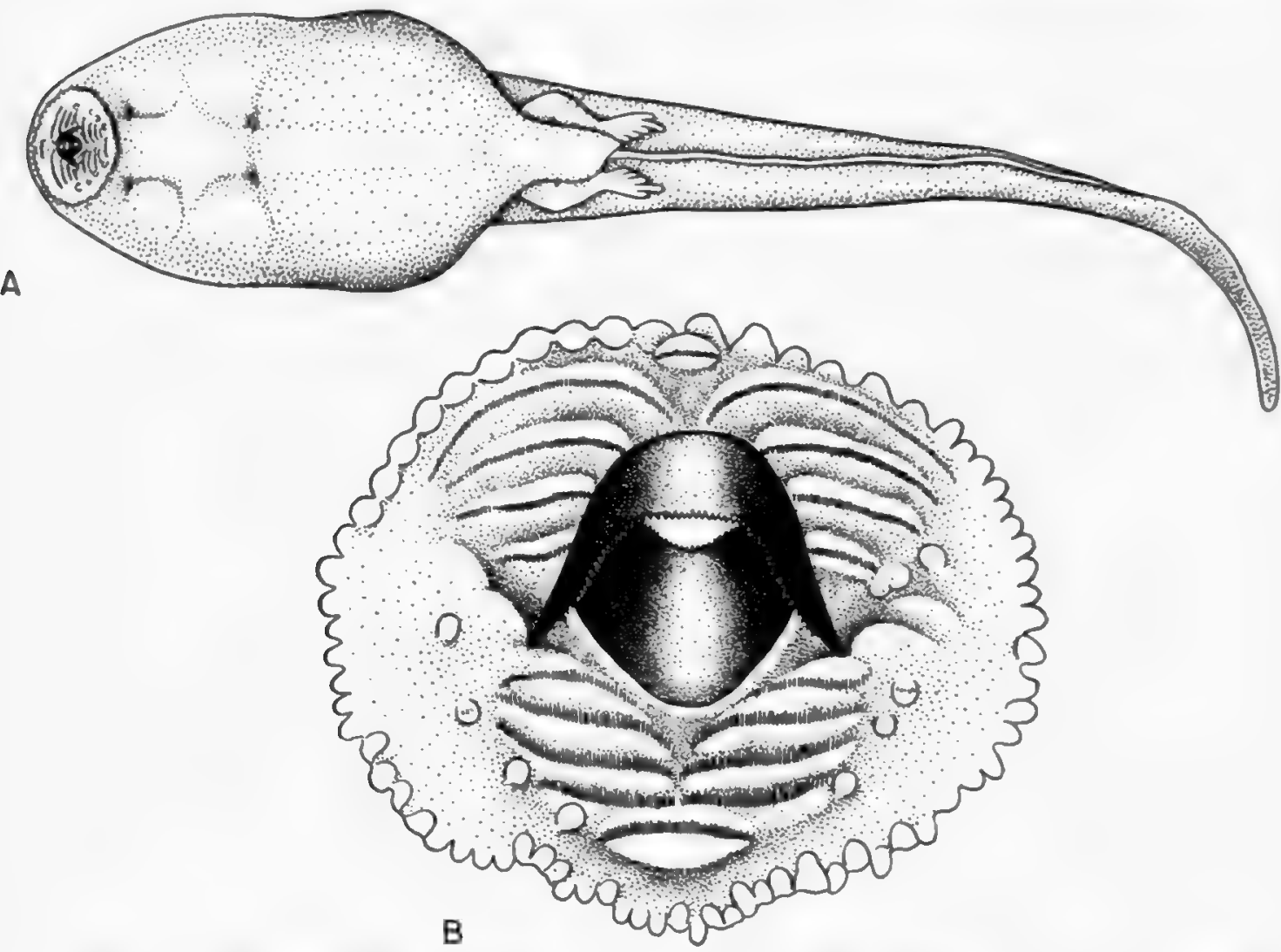
$(\times 16)$.

Fig. 25. Aelurophryne glandulata; tadpole. A. Ventral view $\left(\times 2 \frac{1}{2}\right)$. B. Mouth

as they were in a late stage of development and most of them were already spoiled; they are large and creamy white in color, enclosed in jelly that connects them strongly to each other and attaches them to the under surface of the boulder. The development is similar to that of Rana boulengeri, the embryo being rather small, with the tail bent to one side and applied to the surface of the large yolk of the egg.

After hatching, the tadpoles escape by making a hole in the jelly capsule at the side facing the water. The just-hatched tadpoles may stay with the jelly capsules. One case perplexed me very much; one egg-mass was not attached to the stone, but was found on the bottom of a pool with many tadpoles accumulated on it. This mass of jelly may have become detached from a stone, as in some cases in Staurois chunganensis. The jelly may supply food for the young tadpoles, as many of them are found on the capsules. 
Tadpoles.-The young tadpoles are found in small pools in brooks and also in side pools or in branches of the main stream. In the small brooks they aggregate together on the jelly capsules under stones or on the bottom of the water; those in larger bodies of water, as in the main stream, are scattered and hide under stones. The larger tadpoles scatter and hide under stones, mostly near the bank or in temporary pools of the main stream. The tadpoles are very sensitive; when disturbed they swim very quickly through the crevices between the stones. At the time of metamorphosis, the tadpoles are found under stones at the margin of the water. It seems likely that the tadpoles found in the water of the main river had been washed down from small brooks where the eggs are laid, as no egg-masses were found in the main river.

The young tadpole is dark brownish gray stippled with gold; the snout region is lighter; and the tail fin is pearl gray stippled with brownish gray, the dorsal fin darker than the ventral fin. The tadpole with hind limb-buds developed is similar in coloration, but with much more golden stippling on the body. Conspicuous patches of golden stippling are present on the back of the head and the dorsal part of the muscular portion of the tail. The pupil is round and black, with a black-marked golden iris. The tail fin is darker than that of the young tadpole. The belly is colorless.

Twenty tadpoles (pl. 10, fig. 7; text fig. 25) with hind limb-buds ranging from 2 to $7 \mathrm{~mm}$. long were measured; the average body length from the snout to the base of the tail is $23.3 \mathrm{~mm}$., ranging from 21.5 to $25 \mathrm{~mm}$. The form of the body varies with the habitat. The tadpoles collected from running water or slowrunning water by the side of the river have a somewhat elongated and cylindrical body, and those found in stationary water with very rich vegetation have a very clumsy body with the abdominal region greatly enlarged by food, the head being greater in width than in height. The ratio of head width to body length is 48 per cent and that of the height of head is only 33 per cent. The length of the tail is $\mathbf{1 7 8}$ per cent of the body length, with a moderately developed tail fin and tail muscle.

The snout is rounded, with the mouth more ventral than anterior and about one-fourth of the body length, like that of Megophrys oshanensis. The lips are long. The nostrils are nearer to the snout than to the eye, and are surrounded by lighter-colored rings. The eyes are latero-dorsal in position, the space between them being 23.2 per cent of the body length. The spiraculum is sinistral, ending with a very short tube directed upward and backward and visible from above and below. It is nearer to the base of the tail than to the tip of the snout. The vent is dextral, with a broad oblique opening overlapped by a skin fold continuous with the ventral tail fin. The tail is moderately long, with a blunted tip, and the dorsal tail fin is slightly deeper and darker than the ventral fin. The dorsal fin is very low and thick near the base of the tail and the ventral fin extends to the vent. The thickness of the muscle near the base of the tail is one-fourth of the body length. 
Aelurophryme glandulata: Measurements of Tadpoles

Ten Specimens from Running Water and Ten from Quiet Water

\begin{tabular}{|c|c|c|c|c|}
\hline Measurements & & Range & Average & $\begin{array}{l}\text { Ratio to } \\
\text { body length (\%) }\end{array}$ \\
\hline Body length. & $\begin{array}{l}\text { Running water } \\
\text { Quiet water }\end{array}$ & $\begin{array}{l}21.5-24.5 \\
22.5-25.0\end{array}$ & $\begin{array}{l}23.3 \\
23.4\end{array}$ & $\cdots$ \\
\hline Body height. & $\begin{array}{l}\text { Running water } \\
\text { Quiet water }\end{array}$ & $\begin{array}{l}9-11 \\
9-13\end{array}$ & $\begin{array}{l}10.1 \\
11.0\end{array}$ & $\begin{array}{l}41.2 \\
47.0\end{array}$ \\
\hline Body width. & $\begin{array}{l}\text { Running water } \\
\text { Quiet water }\end{array}$ & $\begin{array}{c}10.2-13.0 \\
11-17\end{array}$ & $\begin{array}{l}11.6 \\
13.5\end{array}$ & $\begin{array}{l}49.7 \\
57.6\end{array}$ \\
\hline Head height. & $\begin{array}{l}\text { Running water } \\
\text { Quiet water }\end{array}$ & $\begin{array}{l}7-9 \\
7-9\end{array}$ & $\begin{array}{l}7.8 \\
7.9\end{array}$ & $\begin{array}{l}33.4 \\
33.3\end{array}$ \\
\hline Head width. & $\begin{array}{l}\text { Running water } \\
\text { Quiet water }\end{array}$ & $\begin{array}{l}9.5-11.5 \\
11-13\end{array}$ & $\begin{array}{l}10.5 \\
11.8\end{array}$ & $\begin{array}{l}45.0 \\
50.4\end{array}$ \\
\hline Mouth width. & $\begin{array}{l}\text { Running water } \\
\text { Quiet water }\end{array}$ & $\begin{array}{l}6.0-6.8 \\
5.5-7.0\end{array}$ & $\begin{array}{l}6.2 \\
6.1\end{array}$ & $\begin{array}{l}25.7 \\
26.0\end{array}$ \\
\hline Space from eye to eye. & $\begin{array}{l}\text { Running water } \\
\text { Quiet water }\end{array}$ & $\begin{array}{l}4.8-5.8 \\
5.2-6.0\end{array}$ & $\begin{array}{l}5.4 \\
5.5\end{array}$ & $\begin{array}{l}23.1 \\
23.5\end{array}$ \\
\hline Space from nostril to nostril. & $\begin{array}{l}\text { Running water } \\
\text { Quiet water }\end{array}$ & $\begin{array}{l}4.0-4.5 \\
4.0-4.5\end{array}$ & $\begin{array}{l}4.1 \\
4.1\end{array}$ & $\begin{array}{l}17.5 \\
17.5\end{array}$ \\
\hline Tip of snout to spiraculum. . & $\begin{array}{l}\text { Running water } \\
\text { Quiet water }\end{array}$ & $\begin{array}{l}13.0-15.5 \\
13.0-15.5\end{array}$ & $\begin{array}{l}14.3 \\
13.7\end{array}$ & $\begin{array}{l}61.3 \\
58.5\end{array}$ \\
\hline Tail length. & $\begin{array}{l}\text { Running water } \\
\text { Quiet water }\end{array}$ & $\begin{array}{l}38-46 \\
39-45\end{array}$ & $\begin{array}{l}41.1 \\
41.9\end{array}$ & $\begin{array}{l}176.3 \\
179.0\end{array}$ \\
\hline Tail height. & $\begin{array}{l}\text { Running water } \\
\text { Quiet water }\end{array}$ & $\begin{array}{c}9.5-10.8 \\
9-12\end{array}$ & $\begin{array}{r}9.9 \\
10.7\end{array}$ & $\begin{array}{l}42.9 \\
45.7\end{array}$ \\
\hline Diameter of tail muscle. & $\begin{array}{l}\text { Running water } \\
\text { Quiet water }\end{array}$ & $\begin{array}{c}5.5-6.2 \\
5-7\end{array}$ & $\begin{array}{l}5.8 \\
6.3\end{array}$ & $\begin{array}{l}24.8 \\
26.9\end{array}$ \\
\hline Length of hind limb. & $\begin{array}{l}\text { Running water } \\
\text { Quiet water }\end{array}$ & $\begin{array}{l}3.8-8.0 \\
2-7\end{array}$ & $\begin{array}{l}5.3 \\
4.2\end{array}$ & $\begin{array}{l}\ldots \\
\cdots\end{array}$ \\
\hline
\end{tabular}

The variation of the labial teeth and papillae (fig. 25, B) in twenty tadpoles was studied. There is a row of papillae on the margin of the upper and lower lips, without or with a very small space on the mid-dorsal side of the upper lip; the papillae at the sides of the lip are larger than those of the lower lip; in some specimens, the smaller ones bend inward and give the appearance of two rows of papillae. A few additional papillae are found at the corners of the mouth, and in many cases there are two or more papillae located lateral to the second and third rows of labial teeth of the lower lip. Normally there are four rows of labial teeth on the upper lip, the first the shortest, and complete, the second the longest and narrowly interrupted, and the other two widely interrupted. On the lower lip, there are four or five rows of labial teeth, the outermost row short and complete and the other four rows all interrupted. In the twenty specimens studied, the frequency of tooth formula is as follows: ten specimens have tooth formula $I: 3-3 / I: 4-4$; six have $I: 4-4 / I: 4-4$; two have $I: 3-3 / I: 5-5$; one has $\mathrm{I}: 3-4 / \mathrm{I}: 5-4$; and one has $\mathrm{I}: 4-4 / \mathrm{I}: 5-5$. The last four groups have the outermost row of the lower lip interrupted. The mandible has a heavily serrated edge.

\section{Genus SGUTIGER Theobald}

Usage of the names Scutiger, Aelurophryne, and Cophophryne has become confused by the assumption of Boulenger (1887, p. 405) that Scutiger Theobald, 
1868, in the Amphibia, is preoccupied by the earlier Scutigera Latreille of 1802, a centipede. According to the subsequent ruling of the International Commission on Zoological Nomenclature, this is not the case, but Procter (1922, p. 583) continued the use of the Boulengerian substitute name Cophophryne, which is a pure synonym of Scutiger. Procter, furthermore, refers Aelurophryne to Cophophryme (and thus to Scutiger). Noble (1931, p. 493) correctly distinguished the toothless Aelurophryne from the toothed Scutiger, and correctly uses Scutiger for the Himalayan genus, but without adequate explanation. The discovery that Scutiger includes several distinct species re-enforces the desirability of maintaining it as a distinct genus.

\section{KEY FOR IDENTIFICATION OF ADULTS OF SCUTIGER}

I. Tibio-tarsal articulation reaching beyond the eye.

A. Rounded black warts on back; very distinct black bars on limbs; webs hardly

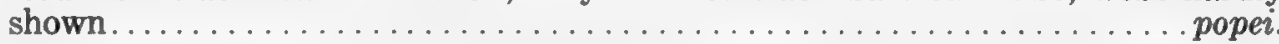

AA. Warts irregular, color dark as background; bars on limbs rather indistinct; toes

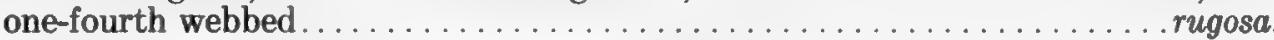

II. Tibio-tarsal articulation not reaching beyond the eye.

A. Skin smooth, color light, toes distinctly webbed................ pingii.

AA. Skin rough, color dark, toes not webbed..........................

\section{KEY FOR IDENTIFICATION OF TADPOLES OF SCUTIGER}

I. Body and tail uniform black, tooth formula $I: 4-4 / I: 4-4 \ldots \ldots \ldots \ldots$ rugosa.

II. Tail much lighter in color than the body.

A. Color not uniform, with dark spots or light markings; tail muscle strong, diameter about one-third of body length.

B. Black spots on the body, diameter of tail muscle about 34 per cent of the

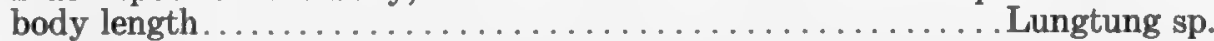

BB. No black spots on the body but with a light mark on the dorsum near the base of the tail (very distinct in living specimens).

C. Diameter of tail muscle about 35 per cent of body length.

Mount Omei sp.

CC. Diameter of tail muscle about 28 per cent of body length

Panlungshan sp.

AA. Color uniform, no spots or marks; tail less than twice as long as the body.

B. Tooth formula I:4-4/I:4-4; tail short and weak, its length about 155 per cent of the body length, tail muscle 19 per cent............. pingii.

BB. Tooth formula more than $I: 4-4 / I: 4-4$.

C. Size small (19-21 mm.); tail short and weak, its length about 168 per cent of the body length, diameter of tail muscle about 23 per cent. schmidti

CC. Size large $(23-29 \mathrm{~mm}$.); tail long, about 196 per cent of the body length, diameter of tail muscle about 27 per cent................ popei

Frogs of the genus Scutiger are rare Himalayan pelobatids first discovered by Blyth in 1854 . The first species was described as Bombinator sikkimensis, from two specimens preserved in the Calcutta Museum. In 1887 Boulenger redescribed this rare frog as Cophophryne sikkimensis from three specimens (a male, a female and a juvenile) collected by W. T. Byntan at the foot of Yakla 
Pass, Sikkim (altitude 13,000 feet). These three specimens in the British Museum are apparently immature, as the measurement of the largest one was given by Boulenger as $50 \mathrm{~mm}$. and Pope measured it as $48 \mathrm{~mm}$. Pope's manuscript notes record two more British Museum specimens, mature males collected from the Burma-Sikang border.

Scutiger alticola was described by Procter (1922) as Cophophryne alticola from a single female specimen, collected from the Kharta Valley, Tibet (altitude 16,500 feet). The fully webbed toes and granulated abdomen of this species are not found in any of the Chinese species of Scutiger since discovered.

The apparently rare frogs of the genus Scutiger now prove to be well represented in China, as I have discovered seven additional species, four species with adults and tadpoles, and three species thus far known only from tadpoles and young. Scutiger sikkimensis and $S$. alticola have not been found in Szechwan or Sikang.

\section{Scutiger pingii Liu}

Scutiger pingii Liu, Jour. West China Border Res. Soc., 14, (B): 35, fig. 5, 1943 Yenwot'ang, Chaochiao, Sikang; idem, op. cit., 14, (B): 71, 1943.

History of species.-Scutiger pingii was discovered in 1942 and is still known only from the type locality.

Comparison with related species.-Scutiger pingii (pl. 4, fig. 1) agrees with schmidti in having the tibio-tarsal articulation extending only to the angle of the mouth, thus differing from the longer-legged popei and rugosa; pingii differs from schmidti in having the toes distinctly webbed, the color lighter, and the skin smoother. Of all the species of this genus in western China only pingii has spines on the outer toes in the male. The body is stouter in pingii than in schmidti, popei or rugosa. Scutiger pingii is much lighter in color and less distinctly spotted on the back than the other three species, which have darker dorsal patterns or spots.

The tadpole of pingii has a short, stout body and a short and weak tail, in association with its habitat of quiet or very slow-running water.

Collection data.-On May 4, 1942, fourteen specimens were collected at two places between Hsuanshenpa and Lolokou, in Chaochiao, Sikang. Four more specimens were collected from the same locality on May 17 and eight more on June 14 and 15 of the same year. The altitude of these localities was from 9,000 to 11,000 feet, with the temperature from $44^{\circ}$ to $68^{\circ} \mathrm{F}$. on May 6 and May 12 . Tadpoles in different stages and young just after metamorphosis were obtained from the same localities and on the same days that the adults were collected.

Original description.- - "Tongue elliptical, free behind and slightly notched, vomerine teeth lacking [fig. 26, B]. Head moderately large, slightly broader than long; snout rounded; canthus rostralis feebly indicated; loreal region oblique and flat; nostrils rather near to the eye and the internasal space about equal to 
the interorbital space, which is slightly broader than the upper eyelid; length of eye about equal to the internasal space; tympanum lacking.

"Fingers [fig. 26, C] long and slender, the first barely longer than the second, and both with nuptial spines on the inner dorsal sides. Subarticular tubercles developed; an inner large and an outer smaller palmar tubercle well developed. Arm rather long, length of the lower arm to the tip of third finger nearly half of the body length and its diameter about one-tenth of the body length; many small, rounded, light-colored warts on the antero-ventral sides of the upper and lower arms; small warts with black spines on the dorsal sides of the upper and lower arms, especially at the elbow region.

"Hind limb rather short, tibio-tarsal articulation reaching the angle of the mouth; heels not meeting when placed at right angles to the body; tibia about
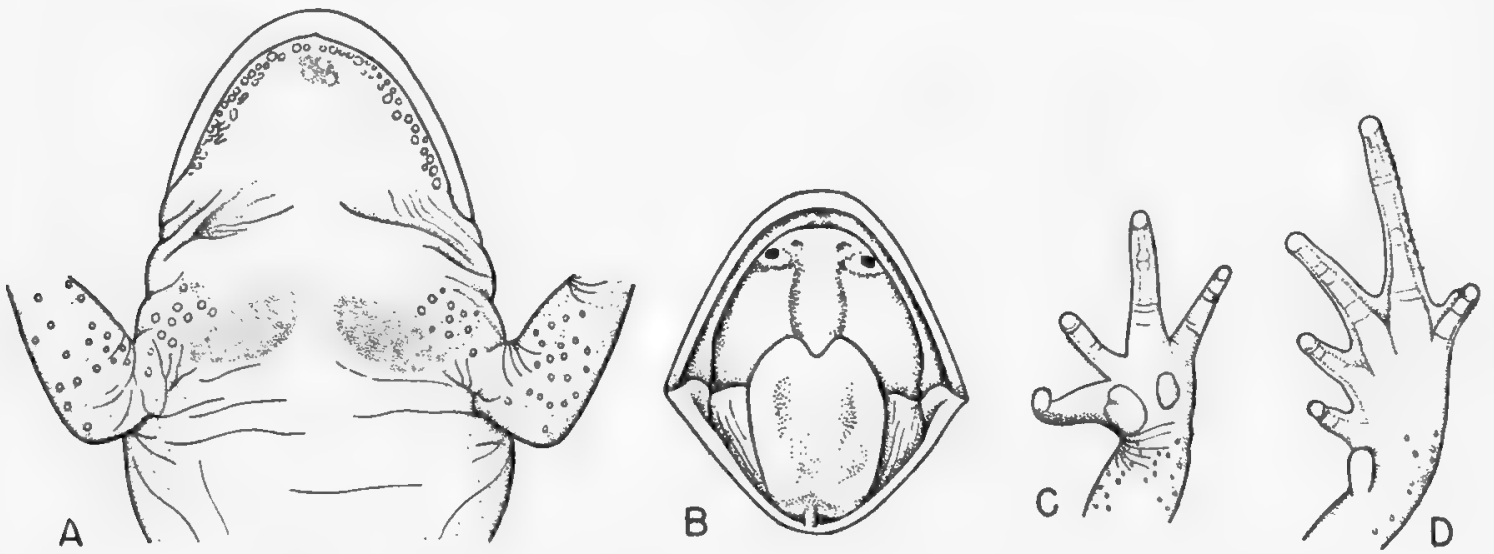

FIG. 26. Scutiger pingii; male. A. Ventral view of head and thoracic region $(\times 1)$. B. Oral cavity $(\times 2)$. C. Ventral view of hand $(\times 2)$. D. Ventral view of foot $(\times 2)$.

42 per cent of the body length. Webs between all the toes [fig. 26, D], about onethird to one-fourth webbed; all the toes fringed, with a row of black spines on the outer and inner fringes of the fifth toe and only the outer fringe of the fourth toe; subarticular tubercles developed but not very distinct; inner metatarsal tubercle elongated, rod-like and greatly elevated, its length about 6.3 per cent of the body length; outer metatarsal tubercle lacking.

"Skin of the back with small flattened warts; warts on the shoulder region and on the dorsal sides of the limbs with black spines. Length from snout to vent $43 \mathrm{~mm}$. Fine black spines developed on the chest glands.

"The dorsum is rufous brown with many indistinct darker spots that usually coincide with warts. The throat and the belly and the under sides of limbs are fleshy-purple as in Kaloula. The color of the upper sides of the limbs is like that of the back, with indistinct bars only on the femur. There is a goldencreamy axillary gland on the chest at the base of each arm. On the middle posterior aspect of each femur there is a more or less round, light-colored, flattened 
gland. In living specimens, the pupil is changeable in shape, but always more or less vertical, with golden iris stippled with black, especially at the lower side.

"There is no sexual dimorphism in size. The average body length of the two mature males is $43.5 \mathrm{~mm}$., ranging from 43 to $44 \mathrm{~mm}$.; and the average body length of the nine females is $40.4 \mathrm{~mm}$., ranging from 37 to $46 \mathrm{~mm}$. The arm of the male is moderately enlarged and much thicker than that of the female. In the male [fig. 26], there are many black nuptial spines on the inner dorsal side of the first finger, extending to the medial side of the wrist, and then less numerous on the inner dorsal side of the second finger. There are many black spines on the ventral margin of the lower jaw and many spines aggregated together on the antero-median ventral side of the floor of the mouth of the male. Two elliptical areas of fine black spines are developed on the chest glands of the male; many strongly developed spines on light-colored bases are scattered on the shoulder and tympanic region and on the dorsal sides of the limbs. It is very interesting to notice that in the male of this species characteristic spines are found on the lateral margins of the fifth toe and on the outer margin of the fourth toe. The three inner toes are about one-fourth webbed, and webs between fourth and fifth are rudimentary in the female and all the toes of the male are about one-fourth to one-third webbed."

Scutiger pingii: Measurements of Two Males and Nine Females

\begin{tabular}{|c|c|c|c|c|}
\hline Measurements & Sex & Range & Average & $\begin{array}{c}\text { Ratio to } \\
\text { body length }(\%)\end{array}$ \\
\hline 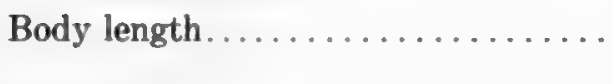 & $\begin{array}{l}0^{7} \\
8\end{array}$ & $\begin{array}{l}43-44 \\
37-46\end{array}$ & $\begin{array}{l}43.5 \\
40.4\end{array}$ & ... \\
\hline Head length. & $\begin{array}{l}0^{7} \\
q\end{array}$ & $\begin{array}{c}13.5-14.5 \\
13-16\end{array}$ & $\begin{array}{l}14.0 \\
14.4\end{array}$ & $\begin{array}{l}32.2 \\
35.6\end{array}$ \\
\hline Head width. & $\begin{array}{l}0 \\
9\end{array}$ & $\begin{array}{c}15.0-15.5 \\
13-16\end{array}$ & $\begin{array}{l}15.3 \\
14.4\end{array}$ & $\begin{array}{l}35.1 \\
35.6\end{array}$ \\
\hline Interorbital space... & $\begin{array}{l}0 \\
8\end{array}$ & $3.6^{4}-8.8$ & $\begin{array}{l}4.0 \\
4.0\end{array}$ & $\begin{array}{l}9.2 \\
9.8\end{array}$ \\
\hline Length of lower arm. . & $\begin{array}{l}7 \\
8\end{array}$ & $\begin{array}{l}20-22 \\
18-24\end{array}$ & $\begin{array}{l}21.0 \\
19.9\end{array}$ & $\begin{array}{l}48.5 \\
48.9\end{array}$ \\
\hline Width of lower arm. & $\begin{array}{l}0 \\
8 \\
9\end{array}$ & $\begin{array}{l}5.0-5.5 \\
3.5-4.0\end{array}$ & $\begin{array}{l}5.3 \\
3.8\end{array}$ & $\begin{array}{r}12.1 \\
9.3\end{array}$ \\
\hline Length of hand. & $\begin{array}{l}9 \\
8\end{array}$ & $\frac{12}{9.5-13.0}$ & $\begin{array}{l}12.0 \\
10.9\end{array}$ & $\begin{array}{l}27.6 \\
27.0\end{array}$ \\
\hline Length of leg.. & $\begin{array}{l}\text { वे } \\
9\end{array}$ & $\begin{array}{l}60-64 \\
51-67\end{array}$ & $\begin{array}{l}62.0 \\
55.8\end{array}$ & $\begin{array}{l}142.5 \\
137.9\end{array}$ \\
\hline Length of tibia. . & $\begin{array}{l}0^{7} \\
8\end{array}$ & $\begin{array}{l}18-19 \\
15-20\end{array}$ & $\begin{array}{l}18.5 \\
16.8\end{array}$ & $\begin{array}{l}42.5 \\
41.5\end{array}$ \\
\hline Length of foot and tarsus. . & $\begin{array}{l}0^{x} \\
9\end{array}$ & $\begin{array}{l}29-31 \\
20-32\end{array}$ & $\begin{array}{l}30.0 \\
26.7\end{array}$ & $\begin{array}{l}69.0 \\
66.0\end{array}$ \\
\hline Length of foot. & $\begin{array}{l}9 \\
8 \\
8\end{array}$ & $\begin{array}{l}20-21 \\
15-22\end{array}$ & $\begin{array}{l}20.5 \\
18.2\end{array}$ & $\begin{array}{l}47.1 \\
45.1\end{array}$ \\
\hline Length of inner metatarsal tubercle. . & $\begin{array}{l}07 \\
0\end{array}$ & $\begin{array}{l}2.5-3.0 \\
2.0-2.6\end{array}$ & $\begin{array}{l}2.8 \\
2.1\end{array}$ & $\begin{array}{l}6.3 \\
5.2\end{array}$ \\
\hline
\end{tabular}

Measurements of type (percentage of body length in parentheses).-Body length $43 \mathrm{~mm}$.; head length $15 \mathrm{~mm}$. (34.9); head width $15 \mathrm{~mm}$. (34.9); interorbital 
space $4 \mathrm{~mm}$. (9.3); length of lower arm $21 \mathrm{~mm}$. (48.8); length of hand $12 \mathrm{~mm}$. (27.9); length of hind limb $54.5 \mathrm{~mm}$. (126.7); length of tibia $18 \mathrm{~mm}$. (42.0); length of tarsus and foot $29 \mathrm{~mm}$. (67.5); length of foot $20 \mathrm{~mm}$. (46.5); length of inner metatarsal tubercle $2.7 \mathrm{~mm}$. (6.3).

Habitat and habits. - Scutiger pingii is a high mountain form found under stones in slow-running water of small mountain streams or under stones on the
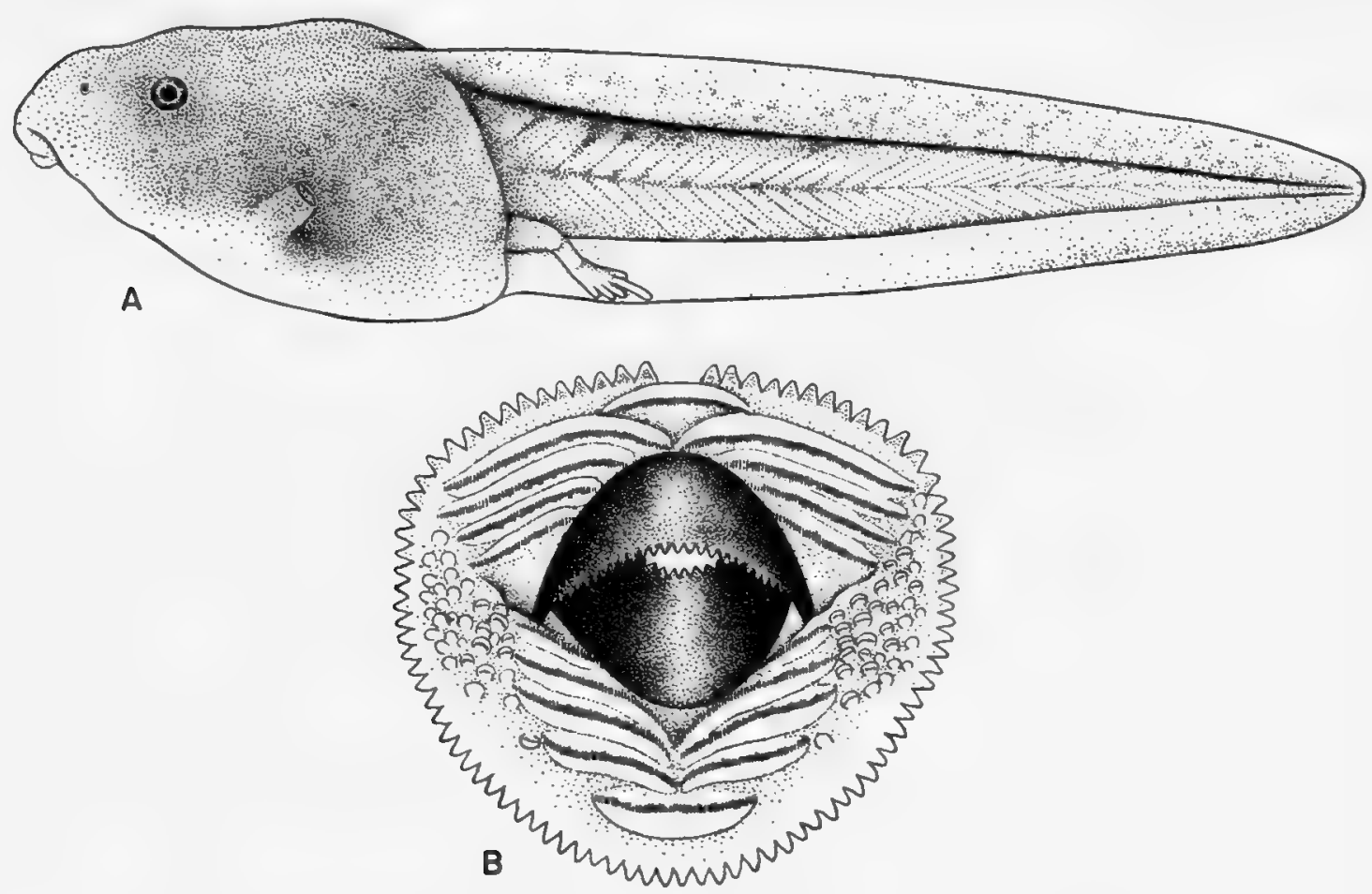

FIG. 27. Scutiger pingii; tadpole. A. Lateral view (X 3). B. Mouth (X 12).

margins of small pools at about 10,000 feet altitude. The adults are very inactive and behave very much like those of Kaloula. They were found to be more abundant the first part of May in quiet or running water and in the first part of June very few specimens were found near water. This may indicate that the breeding season is early in May, although no eggs were found.

Tadpole.-Tadpoles (fig. 27, A) of this new Scutiger are rather sensitive. Under undisturbed conditions, they swim singly or in small groups in slow-running water, but when disturbed they hide in the cracks between stones or under stones. They are bottom feeders with strong mouth-parts (fig. 27, B). Their coloration varies slightly in different stages. The background color of the back and the sides of the body is dark gray, densely stippled with gold and brown. The tail is gray and much lighter toward its tip, where it is also stippled with gold and brown. Toward the time of metamorphosis, the color becomes lighter.

The tadpoles are rather large. Ten tadpoles with hind limbs ranging from 2 to $12 \mathrm{~mm}$. in length were measured. The average body length from the tip of 
the snout to the base of the tail is $25 \mathrm{~mm}$., ranging from 23 to $26.5 \mathrm{~mm}$.; for the tail, the average length is $39 \mathrm{~mm}$., with a range from 36 to $43 \mathrm{~mm}$. The width of the head is 43 per cent of the body length and its height is only 31 per cent. The body is somewhat flattened dorso-ventrally; its height is 42 per cent of the body length and its width is 50 per cent. The length of the tail is about one and a half times the body length and its height two-fifths.

\section{Scutiger pingii: Measurements of Ten Tadpoles}

\begin{tabular}{|c|c|c|c|}
\hline Measurements & Range & Average & $\begin{array}{l}\text { Ratio to } \\
\text { body length }(\%)\end{array}$ \\
\hline Body length...... & $23.0-26.5$ & 25.0 & \\
\hline Body beight. & $9.5-11.0$ & 10.5 & 42.0 \\
\hline Body width. & $11.5-13.0$ & 12.6 & 50.4 \\
\hline Head height. & $7.5-8.0$ & 7.8 & 31.2 \\
\hline Head width. & $10-11$ & 10.8 & 43.2 \\
\hline Mouth width. & $5.2-6.0$ & 5.7 & 22.8 \\
\hline Space between eyes. & $5.5-7.0$ & 6.4 & 25.6 \\
\hline Snout to spiraculum............... & $14-16$ & 15.3 & 61.2 \\
\hline Tail length................ & $36-43$ & 38.8 & 155.2 \\
\hline Tail height. & 9-11 & 9.9 & 39.6 \\
\hline Diameter of tail muscle (near base of tail).. & 4-5 & 4.7 & 18.8 \\
\hline Length of hind $\operatorname{limb} \ldots \ldots \ldots \ldots \ldots \ldots$ & $2-12$ & $\ldots$ & .... \\
\hline
\end{tabular}

The snout is rounded, and the nostril, enclosed by an elevated ring, is about mid-way between the tip of the snout and the eye. The eyes are dorso-lateral in position but more dorsal than lateral, with an average space between the two eyes of 26 per cent of the body length. The spiraculum is sinistral, ending in a semi-tube directed upward and backward and visible from above and below. It is $15.3 \mathrm{~mm}$. from the tip of the snout to the spiraculum, which is nearer to the base of the tail than to the tip of the snout, as the distance from the snout to the spiraculum is 61 per cent of the body length. The vent is dextral, with a large oblique opening, under a broad skin fold that overlies it and is continuous with the ventral tail crest. The tail is weak. The tip of the tail is blunt, with the tail crest about equally developed dorsally and ventrally. The dorsal tail crest is thickened at its base, but is not continued onto the body.

The mouth is ventral, with an average width of $5.7 \mathrm{~mm}$., which is 23 per cent of the body length. A single row of papillae is developed on the margin of the lip. There are five rows of teeth on the upper lip. The outermost row is short and continuous, mostly filling up the gap where there are no papillae. The remaining four rows are all interrupted, the first row next to the short continuous row being the longest, and the innermost row the shortest. On the lower lip, there are also five rows of teeth. The outermost row is short and continuous, but it is longer than the outermost row of the upper lip. The other four rows are all interrupted, the fourth row the longest, and the innermost row the shortest. Teeth are also found on some of the additional papillae at the corners of the mouth. The mandibles are thick and heavy, with strong sharp teeth on the edges of both upper and lower mandibles. The number of rows of labial teeth is constant; the formula is $I: 4-4 / I: 4-4$. 
The young just after metamorphosis has all the characters of an adult except for the secondary sex characters. From sncut to vent, it measures about $25 \mathrm{~mm}$.

\section{Scutiger rugosa Liu}

Scutiger rugosa Liu, 1943, Jour. West China Border Res. Soc., 14, (B) : 37, figs. 1-4Yenwot'ang, Chaochiao, Sikang; idem, op. cit., 14, (B): 73, 1943.

History of species.-Scutiger rugosa was discovered in 1942 in a small mountain stream near Lolokou, Chaochiao, Sikang. The known distribution of this new Scutiger is still limited to the type locality.

Distribution and collection data.-The type series of this species was found under a stone near the margin of a small mountain stream at Chilipa, between Yenwot'ang and Lolokou, in Chaochiao, Sikang, on May 4, 1942. The altitude of the type locality is 11,000 feet. Scutiger rugosa is still known only from the type locality.

Comparison with related species.-Scutiger rugosa (fig. 28, A) agrees with $S$. popei in having the tibio-tarsal articulation reaching beyond the eye, but differs in having the toes distinctly webbed. The dark bars on the limbs, very distinct in popei, are very indistinct in rugosa. The longer leg of rugosa distinguishes it from both schmidti and pingii. In color rugosa is much darker than pingii. The body of rugosa is dorso-ventrally flattened, whereas it is stout in pingii. The tadpole of rugosa is black with black tail crest marbled with dark brownish gold. The tadpoles of other species of Scutiger are much lighter in color and always have a very light-colored tail crest.

Original description.- "Body somewhat flattened, $35 \mathrm{~mm}$. long from snout to vent; vomerine teeth wanting, tongue free behind and distinctly notched [fig. 28, B]. Head large, broader than long, and dorso-ventrally flattened; snout rounded; canthus rostralis obtuse; loreal region concave; nostrils nearer to the tip of the snout than to the eye; internasal space smaller than interorbital space, which is equal to the width of upper eyelid; tympanum hidden.

"Arm slender and long; lower arm about half of the body length; fingers [fig. 28, C] rounded, slender and long with light-colored rounded tips; first finger shorter than the second but the fourth finger longer than the second, the third finger the longest; subarticular tubercles indistinct; an inner large rounded palmar tubercle and an outer smaller elliptical palmar tubercle.

"Legs moderately long and rather slender: the tibio-tarsal articulation reaching the middle of the eye, and the heels slightly overlapping when placed at right angles to the body; tibia 47 per cent of the body length from tip of snout to vent; toes [fig. 28, D] about one-fourth webbed and slightly fringed laterally; subarticular tubercles indistinct; tips rounded; inner metatarsal tubercle oval and highly elevated, about 5.7 per cent of the body length; outer tubercle lacking.

"Skin rough on dorsal sides of head, body and limbs; many small warts with spines scattered on the head and limbs; larger rounded, oval or elongated warts 
provided with spines on the back and sides of the body, a strong glandular fold from the posterior corner of the eye to shoulder; anal region with small rounded light-colored glands; a large oval gland enclosed by dark color on middle posterior aspect of each femur; throat, belly and ventral sides of limbs smooth. The color is dark brown-gray above; lower region of limbs with the same color but the upper arms and legs lighter, with indistinct dark-colored bars; digital
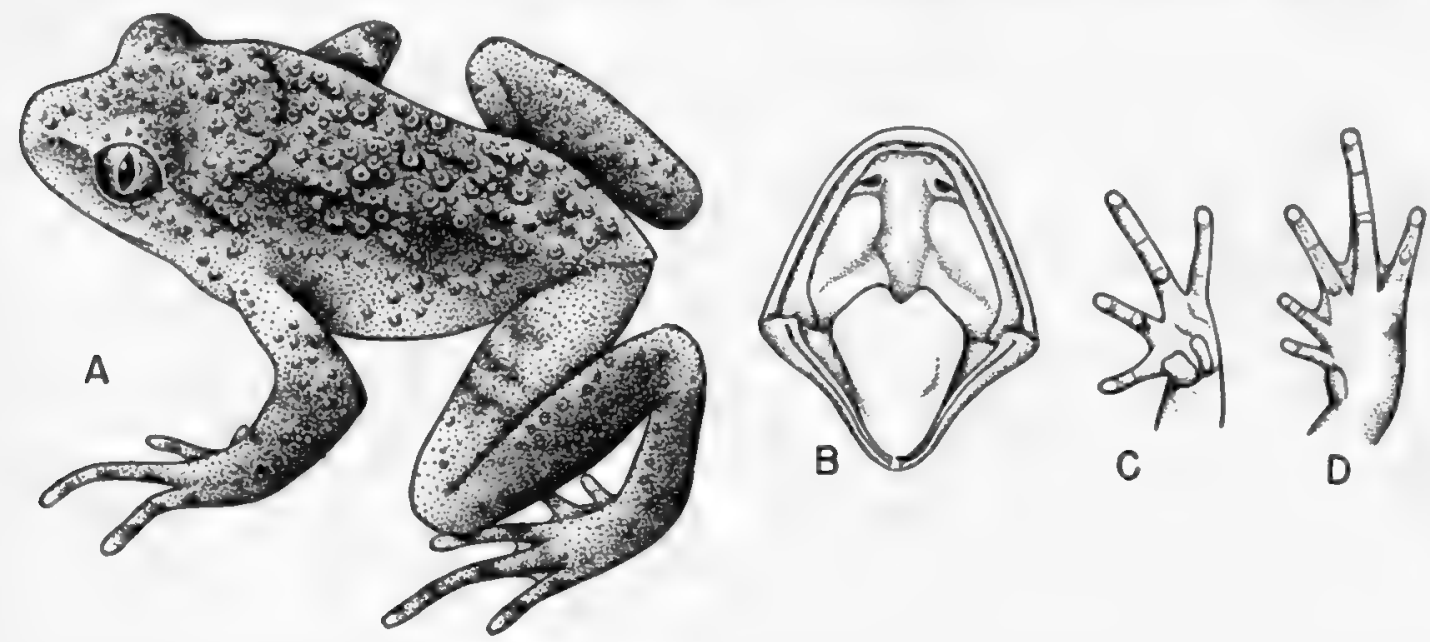

FIG. 28. Scutiger rugosa $(\times 2)$. A. Young adult. B. Oral cavity. C. Ventral view of hand. D. Ventral view of foot.

tips much lighter; jaws marked by dark bars; throat, belly and ventral sides of limbs much stippled with gray."

Habitat and habits.-At first glance the living specimen of rugosa seemed very much like Scutiger schmidti in behavior and in appearance. Sexual behavior and secondary sex characters are still unknown.

Tadpoles.-Tadpoles (pl. 10, fig. 3) were collected from the same locality and on the same date. Tadpoles of various stages, including a specimen nearly completely metamorphosed, were obtained from the same place on June 14, 1942. They were found under the stones of a small mountain stream. They are very active and because of their strongly built tails they can swim against the current. When disturbed they rush into the cracks between or under the stones in the water or hide themselves among vegetation.

Under natural conditions they are black in color except for the dorsoposterior part of the body and the dorsal side of the base of the tail, where the color is dark brownish golden and forms a Y-shaped mark. This brownish golden color runs posteriorly along the dorsal ridge of the tail crest about half of the tail length, and then becomes discontinuous. The black tail crest is marbled with dark brownish gold. The belly is colorless and transparent, with four white spots, two postero-lateral to the heart and two near the anal region. The pupil is rounded and black, enclosed by a silver-golden iris stippled with black. 
The tadpole of this species is rather large. Six tadpoles, with hind legs averaging $4 \mathrm{~mm}$. and varying from 3 to $5 \mathrm{~mm}$., have an average body length of $24.1 \mathrm{~mm}$., ranging from 24 to $25 \mathrm{~mm}$. The width of the head is 49 per cent of the body length while its height is only 34 per cent. The body is somewhat

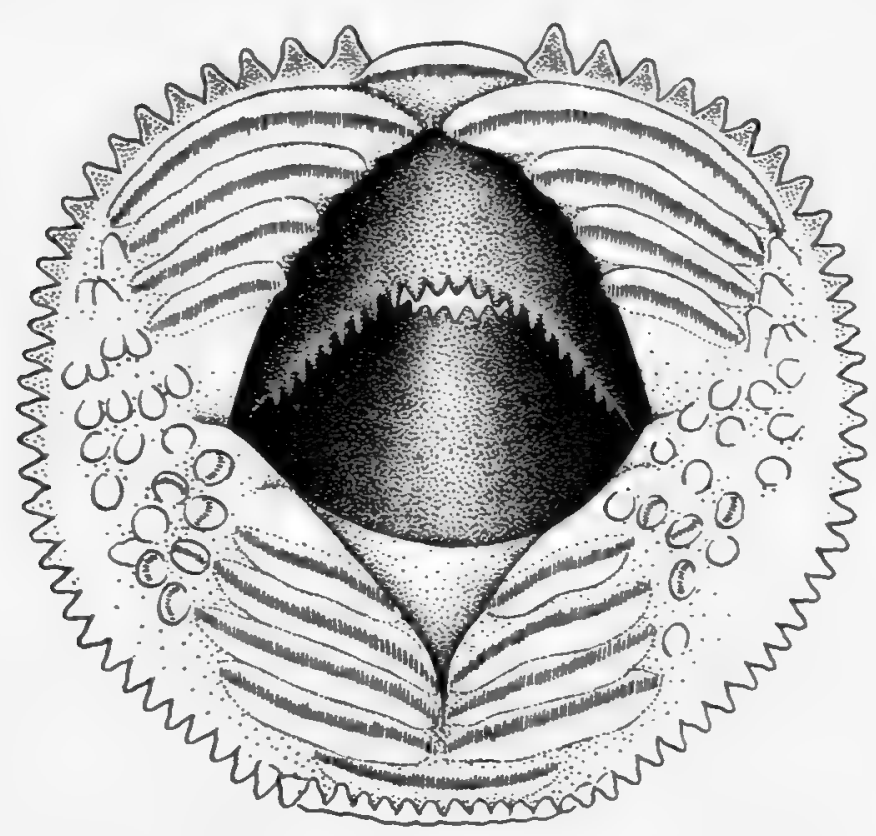

FIG. 29. Scutiger rugosa; mouth of tadpole $(\times 16)$.

flattened, its height 49 per cent and its width 58 per cent of the body length. The length of the tail is $\mathbf{1 7 3}$ per cent of the body length, while its height is $\mathbf{5 3}$ per cent.

The snout is rounded, and the nostril, enclosed by a light-colored ring, is slightly nearer to the tip of the snout than to the eye. The eyes are dorsolaterally located but are more dorsal than lateral. The space between the eyes is 30 per cent of the body length. The spiraculum is sinistral, ending in a semitube, directed upward and backward, visible from above and below. It is nearer to the base of the tail than to the tip of the snout. The vent is dextral, with an oblique opening, under a broad skin fold that overlies it and is continuous with the base of the ventral crest. The tail is very thick, with the muscular portion strongly developed. The lines formed by myocomma are very characteristic for this species, as they bend posteriorly in V-shape and bend again anteriorly at the base of the greatly thickened dorsal and ventral tail crests, especially at the anterior region of the tail. The tip of the tail is blunt, with the tail about equally developed dorsally and ventrally. The anterior region of the tail crests, especially the dorsal one, is greatly thickened.

The mouth (fig. 29) is ventral, with an average width of $6 \mathrm{~mm}$., one-fourth of the body length. A single row of papillae surrounds the mouth, except for a 
small space in the middle of the upper lip. Papillae are larger toward the dorsal side of the upper lip, with a number scattered at the corners of the mouth, especially near the upper sides of the lower lip. Some of these papillae are provided with teeth. Labial teeth and mandibles are remarkably developed and invariable. Five rows of labial teeth are found in the upper lip, the outermost the shortest and continuous and the other four rows all interrupted, the first interrupted row the longest. There are also five rows of teeth on the lower lip, the outermost row complete and much longer than the outermost row of the upper lip, and the rest all interrupted, the second interrupted row being the longest. Mandibles are enormously developed, with very strong large teeth on their margins.

A young specimen with tail stump measured $23 \mathrm{~mm}$. long from tip of snout to vent.

Measurements of type (percentage of body length in parentheses).-Body length $35.0 \mathrm{~mm}$.; head length $13.0 \mathrm{~mm}$. (37.1); head width $13.5 \mathrm{~mm}$. (38.5); interorbital space $3.8(10.8)$; length of lower arm $18.5 \mathrm{~mm}$. (52.8); diameter of lower arm $3.0 \mathrm{~mm}$. (8.5); length of hand $10.5 \mathrm{~mm}$. (30.0); length of hind limb $53.0 \mathrm{~mm}$. (151.4); length of tibia $16.5 \mathrm{~mm}$. (47.1); length of foot and tarsus $23.0 \mathrm{~mm}$. (65.7); length of foot $15.5 \mathrm{~mm}$. (44.2); length of inner metatarsal tubercle $2.0 \mathrm{~mm}$. (5.7).

Scutiger rugosa: Measurements of Six Tadpoles

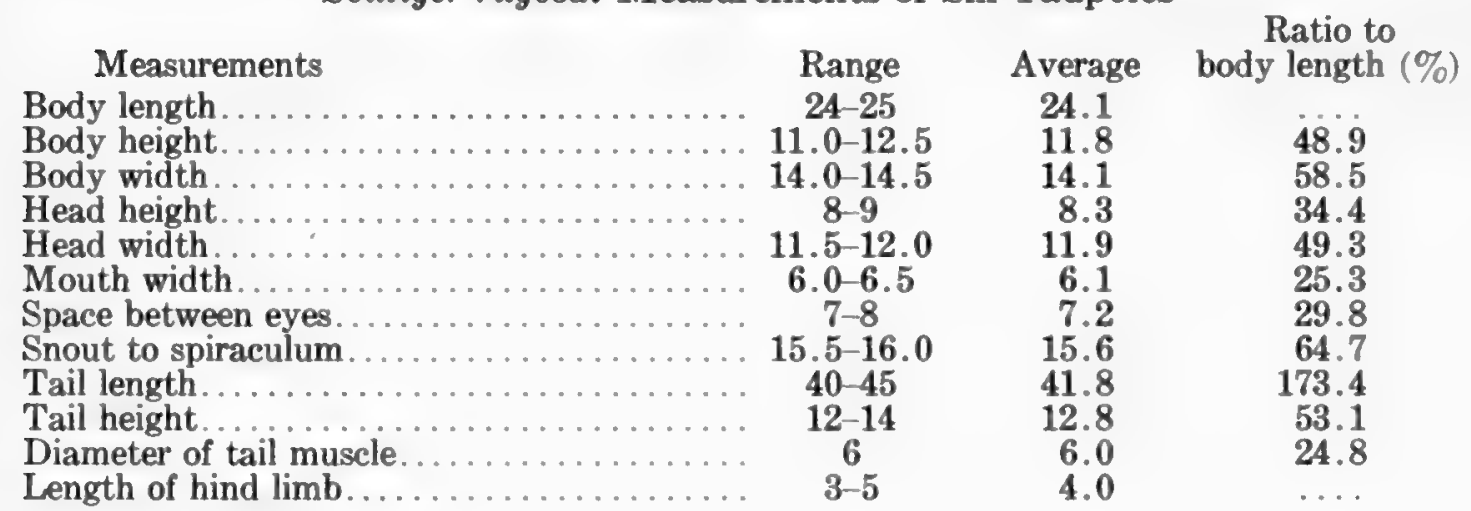

\section{Scutiger popei Liu}

Scutiger sikkimensis Liu, 1940, Jour. West China Border Res. Soc., 12, (B): 12; idem, 1943, op. cit., 14, (B): 51, pl. 1, fig. 1, pl. 2, figs. 6, 10 (not of Blyth).

Scutiger popei Liu, 1947, Copeia, 1947 : 125, fig. 2-Paohsing, Sikang.

History of species. - Specimens collected from Mount Omei, Paohsing, and Panlungshan and described as Scutiger sikkimensis by myself in 1940 and 1943 and by Pope and Boring in 1940, must be referred to Scutiger popel (pl. 5, fig. 5) as still another endemic species of pelobatid frog from western China.

Distribution and collection data.-Scutiger popei is widely distributed in western China. It is found in the mountain ranges between Szechwan and Sikang at altitudes ranging from 3,500 to 7,000 feet. During the summers of 
1938 and 1940, tadpoles of this species at different stages were collected from pools behind large stones, under cascades or in side pools of small mountain streams under Changshouchiao, between Chiulaotung and Yuhsiensze at an altitude of 5,900 feet, on Mount Omei. On August 18, 1939, a large number of tadpoles at various stages were collected from a mountain stream near Lungtung, Paohsinghsien, Sikang (3,400 ft.), and three adults were obtained from the same stream. From April 13 to May 3, 1941, only large tadpoles with hind limbbuds were found in small mountain streams of Shuimokou, Kwanhsien; and no
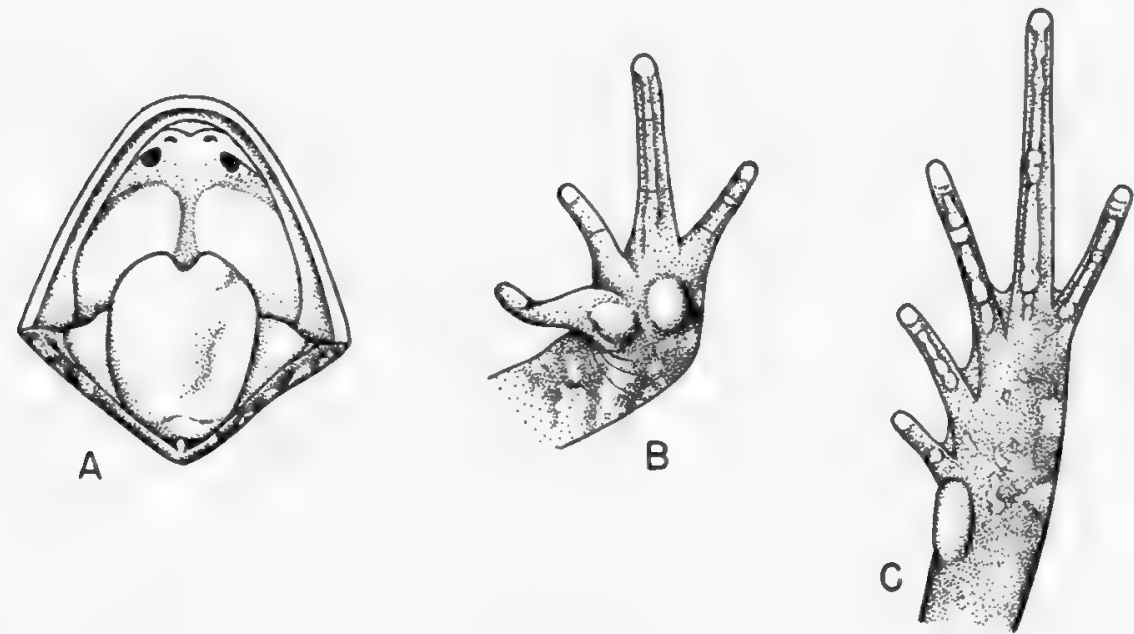

FIG. 30. Scutiger popei $(\times 2)$. A. Oral cavity. B. Ventral view of hand. C. Ventral view of foot.

eggs or young tadpoles were obtained. From June 28 to July 15, 1941, very young tadpoles and tadpoles at the time of metamorphosis were collected from the same stream of Shuimokou. On July 5, 1945, a dead matured male, a living young adult and various tadpoles were obtained from Changshoukou on Mount Omei. An egg-mass was collected in the same stream in its upper reaches but it could not be proved that the eggs were those of popei.

Comparison with related species.-Scutiger popei can be distinguished from all other species of Scutiger, except rugosa, by its longer legs, as the tibio-tarsal articulation extends beyond the eye in popei and rugosa and only reaches the eye in alticola and the angle of the mouth in sikkimensis, schmidti and pingii. Scutiger popei differs from rugosa in the absence of spines on the sides of the shoulder and on the warts of the back, spines being well developed on the shoulder region and on the warts, especially those on the back of rugosa. The coloration of popei is very characteristic; there are distinct large black or dark brown spots on the back and conspicuous dark bars on the limbs, the two outer fingers, and the three outer toes.

Scutiger popei has rounded warts without pores, and the tibio-tarsal articulation reaches beyond the eye, whereas in $S$. sikkimensis the warts are porous and 
the tibio-tarsal articulation only reaches the shoulder or the angle of the mouth. The light triangular spot on the forehead of sikkimensis is not found in popei. The choanae are very small in sikkimensis and very large in popei. The tongue of popei (fig. 30, A) is deeply notched behind, whereas that of sikkimensis is rounded or only slightly notched posteriorly. S. popei is found at altitudes ranging from 3,500 to 7,000 feet; the specimens of sikkimensis in the British Museum were collected from Bhutan, Sikkim, at 13,000 feet.

Scutiger popei (fig. 30, C) can be distinguished from rugosa by the absence of webs and the distinct black bars on limbs. S. alticola differs from popei in having the toes fully webbed. The shorter leg and the indistinct bars on the limbs of pingii and schmidti distinguish them from popei.

Original description.- - "Body moderately slender; head somewhat depressed, as long as broad; tongue broad, free behind and deeply nicked; no vomerine teeth; choanae very large; snout rounded, slightly projecting beyond the mouth, and much longer than the length of the eye; canthus rostralis obtuse; loreal region very oblique, concave; nostrils nearer to the tip of the snout than to the anterior corner of the eye; interorbital space greater than internasal, and broader than the upper eyelid; tympanum hidden.

"Arm strong, fingers slender and long, first and second about equal in length, but shorter and thicker than the third and fourth, the third finger the longest; nuptial spines number eleven on the first and eight on the second finger of the left hand, and respectively ten and five on the right hand; tips of fingers rounded and lighter in color, subarticular tubercles present; thickened skin between the subarticular tubercles, especially the two outer fingers, palmar tubercles large and prominent, a large inner one at the base of the first finger and a much smaller one opposite the base of the third.

"Hind limb slender and long, the tibio-tarsal articulation reaching beyond the eye; length of tibia 48.8 per cent of the body length; foot 49.2 per cent of the body length; toe slightly fringed with rudimentary webs, subarticular tubercles better developed than on the fingers, thickened ridges found between the subarticular tubercles; inner metatarsal tubercle oval, with a free edge; no outer metatarsal tubercle.

"Skin rough; small warts on the top and sides of the head, especially posterior to the angle of the mouth, and on the dorsal sides of the limbs; larger round warts more or less regularly scattered on the back and the sides of the body; fine warts on the inner anterior side of the arm, with a definite warty area on the antero-ventral region at the base of the arm; two well-developed chest glands, covered with fine spines, located on the thorax; the length of this gland is about $8 \mathrm{~mm}$. and the breadth $4 \mathrm{~mm}$.; rounded axillary glands make contact with the postero-lateral corners of the chest glands at the arm pit on each side; a large flattened gland, lighter at center and dark-colored at periphery, on the midposterior aspect of each thigh; skin smooth on the throat, the belly and the ventral sides of the legs. 
"Coloration in life. - Ground color of the top and sides of the head, the back and sides of the body and the dorsal sides of the limbs is brownish yellow; rounded black or dark brown spots with light centers and brown processes radiating out from each spot are correlated with the dorsal warts. The markings extend from spot to spot and form a network on the body; smaller black spots on the top of the head; black bars on the jaw, dorsal sides of the limbs, the two outer fingers, and the three outer toes; throat, belly, and ventral sides of limbs flesh-purple in color; throat, sides of belly and ventral sides of limb strongly marbled with brownish gray. The eye is very large and has a vertical pupil which can be changed from oval to slit-like form as in the cat, the size of which is regulated by the intensity of the light. The color and the shade of the iris is striking. The upper half of the eyeball is bright and the lower half is dark. After preservation the ground color of the back is light cinnamon drab, the black spots cover the warts, and the light brown network disappears."

Variation.-The specimens collected from Lungtung, and those collected from Panlungshan differ slightly in coloration and texture of the skin. Warts, especially those on the top of the head, are smaller and much more numerous in the specimens from Panlungshan than in those collected from Lungtung, so the skin of the former seems much more rugose than that of the latter. Dark brown or black stripes on the femur are different in number and in shape. The Panlungshan specimen has four or five complete narrow stripes alternating with incomplete ones on the thigh, while in the specimens from Lungtung there are only four wide stripes, with no incomplete ones. The coloration is apparently the same, except that the Lungtung specimens are lighter in color with a rather light brown network, formed by bands radiating out from the dark brown center that covers each wart. The background color is brownish yellow. There is no distinct network-like pattern on the specimens collected from Panlungshan, but the light-colored tips on the warts are much clearer than in Lungtung individuals.

Scutiger popei: Measurements of Type and Paratypes

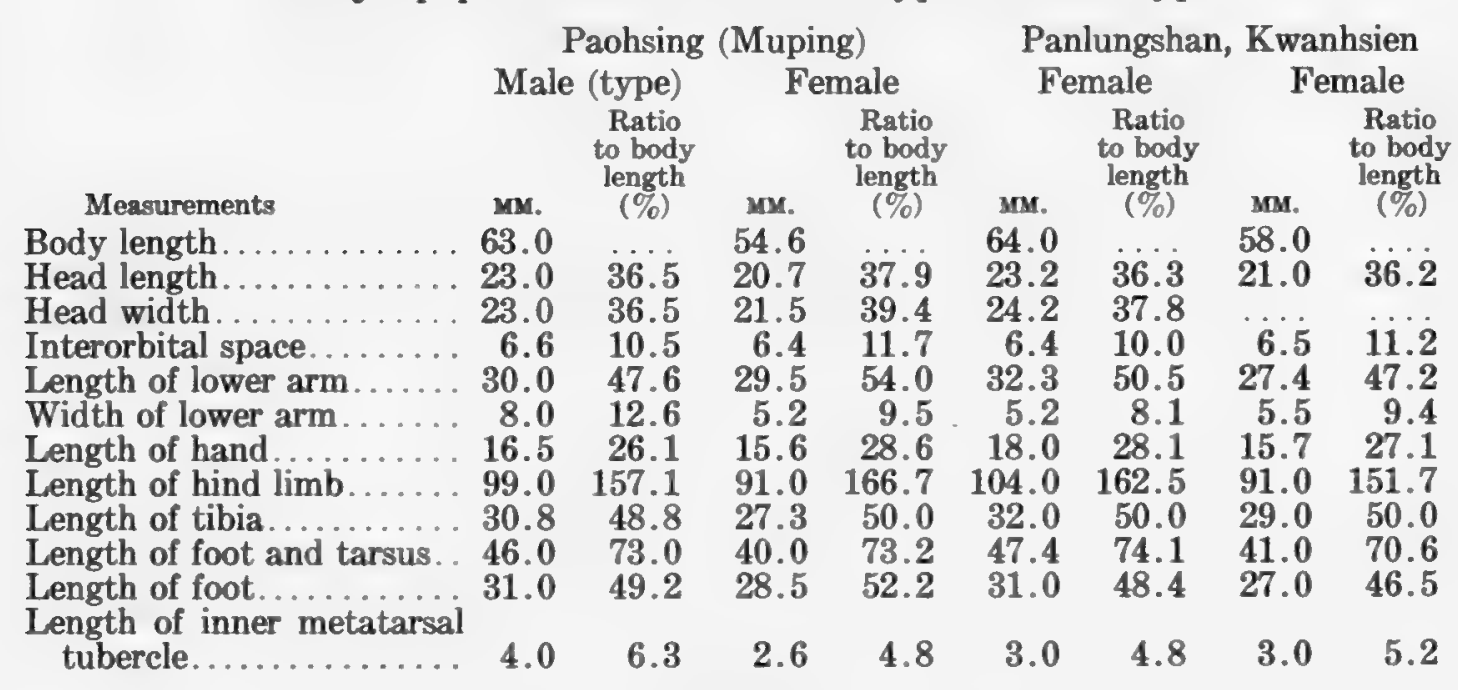


Secondary sex characters. - The adult of Scutiger popei is a medium-sized frog with no sexual dimorphism in size, the body length of the male being $63 \mathrm{~mm}$., while the body length of the females ranges from 54 to $64 \mathrm{~mm}$. The arm of the male is moderately enlarged and is much thicker than that of the female. In the male, from five to eight spines are developed on the dorsal side of the second finger and from ten to eleven on the inner dorsal side of the first finger; there are two well-defined patches of weakly developed nuptial spines on the breast. The length of the hind limb is apparently the same in both sexes. Webs are absent in the female and rudimentary in the male, in which the toes are flattened and laterally fringed. There are no vocal sacs and no lineae masculinae.

Habitat and habits.-Scutiger popei is a species found on high mountains. In four years' collecting only five adults were obtained, though from the number of tadpoles found in so many places on Mount Omei, on Panlungshan, Chungkingchow, Szechwan, and at Lungtung in Paohsing, Sikang, it seems that adults should be abundant. All the specimens I secured were found in small mountain streams, either sitting on stones near the water or concealed under stones in the water. As webs are wanting, this frog seems not to be an aquatic form, especially in mountain streams. Occasionally one or two individuals may pay a visit to the water nearby, so by chance we got these few specimens after much hard work. I suspect that it is a terrestrial form living among vegetation, under stones or in holes on hillsides. The adults may come out in numbers during the breeding season, as does Staurois chunganensis. We searched diligently among the vegetation and turned over thousands of stones along small and large mountain streams where tadpoles of Scutiger popei were abundant, but not one specimen was found in this way. Therefore, the real home of this species is still unknown. It may be a good traveller, coming from a habitat distant from the streams where the eggs are laid.

Tadpoles.-The presence of young tadpoles at the end of June indicates that eggs may be laid from the middle part of May to the early part of July. The breeding habits of this new frog are still unknown. The tadpoles are bottom feeders with strong mouth-parts (fig. 31). When disturbed, they get into cracks between stones to hide themselves, and also under stones, so it is hard to collect them in stony places. They can swim in the current of the stream as their tails are strongly built, especially the muscular portion. They are omnivorous, but rather predacious than herbivorous. They eat larvae of stone flies, caddis flies and such other animals as they can get in small mountain streams, and they also take plant food, especially algae growing on stones in the water. Tadpoles brought to Chengtu ate a lot of tadpoles of Bufo b. gargarizans every day. Tadpoles of Scutiger popei are strongly built, especially the mouth parts and the tail. If they touch a Bufo tadpole, they suck it and carry it from place to place with their strong mandibles and broad lips. Even though it struggles to escape it can rarely get away from the strong hold of the Scutiger tadpole.

The coloration of the tadpoles varies greatly in different stages. Young tadpoles are black on the back and sides of the body. The pupil is black and 
round, enclosed by a thin, whitish golden ring, which in turn is enveloped by a wide iris; this is black below and marked with golden dots on the antero-dorsal side. The muscular portion of the tail is light gray and the tail crests are very light yellowish gray. Above the muscular portion, but below the dorsal crest, there are two lines, the upper light yellowish brown, and the lower dark gray or black. These two lines start from the base of the tail and run beyond the

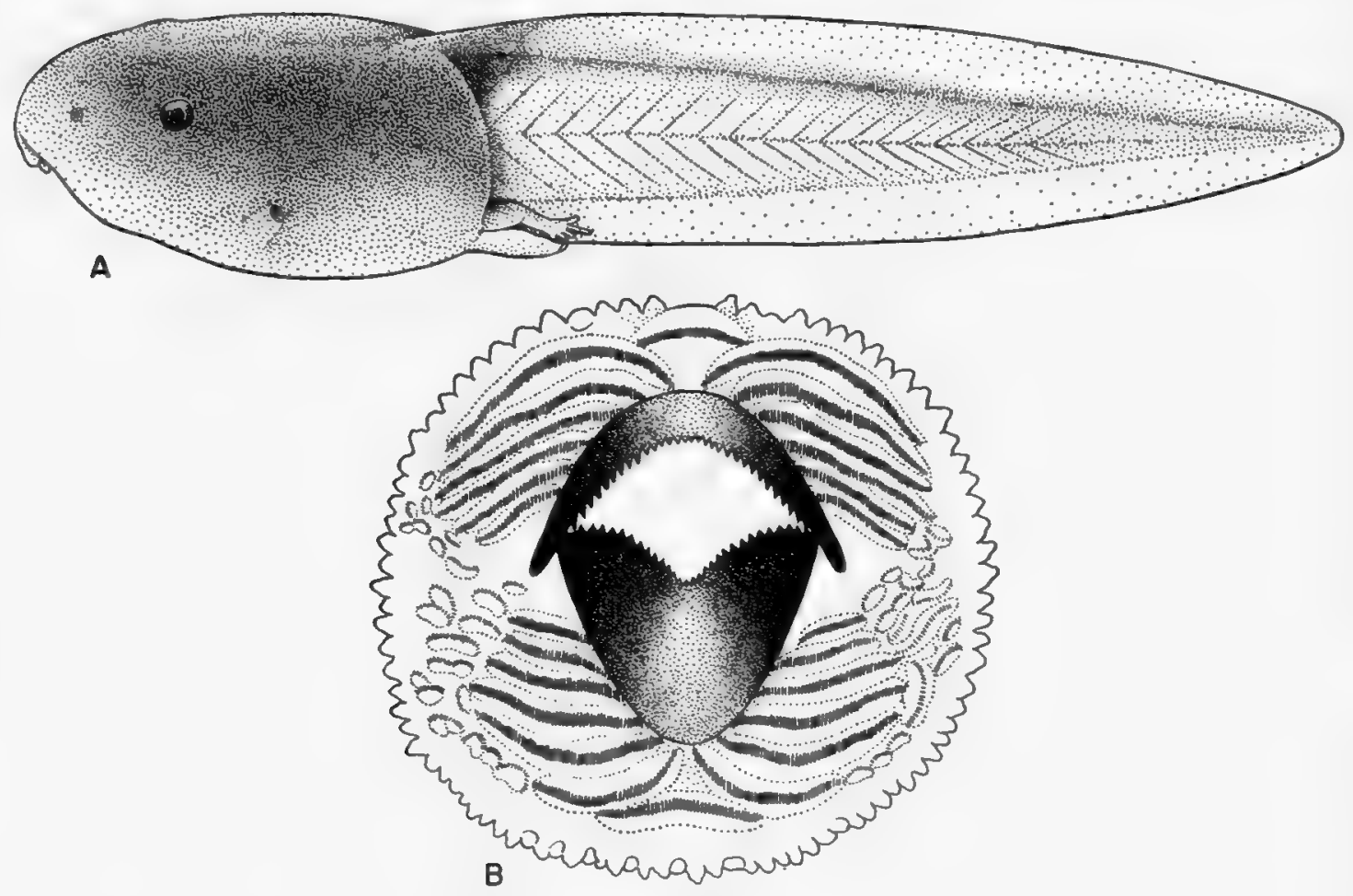

FIG. 31. Scutiger popei; tadpole. A. Lateral view $\left(\times 2 \frac{1}{2}\right)$. B. Mouth $(\times 10)$.

middle portion of the tail, where they become indistinct. The belly is light gray in color.

When the limb-buds are well developed the body becomes umber above, and on the sides this color darkens to bluish black lower down and then fades to dark gray on the belly. The hind limb-buds are grayish blue above and yellowish gray below. The tail is yellowish gray, the ventral tail fin lighter. The yellowish brown and dark gray lines between the dorsal tail fin and the muscular part of the tail have disappeared at this stage but their area is still darker in color than the other parts of the body. When the fore limbs come out, the body is greenish gray above with many round or oval warts enclosed by black rings. The dorsal sides of the limbs have the same coloration as the body, but with a number of discontinuous black stripes.

The tadpole of this species is very large; individuals with hind limb-buds reach $75 \mathrm{~mm}$. in length. In twenty tadpoles measured, in which the hind legs 
averaged $5.2 \mathrm{~mm}$., the average body length from snout to base of tail is $25 \mathrm{~mm}$., ranging from 22.5 to $28.7 \mathrm{~mm}$. The width of the head is 54 per cent of the body length, while its height is only 36 . The body is nearly cylindrical, its height 51 per cent and its width 56 per cent of its length. The length of the tail is about twice that of the body.

\section{Scutiger popei: Measurements of Twenty Tadpoles}

\begin{tabular}{|c|c|c|c|}
\hline Measurements & Range & Average & $\begin{array}{l}\text { Ratio to } \\
\text { body length }(\%)\end{array}$ \\
\hline Body length... & $22.5-28.7$ & 25.2 & \\
\hline Body height. & $11.4-14.5$ & 12.8 & 51.0 \\
\hline Body width. & $10.8-16.0$ & 14.2 & 56.4 \\
\hline Head height. & $8.4-10.2$ & 9.1 & 36.2 \\
\hline Head width. & $12.0-15.5$ & 13.6 & 54.2 \\
\hline Mouth width. & 6.48 .2 & 7.1 & 28.1 \\
\hline Space between eyes. & $7.6-10.7$ & 9.1 & 36.2 \\
\hline Snout to spiraculum. & $14.3-18.0$ & 15.8 & 62.8 \\
\hline Tail length........... & $41.4-56.4$ & 49.3 & 196.0 \\
\hline Tail height. & $12.5-18.4$ & 15.1 & 60.1 \\
\hline Diameter of tail muscle. & $5.5-8.5$ & 6.7 & 26.6 \\
\hline Length of hind limb... & $4.0-6.7$ & 5.2 & $\ldots$ \\
\hline
\end{tabular}

The snout is rounded; the nostril, enclosed by a light-colored ring, is nearer to the snout than to the eye. The eyes are latero-dorsal in position, more dorsal than lateral, with an average space between the eyes of $9 \mathrm{~mm}$., which is 36 per cent of the body length from the snout to the base of the tail. The spiraculum is sinistral, ending in a semi-tube, directed upward and backward, visible from above and below. It is $16 \mathrm{~mm}$. from snout to spiraculum, which is nearer to the base of the tail than to the tip of the snout, the distance from snout to spiraculum being 63 per cent of the body length. The vent is dextral, with a large oblique opening. The broad skin fold that overlies it is continuous with the ventral tail crest. The tail is thick, with the muscular part strongly developed. The tip of the tail is blunt, with the tail fin better developed dorsally. The dorsal fin is thickened at its base but is not continued on to the body.

The mouth is ventral, with an average width of $7 \mathrm{~mm}$., which is 28 per cent of the body length. There is a single row of papillae of varying size all around the mouth, except for a small free space on the mid-dorsal part of the upper lip. Additional papillae, with or without teeth, are found at the corners of the mouth, especially at the latero-dorsal corners of the lower lip. There are seven rows of teeth on the upper lip. The outermost row is short and continuous, partly filling up the gap where there are no papillae. The remaining six rows are all interrupted, and the inner row is the shortest. On the lower lip there are seven rows, with the outermost row continuous and longer than the outer row on the upper lip. The other six rows on the lower lip are all interrupted, the innermost row being the shortest (fig. 31). Teeth are also found on some of the additional papillae at the corner of the mouth. The mandibles are thick and heavy, with sharp strong teeth both above and below. The number of rows of labial teeth varies greatly in the tadpoles of this species. Seventeen tadpoles collected from 
Lungtung, Paohsing, in Sikang, and twenty-two from Mount Omei were studied. For the Paohsing group, the tooth formulae are as follows: ten have I:5-5/I:5-5; five have I:6-6/I:5-5; one has I:5-5/I:6-6; and one has I:6-6/I:6-6. In the Mount Omei group, one has I:4-4/I:4-4; two have I:4-5/I:4-5; four have $\mathrm{I}: 5-5 / \mathrm{I}: 5-5$; ten have I:6-6/I:6-6; one has I:6-7/I:6-7; one has I:6-6/I:7-7; one has I:7-7/I:6-6; and two have I:7-7/I:7-7. Ten tadpoles collected from Panlungshan were studied and the tooth formulae are as follows: nine have $\mathrm{I}: 5-5 / \mathrm{I}: 5-5$ and one is abnormal. The majority of the Paohsing popei tadpoles have a tooth formula $I: 5-5 / I: 5-5$; on Mount Omei the common type is $I: 6-6$ / I:6-6.

The process of metamorphosis is rather slow, but the species characters are clearly shown, even at the time when the fore limbs come out. At this stage small round warts are much more conspicuous and the color on and near the warts becomes much darker than before; dark stripes on limbs are clearly shown. When the absorption of the tail fin begins, warts with creamy centers and black margins are developed, and a row of small creamy warts appears on each dark stripe on the limbs. These stripes are darker and wider on the anterior and posterior sides of the femur and tibia; on the dorsal sides they are weakly developed. Between these strong ones, there are very weak and incomplete stripes. As soon as the tail is half gone, the ground color on the back becomes olive brown. Warts and color patterns become more distinct. At the ear region and the posterior angle of the jaw the skin is smooth and has a purplish coloration.

The young just after metamorphosis has nearly all of the characters of an adult. The web between the toes of all the young individuals of Scutiger popei from Mount Omei, Panlungshan, and Lungtung, is not present in the adult. The coloration of the young is rather uniform. The top of the head is lighter and there is a creamy color at the angle of the jaw and the anterior base of the arm. The sides of the body are also lighter and are washed with scarlet. Many warts, with brownish ashy color enclosed by fuscous or black, are scattered on the back. The limbs are brownish ashy above but with more olive color crossed by black stripes. Margins of the jaw are cream-colored, marbled with black. The throat and the belly are gray. A round, flattened cream-colored gland, enclosed by fuscous, is located on the middle posterior region of the thigh; this is shown in the tadpole even before the fore limbs come out. The size of the young varies greatly; young adults from Mount Omei range from 33 to $33.5 \mathrm{~mm}$. in length, those from Panlungshan from 29 to $32 \mathrm{~mm}$., and those from Lungtung from 28 to $29 \mathrm{~mm}$.

Our knowledge of the life history of this rare frog is still fragmentary, the breeding habits, eggs, and process of hatching being unknown. Very young tadpoles and tadpoles at different stages of metamorphosis were found on Mount Omei during the first part of August, 1938, and again during the summer of 1940. In the spring of 1941, from April 13 to May 3, I went to Panlungshan with the hope of finding Scutiger popei breeding and laying eggs, but only advanced tadpoles were found. The local people told us that they saw tadpoles during 
winter. Again from June 30 to July 15 of the same year I made another trip to the same place and in the same stream I found very young tadpoles and advanced tadpoles with two legs fully developed, four-legged tadpoles, and young near the completion of metamorphosis. The tadpoles in the process of metamorphosis are evidently those found in the latter part of April, but the younger ones must be hatched from eggs laid from early May to the middle part of June. The breeding season of this frog is most likely from May to June. The fully developed tadpoles might be those of the previous year, as indicated by the study in April, by the slow process of growth and metamorphosis, and by the information from the farmer who reported them from the same stream during winter. Further investigation, during the winter, is essential to the solution of this problem.

\section{Scutiger schmidti Liu}

Scutiger schmidti Liu, 1947, Copeia, 1947: 123, fig. 1-Mount Omei, Szechwan.

History of species. - A small Scutiger tadpole was obtained from Maliuwan, Chungkingchow, Szechwan, during the summer of 1941, and remarked upon as an unknown species of Scutiger in 1943. During the summer of 1945, adults of this form, with additional tadpoles, were collected from Mount Omei, and the new species was named Scutiger schmidti in 1947.

Distribution and collection data.-Scutiger schmidti is an endemic form of western Szechwan, found on Mount Omei, at Maliuwan, west of Kwanhsien, and near Shuimokou, Kwanhsien. On July 10, 1941, a number of tadpoles of different stages were obtained from side pools or pools beneath cascades on the main mountain stream of Maliuwan, 5,700-7,000 feet altitude. A tadpole of this species with hind limb-buds and one with four limbs fully developed were found in a pool beneath a cascade near Heifengt'ou near Shuimokou, at an altitude of about 5,500 feet. I found tadpoles of Scutiger schmidti together with some tadpoles of $S$. popei on June 6,1945, at an altitude of 6,100 feet in a pool of a small mountain stream known as Pientankou between Chiulaotung and Yuhsiensze. No adult was found. On June 28, 1945, my collector found two egg-masses in this same small mountain stream and two tadpoles passing through the process of metamorphosis. The new Scutiger tadpole was found in a famous well, known as Lungwangching or Dragon King Well, at an altitude of 7,800 feet and temperature of about $60^{\circ} \mathrm{F}$. on June 7,1945 , very near to Tachengsze. The discovery of this tadpole led me to adults of the new frog, as I heard a peculiar croaking coming from a shallow depression connected with the well. This depression was densely covered by shrubs and bamboo and with only a very limited amount of water running through among small flat stones, dead leaves and roots. Guided by the croaking, I secured my first specimen by turning over a stone. My assistant and I secured fourteen adults, all males, four masses of eggs and many tadpoles in different stages. During the afternoon of the next day (June 8), three females ready for egg-laying, each one watched by three males, were obtained by turning over the bamboo roots; some other males, three 
egg-masses and a few tadpoles were also collected. Twenty-six males, seven masses of eggs with embryos developed, and a few tadpoles were collected from the same locality on July 22 of the same year.

Comparison with related species.-Scutiger schmidti (pl. 5, figs. 1 and 2; text fig. 32) can easily be distinguished from all other species of Scutiger in China by its coloration. It differs from popei especially in the brown marking on the back,
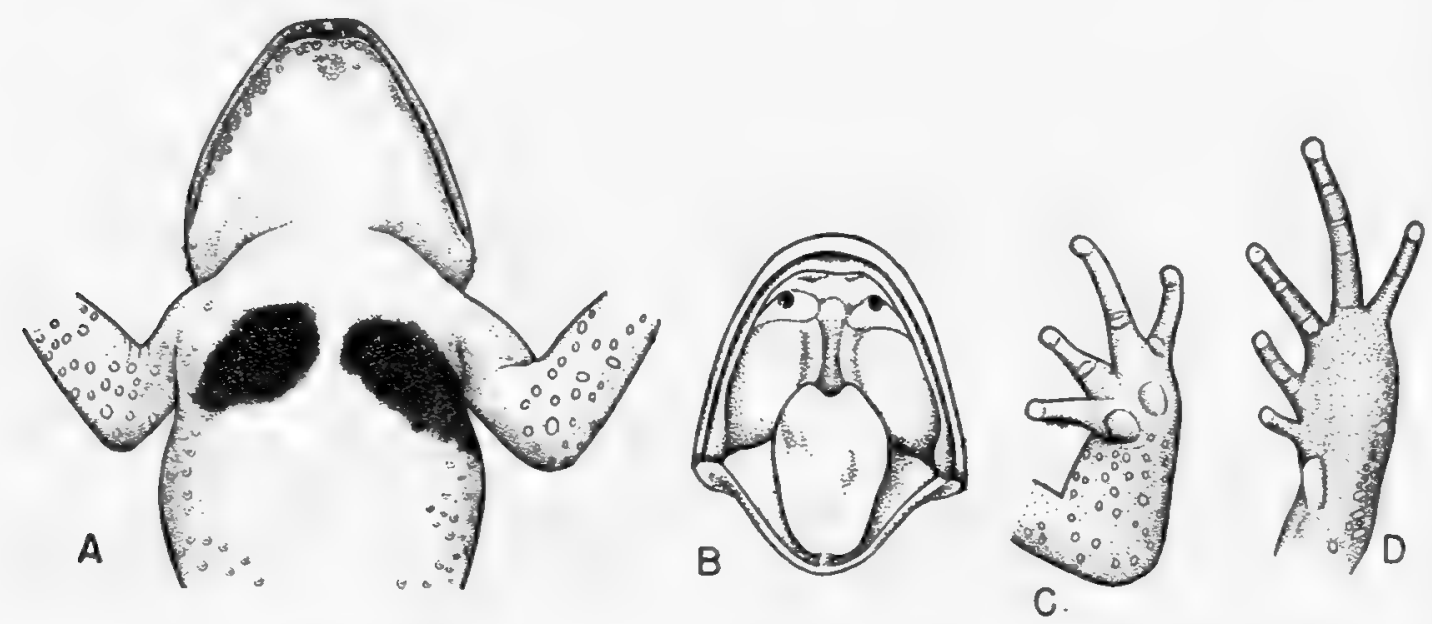

FIG. 32. Scutiger schmidti $(\times 2)$. A. Ventral view of head and thoracic region of male. B. Oral cavity. C. Ventral view of hand of male. D. Ventral view of foot.

the unmarbled belly and the indistinct irregular brown bars on the limbs. $S$. pingii differs from schmidti in having a rufous brown back without any large markings or pattern, and with only a few scattered warts, and in having the toes distinctly webbed. S. schmidti differs from alticola and rugosa by the absence of webs between the toes, alticola having the toes fully webbed and rugosa having them about one-fourth webbed. The tadpoles of schmidti are the smallest of the various species of Scutiger, with a characteristic coloration, especially the dark color near the base of the body and the tail.

Original description.- "Tongue elliptical, free behind and distinctly notched; head moderately large, longer than broad; snout rounded and slightly projecting beyond the mouth; canthus rostralis feebly indicated; loreal region oblique and flat; nostril about mid-way between the tip of the snout and the anterior border of the eye; internasal space about equal to the interorbital space, which is broader than the upper eyelid; length of the eye greater than the orbital space; tympanum hidden; spines on the margins of the upper and lower jaws and a more or less circular spiny area on the median ventral side of the lower jaw; black spines strongly developed on the tympanic region.

"Arm rather long; fingers slender and long, first finger equal in length to the second, both shorter than the fourth finger and the third finger about twice as long as the first two; nuptial spines developed on the inner dorsal sides of 
the first and the second fingers; subarticular tubercles not evident; two large prominent palmar tubercles, the outer one smaller than the inner; warts with spines on the outer side of the arm and smooth warts on the inner sides; in front of the base of the arm a pre-humeral warty area.

"Hind limb moderately long and relatively weak, tibio-tarsal articulation reaching the angle of the mouth; heels just meet when placed at right angles to the body; tibia 43.1 per cent of the body length, webs barely indicated and toes fringed; spines on the outer fringes of the fifth and fourth toes; no subarticular tubercles; inner metatarsal tubercle elongated, rod-like and flat, no outer metatarsal tubercle, many large and small spines scattered on the hind limbs especially on its dorsal side, each femur with a light-colored flattened gland on its posteromiddle region.

"Skin very rough with many small warts on the back of the body and the sides of the head and the body and all over the limbs; warts provided with many small spines especially on the back of the body, very much like those of $B u f o$ bufo gargarizans; larger spines found along the margin of the jaws, tympanic region and the postero-ventral aspect of the thigh; some fine and a few large spines on the belly.

"The dorsum is grayish brown in ground color, with dark brown or nearly black marks on the jaws and the antero-dorsal side of the snout; a similar colored mark starting from the anterior region of the interorbital space, including the eyelids and extending posteriorly covering the whole back to the vent; the posterior part of the back nearly black, from the presence of many small and a few large black spines; the exposed parts of the limbs also grayish brown with irregular dark brown bars; sides of the body lighter and with scattered still lighter colored warts; throat, belly and the ventral sides of the limbs purplish fleshy in color and semitransparent, as in Kaloula; digital tips very light in color; pupil black, vertically oval, sometimes even squarish, with black connections dorsally and ventrally; iris golden, stippled with black, the ventral part slightly darker than the dorsal portion."

Coloration.- The male is always much darker than the female and in the latter the grayish brown mark on the back is very conspicuous on a lighter ground color. The coloration of the males varies only slightly. The much lighter brownish ashy color in females has indications of green, and there are distinct grayish brown marks on the snout, head and body. The female has very few warts and no spines on any part of the body. The coloration of the limbs is similar to that of the body. The throat, belly and ventral sides of the limbs are still lighter than in the male and are spotted with pearly gray. A pair of flattened glands is present on the sides of the chest near the bases of the arms. The vent of the female is heavily spotted with creamy buff to pearly gray. After preservation in formalin, the color of the male specimens is darker and the mark of the back becomes more indistinct; in females, the much lighter color preserves the distinctness of the dorsal pattern. 
Secondary sex characters. - In thirty males and three females measured, sexual dimorphism in size is evident, the average body length of the males being $43 \mathrm{~mm}$., ranging from 40 to $47 \mathrm{~mm}$., while for the females it is $51 \mathrm{~mm}$., with a range from 48 to $54 \mathrm{~mm}$. Other secondary sex characters in males (fig. $32, \mathrm{~A}$ and C) consist of two elongated patches of closely packed fine black spines on the chest, fine black spines on the margin of the jaws and tympanic region, and a more or less circular spiny area on the median ventral side of the lower jaw; black nuptial spines are developed on the inner dorsal sides of the first and second fingers of the male. The arm of the male is stronger than that of the female, the diameter of the lower arm of the male being $\mathbf{1 0 . 5}$ per cent of the body length in the male and only 6.8 per cent in the female. The leg of the female is shorter than that of the male, 133 per cent of the body length as compared with 143 per cent in the male.

Scutiger schmidti: Measurements of Thirty Male and Three Female Adults

\begin{tabular}{|c|c|c|c|c|}
\hline Measurements & Sex & Range & Average & $\begin{array}{c}\text { Ratio to } \\
\text { body length (\%) }\end{array}$ \\
\hline Body length...... & $\begin{array}{l}0^{7} \\
\varnothing\end{array}$ & $\begin{array}{l}40-47 \\
48-54\end{array}$ & $\begin{array}{l}43.1 \\
51.0\end{array}$ & $\ldots$ \\
\hline Head length. & $\begin{array}{l}0^{7} \\
q\end{array}$ & $\begin{array}{l}14.0-15.5 \\
15.5-17.0\end{array}$ & $\begin{array}{l}14.7 \\
16.5\end{array}$ & $\begin{array}{l}34.2 \\
32.3\end{array}$ \\
\hline Head width. & $\begin{array}{l}\sigma^{7} \\
q\end{array}$ & $\begin{array}{c}14.0-15.5 \\
15-16\end{array}$ & $\begin{array}{l}14.5 \\
15.6\end{array}$ & $\begin{array}{l}33.6 \\
30.5\end{array}$ \\
\hline Interorbital space. & $\begin{array}{l}\sigma^{7} \\
q\end{array}$ & $\begin{array}{l}3.6-4.5 \\
4.5-5.0\end{array}$ & $\begin{array}{l}4.1 \\
4.8\end{array}$ & $\begin{array}{l}9.6 \\
9.6\end{array}$ \\
\hline Length of lower arm. & $\begin{array}{l}0^{7} \\
\text { q }\end{array}$ & $\begin{array}{l}18-20 \\
22-23\end{array}$ & $\begin{array}{l}19.0 \\
22.3\end{array}$ & $\begin{array}{l}44.1 \\
43.7\end{array}$ \\
\hline Diameter of lower arm. & \begin{tabular}{l}
$0^{7}$ \\
\hdashline
\end{tabular} & $\begin{array}{l}4-5 \\
3.5\end{array}$ & $\begin{array}{l}4.5 \\
3.5\end{array}$ & $\begin{array}{r}10.5 \\
6.8\end{array}$ \\
\hline Length of hand. & $\begin{array}{l}0^{7} \\
\text { क }\end{array}$ & $\begin{array}{l}10.0-11.5 \\
12-13\end{array}$ & $\begin{array}{l}10.7 \\
12.5\end{array}$ & $\begin{array}{l}24.9 \\
24.5\end{array}$ \\
\hline Length of hind limb. & $\begin{array}{l}0^{7} \\
\wp\end{array}$ & $\begin{array}{l}58-65 \\
63-71\end{array}$ & $\begin{array}{l}61.5 \\
68.0\end{array}$ & $\begin{array}{l}143.3 \\
133.3\end{array}$ \\
\hline Length of tibia. & $\begin{array}{l}0^{7} \\
\wp\end{array}$ & $\begin{array}{l}17.0-20.5 \\
19.5-21.0\end{array}$ & $\begin{array}{l}18.7 \\
20.5\end{array}$ & $\begin{array}{l}43.4 \\
40.1\end{array}$ \\
\hline Length of foot and tarsus.... & $\begin{array}{l}0 \\
0 \\
9\end{array}$ & $\begin{array}{c}27.5-33.0 \\
31-33\end{array}$ & $\begin{array}{l}29.1 \\
32.3\end{array}$ & $\begin{array}{l}67.6 \\
63.3\end{array}$ \\
\hline Length of foot. . & $\begin{array}{l}0^{7} \\
q\end{array}$ & $\begin{array}{l}18-22 \\
20-23\end{array}$ & $\begin{array}{l}19.8 \\
21.8\end{array}$ & $\begin{array}{l}46.0 \\
42.7\end{array}$ \\
\hline Length of inner metatarsal tubercle. . & $\begin{array}{l}0^{7} \\
q\end{array}$ & $\begin{array}{l}2.0-3.5 \\
2.7-3.0\end{array}$ & $\begin{array}{l}2.5 \\
2.9\end{array}$ & $\begin{array}{l}5.8 \\
5.6\end{array}$ \\
\hline
\end{tabular}

The skin of the male is much more rugose, with many minute spines on the warts of the back and sides of the body, much as in the female of Bufo b. gargarizans. Spines are also found on the head and limbs. In the female the warts are without spines of any kind on the body, so that the skin is smooth in texture.

Habitat and habits.-Scutiger schmidti is as inactive as other frogs of the same genus. There were numerous green leeches attached to each specimen. They continue to croak, even when the stones or roots under which they lie are being disturbed by the collector. When a specimen is seen it can always be 
caught by hand. This frog does not breed in larger mountain streams, being found only within the last one hundred meters at the end of the valley. No adults or egg-masses were found below the valley:

Breeding behavior.-The breeding season extends through the month of June. I found egg-masses on June 7 and June 25 from the same locality. No newly hatched tadpoles were found in June, and the advanced tadpoles and tadpoles with four legs in the process of metamorphosis are assumed to be the tadpoles of the previous year, as was found to be the case in S. popei. Near the time of egg-laying the males croak from beneath stones or under roots, especially those of the bamboo.

The croaking is low and broad like the syllables "la-ke," but when the living specimen is kept in a room, the sound is low and sharp and very much like the croaking of Rhacophorus omeimontis. The males croak in the daytime but more vigorously in the evening. Several males croak around a single female, as is indicated by the fact that we found three females under bamboo roots and each was being courted by three males. The male grasps the female just in front of the base of the thigh with the right hand on top of the left and all the fingers bent. The two nuptial patches on the chest of the male seem to be for the purpose of stimulating the anal region of the female to egg-laying.

Eggs.-Eggs are laid in masses (fig. 33, A) attached to the under surface of stones or roots of vegetation in very small mountain streams. The shape and the dimensions of the egg-masses vary according to the site in which they are laid. They are generally oval or rounded with the center free from eggs or with very few eggs and the inner and outer margins much thinner than the middle portion. This is because of the method of egg-laying, which seems to be similar to that of Rhacophorus chunganensis, the vent being pushed against the substratum on which the eggs are laid. One egg-mass measured in the field was $63 \mathrm{~mm}$. long and $50 \mathrm{~mm}$. wide, the middle portion of the thickest part being about $16 \mathrm{~mm}$. in thickness. Three masses of eggs were counted, one with 108 eggs, one with 130, and one with 122 . The egg is rather large, the average diameter of ten eggs being $4 \mathrm{~mm}$. Eggs are absolutely white with very little jelly, as each egg is covered by a thick inner layer, with a thin outer layer that is loosely connected with the outer capsules of other eggs.

The development of the embryo is much like that of Rana boulengeri, as the yolk material is very abundant. As soon as the neural tube is well formed the embryo hatches out through a hole in the jelly, and attaches itself to the jelly. After some time, when the embryo has been detached from the jelly capsule, it lies on one side in a helpless condition. I studied the egg-masses under natural conditions on June 22, 1945. Most of the eggs in each egg-mass were abnormally developed or were destroyed by leeches; very few developed normally into tadpoles. This condition appears also in Aelurophryne glandulata, which has similar breeding adaptations.

Tadpoles.-The coloration of the fully developed tadpole (pl. 10, fig. 13) is very much like that of the tadpole of the same genus collected from Maliuwan, 
Chungkingchow, Szechwan, on July 10, 1941. It is fleshy-ashy on the head, and the body is stippled with golden brown and green. The region near the base of the body and the tail are much darker in color, and toward the tip of the tail it is much lighter. The belly is colorless, with a very slight indication of gray.

The tadpole of this species is one of the smallest among the Scutiger tadpoles of China. Ten tadpoles with hind limbs partly developed were measured (see table).
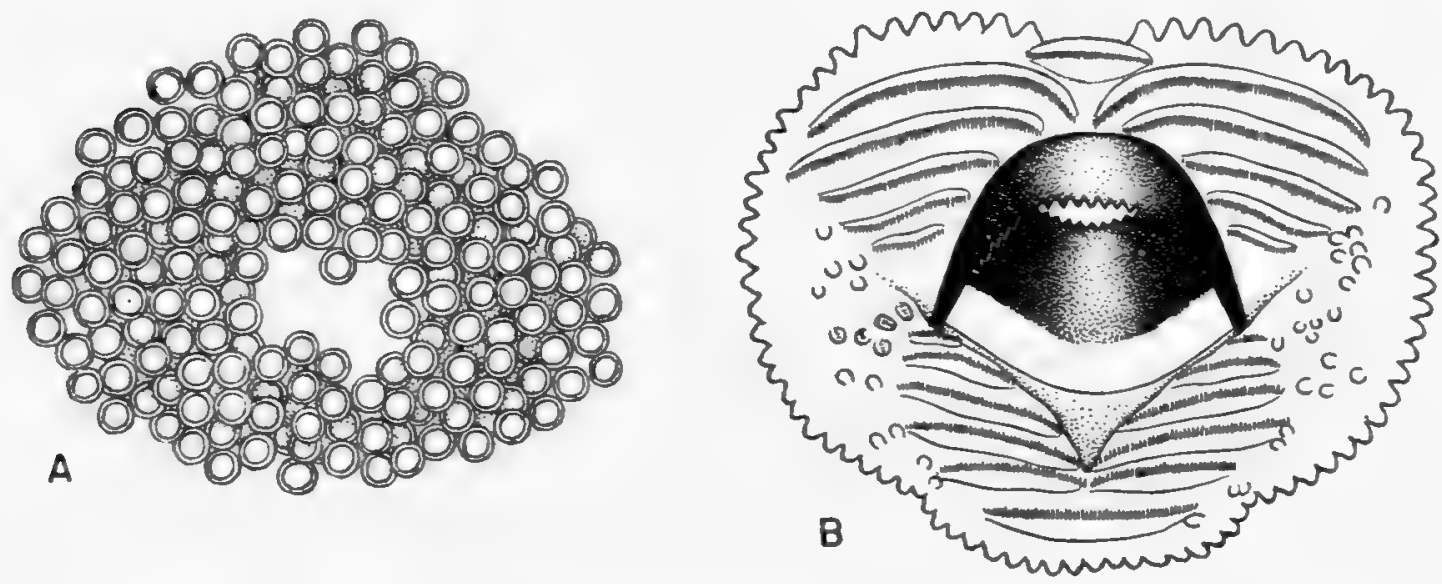

FIG. 33. Scutiger schmidti. A. Egg-mass (X 1). B. Mouth of tadpole (X 15).

The snout is rounded; the nostril, enclosed by a light-colored ring, is nearer to the snout than to the eye; the eyes are latero-dorsal; the spiraculum is sinistral, ending in a semi-tube, directed inward and backward, about at the middle of the body, visible from above and below; the distance from snout to spiraculum is $11 \mathrm{~mm}$. The vent is dextral, with a large oblique opening, under a broad skin fold that is continuous with the ventral tail crest. The tail muscle is moderately developed, with a diameter about 23 per cent of the body length; the tip of the tail is blunt, and the tail crest is equally developed above and below. The dorsal crest is thickened at its base, but does not continue on to the body.

\section{Scutiger schmidti: Measurements of Ten Tadpoles}

\begin{tabular}{|c|c|c|c|}
\hline Measurements & Range & Average & $\begin{array}{c}\text { Ratio to } \\
\text { body length }(\%)\end{array}$ \\
\hline Body length...... & $19-21$ & 19.7 & \\
\hline Body height. & $8-9$ & 8.5 & 43.4 \\
\hline Body width. & $10.0-11.5$ & 10.8 & 54.9 \\
\hline Head height. & $6-7$ & 6.3 & 32.0 \\
\hline Head width. & $7.5-9.0$ & 8.7 & 44.2 \\
\hline Mouth width. & $4.5-5.0$ & 5.1 & 25.9 \\
\hline Interocular space. & $5-6$ & 5.4 & 27.1 \\
\hline Snout to spiraculum. & $10.5-12.0$ & 11.1 & 56.6 \\
\hline Tail length. & $30-35$ & 33.1 & 168.0 \\
\hline Tail height. & $8.0-9.5$ & 8.7 & 44.2 \\
\hline Diameter of tail musc & $4-5$ & 4.4 & 22.6 \\
\hline Length of hind limbs. & 4-10 & 8.0 & $\ldots$ \\
\hline
\end{tabular}


The mouth (fig. 33, B) is ventral, with an average width of $5.1 \mathrm{~mm}$., which is 26 per cent of the body length. There is a single row of papillae all around the mouth, except for a free space on the mid-dorsal part of the upper lip. Additional papillae, with or without teeth, are found at the corners of the mouth and the lateral sides of the lower lip. The labial teeth vary, but usually there are six rows on the upper lip and six on the lower. On the upper lip the outermost row is short and continuous, partly filling up the gap where there are no papillae. The remaining five rows are all interrupted, the innermost row the shortest. On the lower lip the outermost row is continuous and longer than the outermost row of the upper lip. The other five rows are all interrupted, the innermost shorter than the others. To study variation of tooth formula, ten tadpoles were chosen at random. In these the tooth formula varies as follows: five have $\mathrm{I}: 5-5 / \mathrm{I}: 5-5$; two have I:5-5/I:4-5; one has I:4-4/I:5-5; one has I:5-5/I:4-4; and one has $I: 4-4 / I: 4-4$. The mandibles are thick and heavy, with strong and sharp teeth on their upper and lower edges.

\section{Scutiger sp. from Panlungshan}

Scutiger alticola? Liu (not of Procter), 1943, Jour. West China Border Res. Soc., 14, (B): 52 , pl. 1, fig. 4, pl. 2, figs. 8,13 .

History.-Tadpoles and metamorphosed young of a species of Scutiger of which the adult is unknown were mentioned under the name alticola in 1943, though with a query, and reported upon in my Life history of Scutiger sikkimensis ... (1943d). As a result of re-examination of my collection of Scutiger from western China, and after comparison with original descriptions and drawings, I am driven to the conclusion that these tadpoles represent an undescribed species, certainly not alticola. S. alticola was described by Procter (1922) from a single female specimen from the Kharta Valley, altitude 16,500 feet, at the southern border of Tibet. Procter distinguished alticola from sikkimensis by the fact that the toes are fully webbed instead of nearly free.

The Scutiger from Panlungshan has a vertical distribution ranging from 5,200 to 8,000 feet in altitude. It is found in the mountain streams west of Kwanhsien. In a young specimen just after metamorphosis the webs of the toes are poorly developed, which excludes it from alticola. I reserve description of this form for the discovery of the adults.

Collection data.-Tadpoles at different stages were collected from Panch'angkou, on Panlungshan, at 5,200 feet altitude, on April 24, 1941. Others, including young individuals, were found in a large mountain stream known as Maliuwan on the same mountain on July 10, 1941. On July 13, different stages of tadpoles of the same form were found in another mountain stream, namely Tawantou, just beneath Heifengt'ou at Shuimokou in Kwanhsien, from 5,400 feet altitude upward. It is mysterious that no adults were found, even though five of us turned thousands of stones in the water or by the side of water. From the characters of the young individuals, they represent a distinct new species of 
Scutiger, and from the abundance of tadpoles, the species seems not to be rare. My failure to capture adults may be related to some peculiar habit of hiding in holes among stones on hillsides, or in vegetation before and after the breeding season, as is the case of Staurois chunganensis.

Tadpoles. - Tadpoles of this Scutiger are found in pools behind large stones, in side pools of main mountain streams, and under stones. Young tadpoles are generally seen on stones in the water, but the larger or older ones generally hide themselves under stones and mostly in deep water. They are very sensitive; with any disturbance they retreat into the cracks or under the surface of stones. By removing or turning stones piece by piece with great patience and the least possible disturbance, one could get them with a net or by hand. During evenings, they come out from their hiding places to the surfaces of stones. In running water the animal seems to adhere to the stone by the mouth, the throat, and the anterior region of the body, where there are two pairs of depressions. The anterior pair is S-shaped and the posterior pair has two round depressions. These tadpoles can swim against the current with their strongly built tails. Larvae of stone flies, caddis flies, and mayflies, and algae growing on the surface of stones are their chief food.

The coloration varies according to the age of the tadpole. The young tadpole (20 $\mathrm{mm}$. long from the tip of the snout to the tip of the tail) has a black body and a light creamy transparent tail with a dark line at the base of the dorsal tail crest. It is very much like the tadpole of Scutiger popei at the same age except for a light cream-colored area on the dorsal edge of the base of the dorsal fin of the tail. As the tadpole grows large, the color on the body becomes lighter and the light cream-colored area expands with the anterior region, spreading out to the base of the dorsal side of the body. When hind limb-buds are developed the coloration becomes different. The top and sides of the head become dark brownish gray, and latero-ventral to the eye the color is lighter over the welldeveloped jaw muscles. The anterior region of the body is colored like the head, but darker, and both are stippled with golden granules; the middle region is dark grayish brown without any kind of stippling; and the dorso-posterior region and the dorsal side of the base of the tail are covered by a more or less triangle-shaped dark cream-colored pattern. The sides of the body are like the back. The tail is ochraceous buff, lighter on the fin, especially at its tip; near the base it is washed by grayish brown, which is darker near the triangular dark cream-colored pattern. A cream-colored band is found on the dorsal side of the tail muscle, and about the anterior half of the dorsal tail fin. Some tadpoles have a few grayish brown or fuscous spots on the tail. The belly is pale bluish gray. The pupil is round and black, surrounded by a golden iris, and the nostril is enclosed by a light cream-buff ring. When the hind limbs are fully developed, the color of the back becomes lighter and uneven. Wide fuscous bars are clearly shown on the dorsal side of the leg. As soon as fore limbs appear, light cream spots are developed on the dorsal side of the head, and the back and sides of the body. Each cream-colored spot is enclosed by dark grayish brown or fuscous, 
which spreads out and becomes lighter. Between these spots the ground color is greenish gray. Wide fuscous bars, alternate with greenish gray, are found on the dorsal sides of the hind and fore limbs.

The tadpole of this species is somewhat smaller than tadpoles of popei at the corresponding stage and the Y-marked Scutiger tadpole from Mount Omei, but much larger than those of schmidti. Ten tadpoles were measured (see table).

Scutiger sp.: Measurements of Ten Tadpoles from Panlungshan

\begin{tabular}{|c|c|c|c|}
\hline Measurements & Range & Average & $\begin{array}{c}\text { Ratio to } \\
\text { body length }(\%)\end{array}$ \\
\hline Body length...... & $23.0-26.5$ & 24.4 & \\
\hline Body height. & $11.0-13.5$ & 11.9 & 48.7 \\
\hline Body width. & $12.0-15.0$ & 13.6 & 55.8 \\
\hline Head height. & $8.6-10.5$ & 9.5 & 38.7 \\
\hline Head width. & $12.0-14.0$ & 13.3 & 54.5 \\
\hline Mouth width. & $6.3-8.0$ & 7.6 & 31.0 \\
\hline Space between eyes. & $5.5-6.5$ & 6.1 & 25.1 \\
\hline Snout to spiraculum. & $15.5-18.0$ & 16.4 & 67.2 \\
\hline Tail length......... & $45.0-56.0$ & 50.1 & 205.3 \\
\hline Tail height. & $12.0-16.0$ & 14.0 & 57.5 \\
\hline Thickness of tail muscle. & $6.0-8.5$ & 6.8 & 28.1 \\
\hline Length of hind limb. . & $2.0-5.0$ & 3.8 & \\
\hline
\end{tabular}

The snout is broad and rounded; the nostril, enclosed by a light-colored ring formed by a row of papillae, is about mid-way between the snout and the eye, the internasal space equal to the space between the eyes. The eyes are latero-dorsal in position, more dorsal than lateral. The spiraculum is sinistral, with a semi-tube free at the posterior end, directed upward and backward and visible from above and below. It is nearer to the base of the tail than to the tip of the snout, the length from snout to spiraculum being 67 per cent of the body length. The vent is dextral, with an oblique opening under a large skin fold, and is continuous with the ventral tail fin. In the first glance the vent seems ventro-median in position, as the skin fold is ventro-median, unlike that of popei. The dorsal tail fin is thicker toward the body.

The mouth is ventral and wider than the mouth of various Scutiger species from Mount Omei and Lungtung, being about one-third of the body length. There is a single row of papillae all around the mouth, except for a small free space on the mid-dorsal part of the upper lip. The papillae on the lower lip are smaller, much more pointed, and crowded toward the mid-ventral space line; those on the upper lip are larger; and a pair of large papillae is also found at each end, dorsal to the first row of labial teeth. Additional papillae, mostly with but sometimes without teeth, are located at the corners of the mouth, especially at the latero-dorsal corners of the lower lip. Twenty individuals have tooth formulae with the following frequency: seven have I:5-5/I:5-5; six have $\mathrm{I}: 4-4 / \mathrm{I}: 4-4$; five have $\mathrm{I}: 5-5 / \mathrm{I}: 4-4$; one has $\mathrm{I}: 5-5 / \mathrm{I}: 5-4$; and one has $\mathrm{I}: 4-4 /$ $\mathrm{I}: 5-5$. The outermost row of the upper and lower lips is continuous, but the one on the upper lip is always shorter than that of the lower lip. The other rows of labial teeth are all interrupted. The third row is the longest on both 
the upper and lower lip. Mandibles are heavily built, with very heavy sharp long teeth on the edges of both.

Young adults.- Just after metamorphosis, the whole animal is much darker than the same stage of individuals of popei. It is black above, on the sides of the head and back, and on the sides of the body, lightened on the head and the sides by an indication of olive-brown. Small irregular olive-brown or light olive-green spots are scattered on the back and sides of the body, and there is a more or less regular row of creamy warts on the sides. Limbs have broad black bars, which are also found on all fingers and toes. Generally there are four black bars on the thigh, the tibia, the tarso-metatarsal region and the fourth toe of the hind limb. Two incomplete bars are located on the upper arm and four on the lower arm and the third finger. Between these black bars, the color varies from light olive-green to olive-brown, with lighter color near the black bars. Digital tips are cream-colored. When the light is strong, the pupil is narrow and vertical, otherwise it is squarish or oval, but its long axis is still vertical. The iris is black, but greatly stippled with golden granules. The throat is fleshy gray, and the belly and the ventral sides of the limbs are bluish gray. In each armpit, there is an oval-shaped cream-colored gland, and a large flattened cream-colored gland surrounded by a fuscous marking can also be seen in the middle region of the posterior aspect of each thigh.

The body is stout, the length from snout to vent $28 \mathrm{~mm}$, and the width at the middle part $13 \mathrm{~mm}$. The head is wider than long. The nostril is nearer to the snout than to the anterior border of the eye. The interorbital space is convex and much greater than the width of the upper eyelid. A glandular fold extends from the posterior corner of the eye to the shoulder. The tympanum is hidden. The tibio-tarsal joint reaches the middle of the eye. The hind limb is $41 \mathrm{~mm}$. long, which is 146 per cent of the body length. Webs are developed between all the toes, which are also distinctly fringed, especially the third and fourth toes. Webs reach the second segment of the fifth toe, and the middle of the first segment of the fourth toe.

\section{Scutiger sp. from Mount Omei}

Collection data.-During the summer of 1938, on August 10, two tadpoles with hind limb-buds were collected from a small side pool of the Heilungkiang, "Black Dragon River," on Mount Omei, where we were trying to catch some small loaches. From June 26 to August 5, 1940, a few young tadpoles were collected from pools and ponds beneath or by the side of cascades, or from behind the large stones of a swift mountain stream in front of Taosze, at 3,500 feet. A giant tadpole with hind limb-buds was obtained from a deep side pool of Shihsunkou on July 20, 1940. Two big ones were secured from a side pool of Heilungkiang on July 11, 1940. These tadpoles (fig. 34) were found singly at the bottom of the water, and they were rather hard to catch, as slight disturbances made them hide themselves in cracks between stones or in holes beneath them. 
Tadpoles.-These tadpoles vary in coloration at different stages of growth. Until the hind limb-buds are visible, they are dark fuscous on the back and sides of the head and body, with light cinnamon brown on the tail, which is darker on the muscular part and stippled with fuscous. An inconspicuous pale yellowish Y-shaped mark, characteristic of the species, lies over the upper hind part of the body and the upper fore part of the tail. The belly is colorless. As the
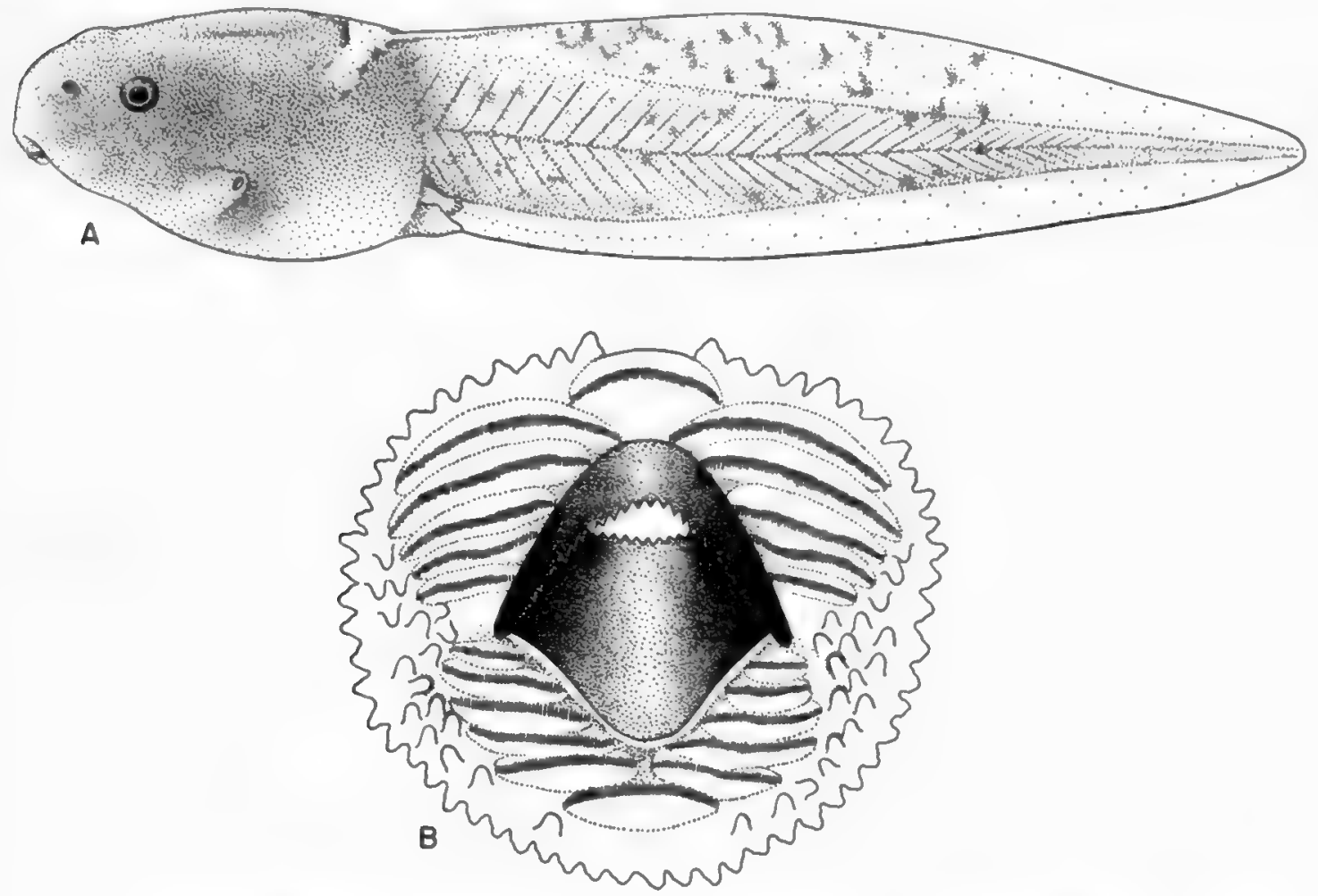

FIG. 34. Scutiger sp. from Mount Omei; tadpole. A. Lateral view ( $\times 11 / 2)$. B. Mouth $(\times 8)$.

hind limb-buds become visible, the body grows rufous on the back with close brown stipplings, and is darkened on the sides. The tail is rufous at its base, shading to ochraceous buff at the tip and on the margins. It is coarsely stippled with cinnamon brown. A pale brown $\mathrm{Y}$-shaped area lies over the tail base, extending to the upper side of the body. The color of the snout is like that of the base of the tail, shading to body color; the ventral surface is colorless, with the viscera showing through the thin body wall. The pupil is round and black, enclosed by a wide, dull-golden iris. As soon as the fore limbs appear, the top and sides of the head and the upper back acquire a golden tan color. Posteriorly the middle of the back is olive. Rows of black, round or elongate warts are visible behind the eye to the level of the hind legs. Pearl gray spines or fine warts are developed on the dorsal side of the limbs, especially on the hind legs. The limbs are clay-colored, without bars. The coloration and the shape of the warts are entirely different from those of popei. 
Just after metamorphosis, the top of the head and the upper back are golden, at times with an olive green area in the middle of the back, while the posterior third of the body varies from a golden tan to a yellow clay color. Five rows of black, round or elongate warts extend from behind the eye to the level of the hind legs. The side of the body has a brown line from the axilla to the groin, punctuated with round or elongate whitish spots. The first spot in the axilla is much larger and more distinct. The four dark vertical bars on each side of the head are separated by a slender light one. A narrow bar of golden brown lies between two wide dark bars on the snout, and a dark bar lies below the anterior region of the eye, with another broader one behind and below it. A dark mark from the posterior border of the eye extends back obliquely to the angle of the jaw. The belly is light gray without spots. The dorsal side of the leg is clay-colored, with many fine clay-colored elevations. There are three inconspicuous dark cross-bars on the dorsal side of the femur, and on its ventral side there is a conspicuous white dot enclosed by the dark color. Bars on the tibia corresponding to those on the femur are even more inconspicuous. The dorsal sides of the digits have distinct dark cross-bars. The ventral sides of the limbs are light gray in color.

This species is less abundant than the other, and is rather hard to collect. The following measurements are taken from a single well-preserved specimen. This tadpole is very large, with a total length of $107 \mathrm{~mm}$. from tip of snout to tip of tail. The tail is strongly built, and is two and a quarter times as long as the body; its height is about equal to the width of the body. The muscular part is strongly developed.

The nostril is enclosed by a ring of papillae, three or four at the upper hind corner of the nostril being distinctly larger than the rest. The nostril is nearer to the tip of the snout than to the eye. The eyes are dorso-lateral, the space between the eyes $(10 \mathrm{~mm}$.) about 34 per cent of the body length. The spiraculum is sinistral, and nearer to the base of the tail than to the tip of the snout; it has a semi-tube, like an oblique pouch, bearing at the tip a small opening that is directed upward and backward and is visible from above as well as from below. The vent is an oblique opening directed to the right and covered by a flap of membrane continuous with the base of the ventral tail fin. The tail is bluntly pointed, with a deeper dorsal and a shallower ventral fin. Both fins decrease in height anteriorly, and near the base of the tail they become very much thickened.

The mouth (fig. 34, B) is ventral. A single row of papillae, larger toward the dorsal side, surrounds the mouth, except for a small space in the middle of the upper lip. There are a few irregularly scattered papillae in the lower lip inside of the marginal row, and also some additional papillae at the corners of the mouth. Labial teeth and mandibles are remarkably developed, as in all tadpoles of the genus Scutiger. The labial teeth are raised on a conspicuous fleshy base. The number of rows of teeth varies, but normally there are six rows above and six below. In twenty tadpoles, seventeen have six rows above and six below. Only the outermost row above and below is continuous and it 
is also the shortest, the outermost row on the upper lip being shorter than that on the lower. The other rows are all interrupted, the second and third rows being the longest above. The mandibles are very strong, with serrated edges. The lower mandible is enormously developed.

The rate of growth in the tadpoles of this species is very slow, since those collected July 11 with hind limb-buds did not extrude their fore limbs until September 9. These tadpoles were carefully brought from Mount Omei to West China Union University and were kept in an aquarium and fed with aquatic plants. Two tadpoles in the same stage of development were kept under observation in the original pool from which those brought back to Chengtu were collected. From July 11 to August 10, H. W. Chang, H. C. Chang and I visited this pool several times. At the time of the last visit, on August 19, these two tadpoles had grown, but the hind legs were still very short.

Metamorphosis, as indicated by the absorption of the tail fin from dorsal and ventral sides, began September 10. Cream-colored spots appeared on the dorsal sides of the limbs, and larger granules developed on the head and dorsal side of the body. Dark color now surrounded a longitudinal row of small warts. The color change started from the head and gradually continued backwards. Metamorphosis goes on very slowly, for until 5:30 P.M., on September 26, the tail was still as before, with only the tail fin near the tip of the tail absorbed. Next morning (7:30 A.M., September 27) two-thirds of the tail was gone. On October 1 it still had a stump. Metamorphosis had been completed by October 7 .

This young specimen is much smaller than other young of the same species. From snout to vent it measures $25 \mathrm{~mm}$., with arm length $17 \mathrm{~mm}$., and leg length $38 \mathrm{~mm}$. The tibio-tarsal joint reaches the middle of the eye. The snout is slightly squarish. The eye is large, with a vertical pupil, dull-golden in color on the upper half of the iris and much darker on the lower half. A glandular fold extends from the posterior corner of the eye to the shoulder. The tympanum is hidden. Very fine warts arranged in rows are developed on the back of the body, with isolated ones scattered between the rows; they also occur on the top of the head, the sides of the body, and the dorsal sides of the limbs. A large, flattened and light-colored gland, enclosed by darker color, is located at the middle region of the posterior side of the thigh, and a small, round, similarly colored gland is found in each armpit. There is no web between the toes. The ground color of the back, the sides of the head, the body, and the dorsal side of the limbs is brownish ashy, washed with cinnamon brown on the back of the body. Indistinct dark bars are found on the margin of the jaw and on the dorsal sides of the limbs, fingers and toes.

It might be suspected that this tadpole might be that of Vibrissaphora boringii, as they are found in the same region of Mount Omei, but after careful study of the young, in comparison with the adult of $V$. boringii, it is clear that they are quite different. They have different coloration of the iris, the lower half of the iris of $V$. boringii being dark cinnamon brown and the upper half bluish green. The arrangement of the fine warts is in rows in the young of this 
species, and in $V$. boringii it is arranged in a network. There are no dark bars on the jaws and the limbs of $V$. boringii. The tibio-tarsal joint reaches the middle of the eye in the former, and only the anterior shoulder region in the juvenile Scutiger. That these tadpoles are different from those collected from Panlungshan, which also have a light-colored pattern on the dorso-posterior region of the body, is shown by comparison of the young adults just after metamorphosis. The young of the Scutiger species of Panlungshan has large, irregularly scattered warts and distinct wide bars on the limbs and better developed webs between the toes. The general coloration is also entirely different. An adult specimen is necessary for an adequate diagnosis of the species.

Measurements (one specimen; percentage of body length in parentheses).Body length $33.0 \mathrm{~mm}$.; body height $17.5 \mathrm{~mm}$. (53.0); body width $21.0 \mathrm{~mm}$. (63.6); head height $12.0 \mathrm{~mm}$. (36.3); head width $16.5 \mathrm{~mm}$. (50.0); mouth width $9.0 \mathrm{~mm}$. (27.3); space between eyes $10.0 \mathrm{~mm}$. (30.6); snout to spiraculum 21.0 mm. (63.6); tail length $74.0 \mathrm{~mm}$. (224.2); tail height $20.5 \mathrm{~mm}$. (62.1); diameter of tail muscle $11.5 \mathrm{~mm}$. (34.8); length of hind limb $4.0 \mathrm{~mm}$. (12.1).

\section{Scutiger sp. from Lungtung, Paohsinghsien}

Collection data.-Two tadpoles were collected from a mountain stream northwest of Lungtung (3,400 feet) on August 19, 1939. One was obtained from a rather large mountain stream, and a smaller one was found in a ditch leading to a mill. This also is a bottom-feeding form.

Tadpoles.--The coloration of the living tadpole is much lighter than that of $S$. popei and the unknown Scutiger tadpole of Mount Omei. The ground color of the body and the tail is light brown, with scattered irregular dark spots. The tail crest is light gray without dark spots. At the base of the dorso-lateral part of the tail, there is a more conspicuous and larger dark spot, and smaller dark spots are found on the muscular part of the tail.

The tadpole (fig. 35) is rather large, its total length being $78.5 \mathrm{~mm}$. at the stage when the hind limb-bud is $5.6 \mathrm{~mm}$. long.

The snout is rounded and broad. The nostril is nearer to the tip of the snout than to the eye and is enclosed by light-colored papillae. Four papillae at the median side are much larger than the rest. The eyes are latero-dorsal, the space between them being $6 \mathrm{~mm}$., about one-fourth of the body length. The spiraculum is sinistral, with its opening directed upward and backward, without an independent tube. It is barely visible from above and below and is nearer to the base of the tail than to the tip of the snout, the distance from the tip of the snout to the spiraculum being 63 per cent of the length of the body. The vent is an oblique slit open on the right side of a fold continuous with the ventral tail crest. The tail is bluntly pointed, with its muscular part strongly developed, and the dorsal tail fin is deeper than the ventral. Both diminish in height near the middle region of the tail, with the anterior part thickened, especially that of the dorsal tail fin. 
The mouth (fig. 35, B) is rather large, about one-third of the body length, ventral in position. The lips are bordered by a single row of papillae, with a notch at the mid-dorsal line, where the outermost row of upper labial teeth are developed; at the corners of the mouth and the latero-ventral parts of the lower lip, additional papillae are irregularly scattered. There are five rows of
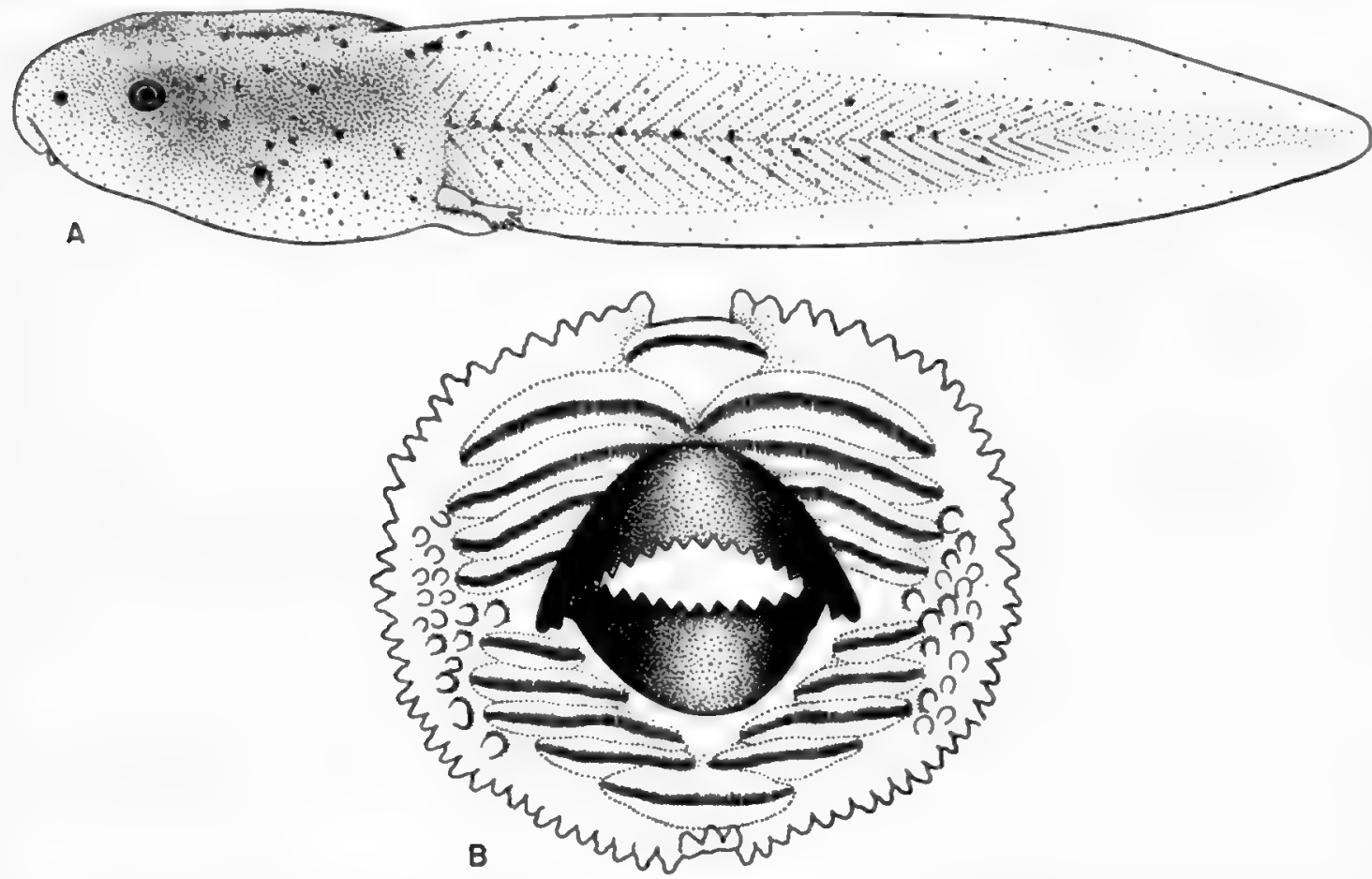

FIG. 35. Scutiger sp. from Lungtung; tadpole. A. Lateral view $\left(\times 2 \frac{1}{2}\right)$. B. Mouth ( $\times 17)$.

teeth in the upper lip, the outer row the shortest and continuous, while the other rows are interrupted. On the lower lip, there are also five rows of teeth, the outermost row the shortest and continuous, the other four all interrupted. More teeth are found on additional papillae at the corners of the mouth. The mandibles are strong, with sharp, serrated edges.

Measurements (one specimen; percentage of body length in parentheses).Body length $23.5 \mathrm{~mm}$; ; body height $12.0 \mathrm{~mm}$. (51.0); body width $13.8 \mathrm{~mm}$. (58.7); head height $8.0 \mathrm{~mm}$. (34.4); head width $12.6 \mathrm{~mm}$. (53.6); mouth width $7.0 \mathrm{~mm}$. (29.8); space between eyes $6.0 \mathrm{~mm}$. (25.5); snout to spiraculum 14.8 mm. (62.9); tail length $55.0 \mathrm{~mm}$. (234.0); tail height $13.6 \mathrm{~mm}$. (57.7); diameter of tail muscle $8.0 \mathrm{~mm}$. (34.4); length of hind limb $5.6 \mathrm{~mm}$. (24.0).

\section{Vibrissaphora boringii Liu}

Vibrissaphora boringii Liu, 1945, Jour. West China Border Res. Soc., 15, (B): 28, fig. 5-Mount Omei, Szechwan. 
History of species. - The first specimen was obtained during the summer of 1938, but the species was not described until 1945. The new genus Vibrissaphora, named for the row of spines on the upper lip of the male (pl. 4, fig. 3; represented by spots on the female) proves to be present also in Fukien (Vibrissaphora liui Pope, 1947).

Distribution and collection data.-The type was collected by P. L. Luh, back of Taosze, Mount Omei, during the rainy night of August 21, 1938. In March, 1940, two males were obtained from a farmer who dug them out when plowing a cornfield on a hillside near P'ilutien of the same mountain; four mature females and a young female were collected around Taosze between the end of July and the end of August, 1940; a mature female was found paired with a male of Rhacophorus leucomystax in a pool back of the temple of Lungshengkang near Taosze on June 22, 1945, and another adult female and three small females were collected around Taosze from the middle of May to the first part of July of 1945. This appears to be an endemic species on Mount Omei, with a vertical distribution ranging from 3,500 to 4,500 feet. Described from type female, No. 237, Liu Collection.

Original description.- "Head as long as broad, snout broad, rounded, and very much depressed, with seven upper labial spots on the right and six on the left side; loreal region oblique and slightly concave, canthus rostralis sharply edged from anterior border of upper eyelid to nostril, nostril mid-way between tip of snout and anterior border of eye; internasal space about two-thirds of interorbital space; orbit broader than eyelid, and about the same diameter as interorbital space; pupil vertical, changeable in shape, lower half of exposed eyeball dark cinnamon brown, and upper half bluish green; a narrow sharp glandular ridge from posterior corner of eye to shoulder; tympanum hidden; no vomerine teeth; tongue broad and large, free posteriorly and notched; maxillary teeth moderately developed. Skin on the back with small granules, which form fine net-work. Forelimb slender and long, more than half the body length; hind limb short, slightly longer than body; digital tips creamy buff; tibio-tarsal articulation barely reaching the angle of the mouth; heels when placed at right angles to the body widely separated, tibia short, webs poorly developed; inner metatarsal tubercle moderately long; a large oval cream-colored gland in each axilla; a narrow vertical glandular area in each groin, and a less conspicuous oval or rounded one at posterior middle part of each femur. A cartilaginous episternum, omosternum, and xiphisternum; sternum with a bony style, clavicle partly cartilaginous, sacral diapophyses greatly dilated, and with wide marginal cartilage.

"Secondary sex characters.--Males are larger than females, and both have a somewhat depressed body. The most interesting character of the male is the epidermal spines on the margin of the upper jaw. One male has sixteen spines, and the other has eleven. In the female there are no spines, but regular creambuff spots are present where the spines are developed in the male. The spine is black, long, and pointed, with a soft core and a wide base. The largest and 
longest spines are located lateral to the nostrils and the anterior region of the eye; the smallest ones are near the angle of the mouth, and this is also true for the corresponding spots in the female. The number of spines and spots is variable, ranging from eleven to sixteen.

"The head is broader than long in males, and about equal in females. The distance between the nostrils is greater in females, and much smaller than the interorbital space. In life the eye is very large, with a changeable vertical pupil, and measurement of preserved specimens indicates that the diameter of the eye

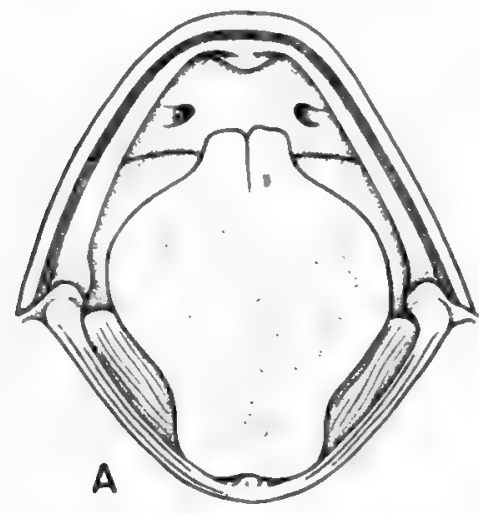

FIG. 36. Vibrissaphora boringii $(\times 2)$. C. Ventral view of foot.

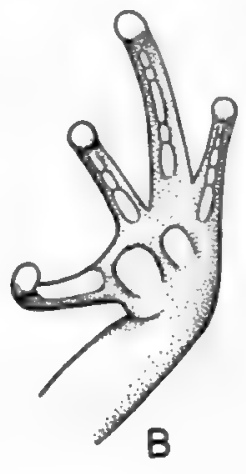

A. Oral cavity. B. Ventral view of hand.

is greater than the interorbital space. The width of the eyelid is about equal to the interorbital space in male specimens, and smaller than the interorbital space in females.

"The arm is rather long, the lower arm being about 58 per cent of the body length in the male, and 56 per cent in the female. The lower arm is much longer than the upper arm, especially in the female. The arm is much more strongly developed in the male, the diameter being about 15 per cent of the body length, while it is only 7 per cent in the female. The fingers [fig. 36, B] are long and strongly built, with rounded, light-colored tips. The first finger is longer than the second, the third is the longest, and the fourth is the shortest. There are no nuptial pads, asperities, or spines on the fingers of the male. Subarticular tubercles are distinct. There is a large, more or less rounded inner-metacarpal tubercle and a smaller, oval, outer-metacarpal tubercle on the palm. Both the palm and the ventral surface of the fingers are covered by thickened and opaque skin.

"The hind limbs are weak and short, the tibio-tarsal articulation only reaching the angle of the jaw. The hind limb is longer in males, being 126 per cent of the body length and in the female only 114 per cent. The tibia is rather short, and when the legs are placed at right angles to the body, the heels are widely separated. The toes [fig. 36, C] are similar in form to the fingers. The webs are poorly developed, both toe-fringes and webs being better developed in males. 
Subarticular tubercles are visible; there is a prominent oval inner metatarsal tubercle, but no outer tubercle. The skin on the sole and ventral sides of the toes is similar to that of the hand.

"The skin is not smooth, but has small granules that form a network on the back. On the dorsal sides of the limbs, small granules close together form oblique ridges, which are much more conspicuous on the arms than on the legs. A narrow glandular fold extends from the posterior border of the eye to the shoulder. Creamy wart-like glands are developed on the sides of the body, and on the posterior and ventral sides of the limbs, throat, and belly. They are more conspicuous in the male, which has a looser skin, like that of the male of Bufo bufo gargarizans. A large cream-colored gland is located in each armpit in both males and females, similar to those of Megophrys, Scutiger, and Aelurophryne. Another smaller and less conspicuous gland is sometimes found in the midposterior region of the femur, but it is less constant than the axillary pair. A long narrow vertical glandular area, of the same color, is in each groin.

"Coloration in life.-The ground color on the back and upper sides of the limbs is bluish-brown with some clouding of purple. Irregularly shaped fuscous spots are scattered on the back and limbs. The color is lighter on the head and the anterior region of the body, the bluish tint being more marked caudad. There is a black line latero-ventral to the canthus rostralis. The sides of the body and the posterior part of the legs are bluish-brown, marbled with black, and dotted with a number of small white warts. The belly is purplish-fleshy in color, with a large number of small white warts. The tips of the digits are cream buff. The throat of the male is much darker than that of the female."

Vibrissaphora boringii: Measurements of Type and Topotypes

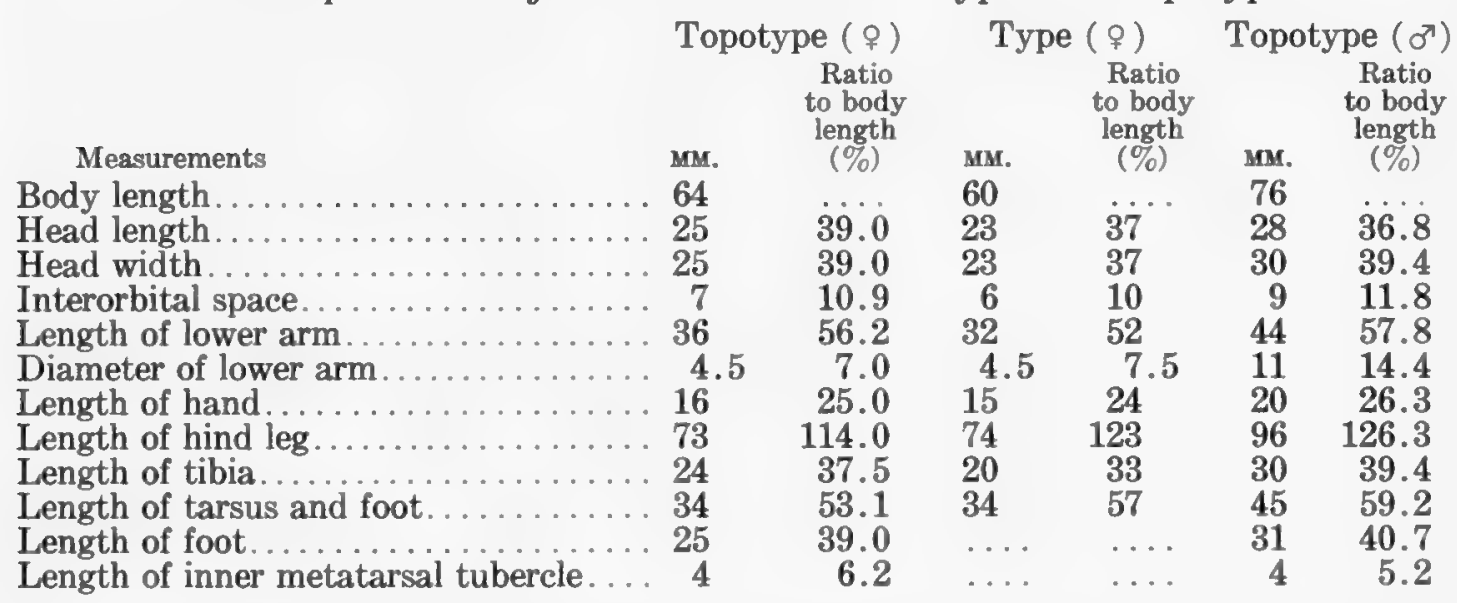

Habitat and habits.-Although the author spent three summers on Mount Omei and had paid special attention to this new pelobatid frog, its natural history is still imperfectly known. It appears to be a terrestrial form, as is indicated by the cornified palms and soles. It is locally known as "gan-ch'i-mei" meaning "dry frog" because it is found mostly in corn fields or on hillsides under stones. 
It comes out from its hiding place during the summer, after or during heavy rain. So far only one specimen was found in a pool, where it was paired with a male of Rhacophorus leucomystax. This frog does not usually jump, but mostly walks rather like a spider, bending the limbs and curving the fingers and toes, with the belly well above the ground.

Genus MEGOPHRYS Kuhl and van Hasselt

Megophrys Kuhl and van Hasselt, 1822, Alg. Konst.-Letter-Bode, pt. 1: 102, 104 (type, $M$. montana $\mathrm{Kuhl}$ and van Hasselt).

Ceratophrys Gravenhorst, 1829, Delic. Mus. Zool. Varatislav., fasc. 1: 47 (part, not of Wied, 1824).

Megalophrys Wagler, 1830, Syst. Amph., p. 204 (emendation).

Leptobrachium Tschudi, 1838, Mém. Soc. Sci. Nat. Neuchâtel, 2: 43 (type, L. hasseltii Tschudi).

Ceratophryne Günther, 1858, Cat. Batr. Sal., Brit. Mus., p. 136 (type, C. nasuta Schlegel). Xenophrys Günther, 1864, Rept. Brit. India, p. 414 (type, X. monticola Günther).

Pelobatrachus Beddard, 1907, Proc. Zool. Soc. Lond., 1907, pt. 2: 909 (type, Megalophrys nasuta Schlegel).

\section{Key for Identification of Chinese SPECIEs of Megophrys}

I. Snout projecting beyond the lower jaw.

A. Size large, with dark stripes on the throat.

B. A median dark stripe on the throat.

C. Tympanum distinct; vomerine teeth present........... omeimontis.

CC. Tympanum hidden; no vomerine teeth.............. shapingensis.

BB. Without median dark stripe on the throat................ lateralis.

AA. Size small, without dark stripes on the throat................ minor.

II. Snout not projecting beyond the mouth.

A. Head as long as broad or slightly broader than long.

B. Tympanum distinct. oshanensis.

BB. Tympanum hidden. boulengeri.

AA. Head almost twice as broad as long carinensis.

\section{Megophrys lateralis Anderson}

Ixalus lateralis Anderson, 1871, Jour. Asiatic Soc. Bengal, 40: 29; idem, 1879, Anat. Zool. Res. Yunnan, p. 844, pl. 78, fig. 5-western Yunnan.

Megalophrys major Boulenger, 1908, Proc. Zool. Soc. Lond., 1908: 416, pl. 23-Darjeeling; Pope and Boring, 1940, Peking Nat. Hist. Bull., 15, pt. 1: 28.

Megophrys longipes Mell, 1922, Arch. Naturg., Berlin, 88, Abt. A, Heft 10: 129; Pope, 1931, Bull. Amer. Mus. Nat. Hist., 61: 437; Boring, 1936, Hong Kong Naturalist, 7: 13 .

History of species.-Anderson (1871) recorded a small frog from western Yunnan as Ixalus lateralis. Adult specimens were described by Boulenger (1908) from the collections of the Yunnan Expedition as major, and others from 
northern Kwangtung have been named longipes by Mell (1922). Pope (1931) identified his Fukien material as longipes, and was followed by Boring (1936) for specimens from Hongkong. In 1940, Pope and Boring placed longipes as a synonym of major. From Boulenger's discussion of the history of this species under his new name major, it seems evident that he willfully disregarded the earlier name of Anderson.

Distribution and collection data.-This beautiful frog has been found in Yunnan, Kwangtung, and Hongkong. I have collected no material.

Comparison with related species.-Megophrys lateralis is closely related to the two species described below as $M$. shapingensis and $M$. omeimontis. The presence of vomerine teeth, the exposed tympanum, and the absence of the median dark stripe on the throat distinguish lateralis from shapingensis. $M$. lateralis is much larger than $M$. omeimontis, and the latter species has a median black stripe on the throat.

Original description.- "Snout short, as long as the eye, rounded in front; canthus rostralis angular and rounded. Tympanum about one-third the size of the eye. Tongue linear, elongate, slightly notched behind. Eustachian tubes about the same size as the choanae. Skin smooth above; sides and sacral region with a few minute scattered tubercles. A fold from the eye over the tympanum to the shoulder, terminated over the latter in a rather prominent white tubercle, under surface smooth, limbs moderately long. The tips of the fingers and toes very feebly dilated. Second finger slightly longer than the first, and the third than the former. Fifth about one-half the length of the fourth. Foot rather short, the fourth toe less than one-half the length of the body. The first toe very small, about one-half the length of the second. The third toe has its distal phalanx longer than the fifth, and the latter reaches only to the distal end of the second phalanx of the fourth. Toes one-fourth webbed, an elongated metatarsal tubercle at the base of the first toe.

"Uniform brown above (spirit specimen). Three black spots, with a white spot in the centre of some, in linear series along the side. A lower oblong black spot on the side of the sacrum above the groin. A narrow white line on the middle of the side between the fore and hind limbs. A black band along the supratympanal fold. A few black spots above the vent. Back of the thighs black, with a white spot at the end of the band. Legs barred with black. Under surface brownish yellow.

"Length 1 ", 1 "', hind limb 1", 10"'."

\section{Megophrys boulengeri Bedriaga}

Leptobrachium boulengeri Bedriaga, 1898, Wiss. Res. Przewalski Cent. Asien Reisen, Zool., 3: 63, pl. 1, fig. 7-Dy-tschju, Jan-tse-kiang Super [Dychu River, upper Yangtse Kiang, China].

Megophrys boulengeri Boulenger, 1908, Proc. Zool. Soc. Lond., 1908: 425; Pope and Boring, 1940, Peking Nat. Hist. Bull., 15, pt. 1: 30. 
Megophrys weigoldi Vogt, 1924, Zool. Anz., 60: 343-Washan, Szechwan; Pope and Boring, 1940, Peking Nat. Hist. Bull., 15, pt. 1: 30.

History of species. - Two adults and a juvenile, collected at Dychu in 1884, were described as Leptobrachium boulengeri by Bedriaga in 1898. In 1908, Boulenger referred the species to Megophrys. In 1924, Vogt described Megophrys weigoldi from Washan, Szechwan. Pope has examined the type of weigoldi in the Berlin Museum and found it in a rather poor state of preservation. In 1940, Pope and Boring noted that weigoldi fits the description of boulengeri remarkably, except that the length of the tibia is half of the body length (31 to 61) in weigoldi

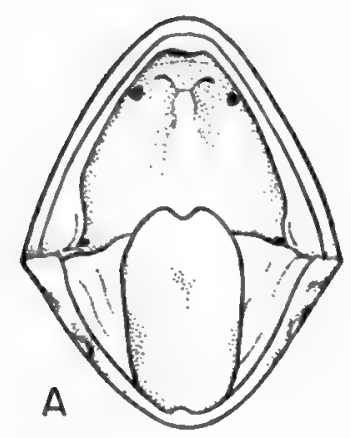

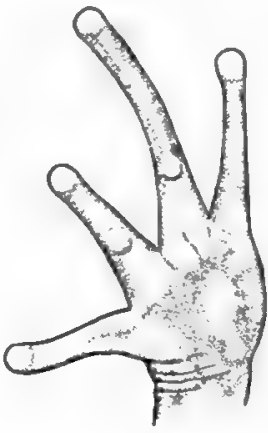

B

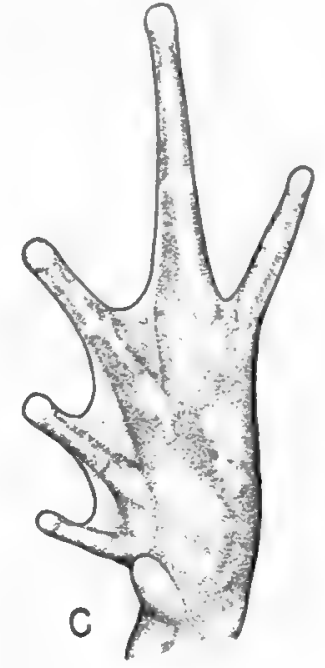

B. Ventral view of hand.

FiG. 37. Megophrys boulengeri $(\times 2)$. A. Oral cavity. C. Ventral view of foot.

and one-third (16 to 49 ) in boulengeri, confirming the statement in Vogt's description. I collected five specimens (two females, two males and a juvenile) from the top of Mount Omei, only about forty miles north of Washan, the type locality of weigoldi. My specimens (pl. 5, fig. 4; text fig. 37) fit the description of boulengeri well, the tibio-tarsal articulation reaching the temple, and not to a point between the eye and the nostril as in weigoldi. In spite of the discrepancy in the tibial measurement, and differences in adult size, I am convinced that the Washan specimens and mine from Mount Omei must represent the same species.

Distribution and collection data.-Besides those taken at the type locality, Dychu, one specimen was collected at Washan. My assistants and I collected five specimens during three summers $(1938,1940,1945)$, from the top of Mount Omei. This species thus appears to be rare and to be limited to altitudes above 10,000 feet.

Comparison with related species.-Megophrys boulengeri is a sharply distinct species within the genus. The hidden tympanum and large size distinguish boulengeri from oshanensis. 
Original description.- "The head is of moderate size, somewhat broader than long, flattened above, with projecting $\epsilon y e s$, and has a rather high, rounded, and somewhat projecting snout. The obliquely directed loreal region is feebly concave. The canthus rostralis is obtusely angulate. The length of the head is contained two and one-half times in the length of the body, and its greatest width two and one-third times in the same measurement. The distance from the tip of the snout to the eye is a little longer than the length of the eye. The eyes are of moderate size and have a vertical pupil in the shape of a triangle with rounded corners. The length of the eye is greater than the distance between the eyelids, which slightly exceeds the width of the upper eyelid. The nostrils, situated just below the canthus, are directed laterally and only a little upward; they are equally distant from the eye and the tip of the snout; the distance between the nostrils is distinctly longer than their distance from the anterior corner of the eye and is about equal to the width of the upper eyelid. The tympanum is hidden. Directly behind the eyes raised glandular ridges begin, extending almost to the base of the arm, narrowed posteriorly. The moderately long cleft of the mouth is inferior and scarcely extends beyond the angles of the mouth. Vomerine teeth not distinguishable. Tongue pear-shaped and occupies nearly the whole of the floor of the mouth; its posterior half and its sides are free, and it is shallowly emarginate anteriorly.

"The trunk is slender, narrowed posteriorly and constricted at the groin. The long arms have rather elongate free fingers. The second finger extends to the penultimate phalange of the third, and the fourth extends considerably beyond this point. The three first fingers are progressively longer, whereas the fourth is shorter than the second. Two small flat palmar tubercles present at the base of the first and fourth fingers, of which the outer is the smaller. The legs are slender, moderately long, the tarsus not reaching the angle of the mouth when the leg is extended forward, but extending beyond the shoulder; the metatarsal joint extends to the posterior border of the eye or somewhat farther. The tibia is longer than the distance from the tip of the snout to the angle of the mouth. The length of the foot, measured from the metatarsal tubercle to the tip of the fourth toe, is half again as long as the distance from the tip of the snout to the posterior corner of the eye. The rather long toes are connected by well-developed webs, extending farther along the outer sides of the toes than the inner; on the first and second toes these webs extend to the last phalange, whereas the third and fifth toes are connected to the penultimate phalange and the fourth toe has three phalanges free. The third and fifth toe extend distinctly beyond the first phalange of the fourth, the fifth being nearly equal in length to the third. The inner metatarsal tubercle is elongate and rather strongly developed; its length is two-fifths of that of the first toe.

"The skin of the upper parts is rather thick and covered with rather large and irregular warts, the largest of which are elongate and few, set among the smaller ones in more or less distinct longitudinal rows in the mid-dorsal region. The warts, the tympanic glandular fold, the inner surface of the upper arm and 
of the lower leg are set with dot-like pits. The eyelids lack any tubercles or projections; there is a faint fold at the rear of the upper eyelids. At the knee and at the tibio-tarsal joint transverse folds are present. The skin at the buttocks is coarsely granulate; otherwise the skin of the lower parts is entirely smooth. At each side of the breast, close to the axillae, there is a large raised area with a few small pits.

"The ground color of the upper side is light gray tinged with green; the entire under surface is uniform yellow. The median dorsal region bears a broad but faint brownish olive band extending to the eyes, where it is expanded to form a transverse marking that encloses a light spot such as is to be seen also in Megophrys monticola and $M$. parum. The elongate dorsal warts are light brown, edged with dark brown. The upper side of the head and of the legs is ornamented with brown dots and irregular spots. The tympanic glandular folds are bordered below by a narrow dark brown line, and the canthus rostralis is marked by brown lines that widen on the anterior part of the eyelid."

Measurements.-Type (St. Petersburg No. 1609a) and paratype (in parentheses; St. Petersburg No. 1609b): total length $27.0 \mathrm{~mm}$. (49.0); length of head $9.5 \mathrm{~mm}$. (14.0); width of head $9.5 \mathrm{~mm}$. (15.0); depth of head $3.7 \mathrm{~mm}$. (5.5); length of eye $3.0 \mathrm{~mm}$. (4.8); breadth of upper eyelid $2.0 \mathrm{~mm}$. (3.5); breadth of interorbital space $3.0 \mathrm{~mm}$. (4.0); tip of snout to anterior border of eye $4.0 \mathrm{~mm}$. (6.3); length of leg $32.0 \mathrm{~mm}$. (58.0); length of tibia $8.5 \mathrm{~mm}$. (16.5); length of foot $10.0 \mathrm{~mm}$. (19.0); length of inner metatarsal tubercle $1.2 \mathrm{~mm}$. (3.5).

Megophrys boulengeri: Measurements of Adults from Mount Omei

\begin{tabular}{|c|c|c|c|c|}
\hline \multirow[b]{2}{*}{ Measurements } & \multicolumn{2}{|c|}{ Female } & \multicolumn{2}{|c|}{ Male } \\
\hline & mM. & $\begin{array}{c}\text { Ratio } \\
\text { to body } \\
\text { length } \\
(\%)\end{array}$ & MOM. & $\begin{array}{c}\text { Ratio } \\
\text { to body } \\
\text { length } \\
(\%)\end{array}$ \\
\hline Body length. & 46.7 & & 41.5 & \\
\hline Head length. & 15.0 & 32.1 & 13.0 & 31.3 \\
\hline Head width & 15.0 & 32.1 & 13.2 & 31.8 \\
\hline Interorbital space. & 5.0 & 10.7 & 3.7 & 8.9 \\
\hline Length of arm. & 31.8 & 68.1 & 25.0 & 60.2 \\
\hline Diameter of lower arm. & 3.2 & 6.8 & 3.7 & 8.9 \\
\hline Length of third finger. & 10.4 & 22.2 & 8.5 & 20.5 \\
\hline Length of hind limb. & 64.0 & 137.0 & 57.5 & 138.6 \\
\hline Length of tibia. & 18.0 & 38.7 & 16.0 & 38.8 \\
\hline Length of foot and tarst & 31.2 & 66.8 & 27.3 & 65.8 \\
\hline Length of foot. & 18.4 & 39.4 & 16.0 & 38.8 \\
\hline
\end{tabular}

Coloration in life.-Rufous brown above, on the sides of the body, and on the dorsal sides of limbs; the back stippled with gold and olive brown; a dark triangular mark on the head, one angle of which extends onto each upper eyelid, the posterior angle extending backward to the shoulder region; dark marks generally along the elongate glandular ridges, and dark markings on the arms and legs; a wide dark band from tip of snout through nostril to anterior corner of eye continued along the margin of the upper eyelid and ventral margin of the glandular fold to the shoulder; latero-ventral side of the body and anterior 
and posterior aspects of the legs stippled with silver and with bluish; pupil vertically elliptic, somewhat squarish, enclosed by a golden ring, latero-ventral sides of the eyeball dark olive brown and dorsal part stippled with gold; throat, breast, belly, and lower sides of the limbs marbled with grayish brown and stippled with silver and gold.

Secondary sex characters.--Secondary sex characters are poorly developed in this species. Light-colored nuptial pads are developed on the inner dorsal sides of the first and second fingers of the male. The male has no vocal sac and no lineae masculinae.

Habitat and habits.-This rare frog inhabits high mountains above 1,000 feet altitude. I found specimens sitting on stones by the side of pools of very small mountain streams, shaded by rich vegetation, or hiding in grasses near water in the open valley. No tadpoles or eggs were found.

\section{Megophrys minor Stejneger}

Megophrys minor Stejneger, 1926, Proc. Biol. Soc. Wash., 39: 53-above Kwanhsien, Szechwan.

Megophrys boettgeri Pope and Boring, 1940, Peking Nat. Hist. Bull., 15, pt. 1: 29; Liu, 1940, op. cit., 15, pt. 2: 165.

History of species.-A single male specimen of this small pelobatid frog was collected by Graham from a mountain at about 3,000 feet altitude above Kwanhsien, and described as Megophrys minor by Stejneger in 1926. Pope and Boring (1940) stated that my material from Mount Omei was certainly either boettgeri or kuatunensis, and in the same year I reported upon my specimens from this mountain as boettgeri. On June 21, 1941, I collected four specimens at Shuimokou, west of Kwanhsien, which is very near the type locality of minor, and I have failed to find any differences between these specimens and my material from Mount Omei. After further comparison of my specimens with the type of minor in the United States National Museum, and with specimens of boettgeri and kuatunensis in Chicago Natural History Museum, the Museum of Comparative Zoology, and the American Museum of Natural History, and after scrutiny of the original description of each species, I am convinced that my material from Mount Omei is not boettgeri or kuatunensis, but minor.

Distribution and collection data.-Megophrys minor (pl. 4, fig. 5) is an endemic species of western Szechwan and eastern Sikang, found among vegetation near small mountain streams at about 3,000 feet altitude. During the summers of 1938, 1940, and 1945, adults and tadpoles were collected around Taosze, on Mount Omei. On June 21, 1941, four specimens and many advanced tadpoles were obtained from the upper reaches of a small stream on Changchiashan, near Shuimokou, Kwanhsien. A male specimen was collected in July, 1939, at Kaohouping, near Tienchuan, Sikang.

Comparison with related species. - Megophrys minor can easily be distinguished from $M$. boettgeri and $M$. kuatunensis, minor having no black marks of any kind 
on its throat, whereas boettgeri and kuatunensis both have symmetrical black marks developed on their throats. The legs of minor are longer than those of boettgeri and kuatunensis, the tibio-tarsal articulation reaching beyond the eye in minor and only beyond the tympanum in the latter two species. The dark brown mark on the back is obscure in minor; in boettgeri there is a solid, very conspicuous dark brown mark on the back, and kuatunensis has an X-shaped dorsal marking. The two semicircular, much lighter-colored areas on the dorsal sides of the scapular region of boettgeri form the best character to separate this species from minor and kuatunensis.

Original description.- "Snout strongly projecting beyond lower jaw; head as broad as long; tympanum distinct; tibio-tarsal articulation reaching between eye and tip of snout; no vomerine teeth; upper eyelid without hornlike tubercle; toes with a slight rudiment of web; diameter of tympanum about two-thirds diameter of eye and greater than distance between eye and tympanum; inner metatarsal tubercle large; male with a large external vocal sac."

Description of type (No. 68816 United States National Museum).-Adult male: Tongue truncate behind, entire; vomerine teeth absent; head about as long as broad; snout truncate in profile, extending strongly beyond the lower jaw, nearly as long as diameter of eye; canthus rostralis sharp; loreal region concave, nostril halfway between eye and snout; interorbital space considerably wider than upper eyelid; tympanum very distinct, about one-half the diameter of eye, and greater than its distance from the latter; finger blunt, second slightly longer than first and shorter than fourth; no subarticular tubercles; toes blunt, with a slight rudiment of web at base and a narrow membranous edge; a flat inner metatarsal tubercle more than half as long as first toe, no outer metatarsal tubercle; tibio-tarsal articulation reaching beyond the eye; tibia about equal to half the length from snout to vent; foot shorter than tibia; skin above more or less distinctly granular, the tubercles larger and more distinct on sacrum and backwards, with indications of linear arrangement; a strong skin fold from eye over tympanum, which it overhangs, to shoulder; under side perfectly smooth.

A large external median subgular vocal sac; a raised pad with slight rugosities on upper side of basal phalange on the first and second fingers.

Color (in alcohol).-Above dark brown; a darker arrow-shaped triangular mark on and between upper eyelids, the point extending backwards to between the shoulders; a dark crescent-shaped mark on each side from above tympanum to as far back as the elbows; scattered tubercles on flanks and sides of sacrum, with whitish tips; a large brown light-edged spot on upper lip below eye, preceded by two small ones. There is a broad brown band behind the eye on the tympanic region extending to the insertion of the arm, sprinkled with whitish tubercular dots; lower lip brown, with a few small whitish dark-edged spots; under side pale brownish gray, darker on throat and vocal sac; on each flank a series of illdefined blackish spots not reaching the groin; legs above with indications of dark cross-bars; posterior aspect of femur with an angular dark line through the vent, 
and whitish tubercular dots as well as a circular whitish spot halfway between vent and knee.

Measurements of type (percentage of body length in parentheses).-Body length $32 \mathrm{~mm}$.; head length $11 \mathrm{~mm}$. (34.3); head width $10 \mathrm{~mm}$. (31.2); head height $5 \mathrm{~mm}$. (15.6); eye length $5 \mathrm{~mm}$. (15.6); diameter of tympanum $2 \mathrm{~mm}$. (6.2); length of lower arm $16 \mathrm{~mm}$. (50.0); diameter of lower arm $2.5 \mathrm{~mm}$. (7.8); length of hand $7 \mathrm{~mm}$. (21.8); length of leg $53 \mathrm{~mm}$. (165.6); length of tibia $16 \mathrm{~mm}$. (50.0); length of tarsus and foot $22 \mathrm{~mm}$. (68.7); length of foot $15 \mathrm{~mm}$. (46.8).

\section{Megophrys minor: Measurements of Eight Male and Four Female Adults}

\begin{tabular}{|c|c|c|c|c|}
\hline Measurements & Sex & Range & Average & $\begin{array}{c}\text { Ratio to } \\
\text { body length (\%) }\end{array}$ \\
\hline Body length... & $\begin{array}{l}0^{7} \\
0\end{array}$ & $\begin{array}{l}34.2-39.4 \\
40.0-44.8\end{array}$ & $\begin{array}{l}36.7 \\
42.8\end{array}$ & $\begin{array}{l}\ldots \\
\ldots\end{array}$ \\
\hline Head length. & $\begin{array}{l}\sigma^{7} \\
9\end{array}$ & $\begin{array}{l}11.2-13.2 \\
13.2-13.7\end{array}$ & $\begin{array}{l}12.0 \\
13.5\end{array}$ & $\begin{array}{l}32.7 \\
31.5\end{array}$ \\
\hline Head width. & $\begin{array}{l}\sigma^{7} \\
0\end{array}$ & $\begin{array}{l}10.5-12.4 \\
12.5-13.5\end{array}$ & $\begin{array}{l}11.4 \\
12.9\end{array}$ & $\begin{array}{l}31.2 \\
30.1\end{array}$ \\
\hline Diameter of tympanum. & $\begin{array}{l}0^{7} \\
\wp\end{array}$ & $\begin{array}{l}2.5-3.0 \\
2.5-3.0\end{array}$ & $\begin{array}{l}2.6 \\
2.8\end{array}$ & $\begin{array}{l}7.1 \\
6.6\end{array}$ \\
\hline Length of arm. . & $\begin{array}{l}0^{7} \\
\wp\end{array}$ & $\begin{array}{l}23-25 \\
25.5-27.0\end{array}$ & $\begin{array}{l}23.9 \\
26.3\end{array}$ & $\begin{array}{l}65.1 \\
61.4\end{array}$ \\
\hline Diameter of lower arm. & $\begin{array}{l}0^{x} \\
9\end{array}$ & $\begin{array}{l}2.3-3.4 \\
2.5-3.0\end{array}$ & $\begin{array}{l}2.9 \\
2.6\end{array}$ & $\begin{array}{l}8.0 \\
6.2\end{array}$ \\
\hline Length of hand. & $\begin{array}{l}0 \\
0 \\
q\end{array}$ & $\begin{array}{l}7.7-8.7 \\
8.0-9.6\end{array}$ & $\begin{array}{l}8.0 \\
9.0\end{array}$ & $\begin{array}{l}21.8 \\
21.0\end{array}$ \\
\hline Length of leg. & $\begin{array}{l}0 \\
0 \\
q\end{array}$ & $\begin{array}{c}56-64 \\
64.0-66.5\end{array}$ & $\begin{array}{l}58.9 \\
65.4\end{array}$ & $\begin{array}{l}160.4 \\
152.5\end{array}$ \\
\hline Length of tibia.. & $\begin{array}{l}0^{x} \\
9\end{array}$ & $\begin{array}{l}17.0-19.5 \\
19.6-20.7\end{array}$ & $\begin{array}{l}18.1 \\
20.3\end{array}$ & $\begin{array}{l}49.5 \\
47.4\end{array}$ \\
\hline Length of tarsus and foot. . & $\begin{array}{l}0^{x} \\
0\end{array}$ & $\begin{array}{l}26-30 \\
30-31\end{array}$ & $\begin{array}{l}27.6 \\
30.5\end{array}$ & $\begin{array}{l}75.3 \\
71.2\end{array}$ \\
\hline Length of foot. & $\begin{array}{l}07 \\
9\end{array}$ & $\begin{array}{l}14.0-16.4 \\
15.3-17.4\end{array}$ & $\begin{array}{l}15.1 \\
16.7\end{array}$ & $\begin{array}{l}41.2 \\
39.9\end{array}$ \\
\hline
\end{tabular}

Coloration in life.-The color of living specimens of Megophrys minor varies greatly. There is usually a yellowish olive ground color, with or without a distinct, dark brown triangular mark on the head, and an X-shaped mark on the back. A dark brown band extends from the eye along the ventral edge of the skin fold to the base of the arm. There are dark brown bars on the limbs and digits. The sides of the posterior region of the body and the posterior aspects of the thighs are scarlet, and in some specimens this color is also found on part of the upper jaw and on the tips of the digits. The dark, vertically oval pupil is enclosed by an iris stippled with gold and scarlet.

Sexual dimorphism.-Males are smaller than females, with gray granular nuptial pads at the base and inner dorsal sides of the first and second fingers. Legs of male are relatively longer than those of female. The median subgular vocal sac may be evident externally, but is usually difficult to distinguish from the outside. There are two round vocal sac openings near the angles of the jaw. 
Habitat and habits.-Megophrys minor is found in grassy areas near small streams or pools and ponds on the hillsides at about 3,000 feet altitude. It is difficult to locate the individuals, as they hide themselves in the vegetation. Sometimes one may find specimens croaking under stones, on hillsides, or in cornfields. During summer evenings these frogs croak loudly from the vegeta-

A
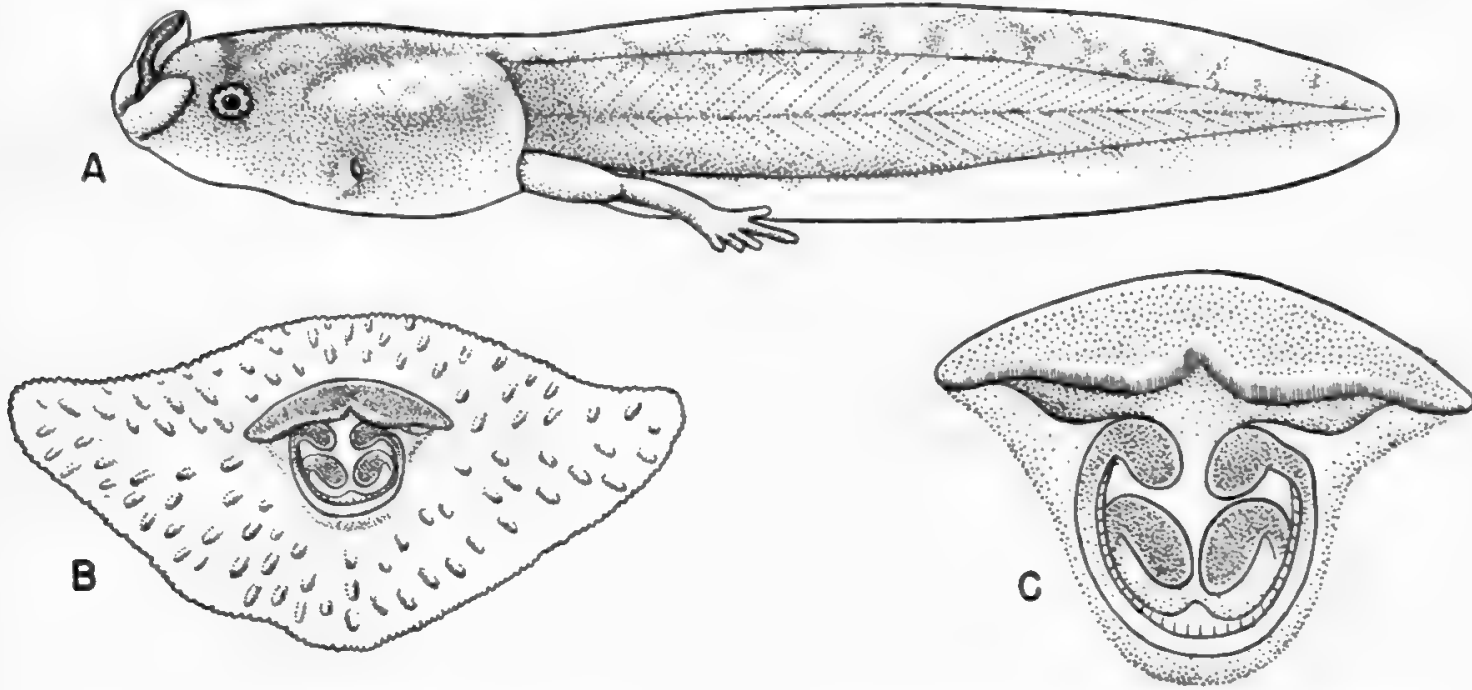

FIG. 38. Megophrys minor; tadpole. A. Tadpole with lips folded (X3). B. Expanded "funnel" (X20). C. Mouth (X30).

tion, and by this means one may locate them with care and patience (and with the help of a flashlight). Consequently most of the specimens collected were males.

I do not know the breeding behavior, the site of egg-laying, or the eggs of this small pelobatid frog, although I have searched for three summers on Mount Omei, and one summer on Panlungshan, west of Kwanhsien. As I found tadpoles of various stages of this species from the middle of May to the end of August at Taosze, Mount Omei, the breeding season must be long, like that of Rana boulengeri and $R$. adenopleura on the same mountain.

Tadpoles.-The tadpoles (pl. 10, figs. 1 and 2) of Megophrys minor are most often found in pools under the cascades of small mountain streams. Their funnel mouth parts (fig. 38) are always directed obliquely toward the current. If they are found in large mountain streams, they live in side pools behind large stones or in bends of the streams where the current is slow. Young tadpoles swim in schools floating on the surface, generally along the edge of the water. When disturbed they may scatter, and, folding the funnel mouth postero-dorsally, go down into the water. If one tries to catch them, they hide themselves in the cracks of stones or burrow into sand with only the head exposed. When slightly disturbed, they try to escape by darting against the current. The cylindrical body and the long powerful tail and low thick fins are perfectly adapted to moun- 
tain streams. Tadpoles with hind legs fully developed change their group behavior and are usually found singly or a few together on the margins of pools and resting against different kinds of objects. Young and advanced tadpoles do not willingly stay on the bottom for long, and the former will again group together on the surface of the water within a minute after disturbance. I agree with Smith (1926) and Pope that surface feeding is the main function of the funnel mouth but not the only function; the funnel proper also acts as a floating apparatus. I have noted in the field and in the laboratory, that when these tadpoles are floating on the surface only the dorsal triangular portion of the funnel is under water and only the bottom of the funnel, or the mouth proper, is filled with water. The lateral wings and the ventral triangular portion of the funnel are on the surface. In this manner, food particles can only reach the mouth with the water current from the submerged portion of the funnel, if there is no strong water current or wave. The real apparatus for food selection consists of the three pairs of projections and a median leaf-like one at the entrance of the mouth. It was noticed that the tadpole will not take every thing that is by chance forced to the bottom of the funnel. If an unfavorable object gets into the funnel the tadpole will eject it by closing up the mouth and withdrawing the snout into the water. Action of these projections, not only to prevent the object from getting into the mouth but also to push the object out of the funnel through their combined action, may be effective. Histological study of the special structures of the mouth may throw some light on this suggestion.

Coloration of the advanced tadpoles varies greatly. Before the hind legs are well developed, the color is rather uniform. Head and body are closely stippled with fuscous, through which a pale rufous brown and a pink shade from the blood can be seen. The eye has a round black pupil encircled by a golden iris spotted with fuscous. The color of the tail is similar to that of the body but with irregular patches of light brown on the dorsal part of the muscular portion. This brownish coloration extends posteriorly to about the middle of the tail. The tail fin, especially at the caudal region, is much paler than the body. The funnel is yellowish and the papillae are fuscous. The belly is nearly colorless, with silver white stipples. Another type of the advanced tadpole is quite different. It is rufous all over the body; only the funnel and the tail crest are lighter. Head, body, tail, and hind limbs are all stippled with umber or fuscous. Papillae in the funnel are light umber and the bottom of the funnel is light yellowish rufous. Different grades between fuscous and rufous are commonly found.

The tadpole of Megophrys minor is large in relation to the size of the adults. Five tadpoles (with average legs $7.6 \mathrm{~mm}$. long, ranging from 6-10 $\mathrm{mm}$.) were measured (see table).

The mouth is terminal, with a large funnel that has two long lateral wings, a short ventral wing and a comparatively narrow convex flap above. The tips of the lateral and ventral wings are bluntly pointed. The width of the funnel is 74.4 per cent of the body length. The funnel can be divided into dorsal and ventral parts by a fold or furrow through the lower middle part of the mouth 
opening. There are four rows of large oval, obliquely arranged papillae on the dorsal part of the funnel, the number of rows decreasing toward the lateral tips of the funnel. Small round papillae are found near the margin and above the mouth opening. There are three rows of oval and obliquely arranged papillae on the lower part of the funnel, but the number decreases from three to two and at last to one, toward its lateral tips. A row of small round papillae lies near the margin of the funnel. There is a ventral groove from the middle of the mouth to near the tip of the ventral wing of the funnel and a long groove going transversely between the tips of the lateral wings of the funnel. There are three or more papillae on the bottom of the transverse groove on either side of the mouth, with some extra papillae near the tip of the ventral wing.

\section{Megophrys minor: Measurements of Five Tadpoles}

\begin{tabular}{|c|c|c|c|}
\hline Measurements & Range & Average & $\begin{array}{c}\text { Ratio to } \\
\text { body length }(\%)\end{array}$ \\
\hline Body length. & $12.0-14.3$ & 12.9 & \\
\hline Body height. & $5.8-6.9$ & 6.4 & 49.5 \\
\hline Body width. & $6.0-8.0$ & 7.1 & 55.0 \\
\hline Head height. & $3.4-4.4$ & 4.0 & 30.7 \\
\hline Head width. & $5.4-6.0$ & 5.7 & 44.2 \\
\hline Mouth width. & $8.0-10.7$ & 9.6 & 74.4 \\
\hline Space between eyes. & $4.8-5.4$ & 5.0 & 38.9 \\
\hline Snout to spiraculum. & $7.0-7.7$ & 7.4 & 57.3 \\
\hline Tail length......... & $30.5-35.5$ & 32.9 & 254.6 \\
\hline Tail height. & $6.6-7.6$ & 6.9 & 53.6 \\
\hline Thickness of tail muscle. & $3.2-4.0$ & 3.8 & 29.4 \\
\hline Length of leg. . & $6.0-10.0$ & 7.6 & $\ldots$ \\
\hline
\end{tabular}

The structure of the mouth proper is quite complicated. Above the mouth opening, the inner margin of the upper lip has a soft semicircular raised border, with a large papilla at each end. Within this semicircle is a second, harder, semilunar structure, notched at the mid-dorsal side. On its margin there is a wide colorless border, with a sharp edge. Inside, behind the last ring, there are four vertical leaf-like projections, one pair at the mid-dorsal notch, and one on each end of the semicircle. A more complicated structure is developed in connection with another semilunar ring on the ventral side of the mouth opening. The free margin of the lower semilunar curve has a row of papilla-like elevations and a row of delicate hair-like structures with a triangular elevation in the center. At each of the corners of the lower semilunar curve there is a spoonshaped projection. Its free end is rounded, with a pouch facing forward, downward, and inward. Below this pair is another pair, with the free ends pointed toward the midline of the mouth; their bases are united to the bases of the lateral pair. The concave surface is not conspicuous. There is another pair of projections posterior to the second pair, with the concave surface facing forward and inward, their bases being connected with those of the first and second pairs. Behind and between the third pair there is a single rounded projection shaped like the bowl of a spoon with the concave surface forward; its base is connected with the floor of the mouth cavity. 
From observation in the field, it is evident that the funnel mouth is a wonderfully constructed surface adaptation in mountain streams. When the tadpole is not taking food, the accessory structures close up so that only water can pass through. Larger particles are prevented from entering by the semilunar curve and the projections in connection with the upper and lower semilunar folds and the floor of the mouth cavity. Hair-like structures on the margin of the upper and lower semilunar folds may be sense organs for selection of food, in addition to the function of preventing fine particles from escaping.

\section{Megophrys omeimontis sp. nov.}

Type.-No. 49406 Chicago Natural History Museum, from Mount Omei, Szechwan, altitude 3,600 feet. Adult male, collected July 26, 1940, by Ch'engchao Liu.

Diagnosis.--Closely allied to lateralis. The new frog has two large and long patches of vomerine teeth converging back of the choanae; in lateralis the vomerine teeth are in two small groups on a line between the posterior borders of the choanae. The tympanum in omeimontis is very distinct, more than half of the length of the eye, whereas in lateralis it is more or less distinct and only about half the diameter of the eye. The inner metatarsal tubercle is distinctly developed in omeimontis and indistinct in lateralis. Breeding males (pl. 4, fig. 2) and females of omeimontis measure 58 and $65 \mathrm{~mm}$., respectively, from snout to vent; those of lateralis (=major) 77 and $94 \mathrm{~mm}$. The tibio-tarsal articulation reaches beyond the eye in omeimontis and to the tip of the snout or a little beyond in lateralis. The upper eyelid of omeimontis has at most only an indication of a hump; in lateralis the hump is always pronounced.

Description of type.-Tongue feebly nicked behind, vomerine teeth in two large groups running from the inner corner of the choanae and converging posteriorly toward the median line, and ending with rounded nodes (fig. 39, A). Head moderate, broader than long; snout short, obliquely truncate, strongly projecting beyond the lower jaw, canthus rostralis sharp (fig. 39, D); loreal region vertical, concave anteriorly and convex posteriorly; nostril equally distant from eye and tip of snout; interorbital space flat, broader than upper eyelid; tym'panum distinct, more than half of the diameter of the eye, the distance between the eye and the tympanum about half of the diameter of the eye. Fingers (fig. 39 , B) with feebly swollen tips, the first as long as the second, which measures about two-thirds of the length of the third; the first finger with a distinct subarticular tubercle. Toes (fig. 39, C) with feebly swollen tips, webbed at base with lateral fringes slightly indicated, a prominent subarticular tubercle on the inner toe; inner metatarsal tubercle large, flat, and very distinct. Tibio-tarsal articulation reaching beyond the eye; tibia a little more than one-half the length of the body from the tip of the snout to the vent; foot shorter than the tibia.

Skin smooth above, with very small warts on the sides of the body and a few on the limbs. A fine glandular ridge from posterior angle of the eye to the 
base of the arm; a V-shaped glandular ridge on the shoulder, another smaller $\mathrm{V}$-shaped glandular ridge on the posterior region of the back, and two longitudinal lateral fine glandular ridges extending from the anterior shoulder region to the groin.

Grayish green above, with a light-edged grayish brown triangular mark on the head, one point of which extends onto either upper eyelid, a brown band capping the tip of the snout as far as the nostrils and extending along the canthus
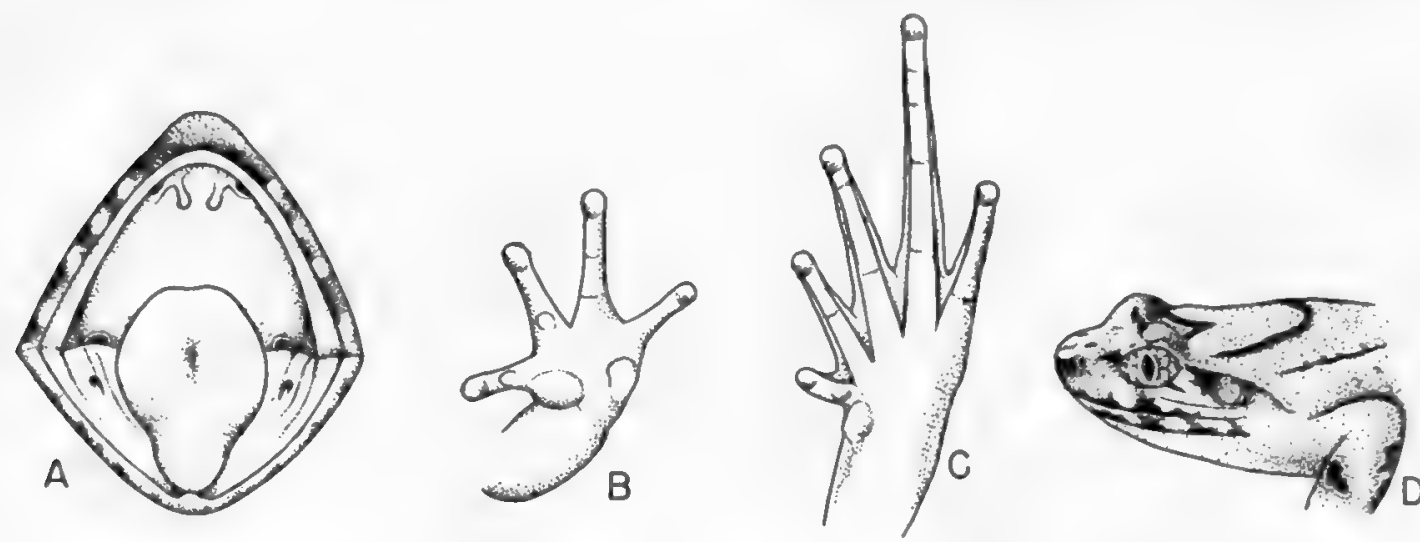

FIG. 39. Megophrys omeimontis. A. Oral cavity $\left(\times 1 \frac{1}{2}\right)$. B. Ventral view of hand $(\times 11 / 2)$. C. Ventral view of foot $(\times 11 / 2)$. D. Lateral view of head $(\times 1)$.

rostralis through the upper eyelid and then along the ventral margin of the glandular fold to the shoulder region; light-edged brown bars on the margin of the jaws, the suborbital one entering the eye; light brown on the tympanic region. Brown bands along the $\mathrm{V}$-shaped and dorso-lateral glandular lines on the back; limbs with irregular dark brown marks, red margined with diffuse yellow on the sides of the groin and the posterior dorsal side of the thigh. Throat, breast and anterior region of the belly spotted with dull dark gray and with light-edged dark brown symmetrical markings; a light-edged brown stripe on the posterior part of the throat, a large marking of similar color from below the angle of the mouth curving to the anterior surface of the arm on each side; an irregular light-edged mark extending from the axilla to the groin on the side of the belly. Anterior side of the femur and tibia marbled with dark and the posterior ventral side of the tarsus and foot banded with brown. Ventral sides of the thigh light, but the ventral sides of the arms and the lower legs marbled with dark gray; hinder side of the thighs, especially near the anus, with lightedged dark brown mark; irregular brown marbling on the postero-ventral side of the arm.

Discussion of paratypes.--Seven specimens (five males and two females) were collected from July 26 to 28,1940 , in a small mountain stream at Taosze, on Mount Omei. Two more males were collected from the same locality on June 18,1945 . These paratypes are comparatively uniform in structure, but vary 
slightly in the shade of the ground color, some being more greenish and some more grayish. Males are darker than females. The light-edged dark triangular mark on the head is constantly present. This mark has a light center in three specimens and is solid in the other three. The anterior V-shaped dark mark is constantly present; the posterior one is $\Lambda$-shaped in three specimens and only a curved line in one. Two poorly preserved male specimens have the anterior $\mathrm{V}$-shaped mark feebly shown and the posterior one not indicated. In lateralis there is an X-mark of light-edged dark color that is never found in omeimontis, and the light streak on the upper lip of lateralis is absent in omeimontis. The light-edged dark stripe on the throat is always present but lateralis has no median stripe.

Megophrys omeimontis: Measurements of Type and Paratypes

\begin{tabular}{|c|c|c|c|c|c|c|c|c|c|}
\hline \multirow[b]{2}{*}{ Measurements } & \multicolumn{7}{|c|}{ Male } & \multicolumn{2}{|c|}{ Female } \\
\hline & $\begin{array}{l}\text { TYPE } \\
\text { MM. }\end{array}$ & мМ. & Ma. & MM. & мм. & Average & $\begin{array}{c}\text { Ratio } \\
\text { to body } \\
\text { length } \\
(\%)\end{array}$ & nм. & $\begin{array}{l}\text { Ratio } \\
\text { to body } \\
\text { length } \\
\text { (\%) }\end{array}$ \\
\hline Body length. & 63.0 & 57.0 & 59.0 & 57.5 & 54.2 & 58.1 & & 65.0 & \\
\hline Head length. & 20.3 & 19.7 & 19.4 & 19.4 & 19.4 & 19.6 & 33.8 & 21.5 & 33.0 \\
\hline Head width. & 22.0 & 21.0 & 20.0 & 20.3 & 20.3 & 20.7 & 35.1 & 22.0 & 33.8 \\
\hline Interorbital space. & 6.4 & 6.0 & 6.0 & 5.6 & 5.7 & 5.9 & 10.2 & 5.5 & 8.4 \\
\hline Tympanum. & 3.6 & 3.5 & 3.5 & 3.4 & 3.4 & 3.5 & 6.0 & 4.0 & 6.1 \\
\hline Length of arm. & 37.0 & 38.1 & 38.0 & 37.3 & 36.5 & 37.4 & 64.3 & 39.0 & 60.0 \\
\hline Diameter of lower arm & 6.4 & 5.8 & 5.5 & 6.0 & 6.0 & 5.9 & 10.2 & 5.5 & 8.4 \\
\hline Length of hind limb. & 105.0 & 108.5 & 104.0 & 104.0 & 100.0 & 104.3 & 179.4 & 105.0 & 161.5 \\
\hline Length of tibia. & 32.8 & 34.5 & 32.8 & 32.8 & 31.8 & 32.9 & 56.7 & 33.0 & 50.7 \\
\hline Length of foot and tarsus. & 46.6 & 48.8 & 45.5 & 45.0 & 44.0 & 46.0 & 79.1 & 47.0 & 72.3 \\
\hline Length of foot. & 27.0 & 28.0 & 25.0 & 25.5 & 24.0 & 25.9 & 44.5 & 29.0 & 44.6 \\
\hline
\end{tabular}

Sexual difference.-Sexual dimorphism in size is slight. Six of the specimens were measured (see table). Both males and females are smaller than Boulenger's specimens from Darjeeling, recorded as major. The specimens of this new frog are all mature, collected during the breeding season. The male has gray nuptial pads on the inner dorsal side of the first and second fingers and an external median subgular vocal sac with two short slit-like openings near the angle of the jaw. The arm of the male is slightly longer and stronger. Lineae masculinae are not developed.

Habits and habitat.-Megophrys omeimontis is rather rare and difficult to collect. I spent three summers on Mount Omei but obtained only nine specimens. Seven of these were collected during the summer of 1940 and two on June 18, 1945. These specimens were collected from a small mountain stream in front of Taosze, Mount Omei. Only one young adult was found in a large mountain stream "Shihsunkou" (4,000 feet) at Fuhusze on the same mountain.

From the middle of June to the middle of August, one may hear this frog croaking loudly in the stream. Two or three at most croak at the same time along the small mountain stream at twilight, especially after rain. They are 
very sensitive to any disturbance. I tried many times to approach one but usually failed to reach it with a flashlight. This frog has the special habit of appearing on the same stone near the margin of the water every night. We failed repeatedly to get one along the mountain stream, and never heard or found one alive on the hillside. On July 27, 1940, a dead female with abdomen punctured and large white eggs exposed was found in the lower reach of the stream in front of Taosze. Again, on the morning of June 17, 1945, a dead male was found on the stairway inside of Taosze.

The breeding habitat and habits are still unknown. According to our knowledge, the breeding season may be from July to August, as five males and a female were collected on the night of July 26, 1940, and on July 27 of the same year the dead female was found in the same mountain stream. Before and after these dates we never found so many males croaking at the same time. We failed to find eggs, although we turned many stones along the stream.

\section{Megophrys shapingensis sp. nov.}

Type--No. 49405 Chicago Natural History Museum, from Shaping, Opienhsien, Szechwan. Adult male, collected June, 1940, by Mr. Tung.

Diagnosis.-Closely allied to lateralis and omeimontis, from which it differs in the absence of vomerine teeth, absence of vocal sac, and hidden tympanum. Megophrys lateralis has two small groups of vomerine teeth and a more or less distinct tympanum; in omeimontis there are two long patches of vomerine teeth and a very distinct large tympanum. The males of lateralis and omeimontis always have a median subgular internal vocal sac. The leg of the new frog is shorter than that of lateralis and omeimontis; the tibio-tarsal articulation in shapingensis reaches the middle of the eye, whereas in lateralis it reaches beyond the snout and in omeimontis beyond the eye. The webs between the toes are much better developed in shapingensis than in either lateralis or omeimontis. Small warts, provided with black spines, are found on the posterior sides of the head; posteriorly the belly and the posterior and ventral sides of the thighs of the male of shapingensis are granulate, which is not true of omeimontis.

Description of type.-Tongue (fig. 40, A) feebly nicked behind, vomerine teeth lacking. Head moderate and very much depressed, longer than broad; snout (fig. 40, D) obliquely truncate in profile, projecting beyond the lower jaw; canthus rostralis well defined; loreal region vertical, concave; nostril equally distant from the eye and the end of the snout; interorbital space flat, and narrower than the upper eyelid; tympanum hidden. Fingers (fig. 40, B) with swollen tips, the first a little shorter than the second; an ill-defined subarticular tubercle on first and second fingers, no metacarpal tubercles. Toes (fig. 40, C) with swollen tips, first and second toes about one-half webbed, third and fourth toes about one-third webbed, the webs extending as lateral fringes to the tips of the toes; no subarticular tubercles, inner metatarsal tubercle flat. Tibio-tarsal articulation reaching the middle of the eye, the tibia a little more than one-half the length from snout to vent; foot shorter than tibia. 
Skin smooth (pl. 5, fig. 3), with warts on back and sides; V-shaped glandular ridges, a small one back of the eyes and a large one on the shoulder region, with two longitudinal short lateral glandular ridges on the back just posterior to the second $\mathrm{V}$; a very strong glandular fold from the eye to the shoulder. Brown above, with a triangular mark on the top of the head and an X-shaped dark mark on the back; a dark band capping the end of the snout as far as the nostril, and then becoming a narrow line to the anterior region of the upper eyelid from
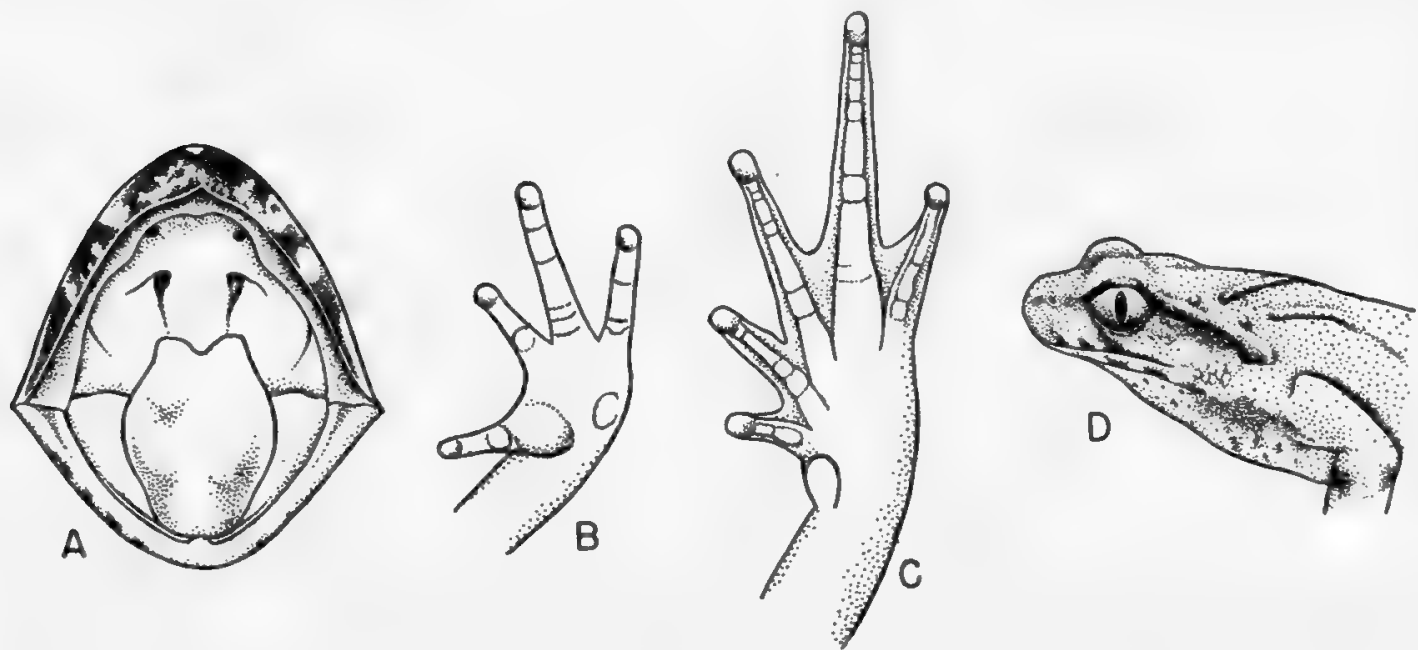

FIG. 40. Megophrys shapingensis. A. Oral cavity $(\times 11 / 2)$. B. Ventral view of hand $\left(\times 1 \frac{1}{2}\right)$. C. Ventral view of foot $\left(\times 1 \frac{1}{2}\right)$. D. Lateral view of head $(\times 1)$.

the posterior part of the eyelid; a wide black band running along the glandular fold to the shoulder; dark bars on the margins of the lips, the largest one entering the orbit; limbs with irregular dark cross-bands; a large light-colored spot on the posterior aspect of the thigh; posterior belly whitish; throat, breast and anterior belly with a gray ground color marbled with light-edged spots; a distinct light-edged dark mark from the ventral side of the angle of the jaw to the anteroventral portion of the upper arm.

Discussion.-In two specimens in amplexus collected during the breeding season, the male is distinctly smaller than the female, the lengths being 68 and $94 \mathrm{~mm}$. The relative length of the arms and legs, and especially of the latter, is much greater in the male than in the female. The female is much darker than the male, especially on the throat, breast and belly, which are dark and much marbled with still darker color. There is no nuptial pad in the male. In the male there are many light-colored granules, each provided with a black spine in the center, scattered on the posterior belly and the ventral sides of the thighs, and much more numerous at the posterior sides of the femurs; such spiny warts are also found posterior to the eye and below the glandular fold.

This new frog can be easily distinguished from lateralis, as the tympanum is hidden, the tibio-tarsal articulation only reaches the eye, the hinder side of 
the thigh is not dark brown, and the male has no vocal sac or nuptial pad asperities, which are found in lateralis. This new frog is not difficult to distinguish from boettgeri, minor, and kuatunensis, as it is much larger, has the tympanum hidden, and is without vocal sac and nuptial asperities in the male. The projecting snout can be used as one of the characters to distinguish it from pelodytoides, weigoldi, boulengeri, hasseltii, and carinensis.

Megophrys shapingensis: Measurements of Type (Male) and Paratype (Female)

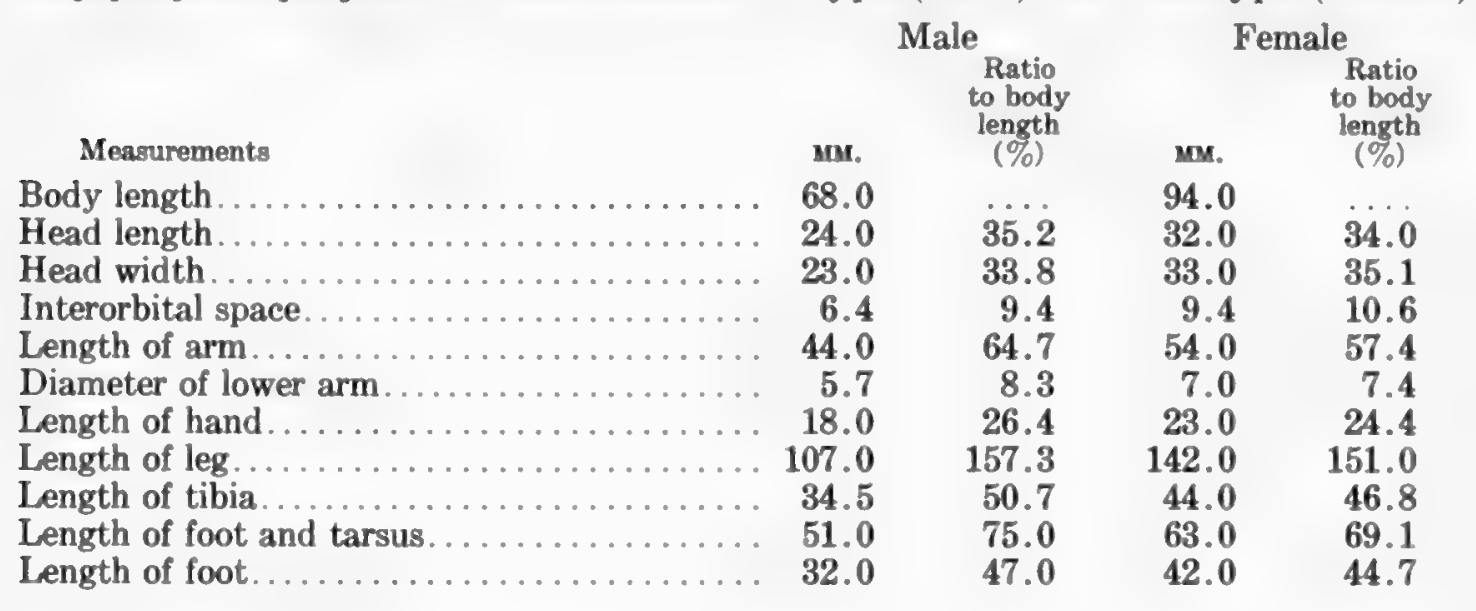

\section{Megophrys carinensis Boulenger}

Leptobrachium carinense Boulenger, 1889, Ann. Mus. Genova, (2), 7: 748-Karin Hills, Burma; Sclater, 1892, Proc. Zool. Soc. Lond., 1892: 347; Boulenger, 1893, Ann. Mus. Genova, (2), 8: 345, pl. 12; Annandale, 1911, Rec. Indian Mus., 6: 215.

Megalophrys carinensis Boulenger, 1908, Proc. Zool. Soc. Lond., 1908: 427.

Megophrys carinensis Pope and Boring, 1940, Peking Nat. Hist. Bull., 15, pt. 1: 30.

History of species.-After the original description of the species, Sclater (1892) re-identified Blyth's montana from western Yunnan as carinensis and in 1911 Annandale reported a specimen from Hsiakwan, Yunnan.

Distribution and collection data.-In China this handsome frog is found only in Yunnan. The center of speciation of carinensis is possibly in northern Burma, its range extending into Yunnan and Siam. I collected no material.

Comparison with related species.-Megophrys carinensis is a distinct species. The greatly widened head distinguishes it from all other Chinese species of Megophrys.

Original description.- "Vomerine teeth none. Tongue large, pyriform, slightly nicked posteriorly. Head enormous, nearly twice as broad as long, extremely depressed, semicircular in outline; the length of the snout equals the diameter of the eye; nostril equally distant from the eye and from the middle of the upper lip, which does not project beyond the lower; interorbital space nearly twice as broad as the upper eyelid, scarcely concave; loreal region slightly 
concave; canthus rostralis well-marked; temporal region very oblique; no distinct tympanum. Habit very stout, limbs short. Fingers and toes short, with slightly swollen tips; first finger not extending beyond second; toes one third webbed; no subarticular tubercles; a very large, oval, flat inner metatarsal tubercle. The tibio-tarsal articulation reaches the axilla in the female, the commissure of the mouth in the male; the tarso-metatarsal articulation reaches the commissure of the mouth in the female, the posterior border of the orbit in the male. Sides of body with irregular flat warts; on oblique dermal ridge, directed outwards and backwards, on each side of the anterior half of the back, some irregular ridges or small scattered tubercles on the posterior half; a strong dermal ridge from the eye to the shoulder; upper eyelid with two to four 'horns,' or long conical tubercles; stellate bony deposits in the skin of the parietal region and of the anterior part of the back; a transverse fold separates the head from the body; slight oblique dermal ridges across the limbs; throat finely granulate, belly nearly smooth. Yellowish, with the back between the dermal ridges purplish-grey; the eyes, the dorsal ridges and the larger lateral tubercles bordered with black; a blackish streak across the interorbital region; some of the lateral tubercles pure white; limbs purplish-grey, hands and feet carneous; gular region purplish black. Male with an internal vocal sac.

"From snout to vent: male, 115 millim.; female, 168."

\section{Megophrys oshanensis sp. nov.}

Type--No. 1000 Liu Collection, from Mount Omei, Szechwan, 3,500 feet altitude. Adult male, collected June 10, 1945, by Ch'eng-chao Liu.

Diagnosis.-This mountain form is closely related to Megophrys pelodytoides, from which it can be distinguished by the following characters: oshanensis has no webs between the toes, and the male has paired internal subgular vocal sacs, whereas in pelodytoides the toes are one-third webbed and the male has an internal single subgular vocal sac. The tadpole of oshanensis differs from that of pelodytoides as the former has no notch between the upper and lower lips and the latter has a deep notch. There are four rows of labial teeth on the upper lip in oshanensis and five and six rows in the Siam specimens of pelodytoides.

Description of type. - Size small, body somewhat depressed and moderately stout (fig. 41, A); head as long as broad, with snout slightly projecting; tongue (fig. 41, B) broad, free behind and deeply nicked, no vomerine teeth; choanae large, with two small depressions anterior to and between the choanae; canthus rostralis well defined; loreal region concave, oblique; nostrils nearer to the tip of the snout than to the anterior corner of the eye; the angle of the mouth only reaching the anterior border of the tympanum, which is very distinct.

Arm weak, fingers (fig. 41, C) moderately slender, the first slightly shorter than the second, which is equal in length to the fourth, the third finger the longest; no nuptial pad developed on any of the fingers; tips of fingers rounded and slightly dilated; no subarticular tubercles, but the third with pad-like 
elongated elevations; inner metacarpal tubercle very large, and outer one very small.

Hind limb weak, the tibio-tarsal articulation reaching the middle of the eye, and the tibia about 43 per cent of the body length; no webs; subarticular tubercles indistinct, with elongated pad-like elevations; inner metatarsal tubercle well developed; no outer metatarsal tubercle.

Skin smooth, with few fine glandular ridges; a few light-colored warts distributed around the vent; a distinct well-developed ridge from the posterior corner of the eye extending postero-ventrad from the shoulder region; a lightcolored gland on the dorso-basal part of the base of the arm; a rounded white
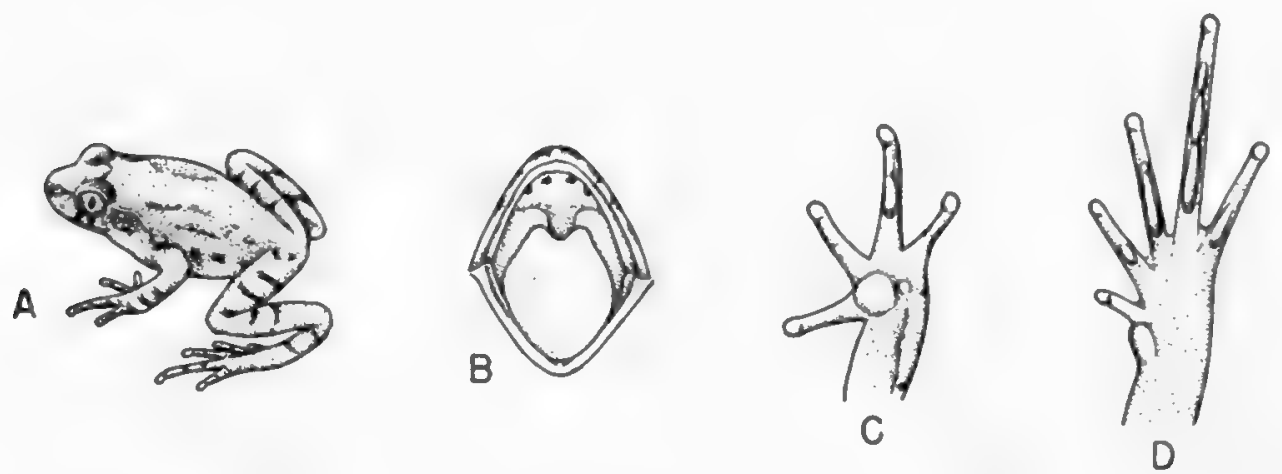

Fig. 41. Megophrys oshanensis. A. Adult $(\times 1)$. B. Oral cavity $(\times 2)$. C. Ventral view of hand $(\times 3)$. D. Ventral view of foot $(\times 3)$.

gland with dark edge on the back of the thigh, nearer to the tibia than the vent; belly very smooth.

Coloration in life.-Reddish brown all over the body, with a black triangular mark on the back of the head, with a few black bars on the mouth, and scattered black spots on the body; black bars are distinctly developed on the limbs and on the fingers and toes. After preservation, the reddish brown becomes grayish brown.

Measurements of type (percentage of body length in parentheses).-Body length $27.0 \mathrm{~mm}$.; head length $9.5 \mathrm{~mm}$. (35.1); head width $9.5 \mathrm{~mm}$. (35.1); length of lower arm $13.0 \mathrm{~mm}$. (46.7); diameter of lower arm $2.0 \mathrm{~mm}$. (7.4); length of hand $7.0 \mathrm{~mm}$. (25.9); length of hind leg $39.0 \mathrm{~mm}$. (143.0); length of tibia 12.0 $\mathrm{mm}$. (43.0); length of tarsus and foot $18.0 \mathrm{~mm}$. (66.9); length of foot $11.5 \mathrm{~mm}$. (41.1); tympanum $1.9 \mathrm{~mm}$. (7.0); length of eye $4.0 \mathrm{~mm}$. (14.7).

History of species.-The closely related species Megophrys pelodytoides was first recorded by Pope (1931, Bull. Amer. Mus. Nat. Hist., 61 : 447) from Sanchiang and Kuatun in the mountains of Ch'unganhsien, Fukien. He mentioned the similarities and differences between the adults and tadpoles of the specimens of Boulenger and Smith and his Chinese material. In 1940, I identified my Mount Omei specimens as pelodytoides and discussed the differences from Pope's 
description and notes. After examination of the Fukien material in New York and Chicago, re-examination of my specimen, and comparison with the original description, it becomes very clear that the Mount Omei form is a distinct species. I have named it for that mountain. I suspect that Mr. Pope's material might be another species of this group. I found no vocal sacs in the male, and the tooth formula of the tadpole is different from the typical pelodytoides tadpole; the notch between the upper and lower lip distinguishes the Fukien tadpoles from those of oshanensis.

Habits and habitat.-Megophrys oshanensis was found under stones in corn fields on hillsides at about 3,500 feet altitude. Adults are difficult to find, as I

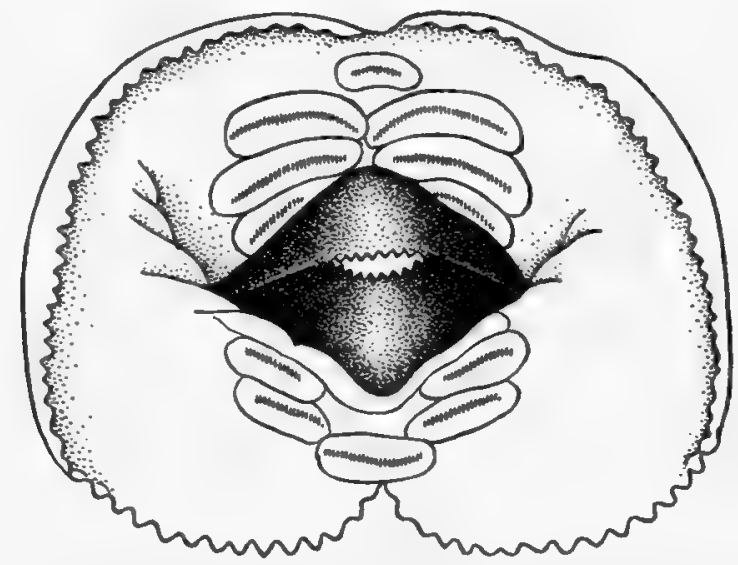

FIG. 42. Megophrys oshanensis; mouth of tadpole $(\times 20)$.

got only two specimens of adult males in three summers' work. Tadpoles are very abundant in small mountain streams.

Tadpoles.-Tadpoles of Megophrys oshanensis (pl. 10, fig. 4) were collected from a side pool of Heilungkiang, Mount Omei, in August, 1938. From June to August, 1940, tadpoles were secured in the pools of small mountain streams, and in pools beneath cascades near Taosze. The tadpoles are elongated, somewhat flattened and eel-like, and are found on the bottom of pools, in cracks between stones, or hiding in vegetation or roots of bamboos and trees at the margin of the water. They stay in shallow running water with the head directed up-stream and the tail curved like an eel. It is very hard to get a large number of them as they are scattered in different parts of small mountain streams. They are good swimmers in running water, their bodies being elongated and flattened, with very strong long tails provided with low thick crests. At any disturbance they hide themselves beneath stones or vegetation. They are difficult to see, as their color is much like that of the red earth or stone in the pools in which they live. They have a habit of resting the body, especially the head, against some object. They are not active and generally lie flat on the bottom, not swimming around as much as other mountain forms. One of the species characters is the enlarged lip (fig. 42), correlated with the cascade habitat, 
a point brought out by Smith (1926), who repeated that the lips serve as an adhesive disk.

In order to observe the function of the enlarged lips, I brought a living tadpole back to the Biology Department of West China Union University. This tadpole lived for nearly a year. The function of the lips can be observed with a hand lens by keeping the tadpole in a clean glass jar with clear water. When the tadpole starts to move, the first indication is the withdrawal of the protruded lips. While it is swimming, the lips are usually folded posteriorly although sometimes they are extended. When it stops, the head and body lie flat on the bottom; but immediately or after a few seconds, the lips begin to expand. Expanding the lips raises the head. When the lips are fully expanded, the papillae on the sides just touch the bottom of the jar, as one might stand on the tips of one's toes. There are two notches, a small shallow one on the median dorsal side of the upper lip, and a large deeper one on the median ventral side of the lower lip. When the sides of the lip are fully expanded, the antero-median area of the lip curves dorsally. Water gets into the mouth through the two notches and the curved area. I conclude that the enlarged lips do not function as an adhesive disk. They form a structure to raise the head for respiration. Another species character is the nostril, which is enclosed by four papillae. They are not movable and cannot close the nostril for protection. Observation in the laboratory indicates that their function is to prevent objects from getting into the nostril, and this may also be correlated with a bottom habitat.

The body has a pale rufous ground color, stippled coarsely with fuscous. The sides and lower half of the sides are lighter, with less stippling. The eye has a round black pupil encircled by a golden iris stippled with black. The tail has a thin rufous brown background color with fuscous stippling, especially on the muscular part; the lower crest is much lighter in color. The belly is colorless.

The body of the tadpole is long and somewhat flattened, with a long tail. Two tadpoles at about the same stage, with hind limb-buds 6.8 and $7.0 \mathrm{~mm}$. long, were measured, and their average length from snout to tip of tail was $60 \mathrm{~mm}$., with a body length of $19 \mathrm{~mm}$. and a tail length of $41 \mathrm{~mm}$. The head is dorsoventrally flattened and its height is only 27 per cent of body length, while its width is 43 per cent. The width of the body is much greater than its height. The tail is long, more than twice as long as the body, with a height of only 43 per cent of the body length; the muscular part is 30 per cent of the body length.

The snout is rounded, with the nostril nearer to it than to the eye. Each nostril is bordered by four colorless conspicuous papillae. The eyes are dorsolateral, the space between them 28 per cent of the body length. The spiraculum is sinistral, ending with a short tube directed upward and backward and visible from above and below. It is near the middle of the body. The skin posterior to the spiraculum on the left side, and on the corresponding part of the right side, is loose and elevated; histological study may throw some light on the function 
of this modified skin. The vent is dextral, with its opening overlapped by a fold that is continuous with the ventral tail crest; on the lower side the crest extends to the vent but on the dorsal side it does not reach the tail base.

The mouth is more ventral than anterior and its width is 26 per cent of the body length. I was unable to find any demarcation between the upper and lower lips such as that which was figured by Pope (1931). The lip is greatly extended laterally and latero-ventrally. A shallow and a deep notch are located on the dorso-median and the ventro-median part of the lip, respectively. There is only one row of papillae on the margin of the lip and no additional ones in the corners of the mouth. Teeth are weakly developed, in short rows, and are located on high, fleshy ridges. Twenty tadpoles have the tooth formula $I: 3-3$ / $\mathrm{I}: 2-2$; four have $\mathrm{I}: 3-3 / \mathrm{I}: 3-3$; two have $\mathrm{I}: 3-3 / \mathrm{I}: 2-3$; one has $\mathrm{I}: 4-3 / \mathrm{I}: 2-2$; one has $I: 4-3 / I: 4-3$; and one has $I: 2-2 / I: 2-2$. The outermost row on the dorsal side is the shortest and is complete; the other three rows are interrupted, the third row being the longest. The outermost row on the lower lip is complete and is the longest; and the second and third rows are widely interrupted. The mandibles are strongly developed, with large mandibular teeth.

\section{Genus BUFO Laurenti}

Taxonomic problems involved in the arrangement of the species of Bufo are among the most difficult among many Chinese amphibian puzzles. Pope and Boring (1940) recognized four distinct species in China. These are the very widespread desert toad raddei in the north, the even more widespread tropical species melanostictus in the south, Bufo bufo gargarizans in central China, overlapping the ranges of both raddei and melanostictus, and a montane subspecies, minshanicus in the west.

From western China, Boulenger (1887) described macrotis from Bhamo, near the very western border of Yunnan. Mocquard (1910) described nouettei from Chachou and Sonchow, Kansu, and Sinkiang. Zarevsky (1925) described tibetanus and tuberculatus from the Kham Plateau and Kokonor (Tsinghai), and brevipes from Kokonor Lake. Stejneger (1926) described minshanicus from Choni, Kansu, and Sungpan, Szechwan. Schmidt (1927) described andrewsi from Likiang, Yunnan. Finally, Schmidt and Liu (1940) described Bufo b. wrighti from Muping, Sikang. Bufo b. gargarizans reaches the Chengtu Plain, being the common toad of lowland western China, and Bufo radde $i$ is a Palearctic form entering the northern part of Szechwan.

On geographical grounds macrotis may be related to andrewsi, but the two are quite distinct forms. Bufo macrotis differs from all other Chinese toads in having vertical bars on the upper lip and cross-bands on the limbs. Pope examined the specimens of macrotis in the British Museum and measured two mature males (36, $39 \mathrm{~mm}$.) and three mature females $(37.5,41.5,46 \mathrm{~mm}$.) and found six poorly preserved tadpoles that have no labial teeth on the upper lip and only 
one row on the lower lip. The small size of the adult and the labial tooth character of the tadpoles of macrotis distinguish it from all other Chinese toads.

Pope and Boring (1940) placed nouettei Mocquard and tibetanus Zarevsky as synonyms of raddei, and regarded Zarevsky's tuberculatus and Schmidt's andrewsi as synonyms of gargarizans. They suggested that minshanicus should be placed in the synonymy of gargarizans, but on account of a specimen collected by $\mathrm{Mr}$. H. C. Chang at Keitaliangsze, Sikang, kept minshanicus as a good species, though with reservations. This specimen now turns out not to be true minshanicus at all, but is a species of the high plateau, Bufo tibetanus Zarevsky, of which tuberculatus is plainly a synonym.

Bufo tibetanus and b. minshanicus inhabit the high mountains and plateaus of western China and are related in having a strongly developed swollen canthus rostralis and globular warts on the top of the head and the upper eyelids. They are medium-sized toads, smaller than either of the other subspecies of $B u f o$ bufo. Bufo tibetanus, like minshanicus, andrewsi, gargarizans, and wrighti, has no large parotoid-like gland on the tibia. The coloration of tibetanus is different from that of all other Chinese toads.

From the study of the types and paratypes of minshanicus and andrewsi, and of the original descriptions of tibetanus, and with my collection of tadpoles and adults referred to tibetanus, my conclusions differ quite radically from those of Pope and Boring (1940). I suggest that minshanicus and andrewsi be placed as subspecies of Bufo bufo. Bufo tibetanus is a distinct species. The elongated weak inner metatarsal tubercle of andrewsi apparently distinguishes it, but the final allocation of this form must be made with more specimens available, and these must include tadpoles, since the tadpole characters have proved to be the key to both relationships and distinctions. Zarevsky described a third species, Bufo brevipes, with some reservation, from a single juvenile specimen.

The complicated topography of western China is the chief factor in the speciation of $B$ ffo in this region.

\section{KEY FOR IDENTIFICATION OF ADULTS OF BUFO}

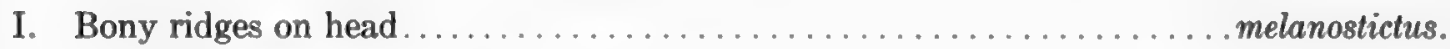

II. No bony ridges on head.

A. Belly not marbled, rarely with black spots; subarticular tubercles not paired; male with internal median subgular vocal sac................... raddei.

AA. Belly generally marbled with black; male without vocal sac.

B. No parotoid-like gland on tibia; a median dorsal bluish stripe.....tibetanus.

BB. Rounded or elongated parotoid-like gland on tibia; no bluish dorsal stripe.

C. Size smaller; large globular tubercles on inner margin of upper eyelid, and on canthus rostralis.................... bufo minshanicus.

CC. Size larger; usually without large globular tubercles on inner margin of upper eyelid or canthus rostralis.

D. Generally with tarsal fold................ bufo wrighti.

DD. No tarsal fold. bufo gargarizans. 
KEY FOR IDENTIFICATION OF TADPOLES OF BUFO

I. Two continuous rows of teeth on upper lip. bufo wrighti.

II. One continuous and one interrupted row of teeth on upper lip.

A. Tail fin black, low, its height about 42 per cent of body length....... tibetanus.

AA. Tail fin nearly colorless and high, its height about 50 per cent of body length.

B. Size larger (body length $19 \mathrm{~mm}$.); body gray................ raddei.

BB. Size smaller (body length $12 \mathrm{~mm}$.); body black......... bufo gargarizans.

\section{Bufo melanostictus Schneider}

Bufo melanostictus Schneider, 1799, Hist. Amph., 1: 216-India orientalis; Boulenger, 1882, Cat. Batr. Sal. Brit. Mus., p. 306; Stejneger, 1907, Bull. U. S. Nat. Mus., 1: 72; Pope, 1931, Bull. Amer. Mus. Nat. Hist., 61: 454.

History of species.-The Indo-Malaysian Bufo melanostictus invades southern China. Boulenger was the first to record this species from Canton and Hongkong. It is so distinct that it does not appear to have been confused with any other form in China.

Distribution and collection data.-Bufo melanostictus is known from Yunnan, Kweichow, Kwangsi, Kwangtung, Fukien, and the Wenchow region in Chekiang. It does not occur in the southwest corner of Szechwan and the southeast corner of Sikang, as far as Sichang and Yenyuan, where I have collected.

Comparison with related species.-The bony ridges on the top of the head of melanostictus distinguish it from all the species of Chinese Bufo. The vocal sac of the male distinguishes it from bufo gargarizans, bufo minshanicus, bufo wrighti, and tibetanus.

\section{Bufo raddei Strauch}

Bufo raddei Strauch, 1876, in Przewalski's Mongoliya i Strana Tungutov, 2, pt. 3: 53-Ordos and Alashan Desert; Stejneger, 1907, Bull. U. S. Nat. Mus., 58: 70 idem, 1925, Proc. U. S. Nat. Mus., 66, art. 25: 8; Liu, 1931, Peking Nat. Hist. Bull., 6, pt. 2: 44; Pope, 1931, Bull. Amer. Mus. Nat. Hist., 61: 459; Pope and Boring, 1940, Peking Nat. Hist. Bull., 15, pt. 1: 31 (part).

Bufo raddii Boulenger, 1882, Cat. Batr. Sal., Brit. Mus., p. 294; Werner, 1904, Abh. Bayer. Akad. Wiss., II Kl., 22, pt. 2: 359.

Bufo raddei var. przewalskii Bedriaga, 1898, Wiss. Res. Przewalski Central Asien Reis., Zool., 3, sec. 1, pt. 1: 48, pl. 1, fig. 6-Kokonor.

Bufo raddei var. pleskei Bedriaga, loc. cit., p. 48-Tola River near Urga, Mongolia.

Bufo nouettei Mocquard, 1910, Bull. Mus. Nat. Hist. Paris, 16: 153-Sachow and Suchow, Kansu; Kashgar, Sinkiang.

Bufo brevipes Zarevsky, 1925, Ann. Mus. Zool. Acad. Sci. USSR., 26: 76 -Ji-us-shan, Lake Kuku-nor.

History of species.--The synonymy above gives a history of Bufo raddei. This Siberian and Mongolian toad is closely related to Bufo viridis, and this has led Bedriaga and Nikolski to misidentify specimens from northern China and Mongolia in the Petrograd Museum as Bufo viridis. The great number of species and subspecies of toads described by Bedriaga, Mocquard, and Zarevsky 
from the specimens from Mongolia, Ningsia, Kansu, Tsinghai, and Sinkiang are evidently based mostly on individual variations of raddei. Pope examined the types of Mocquard's nouettei in Paris, and he found nothing to distinguish them from raddei.

Distribution and collection data.-Bufo raddei is widely distributed in northern and western China. To the south, raddei ranges as far as Taian in Shantung. I collected many specimens from Lanchow to Chiuchuan, Kansu, and around Sining, Tsinghai, during the summer of 1944 .

Comparison with related species.-Bufo raddei can be distinguished from other Chinese species of Bufo by the immaculate cream-colored belly (very rarely
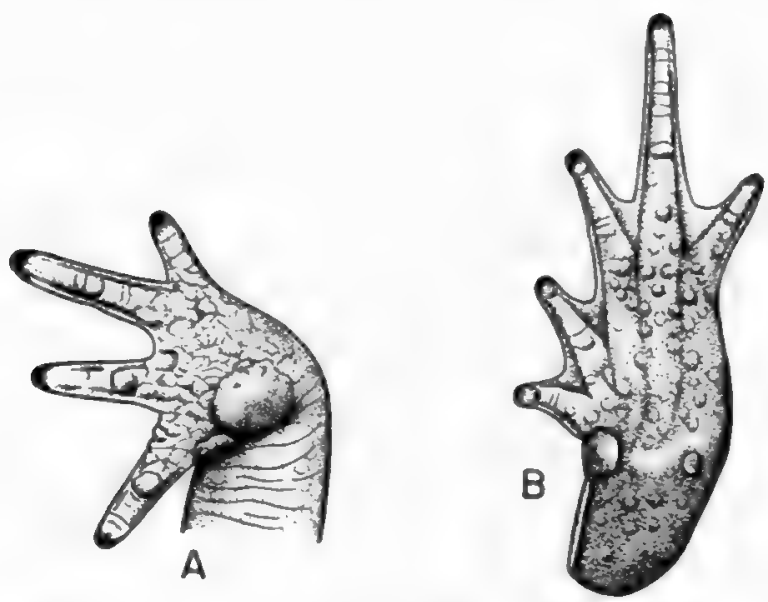

Fig. 43. Bufo raddei $(\times 2)$. A. Ventral view of hand. B. Ventral view of foot.

spotted), and by the internal median subgular vocal sac of the male, since in gargarizans, wrighti, minshanicus and tibetanus there is no vocal sac.

Color in life.-The male is olive yellow on the back with a pale median stripe and irregularly scattered gray warts with deep henna dots. The female has beautiful deep brown markings enclosed by a lighter line on a greenish gray background, with red and gray warts with black dots on the back. This more contrasting brown pattern is constant in the female, very rarely present in the male. The belly in both sexes is cream white, the posterior part grayish blue, and in rare cases there may be rounded dark spots present on the belly. Black or brown markings on the limbs. Tips of digits black (fig. 43).

Sexual dimorphism.- - Sexual difference in size is not conspicuous. The average body length of forty-six adult males is $59 \mathrm{~mm}$., ranging from 45 to 68 $\mathrm{mm}$.; fourteen females have an average body length of $56 \mathrm{~mm}$., ranging from 48 to $82 \mathrm{~mm}$. Pope (1931) states that males are considerably smaller, which does not seem to be the case. In males the skin is much more rugose and warts are much more numerous, with groups of dark or deep brown spines; numerous small nuptial pads are scattered over the inner region of the arm and the whole surface of the inner palmar tubercle, which is larger than in the female; more strongly 
pigmented patches are found on the inner dorsal surfaces of the first, second, and third fingers; the arm is stronger and strongly bent; the fingers are slightly fringed and the first finger is strongly curved toward the palm; and a median internal subgular vocal sac is developed. There are no lineae masculinae.

Habitat and habits.-From 1927 to 1930, I had the opportunity to make field studies of Bufo raddei around Peiping, at Mukden, and at Taian, Shantung,
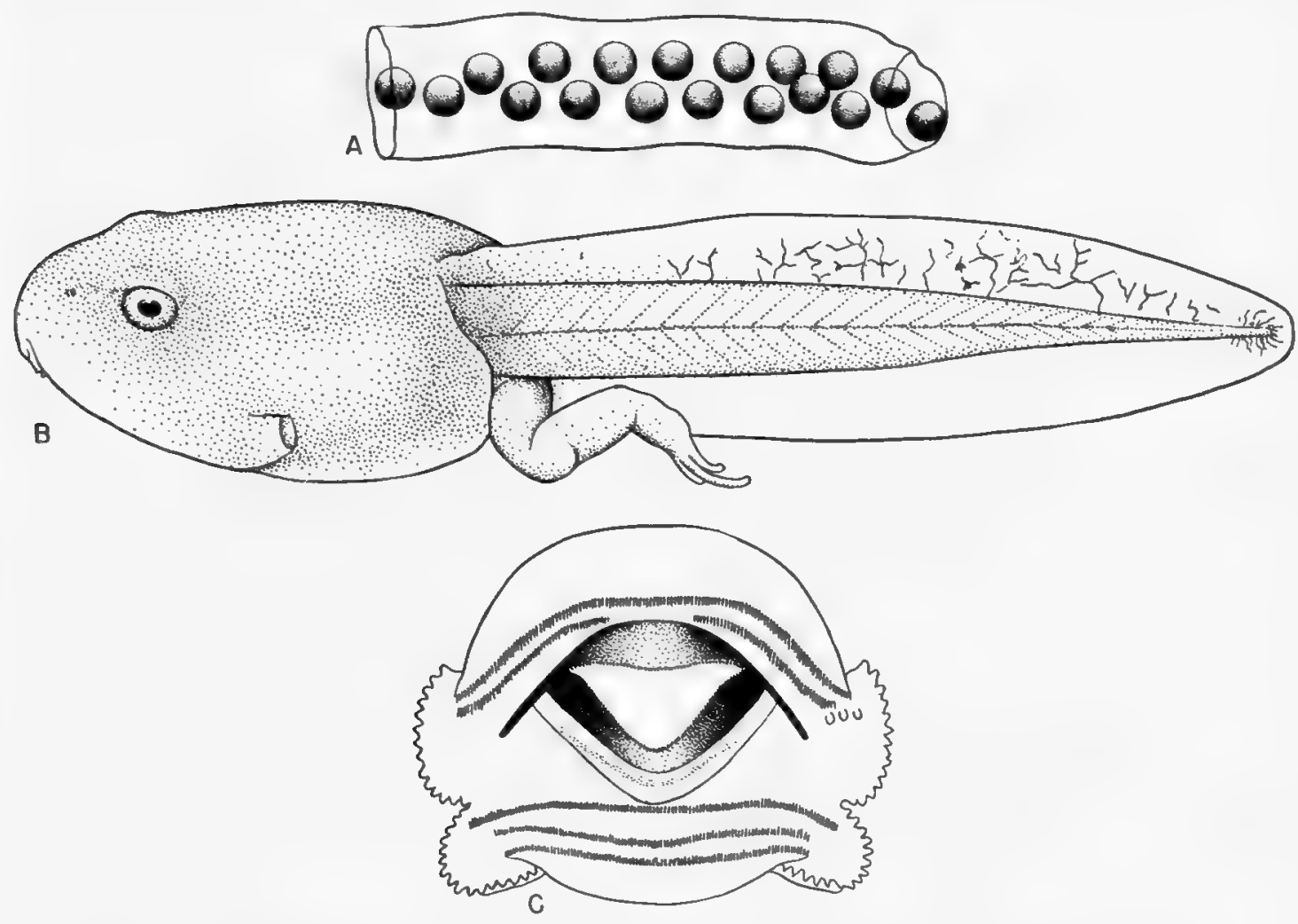

Fig. 44. Bufo raddei. A. Segment of a strand of eggs $(\times 3)$. B. Tadpole $(\times 3)$. C. Mouth of tadpole $(\times 15)$.

(Liu, 1930a, b, 1931). In western China I collected adults, tadpoles, and eggs in Kansu and Tsinghai. Adults were found near ponds and pools, especially at twilight.

The breeding season of Bufo raddei seems to be from May to July. I found paired individuals and eggs, and also advanced stages of tadpoles in a ditch outside of Chiuchuan City, Kansu, July 15, 1944. At Peiping, this toad normally breeds in April.

Eggs.-The egg-strings (fig. 44, A) are laid in ditches, pools, or ponds. The egg is small, about $1.5 \mathrm{~mm}$. in diameter, with a black animal pole and a brown vegetal pole. Each egg is enclosed by a thin envelope of jelly, and the eggs are generally arranged in two rows enveloped by a jelly tube. The "strings" of eggs usually extend over reeds or other objects in the water. 
Tadpole.-Tadpoles are found in the same situations and more rarely may be found in slow-running water. The back and sides of the body and the muscular portion of the tail are dark gray, much darker in the young tadpoles than in those with hind legs well developed. The belly and the tail fins are cream white, except that the dorsal tail fin is slightly colored by capillaries.

The tadpoles (fig. 44, B) of this species are rather stout, and are larger than the tadpoles of Bufo b. gargarizans, Bufo b. wrighti, and Bufo tibetanus. In ten tadpoles collected from Huihuipao, Chiuchuan, Kansu (average hind-limb length $10.7 \mathrm{~mm}$.), the average length from tip of snout to tip of tail is $49 \mathrm{~mm}$., ranging from 46 to $52 \mathrm{~mm}$., with an average body length of $19 \mathrm{~mm}$. and an average tail length of $30 \mathrm{~mm}$. The width of the head is more than half of the body length; its height is only 38 per cent of that length. The body is very stout, its width being 69 per cent of the body length and its height 56 per cent. The tail has a blunt tip, with dorsal and ventral fins about equally developed. The length of the tail is 162 per cent of the body length. The depth of the tail fin is much greater than that in the tails of other Bufo in western China, though the tail muscle is weak.

The snout is rounded, and the nostril is enclosed by a ring slightly nearer to the anterior corner of the eye than to the tip of the snout. The eyes are dorso-lateral, more dorsal than lateral, and the space between them is 26 per cent of the body length. The spiraculum is sinistral, with an incomplete tube free at the posterior end, directed upward and backward and visible from above and below. It is nearer to the base of the tail than to the tip of the snout, 64 per cent of the body length from the tip of the snout to the spiraculum. The vent is median.

The mouth (fig. 44, C) is ventral, its width 23 per cent of the body length. There is a single row of small papillae at the sides of the mouth, with rarely some extra papillae at the corners of the mouth. The labial teeth are constant in arrangement, on the upper lip two rows of teeth, the inner row widely interrupted, and on the lower lip three continuous rows, of which the innermost is the longest. The mandibles are stronger than the mandibles of Bufo b. gargarizans and Bufo $b$. wrighti, with fine sharp teeth on the edges.

\section{Bufo raddei: Measurements of Ten Tadpoles from Kansu}

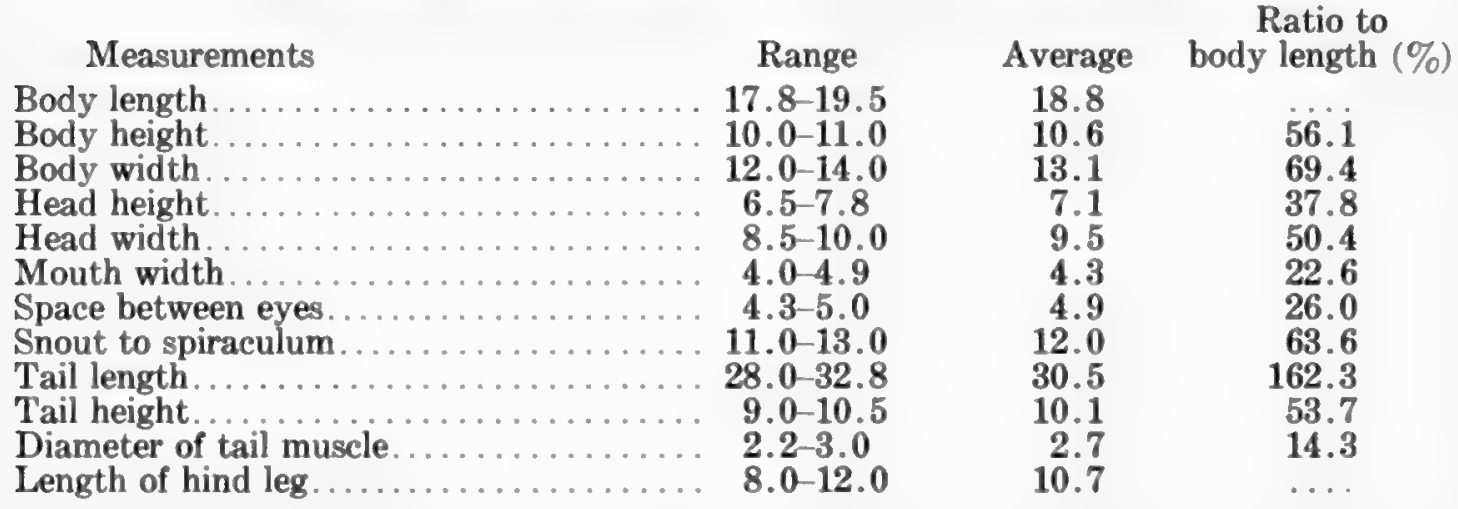




\section{Bufo tibetanus Zarevsky}

Bufo vulgaris Günther, 1896, Ann. Mus. Zool. Acad. Sci. St. Petersburgh, 1: 207 (not of Laurenti).

Bufo tibetanus Zarevsky, 1925, Ann. Mus. Zool. Acad. Sci. USSR., 26: 74-Kham Plateau.

Bufo tuberculatus Zarevsky, 1925, op. cit., p. 75-Kham Plateau.

Bufo raddei Pope and Boring, 1940, Peking Nat. Hist. Bull., 15, pt. 1: 32 (part).

History of species.-Zarevsky's material consisted in part of old specimens collected by Potanin in 1893 and partly of specimens from Kozlov's expedition of 1900 and 1901. Potanin's five specimens are the same that Günther (1896) referred to Bufo vulgaris [Bufo bufo]. Günther remarks: "But I have long hesitated, and still feel some uncertainty, with regard to three other specimens obtained by Potanin in the mountains of Kham. They are covered above and below with deep-black spots, have somewhat broader webs between the toes, and possibly a metatarsal fold .... Unfortunately, the specimens are in a poor state of preservation, so that, if they were of another species, the distinctive characters could not be pointed out. Two other examples found in the same locality by the same traveller are much paler in coloration, and have the lower parts uniform whitish."

Zarevsky described three species of toads in his 1925 paper. Bufo tibetanus was based on three specimens collected by Potanin from the Kham Plateau, together with eight of Kozlov's specimens from "Tibet, Kham, Jeni-tan, riv. Dsa-tshu." In the same paper Zarevsky described Bufo tuberculatus from two of Potanin's specimens and two of Kozlov's male specimens from the mountains of "Ji-us-shan," Lake Kokonor.

The essential characters of tibetanus and tuberculatus are the same, and part of the material came from the same locality and was collected by the same person in 1893. Variation in coloration, tuberculation, webbing of toes, and nature of the metatarsal tubercles, is common in toads. From Zarevsky's description, tuberculatus appears to be clearly a synonym of tibetanus. Zarevsky stated that both tibetanus and tuberculatus have a strongly developed swollen canthus rostralis and a tubercular upper eyelid. Pope and Boring, however, in 1940, placed tibetanus as a synonym of Bufo raddei and tuberculatus as a synonym of gargarizans.

My own field studies and collecting on the "Kham Plateau" during the summer of 1943, and the collection of sixteen specimens of tibetanus in Chicago Natural History Museum, obtained by Herbert Stevens at Taining, prove that tibetanus is a distinct and valid species. In the characters of the adult, tibetanus is closest to Bufo b. minshanicus; in its tadpole, it is closer to Bufo b. wrighti. It is not at all related to Bufo raddei, the male having no vocal sac, whereas in raddei a median subgular vocal sac is conspicuous.

Distribution and collection data.-Bufo tibetanus is a high plateau toad found in Tsinghai and Sikang, with a vertical distribution from about 10,000 to 13,000 
feet. On July 25, 1929, Herbert Stevens collected sixteen specimens (three adult females, five adult males and eight young) from Taining, Sikang; in 1938, H. C. Chang of West China Union University collected three specimens at Pamei, near Taining. From July 25 to August 29, 1943, I collected various tadpoles, four aduit females, and seventeen adult males around Taining.

Comparison with related species.-Bufo tibetanus (figs. 45 and 46) is more closely related to Bufo b. minshanicus and Bufo b. wrighti than to Bufo b. gar-

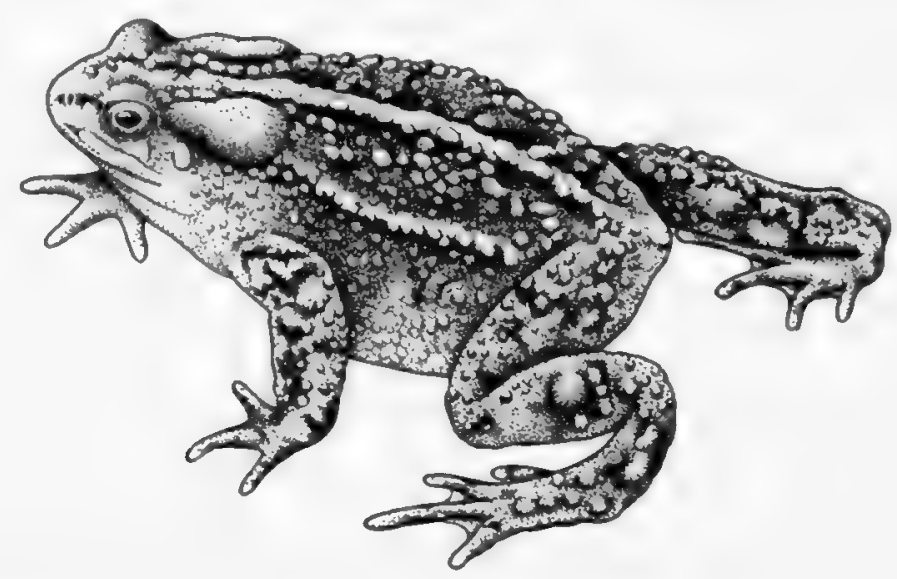

FIG. 45. Bufo tibetanus; adult male ( $\times 1)$.

garizans, but is sharply distinguished by the absence of the tibial gland, smaller size, and a wide bluish gray band on the back on which there are no large warts.

Original description. - "Crown without bony ridges. Snout moderately long and moderately truncated, with strongly developed, swollen canthus rostralis. Interorbital space broader than upper eyelid. Loreal region concave. Tympanum very distinct, oval, about half diameter of eye. First finger extending as far as second or a little beyond. Web between toes extending only as far as basal phalanx of third toe and one half basal phalanx of fourth. Subarticular tubercles on third articulation of fourth toe simple, but may be double, more or less divided, as other subarticular tubercles. Evidently in this species, this character is neither constant nor important. Two metatarsal tubercles, the inner large, compressed, very prominent, the outer small, round, flat. A slight tarsal fold. Tarso-metatarsal articulation reaches anterior angle of eye in males and posterior one in females. Tibia strongly tubercular without parotoid-like gland. Parotoid rather small, its length less than one-sixth of total length of toad, its width less than half of interparotoidal space. Canthus rostralis very swollen. Upper part densely covered with irregularly scattered small warts, intermixed with large prominent ones. Eyelids, interorbital space and snout tubercular. Beneath shagreened with granules on belly and thighs. Males without subgular vocal sac. Total length about $75 \mathrm{~mm}$.

"Colour in alcohol: above olive brown with yellow or greyish stripe on back bordered with dark brown or brown with more or less distinct dark spots 
on sides of back. Beneath yellow or greyish yellow with black markings and spots, sides of body and head and shoulders yellow, greyish yellow or grey with black markings and bands. Members olive-brown with black bands. Females with irregularly scattered carmine red spots, which may be on belly, chest, throat, sides of body and sides of neck, shoulders, thighs and inner surface and on the sides of members."

Coloration in life.--The ground color of the back and dorsal sides of the limbs varies from olive lake to olive brown, with irregular black marbling except
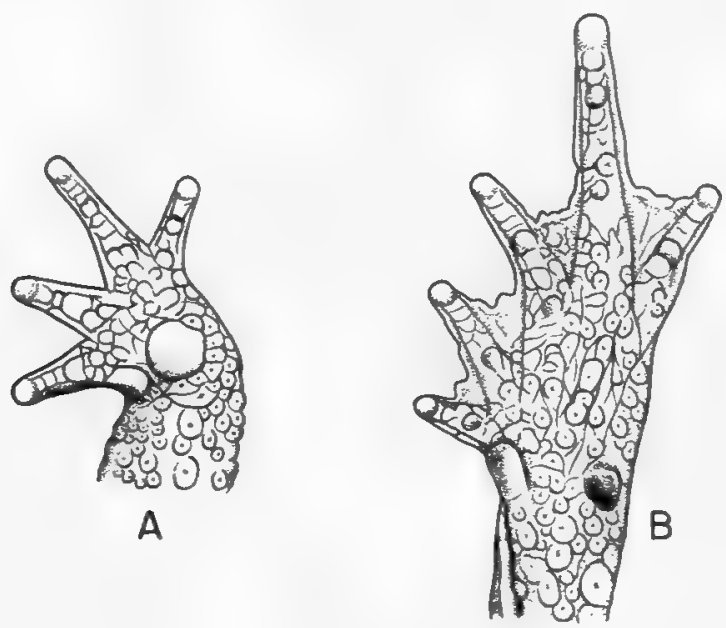

FIG. 46. Bufo tibetanus $(\times 2)$. A. Ventral view of hand. B. Ventral view of foot.

on the wide median bluish gray band extending from the occipital region to the vent. All the specimens I have examined have this wide bluish gray band beneath which the skin is relatively smooth, with only fine glandular granules. A few specimens of bufo wrighti and bufo gargarizans have a dorso-median longitudinal light line, but it is very narrow and completely different from that of tibetanus. The sides are lighter, with more black maculation. Irregular carmine spots are scattered on the sides of the head and body, on the limbs, and even on the throat and belly. The throat is dull cream yellow, together with the belly and ventral sides of the limbs. The pupil is black, horizontally oval, enclosed by a golden ring; the iris is golden but strongly stippled with black.

Secondary sex characters.-The male is smaller than the female, with a stronger arm. Black nuptial asperities are developed on the inner dorsal sides of the first, second and third fingers and on the inner palmar tubercle of the male. No vocal sac or lineae masculinae are developed.

Variation.-The black marbling on the back and belly vary. All the specimens studied have prominent warts on top of the head and more or less of a row of large warts on the inner margin of the upper eyelid. Zarevsky states that there is no parotoid-like gland on the tibia; the larger series now available shows that this is subject to some variation. About two-thirds of the specimens have 
no outstanding large warts on the tibia, but one-third do show some enlarged glands, though never "parotoid-like" and prominent, as in bufo minshanicus, bufo wrighti and bufo gargarizans. The tarsal fold is well developed, but in a few cases longitudinal warts along the tarsal fold make it very inconspicuous.

Habitat and habits.-Bufo tibetanus is found under stones in the fields on the hillsides and a few specimens were collected from small holes in the ground on hillsides not far away from the streams.

Bufo tibetanus: Measurements of Ten Male and Three Female Adults

\begin{tabular}{|c|c|c|c|c|}
\hline Measurements & Sex & Range & Average & $\begin{array}{c}\text { Ratio to } \\
\text { body length (\%) }\end{array}$ \\
\hline Body length. & $\begin{array}{l}\sigma^{7} \\
8\end{array}$ & $\begin{array}{l}51-61 \\
61-67\end{array}$ & $\begin{array}{l}54.2 \\
64.0\end{array}$ & $\ldots$ \\
\hline Head length. & $\begin{array}{l}7 \\
8\end{array}$ & $\begin{array}{l}16-19 \\
20-22\end{array}$ & $\begin{array}{l}17.6 \\
21.0\end{array}$ & $\begin{array}{l}32.5 \\
32.8\end{array}$ \\
\hline Head width. & $\begin{array}{l}7 \\
9\end{array}$ & $\begin{array}{l}19-23 \\
23-27\end{array}$ & $\begin{array}{l}21.1 \\
24.7\end{array}$ & $\begin{array}{l}38.9 \\
38.6\end{array}$ \\
\hline Interorbital space.... & $\begin{array}{l}9 \\
9 \\
9\end{array}$ & $\begin{array}{l}3.8-4.5 \\
5.0-5.8\end{array}$ & $\begin{array}{l}4.0 \\
5.4\end{array}$ & $\begin{array}{l}7.4 \\
8.5\end{array}$ \\
\hline Tympanum. . & $\begin{array}{l}07 \\
9\end{array}$ & $\begin{array}{l}1.9-2.4 \\
2.2-2.8\end{array}$ & $\begin{array}{l}2.2 \\
2.6\end{array}$ & $\begin{array}{l}4.0 \\
4.0\end{array}$ \\
\hline Parotoid length. . & $\begin{array}{l}0^{7} \\
\$\end{array}$ & $\begin{array}{l}8-10 \\
10\end{array}$ & $\begin{array}{r}8.3 \\
10.0\end{array}$ & $\begin{array}{l}15.3 \\
15.6\end{array}$ \\
\hline Parotoid width. . & $\begin{array}{l}07 \\
8\end{array}$ & $\begin{array}{l}5-6 \\
5-6\end{array}$ & $\begin{array}{l}5.2 \\
5.7\end{array}$ & $\begin{array}{l}9.6 \\
8.9\end{array}$ \\
\hline Length of lower arm...... & $\begin{array}{l}0^{x} \\
9\end{array}$ & $\begin{array}{l}23-27 \\
27-30\end{array}$ & $\begin{array}{l}24.0 \\
29.0\end{array}$ & $\begin{array}{l}44.3 \\
45.3\end{array}$ \\
\hline Diameter of lower arm. & $\begin{array}{l}0^{7} \\
9\end{array}$ & $\begin{array}{l}7-10 \\
7-9\end{array}$ & $\begin{array}{l}7.8 \\
7.7\end{array}$ & $\begin{array}{l}14.4 \\
12.0\end{array}$ \\
\hline Length of hand....... & $\begin{array}{l}87 \\
0\end{array}$ & $\begin{array}{l}12-14 \\
15-17\end{array}$ & $\begin{array}{l}12.7 \\
16.0\end{array}$ & $\begin{array}{l}23.5 \\
25.0\end{array}$ \\
\hline Length of leg. . & $\begin{array}{l}0^{7} \\
8\end{array}$ & $\begin{array}{l}63-77 \\
71-80\end{array}$ & $\begin{array}{l}68.8 \\
74.3\end{array}$ & $\begin{array}{l}126.9 \\
116.1\end{array}$ \\
\hline Length of tibia............ & $\begin{array}{l}0^{x} \\
0\end{array}$ & $\begin{array}{l}19-23 \\
21-23\end{array}$ & $\begin{array}{l}20.7 \\
22.3\end{array}$ & $\begin{array}{l}38.2 \\
34.8\end{array}$ \\
\hline Length of foot and tarsus. . & $\begin{array}{l}0 \\
0\end{array}$ & $\begin{array}{l}34-39 \\
35-42\end{array}$ & $\begin{array}{l}35.3 \\
39.0\end{array}$ & $\begin{array}{l}65.1 \\
60.9\end{array}$ \\
\hline Length of foot...... & $\begin{array}{l}0^{x} \\
9\end{array}$ & $\begin{array}{l}23-28 \\
26-29\end{array}$ & $\begin{array}{l}24.4 \\
27.3\end{array}$ & $\begin{array}{l}45.0 \\
42.7\end{array}$ \\
\hline Length of inner metatarsal tubercle. . & o & $\begin{array}{l}3.0-3.5 \\
3.5-4.0\end{array}$ & $\begin{array}{l}3.2 \\
3.7\end{array}$ & $\begin{array}{l}5.8 \\
5.8\end{array}$ \\
\hline
\end{tabular}

Tadpole.-Tadpoles (fig. 47) of this species are found mostly in ponds and pools, generally with rich vegetation. They are bottom-feeding forms. Tadpoles were collected from July 25 to August 2, but no eggs were obtained, indicating a breeding season from May to June.

The tadpole is uniform black except for the tail fin, which is slightly lighter. The coloration of this tadpole is very much like that of the tadpole of bufo wrighti.

The snout is rounded, and the nostril is nearer to the anterior corner of the eye than to the tip of the snout. The eyes are dorso-lateral, more dorsal than 
lateral, the distance between them 22 per cent of the body length. The spiraculum, sinistral and without a free tube, opens upward and backward and is clearly visible from above and barely to be seen from below. It is nearer to the base of the tail than to the tip of the snout. The tail is rounded at the tip, with low tail fins equally developed dorsally and ventrally. The tail muscle is slightly stronger than that of bufo gargarizans and much weaker than that of bufo wrighti.

Adults are much smaller than the adults of bufo gargarizans and bufo wrighti, but the tadpoles of this small toad are larger than the tadpoles of wrighti and

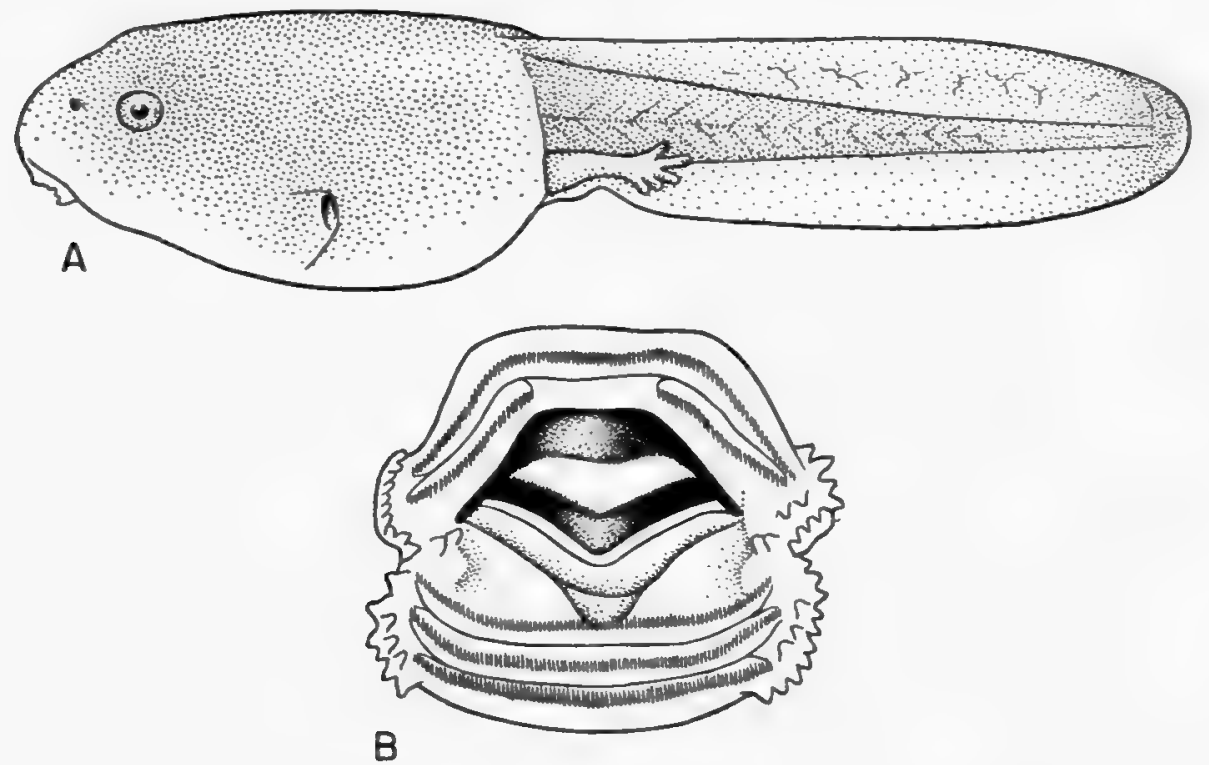

Fig. 47. Bufo tibetanus; tadpole. A. Lateral view (X 4). B. Mouth ( $\times 20)$.

equal to those of gargarizans (see table). The body is longer and the tail shorter and lower than in the tadpoles of Bufo bufo subspp.

The mouth (fig. 47, B) is antero-ventral, directed downward, with an average width of $3 \mathrm{~mm}$., which is 22 per cent of the body length, much smaller than in bufo wrighti, which is found mostly in running water. There is a single regular row of papillae on the margin at the corners of the upper and lower lips, and a few extra papillae are found at the corners of the mouth and the corners of the lower lip. Occasionally a few extra papillae may be found at the corner of the upper lip. The total number of the papillae is fewer in tadpoles of tibetanus than in those of wrighti. There are two rows of labial teeth on the upper lip, the outer row continuous and the inner row discontinuous and the series widely separated. On the lower lip, there are three continuous rows of labial teeth, the outer row slightly shorter than the two inner rows, which are about equal in length. The mandibles are stronger than those of wrighti or gargarizans, and the upper one has a wide median dorsal flattened side. The young just after metamorphosis measures $10 \mathrm{~mm}$. in length from the tip of the snout to the vent. 


\section{Bufo tibetanus: Measurements of Ten Tadpoles}

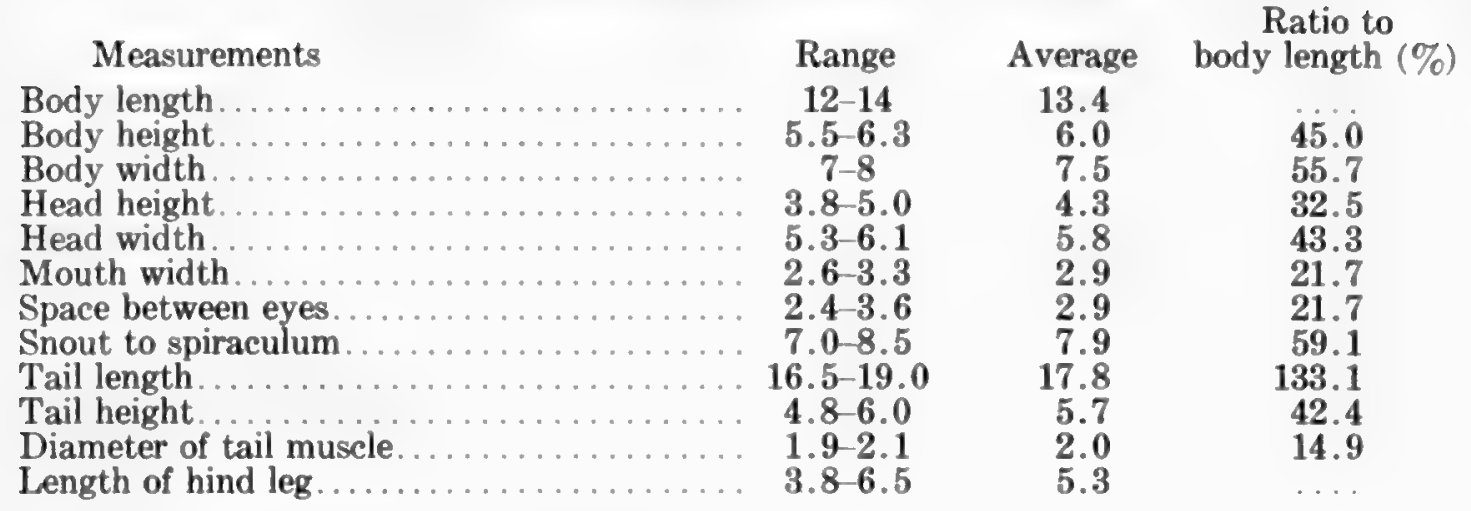

\section{Bufo bufo minshanicus Stejneger}

Bufo minshanicus Stejneger, 1926, Jour. Wash. Acad. Sci., 16: 446 -Choni, on Tao River, Kansu, China; Pope and Boring, 1940, Peking Nat. Hist. Bull., 15, pt. 1: 33 (part).

History of species.-F. R. Wulsin collected the type series of this toad from August 24 to 31, 1923, at Choni, on the Tao River, about 120 miles south of Lanchow, Kansu; D. C. Graham, during his trip to Sungpan, Szechwan, in 1924, also collected specimens, which were referred to the same species in the original description.

Distribution and collection data.-I have collected no material of this species. It is still known only from Choni, Kansu, and Sungpan, Szechwan. Its vertical distribution seems to be from 8,000 to 10,000 feet.

Comparison with related species.-Bufo bufo minshanicus is related to $B$. tibetanus by the character of the tuberculate eyelids and the canthus rostralis, but differs in having a quite different coloration and a large parotoid-like gland on the tibia. The elongated warts on the canthus rostralis and the prominent warts on the top of the head and the inner margin of the upper eyelid distinguish minshanicus sharply from other subspecies of Bufo bufo, and from all the Chinese toads except tibetanus.

Description of type (U.S.N.M. No. 68567).-Profile of snout nearly vertical, slightly curved; canthus well marked, covered by an elongate gland continued backward as a series of large almost globular warts on inner edge of upper eyelid; loreal region slightly concave; nostrils near tip of snout, their distance from each other equalling their distance from the eyes, their distance from labial edge, and the width of upper eyelid; interorbital space slightly concave, wider than upper eyelid; tympanum distinct, small, about three-eighths the diameter of eye, and half its distance from labial edge; parotoid glands almost continuous with upper eyelid, about two and one-half times as long as wide; forelegs long, extended fingers reaching groin; first and second fingers subequal, fourth slightly shorter, third longest; two enlarged palmar pads not prominent, outer three times as large as inner, separated by two rows of granules; heels not meeting when folded 
legs are placed perpendicular to axis of body; toes about half webbed, web extending beyond base of penultimate phalanx of third toe and to tip of basal phalanx of fourth toe; two metatarsal tubercles subequal in size; inner one very prominent, conical, compressed, about two-thirds the length of the fifth toe; a tarsal fold barely indicated; subarticular tubercles under fourth toe double; skin above finely granular with scattered large smooth oblong to globular glands; on canthus a long narrow gland followed by a continuous series of three large rounded glands on inner edge of upper eyelid and continuous posteriorly with the parotoid; frontal, interorbital and interparotoid space with large rounded glands as large as the largest on the back, many of them, especially a series on the line between back and sides, larger than tympanum; sides of face strongly tubercular; on upper side of tibia several large glands, the median one being particularly large and as wide as the parotoid; on outer edge of tarsus an elongated prominent gland as long as the diameter of the eye; underside uniformly granular. Color (in alcohol) above brownish gray obscurely marbled with dusky; tip of large warts pale; underside coarsely marbled with black and whitish in about even proportion, sides with a broad blackish brown band irregularly dotted below with small white warts which form a conspicuous patch below posterior end of parotoids; parotoids pale brownish gray, outer lateral third black.

Bufo bufo minshanicus: Measurements of Two Male and Ten Female Paratypes

\begin{tabular}{|c|c|c|c|c|}
\hline Measurements & Sex & Range & Average & $\begin{array}{c}\text { Ratio to } \\
\text { body length (\%) }\end{array}$ \\
\hline Body length...... & $\begin{array}{l}0^{7} \\
q\end{array}$ & $\begin{array}{c}67 \\
72-90\end{array}$ & $\begin{array}{l}67.0 \\
79.4\end{array}$ & $\cdots$ \\
\hline Head length. . & $\begin{array}{l}07 \\
q\end{array}$ & $\begin{array}{c}22 \\
22-26\end{array}$ & $\begin{array}{l}22.0 \\
23.7\end{array}$ & $\begin{array}{l}32.8 \\
29.8\end{array}$ \\
\hline Head width. & $\begin{array}{l}0^{\pi} \\
q\end{array}$ & $\begin{array}{l}24-25 \\
26-32\end{array}$ & $\begin{array}{l}24.5 \\
29.2\end{array}$ & $\begin{array}{l}36.5 \\
36.7\end{array}$ \\
\hline Eye length... & $\begin{array}{l}0^{7} \\
\text { क }\end{array}$ & $\begin{array}{c}7 \\
7-9\end{array}$ & $\begin{array}{l}7.0 \\
8.2\end{array}$ & $\begin{array}{l}10.4 \\
10.3\end{array}$ \\
\hline Tympanum. & $\begin{array}{l}\sigma^{7} \\
q\end{array}$ & $\begin{array}{l}3-4 \\
3-4\end{array}$ & $\begin{array}{l}3.5 \\
3.5\end{array}$ & $\begin{array}{l}5.2 \\
4.4\end{array}$ \\
\hline Parotoid length. & $\begin{array}{l}0^{7} \\
\$\end{array}$ & $\begin{array}{c}15 \\
14-17\end{array}$ & $\begin{array}{l}15.0 \\
15.5\end{array}$ & $\begin{array}{l}22.3 \\
19.3\end{array}$ \\
\hline Parotoid width. & $\begin{array}{l}0^{7} \\
\wp\end{array}$ & $\begin{array}{l}6-7 \\
7-9\end{array}$ & $\begin{array}{l}6.5 \\
7.6\end{array}$ & $\begin{array}{l}9.7 \\
9.5\end{array}$ \\
\hline Length of lower arm... & $\begin{array}{l}0^{7} \\
9\end{array}$ & $\begin{array}{l}31-33 \\
32-41\end{array}$ & $\begin{array}{l}32.0 \\
35.6\end{array}$ & $\begin{array}{l}47.7 \\
44.8\end{array}$ \\
\hline Length of hand. & $\begin{array}{l}0^{7} \\
9\end{array}$ & $\begin{array}{l}17-18 \\
17-22\end{array}$ & $\begin{array}{l}17.5 \\
19.5\end{array}$ & $\begin{array}{l}26.1 \\
24.5\end{array}$ \\
\hline Length of leg.. & $\begin{array}{l}0^{7} \\
9\end{array}$ & $\begin{array}{l}83-89 \\
84-102\end{array}$ & $\begin{array}{l}86.0 \\
92.1\end{array}$ & $\begin{array}{l}128.3 \\
115.9\end{array}$ \\
\hline Length of tibia. & $\begin{array}{l}8 \\
9\end{array}$ & $\begin{array}{l}25-27 \\
24-30\end{array}$ & $\begin{array}{l}26.0 \\
26.6\end{array}$ & $\begin{array}{l}38.8 \\
33.5\end{array}$ \\
\hline Length of foot and tarsus. . & $\begin{array}{l}\sigma^{7} \\
\wp\end{array}$ & $\begin{array}{l}42-46 \\
41-51\end{array}$ & $\begin{array}{l}44.0 \\
45.5\end{array}$ & $\begin{array}{l}65.6 \\
57.3\end{array}$ \\
\hline Length of foot. & $\begin{array}{l}0^{7} \\
\text { \% }\end{array}$ & $\begin{array}{l}35-36 \\
28-35\end{array}$ & $\begin{array}{l}35.5 \\
31.8\end{array}$ & $\begin{array}{l}52.9 \\
\mathbf{4 0 . 0}\end{array}$ \\
\hline Length of inner metatarsal tubercle. . & $\begin{array}{l}0^{7} \\
8\end{array}$ & $\begin{array}{c}4 \\
4-5\end{array}$ & $\begin{array}{l}4.0 \\
4.4\end{array}$ & $\begin{array}{l}5.9 \\
5.5\end{array}$ \\
\hline
\end{tabular}


Variation.-I examined forty specimens, twenty-six from the type locality and fourteen from Sungpan. The series is remarkably uniform. Some are a little paler than others, and a few have the black markings on the belly less extensive, occasionally almost absent. In all, however, the large globular warts on top of the head are very conspicuous, though varying in size and number. The greatest variation is in the tarsal fold, which, though well marked in nearly all the males, is inconspicuous in many of the females. The large gland along the outside of the tarsus is prominent in all specimens. It is occasionally divided into two.

Sex dimorphism.-Males are smaller. The arm of the male is stronger than that of the female, with blackish brown nuptial pads on the inner palmar tubercle and inner dorsal sides of the first, second and third fingers. The leg of the male is proportionately longer than that of the female.

Measurements of type (percentage of body length in parentheses).-Body length $75 \mathrm{~mm}$.; head length $25 \mathrm{~mm}$. (33.3); head width $28 \mathrm{~mm}$. (37.3); eye length $9 \mathrm{~mm}$. (12.0); tympanum $3 \mathrm{~mm} .(4.0)$; parotoid length $14 \mathrm{~mm}$. (18.6); parotoid width $7 \mathrm{~mm}$. (9.3); length of lower arm $33 \mathrm{~mm}$. (44.0); length of hand $19 \mathrm{~mm}$. (25.3); length of leg $93 \mathrm{~mm}$. (124.0); length of tibia $27 \mathrm{~mm}$. (36.0); length of foot and tarsus $45 \mathrm{~mm}$. (60.0); length of foot $31 \mathrm{~mm}$. (41.3); length of inner metatarsal tubercle $4 \mathrm{~mm}$. (5.3).

\section{Bufo bufo wrighti Schmidt and Liu}

Bufo bufo wrighti Schmidt and Liu, 1940, Field Mus. Nat. Hist., Zool. Ser., 24: 151Mouping (=Paohsing), Sikang; Liu, 1940, Peking Nat. Hist. Bull., 15, pt. 2: 165; idem, 1940, Jour. West China Border Res. Soc., 12, (B): 25.

Bufo bankorensis Stejneger, 1925, Proc. U. S. Nat. Mus., 66, art. 25: 7; Schmidt, 1927, Bull. Amer. Mus. Nat. Hist., 56, art. 5: 557 (part).

History of species.--In May, 1931, Floyd T. Smith collected a large series of toads from Paohsing. In 1933, when Mr. Schmidt and I worked on this collection we observed the much better developed webs and longer legs of this toad. Our original description was drawn up in 1935, naming the new toad for our professor Dr. Albert Hazen Wright, of Cornell University, whom we both hold in affectionate regard. The description was laid aside until 1940, when, after I had worked out the life history of this toad and discovered the mouth parts of the tadpole of bufo wrighti to be different from those of bufo gargarizans, we published an amplified description. Mr. Hsia of the Institute of Zoology, National Academy of Peiping, studied the tadpoles of toads of Yunnanfu and found them to be bufo wrighti, not bufo gargarizans. Stejneger's specimens, misidentified as bankorensis in 1925, are within the range of wrighti.

Distribution and collection data.-Bufo bufo wrighti is widely distributed in the mountains between Szechwan and Sikang and in Yunnan. The vertical distribution is from 2,500 to about 9,000 feet. At the north, this toad reaches the grass land of Sungpan, where bufo minshanicus takes its place; to the west 
it is known to reach Chêtotang, southwest of Kangting. In the mountains of Chêto, and beyond this range, Bufo tibetanus is the only toad to be found. To the east, the range of bufo wrighti extends to just west of Kwanhsien. From 1939 to 1945 many adults, eggs and tadpoles were collected from western Szechwan and eastern Sikang.

Comparison with related species.-Bufo bufo wrighti (figs. 48 and 49 ) is closely related to Bufo b. gargarizans and to Bufo b. minshanicus. For comparison,

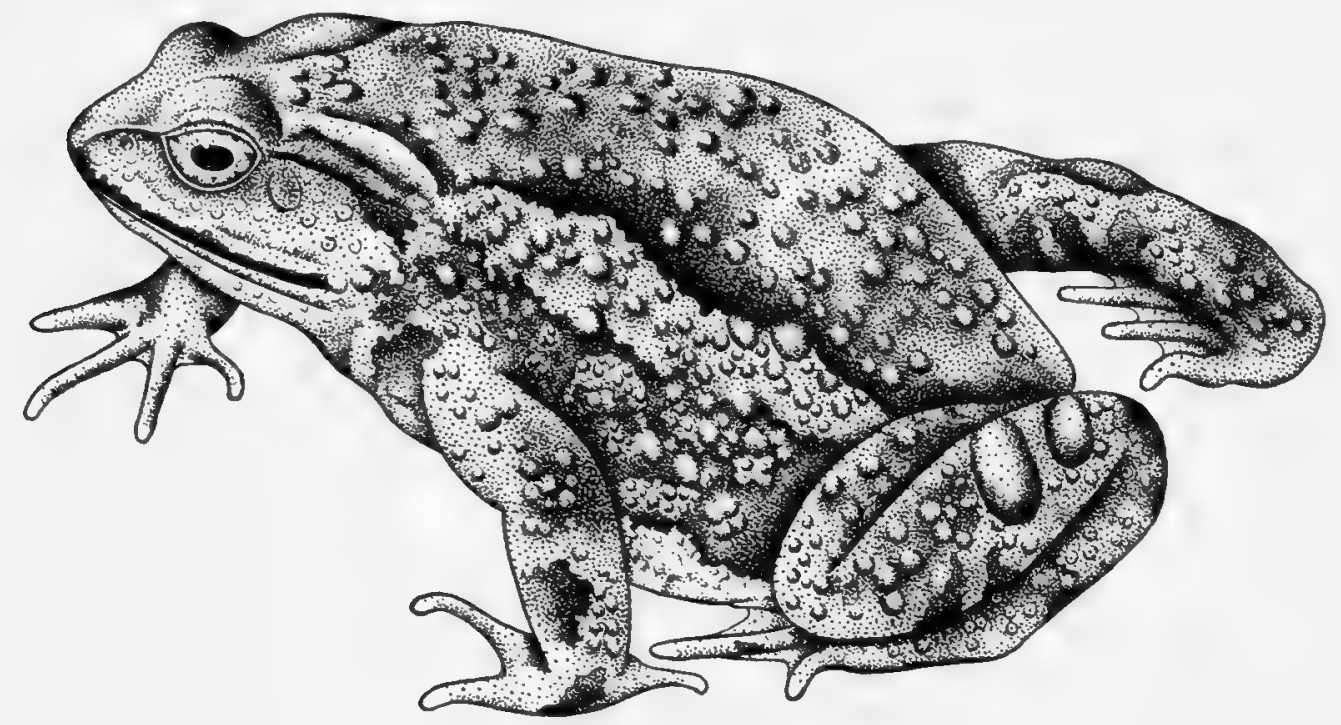

Fig. 48. Bufo bufo wrighti; adult female (× 1).

fifty-eight specimens of wrighti, thirty specimens of gargarizans from various provinces in eastern China, and forty specimens of minshanicus were examined. Ten specimens of wrighti have large tubercles on the upper eyelids, four have warts on the canthus rostralis, and forty-three have a tarsal fold; three specimens of gargarizans have tubercles on the upper eyelid, two have tarsal folds, and none has warts on the canthus rostralis. The tibial gland is found in nearly all of them, so that it is not a subspecific character, as Stejneger thought. Bufo bufo wrighti is considerably larger than minshanicus. From gargarizans, wrighti differs in having longer legs and much more fully webbed toes. There are carmine spots on the sides and belly in wrighti, but not in gargarizans.

The tadpole of wrighti (fig. 50) has a much darker tail, proportionately long, and with a narrower fin than gargarizans (fig. 52). The mouth parts are characterized by the presence in wrighti of two complete labial tooth rows on the upper lip; in gargarizans only the outer tooth row is complete, the inner being widely interrupted.

Original description (somewhat modified).-Head broader than long, snout rounded, with obtuse canthus rostralis; loreal region nearly vertical; nostrils separated by a distance equal to their distance from the eye; legs long; top of 
head smooth, flat; eyelids wrinkled but not tuberculated; tympanum small, oblique, just below the parotoid gland; parotoid glands elongated, wider anteriorly, not kidney-shaped; two very conspicuous post-rictal glands; dorsal surface covered with smooth warts, relatively few in number; large irregular glands on the tibia; a large single gland on the upper surface of the tarsus; fingers

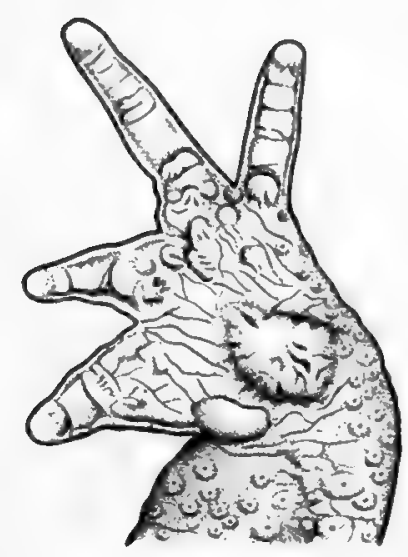

A

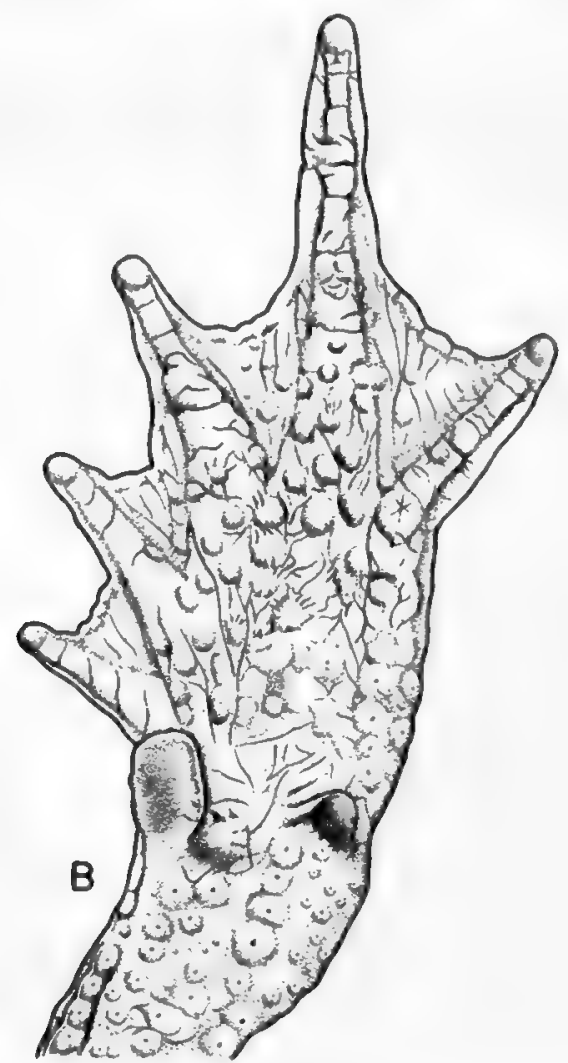

FIG. 49. Bufo bufo wrighti $(\times 2)$. A. Ventral view of hand. B. Ventral view of foot.

free, slightly fringed, first and second equal; toes webbed to the tips except the fourth, which has the three terminal phalanges free but broadly fringed; inner metatarsal tubercle oval, outer rounded; tarsal fold developed; skin of upper surface of body and thighs very loose; forearms much enlarged; belly pale, with indistinct black spots, back dark, without markings.

Measurements of type (percentage of body length in parentheses).-Body length $74 \mathrm{~mm}$.; head length $24 \mathrm{~mm}$. (32.4); head width $29 \mathrm{~mm}$. (39.1); interorbital space $8 \mathrm{~mm}$. (10.8); tympanum $3 \mathrm{~mm}$. (4.0); length of lower arm $41 \mathrm{~mm}$. (55.4); width of lower arm $11 \mathrm{~mm}$. (14.8); length of hand $23 \mathrm{~mm}$. (31.0); length of leg $120 \mathrm{~mm}$. (162.1); length of tibia $34 \mathrm{~mm}$. (45.9); length of foot and tarsus $59 \mathrm{~mm}$. (79.7); length of foot $45 \mathrm{~mm}$. (60.8); length of inner metatarsal tubercle $5.5 \mathrm{~mm}$. (7.4).

Coloration in life.-This toad is olive green to ivy green on the head and back, with dark dorso-lateral markings. The female is usually lighter than the 
male. In the male the back and upper sides of the limbs are the same color, whereas in the female the color of the limbs is lighter than that of the back. Irregular dark markings are more conspicuous in the female than in the male. There are gray bands on the sides of the head and the body in females, with a dark ventral band and carmine spots on the sides. In the male these bands are less sharply defined. The belly is creamy yellow, marbled with black. The digital tips are black or dark carmine.

Sex dimorphism.-Males are smaller than females. In the breeding season, the male has a very loose skin, with black nuptial asperities developed on the inner dorsal sides of the first three fingers and on the inner palmar tubercle. The arm of the male is definitely stronger than that of the female. There is no vocal sac. The lineae masculinae are not developed.

Bufo bufo wrighti: Measurements of Twenty-three Male and Thirty-seven Female Adults

\begin{tabular}{|c|c|c|c|c|}
\hline Measurements & Sex & Range & Average & $\begin{array}{c}\text { Ratio to } \\
\text { body length }(\%)\end{array}$ \\
\hline Body length.... & $\begin{array}{l}0^{7} \\
9\end{array}$ & $\begin{array}{l}63.0-89.5 \\
85.0-116.0\end{array}$ & $\begin{array}{l}73.2 \\
99.8\end{array}$ & $\ldots$ \\
\hline Head length. & $\begin{array}{l}0^{7} \\
\wp\end{array}$ & $\begin{array}{l}18.5-26.5 \\
27.0-34.8\end{array}$ & $\begin{array}{l}22.0 \\
30.9\end{array}$ & $\begin{array}{l}30.0 \\
31.0\end{array}$ \\
\hline Head width. & $\begin{array}{l}0^{x} \\
0\end{array}$ & $\begin{array}{l}21.5-32.7 \\
32.3-42.5\end{array}$ & $\begin{array}{l}25.6 \\
38.5\end{array}$ & $\begin{array}{l}35.0 \\
38.6\end{array}$ \\
\hline Eye length. & $\begin{array}{l}0 \\
9\end{array}$ & $\begin{array}{l}6.3-9.2 \\
8.8-10.7\end{array}$ & $\begin{array}{l}7.8 \\
9.6\end{array}$ & $\begin{array}{r}10.8 \\
9.6\end{array}$ \\
\hline Tympanum. . & $\begin{array}{l}\sigma^{7} \\
9\end{array}$ & $\begin{array}{l}2.2-3.6 \\
2.8-3.7\end{array}$ & $\begin{array}{l}2.6 \\
3.3\end{array}$ & $\begin{array}{l}3.6 \\
3.3\end{array}$ \\
\hline Length of lower arm. & $\begin{array}{l}0^{7} \\
9\end{array}$ & $\begin{array}{l}31.5-46.0 \\
44.0-55.5\end{array}$ & $\begin{array}{l}38.0 \\
49.8\end{array}$ & $\begin{array}{l}51.9 \\
49.9\end{array}$ \\
\hline Diameter of lower arm. . & $\begin{array}{l}8 \\
9\end{array}$ & $\begin{array}{l}7.0-12.0 \\
9.0-14.0\end{array}$ & $\begin{array}{r}9.3 \\
11.7\end{array}$ & $\begin{array}{l}12.8 \\
11.8\end{array}$ \\
\hline Length of hand. & $\begin{array}{l}0^{x} \\
0\end{array}$ & $\begin{array}{l}16.5-23.5 \\
24.0-29.4\end{array}$ & $\begin{array}{l}19.6 \\
27.2\end{array}$ & $\begin{array}{l}26.8 \\
27.3\end{array}$ \\
\hline Length of leg. & $\begin{array}{l}0^{7} \\
\stackrel{+}{+}\end{array}$ & $\begin{array}{r}95.0-125.0 \\
113.0-145.0\end{array}$ & $\begin{array}{l}108.6 \\
129.0\end{array}$ & $\begin{array}{l}148.3 \\
129.3\end{array}$ \\
\hline Length of tibia. & $\begin{array}{l}0^{7} \\
+\end{array}$ & $\begin{array}{l}25.0-36.0 \\
33.3-49.4\end{array}$ & $\begin{array}{l}30.1 \\
39.4\end{array}$ & $\begin{array}{l}41.1 \\
39.5\end{array}$ \\
\hline Length of foot and tarsus. & $\begin{array}{l}\sigma^{7} \\
\$\end{array}$ & $\begin{array}{l}42.0-62.0 \\
55.0-69.0\end{array}$ & $\begin{array}{l}51.8 \\
62.4\end{array}$ & $\begin{array}{l}70.6 \\
62.6\end{array}$ \\
\hline Length of foot. & $\begin{array}{l}8^{7} \\
9\end{array}$ & $\begin{array}{l}27.0-39.0 \\
32.0-43.5\end{array}$ & $\begin{array}{l}33.4 \\
39.2\end{array}$ & $\begin{array}{l}45.6 \\
39.3\end{array}$ \\
\hline Length of inner metatarsal tubercle. . & $\begin{array}{l}\sigma^{7} \\
o\end{array}$ & $\begin{array}{l}3.3-5.5 \\
3.5-6.8\end{array}$ & $\begin{array}{l}4.3 \\
5.8\end{array}$ & $\begin{array}{l}5.8 \\
5.8\end{array}$ \\
\hline
\end{tabular}

Habitat and habits.-Adults of wrighti are found under stones on hillsides. During the breeding season they are found in pools and in ponds near temples or houses or in stationary bodies of water beside mountain streams. The breeding season varies from place to place. In northwestern Szechwan wrighti breeds quite early, perhaps from March to June. I collected tadpoles of early stages about April 25 around Kwanhsien and mature ones from July to August at Paohsing. On May 4, I collected tadpoles and egg-strings around Sichang City, 


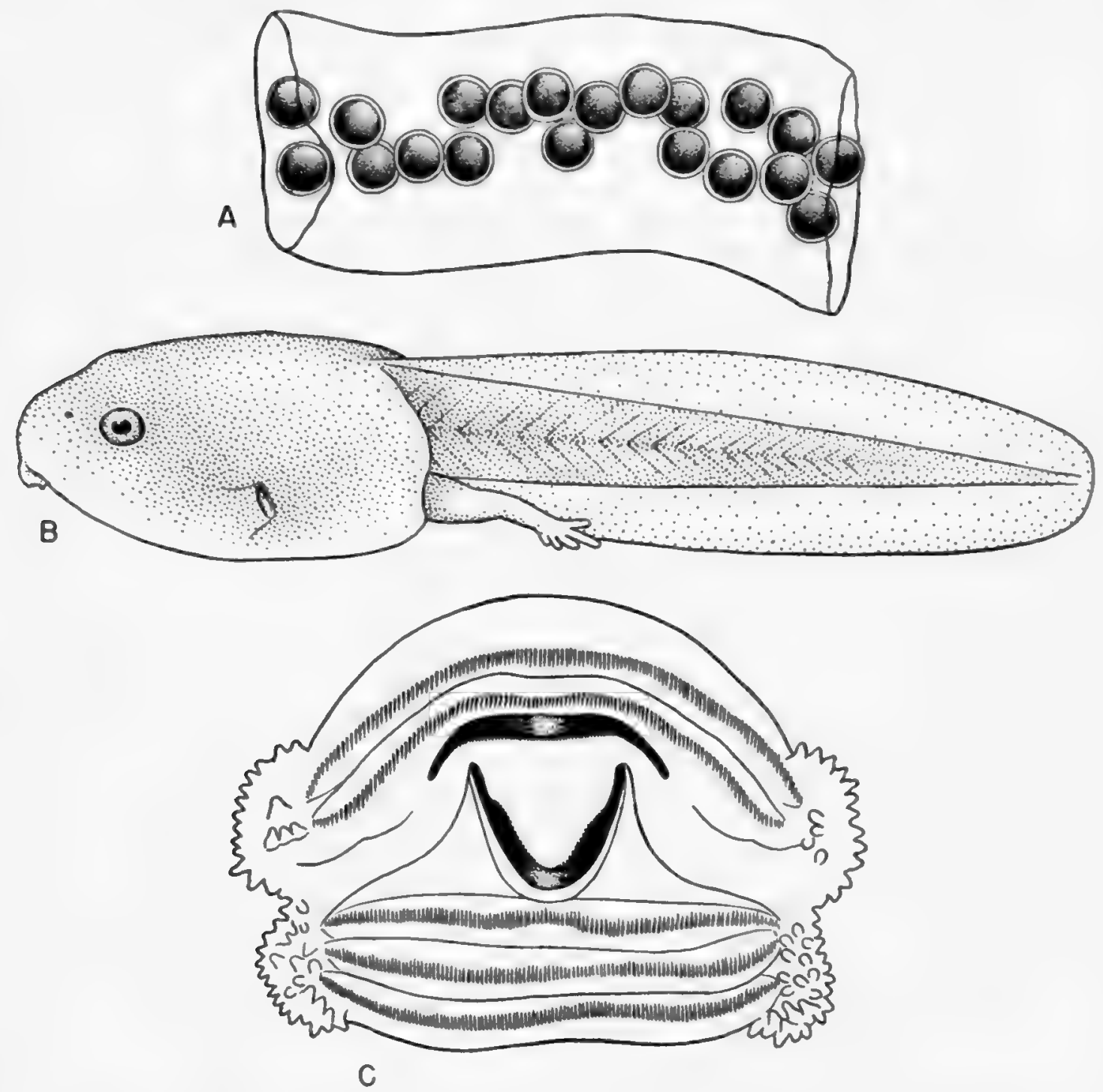

Fig. 50. Bufo bufo wrighti. A. Segment of a strand of eggs $(\times 4)$. B. Tadpole $(\times 5)$. C. Mouth of tadpole $(\times 20)$.

Sikang. Egg-strings (fig. 50, A) are laid in standing water or along the edges of streams. The egg is black, about $2 \mathrm{~mm}$. in diameter, and enclosed by a thin layer of jelly. The eggs are usually arranged in two rows enveloped by a jelly tube.

Tadpole.-Tadpoles (fig. 50, B) of wrighti are generally found on the bottom of the pools and those in streams may be attached to stones by their large mouths. Like tadpoles of gargarizans, they are occasionally found in schools swimming from place to place. They are found singly in running water.

The body is uniformly black above and the belly is dark gray. The muscular part of the tail has the same color as that of the dorsal side of the body, and the 
tail fin is dark gray or nearly black, especially in the basal region. The nostril is slightly nearer to the eye than to the tip of the snout, and is enclosed by a light-colored ring. The eyes are latero-dorsal in position, and much nearer to the tip of the snout than to the spiraculum; this is sinistral and without a tube, just an opening directed upward and backward, with an elevated base. It is visible from above and below and the opening is nearer to the hind limb-bud than to the tip of the snout. The vent, which has a long tube, is at the base of the tail. The tail is blunt at the tip and has equally developed dorsal and ventral fins. The dorsal tail fin is highest at some distance from the tail base. The body is slightly flattened. Twenty tadpoles were measured (see table).

\section{Bufo bufo wrighti: Measurements of Twenty Tadpoles}

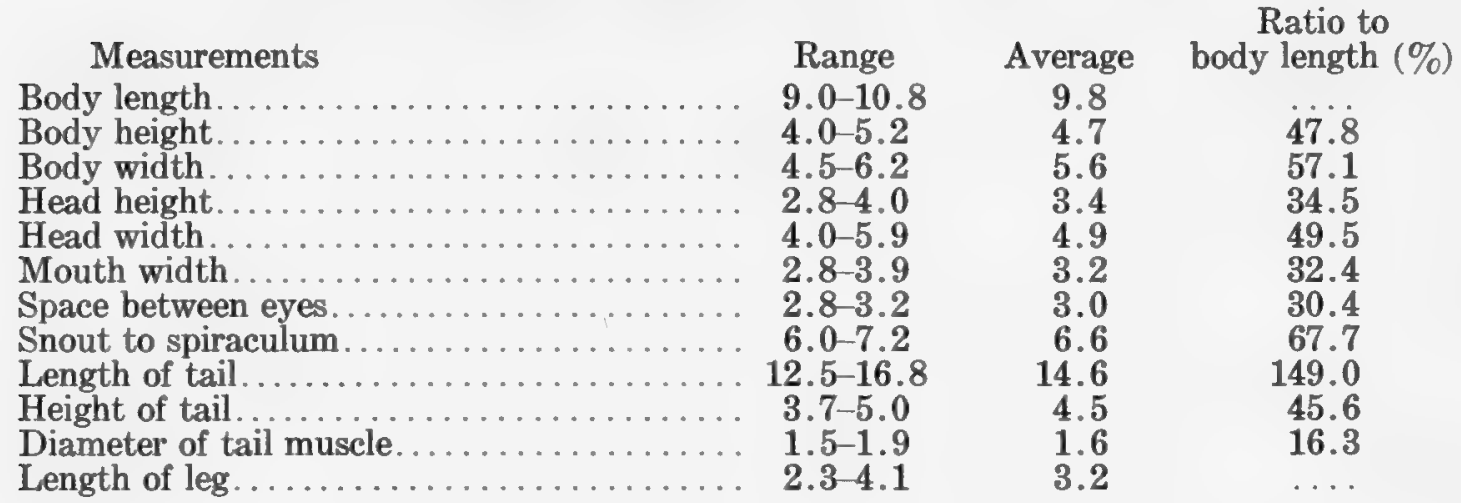

The mouth (fig. 50, C) is a little more ventral than anterior and its average width is $3 \mathrm{~mm}$., a ratio of 32 per cent of the body length. The corners of the mouth are provided with one row of papillae and inside this there are some irregularly scattered ones. The ends of the papillary rows are continuous with the margins of the dorsal and ventral lips, but they are not continuous with the ends of the outermost rows of teeth in either upper or lower lips as in gargarizans. In the upper lip, there are two continuous rows of teeth curved downward at either end. Three continuous rows of teeth are present in the lower lip; of these the middle row is the longest and the outermost row is slightly shorter than the rest. There is no variation in rows of labial teeth within the species. The mandible is moderately developed and has finely serrated edges.

Tadpoles of wrighti and gargarizans differ in habits and in habitat as well as in morphology. Tadpoles of wrighti are found in side pools of large mountain streams and small mountain rivers, and those of gargarizans are found in ponds and pools and sometimes in ditches on the plain. Those of wrighti are distinctly smaller, but with a much larger mouth. The spiraculum of wrighti is much more posteriorly located on the left side of the body than that of gargarizans, which is midway between the snout and the base of the tail. The body of wrighti is slightly flattened and slender while that of gargarizans is slightly longer, with much thinner and wider fins. The dorsal tail fin of wrighti tapers more gradually toward the base of the tail. 


\section{Bufo bufo gargarizans Cantor}

Bufo gargarizans Cantor, 1842, Ann. Mag. Nat. Hist., (1), 9: 483-Chusan, China.

Bufo vulgaris var. asiatica Steindachner, 1869, Novara Exped., Zool., I, Amph.: 39 Shanghai.

Bufo oulgaris japonicus Lataste, 1880, Bull. Soc. Zool. France, 5:506-Peking; Boettger, 1892, Kat. Batr. Mus. Senck., p. 37 (part).

Bufo vulgaris Boulenger, 1880, Proc. Zool. Soc. Lond., 1880 : 569 -(part) Peking.

Bufo japonicus Stone, 1899, Proc. Acad. Nat. Sci. Phila., 51: 183-Tore River, eastern Mongolia.

Bufo bufo asiaticus Stejneger, 1907, Bull. U. S. Nat. Mus., 58: 66.

Bufo bufo gargarizans Stejneger, 1907, Bull. U. S. Nat. Mus., 58: 59; Schmidt, 1927, Bull. Amer. Mus. Nat. Hist., 54: 557; Boring, 1938, Peking Nat. Hist. Bull., 13, pt. 2: 91; Pope and Boring, 1940, Peking Nat. Hist. Bull., 5, pt. 1: 32 (part).

Bufo bankorensis Schmidt, 1927, Bull. Amer. Mus. Nat. Hist., 54: 557 (part, not of Barbour).

History of species.-Boring (1938) published a good account of the variation of this common Chinese toad, and Pope and Boring (1940) give a good account of the history of this subspecies, but miss the fact that Zarevsky's tuberculatus is a synonym of the valid species Bufo tibetanus. Subsequent to their work Schmidt and I described Bufo bufo wrighti, to which Stejneger's West China bankorensis (1925) is evidently to be referred.

The further history of Bufo bufo gargarizans and its relations with the common European toad, Bufo bufo bufo, the relation between the Chinese and Japanese forms and between the northern, southern, eastern and western populations in China, is set forth in Stejneger's papers of 1907 and 1925, and it is reasonable to concede that the relationship of Chinese to European toads is such that both must be considered forms of a single species. That gargarizans from Chusan Island must be identical with the common mainland Bufo of central China was set forth by Schmidt in 1927. In 1931, Chen examined specimens from Chusan (the type locality of gargarizans) and came to the same conclusion. Thus asiaticus is an exact synonym of gargarizans. Mr. Schmidt, unfortunately, confused the problem by identifying the common toad of lowland central China as bankorensis.

The questions as to the validity of Bufo bankorensis Barbour, described from Formosa, and as to its occurrence in Fukien are reserved for further study. Records of bankorensis from other parts of China are obviously to be referred to gargarizans.

Distribution and collection data.-Bufo bufo gargarizans is widespread in China, its range overlapping that of $B$. raddei in the north and that of $B$. melanostictus in the south. On the west, it meets the range of bufo wrighti. From 1938 to 1946 I collected many specimens of adults and tadpoles around Chengtu.

Comparison with related species.-It may be difficult to separate individual specimens of gargarizans and wrighti. The population of one subspecies can be separated from the other, as there is no tarsal fold in gargarizans (fig. 51), while 
in wrighti the tarsal fold is found in most specimens. The web is far better developed in wrighti than in gargarizans. The tadpole of gargarizans has one continuous and one interrupted upper labial tooth row, whereas wrighti has two continuous rows of labial teeth on the upper lip, and the colorless tail fin of gargarizans contrasts with the dark tail fin of wrighti. The presence of a tarsal

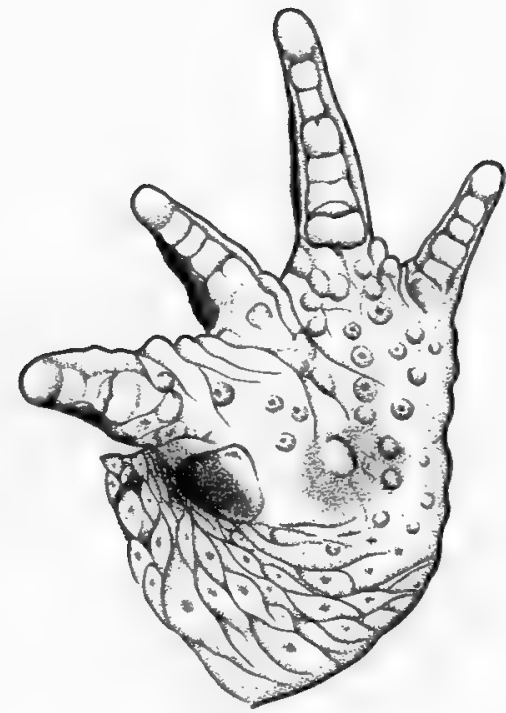

A

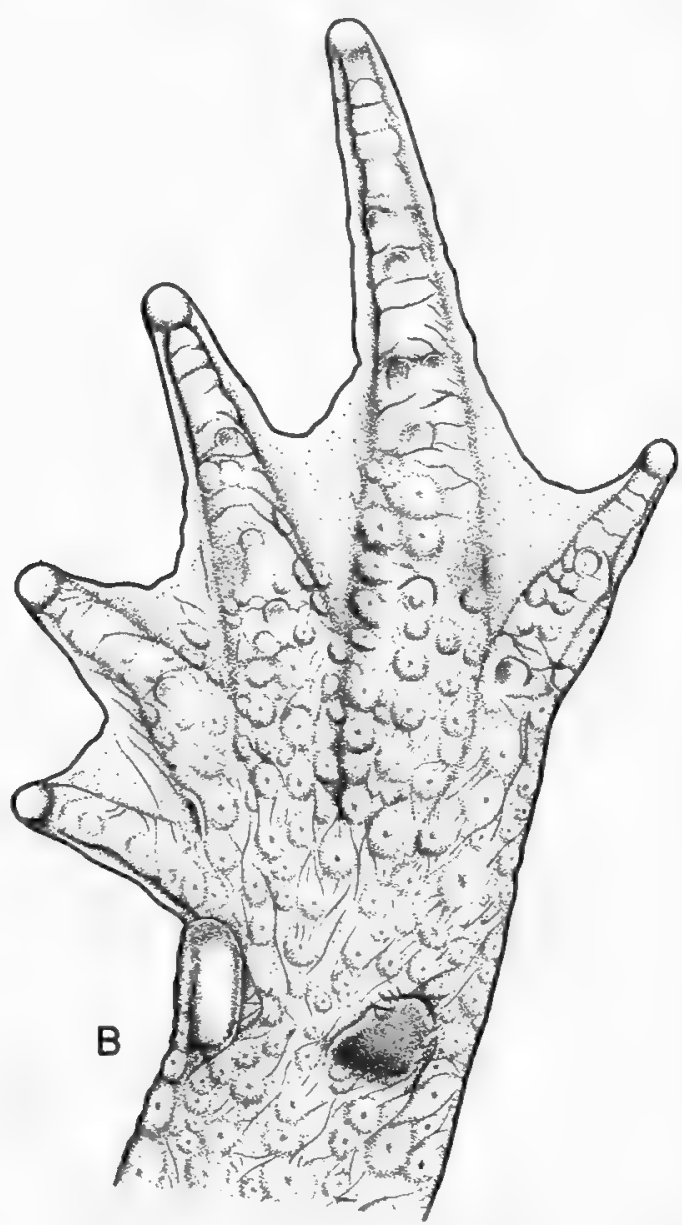

FIG. 51. Bufo bufo gargarizans $(\times 2)$. A. Ventral view of hand of male. B. Ventral view of foot.

fold and of large globular tubercles on the inner margin of the upper eyelid distinguish minshanicus from gargarizans. There is no difficulty in distinguishing gargarizans from melanostictus, tibetanus, and raddei, on the basis of the key characters.

Original description.- "Grayish brown above, with numerous large conical tubercles with black points; the sides grayish lilac; the abdominal surface buff, speckled with black."

Coloration in life.-The coloration of gargarizans varies according to season and sex. During the breeding season the male is dark green on the back and the upper sides of the limbs, while the female is olive green with lighter warts. 
Just before hibernation the coloration is usually light brownish gray with yellowish warts and black spines on the warts. The throat and belly are cream yellow with dark brown or black marbling.

Secondary sex characters.-Males are generally smaller than females. During the breeding season the male has a very loose skin, is darker and more uniform in coloration, and has fewer smooth warts. The light color of the female has a pattern of dark and light band-like stripes on the sides of the body, and the warts are usually provided with spines. The arm of the male is decidedly stronger than that of the female, and is strongly bent toward the thoracic region. Black granular nuptial asperities cover the inner dorsal sides of the first and second fingers, with a small elongated patch on the inner dorsal margin of the third finger. The whole surface of the inner palmar tubercle, which is larger than that of the female, is covered by black nuptial asperities. Lineae masculinae are absent, perhaps in association with the absence of a vocal sac.

Habitat and habits.-Bufo b. gargarizans is associated with man and is found in stone piles and near old buildings. During summer, especially during and after the rain and at twilight, one often sees such a toad walking about slowly, jumping when disturbed, but not capable of very long leaps.

The breeding season in the Chengtu region is in January. The male appears first in the ditches and ponds, and gives voice to its low sharp croaking, by which the females are guided to the breeding aggregation. At the time of egg-laying, the female sinks down to the bottom of the water with the head bent upward and the trunk downward, with the two hind legs outstretched. The male bends his trunk upward and places his hind legs between the legs of the female; the eggs and sperm are discharged at the same time. The whole egg-string is not laid at one time, and during the intervals the female carries the male on her back and moves from place to place among the plants in the water, so that the eggstring is stretched over the vegetation.

The egg is rather small, about $1.5 \mathrm{~mm}$. in diameter, with a black animal pole and a brown vegetal pole. Each egg is enclosed by a thin layer of jelly and these eggs are externally enveloped by two outer jelly tubes.

Tadpoles.-Tadpoles (fig. 52, A) are found mostly in ponds and pools with large amounts of vegetation. Sometimes a few are also found in slow-running water. They are always in schools, led by tadpoles swimming in one direction. This phenomenon is very much like schooling of fishes. It is not unusual to find a few swimming in a different direction, but very soon they come back to the school and follow the group. While feeding, many tadpoles gather on some dead animal or decayed vegetation in the water, looking then very much like a mass of cow dung. They like animal food better than plant food. If a dead cat is put into the water, many of them will come to it very quickly, sucking at the animal with their mouth parts. Their tails swim vigorously to keep them pressed against the dead organism. If vegetation is thrown into the water the reaction is very slow, and generally only a limited number of tadpoles go to it. 
Schooling of the tadpoles is much better shown when the hind legs are well developed.

Twenty tadpoles (average of hind limb-length $3.6 \mathrm{~mm}$.) were measured, the average length being $30 \mathrm{~mm}$., and the average body length $12 \mathrm{~mm}$., ranging from $11.3-12.5 \mathrm{~mm}$. (see table). The muscular part of the tail is only 13 per cent of the body length, the weakest tail among the tadpoles of western China.

The body is black and the belly dark gray to black. The dorsal side of the hind limb-buds and the muscular part of the tail have the same color as the dorsal
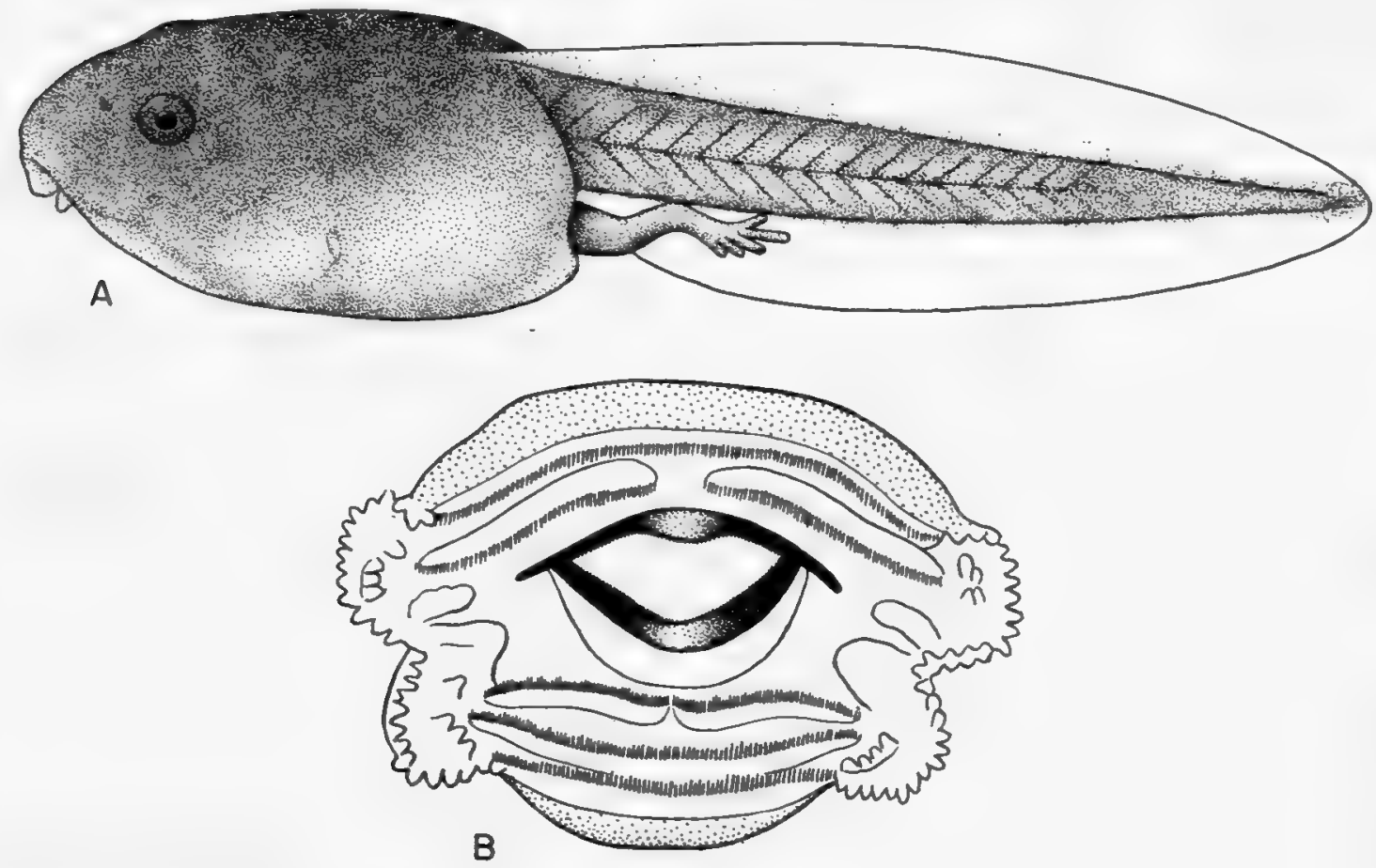

Fig. 52. Bufo bufo gargarizans; tadpole. A. Lateral view $(\times 5)$. B. Mouth $(\times 20)$.

side of the body. The pupil is round and black and is enclosed by a thin golden ring, surrounded by a black iris. The tail fin is white and translucent, with some scattered gray granules. The nostrils, each enclosed by a light-colored ring, are nearer to the eye than to the snout. The eye is latero-dorsal in position, nearer to snout than to spiraculum, and the interorbital space is about one-third of the length of the body from the snout to the base of the tail. The spiraculum is sinistral and without a free tube. Its opening faces upward and backward. It is not visible from above, and can barely be seen from below. It is near the middle of the body. The vent, with a very short tube, is at the base of the tail with the opening directly under the ventral tail fin. The tip of the tail is rounded, and the dorsal and ventral fins are more or less equally developed. The dorsal tail fin is low, near the base of the tail.

The mouth (fig. 52, B) is antero-ventral with an average width (from corner to corner) of $2.8 \mathrm{~mm}$., which is 24 per cent of the body length. Papillae are 
found only at the corners of the mouth. There is a single regular row of papillae on the margin of the corners of the upper and lower lips, and inside of these some extra irregularly scattered ones. The end of each row is continuous with the end of the outermost rows of the upper and lower labial teeth. There are two rows of teeth in the upper lip; the outer row is continuous and the inner row interrupted. In the lower lip, there are three continuous rows of teeth, the outermost row a little shorter than the rest and the innermost row the longest. There is no variation in rows of teeth. A beak, with a serrate edge, is moderately developed.

\section{Bufo bufo gargarizans: Measurements of Twenty Tadpoles}

\begin{tabular}{|c|c|c|c|}
\hline Measurements & Range & Average & $\begin{array}{c}\text { Ratio to } \\
\text { body length (\%) }\end{array}$ \\
\hline Body length....... & $11.3-12.5$ & 11.9 & \\
\hline Body height. & $5.7-6.8$ & 6.3 & 53.0 \\
\hline Body width. & $7.0-8.2$ & 7.6 & 63.9 \\
\hline Head length. & $3.7-4.7$ & 4.2 & 35.3 \\
\hline Head width. & $5.6-6.8$ & 6.0 & 50.5 \\
\hline Mouth width. & $2.6-3.2$ & 2.8 & 23.5 \\
\hline Space between eyes. & $3.3-3.9$ & 3.6 & 30.4 \\
\hline Snout to spiraculum. & $6.5-8.0$ & 7.5 & 63.0 \\
\hline Tail length......... & $16.6-19.0$ & 18.1 & 152.0 \\
\hline Tail height. & $5.2-6.6$ & 6.0 & 50.4 \\
\hline Diameter of tail muscle. & $1.3-1.8$ & 1.5 & 13.0 \\
\hline Length of hind leg. . & $2.7-5.0$ & 3.6 & \\
\hline
\end{tabular}

\section{Hyla annectans Jerdon}

Polypedates annectans Jerdon, 1870, Proc. Asiatic Soc. Bengal, 1870: 84-Khasi Hills. Hyla annectans Günther, 1875, Proc. Zool. Soc. London, 1875: 576; Vogt, 1924, Zool. Anz., 60 : 337; Pope, 1931, Bull. Amer. Mus. Nat. Hist., 61 : 474; Pope and Boring, 1940, Peking Nat. Hist. Bull., 15, pt. 1: 37.

Hyla annectens Boulenger, 1882, Cat. Batr. Sal., Brit. Mus., p. 382.

History of species.-Hyla annectans was described from the Khasi Hills in 1870 and has since been recorded from Burma by Boulenger (1882) and from Tonkin by Parker (1925). Vogt (1924) was the first to record it from Washan, Szechwan. Pope (1931) discussed the species in detail, with thirty-two specimens from Kunyang Hai, near Yunnanfu, at hand. Pope suspected that specimens from Tengyueh, Yunnan, reported as H. chinensis by Anderson (1878), and specimens from Pupiao, western Yunnan, reported under the same name by Annandale (1911), were annectans. Pope and Boring (1940) put Stejneger's (1907) record of chinensis from the Tsingling, Shensi, and Schmidt's (1927) record of chinensis from Yunnan in the synonymy of annectans, concluding that Hyla annectans is a highland form widely distributed in western China.

From April 22 to the end of June, I made a study of the life history of a Hyla I found in the field at Sichang City. I collected also three males, one from Mount Omei and two from Tienchuanhsien, Sikang, and have been privileged to study two good series of specimens in the United States National Museum. These are Nos. 75731-6, collected from Yachow, Sikang, and 68953-69058 from 
Hwangtsaopa, western Kweichow; and in Chicago Natural History Museum there are four males and four females from Kunyang Hai, Yunnan.

The size of individuals of Hyla annectans varies greatly with locality. The number, size, and distribution of the dark spots on the thighs and groin are variable in different groups. I have followed Pope and Boring in putting all of the populations together as Hyla annectans, but I am giving a discussion of the differences between different groups, feeling that a sound taxonomic arrangement must be reserved for the collecting of additional material. I suspect that several subspecies will be found to be recognizable in the topographic regions of western China.

Distribution and collection data.-Hyla annectans is a widely distributed species, ranging from northern India, Burma, and Tongking to western China in Yunnan, Sikang, Kweichow, Szechwan, and possibly Shensi. According to my field study in Szechwan and Sikang, the vertical distribution is from 2,500 to 10,000 feet. From April 22 to the end of June sixty-five males and twentyfive females were collected, mostly around Sichang City; one specimen was obtained from Yenyuan and two from Chaochiaohsien. On July 1, 1943, two males were collected from Lianglukou, Tienchuan, and on June 22, 1945, one male was obtained from Mount Omei.

Comparison with related species.-The invariable presence of dark spots on the sides of the body and the sides of the limbs of $H$.annectans (fig. 53, A) distinguishes this species from $H$. arborea immaculata and $H$. simplex, as the latter two show no trace of any spot. Hyla annectans has a tubercular ridge from eye to shoulder region while $H$. chinensis and sanchiangensis have no such ridge.

Size.-Pope measured eight specimens of the type series of Hyla annectans in the British Museum. The body lengths of the four females are 49, 49, 44, 43 $\mathrm{mm}$.; and of the four males $38.5,37.5,34$ and $30 \mathrm{~mm}$. Five females of the same species, from the Khakien Hills, were measured by Pope as 42.5, 38.5, 35, 32, and $31 \mathrm{~mm}$. (the last not mature), together with three males as $34,34,31 \mathrm{~mm}$. Two large females out of thirty-two specimens from Kunyang Hai, near Yunnanfu, measure 33 and $30 \mathrm{~mm}$. Four females with immature ova and four males with evident external vocal sacs (part of Pope's Kunyang Hai series) are in Chicago Natural History Museum. The females in this series measure 27, 26, 26 , and $24.5 \mathrm{~mm}$., and the males $26,26,26$, and $25 \mathrm{~mm}$. I have measured five adult females $(40,39,37,36$, and $34 \mathrm{~mm}$.) and five mature males $(38,35.5,34.5$, 32.5 , and $31.5 \mathrm{~mm}$.) in the United States National Museum, collected by Graham at Hwangtsaopa, western Kweichow. I collected ten adult males $(33-37 \mathrm{~mm}$.) and five adult females (34-39 $\mathrm{mm}$.) at Sichang. I have also seen three mature males $(36,35$, and $35 \mathrm{~mm}$.$) and one female (32 \mathrm{~mm}$.) from Yaan (Yachow) and one male $(31 \mathrm{~mm}$.) from Tienchuan. The females of the type series are all above $40 \mathrm{~mm}$. in length, whereas none of the female specimens from China are more than $40 \mathrm{~mm}$. Individual populations seem to differ sharply in adult size when the sexes are tabulated separately. 
Variations.-The spots on the arm and postfemoral and inguinal spots exhibit regional variation. It is noteworthy that there are no spots on the anterior aspects of the upper arms in the type series, and in all the specimens from Yunnan, Kweichow, and Sichang, in only 2 per cent of the specimens from the Khakien Hills, and in 4 per cent of the Yachow specimens. On the posterior aspect of the upper arm, 50 per cent of the type series have one spot; 70 per cent of Khakien Hills specimens have from one to three spots; 20 per cent of specimens from Yunnan have one spot; 70 per cent of Kweichow specimens have one spot; and 20 per cent of Yachow individuals have one spot.

The most characteristic spots are those on the posterior aspects of the thighs. These spots are small in the type series and in the specimens from the Khakien Hills; for the Yunnan series the number is reduced, only 10 per cent having many small spots, and 90 per cent having from two to ten, the spots usually small; in Kweichow specimens the spots range from five to fourteen, and in a few cases they are small; 90 per cent of the specimens from Sichang have from one to four large spots, and 10 per cent have none; and the Yaan specimens have very large spots numbering from one to five.

Regardless of the number of spots on the antero-dorsal side of the tarsus, if present they are always small. There are many spots in the type series. In Khakien Hills specimens the number ranges mostly from one to four, a few specimens having many, as in the type series. Fifty per cent of the Yunnan specimens have from one to nine spots and 50 per cent have no spots, whereas in Kweichow specimens 10 per cent have no spots and 90 per cent have from one to six. None of the Sichang and Yachow specimens have spots on the tarsus.

The color of the spots also differs in different populations. In the Sichang specimens they are dark brown and those of the Yachow series are intense black; in the specimens from Yunnan and Kweichow the black is less intense.

Associated with the size of the spots is their degree of confluence. The many small spots are usually distinct, whereas the larger spots and especially the very black ones tend to be confluent.

It seems likely that these related frogs from Yunnan, Kweichow, Sikang, and Szechwan may represent four subspecies of Hyla annectans.

Original description.- "The other Khasi one is a complete link to Rhacophorus, having the basal portion of the fingers webbed. It is a very beautiful species which I shall call Polypedates annectans."

Description of a male specimen.-No. 125, Liu Collection, Sichang, Szechwan. Body stout and somewhat depressed, body length $31 \mathrm{~mm}$. Head short; snout squarish, high, projecting slightly beyond the lower jaw; nostrils near the tip of the snout; canthus rostralis obscure; loreal region nearly vertical, concave; interorbital space flat, much wider than the upper eyelid or the internasal space; tympanum very distinct, about half of the length of the eye, and slightly exceeding its distance from the eye; tongue slightly notched behind; vomerine teeth in 
two rounded series, with a very small space between, and in a line between the choanae.

Arm rather strong; fingers (fig. 53, B) 3, 4, 2, 1 in order of length, all with disks; webs between all the fingers, with fringes extending to the bases of the disks; subarticular tubercles well developed; a long pad on the outer ventral
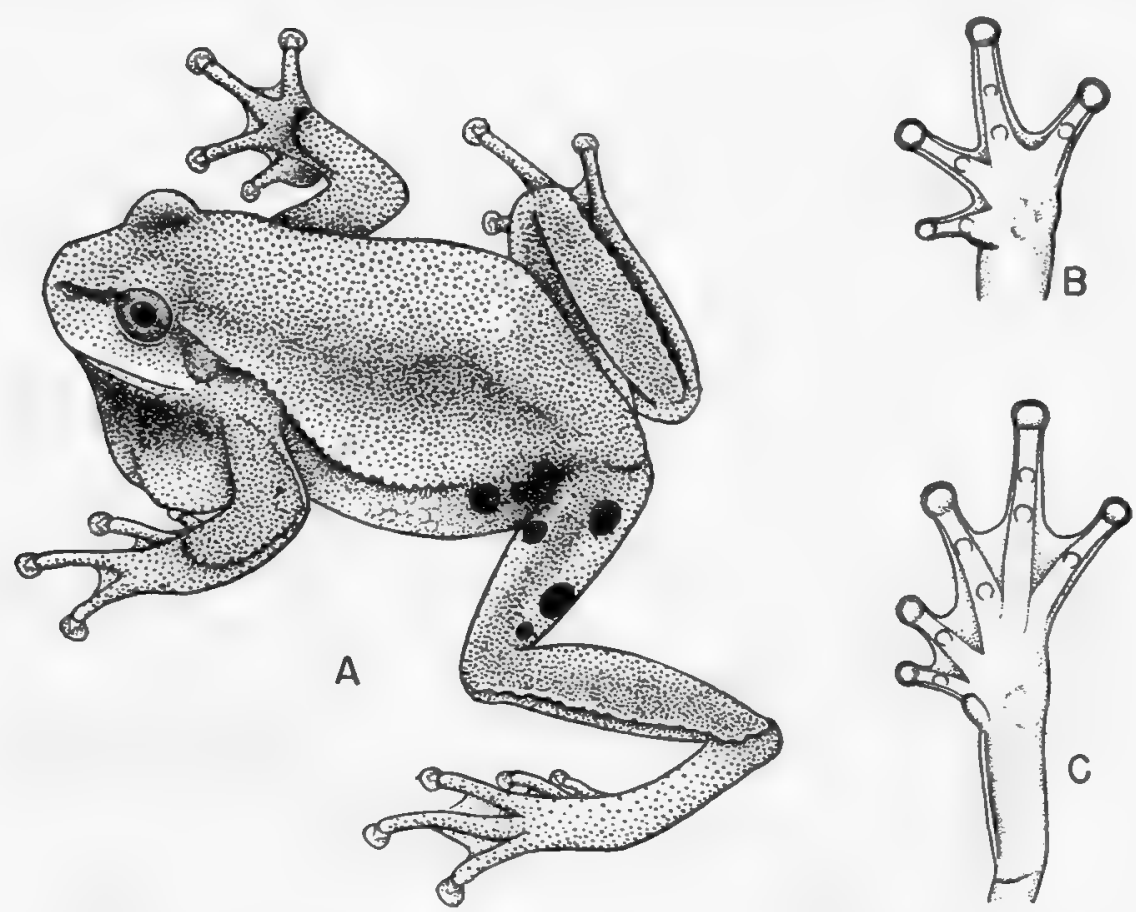

FIG. 53. Hyla annectans $(\times 2)$. A. Adult male. B. Ventral view of hand. C. Ventral view of foot.

part of the first finger, and a rounded palmar tubercle; smaller tubercles on the ventral side of the metacarpus and on the palm.

Leg rather weak, tibio-tarsal articulation reaching the posterior corner of the eye; heels meeting when the legs are placed at right angles to the body; toes (fig. 53, C) short and weak, 4, 5, 3, 2, 1 in order of length, all provided with disks, and lateral fingers extending to the bases of the disks; toes about half webbed, the web reaching the second subarticular tubercle of the fourth toe, to the distal tubercles of the third and fourth, and beyond the distal tubercles in the first and second; subarticular tubercles well developed; many smaller tubercles beneath the basal subarticular tubercles and on the sole; an oval inner metatarsal tubercle well developed; outer metatarsal tubercle rounded, and small but distinct; tarsal fold very prominent.

Skin smooth above, with a discontinuous glandular fold from eye to shoulder; small rounded warts crowded over the belly and the ventral sides of limbs; no warts on throat, except a few posterior to the lower jaw. Dark nuptial asperities 
developed on the inner dorsal side of the base of the first finger. Skin on throat very loose and dark as an external vocal sac.

Coloration in life.-The back is leaf green. A wide grayish golden band starts at the tip of the snout, passes over the nostril, through the eye, covers part of the tympanum, and extends to the shoulder, joining the light color of the sides and belly posteriorly; in the groin the color is light orange yellow with one or more purplish brown or black spots. The dorsal sides of the upper and lower arm are leaf green, the green ending at the wrist; on the femur and tibia the green ends at the tibio-tarsal articulation. A zigzag narrow yellowish golden band margins the leaf green areas. The exposed parts of the wrist, hand, fingers, tarsus, foot, and toes are stippled with gold and gray; the concealed parts of these structures are colorless. The anterior and posterior aspects of the thigh are light orange yellow, with dark purplish brown spots. In most cases, these dark spots are very distinct, but in a few individuals the spots are faint or absent. The throat and the belly are granulated; in the female the throat is golden and the belly colorless; in the male the throat is dark gray. The pupil is oval and black, enclosed by a golden iris stippled with black. Under different

Hyla annectans: Measurements

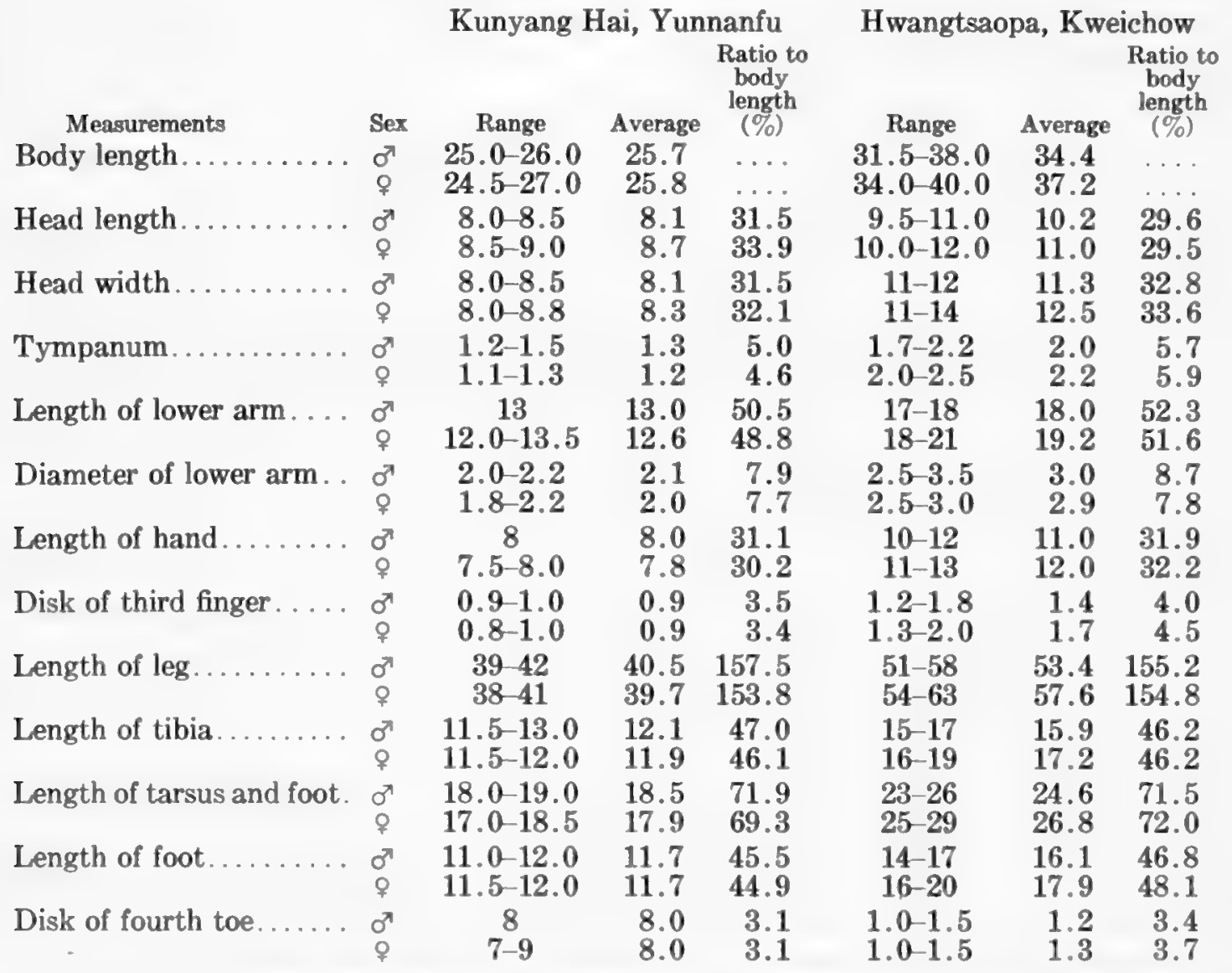

Number of specimens measured: Kunyang Hai, 4 males and 4 females; Hwangtsaopa, 5 males and 5 females. 
conditions, the intensity of coloration is different. In brighter light the green is much darker and the grayish golden band becomes dark gray or black.

Secondary sex characters. - In ten large males and five large females the average body length, from snout to vent, of males is $34.7 \mathrm{~mm}$., ranging from 33 to $37 \mathrm{~mm}$.; in the five females the average is $37 \mathrm{~mm}$., with a range from 34 to 39 $\mathrm{mm}$. Sexual difference in size is definite, though with a broad overlap (see table).

There is an external median subgular vocal sac, with two short slit-like openings near the angle of the lower jaw, lateral to the slightly notched tongue in the male. The skin of the throat of the male is extremely loose and darkened where it stretches out like a ball during croaking. In the male, black nuptial asperities are developed on the inner dorsal basal region of the first finger. There is no linea masculina.

Habitat and habits.-Hyla annectans is a common tree toad of Sichang, Chaochiao, Yenyuan and Yenpien, Sikang, with a vertical distribution ranging from 5,600 to 9,600 feet. From the beginning of April to the end of June, frogs of this species are found in wheat fields, in grass by the side of rivers, streams,

\begin{tabular}{|c|c|c|c|c|c|c|c|}
\hline \multirow[b]{2}{*}{ Measurements } & \multirow[b]{2}{*}{ Sex } & \multicolumn{3}{|c|}{ Sichang, Sikang } & \multicolumn{3}{|c|}{ Yachow, Sikang } \\
\hline & & Range & Average & $\begin{array}{l}\text { Ratio to } \\
\text { body } \\
\text { length }\end{array}$ & Range & Average & $\begin{array}{l}\text { Ratio to } \\
\text { body } \\
\text { length } \\
(\%)\end{array}$ \\
\hline Body length.... & $\begin{array}{l}0^{7} \\
\varnothing\end{array}$ & $\begin{array}{l}33-37 \\
34-39\end{array}$ & $\begin{array}{l}34.7 \\
37.0\end{array}$ & $\ldots$ & $\begin{array}{c}31-36 \\
32\end{array}$ & $\begin{array}{l}34.2 \\
32.0\end{array}$ & $\ldots$ \\
\hline Head length. & $\begin{array}{l}0^{7} \\
0\end{array}$ & $\begin{array}{r}10.0-11.0 \\
9.5-12.0\end{array}$ & $\begin{array}{l}10.5 \\
11.6\end{array}$ & 30.0 & $\begin{array}{c}10-12 \\
10-5\end{array}$ & 11.0 & $\begin{array}{l}32.1 \\
32.7\end{array}$ \\
\hline Head width. & $\begin{array}{l}\sigma^{7} \\
\text { क }\end{array}$ & $\begin{array}{l}10.6-12.0 \\
11.0-13.0\end{array}$ & $\begin{array}{l}11.6 \\
12.4\end{array}$ & $\begin{array}{l}33.4 \\
33.5\end{array}$ & $\begin{array}{c}10-12 \\
11\end{array}$ & $\begin{array}{l}11.4 \\
11.0\end{array}$ & $\begin{array}{l}33.3 \\
34.3\end{array}$ \\
\hline Tympanum. & $\begin{array}{l}0^{7} \\
0\end{array}$ & $\begin{array}{l}1.8-2.0 \\
1.8-2.2\end{array}$ & $\begin{array}{l}1.9 \\
2.0\end{array}$ & $\begin{array}{l}5.4 \\
5.4\end{array}$ & $\frac{2.0-2.5}{2}$ & $\begin{array}{l}2.2 \\
2.0\end{array}$ & $\begin{array}{l}6.4 \\
6.2\end{array}$ \\
\hline Length of lower arm & $\begin{array}{l}0^{7} \\
9\end{array}$ & $\begin{array}{l}16-18 \\
16-20\end{array}$ & $\begin{array}{l}16.8 \\
18.4\end{array}$ & $\begin{array}{l}48.4 \\
49.7\end{array}$ & $\begin{array}{c}15-19 \\
16\end{array}$ & $\begin{array}{l}18.0 \\
16.0\end{array}$ & $\begin{array}{l}52.6 \\
50.0\end{array}$ \\
\hline Diameter of lower arm. & $\begin{array}{l}0^{7} \\
\text { o }\end{array}$ & $\begin{array}{l}3.3-4.0 \\
2.6-3.5\end{array}$ & $\begin{array}{l}3.7 \\
3.1\end{array}$ & $\begin{array}{r}10.7 \\
8.4\end{array}$ & $\begin{array}{c}3.0-3.5 \\
2.4\end{array}$ & $\begin{array}{l}3.4 \\
2.4\end{array}$ & $\begin{array}{l}9.9 \\
7.5\end{array}$ \\
\hline Length of hand & $\begin{array}{l}0^{7} \\
0\end{array}$ & $\begin{array}{l}10.8-12.5 \\
10.0-13.0\end{array}$ & $\begin{array}{l}11.4 \\
12.3\end{array}$ & $\begin{array}{l}32.8 \\
33.2\end{array}$ & $\begin{array}{c}9.0-12.5 \\
10\end{array}$ & $\begin{array}{l}11.5 \\
10.0\end{array}$ & $\begin{array}{l}33.6 \\
31.2\end{array}$ \\
\hline Disk of third finger. & $\begin{array}{l}0^{7} \\
0\end{array}$ & $\begin{array}{l}1.6-1.9 \\
1.3-2.0\end{array}$ & $\begin{array}{l}1.8 \\
1.7\end{array}$ & $\begin{array}{l}5.2 \\
4.5\end{array}$ & $\begin{array}{c}1.6-2.1 \\
1.8\end{array}$ & $\begin{array}{l}1.8 \\
1.8\end{array}$ & $\begin{array}{l}5.0 \\
5.6\end{array}$ \\
\hline Length of leg. & $\begin{array}{l}0^{7} \\
0\end{array}$ & $\begin{array}{l}50-55 \\
55-63\end{array}$ & $\begin{array}{l}53.1 \\
59.0\end{array}$ & $\begin{array}{l}153.0 \\
159.7\end{array}$ & $\begin{array}{c}49-57 \\
50\end{array}$ & $\begin{array}{l}54.7 \\
50.0\end{array}$ & $\begin{array}{l}159.9 \\
156.2\end{array}$ \\
\hline Length of tibia. . & $\begin{array}{l}0^{7} \\
8\end{array}$ & $\begin{array}{l}15-17 \\
16-19\end{array}$ & $\begin{array}{l}16.1 \\
17.7\end{array}$ & $\begin{array}{l}46.3 \\
47.8\end{array}$ & $\begin{array}{c}14.5-17.0 \\
16\end{array}$ & $\begin{array}{l}15.9 \\
16.0\end{array}$ & $\begin{array}{l}46.4 \\
50.0\end{array}$ \\
\hline Length of tarsus and foot. & $\begin{array}{l}\sigma^{7} \\
9\end{array}$ & $\begin{array}{l}23.0-26.5 \\
23.0-28.0\end{array}$ & $\begin{array}{l}24.4 \\
26.4\end{array}$ & $\begin{array}{l}70.5 \\
71.3\end{array}$ & $\begin{array}{c}21.5-25 \\
23\end{array}$ & $\begin{array}{l}24.1 \\
23.0\end{array}$ & $\begin{array}{l}70.4 \\
71.8\end{array}$ \\
\hline Length of foot. & $\begin{array}{l}\sigma^{7} \\
\text { क }\end{array}$ & $\begin{array}{l}15-17 \\
14-18\end{array}$ & $\begin{array}{l}15.9 \\
17.0\end{array}$ & $\begin{array}{l}45.8 \\
45.9\end{array}$ & $\begin{array}{c}15.0-17.5 \\
15\end{array}$ & $\begin{array}{l}16.4 \\
15.0\end{array}$ & $\begin{array}{l}47.9 \\
46.8\end{array}$ \\
\hline Disk of fourth toe & $\begin{array}{l}0^{7} \\
0\end{array}$ & $\begin{array}{l}1.2-1.6 \\
1.3-1.8\end{array}$ & $\begin{array}{l}1.5 \\
1.7\end{array}$ & $\begin{array}{l}4.3 \\
4.5\end{array}$ & $\begin{array}{c}1.2-1.7 \\
1.4\end{array}$ & $\begin{array}{l}1.4 \\
1.4\end{array}$ & $\begin{array}{l}4.0 \\
4.3\end{array}$ \\
\hline
\end{tabular}

Number of specimens measured: Sichang, 10 males and 5 females; Yachow, 4 males and 1 female. 
brooks, ponds, pools, and ditches, and also in flooded rice fields. At twilight, they come out from their hiding places and croak with a sharp, high, interrupted sound. With a flashlight, one can easily catch specimens with the hand. After the breeding season, it is rather hard to find individuals, as they hide away. They are found in trees during rains. At Yenyuan City, it is commonly known as Chuhung ("bamboo-spirit") when it is found on the bamboos or among the roots of the bamboos; and known as Szeanghung ("mulberry spirits") when it is found in the holes of old mulberry trees. It is regarded as a very valuable medicine when it is found in old mulberry trees, and was presented to the Emperor as a valuable gift during the Tsing Dynasty. During the breeding season it is commonly known as Tsingwa ("green frog") in Ningshu. Our first specimen was found by Y. W. Kao, floating on a newly flooded rice field, on April 22, 1942, outside Sichang City.

Breeding site and season.--In the spring of 1942, on the night of April 24, I first heard the males croaking in the flooded rice fields and dry wheat fields outside of Sichang City. When one starts to croak, others near-by will follow and call in unison. The croak is a sharp and high "wa-wu-wa." These toads breed in the flooded rice fields and even in ditches by the roadside, but we failed to find eggs around Sichang. A mass of eggs was found in a rice field near Chaochiao. The breeding season is probably from the end of April to the end of June; I saw some newly hatched tadpoles at the first of July in a rice field at the foot of Lushan, but do not have notes on eggs.

Tadpoles.-The tadpoles (pl. 10, fig. 10) are very sensitive to any disturbance. If one approaches their pool, they swim away quickly and hide in the mud or among and under vegetation. Thus it is rather difficult to collect a large number of them. With patience, they may be observed on the bottom, on decayed vegetation, or on the stems of the growing rice plants.

The tadpole is olive green on the head and back, with a few black spots. The color is much lighter near the eye, the pupil of which is rather small, round, and black, with wide reddish golden iris and a dark line anterior and posterior to the pupil. Sides of the body shade from olive green to reddish golden, and the belly is silvery golden. The muscular part of the tail is marbled with olive green, especially on the dorsal side. The tail fins are stippled with olive green, especially near the base of the dorsal fin.

Ten tadpoles preserved in the field, with very small hind limb-buds, were measured. The average body length, from snout to vent, is $11.5 \mathrm{~mm}$., ranging from 11 to $12 \mathrm{~mm}$. The body is nearly cylindrical at the middle, its height being 62 per cent of the length and its width 58 per cent. The tail, which is about one and a half times as long as the body, is $18 \mathrm{~mm}$. long, ranging from 16 to 19 $\mathrm{mm}$. The head is somewhat flattened, its height 39 per cent of the body length, and its width about half (53 per cent) of that length. The depth of the tail is 69 per cent of the body length, and its average depth $8 \mathrm{~mm}$., ranging from 7.4 to $8.5 \mathrm{~mm}$. The tail is delicate, with a very delicate pointed tip and a thicker 
dorsal fin, especially toward the body, on which it extends anteriorly nearly to the middle region. The muscular part is also weak and only $1.9 \mathrm{~mm}$. thick near its base.

The snout is rounded, the nostril closer to its tip than to the eye. Each nostril is enclosed by a light-colored elevated ring. The eyes are lateral, the interorbital space from 4.5 to $5 \mathrm{~mm}$., 4.2 per cent of the body length. The spiraculum, without a free tube, is sinistral, directed upward and backward and

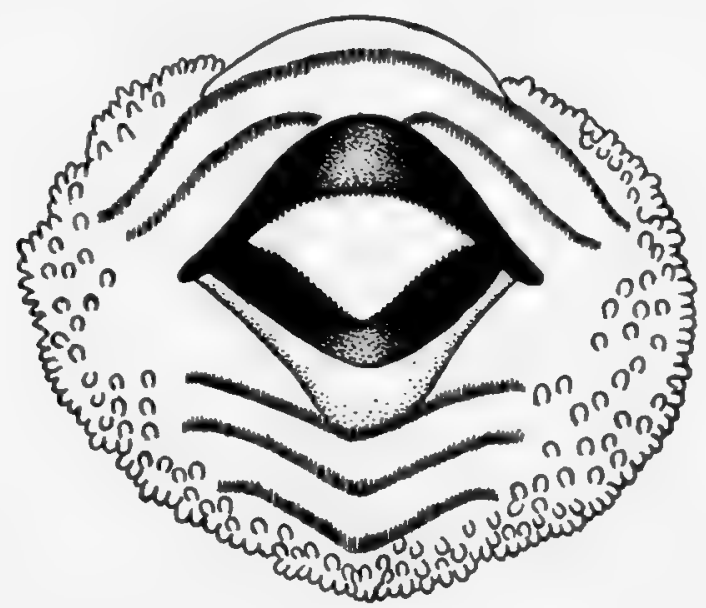

FIG. 54. Hyla annectans; mouth of tadpole ( $\times 25)$.

visible from above and below. It is at the middle of the body. The vent is median, located at the base of the ventral tail fin.

The mouth (fig. 54) is ventral rather than anterior, its average width $3 \mathrm{~mm}$., with a range from 2.5 to $3 \mathrm{~mm}$. The teeth of the upper lip are in one long, continuous and one long, widely interrupted row; those of the lower lip are in three long, uninterrupted rows. There is no variation in number of rows of labial teeth within this species. There are two rows of papillae bordering the lips, broadly interrupted along the middle of the upper lip. Many extra papillae are present at the corners of the mouth. The mandible is weakly developed, with finely serrated edge.

\section{Family MIGROHYLIDAE}

\section{KEY FOR IDENTIFICATION OF GENERA AND SPECIES}

I. Clavicle and precoracoid present.

A. Maxillary teeth present Calluella.

B. Toes fully webbed, fourth finger smaller than first. C. ocellata.

BB. Toes only one-third to two-thirds webbed, fourth finger larger than first.

C. yunnanensis.

AA. Maxillary teeth absent.................................. 
II. Clavicle absent.

A. Size large $(35-50 \mathrm{~mm}$.$) , toes one-third to one-half webbed......... Kaloula.$

B. Tips of digits truncate and expanded.................. rugifera.

BB. Tips of digits rounded and not expanded.

C. With supernumerary tubercles

K. verrucosa.

CC. Without supernumerary tubercles.

K. macroptica.

AA. Size small (20-25 mm.), toes less than half webbed Microhyla.

B. Tips of toes with disks and about one-fourth to one-third webbed. M. butleri.

BB. Tips of toes without disks and with slight webs.

M. ornata.

\section{Calluella yunnanensis Boulenger}

Calluella yunnanensis Boulenger, 1919, Ann. Mag. Nat. Hist., (9), 3: 548-Yunnanfu, Yunnan; Parker, 1934, Monog. Microhylidae, p. 29.

History of species.- Two frogs collected by John Graham at Yunnanfu were described as Calluella yunnanensis, and thought to be related to the dyscophid frogs of Madagascar. Two male specimens of yunnanensis, identified in the $\mathrm{Mu}$ seum of Comparative Zoology, were collected in northern Yunnan by Graham.

Distribution and collection data.-Calluella yunnanensis is endemic in Yunnan. I collected no material of this species.

Comparison with related species.-See Calluella ocellata sp. nov. (below).

Original description.- "Habit rather stout, similar to Microhyla rubra Jerd. Head much broader than long; snout round, not projecting beyond the mouth, as long as the eye; canthus rostralis feeble; loreal region very oblique; nostril equally distant from the eye and from the tip of the snout; interorbital space as broad as the upper eyelid. Pupil round. Fingers with obtuse tips, first shorter than second, half as long as third; subarticular tubercles moderately large, feebly prominent; three carpal tubercles, median smallest. The tibio-tarsal articulation reaches the shoulder or the temple; heels feebly overlapping when the limbs are folded at right angles to the body; tibia shorter than foot, two and one-third to two and one-half times in length from snout to vent; toes moderately long, with slightly swollen tips, the web reaching the tips, but deeply emarginate; subarticular tubercle moderately large, feebly prominent; two metatarsal tubercles, inner oval, somewhat compressed and very prominent, three-fourths the length of the inner toe, outer smaller, round and flat. Skin smooth, except for some feebly raised glandular ridges, which correspond with outlines of the markings. Pale grayish or pinkish brown above, with symmetrical vase-shaped brown markings, edged with darker and lighter, from between the eyes to the sacral region; a dark lateral band from the eye to the groin, bordered above by a series of more or less confluent black spots, which extend forward to the canthus rostralis; limbs with dark cross-bars, one or two on the tibia; lower parts white, mottled with brown, especially on the throat. From snout to vent $29 \mathrm{~mm}$."

\section{Calluella ocellata sp. nov.}

Type.-No. 55870 Chicago Natural History Museum, from Szekuaipa, Chaochiaohsien, Sikang, 7,800 feet. Adult male, collected May 6, 1942, by Y. W. Kao. 
Diagnosis.-A Calluella differing from $C$. yunnanensis by having a very long third finger; a very small fourth finger; toes fully webbed; subarticular tubercles very prominent; very distinct tympanum; a number of elongated warts forming a discontinuous lateral fold from the posterior corner of the eye to the groin region, where two symmetrical black spots enclosed by light color form ocellae. In yunnanensis the second finger is as long as or a little longer than the fourth finger; the toes are fully webbed; the subarticular tubercles are
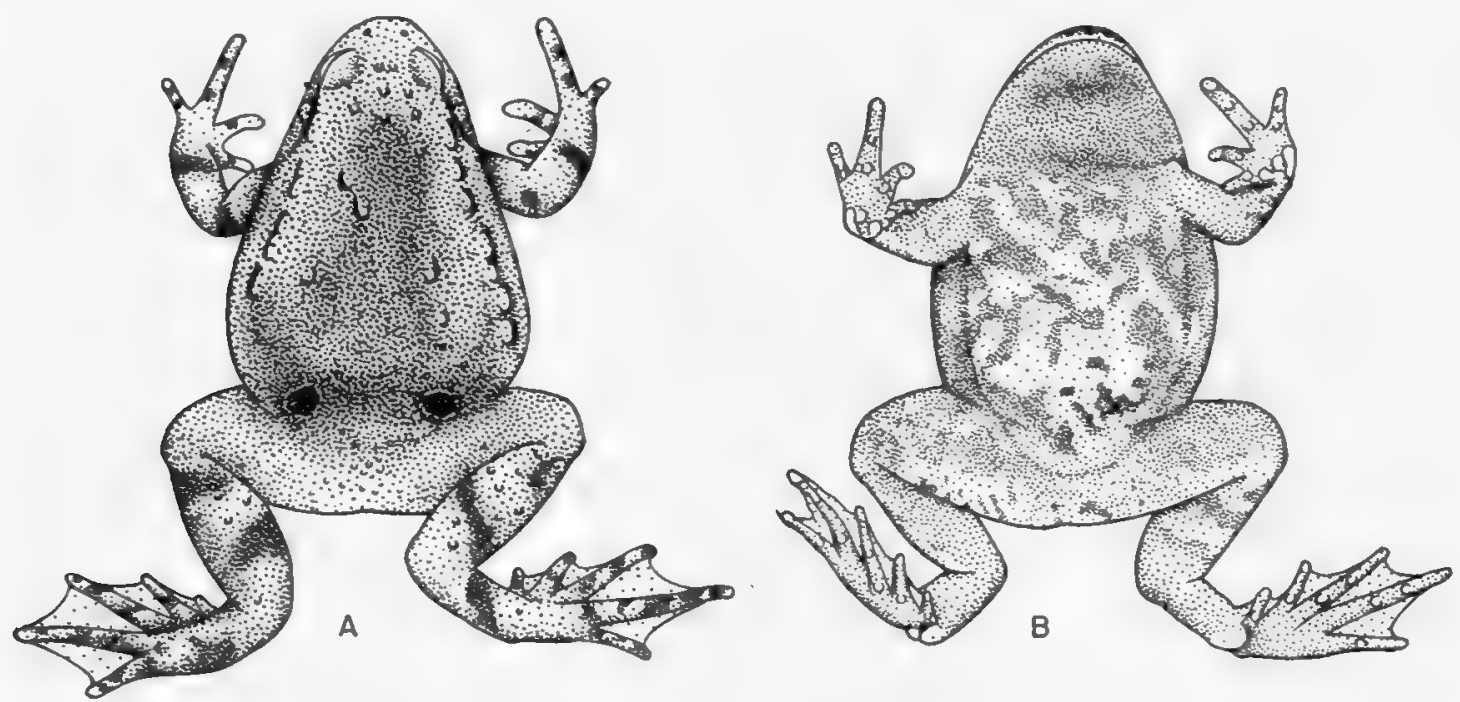

Fig. 55. Calluella ocellata $\left(\times 1 \frac{1}{2}\right)$. A. Dorsal view. B. Ventral view.

moderate; and there is a symmetrical vase-shaped brown marking, edged with darker and lighter, from between the eyes to the sacral region, from the sides of which are derived the dark spots of the groin.

Description of type.-Body stout (fig. 55); head small, broader than long, with a narrow snout; upper eyelid slightly wider than the interorbital space; tongue very large, long, free behind and with slight indication of indentation, and the tip thin, spoon-like and folded dorso-anteriorly; vomerine teeth strong, on two long bony ridges nearly crossing the whole roof of the mouth back of the choanae and separated by a very narrow interspace; maxillary teeth strongly developed; diameter of tympanum two-thirds of the interorbital space and equal to the internasal space; nostril nearer to the tip of the snout than to the anterior corner of the eye; canthus rostralis obtuse and lores slightly concave; interorbital space a little wider than the upper eyelid, which is provided with many rounded warts; arms weak; the first three fingers (fig. 56, A) greatly flattened and blunt at the tips, with lateral fringes, third finger very long, more than two and onehalf times as long as the fourth finger, which is small and rounded; subarticular tubercles of the fingers prominent; three palmar tubercles, the inner one nearly round, the outer one greatly elongated, and the middle one small and oval; legs short, the tibio-tarsal articulation reaching the anterior region of the base of the 
arm and the heels just meeting when placed at right angles to the body; toes (fig. 56, B) slender and pointed, fully webbed; subarticular tubercles well developed; both metatarsal tubercles strongly developed, the inner one with a free cutting edge, the outer one conspicuously elevated and rounded; skin of the back rough, with oval warts on the head, small rounded warts on the upper eyelids, fine elongated ones generally in rows on the body, and rounded ones on the limbs; a row of large elongated warts forming a discontinuous dorsolateral fold from the posterior part of the eye to the groin; a dermal fold from
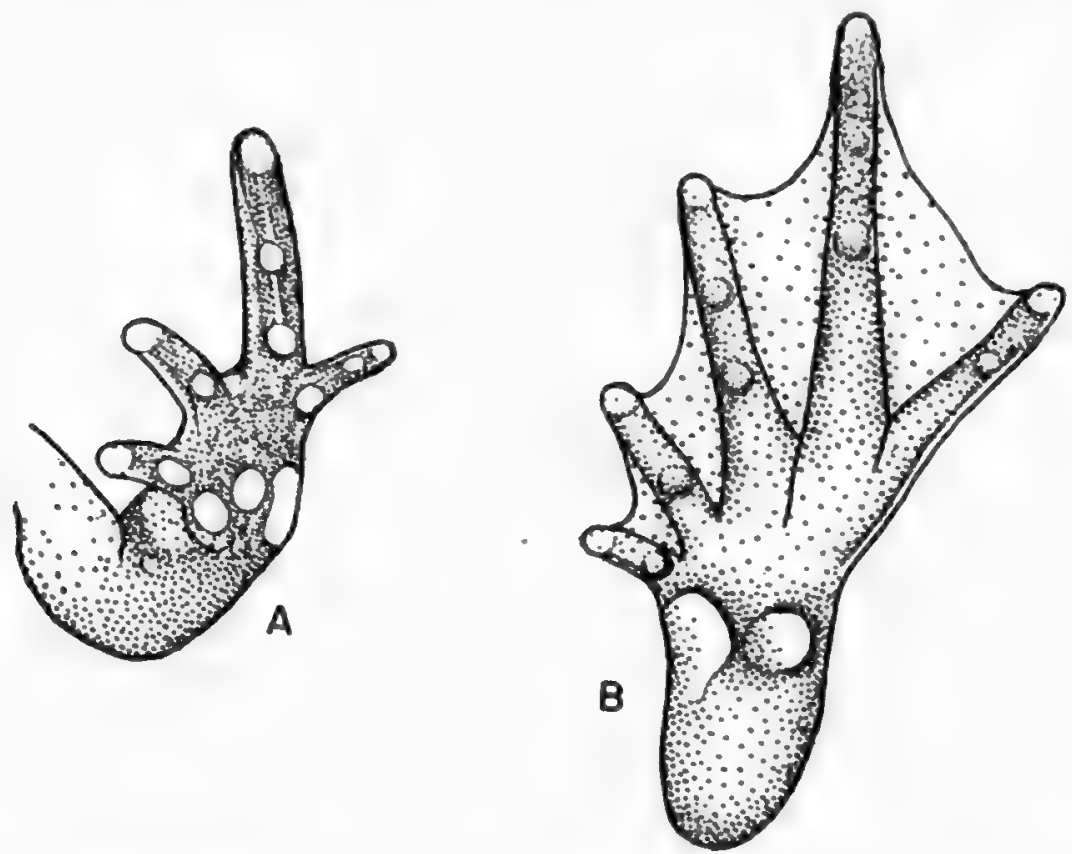

FIG. 56. Calluella ocellata $(\times 4)$. A. Ventral view of hand. B. Ventral view of foot.

the posterior corner of the eye to the base of the arm; numerous wrinkles on the back.

Measurements of type (percentage of body length in parentheses).-Body length (snout to vent) $34 \mathrm{~mm}$.; head length (snout to angle of jaw) $10 \mathrm{~mm}$. (29.4); head width (angle of jaw) $12 \mathrm{~mm}$. (35.2); head height (angle of jaw) $8 \mathrm{~mm}$. (23.5); tympanum $2 \mathrm{~mm}$. (5.8); length of lower arm (elbow to tip of longest finger) $17 \mathrm{~mm}$. (50); length of hand (base of palm to tip of longest finger) $11 \mathrm{~mm}$. (32.3); length of hind limb (vent to tip of longest toe) $49 \mathrm{~mm}$. (144.1); length of tibia $9 \mathrm{~mm}$. (26.4); length of foot (base of inner metatarsal tubercle) $17 \mathrm{~mm}$. (50); length of inner metatarsal tubercle $3 \mathrm{~mm}$. (8.8).

Coloration in life.-The back is Dark Vinaceous Gray, extending to the sides of the body and the dorsal sides of the limbs. Black spots on the back are correlated with the warts. Two large black rounded spots enclosed by light color form ocellae at the groin. There are two black bars on the lower arm, two on the third finger, and one on each other finger; on the hind limb, there are two black 
bars on the tibia and tibio-tarsus, and those on the femur and digits are indistinct. The throat is purplish fleshy-gray, and the belly is marbled with purplish gray on a fleshy cream ground color. The round pupil is black, enclosed by a golden iris stippled with black. The dark throat of the male is correlated with the presence of the subgular external median vocal sac.

Habitat. - The type specimen of this species was obtained in a rice field at the time of plowing, plowed out by the farmer a few moments before we arrived. Efforts to obtain further specimens failed.

\section{Kaloula rugifera Stejneger}

Kaloula rugifera Stejneger, 1924, Occ. Papers Boston Soc. Nat. Hist., 5 : 119 -Kiating, Szechwan; idem, 1925, Proc. U. S. Nat. Mus., 66, Art. 25: 16; Boring, 1931, Peking Nat. Hist. Bull., 5: 42, map 10; Parker, 1934, Monog. Microhylidae, p. 87; Pope and Boring, 1940, Peking Nat. Hist. Bull., 15, pt. 1: 40; Liu, 1943, Jour. West China Border Res. Soc., 14, (B): 39.

History of species. - The type specimen is an adult female collected by D. C. Graham at Kiating and described by Stejneger in 1924. In the United States National Museum there are four more specimens, one female from the type locality and three males from Hsinkaisze, Mount Omei. I worked out the life history of the species in 1943.

Distribution and collection data.-Although Kaloula rugifera, a narrowmouthed toad, is common in Szechwan, especially on the Chengtu Plain, it is not commonly seen, as it remains in its subterranean burrows or under stones during the day, except during the breeding season. From the end of June to the end of August of 1938, 1940 and 1945, several specimens were collected around Taosze (3,600 feet), on Mount Omei. Specimens of adults and tadpoles were obtained from Nanyaomiao, Wenchwan and Shuimokou, west of Kwanhsien, from the end of June to August, 1941. Several specimens were collected from pools and ditches on the campus of West China Union University, Chengtu, after a heavy rain on July 21, 1945.

Comparison with related forms.-The expansion and truncation of the terminal phalanges of the fingers of $K$. rugifera (fig. 57, B, D) separate this species sharply from borealis, verrucosa and macroptica. Kaloula pulchra pulchra agrees with rugifera in the truncate tips of the terminal phalanges of the fingers, but is otherwise quite different. Kaloula rugifera is much smaller than pulchra pulchra, the average body length of rugifera being $41 \mathrm{~mm}$. for twenty-seven males and $48.7 \mathrm{~mm}$. for eight females, while for pulchra pulchra $76 \mathrm{~mm}$. is not unusual. The webs in rugifera are very well developed and in pulchra pulchra rudimentary. The coloration of these two species is totally different. There are two wide yellow dorso-lateral stripes (white in preserved specimens) in pulchra pulchra, but not in rugifera. The tadpoles of these two species differ, the tadpole of rugifera being smaller, with shorter and higher tail. The average length from snout to vent of ten tadpoles of rugifera (with hind limbs well 
developed) is $11.2 \mathrm{~mm}$. and the tail length is $19.8 \mathrm{~mm}$., while for pulchra pulchra the body length from snout to vent of a tadpole with well-developed hind limbs is $14 \mathrm{~mm}$. and the tail length is $26 \mathrm{~mm}$. The tail length of rugifera tadpoles is 177 per cent of the body length, and for pulchra pulchra it is 18 per cent. ${ }^{1}$ The height of the tail is 60 per cent of the body length in rugifera and 54 per cent in pulchra pulchra.

Original description.-_"Tongue oval, slightly emarginate behind; behind the choanae on each side a curved strong ridge without teeth extending outward beyond the choanae and converging backward toward the median line, separated
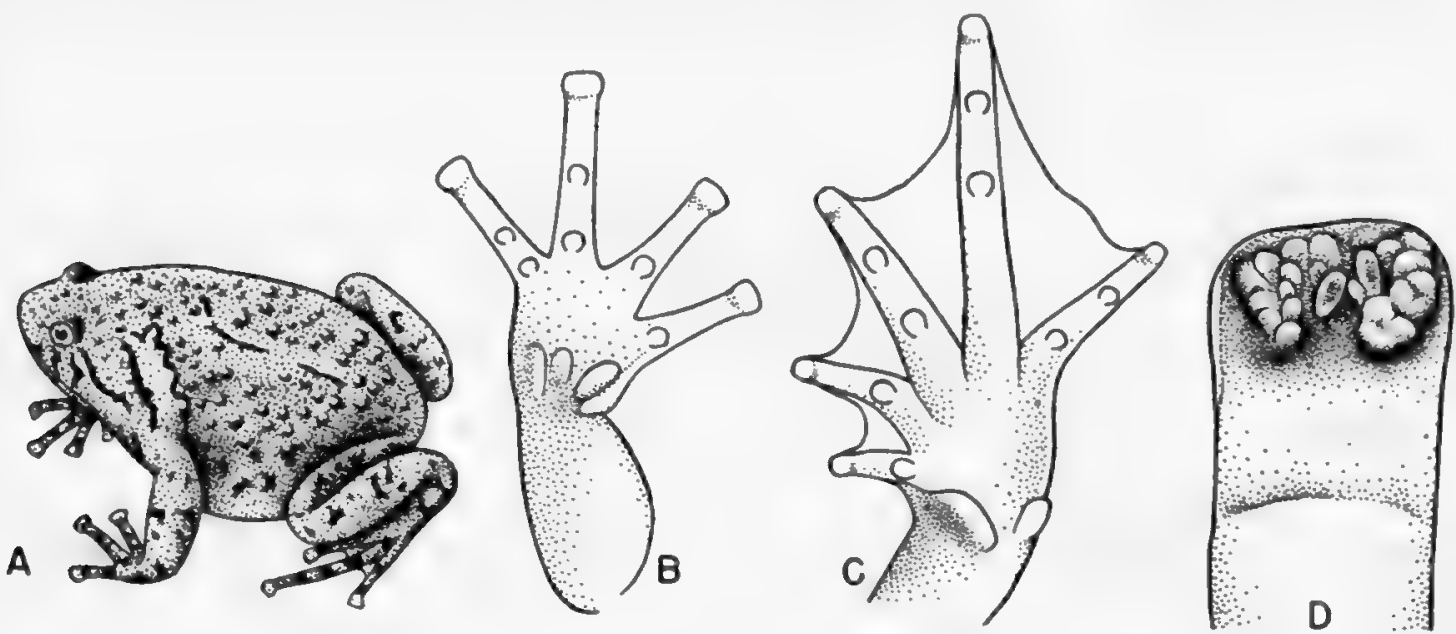

Fig. 57. Kaloula rugifera. A. Adult male $(X 1)$. B. Ventral view of hand $(X 3)$. C. Ventral view of foot of male $(\times 3)$. D. Top of finger tip $(\times 15)$.

by a narrow interspace; snout round, slightly longer than diameter of eye; nostrils nearer the tip of snout than the eye; the latter distance equaling the internarial distance; canthal ridge indicated; lores slightly concave; interorbital space much wider than upper eyelid; fingers slender with well-developed truncated disks, second equaling fourth, first somewhat shorter; subarticular and palmar tubercles prominent, the one at the base of the first finger with free rounded edge; toes long and slender, tips distinctly swollen, about one-third webbed at base; subarticular tubercles well developed; both metatarsal tubercles strongly developed, with free cutting edges, the inner much larger, the outer transverse; extended hind leg reaches beyond the fore leg and eye; skin of upper surface and sides rough with numerous elongated wrinkled tubercles; underside more or less transversely wrinkled; preanal region granular; a slight dermal fold indicated by a faint groove from eye to shoulder; no fold across the top of the head.

"Measurements of type.-Total length from snout to vent $42 \mathrm{~mm}$.; greatest width of head $16.5 \mathrm{~mm}$.; tip of snout to eye $4.5 \mathrm{~mm}$.; interorbital width $4.5 \mathrm{~mm}$.; width of upper eyelid $3 \mathrm{~mm}$.; fore leg $30 \mathrm{~mm}$.; vent to tip of inner metatarsal tubercle $42 \mathrm{~mm}$.; tip of inner metatarsal tubercle to tip of fourth toe $17 \mathrm{~mm}$.

'Measurements from a single specimen, reported by Parker, 1934, p. 87. 
"Color (in alcohol).-Dark brownish gray above with a broad pale band, interrupted in the middle, across the neck between the forelegs, this band edged with a series of small black spots; similar black spots scattered over the upper surface and forming a narrow band across supraorbital region, a line on upper lip and indication of cross bars on the legs and feet; underside light brownish gray with numerous roundish white spots on the chin and throat; all tubercles on the underside of the feet distinctly whitish."

Stejneger's description may be supplemented as follows, as he had only a single female specimen: Body stout, head small, much broader than long (see table). Tongue mostly rounded behind; strong post-choanal bony ridges, slightly curving backwards and mesad, mostly separated by a narrow interspace, sometimes in contact; canthus rostralis rounded; tympanum indistinct or hidden. Toes about one-third webbed in the female and fully webbed in the male, tibiotarsal articulation reaching behind the base of the arm. Skin of the back and sides looser in the male, with a few wrinkled tubercles; under side not transversely wrinkled in living specimens; in preserved specimens, a dermal fold across the nuchal region and a dermal fold from eye to shoulder; preanal region not granular in males, but many rough small glands around the anus in the female.

Coloration in life.-Coloration of living specimens varies. In most cases it is olive green to olive yellowish green on the back and sides, with light-colored oblique markings on each shoulder; the upper and lower jaws are yellowish green; dark olive spots near the jaw enclose small round warts, which are irregularly scattered. In some cases the color may be much lighter or darker. Few preserved specimens have the coloration as described by Stejneger (1925) and Parker (1934). In most cases, the back and sides are dark brownish gray, with irregularly scattered black spots. The dorsal sides of the limbs are like the back. The throat and belly of the female are dark gray, while in the male the throat is grayish yellow and the belly is yellowish. In some females, the throat is white, marbled with dark gray.

Secondary sex characters.-Eight females and twenty-seven males were measured. The average length from snout to vent is $49 \mathrm{~mm}$., ranging from 46 to $54 \mathrm{~mm}$. in females; in males it is $41 \mathrm{~mm}$., ranging from 38 to $44 \mathrm{~mm}$.; thus sexual dimorphism in size is well marked (see table). In the male the toes are fully webbed, while in the female they are only about one-third webbed. In the males a thick area of glandular skin covers the whole belly, which is much lighter in color than that of the female. Lineae masculinae are very conspicuous. A median subgular internal vocal sac with two slit-like openings on the floor of the mouth is present in the male, making the skin of the throat thicker and looser in the male than in the female. In the male, small pustules are developed on the upper surface of the tip of each finger. It is difficult to count the pustules, which are many and small, and in most cases crowded together into two groups, and sometimes this character is not very distinct. Bony cores for the pustules are derived from the terminal phalange. These pustules are deep and prominent 
only during the breeding season. The skin of the male is much looser than that of the female. Around the anus, especially lateral to it, many small rough warts are present in the female but absent in the male.

\section{Kaloula rugifera: Measurements of Twenty-seven Male and Eight Female Adults}

\begin{tabular}{|c|c|c|c|c|}
\hline Measurements & $\operatorname{Sex}$ & Range & Average & $\begin{array}{c}\text { Ratio to } \\
\text { body length (\%) }\end{array}$ \\
\hline Body length...... & $\begin{array}{l}0 \\
\$\end{array}$ & $\begin{array}{l}38.3-43.5 \\
46.0-53.7\end{array}$ & $\begin{array}{l}41.0 \\
48.7\end{array}$ & $\cdots$ \\
\hline Head length. & $\begin{array}{l}\text { o' } \\
\text { क }\end{array}$ & $\begin{array}{l}7.2-10.3 \\
9.2-12.0\end{array}$ & $\begin{array}{r}8.1 \\
10.2\end{array}$ & $\begin{array}{l}19.8 \\
21.1\end{array}$ \\
\hline Head width. & $\begin{array}{l}07 \\
8\end{array}$ & $\begin{array}{l}11.2-13.0 \\
13.2-15.4\end{array}$ & $\begin{array}{l}12.0 \\
14.5\end{array}$ & $\begin{array}{l}29.2 \\
29.7\end{array}$ \\
\hline Interorbital space.. & $\begin{array}{l}0^{7} \\
\text { o }\end{array}$ & $\begin{array}{l}3.2-4.0 \\
4.0-4.8\end{array}$ & $\begin{array}{l}3.6 \\
4.3\end{array}$ & $\begin{array}{l}8.7 \\
8.8\end{array}$ \\
\hline Length of eye... & $\begin{array}{l}0^{x} \\
0\end{array}$ & $\begin{array}{l}3.4-4.0 \\
3.5-4.3\end{array}$ & $\begin{array}{l}3.6 \\
3.7\end{array}$ & $\begin{array}{l}8.7 \\
7.6\end{array}$ \\
\hline Length of lower arm. . & $\begin{array}{l}07 \\
8\end{array}$ & $\begin{array}{l}25-29 \\
27-31\end{array}$ & $\begin{array}{l}27.0 \\
29.0\end{array}$ & $\begin{array}{l}65.7 \\
59.7\end{array}$ \\
\hline Diameter of lower arm.... & $\begin{array}{l}97 \\
9\end{array}$ & $\begin{array}{l}3-4 \\
3.4-4.0\end{array}$ & $\begin{array}{l}3.4 \\
3.8\end{array}$ & $\begin{array}{l}8.3 \\
7.8\end{array}$ \\
\hline Length of hand... & $\begin{array}{l}9 \\
9 \\
9\end{array}$ & $\begin{array}{r}9.5-10.7 \\
12.0-12.5\end{array}$ & $\begin{array}{l}10.2 \\
12.1\end{array}$ & $\begin{array}{l}24.7 \\
24.8\end{array}$ \\
\hline Length of hind limb. . & $\begin{array}{l}7 \\
9 \\
q\end{array}$ & $\begin{array}{l}51-59 \\
55-65\end{array}$ & $\begin{array}{l}55.3 \\
60.4\end{array}$ & $\begin{array}{l}134.7 \\
123.9\end{array}$ \\
\hline Length of tibia. . & $\begin{array}{l}97 \\
9\end{array}$ & $\begin{array}{c}15-17 \\
16.6-19.0\end{array}$ & $\begin{array}{l}15.8 \\
17.7\end{array}$ & $\begin{array}{l}37.9 \\
36.4\end{array}$ \\
\hline Length of foot and tarsus...... & $\begin{array}{l}\text { o7 } \\
\text { क }\end{array}$ & $\begin{array}{l}25.5-29.0 \\
28.0-31.5\end{array}$ & $\begin{array}{l}27.1 \\
30.2\end{array}$ & $\begin{array}{l}66.0 \\
61.9\end{array}$ \\
\hline Length of foot. & $\begin{array}{l}0^{7} \\
9\end{array}$ & $\begin{array}{l}16.0-19.6 \\
17.7-21.0\end{array}$ & $\begin{array}{l}18.1 \\
19.5\end{array}$ & $\begin{array}{l}44.1 \\
40.0\end{array}$ \\
\hline
\end{tabular}

Habitat and habits.-Although Kaloula rugifera is a common narrow-mouthed toad of Szechwan, it is little known because of its retiring habits. Throughout the year, the adults remain in subterranean burrows, leaving them only during the breeding season or in the continuous and heavy rain of the summer. ${ }^{1}$ During the summer, especially after heavy rain, they come out from their burrows after twilight and creep around in search of food among grasses near old houses. The best place to collect this toad is under or near a light, where it feeds on the insects attracted by the light. It does not jump like other toads. The skin of living specimens is smooth and slippery. When held in the hand, the animal may give off a whitish slippery secretion, at the same time inflating its abdomen, so that by a sudden contraction of the body, the toad may escape. If the back of a narrow-mouthed toad is touched, it will often inflate its body like a ball.

' Kaloula rugifera is essentially a burrower, but a specimen was found under the bark of an old tree about 15 feet above the ground by Mrs. Richardson (December 5, 1939) on the campus of West China Union University. By pressing the belly, which makes it function as a sucker, the animal can move upward. I have seen Kaloula borealis move by this means to the upper part of the big glass jar in which they were kept for study, and infer the same capacity for Kaloula rugifera. 
Breeding behavior.--The breeding season of Kaloula rugifera is from the middle of June to the end of August. Males go to pools or ditches by the side of the road, near houses, or in the temples, as on Mount Omei. There they croak with a deep sound very much like the croaking of Kaloula borealis, of eastern and northern China. They float on the water, or may have the anterior part of the body and the fore limbs supported by vegetation near the margin of the water, as they wait for the females. Even during the breeding season, not many females can be collected. This suggests that the females move to the ponds only for egg-laying, and after this process go back to their homes, while the males mate several times through each breeding season, croaking to attract the females and moving around in search of them. Actual mating was not observed.

Eggs.-On June 15, 1940, eggs with embryos near hatching were collected from an artificial pool on the campus of West China Union University, Chengtu; from July 19 to 21, 1941, eggs were observed in a small, artificial pool on the campus of Chunghsin primary school, in Kwanhsien City; and from June 12 to 28,1945 , eggs as well as adults were collected from a small artificial pool inside a temple on Mount Omei. Eggs floating on the surface of the water appear like droplets of oil. It is difficult to see them, as they usually float singly, and two or more are rarely connected. They may be detected by the reflection of light from the oil-droplike caps of the egg jelly. The egg (fig. 58, A) has a brown animal pole and a creamy white vegetal pole; its diameter is $1.5 \mathrm{~mm}$. The reversed cap and its covering of jelly are much thicker than the flattened area, which is at the animal pole and directed toward the surface of the water. The diameter of the jelly cap is from 4.5 to $5 \mathrm{~mm}$. Another thin layer of jelly encloses the whole egg.

Tadpoles.-Tadpoles (fig. 58, B and C) of Kaloula rugifera inhabit small, shallow, artificial pools and small, temporary bodies of rain-water. They are rather sensitive and are generally found on the bottom and at the margins of the pools.

In ten tadpoles with hind limb-buds averaging $3 \mathrm{~mm}$., the average length from snout to tip of tail was $31 \mathrm{~mm}$., with average body length $11 \mathrm{~mm}$., and tail length $20 \mathrm{~mm}$. (see table). The head is very much flattened; its height is about one-third of the body length, and its width is about two-thirds of the length. The height of the body is half of its length, and its width equal to that of the head. The tail is rather short, with poorly developed musculature.

Tadpoles living in dirty and shaded water are dark-colored, the light-colored specimens being found in clear water. The body is olive brown, dotted with fine rufous brown spots, especially toward the tail. The eye has a round black pupil enclosed by a light fuscous iris, which is spotted with gold. The tail has a light olive brown ground color and is richly marbled with dark grayish brown on the fins. A characteristic dark band extends backward from the base of the muscular part of the tail to the middle, where it becomes inconspicuous. Outside this band the tail is heavily dotted with umber and olive green. The belly 

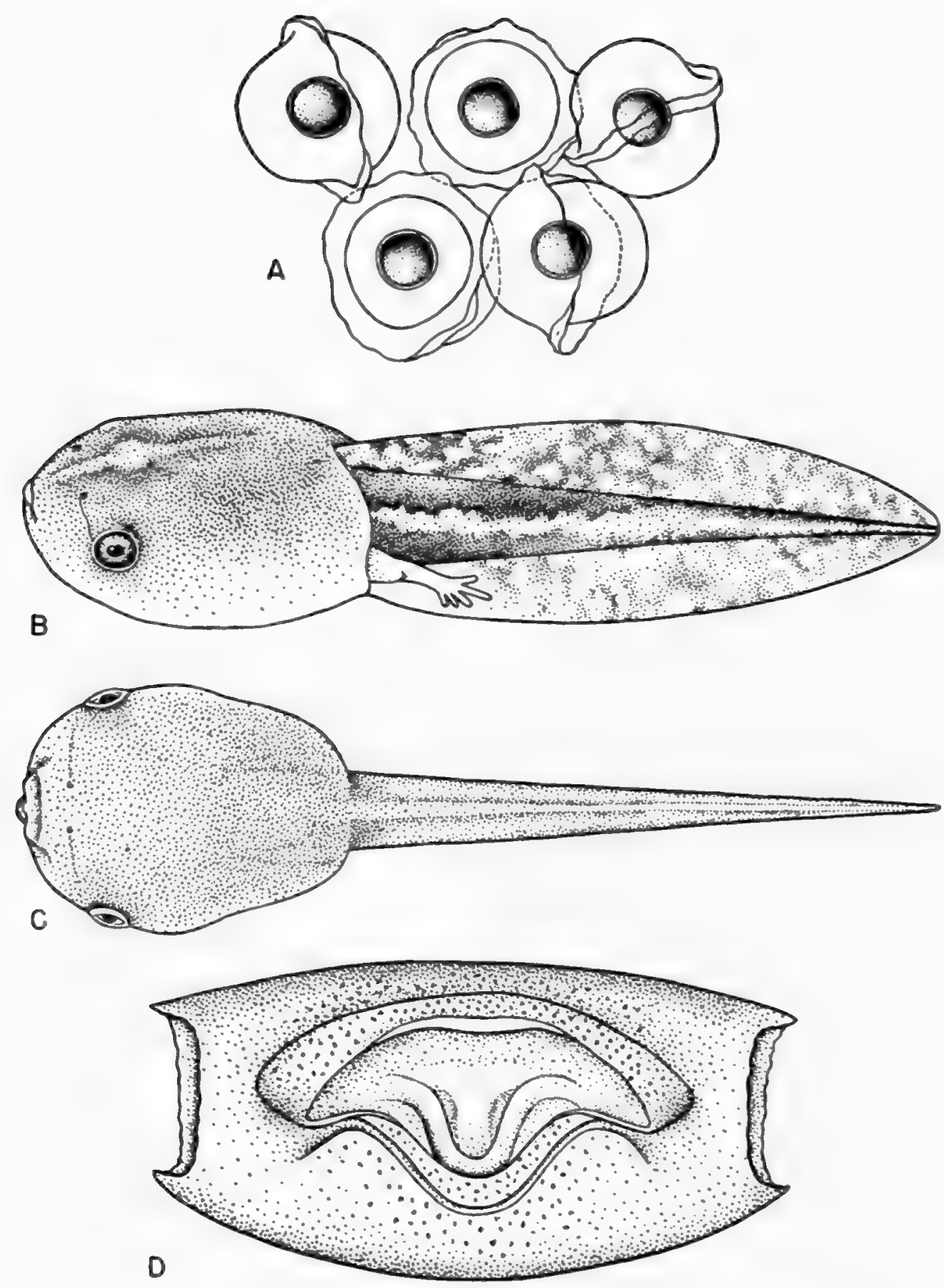

FIG. 58. Kaloula rugifera. A. Eggs $(\times 5)$, B. Lateral view of tadpole $(\times 5)$. C. Dorsal view of tadpole (X 5). D. Mouth of tadpole $(\times 25)$. 
is pinkish gray. Some tadpoles collected at Chengtu have another grayish band running from the tip of the snout to the basal part of the dorsal tail fin.

The mouth (fig. 58, D) is terminal and has no horny beak or labial teeth. The upper lip folds at the lower sides, where it turns medio-dorsally and then ventro-anteriorly to form the lower lip. Inside of the lower lip on the floor of the oral cavity is a U-shaped elevated mucous membrane connected in front with the lower lip. As the head is greatly flattened dorso-ventrally, the nostrils are close to each other on the upper side of the head. They are nearer to a line joining the anterior corners of the eyes than to the tip of the snout. The lachrymal canal is conspicuously developed. The eyes are lateral and the space between them is more than half of the length of the body. The spiraculum is median, at the base of the anal tube. It has a large curved slit-like opening covered by a transparent sheath. The anus is median and has a short broad tube continuous with the thickened base of the ventral tail fin. The tail is pointed.

Kaloula rugifera: Measurements of Ten Tadpoles

\begin{tabular}{|c|c|c|c|}
\hline Measurements & Range & Average & $\begin{array}{c}\text { Ratio to } \\
\text { body length (\%) }\end{array}$ \\
\hline Body length. & $10.5-12.0$ & 11.2 & \\
\hline Body height. & $4.5-6.4$ & 5.7 & 51.1 \\
\hline Body width. & $7.0-7.8$ & 7.3 & 65.2 \\
\hline Head height. & $3.7-4.6$ & 4.3 & 38.3 \\
\hline Head width. & $7-8$ & 7.4 & 66.1 \\
\hline Mouth width. & $1.9-2.1$ & 2.0 & 17.9 \\
\hline Tail length... & $18.0-21.7$ & 19.8 & 177.0 \\
\hline Tail height. & $6.3-7.2$ & 6.7 & 60.0 \\
\hline Diameter of tail muscle. & $2.0-2.4$ & 2.1 & 18.5 \\
\hline Length of hind limb... & $2.0-3.8$ & 3.0 & $\ldots$ \\
\hline
\end{tabular}

\section{Kaloula macroptica Liu}

Kaloula macroptica Liu, 1945, Jour. West China Border Res. Soc., 15, (B) : 31, 4 figs.Hosi, Sichanghsien, Sikang; idem, op. cit., p. 61.

History of species.-The type specimen and the material for its life history were collected on June 23, 1942, and the results were published in 1945.

Distribution and collection data.-Kaloula macroptica is a narrow-mouthed toad endemic to Sichang, Sikang, with a vertical distribution ranging from 6,000 to 7,000 feet. On June 23,1942 , forty-seven males and three females were collected from a pond near Hosi, Sichanghsien, and eggs and tadpoles were found in the same pond. During the very next day, after heavy rain, a male croaked loudly under a stone of the stairway inside the Sanitary Hospital of Sichang City. My artist, Mr. Wang, got it by turning over the stone. Five more males were collected around Sichang City from July 6 to July 23 of the same year.

Comparison with related species. - Kaloula macroptica (fig. 59) can be distinguished from $K$. borealis of central and northern China by the pustules on the slightly knobbed tips of the fingers, much larger belly gland, nearly fully 
developed webs, and large eye. $K$. pulchra of southern China and $K$. rugifera of Szechwan differ from macroptica in having the distal joint of the fingers distinctly wider than the penultimate and truncate tips. In macroptica the distal joint of the fingers is not wider than the penultimate, but is only slightly knobbed and rounded. The web of macroptica is better developed than that of pulchra. $K$. macroptica is without the two dorso-lateral light-colored bands of pulchra. Superficially macroptica is very similar to K. verrucosa of Yunnan, both having slightly knobbed tips of fingers, and pustules on the upper surface of the tip of
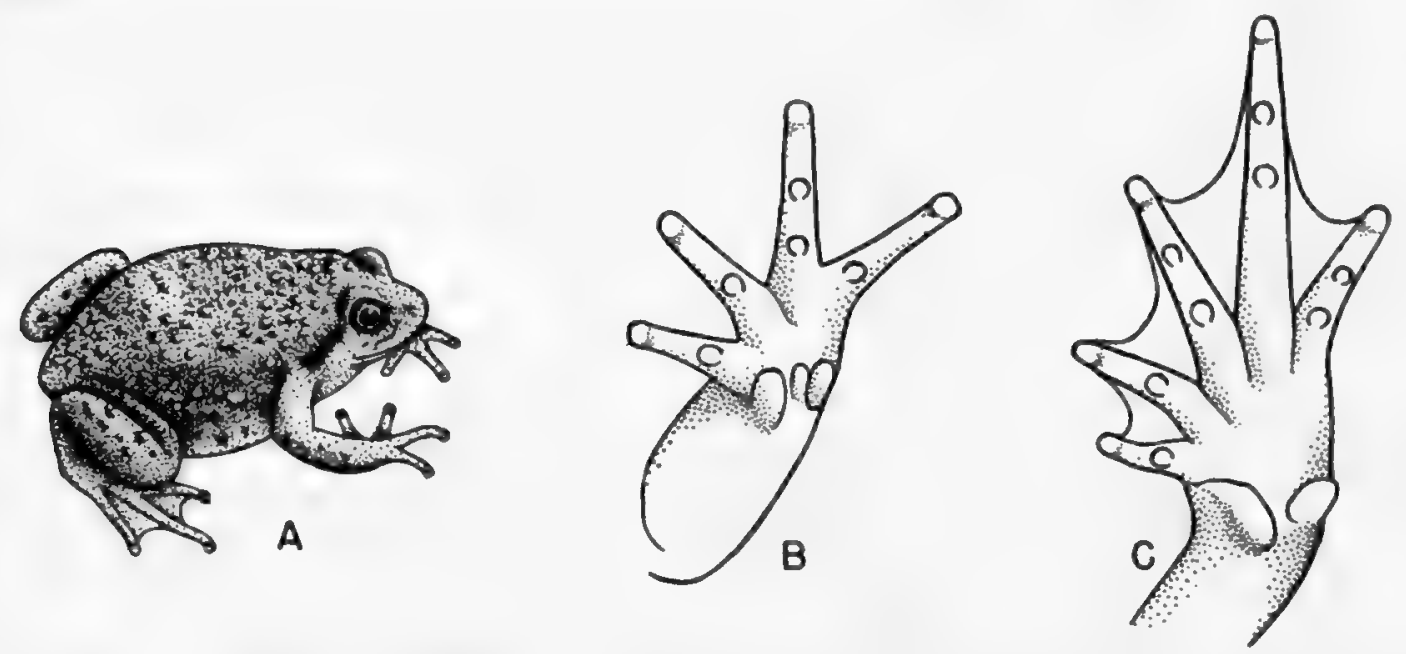

FIG. 59. Kaloula macroptica. A. Adult male $(\times 1)$. B. Ventral view of hand $(\times 3)$. C. Ventral view of foot $(\times 3)$.

each finger of the males. At the base of each finger, just proximal to the basal subarticular tubercle, verrucosa has a distinct small supernumerary tubercle that is mostly wanting in macroptica. One male out of fifty specimens has three supernumerary tubercles on the right hand and two on the left, and three more individuals have one supernumerary tubercle. The size is also different, verrucosa being much larger than macroptica. The name macroptica is given because of the conspicuously large eye.

Original description.- - "Body stout, body length from tip of snout to vent $41 \mathrm{~mm}$.; tongue long, oval, free behind, and rounded, with a thin tip; postchoanal ridges moderately strong, curving backward medial to the inner edge of the choanae; snout round and shorter than the eye, which is about 11 per cent of the body length; nostril nearer to the tip of the snout than to the eye; internasal space about two-thirds of the interorbital space; canthus rostralis rounded; loreal region oblique and slightly concave; upper eyelid equal to the length of the eye; tympanum indistinct; fingers slightly knobbed; first finger shorter than second, which is shorter than the fourth, with many small pustules (not in rows) on the upper surfaces of the tips of the fingers, without supernumerary tubercles; subarticular tubercles prominent; two distinct metacarpal tubercles, with a very small one medial to the outer; toes almost fully webbed; the outer toe a little 
longer than the second; subarticular tubercles well developed; two large metatarsal tubercles developed, with free cutting edges, the inner one much larger than the outer; tibio-tarsal articulation reaching the armpit; skin of the body rough, with rounded and wrinkled warts of varying size scattered irregularly; occipital fold present but inconspicuous; lower surface smooth; anal region granular; skin of the throat loose, wrinkled, and pigmented over the median subgular vocal sac."

Coloration in life.-Coloration in most cases is olive green to olive greenish brown on the back of the head, the body, the dorsal sides of the limbs, and the two outer fingers and toes. Black spots of varying size are scattered on the back and sometimes on the sides of the body. In some specimens, the color is lighter on the shoulder region, and an ill-defined black line extends from the snout through the nostrils to the anterior corner of the eye, and then from the posterior corner of the eye to the shoulder region above the base of the arm. The throat of the male is marbled with purple gray and greenish yellow, and the belly is a creamy yellow; in the female only the ventral side of the lower jaw is yellowish purple-gray, and the throat and the belly are pearl-gray. The pupil is round and black, with a black iris stippled with gold. After preservation in formalin, the color becomes very dull, the green and yellow disappearing.

Kaloula macroptica: Measurements of Ten Male and Three Female Adults

\begin{tabular}{|c|c|c|c|c|}
\hline Measurements & Sex & Range & Average & $\begin{array}{c}\text { Ratio to } \\
\text { body length (\%) }\end{array}$ \\
\hline Body length.... & $\begin{array}{l}0^{7} \\
q\end{array}$ & $\begin{array}{l}40-44 \\
40-48\end{array}$ & $\begin{array}{l}41.8 \\
42.7\end{array}$ & $\begin{array}{l}\ldots \\
\cdots\end{array}$ \\
\hline Head length. & $\begin{array}{l}0^{7} \\
9\end{array}$ & $\begin{array}{c}11-13 \\
11.6-13.5\end{array}$ & $\begin{array}{l}12.2 \\
12.3\end{array}$ & $\begin{array}{l}29.2 \\
28.8\end{array}$ \\
\hline Head width. & $\begin{array}{l}\sigma^{7} \\
q\end{array}$ & $\begin{array}{c}14.5-15.5 \\
14-17\end{array}$ & $\begin{array}{l}15.1 \\
15.0\end{array}$ & $\begin{array}{l}36.0 \\
35.1\end{array}$ \\
\hline Interorbital space. . & $\begin{array}{l}\sigma^{7} \\
9\end{array}$ & $\begin{array}{l}3.4-4.5 \\
3.8-4.2\end{array}$ & $\begin{array}{l}3.9 \\
4.0\end{array}$ & $\begin{array}{l}9.3 \\
9.4\end{array}$ \\
\hline Length of eye. & $\begin{array}{l}\sigma^{7} \\
q\end{array}$ & $\begin{aligned} & 4-5 \\
& 4.0-4.8\end{aligned}$ & $\begin{array}{l}4.6 \\
4.4\end{array}$ & $\begin{array}{l}10.9 \\
10.2\end{array}$ \\
\hline Length of lower arm. & $\begin{array}{l}0^{7} \\
\text { o }\end{array}$ & $\begin{array}{l}18-20 \\
19-22\end{array}$ & $\begin{array}{l}19.1 \\
20.2\end{array}$ & $\begin{array}{l}45.6 \\
47.3\end{array}$ \\
\hline Diameter of lower arm.. & $\begin{array}{l}\text { or } \\
\text { क }\end{array}$ & $\begin{array}{l}4.5-5.0 \\
3.6-5.0\end{array}$ & $\begin{array}{l}4.7 \\
4.1\end{array}$ & $\begin{array}{r}11.3 \\
9.6\end{array}$ \\
\hline Length of hand. & $\begin{array}{l}07 \\
\&\end{array}$ & $\begin{array}{l}10.8-12.3 \\
11.0-12.5\end{array}$ & $\begin{array}{l}11.4 \\
11.7\end{array}$ & $\begin{array}{l}27.3 \\
27.4\end{array}$ \\
\hline Length of hind limb. & $\begin{array}{l}0^{7} \\
8\end{array}$ & $\begin{array}{l}47-52 \\
46-49\end{array}$ & $\begin{array}{l}49.3 \\
47.3\end{array}$ & $\begin{array}{l}117.9 \\
110.8\end{array}$ \\
\hline Length of tibia..... & $\begin{array}{l}\sigma^{7} \\
q\end{array}$ & $\begin{array}{l}14-15 \\
14-16\end{array}$ & $\begin{array}{l}14.4 \\
14.7\end{array}$ & $\begin{array}{l}34.4 \\
34.4\end{array}$ \\
\hline Length of foot and tarsus. & $\begin{array}{l}\sigma^{7} \\
9\end{array}$ & $\begin{array}{l}22-25 \\
23-25\end{array}$ & $\begin{array}{l}24.1 \\
24.0\end{array}$ & $\begin{array}{l}57.6 \\
56.3\end{array}$ \\
\hline Length of foot... & $\begin{array}{l}07 \\
9\end{array}$ & $\begin{array}{c}16.6-19.0 \\
17-19\end{array}$ & $\begin{array}{l}17.9 \\
17.8\end{array}$ & $\begin{array}{l}42.8 \\
41.7\end{array}$ \\
\hline $\begin{array}{l}\text { Length of inner metatarsal } \\
\text { tubercle } . . . . . . . . . .\end{array}$ & $\begin{array}{l}\sigma^{7} \\
q\end{array}$ & $\begin{array}{l}2.8-3.6 \\
3.0-3.7\end{array}$ & $\begin{array}{l}3.2 \\
3.2\end{array}$ & $\begin{array}{l}7.6 \\
7.6\end{array}$ \\
\hline
\end{tabular}


Measurements of type (percentage of body length in parentheses).-Body length $40 \mathrm{~mm}$.; head length $11 \mathrm{~mm}$. (28); head width $15 \mathrm{~mm}$. (38); interorbital space $3.6 \mathrm{~mm}$. (9); length of lower arm $18 \mathrm{~mm}$. (45); diameter of lower arm $4.8 \mathrm{~mm}$. (12); length of hand $11 \mathrm{~mm}$. (28); length of leg $47 \mathrm{~mm}$. (118); length of tibia $14 \mathrm{~mm}$. (35); length of foot and tarsus $22 \mathrm{~mm}$. (55); length of foot 16.5 $\mathrm{mm}$. (41); length of inner metatarsal tubercle $3 \mathrm{~mm}$. (8).

Sex dimorphism.-The average body length in ten males is $42 \mathrm{~mm}$. (40 to $44 \mathrm{~mm}$.) and for three females it is $43 \mathrm{~mm}$. (40 to $48 \mathrm{~mm}$.). The lower arm of the male is thicker than that of the female, 11 per cent of the body length for the male and only 10 per cent for the female. The hind leg of the male is distinctly longer than the leg of the female, especially the femur. In the male, small pustules are developed on the upper surface of the tip of each finger. The number of pustules varies greatly, and they are not arranged in rows. Toes are almost fully webbed in males, and only about half webbed in females. In the males, the whole belly is covered by a thick area of glandular skin, which is not found in the female. Lineae masculinae are very conspicuous in the males, and a median subgular external vocal sac, with two slit-like openings on the floor of the mouth near the angle of the jaw, is present, the skin of the throat being thicker and looser, with a darker color, than in the females. Number and size of warts on the back vary greatly.

Habitat and habits. - The behavior of macroptica is very similar to that of borealis. When touched, the animal stretches out its limbs and the abdominal region becomes greatly enlarged. That is why it is locally known as "air drum." The farmers told us that they sometimes find this animal when they dig or plow the fields. The retiring habit of this species is similar to the other species of Kaloula. They usually remain in subterranean burrows, only leaving them during the breeding season or in the continuous and heavy rains of summer.

Breeding behavior.-During the breeding season at the end of June, and maybe the first part of July, the males go to pools, where they croak with a deep sound very much like that of rugifera and borealis. Fifty-seven specimens were collected, but only three of them are females. This indicates that males mostly stay in the breeding pool day and night, and that females only go there for egg-laying during the evenings. Presumably, as in rugifera and borealis, the males may mate several times.

Eggs.-On June 23, 1942, eggs were found floating in a pool near Hosi, Sichanghsien, Sikang. They float singly on the surface of the water, each egg (fig. 60, A) enclosed in two layers of jelly. The inner layer is thin. The outer layer, which is very thick, has a wing-like projection near the animal pole. This projection is used as a floating apparatus for the egg, similar to the jelly cap of the eggs of rugifera and borealis. The diameter of the jelly capsule is about 5 mm., and the egg is $1.5 \mathrm{~mm}$. in diameter at the gastrula stage. It is black on the animal pole, and creamy yellow on the vegetal pole. The jelly capsule shrinks after preservation in formalin. 
Tadpoles.-The tadpole (pl. 10, fig. 11) is greenish black on the back, and the upper sides of the body are stippled with gold. In tadpoles living in clear water and under direct sunlight, the color is much lighter than in those found in rather dirty water, and even changes to gray, stippled with black and gold, and with a dark line from the nostril to the anterior corner of the eye. Some of the tadpoles have a very conspicuous wide creamy line from the snout, slightly anterior to a line between the nostrils, running posteriorly to the basal region of the tail. The lateral ventral sides of the body are marbled with black on a lighter background color. The belly is purple-gray marbled with black, with a
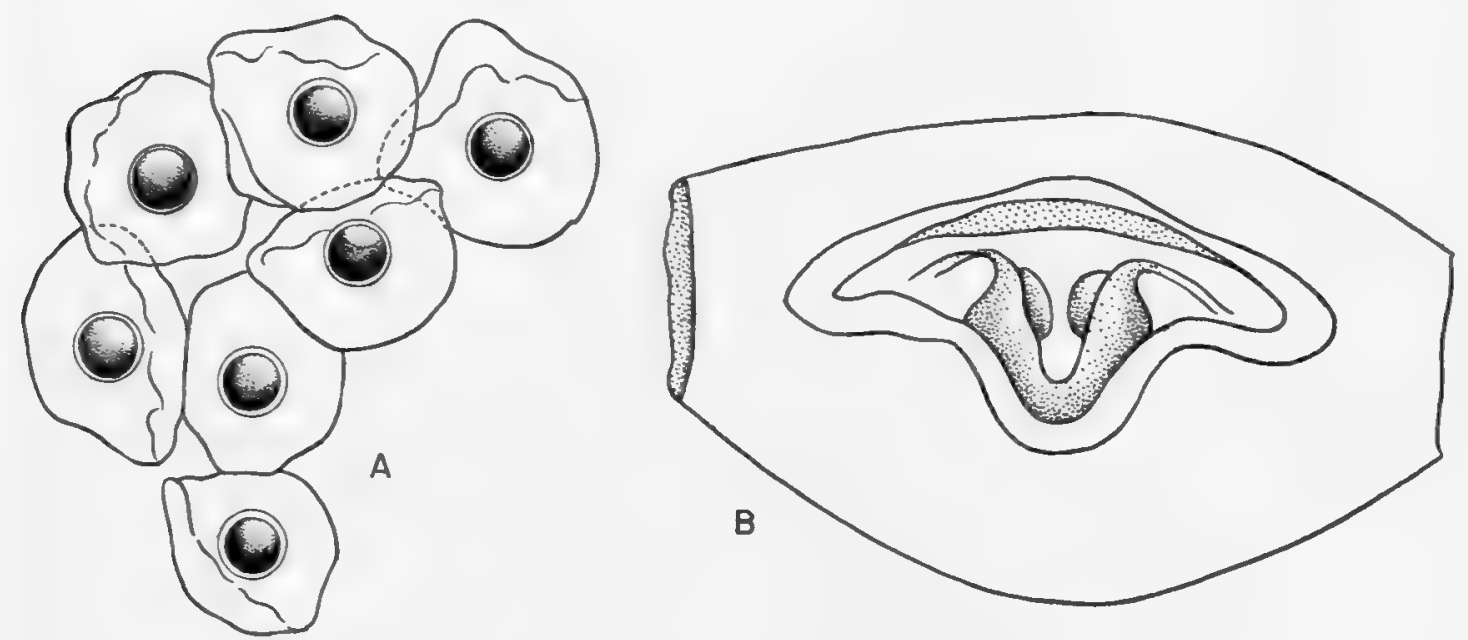

Fig. 60. Kaloula macroptica. A. Eggs $(\times 31 / 2)$. B. Mouth of tadpole $(\times 20)$.

lighter background, except in the median area of the belly. The eye has a round black pupil enclosed by a gold iris stippled with black. The tail is yellowish, much marbled with black, especially near its base.

Ten tadpoles with average hind limb-buds $6.7 \mathrm{~mm}$. long have an average length of $41 \mathrm{~mm}$. (see table). The tail is shorter in proportion than that of Kaloula rugifera, 163 per cent of the body length for macroptica, while in rugifera it is 177 per cent. The head is greatly and the body slightly depressed. The tail is rather weak, and the muscular portion of the tail is even weaker than that of rugifera.

The mouth (fig. 60, B) is terminal without horny beak or labial teeth. The width of the mouth is about one-third of the width of the head, and one-fifth of the body length. The upper lip folds at the lower lateral sides, where it turns medio-dorsally and then ventro-anteriorly to form the lower lip. Inside the lower lip, on the floor of the oral cavity, is a U-shaped elevated mucous membrane, which is greatly pigmented and somewhat hardened, connected in front with the lower lip. Inside this U-shaped elevation is a colorless knoblike elevation. The head is greatly depressed, especially near the tip of the snout. The nostrils are located on the top of the head near the mid-line, and are connected 
with the anterior corners of the eyes by lachrymal canals. The nostril is nearer to the tip of the snout than to the eye. Eyes are lateral. The spiraculum is a large median opening below the posterior end of the body near the base of the anal tube. It is covered by an oval transparent sheath of skin. The anus is median, with a short tube just below the edge of the ventral crest of the tail. The tail is very much pointed, with the crest equally developed dorsally and ventrally, and it is thickened near the base.

As soon as the hind legs are fully developed and the fore limbs are nearly exposed, the color of the back becomes uneven, and warts are indicated. After the fore limbs come out, the shape of the body changes, and the color becomes lighter, with conspicuous warts. When the tail is half gone, all characters of an adult are developed. Some tadpoles have a creamy line on the back, but this is represented in adults only by the occasional presence of a very fine elevated line in the corresponding place. Just after metamorphosis the creamy line is still present, but it usually gradually diminishes as the animal grows older. Just after metamorphosis seven individuals were measured. The average body length, from tip of snout to vent, was $12 \mathrm{~mm}$., ranging from 11.8 to $13 \mathrm{~mm}$.

\section{Kaloula macroptica: Measurements of Ten Tadpoles}

\begin{tabular}{|c|c|c|c|}
\hline Measurements & Range & Average & $\begin{array}{c}\text { Ratio to } \\
\text { body length }(\%)\end{array}$ \\
\hline Body length...... & $15.0-16.5$ & 15.4 & \\
\hline Body height. & $7.5-8.8$ & 8.1 & 52.6 \\
\hline Body width. & $10.0-10.5$ & 10.1 & 64.9 \\
\hline Head height. & $5.0-6.0$ & 5.9 & 38.3 \\
\hline Head width. . & $8.4-9.0$ & 8.9 & 57.5 \\
\hline Mouth width. & 3.0 & 3.0 & 19.4 \\
\hline Tail length... & $23.0-28.0$ & 25.2 & 163.3 \\
\hline Tail height. & $8.0-9.5$ & 8.6 & 55.8 \\
\hline Diameter of tail muscle. & $2.0-3.0$ & 2.5 & 16.4 \\
\hline Length of hind limb. . & $5.0-8.0$ & 6.7 & \\
\hline
\end{tabular}

\section{Kaloula verrucosa Boulenger}

Callula verrucosa Boulenger, 1904, Ann. Mag. Nat. Hist., (7), 13: 131-Yunnanfu.

Kaloula verrucosa Schmidt, 1927, Bull. Amer. Mus. Nat. Hist., 54: 562; Pope and Boring, 1940, Peking Nat. Hist. Bull., 15, pt. 1: 40.

History of species.-This narrow-mouthed toad, described by Boulenger in 1904 as Callula verrucosa, has since been recorded from Talifu by Schmidt (1927), and from Yunnan by Pope (1931). Werner (1924) reported it from "Yunnschan" near Wukang in southwestern Hunan, and from Yunnan. Pope failed to find the Hunan series listed by Werner in the Vienna Museum, and Pope and Boring (1940) regard the Hunan record as erroneous unless corroborated. P. L. Luh collected a male and a female for me from Yunnanfu in 1942.

Comparison with related species.-Kaloula verrucosa (fig. 61) can be distinguished from the related species Kaloula macroptica by the presence of supernumerary tubercles at the bases of the fingers. 
Original description.-- "Snout rounded, not prominent, as long as the eye; interorbital space as broad as the upper eyelid. Fingers slender, with slightly swollen tips, first a little shorter than second; toes moderate, nearly half-webbed, the tips blunt, not swollen, fifth considerably shorter than third; subarticular tubercles well developed; metatarsal tubercles two, oval, compressed, the inner very large. The tibio-tarsal articulation reaches the shoulder or between the

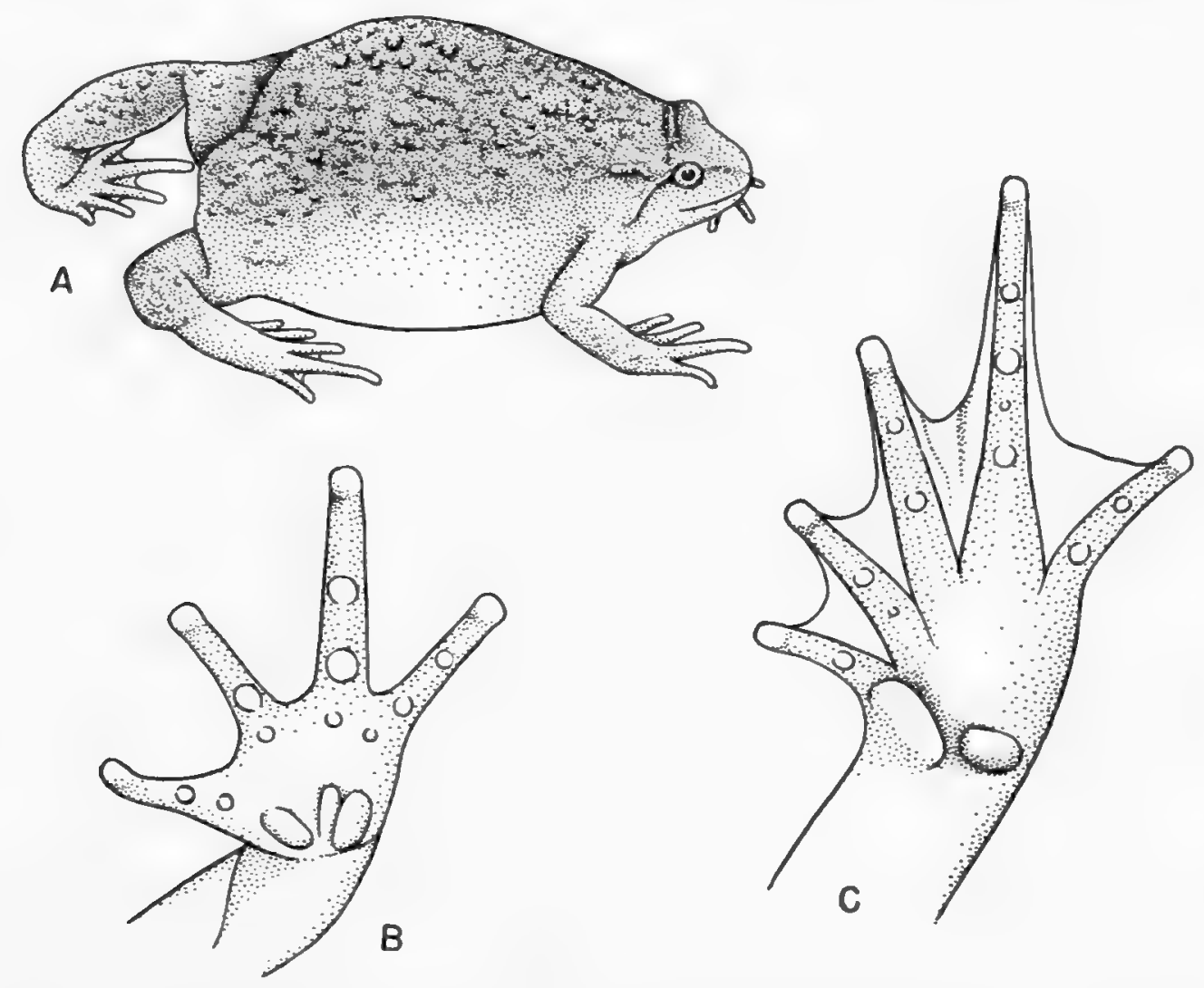

Fig. 61. Kaloula verrucosa. A. Adult female $(\times 1)$. B. Ventral view of hand $(\times 3)$. C. Ventral view of foot $(\times 3)$.

shoulder and the eye. Upper parts with large smooth warts; a fold from the eye to the shoulder. Dark greyish brown above, uniform or with six longitudinal rows of small darker spots; lower parts uniform dirty white. From snout to vent 46 mm."

\section{Kalophrynus pleurostigma interlineatus Blyth}

Engystoma(?) interlineatum Blyth, 1855, Jour. Asiatic Soc. Bengal, 23: 732-Pegu, Burma.

Calophrynus pleurostigma var. sinensis Peters, 1867, Monatsber. Akad. Wiss. Berlin, 1867: 33-Hongkong.

Kalophrynus pleurostigma Van Kampen, 1923, Amph. Indo-Austr. Arch., p. 102 (part); Gee and Boring, 1929, Peking Nat. Hist. Bull., 4, pt. 2: 25; Pope, 1931, Bull. Amer. Mus. Nat. Hist., 61, art. 8: 586. 
Kalophrynus pleurostigma interlineatus Parker, 1934, Monog. Microhylidae, p. 99; Pope and Boring, 1940, Peking Nat. Hist. Bull., 15, pt. 1: 30.

History of species.-Peters (1867) reported this frog from Hongkong, and Mell (1922) refers to it as common in grassy and bushy hills to 300 meters in the region of Canton, Kwangtung. Pope collected twelve specimens on Hainan, and Boring reports two, one from Hongkong and one from Canton. Van Kampen (1923) gives its range as southern China. Parker (1934) separates the IndoChinese form from the more southern material as a distinct subspecies, interlineatus, on the basis of smaller web and a dorsal pattern that tends toward parallel lines or spots grouped into parallel lines, rather than an inverted $Y$. He gives its range as Hongkong, Kwangtung, Yunnan, Hainan, Indo-China, Burma, and Siam. (For full synonymy see Parker, 1934, p. 99.)

Original description.- "Hind-feet more webbed than in typical Engystoma: the belly and under surface of the thighs tuberculated; with also a few larger warts on the thoracic region. Length of head and body, one and one-half in.; of hind-limb, one and three-fourths in. Colour, a golden clay-brown above, with medial blackish vertical streak, diverging into two at the nape, which are continued to the base of each hind-leg, and when the hind-leg is closed, it appears to be continued on to the limb. Anteriorly to the eyes, a narrower branch passes over the orbit and is also continued to the base of the hind-limb; and a median duller line appears on the croup, which abruptly diverges widely towards the vent. Narrower intermediate lines are also traceable; and the principal streaks are set off by a pale golden edge. Limbs beautifully banded: the tarse dusky posteriorly. Throat and breast blackish; the tuberculated belly and thighs tinged with yellow. Sides black continued in a straight line from the nostrils and eye, and strongly contrasting with a bright pale golden edge above."

\section{Microhyla ornata Duméril and Bibron}

Engystoma ornatum Duméril and Bibron, 1841, Erpet. Gén., 8: 745-Malabar Coast, India.

Diplopelma ornatum var. B. Günther, 1858, Cat. Batr. Sal., Brit. Mus., p. 50 (part only: Ningpo).

Ranina symetrica David, 1871, Nouv. Arch. Mus. Hist. Nat. Paris, 7, Bull.: 76-hills near Yangtse-kiang (Ichang).

Diplopelma carnaticum Anderson, 1879, Anat. Zool. Res. Yunnan, p. 841.

Microhyla ornata Boulenger, 1882, Cat. Batr. Sal., Brit. Mus., p. 165; Pope, 1931, Bull. Amer. Mus. Nat. Hist., 61: 597; Parker, 1934, Monog. Microhylidae, p. 139; Pope and Boring, 1940, Peking Nat. Hist. Bull., 15, pt. 1: 41; Liu, 1940, Jour. West China Border Res. Soc., 12, (B): 27, pl. 2, figs. 16-18.

Microhyla fissipes Boulenger, 1884, Ann. Mag. Nat. Hist., (5), 8: 397-Taiwanfu, S. Formosa; Stejneger, 1925, Proc. U. S. Nat. Mus., 66: 12.

Microhyla eremita Barbour, 1920, Occ. Papers Mus. Zool. Univ. Mich., 76:3-Nanking; Schmidt, 1927, Bull. Amer. Mus. Nat. Hist., 54: 562; Fang and Chang, 1931, Contr. Biol. Lab. Sci. Soc. China, Zool., $7: 87$. 
History of species.-The type locality of Microhyla ornata is the Malabar Coast of India. The first Chinese specimen, collected at Ningpo, Chekiang, was recorded as Diplopelma ornatum var. B. by Günther, 1858. In 1871, David described specimens of this small frog from Ichang, Hupeh, as Ranina symetrica. In 1884, Boulenger described Formosan specimens as fissipes, and in 1920 Barbour named mainland specimens from Nanking eremita. In 1934, Parker placed both fissipes and eremita in the synonymy of ornata. Pope and Boring (1940) followed suit.

Distribution and collection data.-Microhyla ornata has the widest geographic range of any Chinese Microhyla. This small frog has been found in Hongkong, Kwangtung, Hainan, Kwangsi, Yunnan, Hunan, Kiangsi, Fukien, Formosa, Chekiang, Kiangsu, Anhwei, Hupeh, Szechwan, Sikang, and Shensi. Its vertical distribution is from sea level to about 3,000 feet. I collected adults, eggs, and tadpoles of ornata in the flooded rice fields around West China Union University in Chengtu; near the foot of Mount Omei; and around Yaan, Sikang. On July 5, 1944, I found many specimens in the flooded field outside of Nancheng City, Shensi, which appears to form the northernmost record.

Comparison with related species.-In general appearance Microhyla ornata is like $M$. butleri, but can easily be distinguished by the fact that the toes of ornata have no digital disks and are only very slightly webbed, whereas in butleri the toes are provided with distinct disks and are from one-half to one-fourth webbed. The hind limb is shorter in ornata and longer in butleri, the tibio-tarsal articulation in ornata reaching beyond the base of the arm, while in the male of butleri it reaches the eye. $M$. heymonsi is readily distinguished from ornata by the disks at the tips of the toes and the presence of a black spot on the center of the back. M. ornata agrees with $M$. pulchra in the absence of digital disks, but ornata is smaller than pulchra, no specimens of ornata ever reaching $25 \mathrm{~mm}$. in body length. The tibio-tarsal articulation reaches beyond the base of the arm in ornata and beyond the eye or even beyond the snout in pulchra. The toes are about half webbed in pulchra and only slightly webbed in ornata.

Description of adult male.-Body moderately slender. Head narrow; snout pointed and projecting beyond the mouth; nostril nearer to the tip of the snout than to the anterior border of the eye; canthus rostralis rounded; loreal region nearly vertical and slightly concave; interorbital space a little broader than the upper eyelid; tympanum hidden; tongue slightly notched at the rear; vomerine teeth wanting.

Arm slender and weak, tips of fingers not dilated into disks; first finger shorter than second, which is slightly shorter than fourth, the third finger the longest; subarticular tubercles large and well developed; a distinct inner palmar tubercle and an indistinct outer one.

Legs rather short but strong; toes somewhat rounded, with small webs, 4-3-5-2-1 in order of length; tips of toes rounded, without disks; subarticular tubercles distinct; two prominent metatarsal tubercles; tibio-tarsal articulation 
reaching to between the shoulder and the posterior corner of the eye, heels overlapping when placed at right angles to the body.

Coloration in life.-Light olive brown stippled with pink is the ground color of the head, back, and dorsal sides of limbs. A fine elevated dorsal median lighter-colored line extends from near the tip of the snout to the vent. A black dorsal pattern connects the posterior upper eyelids, narrows behind the occiput, broadens on the shoulders, narrows slightly again and then broadens on the middle of the body, sending a branch on each side obliquely backward to each groin; narrowing behind this area, it broadens again and bifurcates, each branch being directed obliquely backward and continuing across the thigh. The dorsal pattern may be ill-defined or broken up into spots. Another more or less welldefined dark streak extends from behind the eye over the shoulder to the flank. Some specimens have two red spots above the shoulder in the black pattern. The sides of the body are darker than the background color but lighter than the dorsal black pattern. Dark markings are present above and at the sides of the vent, anterior to the thigh, and posterior to the lower arm, and there are irregular black bars on the limbs. The throat is dark gray; the belly and lower sides of the limbs are cream. After preservation, the ground color becomes much lighter and the black pattern changes to dark brown.

Skin smooth, occasionally with very small tubercles above; a fine glandular ridge on the mid-dorsal line; a skin fold from eye to base of arm; and a gular fold at the back of the throat.

Sex dimorphism.- Sexual dimorphism in size is insignificant, nor is there any modification for grasping during the breeding season in the males of this species. The male has an external median subgular vocal sac with a skin fold at its posterior border crossing the chest just anterior to the fore limbs. The skin covering the vocal sac is darker and thicker than the skin of the throat of females. Lineae masculinae are present in the males.

Habitat and habits.--Microhyla ornata is a very small frog inhabiting grass near flooded rice fields, along ditches, or around pools and ponds. It may also be found in crevices in the earth in an unflooded rice field or between stones on the ground. The frogs of this species are nocturnal. At twilight, they jump or creep about, even crossing roads, where it is not uncommon to step on one of them. They are poor swimmers but excellent jumpers. If there is any disturbance, this small frog jumps actively and continually, so that it is not easy to catch one with the hand. Microhyla ornata belongs to the ecological group associated with the grass habitat on the plain. It ranges upward on the lower slopes of the mountains to about 3,000 feet.

Breeding behavior.-The breeding season of ornata is from the end of June to the first of August. After the rice fields are flooded or after heavy rains, the males croak loudly at twilight, and swim around in the water or at the margin of the water. Considering their small size, they produce an astonishing volume of sound. When they croak, the vocal sac stretches out like a ball, with the 
anterior region of the body well elevated. Males may float on the water or support the anterior part of the body on vegetation near the margin of the pool. I have observed the females moving toward a place where the males were croaking.

Eggs.-Eggs are laid in flooded rice fields or in pools after heavy rain. The most active season in Chengtu for egg-laying is the middle of July. The eggs floating on the surface of pools usually form a round film with a diameter of about $50 \mathrm{~mm}$. The egg is small $(0.6 \mathrm{~mm}$.) with a light brown animal pole and a cream-colored vegetal pole. This species develops much more rapidly than any other frog in western China, and this development seems to be associated with their breeding in small temporary pools in which the water may dry up in a short time.

Tadpole.-The tadpoles of ornata (pl. 10, fig. 5) are not easily seen, as they are transparent and of small size. Thus they are easily concealed. During a clear day they usually avoid the direct rays of the sun by grouping and hiding themselves under shadows thrown upon the water by overhanging leaves, or under the leaves of aquatic plants. If there is any disturbance, they scatter themselves more or less evenly in the water.

The body and the tail are transparent, the former light greenish gray and the latter pearl gray. Both body and tail are finely dotted with brown, except the distal part of the tail, which is colorless and completely transparent. The dorsal and the ventral sides of the muscular part and the free margins of the tail fin are thickly spotted. The eye is small, with a round black pupil enclosed by a yellowish golden iris. The belly is colorless.

Microhyla ornata: Measurements of Twenty Tadpoles

\begin{tabular}{|c|c|c|c|}
\hline Measurements & Range & Average & $\begin{array}{l}\text { Ratio to } \\
\text { body length }(\%)\end{array}$ \\
\hline Body length....... & $6.5-8.2$ & 7.1 & \\
\hline Body height. & $3.6-5.0$ & 4.3 & 60.8 \\
\hline Body width. & $3.0-4.0$ & 3.4 & 48.9 \\
\hline Head height. & $3.0-3.7$ & 3.3 & 46.3 \\
\hline Head width.. & $3.7-4.5$ & 4.2 & 58.8 \\
\hline Space between eyes. & $3.7-4.6$ & 4.2 & 58.8 \\
\hline Snout to spiraculum. & $6.0-7.7$ & 6.8 & 96.2 \\
\hline Tail length......... & $12.0-19.0$ & 15.3 & 216.2 \\
\hline Tail height. & $3.4-5.5$ & 4.3 & 60.9 \\
\hline Diameter of tail muscle & $1.0-1.6$ & 1.3 & 18.4 \\
\hline Length of hind limb. & $2.6-6.0$ & 4.2 & $\ldots$ \\
\hline
\end{tabular}

The tadpoles are small. Measurements of twenty tadpoles are presented in the accompanying table. The head is dorso-ventrally flattened; the height of the body is much greater than its width; the spiraculum is median, near the base of the ventral fin of the tail; the tail is more than twice as long as the body. From its quiet-water habitat one might expect the tail to be shorter than this. As the base of the body is very oblique from back to vent, this measurement is not quite comparable to that of other tadpoles. The character of the tail is that of a quiet-water form, as it has a thin fin with a delicate, pointed tip. 
The mouth is terminal, lacking a horny beak, labial teeth and papillae. Under natural conditions, the upper lip is broad and slightly curved. At the corners of the mouth, it folds medially and slightly dorsally to form the lower lip. Toward the mid-line of the body, the lower lip turns backward and then forward again so that a U-shaped structure is formed projecting forward and upward. This is a most remarkable structure, characteristic of the Microhyla ornata tadpole. The nostrils are near the mid-line and nearer to the tip of snout than to the eyes, with which they are connected by a distinct lachrymal canal. The eyes are lateral, with a space more than half of the length of the body between them. The spiraculum is median, lying near the base of the ventral tail fin. It is covered ventrally by a concave transparent membrane visible from the side, that overlaps the basal part of the ventral tail fin. The opening is large and directed backward. The vent is dextral, with a long curved tube embedded in the ventral tail fin and opening near the margin of the fin. The ventral fin is deeper than the dorsal, widest at the anal tube.

\section{Microhyla butleri Boulenger}

Microhyla sp. Flower, 1899, Proc. Zool. Soc. Lond., 1899: 903, pl. 60, fig. 2.

Microhyla butleri Boulenger, 1900, Ann. Mag. Nat. Hist., (7), 6: 188-Larut Hills, Perak (4,000 ft.); Pope, 1931, Bull. Amer. Mus. Nat. Hist., 61 : 592, fig. 37; Parker, 1934, Monog. Microhylidae, p. 131; Pope and Boring, 1940, Peking Nat. Hist. Bull., 15, pt. 1: 42.

Microhyla boulengeri Vogt, 1913, Sitzber. Ges. Naturf. Fr. Berlin, 1913: 222-Hainan.

Microhyla hainanensis (not of Barbour) Mell, 1922, Arch. Naturg., 88, Abt. A, Heft 10: 131.

Microhyla grahami Stejneger, 1924, Occ. Papers Boston Soc. Nat. Hist., 5: 119 Suifu, Szechwan, China.

Microhyla sowerbyi Stejneger, 1924, Occ. Papers Boston Soc. Nat. Hist., 5: 119-near Yenpingfu, Fukien, China.

History of species.-The rather remarkable wealth of names for Microhyla butleri is indicated in the synonymy above (for a more detailed synonymy see Parker, 1934).

Distribution and collection data.-Microhyla butleri is widely distributed in southern and southwestern China (Fukien, Kwangtung, Hainan, and Szechwan) and ranges to Indo-China, Burma, Siam, and the Malay Peninsula. In western China, the species is known from Graham's specimens collected at Suifu, 1,200 feet altitude, Szechwan. I collected no material of this species. In western China, butleri is limited to the southwestern corner of Szechwan and is presumably common in Yunnan.

Comparison with related species.-Microhyla butleri can be distinguished from ornata and pulchra by the digital disks of the toes, the latter two species having none. A ridge about twice as long as the inner metatarsal tubercle, with which it connects, is present in butleri but not in heymonsi; heymonsi, also with disks 
on the toes, has a much smoother skin, a lighter-colored back, and a characteristic black spot on the mid-back between two dark-colored lines.

Original description. - "Habit slender. Snout rounded, as long as the orbit; interorbital space broader than the upper eyelid. Fingers and toes rather slender, the tips dilated into small but well-developed disks; first finger much shorter than second; toes webbed at the base; subarticular tubercles small, two very small metatarsal tubercles. The tibio-tarsal articulation reaches the eye. Skin smooth. Grey on the back, pale reddish on the sides and limbs, with symmetrical dark brown markings forming bars on limbs; some small scarlet spots on the sides; a whitish oblique streak from the eye to the base of the fore limb and a whitish spot on the end of snout; whitish beneath, throat and breast speckled with dark brown. From snout to vent $21 \mathrm{~mm}$."

Microhyla butleri: Measurements of Adults

\begin{tabular}{|c|c|c|c|c|c|c|}
\hline & \multicolumn{2}{|c|}{ Szechwan ${ }^{1}$} & \multicolumn{2}{|c|}{ Szechwan $^{2}$} & \multicolumn{2}{|c|}{ Fukien $^{3}$} \\
\hline Measurements & MM. & $\begin{array}{c}\text { Ratio to } \\
\text { body } \\
\text { length } \\
(\%)\end{array}$ & MM. & $\begin{array}{c}\text { Ratio to } \\
\text { body } \\
\text { length } \\
(\%)\end{array}$ & MM. & $\begin{array}{c}\text { Ratio to } \\
\text { body } \\
\text { length } \\
(\%)\end{array}$ \\
\hline dy length. & 21.5 & & 24.0 & & 23.0 & \\
\hline lead length. & 7.0 & 32.5 & 7.5 & 31.2 & 7.0 & 30.4 \\
\hline lead width. & 6.0 & 27.9 & 6.5 & 27.0 & 6.5 & 28.2 \\
\hline ength of lower arm. & 9.0 & 41.8 & 10.0 & 41.6 & 10.0 & 43.4 \\
\hline iameter of lower arm ............ & 1.7 & 7.9 & 1.8 & 7.5 & 1.7 & 7.3 \\
\hline ength of hand $\ldots \ldots \ldots \ldots \ldots \ldots$ & 5.0 & 23.2 & 6.0 & 25.0 & 5.0 & 21.7 \\
\hline gth of $\operatorname{leg} \ldots \ldots \ldots \ldots$ & 36.0 & 167.4 & 39.0 & 162.5 & 38.0 & 165.2 \\
\hline 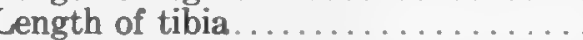 & 11.0 & 51.1 & 12.0 & 50.0 & 11.0 & 47.8 \\
\hline h of foot and tarsus......... & 16.0 & 74.4 & 18.0 & 75.0 & 17.0 & 73.9 \\
\hline 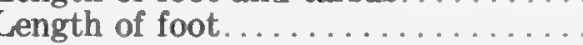 & 12.0 & 55.8 & 12.5 & 52.0 & 11.5 & 50.0 \\
\hline
\end{tabular}

${ }^{1}$ U.S.N.M. No. 78365 , male. $\quad{ }^{2}$ U.S.N.M. No. 79728 , female. $\quad{ }^{3}$ C.N.H.M. No. 28565 , male.

\section{Rana adenopleura Boulenger}

Rana adenopleura Boulenger, 1909, Ann. Mag. Nat. Hist., (8), 4: 492-Fuhacho Village, 4,000 feet altitude, Formosa; Boulenger, 1920, Rec. Indian Mus., 20 : 139; Stejneger, 1925, Proc. U. S. Nat. Mus., 66, art. 25: 23; Pope, 1931, Bull. Amer. Mus. Nat. Hist., 61 : 534; Liu, 1941, Peking Nat. Hist. Bull., 15, pt. 4: 285.

Rana caldwelli Schmidt, 1925, Amer. Mus. Nov., No. 175: 2-Fukien (probably near Yenping); Schmidt, 1927, Bull. Amer. Mus. Nat. Hist., 54: 570.

Rana musica (not of Linnaeus) Chang and Hsu, 1932, Contr. Biol. Lab. Sci. Soc. China, (Zool.), 8, No. 5: 157-Mount Omei.

Rana daunchina Chang, 1933, China Jour., 18, No. 4: 209 (new name for musica Chang and $\mathrm{Hsu}$ ).

History of species.--Boulenger described Rana adenopleura in 1909 from four specimens collected at "Fuhacho," a Formosan village at 4,000 feet. Stejneger, in 1925, recorded a specimen from Yenping, Fukien, secured by Sowerby; Schmidt (1925) described the Fukien representative as Rana caldwelli; Pope (1931) placed caldwelli in the synonymy of adenopleura. In the same paper he gives a detailed account of the adults and tadpoles of this species from Ch'ungan- 
hsien, Fukien. In 1931, Chang and Hsu described a new frog from Mount Omei as Rana musica; when Stejneger pointed out to them that musica was a preoccupied name, Chang in 1933 proposed the new name daunchina.

I studied this frog on Mount Omei for three summers, completed its life history, and published my notes in 1941.

Direct comparison of Fukien specimens with specimens from Mount Omei fails to disclose any difference except that the webbing of the toes of the Fukien

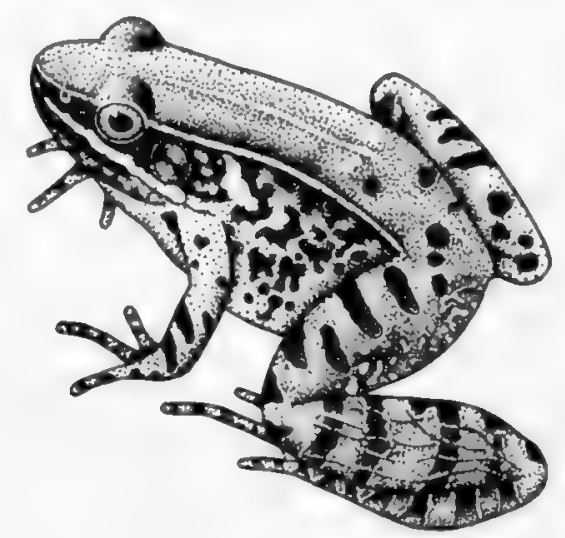

FIG. 62. Rana adenopleura; adult female (X 1$)$.

specimens is a little more extensive. Pope found egg-masses laid in a flooded rice field. On Mount Omei, adenopleura invariably was found to lay its eggs in a nest out of the water. Boulenger (1909), Stejneger (1925), and Chang (1932), fail to mention the fact that the third finger usually bears a distinct disk with a horizontal groove.

Distribution and collection data.-Rana adenopleura is found in Formosa, Fukien, and in the southwest corner of Szechwan. It may be predicted that this frog will be found in Kweichow, Hunan, and Kiangsi. Its vertical distribution in western China is from 2,000 to about 5,500 feet altitude. During the summers of 1938, 1940, and 1945, many adults, tadpoles and egg-masses were collected from Mount Omei. Mr. Tang of Wu Han University collected a few specimens from the northeast slope of Taliangshan, Szechwan.

Comparison with related species.-Rana adenopleura (fig. 62) is closely related to pleuraden, but the tips of its toes are provided with distinct disks, which are absent in pleuraden. The coloration of the two species is different, the upper sides of the limbs in adenopleura being brown with light-edged dark cross bars, whereas in pleuraden they are green, stippled with black, and with dark bars. Rana adenopleura differs from pleuraden in habits, inhabiting dirty pools or ponds, whereas pleuraden is found in small mountain streams.

Original description.- "Vomerine teeth in two small oblique groups between the choanae. Head moderate, as long as broad; snout obtusely pointed, prominent, as long as the orbit; canthus rostralis obtuse; loreal region oblique, concave; 
nostril equally distant from the eye and from the end of the snout; interorbital region nearly as broad as the upper eyelid; tympanum very distinct, two-thirds to three-fourths the diameter of the eye. Fingers slender, with slightly swollen tips, first extending slightly beyond second; toes slender, half webbed, the tips dilated into small but distinct disks; subarticular tubercles moderate; a small oval inner metatarsal tubercle, sometimes a rounded outer one at the base of the fourth toe. The tibio-tarsal articulation reaches the tip of the snout or between the eye and the tip of the snout. Skin smooth; a moderately broad, very prominent, dorso-lateral glandular fold. Greyish brown above, with or without darker spots and marblings, with or without a light vertebral line; a more or less distinct dark band on each side of the head, passing through the eye; a whitish streak along the upper lip; dorso-lateral fold dark edged; limbs with dark cross-bars; hinder side of thighs yellowish, spotted or marbled with brown or black; lower parts white, throat sometimes brownish. Male with an internal vocal sac on each side and a very large flat gland on each side of the body, above and behind the shoulder, as in Rana pleuraden."

Rana adenopleura: Measurements of Thirty-five Male and Seventeen Female Adults

\begin{tabular}{|c|c|c|c|c|}
\hline Measurements & Sex & Range & Average & $\begin{array}{l}\text { Ratio to } \\
\text { body length }(\%)\end{array}$ \\
\hline Body length....... & $\begin{array}{l}\sigma^{7} \\
0\end{array}$ & $\begin{array}{l}41.5-51.0 \\
44.0-53.0\end{array}$ & $\begin{array}{l}46.1 \\
49.1\end{array}$ & ... \\
\hline Head width. & $\begin{array}{l}7 \\
8 \\
8\end{array}$ & $\begin{array}{l}14.0-17.5 \\
15-18\end{array}$ & $\begin{array}{l}15.9 \\
16.5\end{array}$ & $\begin{array}{l}34.4 \\
33.6\end{array}$ \\
\hline Interorbital space. & $\begin{array}{l}\sigma^{7} \\
0\end{array}$ & $\begin{array}{l}3.9-5.0 \\
4-5\end{array}$ & $\begin{array}{l}4.3 \\
4.7\end{array}$ & $\begin{array}{l}9.3 \\
9.6\end{array}$ \\
\hline Tympanum. & $\begin{array}{l}\sigma^{7} \\
\$\end{array}$ & $\begin{array}{l}3.9-5.0 \\
3.8-5.0\end{array}$ & $\begin{array}{l}4.4 \\
4.2\end{array}$ & $\begin{array}{l}9.6 \\
8.6\end{array}$ \\
\hline $\begin{array}{l}\text { Arm length } \\
\text { (Axilla to tip of third finger) }\end{array}$ & $\begin{array}{l}0^{7} \\
\wp\end{array}$ & $\begin{array}{l}22-28 \\
25-30\end{array}$ & $\begin{array}{l}24.6 \\
27.5\end{array}$ & $\begin{array}{l}53.4 \\
56.0\end{array}$ \\
\hline Diameter of lower arm......... & $\begin{array}{l}\sigma^{\top} \\
\wp\end{array}$ & $\begin{array}{l}4.0-6.2 \\
3.6-5.5\end{array}$ & $\begin{array}{l}4.7 \\
4.6\end{array}$ & $\begin{array}{r}10.2 \\
9.4\end{array}$ \\
\hline Length of hand. & $\begin{array}{l}0^{x} \\
\wp\end{array}$ & $\begin{array}{l}10.0-12.4 \\
10.0-12.5\end{array}$ & $\begin{array}{l}11.1 \\
11.5\end{array}$ & $\begin{array}{l}24.0 \\
23.5\end{array}$ \\
\hline Length of leg. & $\begin{array}{l}\sigma^{7} \\
\wp\end{array}$ & $\begin{array}{l}69-81 \\
77-88\end{array}$ & $\begin{array}{l}75.1 \\
79.8\end{array}$ & $\begin{array}{l}163.0 \\
162.5\end{array}$ \\
\hline Length of tibia. & $\begin{array}{l}\sigma^{7} \\
\wp\end{array}$ & $\begin{array}{l}21.8-26.0 \\
24-29\end{array}$ & $\begin{array}{l}23.6 \\
25.2\end{array}$ & $\begin{array}{l}51.2 \\
51.3\end{array}$ \\
\hline Length of foot and tarsus...... & $\begin{array}{l}0^{7} \\
0\end{array}$ & $\begin{array}{l}34-40 \\
35-42\end{array}$ & $\begin{array}{l}35.3 \\
37.6\end{array}$ & $\begin{array}{l}76.8 \\
76.6\end{array}$ \\
\hline Length of foot. & $\begin{array}{l}0^{7} \\
9\end{array}$ & $\begin{array}{c}21-26 \\
22.5-27.6\end{array}$ & $\begin{array}{l}23.7 \\
24.4\end{array}$ & $\begin{array}{l}51.4 \\
49.7\end{array}$ \\
\hline
\end{tabular}

Sex dimorphism.-Dimorphism in size is not clear, the average body length of 35 males being $46 \mathrm{~mm}$. (41.5 to 51 ) and of 17 females, $49 \mathrm{~mm}$. (44 to 53 ). There is a well-defined creamy-white granular nuptial pad on the dorsal and distal part of the first segment of the first finger of the male. The arm of the male is moderately enlarged, and the tympanum is somewhat larger than that 
of the female. Male specimens from Mount Omei have paired subgular internal vocal sacs; in males from Fukien there is a slight modification on the skin of the throat to form loose longitudinal folds (i.e. vocal sac external). On the dorsoposterior side of each arm of the male there is a large flattened gland. The lineae masculinae are well defined.

Coloration in life.--The color on the back is from Medal Bronze to olive green with a lighter fine median line originating at the interorbital space and extending backward to the vent. In some specimens this line is only distinct posteriorly. A Light Antique Brown line begins at the tip of the snout, extends backward through the nostril, the margin of the upper eyelid, and along the dorso-lateral glandular fold to the hip. This line separates the color of the back from the different coloration of the sides of the head and the body. There are a few rounded black spots on the back near the hip region. A yellow band is present on the upper jaw, extending to the base of the arm; this yellowish band divides the dark or dark brown of the sides of the head. The sides of the body are from light yellow brown to grayish brown marbled with black. The color of the limbs is Sudan Brown with light-edged dark bars. The pupil is horizontally oval, black, enclosed by a golden ring. The iris of adenopleura is characteristic, being golden above and reddish golden below.

Habitat and habits.-Rana adenopleura has long been well known on Mount Omei for its musical melody during the breeding season. It is known as the "Fairy Musician." One of the temples on Mount Omei is famous for having some of these frogs in a pool outside of the main gate of Hungchungping $(3,700$ feet), and they may not be collected inside of this temple. I stayed there one night on my way to Chinting, and had my first experience of hearing this frog's voice. At night, even with the help of a flashlight, the frogs are difficult to see clearly. The voice is entirely different from the croaking of most other Salientia. The notes vary during different croaks. There are generally three, but there may be from one to eight. The first note is low and the tone gradually rises in pitch. If the notes are three, the melody is "do, me, sol."

On the morning of August 8, Mr. P. L. Luh heard the song from an unused manure pool, which was grass-lined and held a little water. He discovered that some frogs jumped into the water, and saw some holes around the margin of the pond. The pool is very near to Chungfengsze. During the next few days I tried to find out which frogs produced the beautiful song, as three species were found in the pool: Rana adenopleura, $R$. limnocharis, and $R$. boulengeri, and tadpoles of Rhacophorus omeimontis and $R h$. leucomystax. On August 13 two males were caught at their nests in pool No. 2. Their snouts were bleeding where the epidermis had been rubbed off. Probably this is caused by making the nest with the snout. In the same pool, a pair was found in a nest and the male was croaking; this confirmed the voice as that of Rana adenopleura. In order to make sure that Rana adenopleura is the same species as the frog described as Rana musica by Chang and Hsu, a special study was made on the morning of August 18 of three pools, which were numbered according to date. Six pools 
were studied for the natural habitat of this species, but only three were frequently visited. In pool No. 2, a male was found in a hole among stones, croaking with from one to three notes. As it was in a hole the species could not be identified. Another male in a hole was found at pool No. 1. Three males and three females were found at pool No. 3. Besides these six individuals found near the nests on the margin of the water, there were five more on the floating branches, with their bodies partly in the water. All of them were caught. They were all adenopleura. I observed a female approaching a male, who croaked immediately and turned his head toward her. He croaked for some time, then stopped, and after a while croaked in a different tone, in which other males followed suit. This sound was low and not musical at all, like "wa-wa-wa." As a result of this sound, a female began to approach one of the males. Then all the males sang again.

At the time of croaking, the whole throat is stretched out. Rana adenopleura is not a very active frog, but even when disturbed the males keep on croaking. If stones are thrown at them, they move away or stop their singing. From June to early September is the breeding season, and during this period males are responsible for making the nests, and are provided with a longer snout. Furthermore, on the morning of August 20, two males were found in the process of making excavations. Several males were singing in their burrows, or near them, in order to attract the opposite sex.

The nest burrows are rounded or oval, the diameter and depth varying greatly. If the earth is rather deep and soft, the nests are round, small in diameter, and deeper; if the depth of the earth is limited, the nests generally have a wider opening and are shallow. The inner surface of the nest is smooth and contains a little water. Forty-three nests were measured as to diameter and depth. Generally the opening is slightly narrower than the body of the nest but in a few cases the nest stretched out to one side if the earth was too shallow and limited, lacking mud, so the opening was at one side toward the water.

Rana adenopleura: Measurements of Nests

$\begin{array}{rcccccccc}\text { No. } & \text { Diameter } & \text { Depth } & \text { No. } & \text { Diameter } & \text { Depth } & \text { No. } & \text { Diameter } & \text { Depth } \\ 1 & 75 \times 50 & 35 & 16 & 30 \times 40 & 35 & 31 & 70 \times 70 & 15 \\ 2 & 70 \times 60 & 45 & 17 & 40 \times 40 & 35 & 32 & 75 \times 90 & 10 \\ 3 & 75 \times 40 & 50 & 18 & 40 \times 35 & 25 & 33 & 45 \times 50 & 65 \\ 4 & 50 \times 50 & 55 & 19 & 65 \times 55 & 35 & 34 & 70 \times 35 & 20 \\ 5 & 90 \times 75 & 40 & 20 & 45 \times 25 & 15 & 35 & 40 \times 70 & 15 \\ 6 & 95 \times 50 & 40 & 21 & 35 \times 35 & 15 & 36 & 70 \times 80 & 15 \\ 7 & 45 \times 50 & 35 & 22 & 55 \times 65 & 17 & 37 & 45 \times 60 & 8 \\ 8 & 40 \times 50 & 40 & 23 & 75 \times 85 & 20 & 38 & 50 \times 40 & 12 \\ 9 & 25 \times 30 & 30 & 24 & 80 \times 75 & 20 & 39 & 50 \times 60 & 10 \\ 10 & 65 \times 45 & 30 & 25 & 75 \times 70 & 15 & 40 & 40 \times 45 & 20 \\ 11 & 50 \times 35 & 45 & 26 & 70 \times 55 & 10 & 41 & 40 \times 40 & 15 \\ 12 & 30 \times 30 & 45 & 27 & 75 \times 70 & 25 & 42 & 50 \times 50 & 25 \\ 13 & 40 \times 55 & 30 & 28 & 90 \times 70 & 10 & 43 & 30 \times 40 & 20 \\ 14 & 35 \times 20 & 50 & 29 & 40 \times 60 & 30 & & & \\ 15 & 40 \times 40 & 37 & 30 & 90 \times 60 & 8 & & & \end{array}$


Eggs (fig. 63, A) are always laid in the nests at the margin of pools and ponds. Each egg cluster is indistinctly divided into lobes, which are closely connected with each other. Six clusters were counted and studied as to the lobes and capsules of each egg. The number of eggs laid by females ranges from 93 to 139 . The diameter of the egg varies from 1.9 to $2.1 \mathrm{~mm}$., with an average of $2.0 \mathrm{~mm}$. The number of eggs in each lobe varies greatly. It is generally from nine to fifteen, but in some cases it is even more than thirty and occasionally there may be only one or two. This condition may signify the end of egg-laying. Each egg is enclosed by a thin capsule of its own. A number of eggs have a

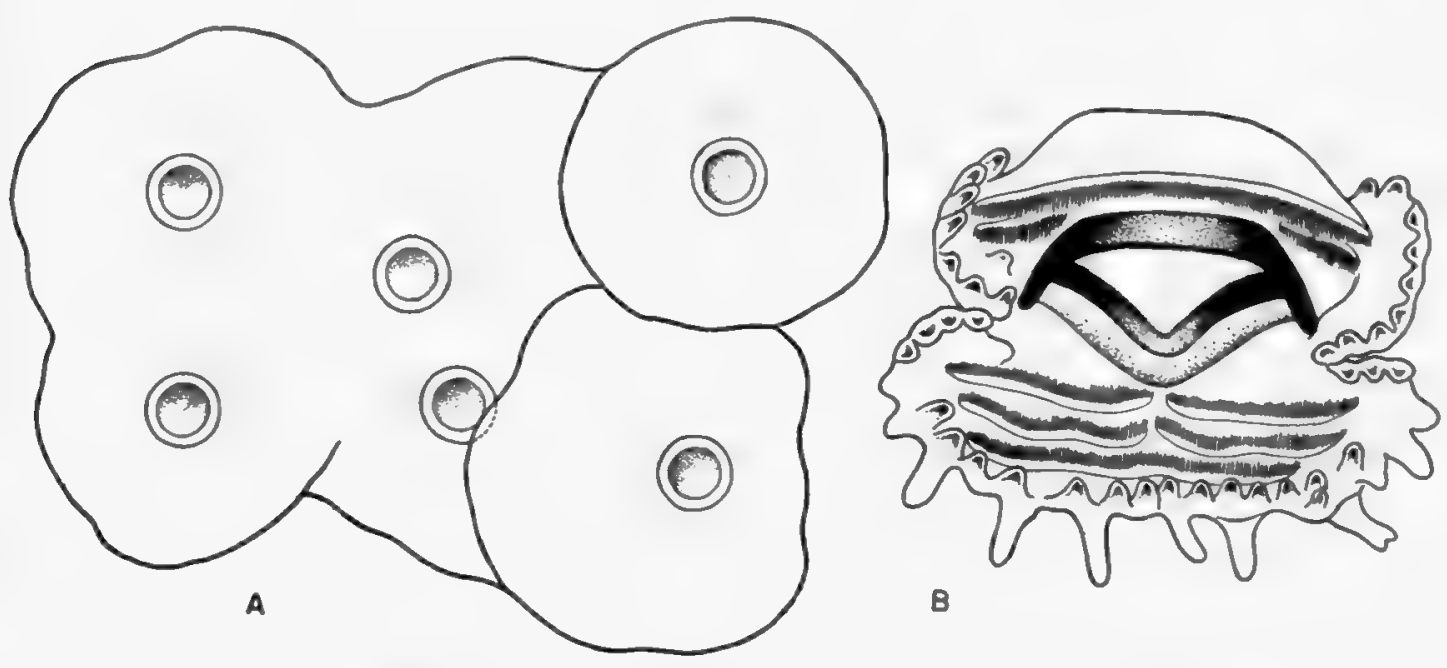

FIG. 63. Rana adenopleura. A. Eggs ( $\times 3)$. B. Mouth of tadpole $(\times 18)$.

common coat, as an external capsule, and this is connected at different places with the external common coat of the other lobes. The jelly inside the common coat is very abundant and dilute, which is necessary for the development of young, as there is no water in the newly built nest.

In order to study the development of the tadpole, a mass of eggs laid during the night of August 19 was brought back to our working place for observation. The eggs were in the blastula stage when collected. At 10:00 A.M. the next day, the dorsal lip was completely formed; neural groove formation was accomplished by 8:00 A.M., August 21. After 24 hours (August 22) the neural tube was formed and the three regions of head, body and tail could be distinguished; at this stage the tadpoles hatched out. External gill-filaments were visible at 10:00 A.M. the same day. So it took about three days from egg-laying to the time of hatching. The color of the young is grayish on the back and light gray on the belly.

There are no communications or channels between the nests and the water of the pools, and rain seems to be the only means of bringing the tadpoles to the pool. As the nests are shallow and always located on the marginal slope of a body of water, a little rain floods them and carries away the hatched individuals. If there is no rain, the tadpoles may live in the liquefied jelly in the nest for some 
time after hatching; fortunately, during the breeding season of this species, it rains nearly every evening, so the tadpoles find little difficulty in reaching the pool for later development and metamorphosis.

The further development of the tadpole is essentially the same as in other frogs. The incubation period of three days is rather brief. After hatching, the growth rate is slow. It takes eight days for full development of external gills; gill-filaments appeared at 10:00 A.M. on August 22 and were fully developed by August 29.

The coloration of the tadpole (pl. 10, fig. 9) varies according to age. Just after hatching, it is light gray. As the external gills and tail fin become fully developed the color becomes darker. When the tadpoles are more than $12 \mathrm{~mm}$. long, the mouth-parts are silver brown marked with black, the dorsal side of the animal has a deeper silver brown color, marbled with black, and the tail is a light silver brown spotted with black. The throat is pinkish in color and the belly is dark gray. Tadpoles with hind legs developed have a dark greenish brown color on the back slightly marbled with black spots, which are scattered irregularly. Two ill-defined lines extend from the posterior corner of the eye to the base of the tail. The eye is golden with a black pupil. The anterior region of the belly is dull flesh color and the posterior is opaque white. The tail has a dark yellowish brown background and is entirely marbled with black, much like the coloration of the dead vegetation in the water. The four-legged tadpoles have more or less the coloration as described above. It takes two days to complete the process of metamorphosis.

As this is a form of stagnant water, the tadpole has a stout body and wide tail fin. Ten tadpoles with hind legs well developed average in body length 16.7 $\mathrm{mm}$., and tail length $30.7 \mathrm{~mm}$. (see table for measurements). The young adult just after metamorphosis measures about $21 \mathrm{~mm}$. from snout to vent.

There are two rows of labial teeth on the upper lip, the first row complete and the second interrupted, with its two short oblique portions located at the dorso-lateral corner of the mouth (fig. 63, B). Three rows of labial teeth are found on the lower lip, the third row the longest, and the two inner rows interrupted. The beak is moderately developed, with a fine serrated edge. The dorsal part of the mouth is free from papillae, which are present laterally and ventrally. There is one row of medium-sized papillae on the dorso-lateral side of the mouth and two rows on the lateral and ventral sides. The outer row consists of long papillae and the number varies in different specimens. The papillae of the inner row are low and small and generally two are found at the base of each long papilla of the outer row.

Pope (1931) gives considerable data on the habits and life history of Rana adenopleura. His data and mine differ in several important points, and it seems possible that the species on Mount Omei may really be distinct, and therefore the name daunchina valid after all. It is possible that the habits of this frog on Mount Omei correspond to the "original habitat" on which Pope speculates 
in his paper (p. 536), thinking that the habits in Fukien represent an adaptation to the rice culture introduced high on the mountain by the industrious Chinese farmers. At Sanchiang Pope found adenopleura laying eggs in the quiet water of the rice fields immediately at the base of the rockwork terrace-facing, instead of in a nest on the sloping bank of a pond, and he found the eggs laid in clusters of egg-sacs, each sac holding from 1 to $4 \mathrm{eggs}$, the whole cluster containing from 308 to 373 eggs; on Mount Omei each cluster consisted of a number of lobes, each containing anywhere from 2 to $30 \mathrm{eggs}$, but usually from 9 to 15, the entire cluster containing from 93 to 139 eggs. If the original mountain ponds with soft sloping banks have been replaced in Fukien with rockbound terraced rice fields, it is easily imaginable that the frogs might have adapted their egg-laying habits to the new conditions.

The differences in Pope's descriptions of the tadpoles from my observations on Mount Omei are of minor importance. The very striking ventral fringe of long papillae and the much mottled tail are present in both. The Sanchiang tadpoles seem to lose the upper teeth very easily, while those on Mount Omei always had one perfect long continuous row supplemented by a very short row on each side of the beak just below the long continuous row; but tadpole teeth so often vary, or get broken, that this difference does not seem to support a distinction of two forms. The most irreconcilable difference is that Pope does not mention the melodious song so famous on Mount Omei.

Rana adenopleura: Measurements of Ten Tadpoles

\begin{tabular}{|c|c|c|c|}
\hline Measurements & Range & Average & $\begin{array}{c}\text { Ratio to } \\
\text { body length }(\%)\end{array}$ \\
\hline Body length. & $16.0-17.3$ & 16.7 & \\
\hline Body height. & $8.3-11.0$ & 9.2 & $\dot{55.2}$ \\
\hline Body width. & $9.7-14.3$ & 12.2 & 73.3 \\
\hline Head height. & $4.4-5.7$ & 5.1 & 30.5 \\
\hline Head width. & $8-10$ & 8.8 & 52.9 \\
\hline Mouth width. & $3.3-3.6$ & 3.4 & 20.4 \\
\hline Space between eyes. & $6.7-7.3$ & 7.0 & 41.9 \\
\hline Snout to spiraculum. & $11.4-12.8$ & 12.3 & 73.5 \\
\hline Tail length......... & $24.0-36.4$ & 30.7 & 184.1 \\
\hline Tail height. & $8.3-10.2$ & 9.6 & 57.4 \\
\hline Diameter of tail muscle & $\mathbf{3 . 3}-\mathbf{3} .8$ & 3.6 & 21.5 \\
\hline Length of hind leg.. & $11.4-12.8$ & 12.3 & \\
\hline
\end{tabular}

\section{Rana pleuraden Boulenger}

Rana pleuraden Boulenger, 1904, Ann. Mag. Nat. Hist., (7), 13: 131-Yunnanfu, Yunnan; idem, 1920, Rec. Ind. Mus., 20: 90; Werner, 1924, Denkschr. Akad. Wiss. Wien, 99: 52; Schmidt, 1927, Bull. Amer. Mus. Nat. Hist., 54: 570; Pope, 1931, op. cit., 61: 539; Pope and Boring, 1940, Peking Nat. Hist. Bull., 15, pt. 1: 57.

History of species.-Boulenger described pleuraden from Yunnan in 1904, and in his 1920 paper lists only the five types and three additional examples from Tungchwan, Yunnan. In 1924, Werner extended the range to Sichang, Sikang (then called Ningyuan), and Schmidt and Pope have reported an abundance of 
specimens from Yunnan. In May, 1942, I studied pleuraden in the field near Chaochiao City, Sikang.

Distribution and collection data.--Rana pleuraden is found in Yunnan, in the southeastern corner of Sikang, and in southwestern Szechwan, with a vertical distribution from 5,500 feet to 8,000 feet. Mr. Shih collected a few specimens from the east side of Taliangshan, Szechwan, and I collected eight males and six females near Chaochiao City to the west of Taliangshan, Sikang, May 7, 1942.

Comparison with related species.-Rana pleuraden is related to Rana adenopleura, but the tips of its toes are obtuse and disks are developed on the toes of adenopleura.

Original description.- "Vomerine teeth in two small oblique groups between the choanae. Head moderate, as long as broad; snout obtusely pointed, prominent, as long as the orbit; canthus rostralis obtuse; loreal region oblique, concave; nostril equally distant from the eye and from the end of the snout; interorbital region narrower than the upper eyelid; tympanum very distinct, two-thirds to three-fourths the diameter of the eye. Fingers and toes rather slender, obtusely pointed; first finger extending beyond the second; toes half webbed; subarticular tubercles rather feeble; a small oval inner metatarsal tubercle. The tibio-tarsal articulation reaches between the eye and the tip of the snout. Skin smooth or with small warts; a moderately broad, very prominent, dorso-lateral glandular fold; no other folds on the body. Olive-brown or greyish above, spotted with black; a light vertebral streak usually present; a dark brown or blackish band on each side of the head, passing through the eye and involving the tympanum; a whitish streak along the upper lip; limbs with more or less regular black crossbars; sometimes a light line along the inner side of the leg, continued to the outer toe; hinder side of the thighs marbled black and yellow; lower parts white, throat sometimes brownish. Male with a vocal sac on each side, forming loose folds on the throat, and a very large flat gland on each side of the body, above and behind the shoulder.

"From snout to vent $63 \mathrm{~mm}$."

Coloration in life.--In living specimens collected in Chaochiao the yellowishgreen ground color of the upper parts is stippled with black, with scattered irregular black spots, especially on the sides, and with black bars on the limbs. The upper jaw has a lighter band along its margin, and between this band and the canthus rostralis there is usually a dark band. The iris is old gold stippled with black and red as in adenopleura. The specimens from Yunnan have more black spots and are much more marbled with black than are those from Chaochiao.

Sex dimorphism.- Sex dimorphism in size is not evident. The inner dorsal side of the basal segment of the first finger of the male is covered by a welldefined creamy white nuptial pad. Males are provided with paired external subgular vocal sacs, and the skin on the sides of the throat is thinner than in females, with inconspicuous longitudinal folds. The openings of the vocal sacs vary. Some have two round openings on the inside of the angles of the jaws, 
some have two slit-like openings, and some have a round opening on one side and a slit-like opening on the other. There is a large lateral gland on each side above and behind the arm. The lineae masculinae are conspicuously developed.

Habitat and habits.-I collected only adult specimens of Rana pleuraden in Chaochiao, Sikang. The frog is mostly found in small mountain streams of very clean and clear water, while the related Rana adenopleura inhabits especially dirty pools, such as are found in unused manure. I did not find adenopleura in streams of any kind in my three summers on Mount Omei. Pope (1931) reported that adenopleura was common in flooded rice fields in Fukien.

Rana pleuraden: Measurements of Eight Male and Six Female Adults

\begin{tabular}{|c|c|c|c|c|}
\hline Measurements & Sex & Range & Average & $\begin{array}{l}\text { Ratio to } \\
\text { body length }(\%)\end{array}$ \\
\hline Body length. & $\begin{array}{l}0^{7} \\
q\end{array}$ & $\begin{array}{l}43-51 \\
45-55\end{array}$ & $\begin{array}{l}47.4 \\
49.8\end{array}$ & $\ldots$ \\
\hline Head length. & $\begin{array}{l}0^{7} \\
\wp\end{array}$ & $\begin{array}{c}16.5-18.5 \\
17-20\end{array}$ & $\begin{array}{l}17.7 \\
18.2\end{array}$ & $\begin{array}{l}37.4 \\
36.6\end{array}$ \\
\hline Head width. & $\begin{array}{l}97 \\
8\end{array}$ & $\begin{array}{c}14.0-17.5 \\
15-19\end{array}$ & $\begin{array}{l}15.9 \\
16.5\end{array}$ & $\begin{array}{l}33.5 \\
33.1\end{array}$ \\
\hline Interorbital space.... . & $\begin{array}{l}0^{7} \\
q\end{array}$ & $\begin{array}{c}3-4 \\
3.4-3.8\end{array}$ & $\begin{array}{l}3.4 \\
3.6\end{array}$ & $\begin{array}{l}7.2 \\
7.3\end{array}$ \\
\hline Tympanum. & $\begin{array}{l}07 \\
9\end{array}$ & $\begin{array}{l}3-4 \\
3-4\end{array}$ & $\begin{array}{l}3.7 \\
3.7\end{array}$ & $\begin{array}{l}7.8 \\
7.4\end{array}$ \\
\hline Length of lower arm. & $\begin{array}{l}07 \\
8\end{array}$ & $\begin{array}{l}20-22 \\
19-22\end{array}$ & $\begin{array}{l}20.8 \\
20.0\end{array}$ & $\begin{array}{l}43.9 \\
40.0\end{array}$ \\
\hline Diameter of lower arm. & $\begin{array}{l}0^{7} \\
8\end{array}$ & $\begin{array}{l}4.2-5.6 \\
5.0-5.5\end{array}$ & $\begin{array}{l}5.0 \\
5.1\end{array}$ & $\begin{array}{l}10.5 \\
10.2\end{array}$ \\
\hline Length of hand. & $\begin{array}{l}0^{7} \\
8\end{array}$ & $\begin{array}{r}11-13 \\
11-13\end{array}$ & $\begin{array}{l}12.2 \\
12.0\end{array}$ & $\begin{array}{l}25.7 \\
24.1\end{array}$ \\
\hline Length of leg. & $\begin{array}{l}0^{7} \\
8\end{array}$ & $\begin{array}{l}71-81 \\
72-83\end{array}$ & $\begin{array}{l}76.6 \\
77.3\end{array}$ & $\begin{array}{l}161.6 \\
155.8\end{array}$ \\
\hline Length of tibia. & $\begin{array}{l}\sigma^{7} \\
q\end{array}$ & $\begin{array}{l}20-26 \\
23-27\end{array}$ & $\begin{array}{l}23.6 \\
24.5\end{array}$ & $\begin{array}{l}49.8 \\
49.2\end{array}$ \\
\hline Length of foot and tarsus...... & $\begin{array}{l}0 \\
9\end{array}$ & $\begin{array}{l}31-38 \\
35-39\end{array}$ & $\begin{array}{l}36.0 \\
37.0\end{array}$ & $\begin{array}{l}76.0 \\
74.3\end{array}$ \\
\hline Length of foot. & $\begin{array}{l}0^{7} \\
8\end{array}$ & $\begin{array}{l}22-28 \\
25-28\end{array}$ & $\begin{array}{l}26.0 \\
26.2\end{array}$ & $\begin{array}{l}54.9 \\
52.6\end{array}$ \\
\hline
\end{tabular}

\section{The Mountain Bullfrogs of Western China}

Key for Identification of Adults of Rana spinosa Group in Western China

I. Tips of digits dilated, male with spines all over the belly . . . . . . . . boulengeri.

II. Tips of digits not dilated, male with two patches of spines on the chest.

A. Blackish, white-edged ocelli at the hip-joint................ feae.

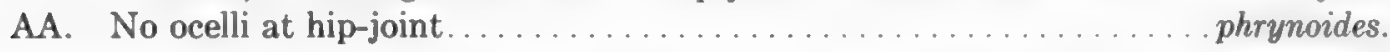

KEY FOR IDENTIFICATION OF TADPOLES OF RANA SPINOSA GROUP IN WESTERN ChINA

I. Nostril enclosed by an elevated white ring provided with minute papillae; abdominal muscle strongly developed.................................... phroides.

II. Nostril enclosed by a low black ring without papillae; abdominal muscle poorly developed 


\section{Rana boulengeri Günther}

Rana boulengeri Günther, 1889, Ann. Mag. Nat. Hist., (6), 4: 222--Ichang, Hupeh; Liu, 1935, Peking Nat. Hist. Bull., 10, pt. 1: 55; idem, 1941, op. cit., 15, pt. 3: 253.

Rana tibetana Boulenger, 1917, Ann. Mag. Nat. Hist., (8), 20: 414-Yintsinwan, Wassu State, Tibet; idem, 1920, Rec. Indian Mus., 20 : 70 (Yintsinwan); Stejneger, 1925, Proc. U. S. Nat. Mus., 66, art. 25: 24; Chang and Hsu, 1932, Contr. Biol. Lab. Sci. Soc. China, (Zool.), 8, No. 5: 169.

Rana spinosa Boulenger, 1920, Rec. Indian Mus., 20 : 74 (part); Werner, 1924, Denkschr. Akad. Wiss. Wien, 99: 52.

History of species.-Günther described Rana boulengeri from Ichang, Hupeh, in 1889, and in 1892 additional examples were reported from Hupeh by the same

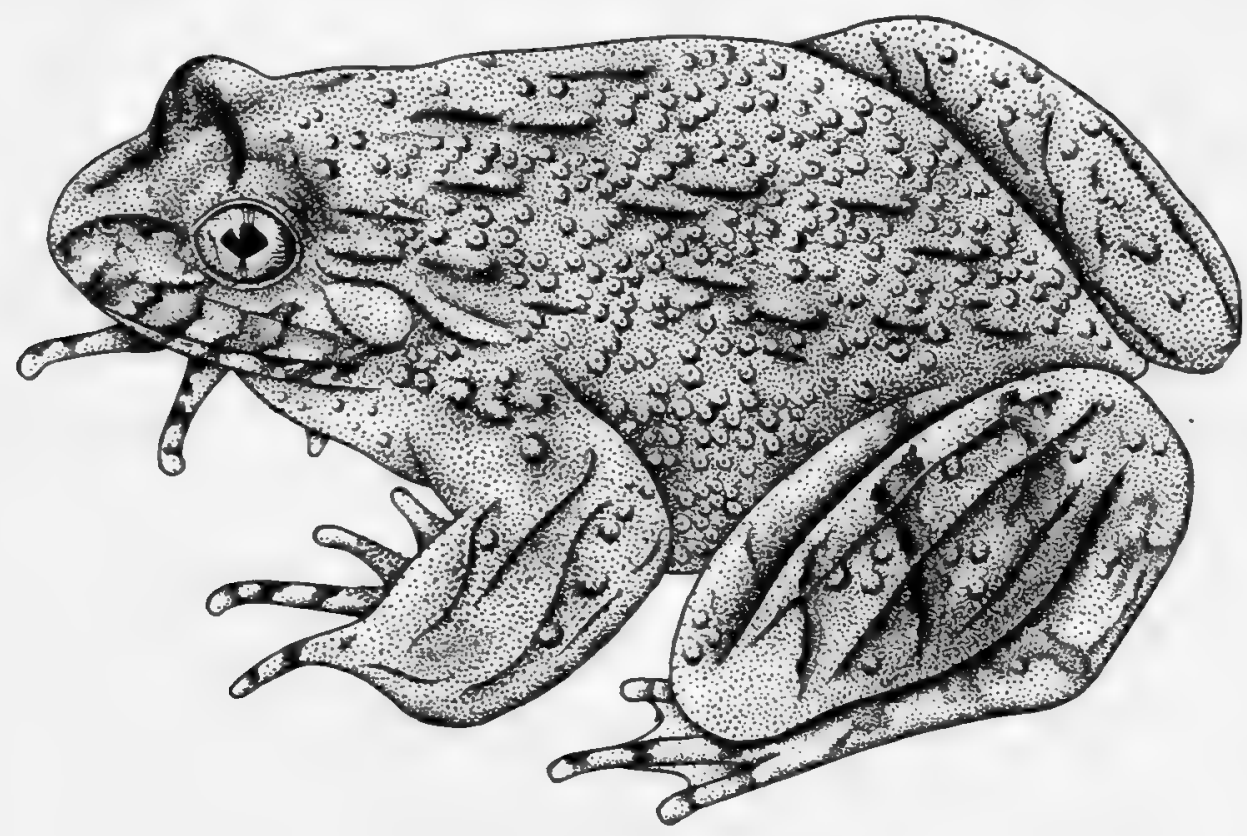

FIG. 64. Rana boulengeri; adult male ( $\times 1)$.

author. In 1920, Boulenger referred the species to Rana spinosa (which is a good species found in eastern and southern China) and subsequently redescribed the true boulengeri as Rana tibetana, basing it on specimens from Yintsinwan, Wassu State, Tibet. In 1925, Stejneger recorded tibetana from Mount Omei, and discussed its type locality as near Wenchwan; and, in 1932, Chang and Hsu reported tibetana from Tsingch'engshan, Kwanhsien, and Mount Omei. In 1935, I demonstrated that boulengeri is distinct from spinosa, but kept tibetana as a valid species. In 1940, Pope and Boring tentatively considered the type of tibetana to be a young male of boulengeri. My field work in the mountains of Wenchwan has now shown that tibetana is a strict synonym of boulengeri.

Distribution and collection data.-Rana boulengeri (fig. 64) is a frog belonging to the spinosa group and found in the mountain streams of central and western 
China. Its geographic range is from western Hupeh to eastern Sikang, with a vertical distribution ranging from 1,500 feet to 4,500 feet. To the north, I found specimens around Kwanhsien and Wenchwan, but I obtained none around Lifan City; to the south, I collected many specimens of adults, tadpoles, and

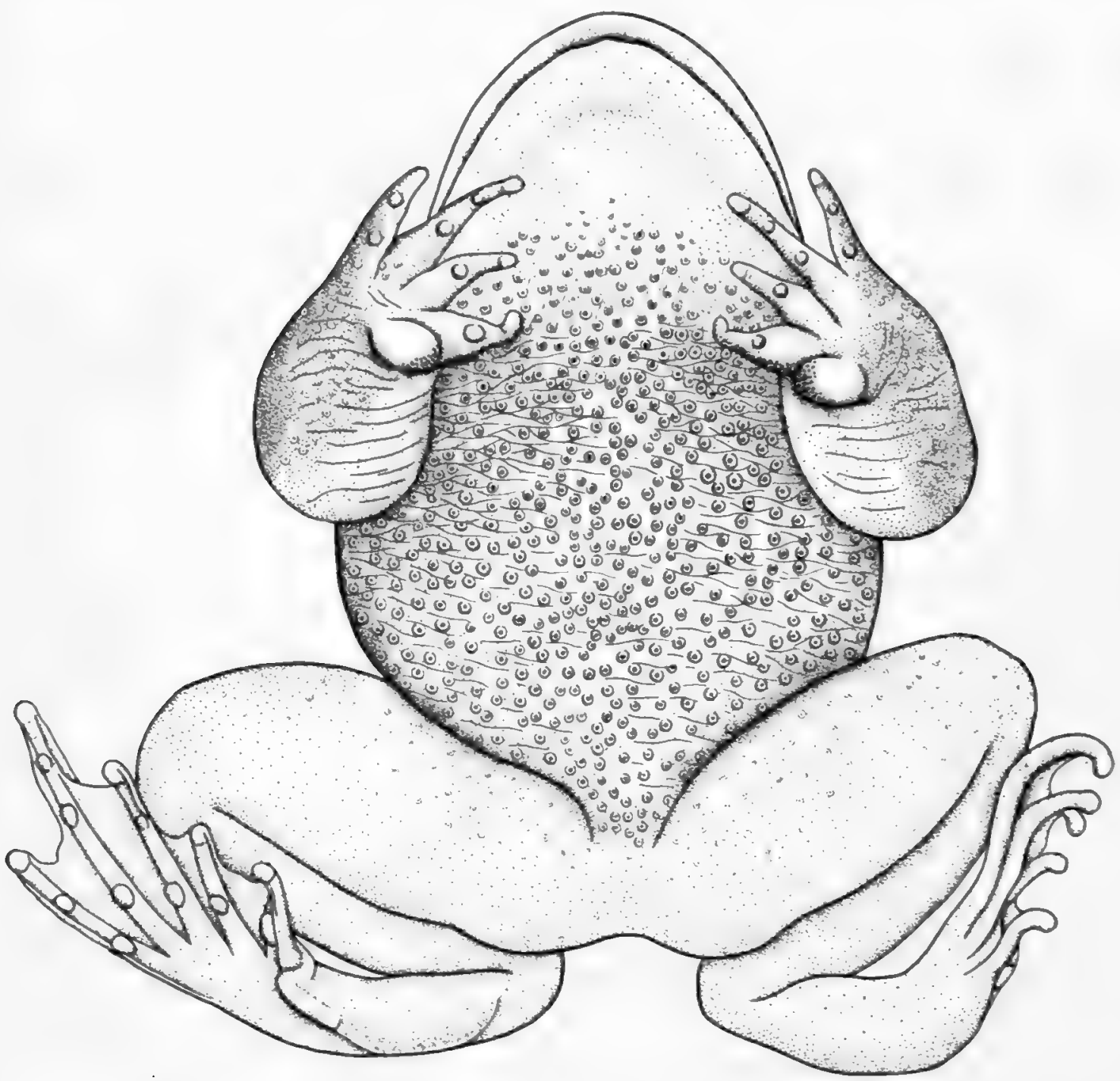

FIG. 65. Rana boulengeri; adult male, showing spines on belly ( $\times 1$ ).

eggs on Mount Omei during the summers of 1938, 1940 and 1945; to the west, I found many adults and tadpoles around Yaan, Tienchuan, and Lushan, but I did not see a single specimen around Paohsing, Luting, or Kangting. Rana boulengeri seems to inhabit the lower altitudes of the eastern slopes of the mountain ranges between Sikang and Szechwan, with a semicircle of distribution from Wenchwan, via Kwanhsien, Lushan, Tienchuan, and Yaan southward to the Mount Omei region. South and southwest of Taliangshan the related species phrynoides is found. Pope and Boring (1940) state that Boring had found in 
the Musée Hoangho-Paiho specimens collected from mountains in southern Kansu, Shensi, and Shansi, and tentatively referred to Rana boulengeri. Boring also reports specimens in the Fan Memorial Institute from Chensiung, northeastern Yunnan, and Kienshui in southern Yunnan. Rana boulengeri may well occur in southern Kansu and Shensi, and in northeastern Yunnan. The southern Shansi and the southern Yunnan records are questionable.

Comparison with related species. - The dilated tips of the digits and the black spines all over the belly of the male are the best characters by which to distinguish boulengeri (fig. 65) from phrynoides (fig. 67), which has two patches of spines on the thorax of the male, and does not have dilated digital tips. In the male of Rana spinosa the black spines are limited to the thoracic region but are not divided into patches.

Rana boulengeri: Measurements of Fifteen Male and Sixteen Female Adults

\begin{tabular}{|c|c|c|c|c|}
\hline Measurements & Sex & Range & Average & $\begin{array}{c}\text { Ratio to } \\
\text { body length (\%) }\end{array}$ \\
\hline Body length. . & $\begin{array}{l}\sigma^{7} \\
q\end{array}$ & $\begin{array}{c}83.5-123.0 \\
82-118\end{array}$ & $\begin{array}{c}104.1 \\
96.6\end{array}$ & $\ldots$ \\
\hline Head length. & $\begin{array}{l}\sigma^{2} \\
0\end{array}$ & $\begin{array}{c}30-44 \\
28.7-39.0\end{array}$ & $\begin{array}{l}37.3 \\
34.0\end{array}$ & $\begin{array}{l}35.8 \\
35.1\end{array}$ \\
\hline Head width. & $\begin{array}{l}0^{7} \\
0\end{array}$ & $\begin{array}{l}34-51 \\
31-44\end{array}$ & $\begin{array}{l}42.7 \\
37.4\end{array}$ & $\begin{array}{l}41.0 \\
38.8\end{array}$ \\
\hline Interorbital space............ & $\begin{array}{l}\sigma^{7} \\
0\end{array}$ & $\begin{array}{l}6-10 \\
5.8-9.0\end{array}$ & $\begin{array}{l}7.8 \\
6.9\end{array}$ & $\begin{array}{l}7.4 \\
7.1\end{array}$ \\
\hline Tympanum. & $\begin{array}{l}0^{7} \\
9\end{array}$ & $\begin{array}{c}5-7 \\
4.4-7.0\end{array}$ & $\begin{array}{l}5.9 \\
5.4\end{array}$ & $\begin{array}{l}5.6 \\
5.6\end{array}$ \\
\hline Length of lower arm..... & $\begin{array}{l}0^{7} \\
q\end{array}$ & $\begin{array}{l}37.0-58.5 \\
33-50\end{array}$ & $\begin{array}{l}48.1 \\
40.9\end{array}$ & $\begin{array}{l}46.1 \\
42.4\end{array}$ \\
\hline Diameter of lower arm. & $\begin{array}{l}\sigma^{7} \\
\text { क }\end{array}$ & $\begin{array}{l}14-27 \\
8.8-13.5\end{array}$ & $\begin{array}{l}19.7 \\
11.8\end{array}$ & $\begin{array}{l}18.8 \\
12.2\end{array}$ \\
\hline Length of hand. & $\begin{array}{l}\sigma^{7} \\
\text { क }\end{array}$ & $\begin{array}{c}18.7-28.0 \\
18-26\end{array}$ & $\begin{array}{l}23.9 \\
21.3\end{array}$ & $\begin{array}{l}23.0 \\
22.1\end{array}$ \\
\hline Length of leg. . & $\begin{array}{l}7 \\
0\end{array}$ & $\begin{array}{l}135-204 \\
131-180\end{array}$ & $\begin{array}{l}172.2 \\
154.8\end{array}$ & $\begin{array}{l}165.0 \\
160.2\end{array}$ \\
\hline Length of tibia. & $0^{7}$ & $\begin{array}{l}45-66 \\
43-61\end{array}$ & $\begin{array}{l}55.3 \\
50.1\end{array}$ & $\begin{array}{l}53.2 \\
51.7\end{array}$ \\
\hline Length of foot and tarsus...... & $0^{7}$ & $\begin{array}{l}58-87 \\
61-81\end{array}$ & $\begin{array}{l}75.2 \\
71.1\end{array}$ & $\begin{array}{l}72.3 \\
73.5\end{array}$ \\
\hline Length of foot.......... & $\begin{array}{l}1 \\
0 \\
0\end{array}$ & $\begin{array}{c}36-56 \\
33.4-44.0\end{array}$ & $\begin{array}{l}46.7 \\
39.9\end{array}$ & $\begin{array}{l}44.8 \\
41.2\end{array}$ \\
\hline $\begin{array}{l}\text { Length of inner metatarsal } \\
\text { tubercle................. }\end{array}$ & $\begin{array}{l}0 \\
9\end{array}$ & $\begin{array}{l}6.2-9.8 \\
6.5-8.4\end{array}$ & $\begin{array}{l}8.1 \\
7.5\end{array}$ & $\begin{array}{l}7.7 \\
7.8\end{array}$ \\
\hline
\end{tabular}

Original description.- "Vomerine teeth in two short oblique series, each starting from the inner edge of the choana. Head large, broad, much depressed; snout very short and rounded; canthus rostralis short but distinct; upper eyelid a little broader than the interorbital space, tympanum hidden. First finger longer than the second; toes with swollen extremity, entirely webbed; subarticular tubercles well developed; inner metatarsal tubercle elongate; no outer metatarsal tubercle. The tibio-tarsal joint does not reach the end of the snout when 
the limb is carried forward. Skin of the upper parts covered with large elongated warts and small rounded tubercles; a strong fold of the skin above the tympanum; no glandular fold on the side of the back. Uniform blackish brown above. Male with two internal vocal sacs.

"As in Rana liebigii, the breeding male has an extremely thick forearm, but without any special armature. The vestigial thumb and a large rounded tubercle on the upper side of the first finger are thickly studded with horny spines, the second and third fingers having similar spines, but less numerous. The whole of the chest is covered with smaller and larger rounded tubercles, each armed with a black conical horny spine, and similar but smaller dermal structures are scattered over the abdomen and also over the throat.

"Two specimens of this large species were sent by Mr. Pratt from Ichang. The length from snout to vent is 4 inches."

Habitat and habits.-Rana boulengeri is usually found in small mountain streams, in recesses of boulders near the margin of the water or below cascades; it is rarely found in large streams or independent pools. It is commonly known as the "Stone Frog," for it is so much associated with boulders. People of Mount Omei do not eat this frog, but in Lushan it is a delicacy to be used when entertaining guests. The flesh is tender and delicious.

Rana boulengeri has a peculiar habit of remaining in one place. If there is some disturbance, it may dive into the water and hide under vegetation, in cracks, or under stones on the bottom of the pond, and occasionally may get into holes under large stones on the bank of the pool; but after a while it will come back again. It is clumsy and slow in comparison with other forms found in mountain streams. One can approach it as close as five feet and watch it for a long time without causing it to jump away, and it is very easy to catch by hand at night with the help of a flashlight. One individual is usually found in each place, although sometimes two or more animals stay together. Males croak in the places where they sit, uttering single loud notes that sound like "kung, kung, kung." After the breeding season, specimens collected are mostly females. This is also true for Rana margaretae, another mountain form; for most Salientia, males are easier to secure at all seasons.

Breeding season.-The breeding season of Rana boulengeri varies even in the same place and under the same conditions. Tadpoles with hind limb-buds were collected from Tsingch'engshan on April 28, 1940. On Mount Omei, in front of Taosze, tadpoles with hind legs fully developed were found in a mountain stream on June 26 of the same year. Tadpoles of different stages, from newly hatched individuals up to tadpoles with hind limbs, were collected back of Yangkiashan, Mount Omei, on June 28. Eggs were found on July 4 and July 21 that summer in front of Taosze. On August 5, another mass of eggs in the cleavage stage was found under stones by the side of a cascade back of Yangkiashan. The above facts indicate that the breeding season of this species is from April to August. As its developmental process is slow, the breeding season may begin in the middle of March. 
Eggs and breeding site.-Eggs of Rana boulengeri are found in small mountain streams, and the exact site of deposition is unique. The most favorable site for egg-laying is beneath a large stone or boulder about four or five inches above the bottom of the pool and directly beneath or by the side of a cascade. The second choice of site is on branches of vegetation immersed in the water, or on small boulders on the bottom of a pool. Sometimes a few free isolated eggs are found in pools and ponds.

It is hard to make direct observations on eggs that are attached to the under surface of a large stone as the eggs are only about four or five inches above the bottom and the depth of water sometimes reaches two feet. The reasons for this choice for an egg-laying site may be because the egg-laying process is similar to that of Staurois chunganensis (see p. 341). The limited number of free isolated eggs in water may be those laid at the end of the egg-laying process or may be eggs that have failed to become attached to the stone or stick. The only way to study their distribution and manner of attachment is by feeling with the fingertips. The eggs are strongly attached to the stone in one or two layers and are irregularly distributed. They are crowded in recesses of the stone and absent on the sharp elevations. It is nearly impossible to remove them with the fingers; in most cases only an egg and part of the jelly can be taken off by scraping hard with the fingertips. Eggs (fig. 66, A) attached to vegetation in the water are in single or double rows along branches; they lie in small clusters on the free surface of stone. The eggs have a jelly cable to attach them to the object. Where the cables are thick they are more or less continuous with the external jelly capsules. Eggs near the object to which they are attached have thicker and shorter cables and larger capsules than those farther away. The eggs of the second layer may have their own cables visible or indirectly connected with the object through the cables of the eggs of the first layer. Eggs attached to small boulders on the bottom of the water, and unattached isolated eggs, have rounded capsules and indistinguishable cables under their natural conditions. Many of these points correspond to conditions of egg-laying in $R$. spinosa described by Pope (1931, pp. 505-506).

It was a great surprise to find how great an effort was required to dislodge a boulengeri egg-capsule from its moorings of jelly. As mentioned above, some eggs are attached singly or in small groups to objects, and even these are so difficult to remove with the fingers that it is easy to see why floods do not wash them away. In view of the large number of eggs deposited, it is strange how few tadpoles of this species are found in the pools of the small mountain streams where the eggs are laid.

One of the frog-egg enemies is a species of giant planaria reaching more than an inch in length. I found many of them with the egg-clusters. These planaria eat up many eggs without spoiling the jelly; the eggs inside are merely broken and the fragments left, or outside of the jelly a large amount of eggfragments may be found. I had an experience that shows the destructive work 
of the planaria. When I tried to rear tadpoles of Staurois chunganensis in screened cages kept in a small mountain stream outside of Taosze, planaria got in through the gauze of the cage and ate up or spoiled all the eggs in one day. As the incubation of Rana boulengeri is slow and the eggs are attached, it is possible for all or most of them to be spoiled or eaten up by such an enemy. The second adverse factor for the eggs is the rapid and repeated change of water level in mountain streams. Eggs are generally laid after rain. Although the water level is rather high at that time, after half a day or so it usually goes down, leaving the eggs attached to the under surface of stones only partly immersed. If the water level continues to go down some of the eggs will be spoiled. The abundant yolk in the newly hatched tadpoles makes them very delicate, the belly being very easily crushed, and any rapidly running water or flood may cause many deaths. My experience in fixing some newly hatched individuals was that it was very easy to collapse the belly of such tadpoles with forceps or finger. It is nearly impossible even to move a newly hatched tadpole on a rough surface. Lastly, floods probably carry away to large streams some of the limited number of surviving tadpoles.

On the afternoon of July 4,1940, clusters of eggs were found in a small pool beneath a cascade. Most of the eggs were attached to the under surface of a large stone, although some were attached to vegetation in the pool. A few small clusters were fastened to small stones on the bottom of the water, and a very few were isolated and free. Most of the eggs under the stone were not visible. On the morning of July 15 (10:00 A.M.), 1940, paired individuals in the process of egg-laying were found beneath a big stone under a cascade, in water about eighteen inches deep. About two feet under the surface of this stone, where an arm could reach, eggs were attached; the deeper portion could not be reached. Some of the eggs had not started to cleave, and some were in the two- to sixteen-cell stages. This may indicate that the process of egg-laying is rather slow, or that the developmental process is rapid. In the same place, under a mass of entangled roots parallel with the cascade, fully developed embryos in jelly capsules were found. In the pool below this cascade, tadpoles of different stages of Rana boulengeri, Megophrys minor, and $M$. oshanensis were collected. On July 17, at 3:00 P.M., another egg-mass was found under roots of an old tree and under a big stone by the side of a cascade near Taosze. Onethird of the eggs were spoiled. On the morning of July 24, another mass of eggs was found in the place where the eggs had been collected on July 4, but this time the eggs were all attached to the under surface of the stone. Again, on August 5, a mass of eggs was found under a stone about five inches above the bottom at the side of the cascade. The eggs when freshly laid are gray at the animal pole and yellowish white at the vegetal pole. They are very large, the average diameter of fifty eggs (early cleavage stage) being $4.0 \mathrm{~mm}$., ranging from 3.6 to $4.2 \mathrm{~mm}$. The smaller eggs are not in good condition or have not developed. The capsule of the egg is formed by three layers, the outer layer the thickest and the inner very thin, with a moderate layer between. The two outer 
layers are formed by jelly, as are those of the eggs of other frogs. The average diameter of fifty eggs, including the layers of the capsule, was $15.8 \mathrm{~mm}$., ranging from 13.5 to $17.0 \mathrm{~mm}$., the diameter of the capsules being greater in advanced embryos.

The duration of incubation varies according to temperature. Indoors the developmental process is more rapid than in the continuously running water in the valley, where it is colder and shaded by vegetation. This was shown by taking indoors a portion of an egg-mass to study the development, and keeping another portion of the same egg-mass in the original place for control. Indoors, it took nine days for incubation; under natural conditions, this process takes from one to two weeks. The color of the egg changes according to the degree of development. During the process of development, the dimensions of the capsule change greatly. The greatest diameter is reached at the neurula stage, and as the embryo approaches the time of hatching, the capsule gradually becomes larger and larger, as the inner fluid increases in order to protect the embryo and give enough room for its development. Finally, the fully developed embryo is enclosed only by the innermost layer of the jelly membrane.

Just before hatching, an embryo has external gills, eyes, and tail fully developed. Because of the limited space in the inner capsule, the tip of the tail bends to one side. The tail may be moved sidewise when any disturbance occurs, as the embryo is quite free inside the fluid. Near the time of hatching, the embryo, surrounded by its inner capsule, works its way through the outer two layers of the capsule. It may remain enclosed in the inner capsule for two or more days. The capsule has a very delicate membrane, which may be broken to free the embryo, by random movements of the tail. After emerging from the capsule the young tadpole swims for a short time and then comes to rest in one place. It is impossible for the tadpole to be very active, as the yolk material is still very large. The tadpole of this species is very delicate; if it is taken out of the water, the belly collapses and it dies. Just after hatching, the external gills are long, the eyes are black, and the head and body are gray, with two darker marks, one near the eye, the other in front of the tail.

Tadpole.-Changes after hatching are not as great as in other forms. After two days, the $\mathrm{V}$-shaped black or dark gray mark on the dorsal tail base is well marked and the external gills are mostly concealed, with only the tips exposed. By the third day after hatching, the head is very much flattened, with colored spots on the body; external gills have disappeared. Because of the large amount of yolk a young tadpole eats nothing.

The coloration of these tadpoles (pl. 10, fig. 6) varies according to the stage of development and the conditions of the place where they are found. The color of the belly depends upon the food stuff in the intestine and the blood of the large vessels and heart in the throat region. After the hind legs are well developed, the body, legs and tail have a yellowish-brown ground color, the dorsal and lateral sides of the body being much darker, with a large number of gray and 
black granules. The muscular part of the tail is brown, spotted with dark gray. The tail fin is nearly colorless, with scattered dark spots. At this stage there is a dark gray bar across the interorbital space. At the time when the forelimbs are ready to come out, the brown back shows ridges enclosed by black pigment, and the interorbital bar is conspicuous. Limbs have dark bars developed on a brown background. The belly is more or less transparent, and the viscera, especially the fat bodies, can be clearly seen. Where there is a dark background in a pool, the coloration of the tadpoles seems darker. The form of the body is greatly influenced by the foodstuff in the water. If there is no decayed matter the tadpole will eat mud and the body will be thinner than otherwise. Just after metamorphosis, which takes five or more days, the body of the young frog is $18.5 \mathrm{~mm}$. in length with all adult features except the secondary sex characters.

Ten tadpoles with hind legs averaging $4.1 \mathrm{~mm}$. (2.3-6.0) were measured. The average body length is $18.2 \mathrm{~mm}$., and the tail is twice as long as the body. The width of the head is as much as the height of the body but less than the width of the body. The tail, including fins, measures more than the width or the height of the body. The interorbital space is greater than the height of the head. The spiraculum is sinistral, ending in a short tube, directed dorsoposteriorly at the middle posterior part of the body. The anal opening is dextral and is covered up by a skin fold continuous with the fin of the tail.

\section{Rana boulengeri: Measurements of Ten Tadpoles}

\begin{tabular}{|c|c|c|c|}
\hline Measurements & Range & Average & $\begin{array}{l}\text { Ratio to } \\
\text { body length (\%) }\end{array}$ \\
\hline Body length. & $17.0-19.4$ & 18.2 & \\
\hline Body height. & $8.2-9.0$ & 8.7 & 47.6 \\
\hline Body width. & $9.0-12.8$ & 10.4 & 56.9 \\
\hline Head height. & $5.6-6.4$ & 6.0 & 32.9 \\
\hline Head width. & $8.2-9.7$ & 9.0 & 49.5 \\
\hline Mouth width. & $4.6-5.0$ & 4.8 & 26.1 \\
\hline Space between eyes. & $5.9-6.5$ & 6.2 & 34.3 \\
\hline Snout to spiraculum. & $9.7-11.2$ & 10.5 & 57.7 \\
\hline Tail length..... & $34.0-39.6$ & 37.0 & 203.4 \\
\hline Tail height. & $10-12$ & 11.0 & 60.2 \\
\hline Diameter of tail muscle. & $4.2-6.0$ & 5.3 & 29.2 \\
\hline Length of hind leg..... & $2.3-6.0$ & 4.1 & \\
\hline
\end{tabular}

The mouth (fig. 66, B) is antero-ventral in position. The lower lip is bordered by two rows of papillae; at the middle of the external row they are about the same size and close to each other. At the corner of the mouth the external row is regular and continuous with the external row of the lower lip, and the inner row is disordered and may be subdivided into two or three rows. On the sides of the upper lip there is only one row of papillae. Labial teeth vary in this species. In thirty tadpoles with hind legs well developed there are normally four rows on the upper lip and three on the lower. Twenty individuals have four rows of labial teeth on the upper lip, the first continuous, the second the longest and very narrowly interrupted at the middle, and the remaining two rows widely interrupted. The lower lip of these twenty specimens has three rows of teeth, 
the outer the shortest and the inner row narrowly interrupted. The mandible is moderately developed, with serrated edges, and is black. Four tadpoles out of thirty have three rows of teeth in the upper lip, the first row complete and the other two rows interrupted. The labial teeth of the lower lip are normal. Two tadpoles have labial teeth normally developed, but only two complete rows of teeth on the lower lip. The other four individuals have three combinations

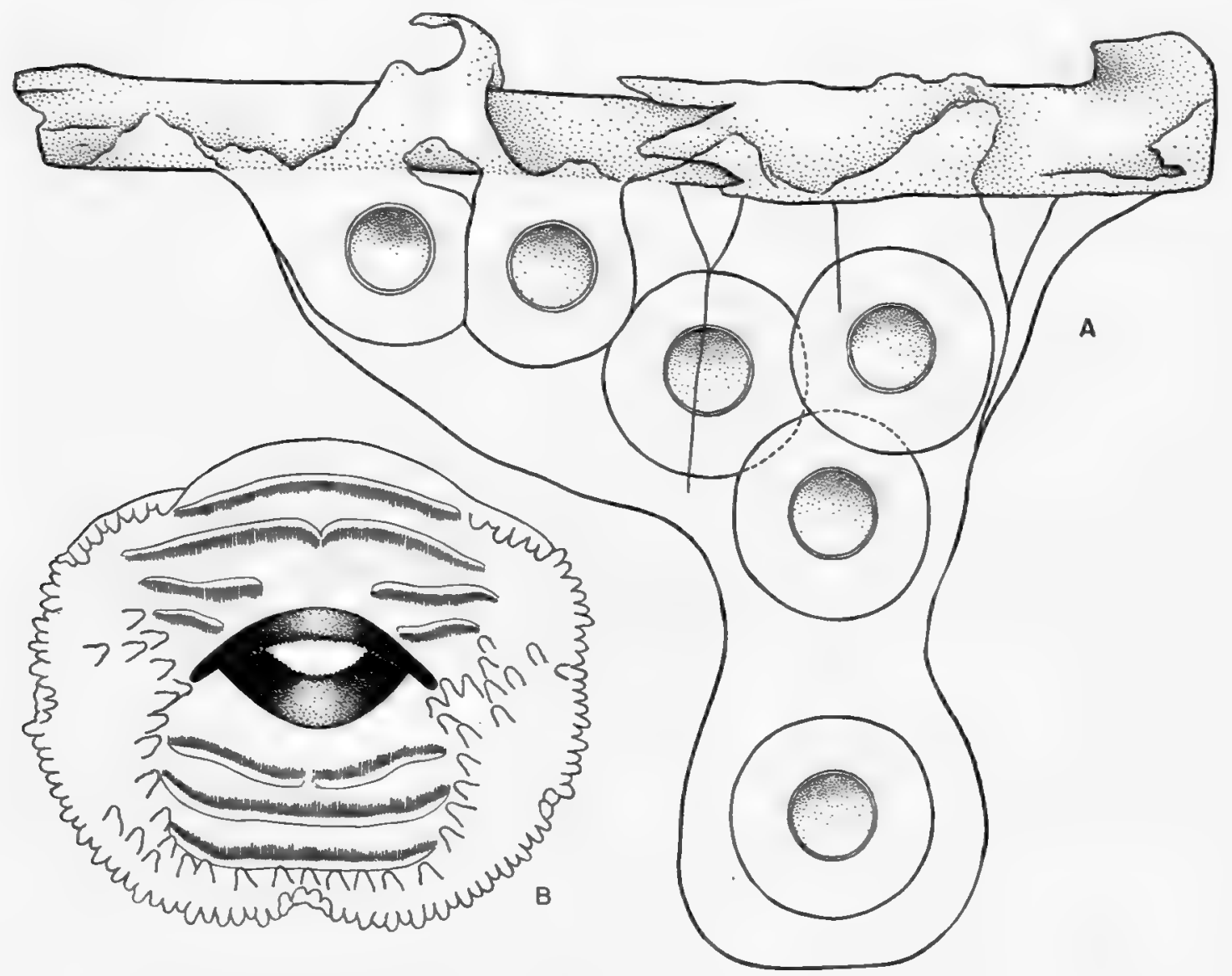

FIG. 66. Rana boulengeri. A. Eggs (X 3). B. Mouth of tadpole (X 15).

of labial teeth on the upper lip, but have the lower labial teeth normally developed. For the upper labial teeth, two have the first row complete, two short rows on the right side of the lip, and three on the left; one has the first row complete, three short rows on the right side, and two on the left; the last has the first row complete, four short rows on the right side, and three on the left. Thus there are five combinations besides the usual one. The modifications rarely involve the lower lip.

Tadpoles are found singly or a few together on the bottom of pools beside or below cascades or in quiet side waters of the mountain streams. They are rather inactive, not moving as much as other tadpoles. When one tries to catch them they get into the cracks of stones or into decayed vegetation for protection. 
They are bottom-feeding forms, living on decayed vegetation or other organisms. If such food is wanting, mud takes its place as food; many of the tadpoles collected in a red-mud-bottomed pool had the alimentary canal filled with red mud, which was easily seen through the gray semi-transparent belly.

According to Pope's description the lower lip of Rana spinosa is bordered by three rows of papillae, the two outer rows arising from one base and separated from the third and inner row by a distinct space, which disappears in the middle of the lip where the rows come together. For the boulengeri tadpole, there are two rows of papillae and at the corners of the mouth there are added papillae, rarely with a few additional papillae between the outer and inner rows of the lower lip near the corner of the mouth. The spinosa tadpole has five rows of labial teeth in the upper lip, the first continuous, the second slightly longer than the first and very narrowly interrupted, the remaining three successively shorter and broadly interrupted. The tadpole of Rana boulengeri normally has four rows of teeth in the upper lip as described above, the rare and abnormal tooth formula being I:2-2/II:1-1; I:3-3/II:0-0; I:3-2/II:1-1; I:2-3/II:1-1; and $\mathrm{I}: 4-2 / \mathrm{II}: 1-1$. In spinosa the tadpole is dark above, the belly is usually quite black, and the tail is conspicuously dark-spotted. In boulengeri the coloration of the tadpole is quite different from that of spinosa. The study of the tadpoles confirms the distinctness of boulengeri.

\section{Rana phrynoides Boulenger}

Rana phrynoides Boulenger, 1917, Ann. Mag. Nat. Hist., (8), 20 : 413 -Tongchuanfu, Yunnan; idem, 1920, Rec. Indian Mus., 20 : 73; Schmidt, 1927, Bull. Amer. Mus. Nat. Hist., 54: 563; Pope, 1931, op. cit., 61 : 499; Liu, 1935, Peking Nat. Hist. Bull., 10, pt. 1: 55 .

History of species.-Many specimens were collected from Tongchuanfu, Yunnan, by John Graham and described in 1917 as Rana phrymoides by Boulenger. Until I published an account of the species in 1935 it had been reported only from Yunnan. In 1942 I discovered this frog at Sichang City, and from April to August I studied it in the field.

Distribution and collection data.-Rana phrynoides is found only in Yunnan and the Ningshu region of Sikang. Its vertical distribution ranges from 5,000 to about 8,000 feet. I collected many adults and tadpoles on the way from Sichang to Chaochiao from May 1 to 7, 1942.

Comparison with related species.-The two patches of spines on the chest of the male and the obtuse but not dilated digital tips of Rana phrynoides (fig. 67) distinguish it from boulengeri (fig. 65) and spinosa. Rana phrynoides is directly related to feae, in which the males have chest spines similarly in two patches, but the blackish, white-edged ocellus at the hip joint of feae is not found in phrynoides. In the males of liebigii of Darjeeling there are two patches of spines on the chest, the spines spreading to the inner sides of the arm. The male of sternosignata of India is also provided with two patches of spines on the chest, but has large isolated spines scattered on the sides and posteriorly. Rana 

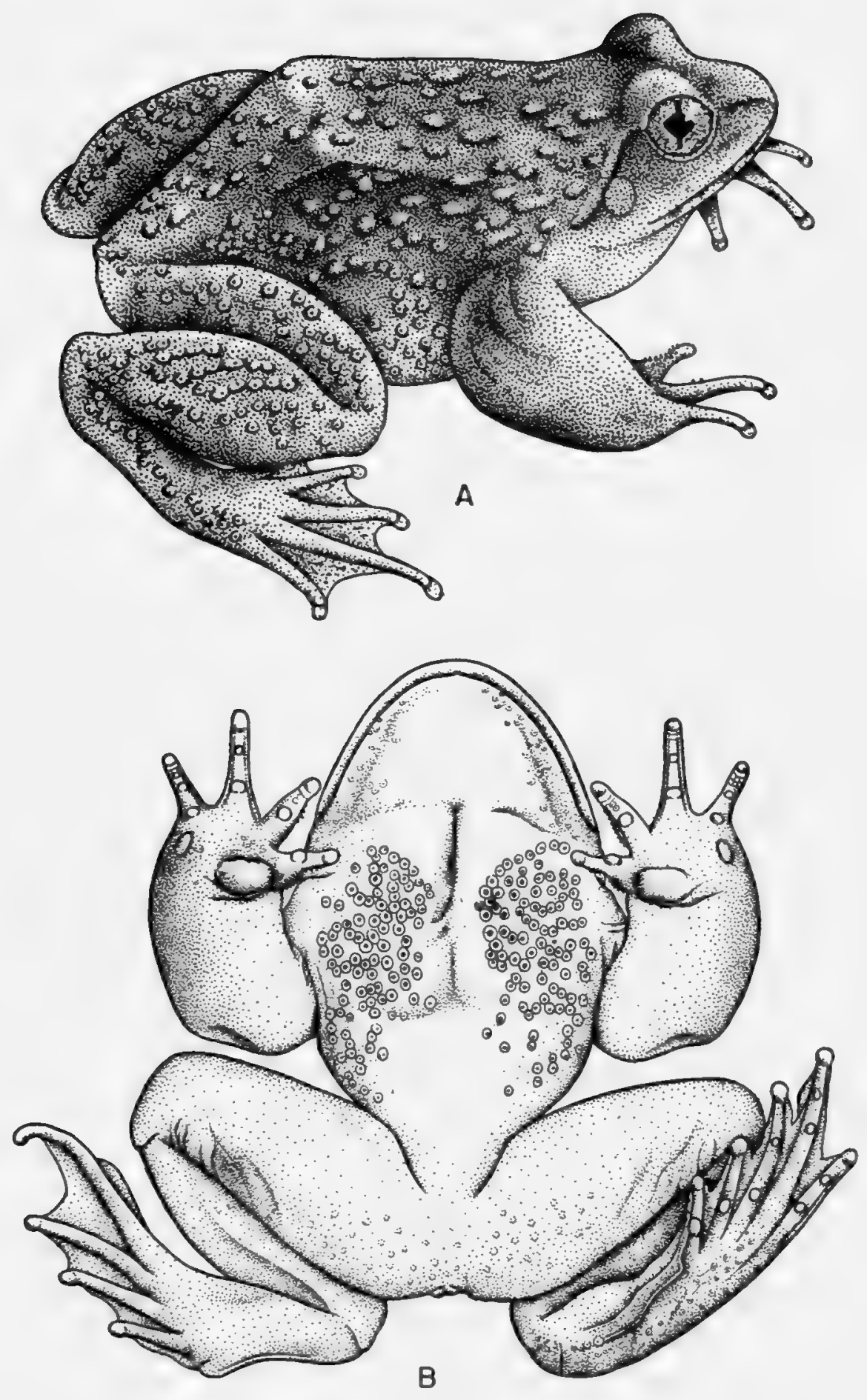

Fig. 67. Rana phrynoides; male (X 1). A. Adult. B. Ventral view. 
ynnanensis, described by Anderson from Husa, Yunnan, is related to phrynoides, but as Pope and Boring (1940) suggest, opinion as to its validity must await fresh material from the type locality.

Original description.- "Vomerine teeth in small oblique groups just behind the choanae. Head much broader than long, much depressed; snout rounded, scarcely projecting beyond the mouth, as long as the eye; canthus rostralis indistinct; loreal region very oblique, slightly concave; interorbital space narrower than the upper eyelid; tympanum hidden or very indistinct, one-third to twothirds the diameter of the eye. Fingers obtuse, first longer than the second; subarticular tubercles small, moderately prominent. Hind limb short, the tibiotarsal articulation reaching the shoulder or the temple, the heels just meeting when the limbs are folded at right angles to the body; tibia two and one-fifth to two and a half times in length from snout to vent. Toes short, with obtuse tips, entirely webbed; subarticular tubercles small, moderately prominent; a feeble tarsal fold; inner metatarsal tubercle narrow, feebly prominent, one-half the length of the inner toe; no outer tubercle. Upper parts granular, with numerous small warts on the back, some of which may be elongate; these granules and warts may bear black horny spinules; a strong fold across the head behind the eyes, and a very strong glandular fold from the eye to the shoulder; lower warts smooth. Dark olive above, uniform or with rather indistinct darker spots; lips with or without dark vertical bars; dark cross-bars on the limbs very irregular, if present; lower parts whitish, uniform, or throat and limbs spotted or marbled with blackish. Male with internal vocal sacs; during the breeding-season the arms are remarkably thickened and black horny spines form two patches on the breast and more crowded patches on the inner metacarpal tubercle and on the upper side of the two inner fingers.

"From snout to vent $110 \mathrm{~mm}$."

Coloration in life.-The coloration varies according to the environment. If this frog is sitting on a dark substrate and is surrounded by rich vegetation, it is much darker than are those found in shallow open small mountain streams. In most cases the head, body, and limbs are uniform Dresden Brown, and the throat, belly and ventral sides of limbs are yellowish stippled with purple on the throat. A distinct or indistinct dark bar crosses the interorbital space, with similar bars on the jaws. Rarely there may be indistinct bars on the limbs. Some specimens may have Buffy Citrine as the ground color, and a few have a darker brown ground color.

Sex dimorphism. - There is no sex dimorphism in size, the ten largest specimens of each sex showing an average body length for males of $98 \mathrm{~mm}$., and $99 \mathrm{~mm}$. for females. Strong nuptial asperities are developed on the prepollex of the male, and on the inner dorsal sides of the first, second and third fingers. There are two patches of spines on the chest (fig. $67, \mathrm{~B}$ ) of the male, with weaker spines on the throat. Spines are also present on the rounded warts of the sides of the body and the upper sides of the hind limbs. The arm of the male is tremendously 
developed in comparison with that of the female. The male has an internal vocal sac with two round openings.

A hermaphroditic condition is commonly found in this species. In 1933, I found in the Museum of Comparative Zoology a female specimen (No. 2473) with spines developed on the prepollex and on the first and second fingers. In 1942, I collected several specimens of phrynoides at Sichang with varying combinations of male and female characteristics.

Rana phrynoides: Measurements of Ten Male and Ten Female Adults

\begin{tabular}{|c|c|c|c|c|}
\hline Measurements & Sex & Range & Average & $\begin{array}{c}\text { Ratio to } \\
\text { body length }(\%)\end{array}$ \\
\hline Body length. . & $\begin{array}{l}0^{7} \\
\wp\end{array}$ & $\begin{array}{l}80-103 \\
89-109\end{array}$ & $\begin{array}{l}98.0 \\
99.0\end{array}$ & $\ldots$ \\
\hline Head length. & $\begin{array}{l}0^{7} \\
0\end{array}$ & $\begin{array}{l}30-36 \\
33-39\end{array}$ & $\begin{array}{l}32.4 \\
35.2\end{array}$ & $\begin{array}{l}33.1 \\
35.6\end{array}$ \\
\hline Head width....... & $\begin{array}{l}\sigma^{\top} \\
\wp\end{array}$ & $\begin{array}{l}30-38 \\
34-43\end{array}$ & $\begin{array}{l}34.8 \\
37.8\end{array}$ & $\begin{array}{l}35.5 \\
38.2\end{array}$ \\
\hline Interorbital space... & $\begin{array}{l}0^{7} \\
\wp\end{array}$ & $\begin{array}{l}5.0-6.8 \\
5.0-7.0\end{array}$ & $\begin{array}{l}5.7 \\
6.1\end{array}$ & $\begin{array}{l}5.9 \\
6.2\end{array}$ \\
\hline Tympanum........ & $\begin{array}{l}0^{7} \\
\circ\end{array}$ & $\begin{array}{l}4.2-5.5 \\
5.0-5.5\end{array}$ & $\begin{array}{l}4.9 \\
5.2\end{array}$ & $\begin{array}{l}5.0 \\
5.3\end{array}$ \\
\hline Length of lower arm... & $\begin{array}{l}0^{7} \\
\text { o }\end{array}$ & $\begin{array}{l}37-48 \\
38-46\end{array}$ & $\begin{array}{l}42.2 \\
42.1\end{array}$ & $\begin{array}{l}43.1 \\
42.5\end{array}$ \\
\hline Diameter of lower arm........ & $\begin{array}{l}\sigma^{7} \\
\$\end{array}$ & $\begin{array}{l}15-27 \\
11-14\end{array}$ & $\begin{array}{l}20.6 \\
12.5\end{array}$ & $\begin{array}{l}21.0 \\
12.6\end{array}$ \\
\hline Length of hand... & $\begin{array}{l}\sigma^{7} \\
\wp\end{array}$ & $\begin{array}{l}24-29 \\
24-30\end{array}$ & $\begin{array}{l}26.3 \\
26.3\end{array}$ & $\begin{array}{l}27.0 \\
26.6\end{array}$ \\
\hline Length of leg..... & $\begin{array}{l}0^{7} \\
\wp\end{array}$ & $\begin{array}{l}117-145 \\
130-151\end{array}$ & $\begin{array}{l}133.7 \\
138.8\end{array}$ & $\begin{array}{l}136.5 \\
140.2\end{array}$ \\
\hline Length of tibia. . & $\begin{array}{l}\sigma^{7} \\
\wp\end{array}$ & $\begin{array}{l}38-47 \\
42-49\end{array}$ & $\begin{array}{l}43.5 \\
45.3\end{array}$ & $\begin{array}{l}44.4 \\
45.7\end{array}$ \\
\hline Length of foot and tarsus...... & $\begin{array}{l}0^{x} \\
0\end{array}$ & $\begin{array}{l}57-68 \\
61-69\end{array}$ & $\begin{array}{l}63.0 \\
64.9\end{array}$ & $\begin{array}{l}64.3 \\
65.6\end{array}$ \\
\hline Length of foot. & $\begin{array}{l}0^{7} \\
\$\end{array}$ & $\begin{array}{l}39-47 \\
43-48\end{array}$ & $\begin{array}{l}43.0 \\
45.4\end{array}$ & $\begin{array}{l}43.9 \\
45.9\end{array}$ \\
\hline
\end{tabular}

Habitat and habits.-Rana phrynoides is found in small mountain streams, like Rana boulengeri, but it sometimes appears even in very slow-running water in ditches connected with small pools.

I failed to collect eggs and tadpoles in their early stages, but obtained advanced tadpoles and nearly metamorphosed young from May 1 to May 7,1942. This indicates that the breeding season must be very early in the year.

Tadpole.-The tadpoles inhabit pools or ponds along small mountain streams. To collect them is far easier than to collect tadpoles of boulengeri, as they are more abundant and less agile.

The ground color of the living tadpole (fig. 68, A), with hind legs well developed, is dull yellowish brown, and the sides of the body are darker than the dorsum. The tail is light brown, marbled with dark gray, especially on the muscular portion. The marginal part of the tail fin is especially darkened. The 
basal part of the tail is much darker than the distal part or the body. The belly is pearl gray, with a narrow median transparent band. In preserved specimens as well as in life there are two pairs of white spots on the belly. The anterior pair is more conspicuous, one on each side just in front of the intestinal coils and latero-ventral to the internal gills. The posterior pair lies postero-lateral to
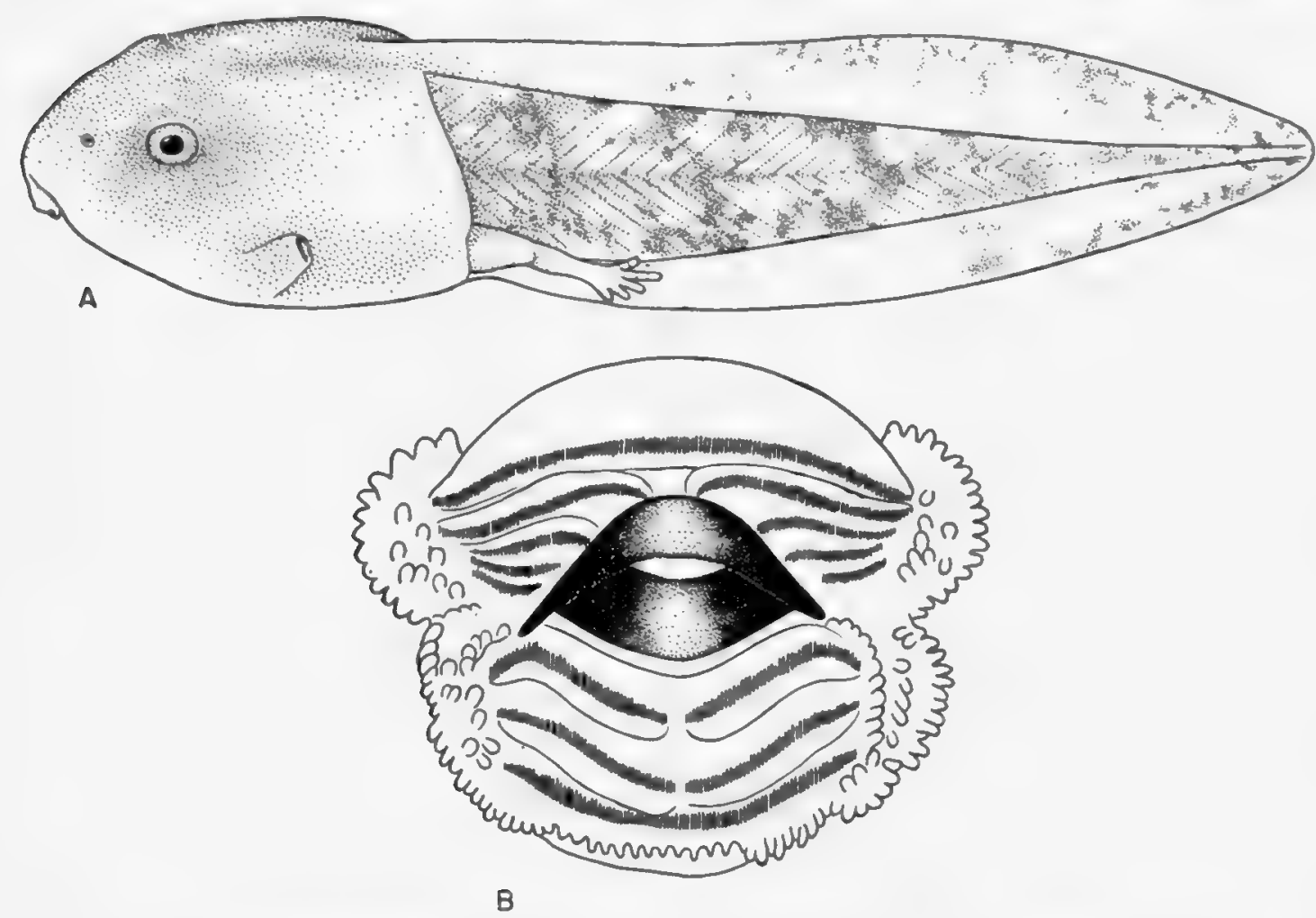

FIG. 68. Rana phrynoides; tadpole. A. Lateral view $(\times 2)$. B. Mouth (X 11).

the intestinal coils. These spots are also present in the tadpole of boulengeri, but in that species, after preservation, they become inconspicuous.

Ten tadpoles, with average length of hind leg $12.2 \mathrm{~mm}$., average $71.9 \mathrm{~mm}$. in length (see table). The tail muscle is rather strong, with a deeper dorsal tail fin extending onto the body. The head of the tadpole is depressed. The nostril is enclosed by an elevated ring provided with several minute papillae, of which the dorsal one is largest. The lachrymal canal is distinct. The eyes are dorsolateral. The spiraculum is sinistral, ending in a short free tube pointed upwards and backwards, which is barely visible from above and shows clearly from below. The vent is dextral, covered by a very broad skin fold continuous with the ventral tail fin and turned to the right. The tail tip is bluntly pointed.

The mouth (fig. 68, B) is antero-ventral, with a single row of small papillae on the margin of the sides of the upper lip and on the whole margin of the lower lip. Extra papillae are found at the corners of the upper lip, and there is more or less of a row of papillae at the lateral and latero-ventral side of the lower lip, 
with some additional papillae between. The normal condition of the labial teeth of this species is $I: 4-4 / \mathrm{II}: 1-1$; in a few cases the tooth rows may break into segments. The mandibles, especially the upper one, are much stronger than in boulengeri, and have serrated edges.

Rana phrynoides: Measurements of Ten Tadpoles

\begin{tabular}{|c|c|c|c|}
\hline Measurements & Range & Average & $\begin{array}{l}\text { Ratio to } \\
\text { body length }(\%)\end{array}$ \\
\hline Body length...... & 24-28 & 26.2 & \\
\hline Body height. & $12-15$ & 13.5 & 51.5 \\
\hline Body width. & $15-20$ & 18.2 & 693 \\
\hline Head height. & $7.5-10$ & 9.1 & 34.5 \\
\hline Head width. & $13-16$ & 14.6 & 55.2 \\
\hline Mouth width. & $5-7$ & 6.3 & 23.9 \\
\hline Space between eyes. & $7-8$ & 7.2 & 27.7 \\
\hline Snout to spiraculum & $14-18$ & 16.4 & 62.4 \\
\hline Tail length... & $43-49$ & 45.7 & 174.4 \\
\hline Tail height. & $14-16$ & 14.6 & 55.5 \\
\hline Diameter of tail muscle & $7-9$ & 7.8 & 29.8 \\
\hline Length of hind leg..... & $8-20$ & 12.2 & $\ldots$. \\
\hline
\end{tabular}

\section{Rana feae Boulenger}

Rana feae Boulenger, 1887, Ann. Mus. Genova, (2), 5: 418, pl. iii-Kakhien Hills, Burma; Sclater, 1892, Proc. Zool. Soc. Lond., 1892: 343; Boulenger, 1920, Rec. Indian Mus., 20 : 68.

History of species.-After the original description of a single male specimen from the Kakhien Hills of Burma, Sclater (1892) and Boulenger (1920) recorded this frog from Yunnan. Pope and Boring (1940) state that Rana feae, if valid, certainly must belong to the spinosa group. From the figure of the type and from Boulenger's description, Rana feae seems to be a distinct species, more closely related to phrynoides than to spinosa or boulengeri.

Distribution and collection data.-In China, Rana feae has been reported only from Yunnan. I have collected no material.

Comparison with related species.--The two patches of spines on the chest of the male and the undilated digital tips distinguish Rana feae from spinosa and boulengeri. The species is distinguished from the closely related phrynoides by the presence of a white-edged blackish ocellus at the hip joint.

Original description.- "Vomerine teeth in two small oblique groups extending beyond the hinder edge of the choanae. Habit stout. Head much broader than long; snout very short, broadly rounded; no canthus rostralis; nostril a little nearer the eye than the end of the snout; interorbital space narrower than the upper eyelid; tympanum distinct, three-fifths the diameter of the eye. Fingers moderate, first extending beyond second; toes rather short, entirely webbed; subarticular tubercles moderate; tips of fingers and toes obtuse; inner metatarsal tubercle narrow, elongate, three-fifths the length of the inner toe; no outer tubercle; a narrow fold along the inner edge of the tarsus. The tibiotarsal articulation reaches the eye, tibia measuring half the distance from snout 
to vent. Sides of body warty, large elongate smooth warts being intermixed with small round ones; posterior part of upper eyelid warty; a fold from the eye to the shoulder. Olive brown above, with rather indistinct darker spots and a blackish, white-edged ocellus at the hip-joint; interrupted cross-bands on the limbs; lower parts dirty white. Male with internal vocal sacs; arms, during the breeding season, extremely thickened; a patch of black spines on each side of the breast and others on the inner metacarpal tubercle and the inner side of the two inner fingers; the arrangement of these nuptial excrescences very similar to that of $R$. liebigii, in which species, however, they are also present on the inner side of the arms.

"From snout to vent 92 millim."

\section{The Woodfrogs of Western China}

Among the Chinese amphibians, the "woodfrog" group presents one of the most complicated taxonomic problems. Great confusion exists in the literature, as there has been neither a satisfactory comparative study of preserved museum specimens of the different forms, nor a careful investigation in the field. Pope and Boring (1940) call the north Chinese form Rana temporaria chensinensis and the south Chinese woodfrog Rana japonica. This is clearly an over-simplification of the problem of classification. The present discussion is limited to the woodfrogs of western China, but I have been able to compare them with the woodfrogs of Manchuria and with those of the Peiping and Soochow regions, through personal acquaintance in the field. I have also examined preserved materials from Europe and from the Chinese provinces of Shansi, Nanking, Anhwei and Fukien.

Rana japonica is not uncommon in Szechwan and Sikang; it is in general similar to japonica in eastern and southeastern China, but the forms from western China are larger and stouter and have better developed webs and a different coloration. The mouth parts of the tadpole of japonica are alike in western, eastern, and southeastern China. Further field investigation and careful comparative study of adults and tadpoles may make it possible to distinguish subspecies in this group.

Rana chaochiaoensis is a woodfrog of southwestern China closely related to japonica but with the mouth parts of the tadpoles similar to those of $R$. temporaria chensinensis; for this reason I have not made chaochiaoensis a subspecies of japonica. The stouter body, the broader head, and the strong dorso-lateral glandular fold of chaochiaoensis also distinguish it from japonica.

Rana temporaria chensinensis is the name suggested by Pope and Boring (1940) for the woodfrog of northern China; the reference of the subspecies to temporaria expresses its close relation to the European form, and chensinensis is the earliest name for this woodfrog in eastern Asia, applied by David in 1875 to woodfrogs from "Chinling" (Tsingling Mountains) of southern Shensi. This arrangement is followed, though with reservations. 
Rana amurensis is very possibly a valid subspecies of temporaria, limited to the three eastern provinces of China, larger in size than other Chinese woodfrogs and with very narrow dorso-lateral glandular folds. The capacity of the oviduct to absorb water is a remarkable specific character of this form. All the female specimens in my collection, and the specimens in the Biology Department of Yenching University have their abdomens fully expanded and in some cases the abdominal wall is ruptured near the pelvic region, where the jelly-like substance of the enlarged oviduct can be seen. This phenomenon has not been seen in the closely related Chinese woodfrogs of other species, although all were preserved in the same way, in 5 per cent formalin. Rana temporaria amurensis (in this sense) is well known in China as Ha-shih-ma, the oviducts being misinterpreted as fat-bodies by the common people, who believe that they are very nutritive and especially good for aged persons or invalids. The oviducts are accordingly expensive, and can be obtained from shops in the larger cities all over China. A study of the life history of this species would throw more light on this problem. For the time being, at least, I prefer to regard amurensis as a distinct subspecies of temporaria. Rana weigoldi and asiatica are to be placed in the synonymy of temporaria chensinensis, which is limited to northern and northwestern China. Rana japonica is widely distributed in the western, central, and southeastern parts of China. Rana chaochiaoensis is limited to the southwest, in Yunnan and in Ningshu, Sikang. My Yunnan material has the same characters as chaochiaoensis from the type locality.

\section{KEY FOR IDENTIFICATION OF WOODFROGS OF WESTERN CHINA \\ (Rana temporaria and related forms)}

I. Tibio-tarsal articulation extending beyond nostril; males without vocal sacs; dorsolateral glandular fold not angulated near the tympanic region.

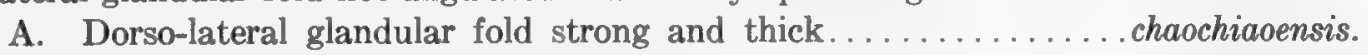
AA. Dorso-lateral glandular fold narrow.................... japonica.

II. Tibio-tarsal articulation not extending beyond nostril; male with vocal sacs; dorsolateral glandular fold angulated near tympanic region......... temporaria chensinensis.

\section{KEY FOR IDENTIFICATION OF TADPOLES OF WOODFROGS OF WESTERN CHINA}

I. Lower labial teeth in three rows, the innermost row interrupted........... japonica.

II. Lower labial teeth in four rows, the innermost interrupted.

A. A continuous row of papillae on the margin of the lower lip; tail length about 150 per cent of the body length..................temporaria chensinensis.

AA. Papillae not always continuous on the lower lip; tail length about 170 per cent

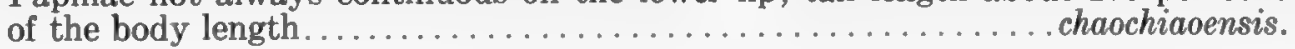

\section{Rana temporaria chensinensis David}

Rana chensinensis David, 1875, Jour. Trois. Voy. Chinois, 1: 159-Inkiapo, Valley of Laoyu, Tsingling Mountains (Chinling), Shensi; Stejneger, 1925, Proc. U. S. Nat. Mus., 66, art. 25: 20.

Rana temporaria Strauch, 1876, in Przewalski's Mongliya i Strano Tangutov, 2, pt. 3: 53 (not of Linnaeus); Günther, 1896, Ann. Mus. Zool. St. Petersbourg, 1: 206. 
Rana japonica Boettger, 1885, Ber. Offenb. Ver. Naturk., 24-25: 150 (not of Günther); idem, 1888, op. cit., 26-28: 96; Sowerby, 1912, in Clark and Sowerby, Through Shen-Kai, p. 112; Shaw, 1929, Bull. Fan. Mem. Inst., 1, No. 5: 86.

Rana temporaria var. asiatica Bedriaga, 1898, Wiss. Res. Przewalski, Central Asien Reisen, Zool., 3, sec. 1, pt. 1: 23, pl. 1, fig. 4-Kansu; Ordos, Mongolia.

Rana amurensis Bedriaga, 1898, Wiss. Res. Przewalski, Central Asien Reisen, Zool., 3, sec. 1, pt. 1: 27 (not of Boulenger); Nikolski, 1905, Zap. Imp. Akad. Nauk, St. Petersburg, (8), 17, No. 6: 369; Barbour, 1909, Proc. New England Zool. Club, 4: 59 .

Rana asiatica Nikolski, 1914, Trudi Troitsko-Savsk. Kiakht Otd. Geogr. Obshtch., 15: 33; idem, 1918, Faune de la Russie, Amphibia, p. 62; Stejneger, 1925, Proc. U. S. Nat. Mus., 66, art. 25: 19; Schmidt, 1927, Bull. Amer. Mus. Nat. Hist., 54: 569; Pope, 1931, Bull. Amer. Mus. Nat. Hist., 61:521; Liu, 1931, Peking Nat. Hist. Bull., 5, pt. 2: 53.

Rana weigoldi Vogt, 1924, Zool. Anz., 60 : p. 339 -Ngolo Pass, Sikang.

Rana temporaria chensinensis Pope and Boring, 1940, Peking Nat. Hist. Bull., 15, pt. 1: 57 (part).

History of species.-Père David's woodfrog from Inkiapo, collected November 19,1872 , at a small spring at an altitude of more than 1,000 meters in Chinling, Shensi, was described as Rana chensinensis in 1875.

Rana amurensis was originally described by Boulenger from specimens collected in the Russian Coast province. It was afterwards (1898) recorded by Bedriaga from material collected by Przewalski and Grum-Grzymailo at Kokonor. Neither of these authors had seen specimens from the other's locality. Nikolski was able to compare specimens from both localities, which are more than 1,500 miles apart. Stejneger (1907) discussed the relationship of amurensis and temporaria and distinguished amurensis as a valid species. Barbour (1909) recorded several specimens of woodfrogs from the west of Taipaishan, not far from the type locality of chensinensis, as amurensis. In 1925, Stejneger re-examined the specimens in the United States National Museum and as a result he placed amurensis as a synonym of chensinensis but he kept Rana asiatica as a valid species of northern China. Schmidt (1927) and Pope (1931) reported amurensis from Hsinglungshan, northwest of Peiping. The species from Hsinglungshan is known to me from personal collecting. I regard it as definitely chensinensis, not amurensis.

Specimens of Rana temporaria chensinensis from Kansu and Hopei were misidentified as japonica by Boettger in 1885 and 1892; Sowerby mentioned frogs from northern Shensi and Kansu under this name, and T. H. Shaw recorded japonica from Peiping in 1929. Bedriaga in 1898 described Rana temporaria var. asiatica from Kansu, Ordos, and Mongolia; and Nikolski, 1918, placed this simply as Rana asiatica. Most herpetologists reported the northern Chinese woodfrogs as Rana asiatica until 1940.

In 1940, Pope and Boring stated: "We are calling this north China form temporaria chensinensis; temporaria to express its close alliance to the European form and chensinensis instead of amurensis or asiatica because this name holds 
priority in eastern Asia, having been used by David in 1875 for wood frogs from the Tsinling Mountains of southern Shensi." Pope and Boring mentioned Rana weigoldi Vogt, 1924, known only from the type locality, as probably a synonym of chensinensis. This I regard as correct, after collecting many adults and tadpoles near the type locality.

Distribution and collection data.-Rana temporaria chensinensis is widely distributed in northern China, extending westward into Szechwan and Sikang. In western China the southern boundary line of the range runs north and northwest of Paohsing, Sikang, and north of Wenchwan and around Peip'ei, Szechwan. The vertical distribution in western China is from about 6,000 feet to 13,000 feet altitude.

From July 25 to August 25, 1943, I collected many adults and tadpoles of various stages from Taining, Taofu, Luho and Kantze, Sikang. During the summer of 1944, I obtained specimens of adults and tadpoles from Kansu and Tsinghai. These woodfrogs are the true Rana temporaria chensinensis. On January 16, 1946, I visited Peip'ei, north of Chungking, Szechwan, where I found chensinensis still breeding. From the same locality Mr. H. W. Chang collected specimens of what I regard as true japonica during the autumn and winter of 1945 .

Comparison with related species.-Rana temporaria chensinensis is much smaller than temporaria of Europe, the body length of the north China woodfrogs ranging from 49 to $56 \mathrm{~mm}$. in males and 47 to $56 \mathrm{~mm}$. in females; in European temporaria the body length of the males is from 59 to $84 \mathrm{~mm}$., and from 60 to 97 in females. In the male of temporaria chensinensis the subgular internal vocal sacs are paired, and the dorso-lateral glandular fold is prominent and angulate near the tympanum. There are no vocal sacs in the male of either japonica or chaochiaoensis, and the dorso-lateral glandular fold is generally narrow and without angulation.

Description of adult female. ${ }^{1}$-Body stout (fig. 69), body length $56 \mathrm{~mm}$. Head slightly broader than long; snout round, projecting beyond the mouth; nostrils nearer the eye than the tip of the snout; loreal region oblique and concave; interorbital space as wide as the upper eyelid and slightly narrower than the internasal space; tympanum about half of the diameter of the eye and wider than the space from the tympanum to the eye; tongue free behind and deeply notched; vomerine teeth in two rounded patches between and somewhat posterior to the choanae.

Arm short; first finger longer than the second, which is equal to the fourth, the third finger the longest; tips of fingers rounded; subarticular tubercles prominent; two large palmar tubercles, the outer one more elongated and the inner one large and rounded.

Leg short, tibio-tarsal articulation reaching the anterior border of the tympanum; heels meeting when placed at right angles to the body; tips of toes

' Based on C.N.H.M. No. 49445, collected at Taining, Sikang, July, 1943. 
narrow, rounded; fourth toe the longest, third and fifth about equal in length, longer than the second, and the first the shortest; toes fully webbed; subarticular tubercles well developed; inner metatarsal tubercle prominent, oval and with a free edge; no outer metatarsal tubercle.

Skin with small rounded warts scattered on the back, irregular warts on the sides, and small rounded ones on the posterior aspects of the thighs; dorsolateral glandular folds prominent, extending backward from the posterior corner of the eye to the hip, and angulated above and behind the tympanum; another

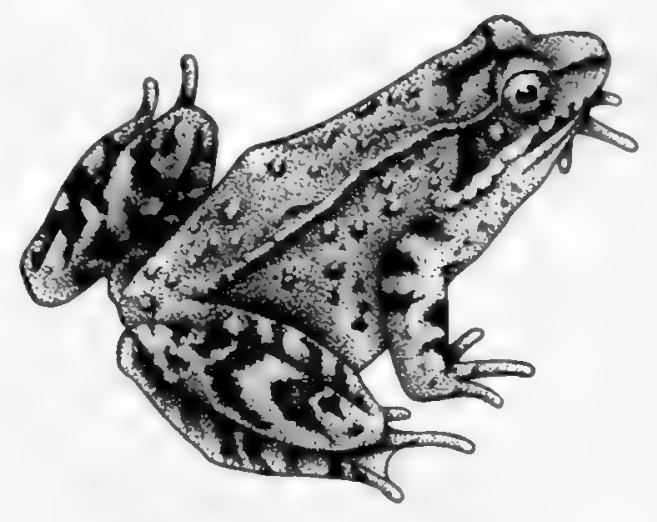

FiG. 69. Rana temporaria chensinensis; adult female ( $\times 1)$.

glandular fold extending from the posterior angle of the upper jaw to the base of the arm.

Coloration in life.-Sepia, stippled with red on the body and the limbs; a black band extending from the tip of the snout through the nostril to the anterior border of the eye; a cream-colored band running along the upper jaw to the base of the arm and ventrally margined by an irregular dark band; a dark bar crossing the interorbital space and extending to the upper eyelid; pupil round, black, enclosed by a golden ring; iris golden, stippled with black and, on the lower half, also with red; tympanum covered with a dark triangular mark; dorsolateral fold pinkish; warts on the body partly black; more or less irregular black bars on the arms and legs; margins of jaws pinkish, throat, belly and ventral sides of limbs cream, stippled with pink. After preservation the sepia becomes dark gray and the pink color disappears except on the dorso-lateral fold.

Sex dimorphism.-Sex dimorphism in size is not shown in my collection. The arm of the male is only slightly stronger than that of the female. A dark gray nuptial pad is developed on the inner dorsal side of the first finger of the male. The male has paired internal subgular vocal sacs and lineae masculinae.

Variation.--Specimens collected from Sikang differ from specimens from Shansi and Peiping in having a stouter body, shorter legs, and rougher skin. In most cases there is no outer metatarsal tubercle in the population of Sikang, whereas the Shansi and Peiping specimens have a distinct outer metatarsal tubercle. The length of the third toe in proportion to the length of the fourth 
differs in the population of western China as compared with that of northern China, the tip of the third toe reaching or nearly reaching the distal subarticular tubercle of the fourth toe in the form from western China and reaching about halfway between the distal and the second subarticular tubercle of the fourth toe in the Shansi and Peiping specimens.

Rana temporaria chensinensis: Measurements of

Four Male and Four Female Adults

\begin{tabular}{|c|c|c|c|c|}
\hline Measurements & Sex & Range & Average & $\begin{array}{c}\text { Ratio to } \\
\text { body length }(\%)\end{array}$ \\
\hline Body length.... & $\begin{array}{l}0^{7} \\
\text { q }\end{array}$ & $\begin{array}{l}49-56 \\
47-56\end{array}$ & $\begin{array}{l}52.2 \\
52.0\end{array}$ & $\cdots$ \\
\hline Head length. & $\begin{array}{l}0^{7} \\
9\end{array}$ & $\begin{array}{l}16-19 \\
16-19\end{array}$ & $\begin{array}{l}17.0 \\
17.9\end{array}$ & $\begin{array}{l}32.5 \\
34.4\end{array}$ \\
\hline Head width. & $\begin{array}{l}0^{7} \\
\text { क }\end{array}$ & $\begin{array}{l}17.0-19.5 \\
17-0.20 .0\end{array}$ & $\begin{array}{l}18.2 \\
18.5\end{array}$ & $\begin{array}{l}34.8 \\
35.5\end{array}$ \\
\hline Interorbital space... & $\begin{array}{l}0^{7} \\
q\end{array}$ & $\begin{array}{l}3.0-3.5 \\
3.0-3.5\end{array}$ & $\begin{array}{l}3.1 \\
3.1\end{array}$ & $\begin{array}{l}5.9 \\
5.9\end{array}$ \\
\hline Tympanum. & $\begin{array}{l}\sigma^{7} \\
\text { क }\end{array}$ & $\begin{array}{l}2.5-3.5 \\
2.5-3.5\end{array}$ & $\begin{array}{l}3.0 \\
2.8\end{array}$ & $\begin{array}{l}5.7 \\
5.4\end{array}$ \\
\hline Length of lower arm... & $\begin{array}{l}0^{7} \\
9\end{array}$ & $\begin{array}{l}21.0-25.5 \\
21.5-24.0\end{array}$ & $\begin{array}{l}23.4 \\
22.4\end{array}$ & $\begin{array}{l}44.8 \\
43.0\end{array}$ \\
\hline Diameter of lower arm. & $\begin{array}{l}0^{7} \\
9\end{array}$ & $\begin{array}{l}5.0-6.5 \\
4.5-6.0\end{array}$ & $\begin{array}{l}6.0 \\
5.3\end{array}$ & $\begin{array}{l}11.3 \\
10.1\end{array}$ \\
\hline Length of hand. & $\begin{array}{l}\sigma^{7} \\
q\end{array}$ & $\begin{array}{l}12.0-14.5 \\
12.5-14.0\end{array}$ & $\begin{array}{l}13.8 \\
13.4\end{array}$ & $\begin{array}{l}26.4 \\
25.7\end{array}$ \\
\hline Length of leg. & $\begin{array}{l}0^{7} \\
8\end{array}$ & $\begin{array}{l}75-90 \\
77-87\end{array}$ & $\begin{array}{l}82.5 \\
82.2\end{array}$ & $\begin{array}{l}158.0 \\
158.0\end{array}$ \\
\hline Length of tibia. & $\begin{array}{l}0^{7} \\
\wp\end{array}$ & $\begin{array}{l}22.5-28.0 \\
23.0-27.0\end{array}$ & $\begin{array}{l}25.1 \\
25.0\end{array}$ & $\begin{array}{l}48.0 \\
48.0\end{array}$ \\
\hline Length of tarsus and foot. & $\begin{array}{l}0^{7} \\
\text { क }\end{array}$ & $\begin{array}{l}34.0-42.5 \\
36.0-39.0\end{array}$ & $\begin{array}{l}38.4 \\
37.0\end{array}$ & $\begin{array}{l}73.5 \\
71.1\end{array}$ \\
\hline Length of foot. & $\begin{array}{l}0 \\
9 \\
7\end{array}$ & $\begin{array}{l}24-32 \\
26-29\end{array}$ & $\begin{array}{l}28.7 \\
28.0\end{array}$ & $\begin{array}{l}54.9 \\
53.8\end{array}$ \\
\hline
\end{tabular}

Habitat and habits.-The woodfrog of northern China has great ability to adjust itself to different ecological surroundings. It is a mountain inhabitant rather than a frog of the plain. In northern China, I found them among vegetation along mountain streams.

Northwest of the Gobi Desert, in Kansu, I found many of them in damp places along streams or near ponds. On the high plateau of Sikang, they are very abundant in marshes and along mountain streams, and much more abundant than along the mountain streams or on hillsides at lower altitudes. In the Gobi Desert, in Kansu, I found only two salientians, Bufo raddei and Rana temporaria chensinensis, and on the high plateau the only ranid present is chensinensis. This woodfrog seems to be a newly derived subspecies with vigorous potentiality for dispersal.

From 1926 to 1930 , when I studied the amphibians of the Peiping region I found chensinensis in the Western Hills breeding in small pools of small mountain streams occasionally as early as March. Judging from the tadpoles of 
chensinensis from the plateau of Sikang, this woodfrog breeds in the latter part of June or early July. I collected tadpoles with hind limb-buds in Luho, in the middle of August, 1943.

Egg-masses are presumably laid in pools and ponds of high plateau marshes and small mountain streams, where I obtained many tadpoles.
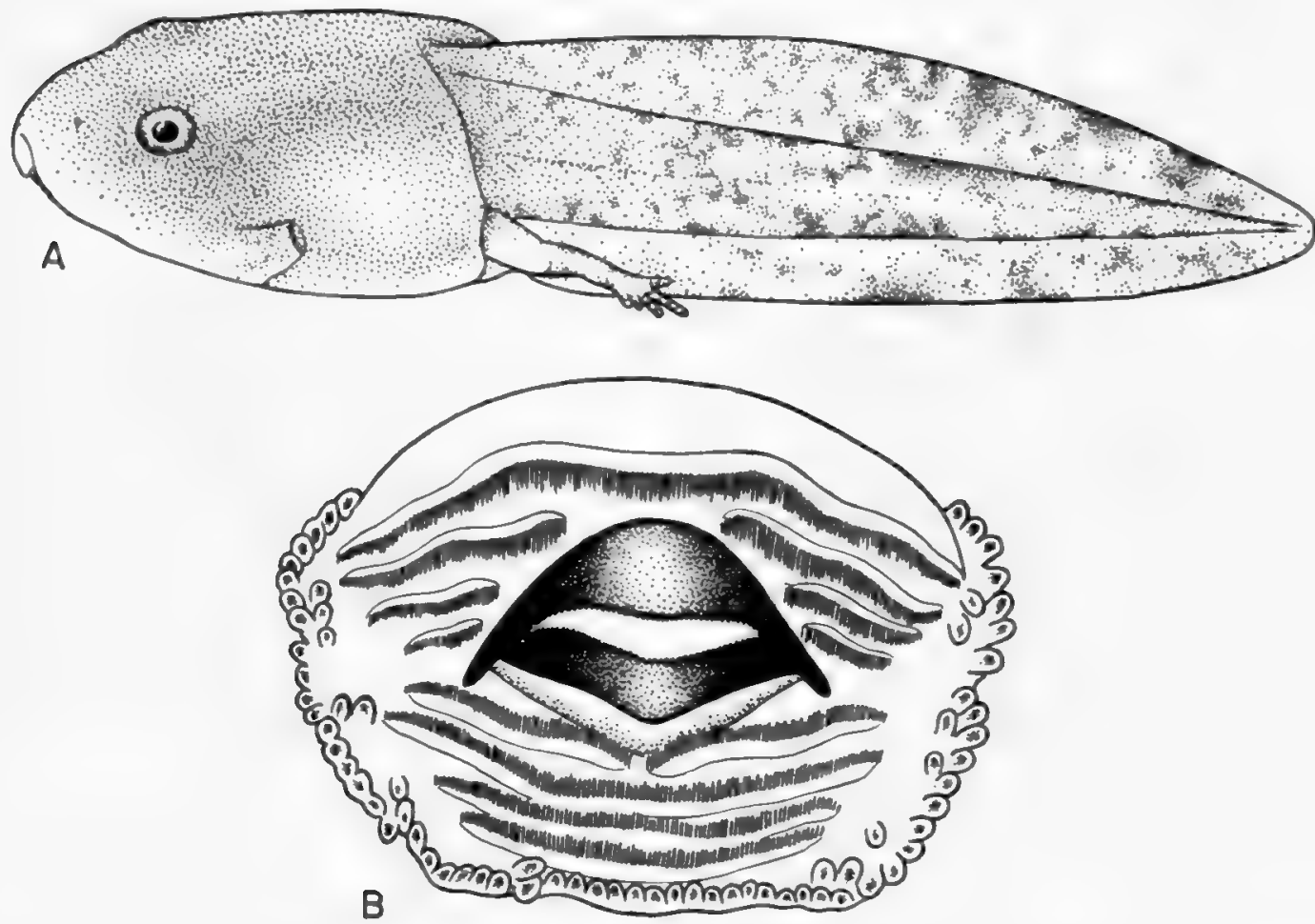

FIG. 70. Rana temporaria chensinensis; tadpole. A. Lateral view (X 4). B. Mouth $(\times 25)$.

Tadpole.-The tadpoles (fig. 70) of Rana temporaria chensinensis are bottomfeeding forms. They are less active and sensitive than those of japonica.

The coloration of the tadpoles found in bodies of water without vegetation is much lighter than in those found in pools and ponds with vegetation. The Peiping form is golden brown on the back, whereas the tadpoles of Sikang are nearly black, with the tail fin much stippled with dark gray; the belly is creamy white.

The body of the tadpole is stout and much wider than high. The average body length in ten tadpoles was $19.2 \mathrm{~mm}$., and the average tail length was $29 \mathrm{~mm}$. The tail is about one and a half times as long as the body; the tail muscle is weak, the tip of the tail blunt, and the dorsal fin deeper than the ventral.

The head is depressed, with a rounded snout; the nostril is nearer to the eye than to the tip of the snout; the eyes are dorso-lateral, and the space from eye to eye is greater than the internasal space; the spiraculum is sinistral, without a 
free tube, is directed upward and backward and is visible from above and below; the vent is large, with a very broad short tube, and with the opening at the right side of the base of the ventral tail fin.

The mouth (fig. 70, B) is antero-ventral, with a single row of papillae on the sides of the upper lip and on the whole edge of the lower lip; the papillae at the sides of the lips are larger than those on the ventral edge of the lower lip, but all have dark cores; additional papillae are found at the corners of the mouth and at the latero-ventral corners of the lower lip. The rows of labial teeth are rather constant within the species. In ten tadpoles, nine have the tooth formula I:3-3/III:1-1 and one has I:2-3/III:1-1. The outermost row of lower labial teeth is much weaker than the other rows and in a few cases is barely discernible. The mandibles are moderately developed, with serrated edges.

\section{Rana temporaria chensinensis: Measurements of Ten Tadpoles}

\begin{tabular}{|c|c|c|c|}
\hline Measurements & Range & Average & $\begin{array}{c}\text { Ratio to } \\
\text { body length (\%) }\end{array}$ \\
\hline Body length. & $17.5-20.0$ & 19.2 & \\
\hline Body height. & $7.0-10.5$ & 9.2 & 47.7 \\
\hline Body width. & $11-12$ & 11.1 & 57.8 \\
\hline Head height. & $6-7$ & 6.2 & 32.3 \\
\hline Head width. & $9.0-10.5$ & 9.7 & 50.5 \\
\hline Mouth width. & $3.5-4.0$ & 3.9 & 20.6 \\
\hline Space between eyes. & $4.5-5.0$ & 4.9 & 25.5 \\
\hline Snout to spiraculum. & $11-12$ & 11.7 & 60.7 \\
\hline Tail length......... & $26-30$ & 28.8 & 150.0 \\
\hline Tail height. & 9 & 9.0 & 46.9 \\
\hline Diameter of tail muscle & $3.5-4.0$ & 3.8 & 19.5 \\
\hline Length of hind leg... & $3.5-12.0$ & 8.1 & .. \\
\hline
\end{tabular}

\section{Rana japonica Günther}

Rana temporaria Schlegel, 1838, Fauna Japonica, Rept., pp. 109, 139, Saur. Batr., pl. 3, fig. 2c-Japan (not of Linnaeus).

Rana temporaria var. japonica Günther, 1858, Cat. Batr. Sal., Brit. Mus., p. 17Ningpo and Chusan, China.

Rana silvatica Swinhoe, 1870, Proc. Zool. Soc. Lond., 1870: 412.

Rana japonica Boulenger, 1879, Bull. Soc. Zool. France, p. 190; idem, 1882, Cat. Batr. Sal. Brit. Mus., p. 47; idem, 1886, Bull. Soc. Zool. France, p. 599; Boettger, 1892, Kat. Batr. Mus. Senckenberg, p. 9 (part); idem, 1894, Ber. Senck. Naturf. Ges., p. 146; Werner, 1904, Abh. Bayer. Akad. Wiss. (Muenchen), Kl. II, 22, pt. 2: p. 358; Stejneger, 1907, Bull. U. S. Nat. Mus., p. 107; Vogt, 1914, Sitzber. Ges. Naturf. Freunde, Berlin, 1914: 339; Boulenger, 1920, Rec. Ind. Mus., 20: 93; Werner, 1924, Denkschr. Akad. Wiss. Wien, 99: 53; Stejneger, 1925, Proc. U. S. Nat. Mus., 66: 22; Schmidt, 1927, Bull. Amer. Mus. Nat. Hist., 54: 568; Pope, 1931, Bull. Amer. Mus. Nat. Hist., 61 : 525; Chang, 1932, Contr. Biol. Lab. Sci. Soc. China, 8, No. 5: 151; Pope and Boring, 1940, Peking Nat. Hist. Bull., 15, pt. 1: 58; Liu, 1940, op. cit., pt. 2: 165; idem, 1940, Jour. West China Border Res. Soc., 7, (B): 39.

Rana longicrus Stejneger, 1898, Jour. Col. Soc. Imp. Univ., Japan, 12: 104-Formosa; Schmidt, 1927, Bull. Amer. Mus. Nat. Hist., 54: 569. 
History of species.-The type locality of Rana japonica is Japan. Günther, in 1858, recorded japonica from Ningpo and Chusan. Swinhoe's woodfrog from Ichang, referred to as Rana silvatica, was unquestionably japonica. Records from northern China by various authors are based on misidentification of Rana temporaria chensinensis David. Pope, in 1931, placed Stejneger's supposed species longicrus in the synonymy of japonica.

Distribution and collection data.-Rana japonica is a Yangtze Valley form, widely distributed in southeastern, southern and southwestern China. In western China, japonica is found around Paohsing City; at Shuimokou, about 30 miles northwest of Kwanhsien; in central Szechwan as far as Peip'ei; and to the Tatuho, southwest of Mount Omei. The vertical distribution in western China is from about 1,000 feet to 4,000 feet; on the coastal plain this frog is found near sea level. Adults and tadpoles were collected at Kiating on March 23, 1939, at Mount Omei during the summers of 1938, 1940, and 1945, and outside of Paohsing City from July 21 to August 20, 1939. Tadpoles of different stages were obtained in small pools by the side of a mountain stream near Nanyaomiao, Wenchwanhsien, on April 27, 1940, and from a pool near the Min River, outside of Kwanhsien City, on May 10, 1940.

Comparison with related species.-Rana japonica can be distinguished from temporaria chensinensis by its slender head, body, and legs, the straight dorsolateral folds, and the absence of vocal sacs in the males. The more prominent dorso-lateral folds and the stouter body of Rana chaochiaoensis distinguish it from japonica. The lower labial tooth formula of the tadpole of japonica is II:1-1; in chaochiaoensis it is III:1-1.

Original description.--The original description of japonica consists only of the reference to Schlegel's plate (Fauna Japonica, pl. 3, fig. 2).

Description of adult male. ${ }^{1}$ - Body moderate, slender, length $60 \mathrm{~mm}$. Head longer than broad; snout round, pointed, and projecting; nostril about midway between the tip of the snout and the anterior border of the eye; canthus rostralis obtuse, loreal region oblique, with a shallow groove from the nostril to the anterior border of the lower eyelid; interorbital space narrower than the upper eyelid, and narrower than the internasal space; diameter of tympanum about two-thirds the length of the eye, equal to the width of the upper eyelid, and twice as great as the space from the tympanum to the eye; tongue long and deeply notched behind; vomerine teeth in two long oblique series, situated between the choanae.

Arm moderately long and strong; first finger slightly longer than the second, which is shorter than the fourth; third finger the longest; tips of fingers round; subarticular tubercles well developed; two palmar tubercles, an outer elongate one and a rounded inner one; granular nuptial pad very strongly developed on the inner dorsal side of the first finger, with a bilobed, greatly enlarged basal portion and a thin distal portion covering the last two segments of the first finger.

'No. 3602, Liu Collection, Peip'ei, Szechwan, collected by H. W. Chang. 
Legs long, tibio-tarsal articulation reaching the tip of the snout; heels strongly overlapping when placed at right angles to the body; toes somewhat flattened and with rounded tips, the fourth toe the longest, the third equal to the second, the fifth longer than the second, and the first the shortest; toes nearly fully webbed except the fourth, on which the web reaches the distal subarticular tubercle; subarticular tubercles well developed; inner metatarsal tubercle prominent, oval, and with a free edge; outer metatarsal tubercle indicated.

Skin of back slightly rough with a few small rounded warts irregularly placed; a straight narrow dorso-lateral glandular fold on each side of the back from the eye to the insertion of the hind limb; a short glandular ridge from the posterior angle of the upper jaw to the base of the arm; very small tubercles on the limbs; numerous small regular tubercles on the thighs, especially around the vent; a few white spines near the tympanic region; white spines on the granules of the nuptial pad.

Coloration in life.-The color varies greatly and changes from time to time; it is generally honey-yellow stippled with light brown and dark gray; a distinct or indistinct dark bar crosses the interorbital space; a dark triangular mark covers the tympanic region; dark spots are usually associated with the tubercles on the back and sides of the body; the dorso-lateral glandular fold and glandular ridge posterior to the jaw are yellow ocher; the bars on arms and legs are dark gray or black; the webs are gray; there is a light-edged dark line on the back of the arm, and on the postero-lateral aspect of the tibia; the belly is yellowishcream. After preservation, the color varies from pale clay-color to dull gray or brown, with dark markings and bars still visible, and the belly whitish, with or without dark spots.

Sex dimorphism.- Sex dimorphism in size is not shown in the japonica of western China. Males have a stronger arm, and gray nuptial asperities strongly developed and greatly enlarged at the inner dorsal side of the base of the thumb, with a narrow band of nuptial asperities extending along the dorsal side of the last two segments. There are no vocal sacs. The lineae masculinae are developed. The leg of the male tends to be longer than that of the female, and the webs tend to be better developed.

Variation.-Thirty mature males and five mature females were collected from Mount Omei on September 24, 1931.

In these, the length of the hind limb varies from specimen to specimen, and they fall into two groups. The tibio-tarsal articulation extends beyond the tip of the snout in eighteen males and in two females; it only reaches the tip of the snout in the remaining twelve males and three females. The outer metatarsal tubercle is distinctly shown only on one foot of a single male, is lacking in nineteen males and three females, and is indistinct in ten males and two females. Seventeen males have fully developed webs connecting the first, second, third, and fifth toes, extending only to the base of the terminal phalanges of the fourth toe; thirteen males have the webs extending to the base of the terminal phalanges of 
the first, second, third and fourth toes, and only to between the distal and second subarticular tubercles of the fourth. The webs in the five female specimens correspond with those of the second group of male specimens, or are slightly less developed. The vomerine teeth in ten specimens consist of two oblique patches anteriorly between the choanae, the number of teeth being $6-7,5-7,6-5,4-5$, $5-4,4-5,5-3,4-4,3-4$ and $3-3$; in two there are two rounded patches (teeth $3-3$, $3-4)$ between the choanae; in two there are two horizontally elongated patches (teeth 4-4, 4-5) somewhat posterior to the choanae; and in one the two rounded patches (teeth 3-4) are distinctly behind the choanae. Twenty specimens have dark markings or spots on the margins of the lower jaws, and fifteen have small irregular dark spots but no regular markings. There are no dark marks in front of the base of the arm in twenty-three specimens, and diffuse dark marks are present in twelve. The dark bars on the limb are either totally lacking or are rather indistinct in specimens from western China. Fifteen specimens out of thirty-five have no bars on the arms and eight have none on the legs.

Comparisons. - Specimens from west China are larger than those from $\mathrm{Fu}$ kien and Anhwei. In Szechwan material the average body length of fourteen male specimens is $60 \mathrm{~mm}$. (54-65); in eight females it is $59.5 \mathrm{~mm}$. (50-72.5). Two mature males and two mature females from Fukien have the body length respectively 42 and $43 \mathrm{~mm}$. and 47 and $47 \mathrm{~mm}$. Pope (1931) measured twelve of his largest males and females collected at Ningkwo, Anhwei. The males range from 36 to $46 \mathrm{~mm}$. in length, averaging $39 \mathrm{~mm}$., and the females from 45 to 54 $\mathrm{mm}$., averaging $50.5 \mathrm{~mm}$.

The body of the japonica from western China is more heavily built and stouter, with a shorter and wider head than in frogs from eastern and southeastern China (see table). The nostril is nearer to the tip of the snout in the japonica of eastern and southeastern China than in that of Szechwan, and the snout is more pointed in the eastern and southeastern frogs.

The leg length of the west China form is equal to that of Fukien frogs and longer than that of the Anhwei series. A distinct outer metatarsal tubercle is found in about 50 per cent of the specimens from the east and southeast and it is rarely distinguishable in Szechwan specimens. The webs between the toes are much less developed in the Fukien and Anhwei specimens, with the first and fourth toes about half webbed and the second, third, and fifth toes about two-thirds webbed, the Szechwan individuals having the toes more or less fully webbed as described above.

The coloration in life and that of preserved specimens also differs in the regions in question. The japonica of Soochow, which I studied in the field and in the laboratory (1934-37), has much more light or reddish brown on the back, the form in western China being more yellow and in a few cases even bright yellow, a coloration never seen in eastern China. The lower jaw is definitely marked with black in most cases in the east and only irregularly spotted in less than 50 per cent of the specimens from western China. Definite, distinct, 
and narrow dark bars are developed on the limbs of Anhwei and Fukien specimens while the individuals from western China may have wide indistinct dark bars on their limbs. More than 50 per cent of the forms from western China have no black markings on the base of the arms. When present they are diffused, whereas the Anhwei and Fukien specimens have distinct black marks in this region. Only japonica of eastern China has supernumerary tubercles on the palm.

Rana japonica: Measurements of Fourteen Male and

Eight Female Adults from Szechwan

\begin{tabular}{|c|c|c|c|c|}
\hline Measurements & Sex & Range & Average & $\begin{array}{c}\text { Ratio to } \\
\text { body length (\%) }\end{array}$ \\
\hline Body length...... & $\begin{array}{l}0^{x} \\
0\end{array}$ & $\begin{array}{l}54.0-65.0 \\
50.0-72.5\end{array}$ & $\begin{array}{l}60.0 \\
59.5\end{array}$ & $\ldots$ \\
\hline Head length. & $\begin{array}{l}0^{7} \\
9\end{array}$ & $\begin{array}{l}17.3-21.3 \\
17.5-24.0\end{array}$ & $\begin{array}{l}19.1 \\
20.3\end{array}$ & $\begin{array}{l}31.9 \\
34.1\end{array}$ \\
\hline Head width. & $\begin{array}{l}0^{7} \\
\wp+7\end{array}$ & $\begin{array}{l}17.2-19.5 \\
14.0-22.2\end{array}$ & $\begin{array}{l}18.0 \\
18.1\end{array}$ & $\begin{array}{l}30.0 \\
30.4\end{array}$ \\
\hline Interorbital space. . & $\begin{array}{l}0^{7} \\
\text { o }\end{array}$ & $\begin{array}{l}4.2-5.2 \\
3.5-5.5\end{array}$ & $\begin{array}{l}4.6 \\
4.6\end{array}$ & $\begin{array}{l}7.7 \\
7.6\end{array}$ \\
\hline Tympanum. & $\begin{array}{l}\sigma^{7} \\
q\end{array}$ & $\begin{array}{l}4.5-5.8 \\
4.0-5.5\end{array}$ & $\begin{array}{l}5.2 \\
4.5\end{array}$ & $\begin{array}{l}8.7 \\
7.6\end{array}$ \\
\hline Length of lower arm.... & $\begin{array}{l}0^{2} \\
0\end{array}$ & $\begin{array}{l}25.0-29.8 \\
21.2-30.5\end{array}$ & $\begin{array}{l}26.8 \\
25.6\end{array}$ & $\begin{array}{l}44.6 \\
42.9\end{array}$ \\
\hline Diameter of lower arm.. & $\begin{array}{l}0^{7} \\
\&\end{array}$ & $\begin{array}{l}6.2-8.0 \\
3.5-7.1\end{array}$ & $\begin{array}{l}7.5 \\
5.3\end{array}$ & $\begin{array}{r}12.5 \\
8.8\end{array}$ \\
\hline Length of hand. . & $\begin{array}{l}0^{7} \\
\&\end{array}$ & $\begin{array}{r}11.0-12.2 \\
9.3-13.4\end{array}$ & $\begin{array}{l}11.5 \\
11.2\end{array}$ & $\begin{array}{l}19.2 \\
18.8\end{array}$ \\
\hline Length of leg. & $\begin{array}{l}0^{7} \\
\text { o }\end{array}$ & $\begin{array}{r}109-130 \\
89-135\end{array}$ & $\begin{array}{l}116.7 \\
108.6\end{array}$ & $\begin{array}{l}194.5 \\
182.6\end{array}$ \\
\hline Length of tibia... & $\begin{array}{l}0^{7} \\
\$\end{array}$ & $\begin{array}{l}34.0-41.3 \\
28.0-43.4\end{array}$ & $\begin{array}{l}37.3 \\
35.2\end{array}$ & $\begin{array}{l}62.2 \\
59.2\end{array}$ \\
\hline Length of tarsus and foot...... & $\begin{array}{l}0^{x} \\
0\end{array}$ & $\begin{array}{l}51-60 \\
42-61\end{array}$ & $\begin{array}{l}54.7 \\
50.3\end{array}$ & $\begin{array}{l}91.2 \\
84.5\end{array}$ \\
\hline Length of foot. & $\begin{array}{l}0^{7} \\
\$\end{array}$ & $\begin{array}{l}29-35 \\
25-37\end{array}$ & $\begin{array}{l}33.1 \\
30.7\end{array}$ & $\begin{array}{l}55.1 \\
51.7\end{array}$ \\
\hline
\end{tabular}

Rana japonica: Measurements of Fifty Male and Fifty Female Adults from Soochow

\begin{tabular}{|c|c|c|c|c|}
\hline Measurements & Sex & Range & Average & $\begin{array}{c}\text { Ratio to } \\
\text { body length (\%) }\end{array}$ \\
\hline Body length...... & $\begin{array}{l}0^{7} \\
9\end{array}$ & $\begin{array}{l}38-48 \\
35-55\end{array}$ & $\begin{array}{l}42.3 \\
42.7\end{array}$ & $\ldots$ \\
\hline Head length. . & $\begin{array}{l}0^{7} \\
\wp\end{array}$ & $\begin{array}{l}11-15 \\
10-17\end{array}$ & $\begin{array}{l}12.6 \\
12.9\end{array}$ & $\begin{array}{l}29.89 \\
30.15\end{array}$ \\
\hline Interorbital space. . & $\begin{array}{l}0^{7} \\
\text { o }\end{array}$ & $\begin{array}{l}3-4 \\
3-4\end{array}$ & $\begin{array}{l}3.1 \\
3.2\end{array}$ & $\begin{array}{l}7.24 \\
7.58\end{array}$ \\
\hline Tympanum.. & $\begin{array}{l}7 \\
0\end{array}$ & $\begin{array}{l}3-4 \\
3-4\end{array}$ & $\begin{array}{l}3.0 \\
3.2\end{array}$ & $\begin{array}{l}7.14 \\
7.49\end{array}$ \\
\hline Length of leg. . & $\begin{array}{l}0^{7} \\
\text { क }\end{array}$ & $\begin{array}{l}66-85 \\
62-101\end{array}$ & $\begin{array}{l}75.7 \\
78.0\end{array}$ & $\begin{array}{l}178.96 \\
182.65\end{array}$ \\
\hline Length of tibia... & $\begin{array}{l}\sigma^{7} \\
\text { क }\end{array}$ & $\begin{array}{l}18-25 \\
19-31\end{array}$ & $\begin{array}{l}22.5 \\
23.5\end{array}$ & $\begin{array}{l}53.17 \\
55.01\end{array}$ \\
\hline Length of tarsus and foot. . & $\begin{array}{l}\text { o } \\
\text { क }\end{array}$ & $\begin{array}{l}30-38 \\
28-44\end{array}$ & $\begin{array}{l}33.4 \\
34.5\end{array}$ & $\begin{array}{l}78.96 \\
80.80\end{array}$ \\
\hline
\end{tabular}


Habitat and habits.-Rana japonica is generally found in vegetation on hillsides, but during the breeding season it visits pools, ponds, and even streams, to lay its eggs. It is not easy to find specimens before or after the breeding season.

The breeding habits of Rana japonica in western China are still not completely known. The breeding season seems to be very early, as I collected only
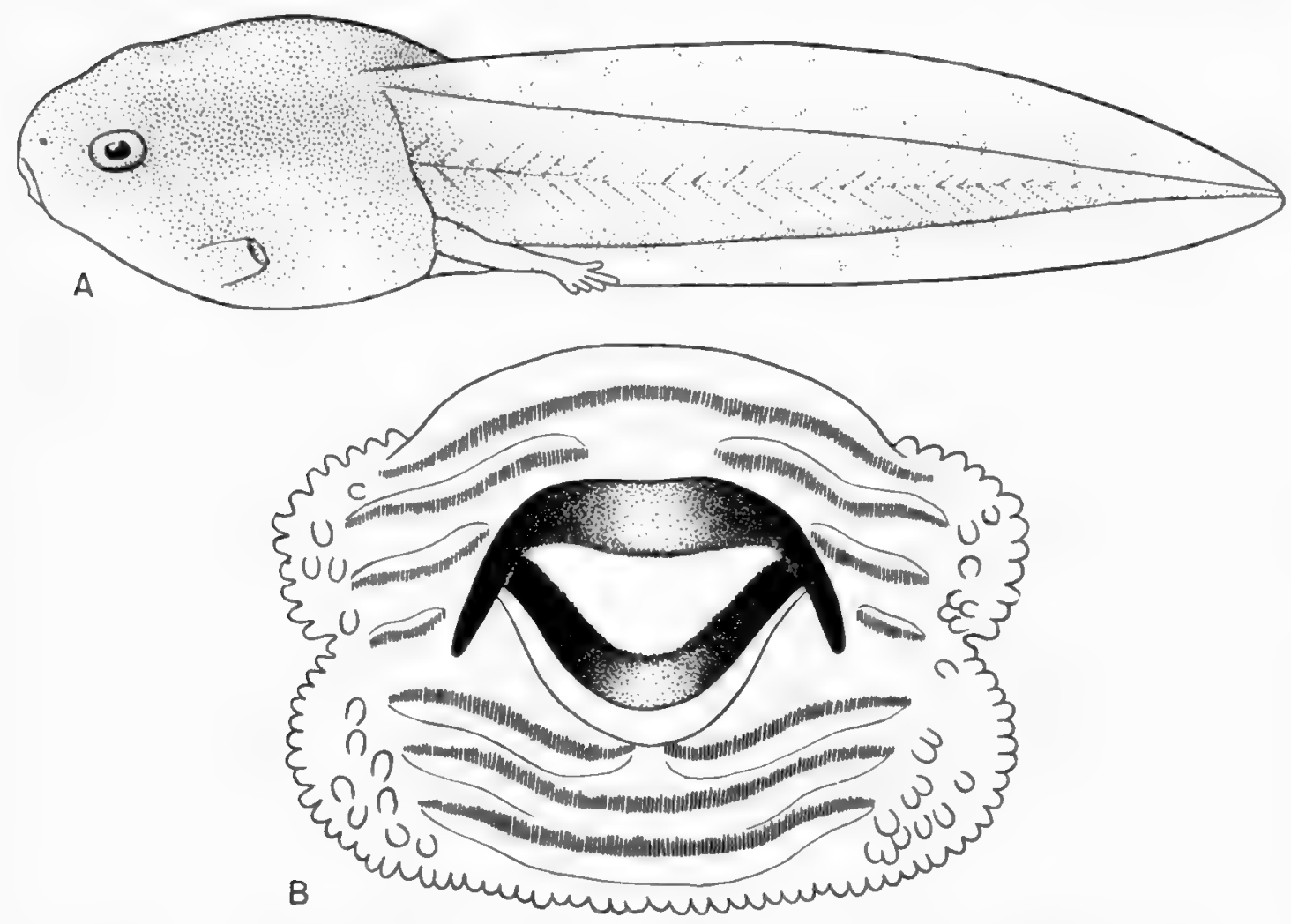

FIG. 71. Rana japonica; tadpole. A. Lateral view (X 3). B. Mouth (× 25).

tadpoles at Kwanhsien in April and found no eggs of this species; I obtained tadpoles of the Muping yellow woodfrog in July and August. At lower altitudes in Szechwan Rana japonica may lay its eggs during the winter or very early spring. From the presence of tadpoles in pools and ponds on hillsides, and in pools along larger mountain streams, these may be assumed to be the egg-laying sites for Rana japonica.

Tadpole.-Tadpoles are bottom-feeding, and may be found among algae, which form their main food. They are not very active and one can easily catch them with a dip-net. A large number were collected from a pool on a hillside outside of Paohsing City, July 21 to August 20, 1939.

The coloration of the living tadpole is uniform dark brownish on the body and the muscular part of the tail, lighter toward the belly and the tip of the tail, and finely spotted with fuscous and olive brown. The eye is small, with a round 
dark pupil enclosed by a reddish golden iris. The tail fin is marbled and spotted with dark vinaceous and pearl gray. The sides of the belly and the throat are dark gray, with the center of the belly lighter. There are two white spots on the belly antero-lateral to the base of the vent.

The tadpole (fig. 71) is of medium size. The average length of ten tadpoles with hind limb-buds of $4.4 \mathrm{~mm}$. is $51 \mathrm{~mm}$., $17 \mathrm{~mm}$. for the body and 34 for the tail (see table). Tadpoles collected from Paohsing are smaller and the tail fin is less deep than that of tadpoles from Kiating and Kwanhsien. Just after metamorphosis the length of the body from snout to vent is $20 \mathrm{~mm}$. for Kiating specimens and only $14 \mathrm{~mm}$. for Paohsing individuals.

\begin{tabular}{|c|c|c|c|}
\hline Measurements & Range & Average & $\begin{array}{l}\text { Ratio to } \\
\text { body length (\%) }\end{array}$ \\
\hline Body length. & $15.0-19.0$ & 17.1 & \\
\hline Body height. & $8.3-10.5$ & 9.6 & 56.6 \\
\hline Body width. & $9.0-12.4$ & 11.1 & 64.8 \\
\hline Head height. & $5.4-7.0$ & 6.3 & 37.2 \\
\hline Head width. & $6.6-9.1$ & 8.2 & 47.9 \\
\hline Mouth width. & $3.8-4.6$ & 4.1 & 23.0 \\
\hline pace between eyes. & $4.5-6.4$ & 5.7 & 33.3 \\
\hline out to spiraculum. & $10.2-12.8$ & 11.9 & 69.9 \\
\hline 1 length........... & $26.8-40.0$ & 34.0 & 199.0 \\
\hline il height. & $7.5-12.1$ & 10.3 & 60.1 \\
\hline Diameter of tail muscle & $2.6-6.0$ & 4.3 & 25.1 \\
\hline Length of hind leg..... & $0.5-9.0$ & 4.4 & $\ldots$ \\
\hline
\end{tabular}

The body is oval, rounded at the snout, and slightly depressed. The nostrils lie in a depressed area rather nearer to the snout than to the eye. They are directed forward and outward and surrounded by a lighter-colored, elevated ring. The eyes are located at the sides of the head. The spiraculum is sinistral; it has no free tube, but the opening is directed upward and backward and is visible from above as well as from below. The vent is dextral, with a short broad tube connected with the tail fin. The tail is rounded at the tip and has a slightly deeper dorsal fin, thickened and lower near the base of the tail (fig. 71).

The mouth (fig. 71, B) is ventral. There is one row of papillae at the side of the upper lip and on the free margin of the lower lip, with additional papillae at the corners of the lips. Rows of labial teeth vary in tadpoles collected from the same pond as well as in those from different localities. Such variation is mostly found in the upper lip. The outermost tooth row of the upper lip is always complete, but the number of inner rows varies greatly. For the lower lip it is rather uniform as there are three rows, with the innermost interrupted and the two outer rows complete, in fifty-three tadpoles; one tadpole has two inner rows interrupted and only the outermost row complete. In twenty tadpoles from Kwanhsien the labial tooth formulae are as follows: one $\mathrm{I}: 2-2 / \mathrm{I}: 2-2$; one I:2-3/II:1-1; two I:3-2/II:1-1; sixteen I:2-2/II:1-1. In fourteen tadpoles from Kiating the tooth formula for three is I:2-2/II:1-1; two I:3-2/II:1-1; eight I:3-3/II:1-1; one I:4-3/II:1-1. In fourteen Paohsing tadpoles four have 
I:2-2/II:1-1; one I:3-2/II:1-1; two I:2-3/II:1-1; and seven I:3-3/II:1-1. Pope (1931) states that the Rana japonica tadpole has teeth I:2-2/II:1-1. Okada (1931) gives the same tooth formula for the japonica tadpole. The majority of the tadpoles from Kwanhsien have I:2-2/II:1-1, while the majority of the tadpoles from Kiating and Paohsing have I:3-3/II:1-1. A comparative study of large numbers of Rana japonica tadpoles must be combined with study of adults collected from different parts of Asia to straighten out the forms of Rana japonica. The mandible of the tadpole is moderately developed and has a serrated edge.

\section{Rana chaochiaoensis Liu}

Rana chaochiaoensis Liu, 1946, Jour. West China Border Res. Soc., p. 7-Chaochiao City, Sikang.

History of species.-On May 7, 1942, six adult male woodfrogs and one female were collected from ditches just outside of the south gate of Chaochiao City. These proved to be distinct from both chensinensis and japonica and were described in 1946.

Distribution and collection data.-Rana chaochiaoensis is found in Ningshu, Sikang, and in Yunnan. The vertical distribution is from 5,500 feet to about 10,000 feet altitude. From May 5 to July 25, 1942, fifty-nine males, eighteen females, fifty-six juveniles, eggs and different stages of tadpoles were collected around Sichang City, all the way from Sichang City to Chaochiao City in the east and to Yenyuan City in the west.

Comparison with related species.-Rana chaochiaoensis (pl. 6, fig. 2) differs from temporaria chensinensis in lacking vocal sacs. The length of the hind limb of chaochiaoensis is not less than 180 per cent of the body length, and in chensinensis it is not more than 160 per cent. Rana chaochiaoensis is related to japonica in having straight dorso-lateral glandular folds and in being without vocal sacs; it can easily be distinguished by the distinct outer metatarsal tubercle, japonica being mostly without such a tubercle. In chaochiaoensis there is a thinner-skinned triangular area with yellowish rounded glands on the breast near the base of the arm, not found in japonica. There are constantly four rows of lower labial teeth in the tadpole of chaochiaoensis and constantly three rows in the tadpoles of japonica.

Original description.- "The vomerine teeth are in short oblique series, their anterior edges on a line with the centers of the choanae, and extending slightly behind the latter. The head is scarcely longer than broad, the snout pointed and projecting. From the orbit to the tip of the snout is much longer than the length of the eye. The nostrils are about midway between the tip of the snout and the anterior border of the eye, the interorbital space being about threefourths of the width of the upper eyelid; the tympanum is about one and onehalf times the length of the eye, with the canthus rostralis obtuse, and the loreal region concave. The fingers are obtuse, the first extending slightly beyond the 
second and provided with two nuptial pads on the inner dorsal side; the fourth finger is equal to the first, the third being the longest. The subarticular tubercles are well developed. The toes also are obtuse, and are three-fourths webbed, with subarticular tubercles well developed. The inner metatarsal tubercle is elongate and projects strongly; the outer metatarsal tubercle is prominent and rounded. The tibio-tarsal joint nearly reaches the tip of the snout, the tibia being about 62 per cent of the body length, with the heels overlapping.

"The skin on the upper side is rather smooth, except for a few warts near the hip region; there are more black warts, on the sides of the body; a wide, straight, dorso-lateral fold runs on each side from the eye to the insertion of the hind leg. The under side is smooth, except for the posterior, median aspects of the thighs, which are coarsely granulated. The vocal sac is wanting.

"In life this frog is yellowish-olive brown on the back of the head, the body, and the dorsal side of the limbs; the dorso-lateral folds are slightly paler, and are marked on the outside with a series of large, black spots almost forming a continuous line; a darker ill-defined interorbital bar is also present, but the sides of the head and the body are lighter, with more reddish stippling than the dorsum. The warts on the back and sides of the body coincide with black spots. A black line runs from the tip of the snout through the nostril to the anterior corner of the eye; from the posterior corner of the eye it becomes discontinuous along the outer ventral side of the dorso-lateral glandular fold as far as the hip region. There is also a large triangular patch of the same color behind the eye, descending obliquely towards the insertion of the fore limb, and covering the tympanum. An ill-defined blackish line is present on the anterior face of the upper arm and on the posterior face of the lower arm, with black cross bars on both arms and legs. The color of the throat and the belly is a cream-yellow, pinkish towards the groin and on the posterior face of the thigh.

"Description of paratypes. - Seventy-seven adult specimens were collected from the type locality, 59 males, 18 females; and 56 juveniles. Ten large females and twenty large males were measured. There is hardly any sexual dimorphism in size, as the average body length of the female is $56 \mathrm{~mm}$. (52-61), and of the male $53.6 \mathrm{~mm}$. (50-57). The tympanum of the male is larger than that of the female, 8.2 per cent of the body length compared with 7.5 per cent. The lower arm is distinctly thicker in the male than in the female.

"Variation is rather marked. The back is usually smooth. The preserved specimens are very much like those of Rana guentheri in texture and coloration. The V-shaped mark on the shoulder region is present in thirty-two specimens, but all have a dark bar crossing the interorbital space posteriorly. Warts coinciding with black spots are usual on the sides of the body. The dorso-lateral glandular folds are always prominent and wide. The number and size of the dark bars on the legs varies greatly, ranging from 3 to 6 bars on the femur and 3 to 6 also on the tibia. The males are provided with a strongly developed nuptial pad on the inner dorsal side of the first finger, only partially divided on 
the ventral side. The length of the hind limbs varies, the tibio-tarsal joint extending beyond the tip of the snout in some specimens and only to the tip in others. The outer metatarsal tubercle is not always equally prominent; it is very distinct in 52.5 per cent of the specimens and is not distinguishable in 5 per cent.

"The coloration of the adults varies greatly. In most cases it is a yellowish brown; it may be dark ochraceous buff on the dorsal sides of the head, the body and the limbs; sometimes it may be light rufous to brown, or light brownish gray to dark brownish gray. Orange golden stippling is present on the head and back, and is especially conspicuous just median to the dorso-lateral glandular folds. The color of the sides of the body is from cream-gray to bluish gray, with many black spots. The ground color of the throat and belly is cream to cream-yellow, yellowish orange near the groin. Fine red spots are usually present on the thoracic and groin regions. In some cases irregular brown spots may be found on the belly. The ventral sides of the limbs are purplish red. The black pupil is horizontally oval, enclosed by a black iris stippled with gold. The dorsal, median region of the iris is greenish golden in color."

Sex dimorphism.-Males are generally smaller, but the difference is slight. Males have stronger arms, with well-developed nuptial pads on the inner dorsal side of the first fingers. There are no vocal sacs. Lineae masculinae are well developed.

Rana chaochiaoensis: Measurements of Twenty Male and Ten Female Adults

\begin{tabular}{|c|c|c|c|c|}
\hline Measurements & Sex & Range & Average & $\begin{array}{c}\text { Ratio to } \\
\text { body length }(\%)\end{array}$ \\
\hline Body length................ & $\begin{array}{l}0^{2} \\
9\end{array}$ & $\begin{array}{l}50-57 \\
52-61\end{array}$ & $\begin{array}{l}53.6 \\
56.0\end{array}$ & $\cdots$ \\
\hline Head length. & $\begin{array}{l}\sigma^{7} \\
9\end{array}$ & $\begin{array}{l}17-19 \\
17-21\end{array}$ & $\begin{array}{l}18.4 \\
19.2\end{array}$ & $\begin{array}{l}34.4 \\
34.3\end{array}$ \\
\hline Head width. & $\begin{array}{l}8 \\
8\end{array}$ & $\begin{array}{l}16-19 \\
17-21\end{array}$ & $\begin{array}{l}17.4 \\
18.0\end{array}$ & $\begin{array}{l}32.4 \\
32.1\end{array}$ \\
\hline Interorbital space. & $\begin{array}{l}8^{7} \\
9\end{array}$ & $\begin{array}{l}2.5-3.4 \\
2.5-3.5\end{array}$ & $\begin{array}{l}3.0 \\
2.9\end{array}$ & $\begin{array}{l}\mathbf{5 . 8} \\
\mathbf{5 . 3}\end{array}$ \\
\hline Tympanum. . & $\begin{array}{l}\sigma^{7} \\
9\end{array}$ & $\begin{array}{l}3.8-5.0 \\
3.6-5.0\end{array}$ & $\begin{array}{l}4.4 \\
4.2\end{array}$ & $\begin{array}{l}8.2 \\
7.5\end{array}$ \\
\hline Length of lower arm. & $\begin{array}{l}\sigma^{7} \\
9\end{array}$ & $\begin{array}{l}22-26 \\
23-26\end{array}$ & $\begin{array}{l}23.6 \\
23.8\end{array}$ & $\begin{array}{l}44.1 \\
42.5\end{array}$ \\
\hline Diameter of lower arm.... & $\begin{array}{l}07 \\
9\end{array}$ & $\begin{array}{l}6-9 \\
4-7\end{array}$ & $\begin{array}{l}7.0 \\
5.2\end{array}$ & $\begin{array}{r}13.0 \\
9.3\end{array}$ \\
\hline Length of hand. & $\begin{array}{l}0 \\
8 \\
9\end{array}$ & $\begin{array}{l}12-15 \\
13-16\end{array}$ & $\begin{array}{l}14.3 \\
14.2\end{array}$ & $\begin{array}{l}26.7 \\
25.4\end{array}$ \\
\hline Length of leg. & $\begin{array}{l}8 \\
9 \\
9\end{array}$ & $\begin{array}{l}92-110 \\
91-106\end{array}$ & $\begin{array}{r}99.3 \\
101.5\end{array}$ & $\begin{array}{l}185.4 \\
181.3\end{array}$ \\
\hline Length of tibia. & $\begin{array}{l}8 \\
8\end{array}$ & $\begin{array}{l}29-35 \\
31-36\end{array}$ & $\begin{array}{l}32.4 \\
33.3\end{array}$ & $\begin{array}{l}60.5 \\
59.5\end{array}$ \\
\hline Length of foot and tarsus....... & $\begin{array}{l}8 \\
\varnothing\end{array}$ & $\begin{array}{l}41-49 \\
42-48\end{array}$ & $\begin{array}{l}44.1 \\
45.8\end{array}$ & $\begin{array}{l}82.4 \\
81.8\end{array}$ \\
\hline Length of foot. . & $\begin{array}{l}8 \\
8\end{array}$ & $\begin{array}{l}29-34 \\
28-34\end{array}$ & $\begin{array}{l}30.8 \\
31.3\end{array}$ & $\begin{array}{l}57.5 \\
55.9\end{array}$ \\
\hline
\end{tabular}


Habitat and habits.--During the breeding season, adults of Rana chaochiaoensis are found in pools, ponds and ditches around rice fields. They generally remain out of the water, sitting on or among vegetation. Before and after the breeding season, they are usually found on hillsides quite far from water.

The breeding season seems to be very long, as I found tadpoles with hind legs developed in the last part of April, 1942, at Sichang City. On May 2 and 3
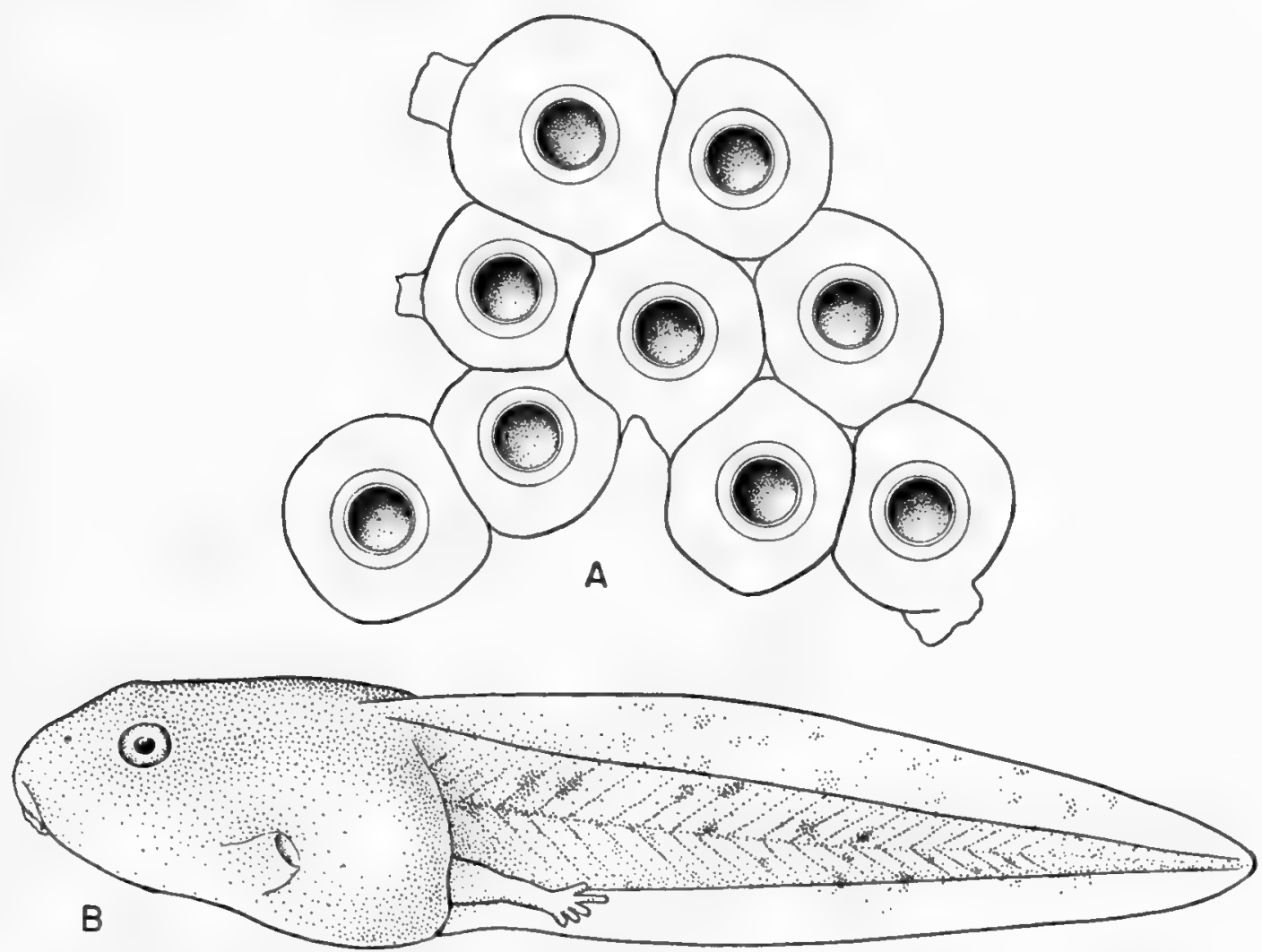

FIG. 72. Rana chaochiaoensis. A. Eggs $\left(\times 4 \frac{1}{2}\right)$. B. Lateral view of tadpole $(\times 3)$.

of the same year I collected tadpoles of different stages on the large mountain near Tahsingchang and Hsuanshenpa, on the way to Chaochiao City. Many egg-masses were found in ditches just outside of Chaochiao City on May 7, 1942. Egg-masses and tadpoles of different stages were obtained around Yenyuan City on July 4, 1942. The breeding season appears to be from March to August.

Egg-masses were laid in various bodies of water such as pools, ponds, ditches, small mountain streams, and residual pools along large mountain streams. The eggs (fig. 72, A) are nearly black or dark brown on the animal pole and light brown on the vegetatgole. The diameter of the egg is $1.7 \mathrm{~mm}$. Each egg is enclosed by three layers of jelly, the outer the thickest and the very thin inner layer applied to the surface of the egg. The outer surface of the external jelly layer connects with those of other eggs to form egg-masses. 
Tadpoles.-Tadpoles are found in the same situations as the eggs. They are active and shy. They are good swimmers, the tail muscle being much better developed than in other Chinese woodfrog tadpoles. The color of the back is light grayish brown, the tail muscle being lighter than the back but with darker spots. The tail fin is cream color, with light brown spots. The belly is cream.

The tadpole (fig. 72, B) is quite large, the average body length of ten specimens being $21 \mathrm{~mm}$. and the tail length $35 \mathrm{~mm}$. The width of the body is a little greater than its depth. The length of the tail is about 169 per cent of the body length. The tip of the tail is rounded and the dorsal tail fin is deeper than the ventral.

\section{Rana chaochiaoensis: Measurements of Ten Tadpoles}

\begin{tabular}{|c|c|c|c|}
\hline Measurements & Range & Average & $\begin{array}{c}\text { Ratio to } \\
\text { body length (\%) }\end{array}$ \\
\hline Body length...... & $18.5-22.0$ & 20.7 & \\
\hline Body height. & $8.5-11.5$ & 10.4 & 50.0 \\
\hline Body width. & $11.0-13.5$ & 12.5 & 60.2 \\
\hline Head height. & $6.4-7.5$ & 6.9 & $33 . \overline{5}$ \\
\hline Head width. & $9-11$ & 10.0 & 48.3 \\
\hline Mouth width. & $4-5$ & 4.5 & 21.6 \\
\hline Space between eyes. & $4.8-6.0$ & 5.4 & 25.9 \\
\hline Snout to spiraculum. & $12-14$ & 13.0 & 62.8 \\
\hline Tail length........ & $32-37$ & 34.9 & 168.6 \\
\hline Tail height. & $9.7-12$ & 10.9 & 52.6 \\
\hline Diameter of tail muscle. & $5.0-5.5$ & 5.1 & 24.6 \\
\hline
\end{tabular}

The snout is rounded, with the nostril nearer to the tip of the snout than to the eye; the eyes are latero-dorsal in position, the space between them greater than the internasal space; the spiraculum is sinistral, without a free tube, directed upward and backward and visible from above and below; the long, very broad tubular vent is attached to the right side of the base of the ventral tail fin.

The mouth is antero-ventral; the papillae vary greatly, with, in most specimens, a row of small papillae on the sides of the upper lip and a continuous row on the lower lip, with additional ones at the corners of the mouth and the lateroventral corners of the lower lip. In some specimens the row of papillae on the lower lip is not continuous. Very rarely there are numerous small papillae crowded together on the sides of both upper and lower lip. Whereas the adult resembles japonica in structural characters, the tadpoles more closely resemble temporaria chensinensis.

Sixty tadpoles (twenty from Chaochiao; twenty from Sichang; and twenty from Yenyuan) were examined as to their variation.

Among the tadpoles from Chaochiao nine have the labial tooth formula I:2-2/III:1-1; eight have I:3-3/III:1-1; one has I:2-2/IV:0-0; and one has $\mathrm{I}: 3-3 / \mathrm{IV}: 0-0$. In one the teeth are irregular. Out of twenty specimens from Sichang fourteen have the formula I:3-3/III:1-1; four have I:2-2/III:1-1; one has I:2-3/III:1-1; and one has I:3-3/IV:0-0. The labial tooth formula of the Yenyuan tadpoles is similar to that of the Chaochiao specimens, fourteen 
having teeth I:2-2/III:1-1; four I:3-3/III:1-1; one I:2-3/III:1-1; and one I:2-3/II:2-2. The mandibles are moderately developed, with serrated edges.

\section{Rana andersonii Boulenger}

Polypedates yunnanensis Anderson (not Rana yunnanensis Anderson), 1879, Anat. Zool. Res. Yunnan, p. 846, pl. 78, fig. 3-Husa Valley, Yunnan.

Rana andersonii Boulenger, 1882, Cat. Batr. Sal., Brit. Mus., p. 55; Boulenger, 1920, Rec. Ind. Mus., 20: 174; Werner, 1924, Denkschr. Akad. Wiss. Wien, 99: 53; Schmidt, 1927, Bull. Amer. Mus. Nat. Hist., 54: 51 (in part).

Rana grahami Boulenger, 1917, Ann. Mag. Nat. Hist., (8), 20 : 415-Yunnanfu, Yunnan. Rana macrodon Mell, 1922, Arch. Naturg. Berlin, 88, Abt. A, Heft 10: 132.

Rana schmackeri Chang, 1932, Contr. Biol. Lab. Sci. Soc. China, 8, No. 5: 165; Pope and Boring, 1940, Peking Nat. Hist. Bull., 15, pt. 1: 62.

History of species.-In 1878, Anderson described a Rana from Yunnan as Polypedates yunnanensis, and in the same publication, on an earlier page, he described a Rana yunnanensis. In 1882 Boulenger studied the same material and found Anderson's Polypedates yunnanensis to be a Rana. As the specific name yunnanensis was pre-occupied in the genus Rana, Boulenger renamed Polypedates yunnanensis as Rana andersonii. In 1917, Boulenger described Rana grahami from Yunnan, based upon the character of the digital tips, stated to be swollen but without disks, whereas Rana andersonii was regarded as having disks. Pope found the lateral groove of the digital tip either present or absent in six Kweichow specimens, and I found the same condition in my collection from Sichang, Chaochiao, and Yenyuan, Sikang. I accordingly agree with Pope and Boring in placing grahami in the synonymy of andersonii. Mell's Rana macrodon record was merely a misidentification of andersonii. In 1932, Chang recorded Rana schmackeri from Chinkouho, Opienhsien, in southwestern Szechwan, and gave a detailed description with figures. He described the male as having indistinct internal vocal sacs and a more rugose belly. The internal vocal sacs and the spiny belly of the male agree completely with my specimens from Sichang, which is much nearer to Yunnan than the locality from which Chang recorded his specimens. Pope and Boring (1940) report that Pope had examined the type of schmackeri and failed to find any character to distinguish it from the common cascade frog of Fukien, which he had identified as andersonii in 1931. Thus they were led to keep andersonii as the Yunnan form and apply the name schmackeri to the eastern species; but they relied upon Chang's identification of schmackeri from southwestern Szechwan and of andersonii as correctly identified. In 1940 I followed Pope and Boring in publishing my specimens from northwestern Szechwan and Mount Omei as andersonii. The results of further detailed study indicate definitely that from Mount Omei to the north andersonii is replaced by an entirely different and larger species. The male of this species has no vocal sacs and has fine spines limited to the anterior part of the belly. It seems clear that the form from central and eastern China is schmackeri, that the form from western and northern Szechwan and eastern Sikang is a new species (Rana margaretae) and that the range of the true andersonii is south of the 
Tatuho, including parts of Szechwan, Sikang, Kweichow, and Yunnan. In 1927, Schmidt suggested this disposal of schmackeri, and Pope's identification of his Fukien specimens as identical with schmackeri is also in accord with it. The confusion has been in misidentification of specimens from western China. ${ }^{{ }^{1}}$

Distribution and collection data.-Rana andersonii has been so much misidentified that the published records must be disregarded. True Rana andersonii is distributed through Yunnan and into western Kweichow, southwestern Szechwan, and southeastern Sikang, with a vertical distribution ranging from 3,000 to 8,000 feet. From April to July of 1942 , I collected twenty-six females and twenty-one males from Sichang, Chaochiao, and Yenyuan in Ningshu, Sikang. Tadpoles of different stages were collected in a large river outside of Sichang City.

Comparison with related species.--Rana andersonii (pl. 6, fig. 3) can easily be distinguished from Rana margaretae (pl. 6, fig. 6) by much larger tympanum, by the presence of paired subgular internal vocal sacs in the male, and by the fact that the whole belly of the male is covered by fine colorless spines. Rana margaretae has no vocal sacs and the fine colorless spines are limited to the anterior portion of the belly. Rana andersonii is definitely smaller than margaretae. The sides of the body of andersonii are much more rugose and have many large rounded warts, whereas in margaretae the sides of the body are much smoother.

Rana andersonii can easily be distinguished from Rana schmackeri by the following characters: The male of andersonii is much larger than the male of schmackeri, the average body length of andersonii being $71 \mathrm{~mm}$., ranging from 61 to 77, while for the latter the type male measures $42 \mathrm{~mm}$. and twelve males from Fukien have an average body length of $43 \mathrm{~mm}$., ranging from 37 to 46 . The male of andersonii has more prominent and crowded spines covering the whole belly but absent from the thorax and throat, whereas the male of schmackeri has very fine scattered spines all over the throat, thorax, and belly. The digital disks are far better developed in schmackeri than in andersonii. Rana schmackeri has constant and very conspicuously brown or black round spots on the head and back; spotting is inconstant in andersonii. The sides of the body are much rougher in andersonii than in schmackeri. The male of andersonii has internal paired subgular vocal sacs; in the male of schmackeri the vocal sacs may be discerned externally. Boulenger, Mell, Werner, Schmidt, and Pope, who studied andersonii, all failed to mention the spiny belly of the male.

Original description.- "Vomerine teeth in two small groups between the choanae. Head moderate; snout short, rounded, with rounded canthus rostralis,

${ }^{1}$ The synonymy of Rana schmackeri may be disentangled as follows:

Rana schmackeri Boettger, 1892, Kat. Batr. Samml. Senck. Ges., p. 11-Kaochahsien, Ichang, Hupeh; Boulenger, 1920, Rec. Ind. Mus., 20: 176; Pope and Boring, 1940, Peking Nat. Hist. Bull., 15, pt. 1: 62 (in part).

Rana andersonii Boulenger, 1920, Rec. Ind. Mus., 20 : 174 (in part); Schmidt, 1927, Bull. Amer. Mus. Nat. Hist., 54: 51 (in part); Pope, 1931, Bull. Amer. Mus. Nat. Hist., $61: 550$ (in part).

Rana melli Vogt, 1922, Arch. Naturg. Berlin, 88, Abt. A, Heft 10: 144-Lienping, Kwangtung. 
interorbital space a little broader than the upper eyelid; tympanum distinct, half the width of the eye. Fingers moderate, first not extending beyond the second; toes moderate, nearly entirely webbed; tips of fingers and toes dilated into very small discs; subarticular tubercles rather small; a single, small, inner metatarsal tubercle. The hind limb being carried forwards along the body, the tibio-tarsal articulation reaches beyond the tip of the snout. Flat warts on the sides of the body, a fold above the tympanum. Olive above, indistinctly spotted; limbs cross-barred; beneath immaculate. Male with two internal vocal sacs."

In 1920, Boulenger amplified this description as follows:

"Vomerine teeth in transverse or slightly oblique series between the choanae or extending a little beyond the level of the posterior borders of the latter.

"Head as long as broad or slightly broader than long, much depressed; snout rounded or obtusely pointed, feebly projecting beyond the mouth, as long as the eye or a little shorter; canthus rostralis obtuse; loreal region feebly oblique, concave; nostril equidistant from the eye and from the tip of the snout or a little nearer the former; the distance between the nostrils equals or a little exceeds the interorbital width, or that of the upper eyelid; tympanum very distinct, two-fifths to one-half the diameter of the eye and one and one-third to two times its distance from the latter.

"Fingers rather long, terminating in small dises, which are longer than broad and divided by a groove into an upper and a lower portion; first finger as long as or a little longer than the second, third much longer than the snout; subarticular tubercles moderately large, moderately prominent.

"Hind limb long; tibio-tarsal articulation reaching the tip of the snout or a little beyond; heels overlapping when the limbs are folded at right angles to the body; tibia 4 to 5 times as long as broad, one and three-fifths to one and threefourths times in length from snout to vent, as long as or a little shorter than the fore limb, slightly or a little longer than the foot. Toes ending in small discs, same as those of the fingers, webbed to the discs; subarticular tubercles rather small, moderately prominent; no tarsal fold; inner metatarsal tubercle rather small, feebly prominent, one-third to two-fifths the length of the inner toe; no outer tubercle.

"Back finely areolate or granulate, sides often with large flat warts; males with minute white spinose tubercles on the sides. Lower parts smooth.

"Olive above with large roundish brown spots, the ground colour sometimes forming a mere network between them; sides with black spots; limbs with numerous dark cross-bands; hinder side of thighs yellow, spotted or marbled with black. Lower parts white, throat sometimes marbled with brown.

"Males with internal vocal sacs; fore limb much thickened, the inner finger with a large pad, covered, during the breeding season, with a velvety grey horny layer.

"Nasals small and widely separated from each other and from the frontoparietals; upper part of ethmoid largely uncovered anteriorly. 
"Measurements (in millimetres; male type): From snout to vent 53; head 18; width of head 18; snout 6 ; eye 7 ; interorbital width 4.5 ; tympanum 3.5 ; fore limb 35 ; first finger 7; second finger 6.5; third finger 10; fourth finger 6 ; hind limb 100 ; tibia 32 ; third toe 16 ; fourth toe 24 ; fifth toe 18 ; foot $31 . "$

Coloration in life.-Upper parts with an umber ground color, the elevated ridges of the wrinkled skin closely spotted with golden. Dark green spots rarely developed on the anterior parts of the body, usually present on the upper eyelid. Large round warts on the anterior region of the back, and many small ones
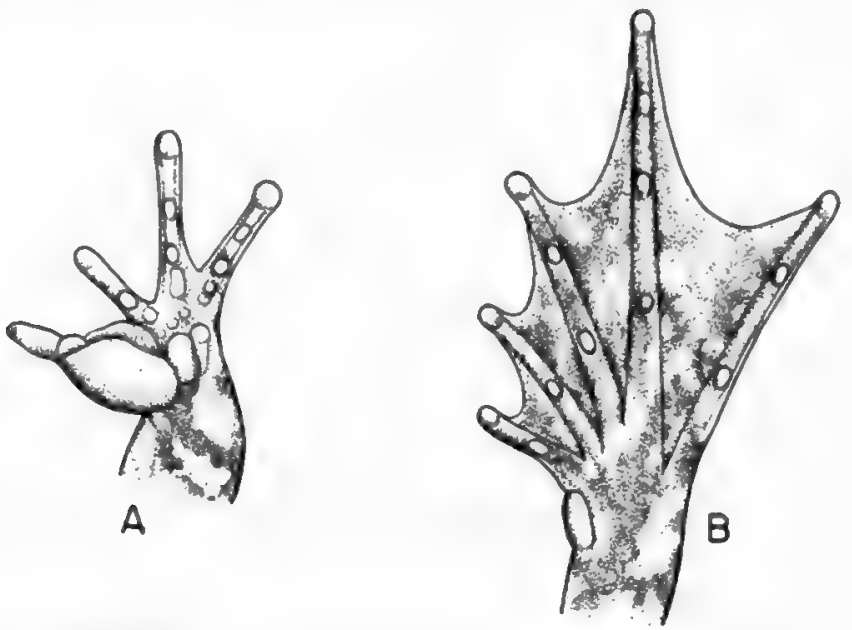

FIG. 73. Rana andersonii. A. Ventral view of hand of male $(\times 11 / 2)$. B. Ventral view of foot $\left(\times 1 \frac{1}{2}\right)$.

posterior to the sacral vertebra, darker than the ground color. The dorsal sides of the limbs with umber bars alternating with closely stippled golden bars on the arms and legs; on the antero-ventral side of the thigh, the dark bars alternating with yellowish green. Elongated glands on the dorso-lateral parts of the body generally golden. Ventro-lateral sides of the body marbled with light yellowish green and umber. The armpit and groin yellowish green. The jaws marbled with umber and light greenish gold. In most cases the throat and the belly gray. More rarely cream-white on the belly, the ventral sides of the limbs, especially the legs, fleshy light yellowish green. Pupil black, the iris golden above and reddish below.

Sex dimorphism.--Sex dimorphism in size is marked, average body length of twenty males $71 \mathrm{~mm}$., ranging from 61 to $77 \mathrm{~mm}$., and of fourteen females $95 \mathrm{~mm}$., with a range from 88 to $107 \mathrm{~mm}$. The arm of the male is proportionately stronger. In the male (fig. $73, \mathrm{~A}$ ) a very strong nuptial pad is developed on the inner dorsal side of the basal segment of the first finger. Males have a pair of internal subgular vocal sacs, and fine lineae masculinae. Fine colorless spines are present on the whole belly of the male, the belly being smooth in the female. Similar, very fine, white spines are present on the ventro-lateral sides of the lower jaw and posterior to the angles of the mouth in males. The webs are much better developed in the male. 
Rana andersonii: Measurements of Twenty Male and Fourteen Female Adults

\begin{tabular}{|c|c|c|c|c|}
\hline Measurements & Sex & Range & Average & $\begin{array}{c}\text { Ratio to } \\
\text { body length }(\%)\end{array}$ \\
\hline Body length...... & $\begin{array}{l}\sigma^{7} \\
0\end{array}$ & $\begin{array}{l}61-77 \\
88-107\end{array}$ & $\begin{array}{l}71.3 \\
95.0\end{array}$ & ... \\
\hline Head length.......... & $\begin{array}{l}\sigma^{7} \\
9\end{array}$ & $\begin{array}{l}23-27 \\
31-37\end{array}$ & $\begin{array}{l}24.9 \\
33.2\end{array}$ & $\begin{array}{l}34.9 \\
34.9\end{array}$ \\
\hline Head width. & $\begin{array}{l}\sigma^{7} \\
0\end{array}$ & $\begin{array}{l}20-25 \\
29-36\end{array}$ & $\begin{array}{l}23.0 \\
31.7\end{array}$ & $\begin{array}{l}32.3 \\
33.4\end{array}$ \\
\hline Interorbital space... & $\begin{array}{l}\sigma^{7} \\
\wp\end{array}$ & $\begin{array}{l}4.5-6.0 \\
5.5-7.5\end{array}$ & $\begin{array}{l}5.2 \\
6.6\end{array}$ & $\begin{array}{l}7.2 \\
6.9\end{array}$ \\
\hline Tympanum. & $\begin{array}{l}\sigma^{7} \\
9\end{array}$ & $\begin{array}{c}4.5-6.0 \\
5-7\end{array}$ & $\begin{array}{l}5.5 \\
6.0\end{array}$ & $\begin{array}{l}7.7 \\
6.3\end{array}$ \\
\hline Length of lower arm.. & $\begin{array}{l}0 \\
0 \\
0\end{array}$ & $\begin{array}{l}28-36 \\
38-49\end{array}$ & $\begin{array}{l}32.5 \\
42.9\end{array}$ & $\begin{array}{l}45.6 \\
45.2\end{array}$ \\
\hline Diameter of lower arm... & $\begin{array}{l}\sigma^{7} \\
\vdots\end{array}$ & $\begin{array}{l}7-11 \\
8-11\end{array}$ & $\begin{array}{l}9.3 \\
9.4\end{array}$ & $\begin{array}{r}13.0 \\
9.9\end{array}$ \\
\hline Length of hand... & $\begin{array}{l}0^{x} \\
0\end{array}$ & $\begin{array}{l}17-24 \\
25-31\end{array}$ & $\begin{array}{l}20.7 \\
26.7\end{array}$ & $\begin{array}{l}29.0 \\
28.1\end{array}$ \\
\hline Length of leg. . & $\begin{array}{l}\sigma^{7} \\
0\end{array}$ & $\begin{array}{l}100-134 \\
150-184\end{array}$ & $\begin{array}{l}122.5 \\
163.9\end{array}$ & $\begin{array}{l}171.8 \\
172.5\end{array}$ \\
\hline Length of tibia.. & $\begin{array}{l}\sigma^{7} \\
\$\end{array}$ & $\begin{array}{l}35-44 \\
50-60\end{array}$ & $\begin{array}{l}40.1 \\
53.6\end{array}$ & $\begin{array}{l}56.2 \\
56.4\end{array}$ \\
\hline Length of foot and tarsus. . & $\begin{array}{l}\sigma^{7} \\
9\end{array}$ & $\begin{array}{l}42-60 \\
68-88\end{array}$ & $\begin{array}{l}54.3 \\
72.8\end{array}$ & $\begin{array}{l}76.2 \\
76.6\end{array}$ \\
\hline Length of foot. & $\begin{array}{l}\sigma^{7} \\
+\end{array}$ & $\begin{array}{l}28-44 \\
46-55\end{array}$ & $\begin{array}{l}38.4 \\
51.1\end{array}$ & $\begin{array}{l}53.9 \\
53.8\end{array}$ \\
\hline
\end{tabular}

Habitat and habits.-Rana andersonii is found in large mountain streams. During the day, frogs of this species hide in holes between boulders near the water, but at twilight they come out from their hiding places and sit under stones by the side of the water, or in the current, with their heads outside. This habit is different from that of the allied species margaretae, as margaretae is found sitting on stones or on vegetation, on stones under cascades, or by the side of or in the water. It is much easier to collect andersonii than margaretae.

The breeding site, the breeding season and breeding behavior of andersonii are not definitely known. As I collected quite mature tadpoles from a large mountain stream on April 24, 1942, such streams must be the breeding site, and the breeding season must be some time in February or early March.

Tadpole.-Tadpoles (fig. 74) of this species are found under algae or stones of mountain streams where the current is rather slow, or in side pools of the main stream. Without turning the stones or the aquatic vegetation, tadpoles are not seen. The habits and habitat of these tadpoles are similar to those of margaretae.

The coloration of the living tadpole of andersonii is very much like that of margaretae. The ground color is ochraceous buff, stippled with dark brown and gold. The dorsal side of the body is much darker, and the muscular portion of the tail is marbled with a lighter color. The tail fin is lighter and spotted with 
gray. The throat and the belly are purplish gray, stippled with silver and gold. The round pupil is black, enclosed by a golden iris. When the hind limbs are fully developed, the color of the back is uneven, with elevated warts enclosed by dark color and the sides darker than the back.

When the four limbs are completely developed and before the absorption of the tail, the color of the back becomes golden, with conspicuous warts enclosed
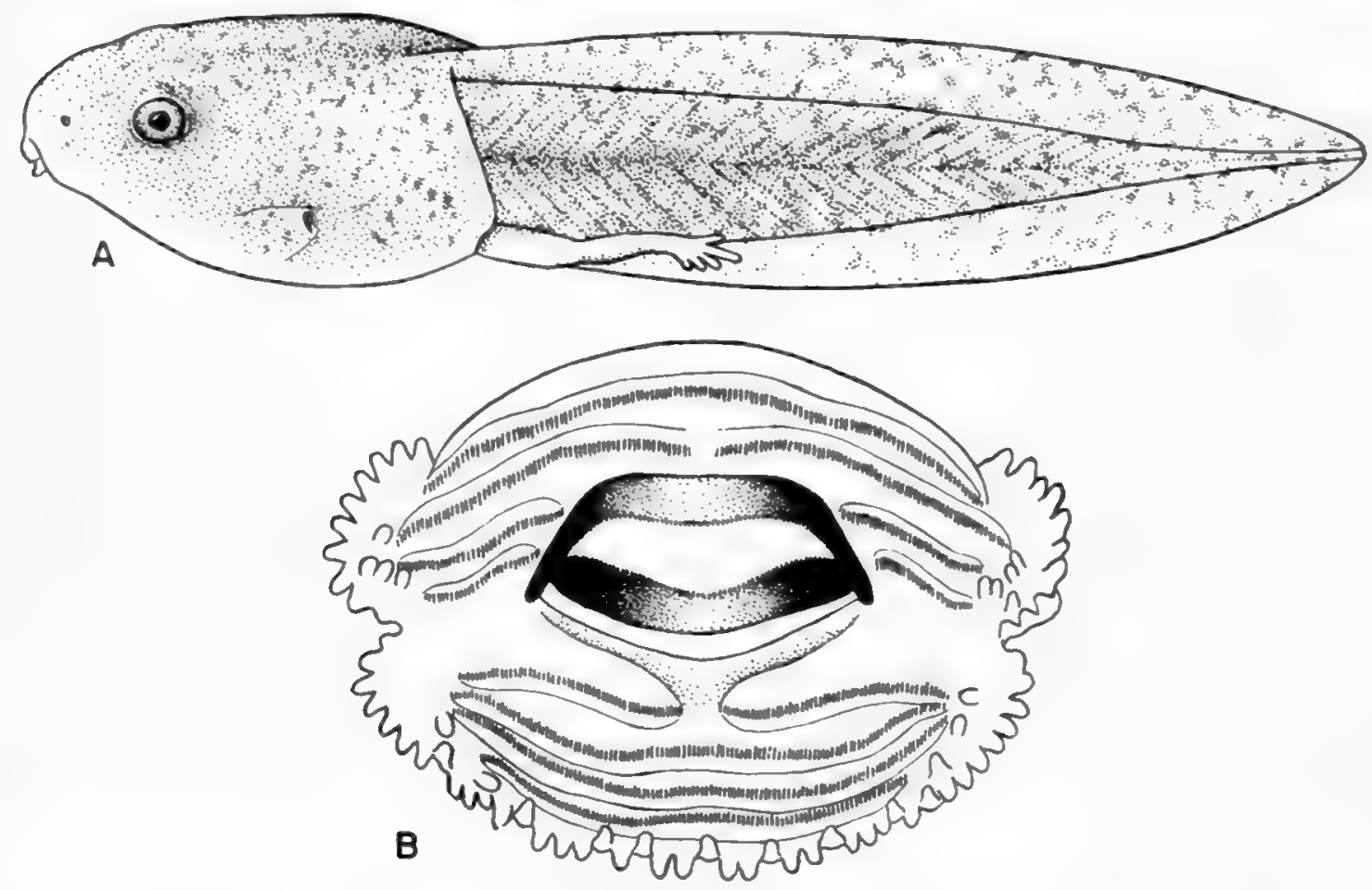

FIG. 74. Rana andersonii; tadpole. A. Lateral view $(\times 3)$. B. Mouth $(\times 20)$.

by darker color. The sides of the head and body are darker than the back. Dark brown bars are conspicuously developed on the limbs. When the tail is almost gone, the young has all the characters of the adult except that there is no greenish color like that of the spots on the back of the adult. It takes seven days to complete the process of metamorphosis.

Twenty tadpoles with hind limbs ranging from 10-17 $\mathrm{mm}$. in length have an average total length of $54 \mathrm{~mm}$., with a range from 50 to $58 \mathrm{~mm}$. (see table). The length of the tail is about twice that of the body, and its height more than half the body length. The snout is rounded; the nostril, with a light-colored flap at the posterior side, is dorsal in position and nearer to the snout than to the eye. The eyes are latero-dorsal. The spiraculum is sinistral, ending in a very short tube, directed upward and backward, visible from above and below. The vent is dextral, with a long tube continuous with the ventral tail fin. The tail is strongly built; the fin is moderately developed and about equal above and below, with a blunted tip. The dorsal fin becomes thickened toward the 
base of the tail, and does not reach its basal part. The mouth (fig. 74, B) is ventral. There is a single row of somewhat pointed papillae at the lower corners of the upper lip and on the whole margin of the lower lip, with some extra papillae inside of the marginal row at the corners of the upper and lower lips. The papillae are colorless. The rows of labial teeth are constant; the four rows on the upper lip have the outermost row longest and continuous and the remaining three rows interrupted, the innermost the shortest; on the lower lip, with four rows of labial teeth, the three outer rows are continuous and only the innermost is interrupted, the second row being the longest and the outermost the shortest. The tooth formula is constantly I:3-3/III:1-1. The mandibles are weakly developed, with rather long but blunt denticulation of the margins.

\section{Rana andersonii: Measurements of Twenty Tadpoles}

\begin{tabular}{|c|c|c|c|}
\hline Measurements & Range & Average & $\begin{array}{c}\text { Ratio to } \\
\text { bodv length }(\%)\end{array}$ \\
\hline Body length... & $17.5-20.0$ & 18.6 & \\
\hline Body height. & $8-10$ & 9.6 & 51.6 \\
\hline Body width. & $10.5-13.0$ & 11.7 & 62.9 \\
\hline Head height. & $6.0-7.5$ & 6.6 & 35.5 \\
\hline Head width. & $8-9$ & 8.8 & 47.2 \\
\hline Width of mouth. & $4-5$ & 4.6 & 24.7 \\
\hline Space between eyes. & 4-5 & 4.5 & 24.1 \\
\hline Snout to spiraculum. & $12.0-13.3$ & 12.6 & 67.7 \\
\hline Tail length........ & $32.5-38.0$ & 35.6 & 191.3 \\
\hline Tail height. & $9.8-12.0$ & 10.6 & 56.9 \\
\hline Diameter of tail muscle. & $5-6$ & 5.3 & 28.4 \\
\hline Length of hind leg. & $10-17$ & 13.8 & \\
\hline
\end{tabular}

\section{Rana margaretae sp. nov.}

Type.-No. 49418 Chicago Natural History Museum, from Panlungshan, Kwanhsien, Szechwan, 3,500 feet altitude. Adult male, collected June 20, 1941, by Ch'eng-chao Liu.

Diagnosis.-A mountain stream frog (pl.6, fig. 6) related to Rana andersonii; the male larger than in andersonii; the tympanum not broader than its distance from the eye; the fine white spines of the under side of the male limited to the anterior part of the belly in margaretae and much stronger and covering the whole belly in andersonii; no vocal sac in the male of margaretae, but vocal sacs present in andersonii. The much smaller Rana schmackeri has a feeble tarsal fold and a larger tympanum (three-fourths the length of the eye), whereas margaretae has no trace of tarsal fold and the tympanum is about one-half the length of the eye.

Description of type.-Body slender and depressed. Head greatly depressed, much longer than broad, top flat with a small round white spot between the anterior parts of the upper eyelids; snout rounded, strongly projecting; nostril about midway between the tip of the snout and the anterior corner of the eye; canthus rostralis obtuse, loreal region oblique, with a groove from the nostril to the antero-ventral side of the lower eyelid; interorbital space smaller than the internasal space and equal to the width of the upper eyelid; the space between 
eye and tympanum about equal to the size of the tympanum, which is about one-half the length of the eye; the tongue notched behind; the vomerine teeth very strong, in two slightly oblique series between the choanae.

Arm short but strong, fingers $3-4-2-1$ in order of length; tips of fingers (fig. 75, A) provided with rounded disks slightly larger than the diameter of the terminal phalanges, horizontal grooves distinct in the three outer fingers and

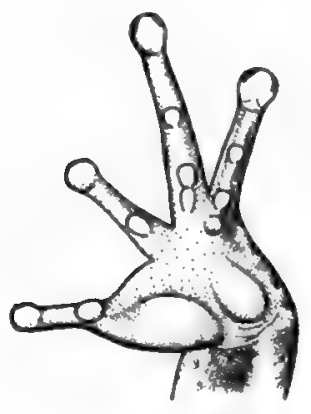

A

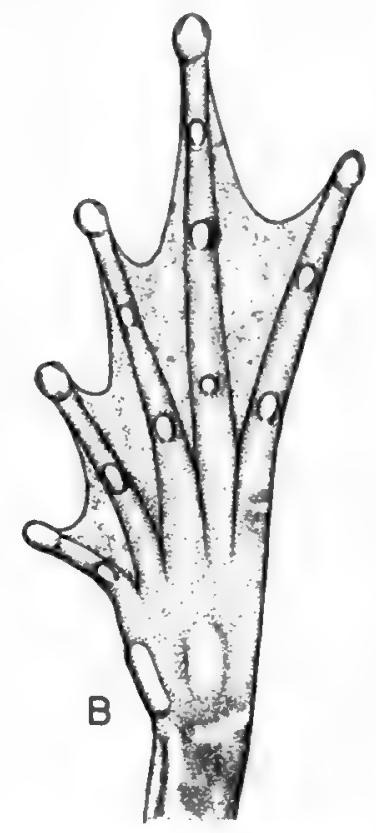

FIG. 75. Rana margaretae $\left(\times 1 \frac{1}{2}\right)$. A. Ventral view of hand of male. B. Ventral view of foot.

indicated on the first finger; a very strong nuptial pad on the inner dorsal side of the basal segment of the first finger, the terminal segment of which is bent downward; subarticular tubercles strongly developed; supernumerary tubercles developed at the base of each of the three outer fingers; two elongated tubercles on the postero-ventral side of each palm.

Legs strong and long, the tibio-tarsal articulation reaching the tip of the snout; heels strongly overlapping when placed at right angles to the body; the fourth toe (fig. 75, B) longest, the third and fifth about equal, the second toe shorter than the third and fifth, and the first toe the shortest; disks with horizontal grooves developed on all the toes; webs fully developed, reaching the bases of the disks on the inner side of the fifth toe, the outer sides of the fourth and third toes, both sides of the second toe and the outer side of the first toe; a narrow fringe along the inner side of the first toe and the outer side of the fifth; subarticular tubercles well developed; a very distinct elongate rod-like inner metatarsal tubercle; no outer metatarsal tubercle.

Skin smooth above, with a few flattened warts near the hip region; some small flattened warts on the side of the body and small light-colored spiny warts on 
the arms and legs; small white warts crowded on the postero-median aspects of the thighs, especially below the vent; the throat, belly and ventral sides of the limbs smooth, with very fine spines forming a definite transverse oval area on the thorax; a weak glandular fold from the posterior corner of the eye extending backward to the shoulder region.

Coloration in life.--Uniform dark green on the back with black and light brown marks on the hip region; the upper sides with a brown ground color marbled with black; yellowish ground color on lower sides of the body, less marked with black; an ill-defined black band from the snout through the nostril, and extending to the anterior corner of the eye; black bars on the yellowish background of the upper and lower jaws; the limbs with a light brown ground color with distinct black bars and green patches on the upper arm and lower legs; the throat, thorax and belly dusky on a yellowish cream ground, darker on the throat and thorax; the ventral sides of the limbs yellowish cream, less dusky than the belly, with dark spots on the legs; the dorsal sides of the three outer fingers and two outer toes like the upper sides of the limbs, spotted with black; the pupil black, transversely oval, enclosed by a golden ring, the iris golden spotted with dark brown. After preservation, the back becomes dark bluish gray, lighter on the sides, with light-edged black markings; the limbs are lighter than the back with black bars and markings, especially on the thighs; the yellow and green all disappear.

Variation in color is slight. In most specimens the back is uniform green, rarely with large dark spots. The skin is usually smooth on the back, but in a very few cases is areolated or granulated, as is the normal condition in Rana andersonii.

Sex dimorphism.-Males are smaller than females (see table). The arm of the male is proportionately much stronger than that of the female, and has a very strong nuptial pad on the inner dorsal side of the basal segment of the first finger. A transverse oval area covered with fine white spines is developed in the very anterior part of the belly of the male, but is absent in the female. There are no vocal sacs in the male. Fine lineae masculinae are present.

Discussion.-Rana margaretae has long been misidentified as Rana andersonii. Chang and Hsü (1932) described this species in detail, with figures of specimens, two from Tsingch'engshan, Kwanhsien, at about 3,000 feet altitude, and one from Fuhusze, Mount Omei, at about 3,500 feet altitude, supposing it to be andersonii. My own life history studies of this species on Mount Omei were published in 1940 as pertaining to andersonii. The new distinct species, related to andersonii, is named for Mrs. Margaret W. Schmidt, whom I hold in affectionate regard.

There is no possible confusion of margaretae with schmackeri. Pope's notes on the type of schmackeri in the Frankfort Museum record the type as a mature male with well-developed nuptial pad and enlarged arm; Boettger (1892) and Boulenger (1920) failed to mention these characters. Pope did not observe the 
vocal sacs or the fine white spines of the belly, but from the evidence of the Fukien specimens I believe them to be present. I examined twelve adult males and thirty-one adult females from Chunganhsien, Fukien, all of which are clearly schmackeri, as the body length of the males ranges from 37 to $46 \mathrm{~mm}$. Males of schmackeri have vocal sacs and have spines all over the throat, thorax and belly.

\section{Rana margaretae: Measurements of Fourteen Male and} Fifty Female Adults

\begin{tabular}{|c|c|c|c|c|}
\hline Measurements & Sex & Range & Average & $\begin{array}{c}\text { Ratio to } \\
\text { body length (\%) }\end{array}$ \\
\hline Body length...... & $\begin{array}{l}0^{x} \\
9\end{array}$ & $\begin{array}{l}78-88 \\
93-113\end{array}$ & $\begin{array}{r}81.4 \\
103.4\end{array}$ & $\ldots$ \\
\hline Head length. & $\begin{array}{l}\sigma^{7} \\
0\end{array}$ & $\begin{array}{l}25.0-29.0 \\
32.5-39.0\end{array}$ & $\begin{array}{l}27.5 \\
35.8\end{array}$ & $\begin{array}{l}33.8 \\
34.6\end{array}$ \\
\hline Head width. & $\begin{array}{l}0^{7} \\
\wp\end{array}$ & $\begin{array}{l}24.5-28.3 \\
31.2-37.5\end{array}$ & $\begin{array}{l}26.4 \\
34.9\end{array}$ & $\begin{array}{l}32.4 \\
33.8\end{array}$ \\
\hline Interorbital space. . & $\begin{array}{l}0^{7} \\
0\end{array}$ & $\begin{array}{l}6.5-8.0 \\
8.2-11.0\end{array}$ & $\begin{array}{l}7.3 \\
9.5\end{array}$ & $\begin{array}{l}9.0 \\
9.2\end{array}$ \\
\hline Tympanum. & $\begin{array}{l}9 \\
9 \\
9\end{array}$ & $\begin{array}{l}3.3-4.3 \\
3.8-5.5\end{array}$ & $\begin{array}{l}3.9 \\
4.4\end{array}$ & $\begin{array}{l}4.8 \\
4.3\end{array}$ \\
\hline Length of lower arm.. & $\begin{array}{l}\sigma^{7} \\
0\end{array}$ & $\begin{array}{l}37.0-41.5 \\
45.5-55.0\end{array}$ & $\begin{array}{l}38.7 \\
49.5\end{array}$ & $\begin{array}{l}47.6 \\
48.0\end{array}$ \\
\hline Diameter of lower arm. & $\begin{array}{l}\sigma^{7} \\
\wp\end{array}$ & $\begin{array}{l}7.0-11.5 \\
7.4-11.8\end{array}$ & $\begin{array}{l}9.5 \\
9.6\end{array}$ & $\begin{array}{r}11.7 \\
9.3\end{array}$ \\
\hline Length of hand. & $\begin{array}{l}\sigma^{7} \\
q\end{array}$ & $\begin{array}{l}20.5-22.5 \\
23.0-32.0\end{array}$ & $\begin{array}{l}21.6 \\
26.4\end{array}$ & $\begin{array}{l}26.5 \\
25.6\end{array}$ \\
\hline Disk of third finger. & $\begin{array}{l}0^{7} \\
0\end{array}$ & $\begin{array}{l}2.1-2.8 \\
2.5-3.7\end{array}$ & $\begin{array}{l}2.4 \\
2.9\end{array}$ & $\begin{array}{l}3.0 \\
2.8\end{array}$ \\
\hline Length of leg...... & $\begin{array}{l}9 \\
9 \\
9\end{array}$ & $\begin{array}{l}140-162 \\
166-201\end{array}$ & $\begin{array}{l}151.6 \\
187.4\end{array}$ & $\begin{array}{l}186.4 \\
181.0\end{array}$ \\
\hline Length of tibia.. & $\begin{array}{l}8 \\
9\end{array}$ & $\begin{array}{l}46.2-50.0 \\
55.5-64.0\end{array}$ & $\begin{array}{l}48.1 \\
59.9\end{array}$ & $\begin{array}{l}59.1 \\
57.9\end{array}$ \\
\hline Length of foot and tarsus...... & $\begin{array}{l}\sigma^{7} \\
0\end{array}$ & $\begin{array}{l}67-77 \\
81-94\end{array}$ & $\begin{array}{l}71.0 \\
85.9\end{array}$ & $\begin{array}{l}87.5 \\
83.1\end{array}$ \\
\hline Length of foot. & $\begin{array}{l}\sigma^{7} \\
\&\end{array}$ & $\begin{array}{l}41-45 \\
48-63\end{array}$ & $\begin{array}{l}43.8 \\
54.9\end{array}$ & $\begin{array}{l}53.8 \\
53.0\end{array}$ \\
\hline Disk of fourth toe............ & $\begin{array}{l}7 \\
0 \\
9\end{array}$ & $\begin{array}{l}2.2-3.0 \\
2.6-3.6\end{array}$ & $\begin{array}{l}2.5 \\
3.0\end{array}$ & $\begin{array}{l}3.1 \\
2.9\end{array}$ \\
\hline
\end{tabular}

The vertical distribution of margaretae and andersonii are different; margaretae ranges from about 2,500 to 4,500 feet altitude and andersonii from 3,000 to 8,000 feet.

Habitat and habits.-Rana margaretae is commonly seen adhering to the surface of rocks on the steep banks of swift mountain streams from 2,500 to 4,500 feet altitude. It may be found sitting on mats of green vegetation on the rocks of the bank or on the rocks in the current of the water. This frog usually directs its head toward the current, into which it dives at the slightest disturbance. The places where these frogs sit are usually from one to about four feet above the water level. They are sometimes found with Staurois mantzorum.

Although many adults and tadpoles were collected from different places, the site and time for breeding are still unknown. I collected no eggs. 
Tadpole.-Tadpoles (fig. 76) of Rana margaretae are found in large mountain streams behind stones where there is no direct or swift current. They are bottom forms, feeding among dead leaves or twigs. Sometimes a few tadpoles may be found in side pools that are poorly connected with the main stream. Very rarely one can see them in their hiding places. By chance, with a dip-net
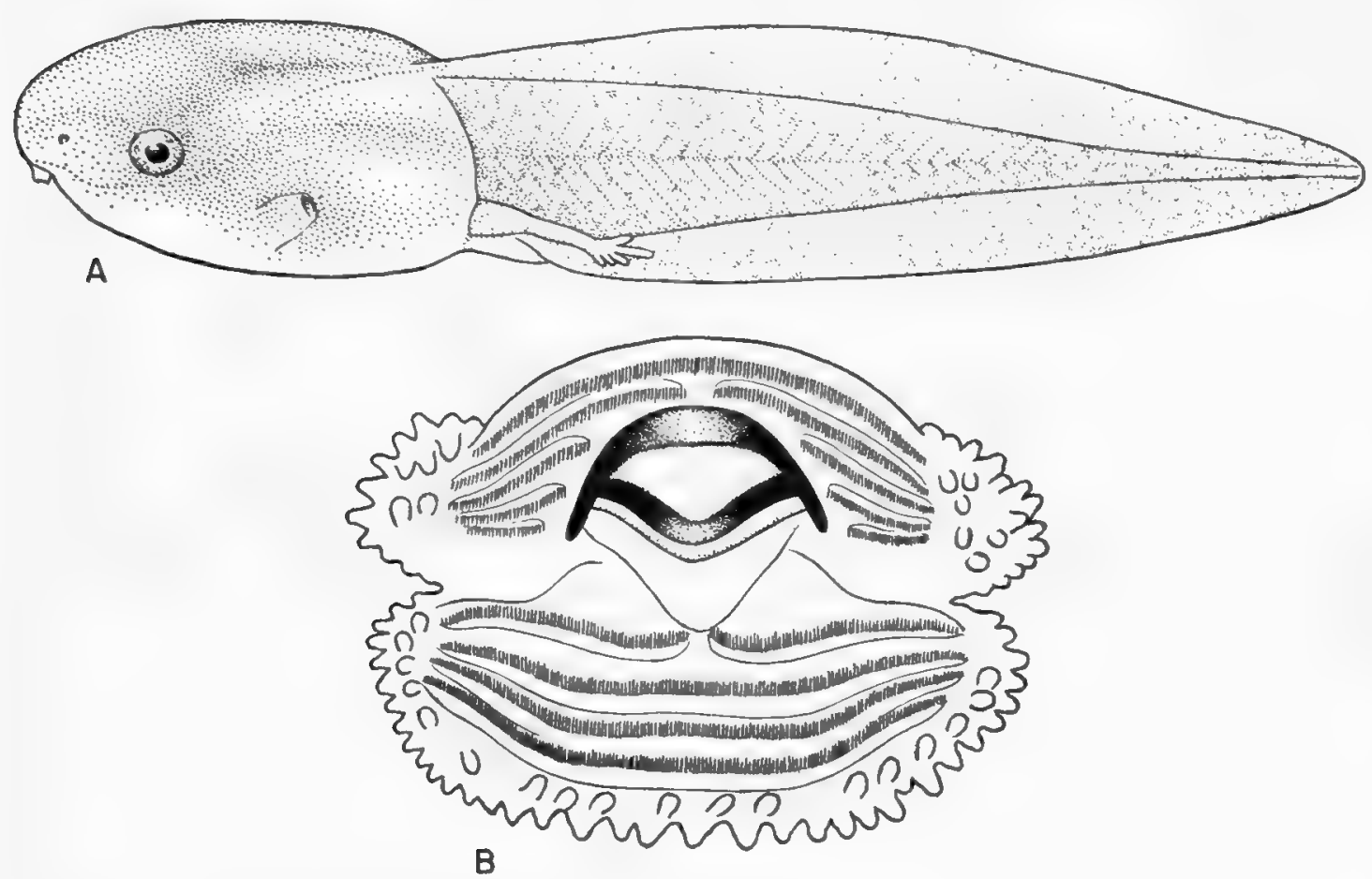

FIG. 76. Rana margaretae; tadpole. A. Lateral view $(\times 31 / 2)$. B. Mouth $(\times 18)$.

one can get some specimens, but as they are scattered and not so abundant as other forms it is rather hard to collect a large number. Tadpoles of this species were collected from Heilungkiang, on Mount Omei, and a large number were collected (July 19 to August 5, 1940) from Shihsunkou (3,500 ft.), at Fuhusze. Although margaretae is a form of large mountain streams, the tadpoles will live in a jar for a long time, and some of the above specimens were brought back to Chengtu in good condition. I kept them in a small aquarium from the end of August of 1940 to March of 1941, when they were still in good condition.

The coloration of the tadpole is very characteristic of the species. The body and head are pale olive brown covered with very fine fuscous marblings. The eye is moderately developed, with a round black pupil enclosed by a wide dull-golden iris. The tail is pale and has a nearly colorless crest, but with fine black or fuscous marblings all over it. The belly is nearly colorless, with a large pink liver showing clearly through it; this may be used as a field character to identify the species.

In proportion to the size of the adult (female $103 \mathrm{~mm}$., male $81 \mathrm{~mm}$.) the tadpole is small. If its life history had not been worked out it would be hard 
to believe that it is the tadpole of Rana margaretae. From snout to tip of tail, it measures $38.6 \mathrm{~mm}$. The average body length is only $12.3 \mathrm{~mm}$., while the tail is more than twice as long as the body (see table). The tail has a rounded tip and the dorsal crest is slightly deeper than the ventral crest. Just after metamorphosis the juvenile frog measures $17 \mathrm{~mm}$. from snout to vent.

\section{Rana margaretae: Measurements of Three Tadpoles}

\begin{tabular}{|c|c|c|c|}
\hline Measurements & Range & Average & $\begin{array}{l}\text { Ratio to } \\
\text { body length (\%) }\end{array}$ \\
\hline Body length... & $12.0-12.5$ & 12.3 & \\
\hline Body height. & $5.4-5.6$ & 5.5 & 44.8 \\
\hline Body width. & $6.7-7.6$ & 7.2 & 58.5 \\
\hline Head height. & $3.9-4.1$ & 4.0 & 32.4 \\
\hline Head width. & $6.0-6.7$ & 6.2 & 50.6 \\
\hline Mouth width. & $3.7-3.9$ & 3.8 & 30.7 \\
\hline Space between eyes.................. & $4.0-4.4$ & 4.2 & 34.2 \\
\hline 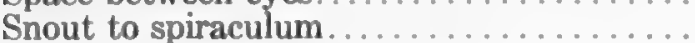 & $9.0-9.5$ & 9.2 & 74.8 \\
\hline Tail length.......... & $25-27$ & 26.3 & 214.1 \\
\hline Tail height......... & $7.0-7.5$ & 7.2 & 58.5 \\
\hline Diameter of tail muscle.............. & $3.5-3.7$ & 3.6 & 29.2 \\
\hline 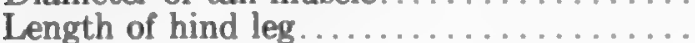 & $5.5-6.8$ & 6.0 & $\ldots$ \\
\hline
\end{tabular}

The snout is rounded, with the nostrils nearer to the snout than to the eye. The eyes are dorso-lateral in position, and the space between them is about onethird of the body length. The spiraculum is sinistral, directed upward and backward, and ending with a pointed tube that is barely visible above and below. It is nearer to the base of the tail than to the snout, as the distance from the snout to the spiraculum is 74.8 per cent of the body length. The vent is dextral, with the posterior half as a free tube and the anterior half continuous with the ventral crest of the tail. The tail is strongly developed, with the muscular part about one-third of the length of the body. The crest is low and thick, especially near the base of the tail.

The mouth (fig. 76, B) is antero-ventral in position, slightly less than onethird of the length of the body in width. There is one close row of papillae on the lateral posterior margin of the upper lip and some additional ones lateral to the tips of rows of upper labial teeth. On the lower lip, there are two rows of papillae but the bases of these papillae originate in the same line. There are no extra papillae at the corner of the mouth. Normally there are five rows of teeth in the upper lip. The outermost row is always continuous; the second row is narrowly interrupted and the other three rows are broadly interrupted. The number of rows in the upper lip is variable; in twenty specimens studied the frequency of tooth formula is as follows: fifteen have I:4-4/III:1-1; two have I:3-4/III:1-1; two have I:3-3/III:1-1; and one has I:2-2/III:1-1. In the lower lip, there are always three complete rows of teeth plus an innermost interrupted row. The mandible is weakly developed, with a fine serrated edge.

Cross-bars on the legs are characteristic of adult Rana margaretae. Just after metamorphosis, it is $16.7 \mathrm{~mm}$. in length from tip of snout to vent; it is gray on the back and marbled with dark brownish gray; the limbs are lighter 
in color, with dark cross-bars. Four days after metamorphosis, uneven green patches have developed on the back, especially toward the head; the throat is finely dotted with dark gray; the belly is nearly colorless; and the skin is granulate on the dorsal side. One can easily recognize the young frog just after metamorphosis as Rana margaretae by the digital disks, the cross-bars on limbs and digits, and the general shape of the body.

\section{Rana nigromaculata Hallowell}

Rana esculenta var. Cantor, 1842, Ann. Mag. Nat. Hist., 9: 483.

Rana esculenta var. japonica Maak, 1859, Putsh. na Amur, p. 153 (not of Günther); Boulenger, 1882, Cat. Batr. Sal., Brit. Mus., p. 40.

Rana nigromaculata Hallowell, 1860, Proc. Acad. Nat. Sci. Phila., 12: 500-Japan; Stejneger, 1907, Bull. U. S. Nat. Mus., 58: 94, pl. 10, fig. 1, text figs. 76-80; Boring, 1938, Peking Nat. Hist. Bull., 13, pt. 2: 95; Pope and Boring, 1940, Peking Nat. Hist. Bull., 15, pt. 1: 55.

Hoplobatrachus reinhardtii Peters, 1867, Monatsber. Akad. Wiss. Berlin, 1867: 711 Malacea or China (restr. to China).

Rana reinhardti Moellendorff, 1877, Jour. N. China Br. Roy. Asiatic Soc., (n.s.), 11 : 105. Rana esculenta marmorata Lataste, 1880, Bull. Soc. Zool. France, 5: 40-Peiping.

Rana esculenta var. nigromaculata Boettger, 1892, Kat. Batr. Mus. Senckenberg, p. 5. Rana esculenta var. chinensis Boulenger, 1897, Tailless Batr. Europe, 2: 272 (not of Osbeck).

Rana chinensis Stone, 1899, Proc. Acad. Nat. Sci. Phila., 51: 183--eastern Mongolia (not of Osbeck).

Rana nigromaculata nigromaculata Schmidt, 1927, Bull. Amer. Mus. Nat. Hist., 54 : 563.

Rana nigromaculata reinhardtii Schmidt, op. cit., p. 564.

Rana nigromaculata mongolia Schmidt, loc. cit.-Mai Tai Chao, Shansi.

History of species.- This frog appeared in the herpetological literature of China for the first time in 1842, when mentioned by Cantor as from the Chusan Islands. Its subsequent history is presented in the synonymy above.

In 1927, Schmidt divided the common Chinese and Japanese pond frog into three subspecies, distinguished by the shape of the head, the length of the limbs, the length of the snout, and the nature of the metatarsal tubercle, describing the northernmost form as Rana nigromaculata mongolia. In a subsequent paper (1938), he shows that the leg length character forms a geographic gradient, a cline; and this seems to be the best reason for dropping the subspecific classification until discontinuities (i.e., the formation of a "step-cline") can be shown.

The name chinensis Osbeck is often cited in the synonymy of this species, with a query. If cited, it should be used, as it long antedates nigromaculata. I am convinced, however, that it is unidentifiable even as to genus.

Distribution and collection data.-Rana nigromaculata is widely distributed in China, more abundant in central China than in the north and south. In western China, this frog reaches Lingkwan, Tienchuan, about fifteen miles east of Paohsing. To the northwest it ranges as far as Weichow of Wenchwanhsien 
and southwest to the Tatuho, southeast of Mount Omei. The vertical distribution of this frog in western China is from 1,000 to 3,000 feet. Many adults, tadpoles and egg-masses were collected around Chengtu, Kwanhsien, Wenchwan, Kiating, the foot of Mount Omei, Szechwan, and at Yaan, Tienchuan, Lingkwan and Lushan, of Sikang.

Comparison with related species.-Rana nigromaculata (pl. 6, fig. 1) is a distinct species, with no closely related form in China. It appears to be clearly more closely related to Rana esculenta of Europe than to any Chinese form. Rana plancyi is perhaps its closest relative in eastern Asia. The longitudinal ridges on the back, the great variation of coloration, the black spots on the body, and the dark bars on the limbs distinguish nigromaculata from plancyi, which is uniform green with a smooth back.

Original description.- "Vomerine teeth in two patches between the internal nares; olive colored, with numerous black spots upon the back, of considerable size, but varying in this respect; a black band extending from the eye to the snout on each side; legs and tarsi banded with black, thighs mottled posteriorly with blotches of the same color; under parts white; web of the toes extending as far as the base of the antepenultimate phalange, except in the third, in which it reaches to the base of the proximal extremity of the third phalange.

"Dimensions: Length of head and body one inch; of anterior extremities one-half inch; of posterior one and one-quarter inches."

Rana nigromaculata: Measurements of Ten Male and

Ten Female Adults

\begin{tabular}{|c|c|c|c|c|}
\hline Measurements & Sex & Range & Average & $\begin{array}{l}\text { Ratio to } \\
\text { body length (\%) }\end{array}$ \\
\hline Body length...... & $\begin{array}{l}0 \\
8\end{array}$ & $\begin{array}{l}66-79 \\
75-81\end{array}$ & $\begin{array}{l}70.7 \\
79.0\end{array}$ & $\ldots$ \\
\hline Head length..... & $\begin{array}{l}07 \\
8\end{array}$ & $\begin{array}{l}25-28 \\
27-31\end{array}$ & $\begin{array}{l}26.2 \\
28.4\end{array}$ & $\begin{array}{l}37.6 \\
36.0\end{array}$ \\
\hline Head width. & $\begin{array}{l}\sigma^{7} \\
\text { क }\end{array}$ & $\begin{array}{l}23-28 \\
23-28\end{array}$ & $\begin{array}{l}25.0 \\
25.7\end{array}$ & $\begin{array}{l}35.3 \\
32.5\end{array}$ \\
\hline Interorbital space... & $\begin{array}{l}0^{7} \\
8\end{array}$ & $\begin{array}{l}3-4 \\
3-4\end{array}$ & $\begin{array}{l}3.5 \\
3.6\end{array}$ & $\begin{array}{l}5.0 \\
4.6\end{array}$ \\
\hline Tympanum. & $\begin{array}{l}\text { o' } \\
\text { क }\end{array}$ & $\begin{array}{l}5.0-6.5 \\
5.2-6.3\end{array}$ & $\begin{array}{l}5.4 \\
6.0\end{array}$ & $\begin{array}{l}7.6 \\
7.6\end{array}$ \\
\hline Length of lower arm... & $\begin{array}{l}7 \\
0 \\
9\end{array}$ & $\begin{array}{l}26-30 \\
29-34\end{array}$ & $\begin{array}{l}28.4 \\
31.9\end{array}$ & $\begin{array}{l}40.2 \\
40.0\end{array}$ \\
\hline Diameter of lower arm. . & $\begin{array}{l}\text { के } \\
\text { के }\end{array}$ & $\begin{array}{l}6-9 \\
6-9\end{array}$ & $\begin{array}{l}7.5 \\
7.1\end{array}$ & $\begin{array}{r}10.6 \\
9.0\end{array}$ \\
\hline Length of hand. & $\begin{array}{l}7 \\
9\end{array}$ & $\begin{array}{l}16-19 \\
16-20\end{array}$ & $\begin{array}{l}16.7 \\
17.8\end{array}$ & $\begin{array}{l}23.6 \\
22.5\end{array}$ \\
\hline Length of leg. & $\begin{array}{l}0^{7} \\
8\end{array}$ & $\begin{array}{l}101-118 \\
112-132\end{array}$ & $\begin{array}{l}109.8 \\
121.5\end{array}$ & $\begin{array}{l}155.3 \\
153.7\end{array}$ \\
\hline Length of tibia. & $\begin{array}{l}0^{7} \\
8\end{array}$ & $\begin{array}{l}31-37 \\
35-41\end{array}$ & $\begin{array}{l}34.0 \\
37.6\end{array}$ & $\begin{array}{l}48.9 \\
47.6\end{array}$ \\
\hline Length of foot and tarsus....... & $\begin{array}{l}07 \\
9\end{array}$ & $\begin{array}{l}49-57 \\
51-61\end{array}$ & $\begin{array}{l}53.2 \\
56.2\end{array}$ & $\begin{array}{l}75.2 \\
71.1\end{array}$ \\
\hline Length of foot. & $\begin{array}{l}0^{7} \\
\text { क }\end{array}$ & $\begin{array}{l}37-42 \\
44-48\end{array}$ & $\begin{array}{l}39.6 \\
46.5\end{array}$ & $\begin{array}{l}56.0 \\
58.9\end{array}$ \\
\hline
\end{tabular}


Description of adult female (collected at Yaan, Sikang, July, 1939, by C. C. Liu).-Body stout, length $82 \mathrm{~mm}$. Head longer than broad; snout somewhat pointed; nostrils nearer to the eye than to the tip of the snout; canthus rostralis obtuse, loreal region very oblique, with a deep groove from below the nostril to the anterior border of the lower eyelid; interorbital space smaller than the internasal space and the width of the upper eyelid; tympanum large and very distinct, slightly smaller than the length of the eye; vomerine teeth in two slightly backward converging elongated patches between the choanae; tongue large and deeply notched behind.

Arm rather short, tips of fingers not dilated, the first finger longer than the second, about equal to the fourth, and the third finger the longest; subarticular tubercles well developed; lateral fringes on all fingers, better developed on the second, which is flattened and broader than the others; two elongated palmar tubercles; a narrow swelling (the prepollex?) on the basal inner margin of the first finger.

Leg moderately short but strong, the tibio-tarsal articulation reaching the posterior part of the eye; when placed at right angles to the body, the heels barely meet; toes nearly fully webbed, the web reaching the distal subarticular tubercle on the fourth toe; a conspicuous outer fringe on the first and fifth toes; subarticular tubercles well developed; inner metatarsal tubercle strongly developed, with a sharp free cutting edge; outer metatarsal tubercle distinct but small.

Coloration in life.--The coloration in life varies greatly, especially among the males. There are three common types of ground color in the males, one a delicate yellowish green, one a beautiful deeper green, and the third deep grayish olive. The female may have a deep greenish gray or light brown ground color, with many more black spots or markings on the back and the sides of the body than in the male; in a few cases the black is dominant on the back in the female. There are three light color bands on the back, the median wider. The median band may be green, cream, white or light gray. The lateral light bands are on and just below the dorso-lateral glandular folds, which may be golden, yellow or light brown but never green. Black spots or bars are present on the limbs. A black band originates near the tip of the snout and extends posteriorly through the nostril to the anterior border of the eye and posterior to the eye, generally becoming discontinuous, and extending caudally along the lower margin of the dorso-lateral glandular fold to the hip. The tympanum may be gray or dark. The pupil is black, horizontally oval, and enclosed by a light golden ring; the iris is old gold stippled with black. The throat, belly and ventral sides of limbs are cream white, pinkish below the vent.

Sex dimorphism.--The male is smaller than the female, has well-developed nuptial pads covering the inner dorsal and inner ventral sides of the first finger, and is equipped with external lateral vocal sacs protected by a flap of skin when withdrawn. The arm of the male is stronger than that of the female. Lineae masculinae are well developed. 
Habitat and habits.--During the breeding season, Rana nigromaculata, especially the male, is found in any body of water, such as ponds, ditches and flooded rice fields. Before and after the breeding season, these frogs hide themselves among vegetation or in holes on the banks of streams or ponds. It is easy to catch this frog with a flashlight in the evening, or with a bait and a line during the daytime.

The breeding season varies from place to place and from year to year. Around Chengtu, it is generally from March to June. Eggs are laid in masses; the size of the egg is $1.8 \mathrm{~mm}$., with a dark brown or nearly black animal pole and a creamy vegetal pole. Each egg is enclosed by three layers of jelly, the inner layer the thinnest, and the outer layer connected with outer jelly capsules of other eggs to form a mass.

Tadpole.-Tadpoles of this species are inhabitants of pools, ponds, ditches and rice fields, feeding on vegetation and dead animals. If there is no favorable food, they may take mud on the bottom of the water, since organic matter can be taken in with earth. Although a bottom-feeding species, they may swim singly or in groups in the water and now and then come up to the surface for oxygen.

The coloration of living tadpoles varies only slightly. They are bluish olive green on the body, with fine brown and umber spots. The color is lighter near the snout and head region. On the sides of the body golden red spots are mingled with black pigments. The pupil is round and black with a wide, pigmented golden iris. The base of the tail above is very much like the head region in color except that it is lighter and uneven. A dark-colored band is developed on the dorsal muscular part of the tail and this band diminishes backwards, disappearing beyond the first third of the length of the tail. Ventral to this band is a lightcolored band of greenish ochraceous buff and next to it is a diffuse dark band. Most of the muscular part is light ochraceous buff with scattered fine fuscous spots mingled with golden dots. The tail fin is light cream buff finely spotted with golden and fuscous dots. The throat region is flesh-colored and around the heart is bluish green; the belly is white with a tinge of red iridescence.

The size of the tadpole varies greatly according to the food supply. Twenty tadpoles, with an average length of hind leg-buds of $5 \mathrm{~mm}$., have an average length of $48 \mathrm{~mm}$. (see table). The tail is short in comparison with the tail of other Rana tadpoles found in Szechwan or Sikang. The tail fin is deeper than that of other Rana tadpoles of western China, its muscular part being poorly developed. The body is stout with a bluntly pointed snout. The nostril is nearer to the snout than to the eye. The eyes are dorso-lateral, the eyeball facing to the side. The spiraculum is sinistral and has no free tube; the opening, directed dorsally and posteriorly, is visible from above and below. The vent is dextral and is continuous with the ventral fin. The tail is pointed and weakly developed; its dorsal fin is deeper in the middle and is continuous in front with the basal region of the body. 
Rana nigromaculata: Measurements of Twenty Tadpoles

\begin{tabular}{|c|c|c|c|}
\hline Measurements & Range & Average & $\begin{array}{c}\text { Ratio to } \\
\text { body length }(\%)\end{array}$ \\
\hline Body length. & $16.3-19.8$ & 17.3 & \\
\hline Body height. & $8.8-11.5$ & 9.8 & 56.5 \\
\hline Body width. & $10-13$ & 11.1 & 64.2 \\
\hline Head height. & $6.0-7.8$ & 7.1 & 41.1 \\
\hline Head width. & $9.0-10.5$ & 9.5 & 55.0 \\
\hline Mouth width. & $3.4-4.3$ & 3.8 & 22.2 \\
\hline Space between eyes. & $7-9$ & 8.0 & 46.2 \\
\hline Snout to spiraculum. & $11.3-13.4$ & 12.4 & 71.9 \\
\hline Tail length. & $28.6-33.3$ & 30.5 & 176.1 \\
\hline Tail height. & $9.5-12.0$ & 10.8 & 62.1 \\
\hline Diameter of tail muscle. & $3.0-4.4$ & 3.6 & 20.7 \\
\hline Length of hind leg..... & $3.7-7.4$ & 5.1 & $\ldots$ \\
\hline
\end{tabular}

The mouth is ventral rather than anterior, its width 22 per cent of the body length. There is only one row of papillae on the sides of the upper lip. One row of papillae is found all along the margin of the lower lip. Inside this row, at the sides of the lower lip, are two irregular rows of papillae that are much more irregular toward the corners of the mouth. Three tadpoles out of twenty have a notch on the ventral middle portion of the lower lip and a gap without papillae. In twenty tadpoles fourteen have the tooth formula $I: 1-1 / \mathrm{II}: 1-1$; four have $\mathrm{I}: 2-2 / \mathrm{II}: 1-1$; one has I:1-1/I:1-1; and one has I:2-1/I:2-2. When there are three rows of teeth in the upper lip, the innermost row may be extremely short and just indicated by a group of teeth on the small base of a papilla. When two inner rows of teeth in the lower lip are interrupted, the middle row is generally abnormal, with some small groups of teeth in the interrupted space. The mandible is rather strongly developed and has a finely serrated edge.

The body length of just metamorphosed young is about $23 \mathrm{~mm}$.

\section{Rana shuchinae sp. nov.}

Type.-No. 55871 Chicago Natural History Museum, from Lolokou, Chaochiaohsien, Sikang, 10,000 feet altitude. Young adult, collected by a Lolo, July 10, 1942.

Diagnosis.-A distinct species of Rana (pl. 6, fig. 4), Light English Red on the back and the posterior aspect of the thigh; a large elongate gland on the laterodorsal side of the tibia, and a similar gland on the postero-dorsal side of the tarsus; weaker and smaller glands on the anterior and posterior aspects of the lower arm; a rounded gland on the side of the shoulder above the base of the arm.

Description of type.-Body slender, somewhat depressed; head depressed, longer than broad; snout bluntly pointed, projecting beyond the mouth; nostril about mid-way between the tip of the snout and the anterior border of the eye; canthus rostralis distinct, loreal region oblique with a shallow groove from the nostril to the anterior side of the lower eyelid; interorbital space flat, a little narrower than the internasal space and equal to the width of the upper eyelid; tympanum very distinct, equal to the interorbital space and about three-fifths 
of the length of the eye; tongue large and notched behind; vomerine teeth in two small patches, with a ridge reaching the anterior corner of the choanae.

Arm strong and long with flattened long fingers (fig. 77, A); tips of digits flattened and rounded, but without disks; first finger as long as the second, the third finger the longest; subarticular tubercles large but flattened; a large rounded indistinct inner palmar tubercle and an elongated indistinct outer one.

Leg short, the tibio-tarsal articulation reaching the tympanum; tips of toes (fig. 77, B) rounded and flattened; toes flattened, all with lateral fringes; the third
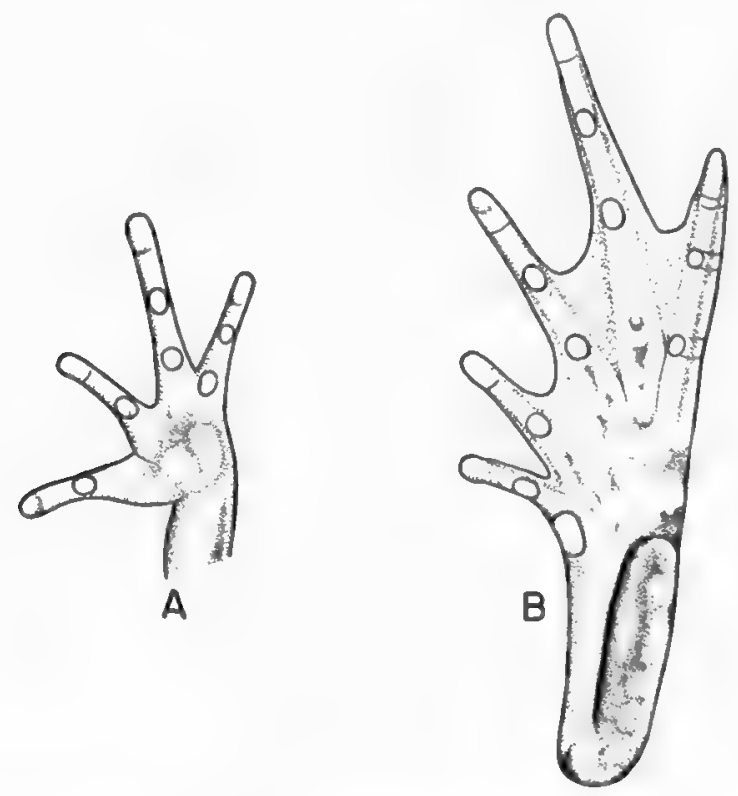

FIG. 77. Rana shuchinae ( $\times 3$ ). A. Ventral view of hand. B. Ventral view of foot.

and fifth toes equal, longer than the second, the fourth the longest and the first the shortest; the first, second and fourth toes about one-third webbed and the third and fifth about half webbed; on the outer side of the fifth toe there are indications of the development of a gland; subarticular tubercles large and flat; inner metatarsal tubercle elongated, flat, without free cutting edge.

Skin smooth above and below; the dorso-lateral glandular fold well-developed; a well-marked glandular fold from the posterior part of the upper jaw to the anterior side of the base of the arm; an elevated and rounded gland above the base of the arm; elongated glandular ridges on the anterior and posterior aspects of the lower arm; a well-developed elongated gland on the upper and outer side of the tibia, and an even broader one on the postero-dorsal side of the tarsus; an interrupted gland on the outer side of the fifth toe; only a few small rounded warts on the back near the hip region.

Measurements of type (percentage of body length in parentheses).--Body length $39 \mathrm{~mm}$.; head length $14 \mathrm{~mm}$. (35.8); head width $13 \mathrm{~mm}$. (33.3); interorbital space $2.5 \mathrm{~mm}$. (6.3); tympanum $2.5 \mathrm{~mm}$. (6.3); length of lower arm 
$16 \mathrm{~mm}$. (41.0); diameter of lower arm $3.4 \mathrm{~mm}$. (8.7); length of hand $9 \mathrm{~mm}$. (23.0); length of leg $54 \mathrm{~mm}$. (138.4); length of tibia $16 \mathrm{~mm} .(41.0)$; length of foot and tarsus $26 \mathrm{~mm}$. (66.6); length of foot $19 \mathrm{~mm}$. (48.7).

Coloration in life.-The top of the head is greenish yellow and the back English Red, with a dark line dividing the yellow and red at the middle of the interorbital space; a yellowish band extends posteriorly along the vertebral groove from the occipital region toward the hip region; a black band from the snout extends through the nostril to the eye and continues as a much expanded, very wide black band to the hip. Below this black band, and on the dorsal side of the limbs, the color is greenish yellow like that of the head, with black markings on the sides and black bars on the limbs; the posterior aspects of the thighs are English Red. The pupil is black with an old gold iris, stippled with red and black. The tympanum is reddish brown. The belly is yellowish cream.

Notes on paratypes.-Beside the type, six juvenile specimens of this new frog were taken by a Lolo from a mountain stream and given to my assistant. ${ }^{1}$

\section{Rana limnocharis Boie}

Rana limnocharis Boie, in Wiegmann, 1835, Nova Acta Acad. Leop. Carol., 17, pt. 1: 255 (no type locality; apparently based on specimens in the Leiden Museum from Java, collected and named by H. Boie); Boulenger, 1890, Fauna Brit. India, Rept., p. 450; Stejneger, 1907, Bull. U. S. Nat. Mus., 58: 127, figs. 107-110; Pope, 1931, Bull. Amer. Mus. Nat. Hist., 61: 491.

Rana gracilis Wiegmann, 1835, Nova Acta Acad. Leop. Carol., 17, pt. 1: 257-Cape Syng-more, China; Hallowell, 1860, Proc. Acad. Nat. Sci. Phila., 12: 409; Boulenger, 1882, Cat. Batr. Sal., Brit. Mus., p. 28.

Rana vittigera Günther, 1858, Cat. Batr. Sal., Brit. Mus., p. 9 (not of Wiegmann).

History of species.-As Rana limnocharis is one of the easiest of the Asiatic frogs to identify, taxonomic problems have not arisen in this species. The earliest record of this rice field frog is Wiegmann's double description in 1835 , as Rana limnocharis and $R$. gracilis.

Distribution and collection data.-Rana limnocharis is the common IndoMalaysian frog of rice fields. It is of more general occurrence than any other frog found in southern, central and western China and extends north as far as Taian, Shantung, and Chikungshan in Honan. Its vertical distribution in western China extends from 1,000 to 6,000 feet. I collected many adults, tadpoles and egg-masses in Chengtu, Kiating, Mount Omei, Kwanhsien, and Wenchwan, Szechwan; and at Yaan, Tienchuan, and Lushan, Sikang.

Comparison with related species.-Rana limnocharis can easily be distinguished from tigerina rugulosa, being much smaller $(40-46 \mathrm{~mm}$.) than rugulosa (80 to $100 \mathrm{~mm}$.). The vocal sac is single in limnocharis and paired in rugulosa. From Rana rugosa, limnocharis is distinguished by its longer legs and lessdeveloped webs.

${ }^{1}$ I name this frog after my wife in recollection of her faithful aid throughout my studies. 
Original description.-Rana limnocharis was described indirectly by Wiegmann, who compared with it the Philippine Rana vittigera and the Chinese Rana gracilis. I derive the original description as follows: "Related to Rana vittigera, from which it is distinguished by its longer legs; the heels, when the legs are placed at right angles to the body, barely overlap. Gray above, with black spots, a wide whitish median line; white beneath; throat gray; black granulate and plicate, the longitudinal plicae interrupted; posterior part of belly and thighs granulate, belly otherwise smooth; thighs moderate, nearly smooth above; a raised line on the median line of the head between the eyes."

Sex dimorphism.- Sex dimorphism in size appears in Rana limnocharis, the average body length of the ten largest males measured being $40 \mathrm{~mm}$. (38-42) and of the ten largest females $46 \mathrm{~mm}$. (43-49). There are two feebly separated nuptial pads in the male, one on the inner portion of the inner metacarpal tubercle and the inner basal part of the thumb, the other on the dorsal side of the first finger. The male has a median subgular external vocal sac, usually with two slit-like openings situated near the corner of the mouth. Stejneger (1907, p. 129) and Boulenger (1920, p. 29) state that the male of this species has paired external vocal sacs. Observations while the frog croaks show that there is only one median subgular external vocal sac with two latero-posterior lobes (Liu, 1935b, pl. 6, fig. 1). Fine lineae masculinae are developed in the male.

Rana limnocharis: Measurements of Ten Male and Ten Female Adults

\begin{tabular}{|c|c|c|c|c|}
\hline Measurements & Sex & Range & Average & $\begin{array}{c}\text { Ratio to } \\
\text { body length }(\%)\end{array}$ \\
\hline Body length....... & $\begin{array}{l}\sigma^{7} \\
9\end{array}$ & $\begin{array}{l}38-42 \\
43-49\end{array}$ & $\begin{array}{l}40.2 \\
46.0\end{array}$ & $\ldots$ \\
\hline Head length. & $\begin{array}{l}\sigma^{7} \\
\text { क }\end{array}$ & $\begin{array}{l}13-14 \\
14-16\end{array}$ & $\begin{array}{l}13.7 \\
15.2\end{array}$ & $\begin{array}{l}34.1 \\
33.0\end{array}$ \\
\hline Head width. & $\begin{array}{l}\sigma^{7} \\
8\end{array}$ & $\begin{array}{l}13-14 \\
14-16\end{array}$ & $\begin{array}{l}13.4 \\
15.1\end{array}$ & $\begin{array}{l}33.3 \\
32.8\end{array}$ \\
\hline Interorbital space. . & $\begin{array}{l}\sigma^{7} \\
\text { क }\end{array}$ & $\begin{array}{l}1.9-2.1 \\
2.4-2.6\end{array}$ & $\begin{array}{l}2.0 \\
2.5\end{array}$ & $\begin{array}{l}5.0 \\
5.5\end{array}$ \\
\hline Tympanum. & $\begin{array}{l}\sigma^{7} \\
\text { क }\end{array}$ & $\begin{array}{l}2.2-2.8 \\
2.5-3.0\end{array}$ & $\begin{array}{l}2.4 \\
2.9\end{array}$ & $\begin{array}{l}6.0 \\
6.2\end{array}$ \\
\hline Length of lower arm. & 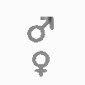 & $\begin{array}{l}14-15 \\
15-19\end{array}$ & $\begin{array}{l}14.6 \\
16.8\end{array}$ & $\begin{array}{l}36.3 \\
36.5\end{array}$ \\
\hline Diameter of lower arm......... & $\begin{array}{l}97 \\
8\end{array}$ & $\begin{array}{l}3.5-4.0 \\
3.8-5.0\end{array}$ & $\begin{array}{l}3.9 \\
4.1\end{array}$ & $\begin{array}{l}9.6 \\
9.0\end{array}$ \\
\hline Length of hand. & $\begin{array}{l}07 \\
8\end{array}$ & $\begin{array}{l}7-9 \\
8-11\end{array}$ & $\begin{array}{l}8.0 \\
9.6\end{array}$ & $\begin{array}{l}19.9 \\
20.9\end{array}$ \\
\hline Length of leg. & $\begin{array}{l}9 \\
9\end{array}$ & $\begin{array}{l}48-52 \\
52-72\end{array}$ & $\begin{array}{l}50.3 \\
61.0\end{array}$ & $\begin{array}{l}125.1 \\
132.6\end{array}$ \\
\hline Length of tibia.............. & $\begin{array}{l}\text { ơ } \\
\text { क }\end{array}$ & $\begin{array}{l}15-17 \\
18-22\end{array}$ & $\begin{array}{l}16.0 \\
19.5\end{array}$ & $\begin{array}{l}39.7 \\
42.4\end{array}$ \\
\hline Length of foot and tarsus. . & $\begin{array}{l}\text { o' } \\
\text { क }\end{array}$ & $\begin{array}{l}22-27 \\
26-34\end{array}$ & $\begin{array}{l}24.0 \\
29.1\end{array}$ & $\begin{array}{l}60.0 \\
63.3\end{array}$ \\
\hline Length of foot. & $\begin{array}{l}0^{7} \\
\text { क }\end{array}$ & $\begin{array}{l}16-18 \\
19-25\end{array}$ & $\begin{array}{l}17.5 \\
20.8\end{array}$ & $\begin{array}{l}43.5 \\
45.2\end{array}$ \\
\hline
\end{tabular}


Habitat and habits.-Rana limnocharis is known as the rice field frog. It is generally found in either dry or flooded fields. This frog is very widely distributed, and appears always to be present in large populations in every part of its range. Before and after the breeding season, these frogs hide themselves among vegetation and in crevices of stones or in holes in the earth. During the
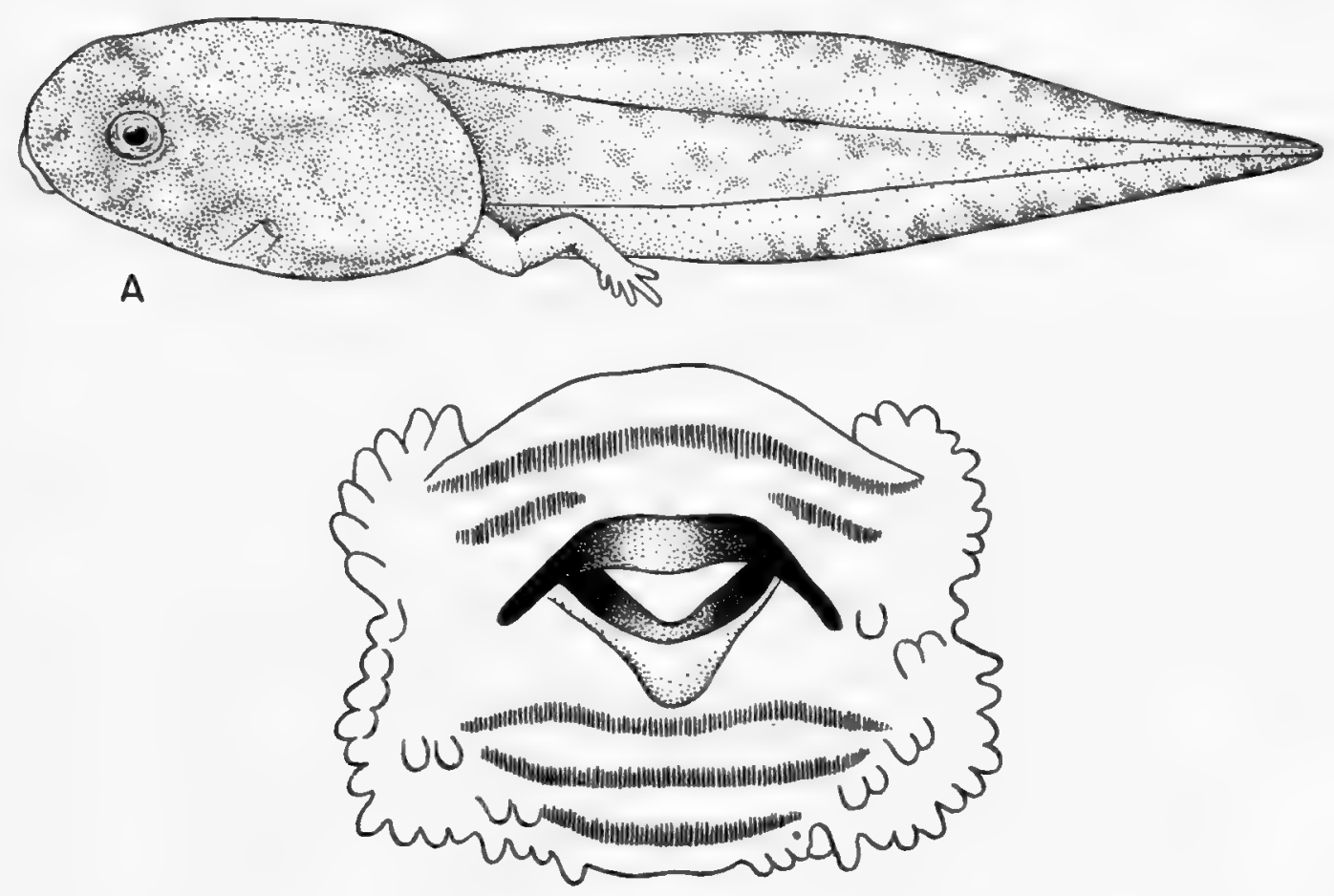

B

FIG. 78. Rana limnocharis; tadpole. A. Lateral view $(\times 4)$. B. Mouth (X 25).

breeding season, they are found in flooded rice fields and more rarely also in pools and ponds.

Tadpoles.-Tadpoles (fig. 78) of Rana limnocharis are very abundant in suitable waters on the low lands of Szechwan from May to August. Tadpoles were also collected from a pool near Hsinkaisze (4,920 ft.), on Mount Omei, July 28,1938 . Tadpoles as well as adults are commonly found around Lingkwan, Sikang.

The body is olive green marbled with patches of fuscous. The snout and sides of the head are marked with light cinnamon brown. The pupil is round and black and is enclosed by a narrow golden ring, outside of which is a wide dull golden ring. The coloration of the muscular part of the tail is similar to that of the body but it is lighter toward the tip. The tail fin is ochraceous buff, pigmented with brown to black. On the periphery of the fin, black bars are conspicuously developed; they are very characteristic of the tadpole of this species. The belly is colorless. 
The tadpole of this species is rather small. Twenty-five specimens with average hind limb-bud $5 \mathrm{~mm}$. long have an average length from snout to tip of tail of $33 \mathrm{~mm}$. (see table). The tail is twice as long as the body, and the height of the tail is about half the body length; the muscle is about one-fifth of the body length. The snout is blunt, the nostril nearer to its tip than to the eye; the eyes are latero-dorsal. The spiraculum is sinistral, with a very short free tube directed upward and backward, visible from above and below, and nearer to the base of the tail than to the snout. The long, broad, tubular vent is attached to the right side of the lower tail fin; only its distal part is free.

The mouth (fig. 78, B) is antero-ventral. There is a single row of papillae on the sides of the upper lip, another row on the lower lip interrupted in the middle, and some additional papillae on the lower lip. The rows of labial teeth are constant, two rows of teeth on the upper lip, the outer row complete and the inner widely interrupted, and the lower lip with three complete rows of teeth. The mandible is moderately developed and its edge is serrate.

\section{Rana limnocharis: Measurements of Twenty-five Tadpoles}

\begin{tabular}{|c|c|c|c|}
\hline Measurements & Range & Average & $\begin{array}{c}\text { Ratio to } \\
\text { body length (\%) }\end{array}$ \\
\hline Body length... & $10.4-12.3$ & 11.3 & \\
\hline Body height. & $4.5-6.2$ & 5.3 & 47.1 \\
\hline Body width. & $5.7-7.5$ & 6.6 & 58.2 \\
\hline Head height. & $3.4-4.8$ & 4.2 & 37.2 \\
\hline Head width. & $5.0-6.2$ & 5.6 & 49.4 \\
\hline Space between eyes. & $3.2-4.6$ & 3.8 & 33.7 \\
\hline Snout to spiraculum. & $6.7-8.2$ & 7.4 & 65.5 \\
\hline Tail length......... & $20-25$ & 22.6 & 200.0 \\
\hline Tail height. & $5.2-6.7$ & 5.9 & 52.3 \\
\hline Diameter of tail muscle & $1.8-2.8$ & 2.4 & 21.0 \\
\hline Length of hind leg. & $4.3-6.8$ & 5.2 & 12.0 \\
\hline
\end{tabular}

\section{Rana guentheri Boulenger}

Hylorana malabarica Steindachner, 1867, Reise Nov., Zool., 1, Amph.: 48-Hongkong (not of Duméril and Bibron).

Rana guentheri Boulenger, 1882, Cat. Batr. Sal., Brit. Mus., p. 48, pl. 4, fig. 2-Amoy; idem, 1920, Rec. Indian Mus., 20 : 133; Stejneger, 1925, Proc. U. S. Nat. Mus., 66, art. 25: 24; Pope, 1931, Bull. Amer. Mus. Nat. Hist., 61 : 529.

History of species.-Rana guentheri was described and figured from Amoy in 1882. The coloration and pattern of this frog are so striking and there is so little variation in its main features that the species has usually been correctly identified and it does not have a long synonymy. Pope (1931) gives a detailed account of its life history.

Distribution and collection data.-Rana guentheri is widely distributed over southeastern China, including Chekiang, Fukien, Kiangsi, Hainan, and through Tongking to Annam. This frog is commonly found on the Chengtu Plain, with a vertical distribution ranging from 1,000 to 2,000 feet altitude. Adults, tadpoles and eggs were collected around Chungking by H. W. Chang. I have collected 
many adults around Chengtu and at the foot of Mount Omei during my visits in 1940 and 1945.

Comparison with related species.-The kidney-shaped humeral gland of the male and the small digital disks distinguish Rana guentheri from all other species of Rana in China.

Original description.- "Vomerine teeth in two slightly oblique series commencing close to the inner front edge of the choanae. Head moderate, depressed; snout rather long, subacuminate, with distinct canthus rostralis; interorbital space as broad as the upper eyelid; tympanum very distinct, nearly as large as the eye. Fingers rather slender, first extending beyond the second; toes moderate, rather more than two-thirds webbed; subarticular tubercles of fingers and toes well developed; inner metatarsal tubercle small, oval; a rather indistinct tubercle at the base of the fourth toe. The hind limb being carried forwards along the body, the tibio-tarsal articulation reaches nearly the tip of the snout. A moderately prominent glandular lateral fold; another from beneath the eye to the shoulder. Grey above, spotted with black on the sides; glandular lateral fold black-edged; tympanum reddish brown; hind limbs cross-barred; hinder side of thighs black and white marbled; beneath yellowish, the throat speckled with brown. From snout to vent 80 millim."

Coloration in life.-Coloration in this species is not very variable. The back and the dorsal sides of the limbs vary from brownish golden to brown. Irregular black marks are present on the limbs, and there may be black spots on the back in some specimens. The sides are generally light greenish gray with large irregular black spots. A black band from the snout extends posteriorly through the nostril to the anterior border of the eye, and from the posterior corner of the eye extends backward below the dorso-lateral glandular fold to the hip region. Another black band from the dorsal side of the tympanum runs obliquely toward the posterior part of the base of the arm. The tympanum is reddish brown. The pupil is black, enclosed by a golden ring, and the iris is gold, stippled with black. There is an ill-defined black band on the postero-ventral part of the lower arm and the tarsus. In most cases, the throat is creamy white and in a few cases, especially in the males, the throat is conspicuously marbled with gray. The belly is creamy white. The otherwise white posterior aspects of the thighs are marbled with black.

Sex dimorphism.--Sex dimorphism in size is not evident in this species. The nuptial pad of the male is slightly developed, present only on the inner dorsal side of the first finger, and it is better shown during the breeding season. The tympanum is larger in the male than in the female. There is a prominent kidney-shaped gland in male specimens at the anterior base of each arm, below the postrictal glandular fold. The male has paired subgular external vocal sacs with round openings near the angles of the jaw. The lineae masculinae are well developed.

Habitat and habits.-Rana guentheri inhabits the quiet water of ponds and flooded rice fields and is found on the margins of the slow-running water of 
ditches. This frog tends to be solitary; usually only one frog at a time is found. The croaking of the male is very much like the barking of a dog.

Rana guentheri: Measurements of Twenty Male and Twenty Female Adults

\begin{tabular}{|c|c|c|c|c|}
\hline Measurements & Sex & Range & Average & $\begin{array}{l}\text { Ratio to } \\
\text { body length }(\%)\end{array}$ \\
\hline Body length....... & $\begin{array}{l}0^{7} \\
8\end{array}$ & $\begin{array}{l}63-75 \\
64-74\end{array}$ & $\begin{array}{l}67.9 \\
68.4\end{array}$ & $\ldots$ \\
\hline Head length. & $\begin{array}{l}0^{x} \\
q\end{array}$ & $\begin{array}{l}23-28 \\
24-28\end{array}$ & $\begin{array}{l}25.2 \\
25.4\end{array}$ & $\begin{array}{l}37.1 \\
37.2\end{array}$ \\
\hline Head width. . & $\begin{array}{l}89 \\
\wp\end{array}$ & $\begin{array}{l}19-24 \\
19-22\end{array}$ & $\begin{array}{l}21.1 \\
20.9\end{array}$ & $\begin{array}{l}31.1 \\
30.5\end{array}$ \\
\hline Interorbital space... & $\begin{array}{l}97 \\
9\end{array}$ & $\begin{array}{l}4.5-5.0 \\
4-5\end{array}$ & $\begin{array}{l}4.7 \\
4.6\end{array}$ & $\begin{array}{l}7.0 \\
6.7\end{array}$ \\
\hline Tympanum. & $\begin{array}{l}8^{7} \\
9\end{array}$ & $\begin{array}{l}5.0-6.4 \\
4.5-5.5\end{array}$ & $\begin{array}{l}5.5 \\
5.1\end{array}$ & $\begin{array}{l}8.1 \\
7.5\end{array}$ \\
\hline Length of lower arm. & $\begin{array}{l}0^{7} \\
9\end{array}$ & $\begin{array}{l}27-31 \\
28-33\end{array}$ & $\begin{array}{l}29.5 \\
30.4\end{array}$ & $\begin{array}{l}43.4 \\
\mathbf{4 4 . 4}\end{array}$ \\
\hline Diameter of lower arm. & $\begin{array}{l}9 \\
8\end{array}$ & $\begin{array}{l}5-8 \\
5-7\end{array}$ & $\begin{array}{l}6.3 \\
6.0\end{array}$ & $\begin{array}{l}9.3 \\
8.8\end{array}$ \\
\hline Length of hand. . & $\begin{array}{l}8 \\
\$+7\end{array}$ & $\begin{array}{c}16.5-19.0 \\
17-20\end{array}$ & $\begin{array}{l}17.1 \\
18.0\end{array}$ & $\begin{array}{l}25.3 \\
26.5\end{array}$ \\
\hline Length of leg... & $\begin{array}{l}8 \\
\%\end{array}$ & $\begin{array}{r}100-115 \\
99-116\end{array}$ & $\begin{array}{l}107.9 \\
108.4\end{array}$ & $\begin{array}{l}158.9 \\
158.5\end{array}$ \\
\hline Length of tibia. & $\begin{array}{l}9 \\
9 \\
9\end{array}$ & $\begin{array}{l}32-37 \\
32-39\end{array}$ & $\begin{array}{l}34.6 \\
35.1\end{array}$ & $\begin{array}{l}51.0 \\
51.3\end{array}$ \\
\hline Length of foot and tarsus. . & $\begin{array}{l}9 \\
8\end{array}$ & $\begin{array}{l}47-56 \\
43-55\end{array}$ & $\begin{array}{l}51.2 \\
51.7\end{array}$ & $\begin{array}{l}75.4 \\
75.6\end{array}$ \\
\hline Length of foot. & $\begin{array}{l}0^{7} \\
\text { q }\end{array}$ & $\begin{array}{l}33-38 \\
27-40\end{array}$ & $\begin{array}{l}34.9 \\
35.2\end{array}$ & $\begin{array}{l}51.4 \\
51.5\end{array}$ \\
\hline
\end{tabular}

Tadpole. - I have collected no eggs or tadpoles. The material described was collected by Chang around Chungking, and I have referred to Pope's description (1931).

The egg is small, with a diameter of $1.2 \mathrm{~mm}$. The animal pole is black and the vegetal pole cream-colored. Within the egg-masses, each egg is enclosed by very thick jelly.

In life, the body of this tadpole (fig. 79) is finely mottled with a mixture of brown and dull green, the brown predominant. The skin of the belly in mature examples is unpigmented and opaque; the throat is stippled with black. The tail is gaudily mottled with a bold mixture of reddish brown and bluish green.

In general shape the tadpole of guentheri is very much like that of Rhacophorus leucomystax, with the body dorso-ventrally depressed and with a high and pointed tail. The body of a tadpole with hind limb fully developed is $18 \mathrm{~mm}$. long, with tail $35 \mathrm{~mm}$. The head is depressed, with the nostril nearer to the tip of the snout than to the eye, and the lachrymal canal distinct. The eyes are more lateral than dorsal, the interorbital space twice as great as the internasal space. The spiraculum is sinistral, with a short free tube pointed upward and backward and visible from above and below. The vent is dextral, and is 
protected by a wide flap that is continuous with the ventral tail fin and folded over the right side.

The mouth (fig. 79, B) is small and ventral rather than anterior, the lower lip bordered below by long flattened finger-like projections. A row of low papillae extends parallel to the bases of these projections, between them and the

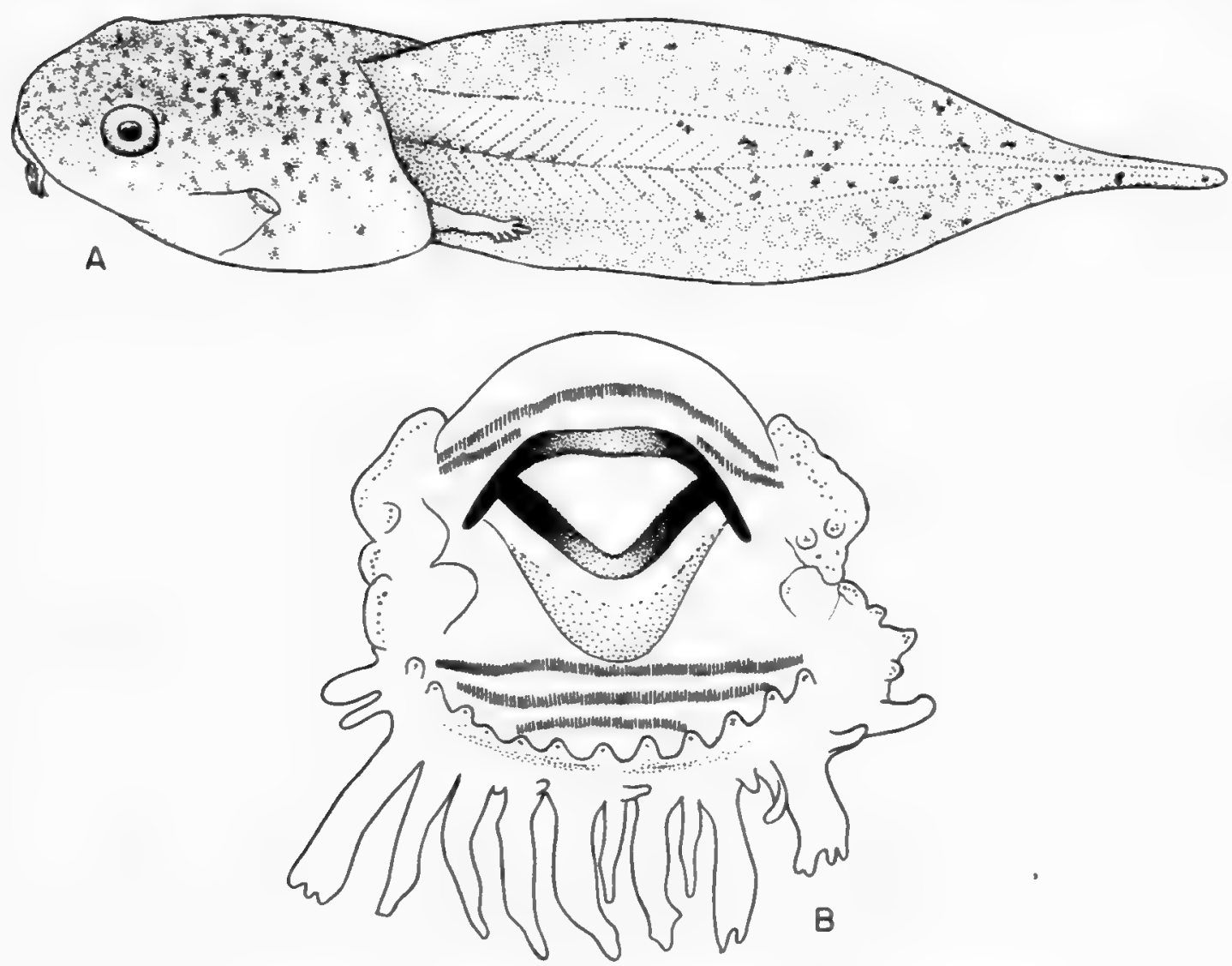

FIG. 79. Rana guentheri; tadpole. A. Lateral view $(\times 3)$. B. Mouth $(\times 25)$.

lower labial teeth. Some extra papillae may be developed between these two rows. The sides of the lower lip are provided with irregular papillae and the corners of the upper lip are bordered by wide flaps with distinct (sometimes indistinct) small papillae. There are three rows of lower labial teeth, the innermost the longest; the two outer rows are continuous, the outermost row the shortest. On the upper lip, there are two rows of labial teeth, a continuous outer row and a widely interrupted inner row. The mandibles are weakly developed, with very finely serrated edges.

\section{Rana tigerina rugulosa Wiegmann}

Rana rugulosa Wiegmann, 1835, Nova Acta Acad. Leop. Carol., 17, pt. 1: 258, pl. 21, fig. 2 - Cape Syng-more, China; Stejneger, 1925, Proc. U. S. Nat. Mus., 66, art. 25: 28. 
Rana viltigera Wiegmann, 1835, Nova Acta Acad. Leop. Carol., 17, pt. 1: 255 (part; Macao, China).

Rana rugosa Lichtenstein and Martens, 1856, Nomencl. Amph. Mus. Berol., p. 38 China (not of Schlegel).

Hydrostentor pantherinus Fitzinger, 1861, Sitz. Ber. Akad. Wiss. Wien, math.-nat. Kl., 42: 414 (nomen nudum).

Rana tigrina var. pantherina Steindachner, 1867, Reise Nov., Zool., 1, Amph.: pl. 1, figs. 14-17-Hongkong.

Rana tigerina Stejneger, 1907, Bull. U. S. Nat. Mus., 58: 139 (part; Hongkong; Formosa).

Rana tigrina var. burkilli Boulenger, 1918, Rec. Ind. Mus., 15: 58.

Rana tigrina rugulosa Fang and Chang, 1931, Contr. Biol. Lab. Sci. Soc., China, 7, Zool. Ser., No. 2: 107, figs. 16, 17; Pope and Boring, 1940, Peking Nat. Hist. Bull., 15, pt. 1: 49 (tigerina).

History of species.-The synonymy above gives an account of the somewhat complicated history of this species in China (for detailed synonymy see Stejneger, 1925, p. 28).

Distribution and collection data.-Rana tigerina rugulosa is commonly called the Chinese bullfrog. It is the commonest frog of southern and central China, as far north as the Yangtze River. In the west, it is found only in Yunnan. I failed to find specimens in Szechwan and Sikang and have no material from Yunnan.

Comparison with related species.-Rana tigerina rugulosa is closely related to the Indian bullfrog Rana tigerina tigerina, from which rugulosa can be distinguished by the more rugose back, with a greater number of dorsal longitudinal ridges, legs mottled rather than barred, and with more mottling on the throat and belly.

\section{Rana kuhlii Duméril and Bibron}

Rana kuhlii Duméril and Bibron, 1841, Erp. Gén., 8: 384; Anderson, 1879, Anat. Zool. Res. Yunnan, p. 838; Boulenger, 1920, Rec. Indian Mus., 20 : p. 62; Pope, 1931, Bull. Amer. Mus. Nat. Hist., 61 : 495, fig. 13.

Nyctibatrachus sinensis Peters, 1882, Sitzber. Ges. Naturf. Freunde Berlin, 1882, p. 146 - Lofau Mountains, Province of Canton.

History of species.-This Malaysian frog was first recorded from Yunnan by Anderson (1879). Boulenger, in various papers, reports it from Chekiang, Yunnan, Fukien, Kwangtung, and Formosa; Annandale (1917) from Hongkong; Mell (1922) from Kwangtung; Smith (1923) from Hainan; Pope (1931) from Fukien, with a detailed account of adults and tadpoles; and Pope and Boring (1940) from northern Kiangsi.

Comparison with other species.-Rana kuhlii is a very distinct form. It has been confused with the young of Rana spinosa. In kuhlii, the legs are less muscular than in spinosa, and kuhlii has a forked omosternum. The mature male of kuhlii has a huge head, with long bony protuberances on the lower jaw, and without nuptial spines on the chest as in the male of spinosa. 


\section{Nanorana pleskei Günther}

Nanorana pleskei Günther, 1896, Ann. Mus. Zool. Acad. Sci. St. Petersbourg, $1: 207$ Sungpan and Inchuan, the Kham Mountains, Szechwan; Bedriaga, 1898, Wiss. Res. Przewalski Central Asien Reis., Zool., 3, sec. 1, Amph. Rept., pt. 1: 32, pl. 1, figs. 5-5c; Pope and Boring, 1940, Peking Nat. Hist. Bull., 15, pt. 1: 44; Liu, 1940, Jour. West China Border Res. Soc., 12, (B): 29, figs. 21, 22.

Nannorana pleskei Werner, 1903, Abh. Bayer. Akad. Wiss., II Kl., 22, pt. 2: 369.

Rana pleskei Boulenger, 1905, Ann. Mag. Nat. Hist., (7), 15: 378; Annandale, 1908, Rec. Ind. Mus., 2: 345; idem, 1917, op. cit., 13: 417, fig.; Boulenger, 1920, op. cit., $20: 107$ (in part).

Montorana ahli Vogt, 1924, Zool. Anz., 60 : 340-Dschiesongla, 3,400 meters, southwest of Tatsienlu, Sikang.

History of species.-As shown by the above synonymy the genus Nanorana and its single species pleskei were established by Günther in 1896, being described from two female specimens collected by Berezowski (June, 1894) at Sungpan and one male collected by Potanin (March, 1894) at Inchuan in the Kham Mountains of Szechwan.

Two years later Bedriaga gave a very detailed description with measurements of some specimens collected by Przewalski that are referred to this species. An adult female was from Dytochju [Dychu], the local name of the upper Yangtze River, and two males were collected at Guidui, upper Hwangho, Kansu. Bedriaga found several differences between the specimens, which he attributed to difference in sex rather than to geographic variation. With one exception he found Günther's description "perfectly adequate."

In 1905 Boulenger announced the occurrence of Günther's species in southern Tibet and in 1920 he gave a concise description with measurements of the ten specimens collected by the India-Tibet Frontier Commission at Lake Yamdok, 15,000 feet altitude, Kamba Jong and Gyantze. His description differs in many points from those of Günther and Bedriaga, and the specimens in question represent an entirely distinct form, now known by the name of Altirana parkeri.

It has been shown by Stejneger (1927, p. 319) how Vogt was led to establish the genus and species Montorana ahli for the true Nanorana pleskei as a result of Boulenger's misapplication of this name, Vogt's specimens being distinguished by having a "visible tympanic membrane." Vogt also stressed the absence of glandular folds over the tympanum. The late Dr. G. K. Noble had informed Stejneger that the apparent absence is due to the state of preservation of Vogt's material and that a glandular fold is actually present. Another Montorana character, a poorly developed precoracoid, verified and figured by Noble (1926, p. 6, fig. 4a), is now shown to be the essential differential character of true Nanorana. This character was seen in the type material by Zarevsky, who wrote that the precoracoid "is very slender, very thin, with slight ossification." This being so there can be no doubt as to the identity of Montorana and Nanorana, and the generic distinctness of the latter from Rana. Pope also examined 
the seven cotypes of Montorana ahli in the Naturhistorisches Museum, Berlin, and Pope and Boring (1940) place Montorana ahli in the synonymy of Nanorana pleskei.

In 1923, Graham obtained three specimens for the United States National Museum at Nganyangba near Kangting, consequently not far from the type locality of Montorana ahli Vogt. During the summer of 1938, Mr. H. C. Chang collected specimens north of Kangting, and from July 25 to September 3, 1942, I collected many specimens north and northwest of the same city.

Comparison with related forms.--Nanorana pleskei (pl. 6, fig. 5) is an endemic genus and species in western China. This small dwarf frog is related to Altirana parkeri of southern Tibet, but differs from the latter in having the tympanum visible and in having a poorly ossified precoracoid.

Original description.- - "In form similar to a Rana esculenta; snout depressed, with the sides and front sloping, the canthus rostralis being rather obtuse. Snout rather longer than the eye; nostril in the middle of its length. Interorbital space as wide as the eyelid. Tympanum covered by the general integument, not quite half as large as the eye. Skin of the upper and lower parts smooth. The two inner fingers subequal in length. If the hind limb be carried forwards, the tarso-metatarsal joint does not reach the end of the snout. Only one very indistinct metatarsal tubercle. Toes half webbed, but the web, extending along the toes, forms a narrow fringe along the sides of each toe. Inner finger of the male thickened.

"Tongue emarginate behind; a very low, linear, oblique bony ridge inside each choana, but without any dental structure. Choanae and particularly Eustachian openings small. Male without vocal sac.

"Upper parts olive, with elliptic brown, black-edged spots. Lower parts white.

"Length of the body of adult female $40 \mathrm{~mm}$.; length of third finger $9 \mathrm{~mm}$.; length of hind-limb $55 \mathrm{~mm}$.; length of fourth toe with metatarsal tubercle $19 \mathrm{~mm}$.

"This frog is a dwarf-form of Rana; fortunately an adult female (with matured ova) and adult male are in the collection. Two females were collected by Berezowski at Sungpan and one male by Potanin at Inchuan in the Kham mountains (March 1894)."

Description of adult female (No. 49474, C.N.H.M., from Taining, Sikang).Body depressed. Head strongly depressed, slightly broader than long; snout rounded, slightly projecting beyond the mouth; nostril nearer to the eye than to the tip of the snout; canthus rostralis very obtuse, loreal region oblique, with a shallow groove from the nostril to the eye; interorbital space narrower than the upper eyelid; internasal space much greater than the interorbital space; tympanum covered by skin but distinct, rounded, and smaller than the space between the eye and the tympanum; tongue (fig. 80, A) large, slightly notched behind; vomerine teeth in two long, very oblique series, separated by a space about half the length of one series, in a line just behind the choanae. 
Arm short; the fingers flattened and obtuse, the first finger slightly shorter than the second, the second about equal in length to the fourth, and the third finger the longest; a large flattened subarticular tubercle at the base of each finger; an indistinct elongated outer and a rounded inner palmar tubercle; an elongated light-colored tubercle at the latero-ventral base of the first finger.

Leg short, the tibio-tarsal articulation reaching the shoulder, the heels hardly meeting when the legs are folded at right angles to the body; the toes (fig. 80, C) flattened and obtusely pointed, nearly fully webbed for the first, second, third, and fifth toes, the two terminal phalanges of fourth toe free from

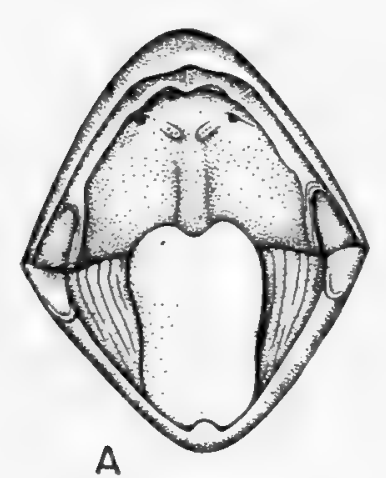

FIG. 80. Nanorana pleskei $(\times 3)$. A. Oral cavity. C. Ventral view of foot.

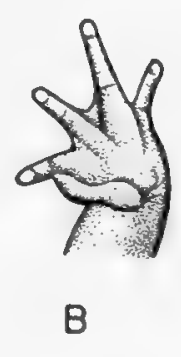

A. Oral cavity. B. Ventral view of hand of male.

web; a thick fringe on the outer side of the third and fourth phalanges of the fifth toe; subarticular tubercles indistinct; inner metatarsal tubercle small, oval, without free cutting edge; no outer metatarsal tubercle; no tarsal fold.

Skin rough with elongated ridges on the back forming regular longitudinal interrupted folds; a glandular fold from the eye to the shoulder; a glandular ridge behind the angle of the mouth; more irregular rounded warts on the sides of the body; small rounded warts and ridges on the legs, but not on the arms; crowded round warts on the posterior aspects of the thighs at the base, extending anteriorly onto the posterior part of the belly; lower parts otherwise smooth.

Coloration in alcohol.-Bluish gray above, with elongated and rounded dark brown spots corresponding to the glandular ridges and warts, the spots with lighter centers and margins; a wide, dark brown band from the tip of the snout to the shoulder, passing through the nostril to the anterior corner of the eye and from the posterior corner of the eye along the glandular fold to the shoulder; limbs with irregular dark brown spots on the same ground color; upper jaw lighter; lower jaw and lower parts uniform cream; the upper sides of the two inner fingers and three inner toes like the belly.

Coloration in life.--The coloration of living specimens varies greatly. The ground color on the back and the dorsal sides of the limbs varies from yellowish 
green to dark green; in a few cases it is from Isabella to Buffy Olive. The spots on the back and the limbs are dark brown to black but mostly dark brown. These spots are lighter in the center and enclosed by a light-colored edge. The upper jaw is from Light Isabella to Light Brownish Gray, and sometimes Yellowish Green. The throat, belly and ventral sides of limbs are yellowish cream. The pupil is oval and black. The iris is dark below and greenish above.

Variation.-Variation in vomerine teeth has been the source of confusion. Günther (1896) said that vomerine teeth were absent, regarding this as a character of the genus. Pope and Boring (1940) found them present. Others gave different descriptions of the condition of the teeth. I examined the teeth of eight females and eight males in my collection. Each of four females (Nos. 992, 898, 999, 2419) has two well-developed long and oblique vomerine tooth series; two females (Nos. 944, 2070) have two small oblique series; one (No. 2906) has a very small round patch of vomerine teeth; and one (No. 2408) has none at all. In the males, two (Nos. 453, 465) have two long oblique vomerine tooth series; two (Nos. 2103, 2107) have smaller oblique series; two (Nos. 2327, 2449) have two very small rounded vomerine tooth patches; one (No. 2487) has a large vomerine tooth series on the right side and none on the left; and one (No. 2492) has a small rounded vomerine tooth patch on the right side and none on the left.

Sex dimorphism.-There is little difference between the sexes in size (see table). In the male the arm is slightly stronger than that of the female; a very strong nuptial pad (fig. 80, B) is developed on the inner basal part of the first finger; there are no vocal sacs; lineae masculinae are developed.

Nanorana pleskei: Measurements of Ten Male and Ten Female Adults

\begin{tabular}{|c|c|c|c|c|}
\hline Measurements & Sex & Range & Average & $\begin{array}{c}\text { Ratio to } \\
\text { body length (\%) }\end{array}$ \\
\hline Body length.... & $\begin{array}{l}0^{x} \\
0\end{array}$ & $\begin{array}{c}34.5-40.0 \\
33-42\end{array}$ & $\begin{array}{l}36.6 \\
37.3\end{array}$ & $\cdots$ \\
\hline Head length. & \begin{tabular}{l}
$\sigma^{7}$ \\
\hdashline
\end{tabular} & $\begin{array}{l}11.0-12.5 \\
11.0-13.5\end{array}$ & $\begin{array}{l}11.7 \\
12.2\end{array}$ & $\begin{array}{l}32.0 \\
32.7\end{array}$ \\
\hline Head width. & $\begin{array}{l}\sigma^{7} \\
9\end{array}$ & $\begin{array}{l}11-12 \\
11-13\end{array}$ & $\begin{array}{l}11.7 \\
12.2\end{array}$ & $\begin{array}{l}32.0 \\
32.7\end{array}$ \\
\hline Interorbital space. & $\begin{array}{l}8 \\
0 \\
0\end{array}$ & $\begin{array}{l}1.6-2.0 \\
1.5-2.0\end{array}$ & $\begin{array}{l}1.9 \\
1.8\end{array}$ & $\begin{array}{l}5.2 \\
4.8\end{array}$ \\
\hline Length of lower arm.... & $\begin{array}{l}8 \\
8 \\
9\end{array}$ & $\begin{array}{c}13.0-15.6 \\
13-16\end{array}$ & $\begin{array}{l}14.4 \\
14.6\end{array}$ & $\begin{array}{l}39.2 \\
39.1\end{array}$ \\
\hline Diameter of lower arm. & $\begin{array}{l}9 \\
9 \\
9\end{array}$ & $\begin{array}{l}3-5 \\
3-4\end{array}$ & $\begin{array}{l}4.2 \\
3.8\end{array}$ & $\begin{array}{l}11.5 \\
10.2\end{array}$ \\
\hline Length of hand.. & $\begin{array}{l}8 \\
8 \\
8\end{array}$ & $\begin{array}{c}7.5-8.5 \\
8-9\end{array}$ & $\begin{array}{l}8.0 \\
8.5\end{array}$ & $\begin{array}{l}21.8 \\
22.8\end{array}$ \\
\hline Length of leg. & $\begin{array}{l}9^{7} \\
9\end{array}$ & $\begin{array}{l}47-55 \\
45-52\end{array}$ & $\begin{array}{l}50.4 \\
50.4\end{array}$ & $\begin{array}{l}137.7 \\
135.1\end{array}$ \\
\hline Length of tibia.............. & $\begin{array}{l}0^{7} \\
9\end{array}$ & $\begin{array}{c}14.8-17.4 \\
14-16\end{array}$ & $\begin{array}{l}15.8 \\
15.4\end{array}$ & $\begin{array}{l}43.3 \\
41.3\end{array}$ \\
\hline Length of tarsus and foot...... & $\begin{array}{l}0^{7} \\
9\end{array}$ & $\begin{array}{c}24.7-27.7 \\
22-27\end{array}$ & $\begin{array}{l}25.6 \\
25.5\end{array}$ & $\begin{array}{l}69.9 \\
68.4\end{array}$ \\
\hline Length of foot... & $\begin{array}{l}8 \\
0 \\
0\end{array}$ & $\begin{array}{l}17-19 \\
17-19\end{array}$ & $\begin{array}{l}17.4 \\
18.3\end{array}$ & $\begin{array}{l}47.6 \\
49.0\end{array}$ \\
\hline
\end{tabular}


Habitat and habits.-Nanorana pleskei inhabits the high plateaus of northwestern Szechwan, and Kangshu, Sikang, from 10,000 to 14,000 feet altitude. These frogs are found among vegetation in or near the marshes, ponds, or pools of the plateau, and along mountain streams. Sometimes they hide themselves under stones at the margin of the water. At evening they come out from their hiding places and sit on open ground. They are rather inactive and are relatively
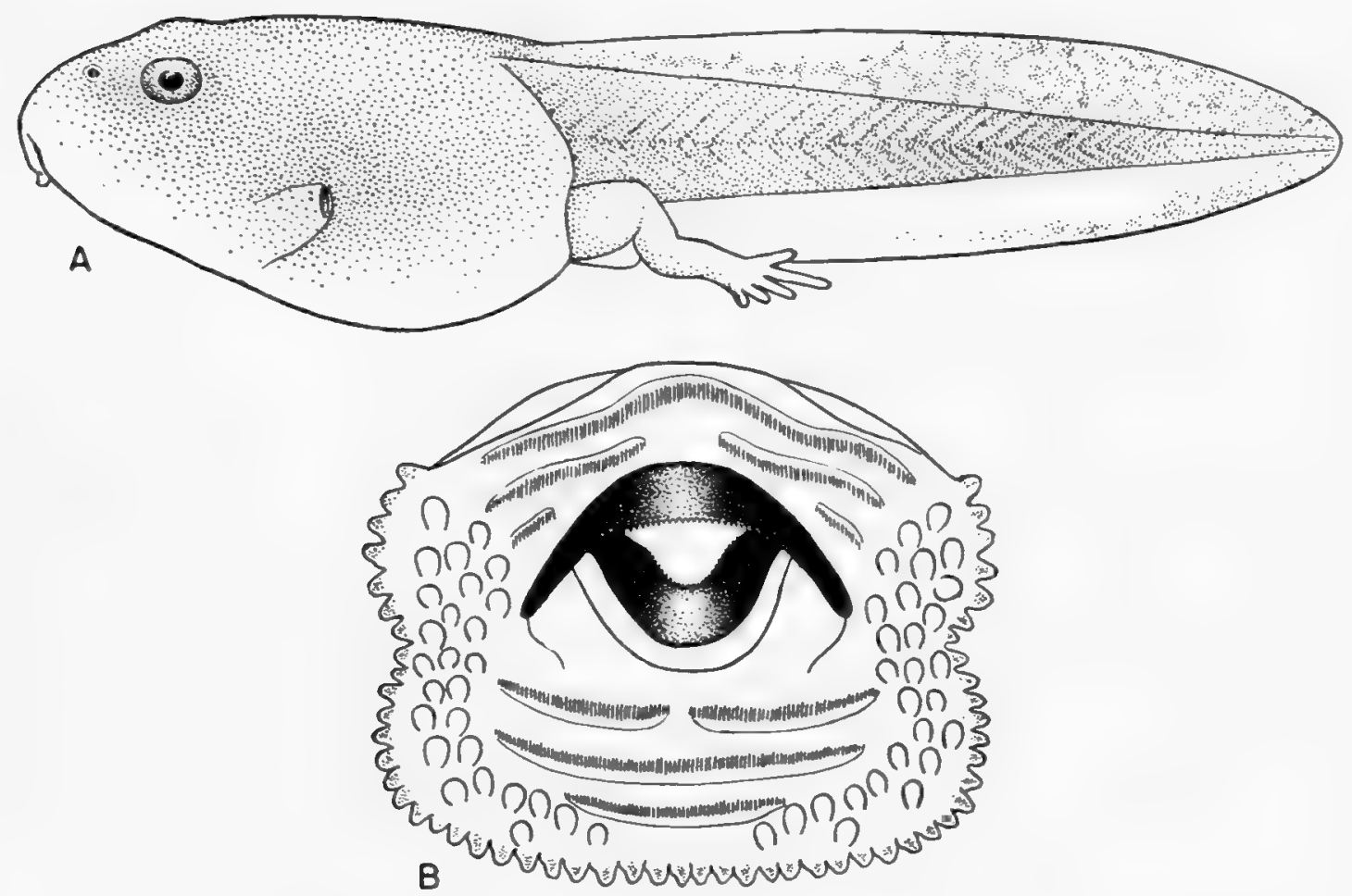

FIG. 81. Nanorana pleskei; tadpole. A. Lateral view $(\times 4)$. B. Mouth (X 25).

poor jumpers and swimmers. It is easy to collect them in large numbers, and the impression gained from the rarity of the species in museum collections-that it must be rare in nature - is quite erroneous.

The breeding habits and time of egg-laying are still unknown. Tadpoles at different stages and metamorphosed young were collected from July 25 to September 3, 1942. Female specimens collected at Taining on July 28, 1942, have mature eggs in the uterus, indicating that the breeding season may be rather long, possibly extending from May to August. The breeding sites are stationary waters of marshes, pools and ponds.

No eggs were found. Eggs from the females mentioned above are $2 \mathrm{~mm}$. in diameter. The animal pole is black and the vegetal pole is old ivory.

Tadpole.-Tadpoles (fig. 81, A) are very abundant, and specimens in different stages of metamorphosis are commonly found in the grass on the margin of the water. 
The coloration of the tadpoles is relatively uniform. The back and sides of the body are black to dark gray, or dark brownish gray, stippled with gold. Advanced tadpoles have longitudinal light-colored bars, which later develop into the color pattern on the back of the adult. The muscular portion of the tail is generally dark gray, the dorsal tail fin stippled with black, and the ventral fin only slightly stippled at the rear. The middle line of the belly is very transparent and colorless, and the rest of the belly is gray.

Ten tadpoles average $41 \mathrm{~mm}$. in length (see table). The body is stout, with a rather pointed snout. The nostril is directed antero-laterally, about midway between the tip of the snout and the anterior border of the eye. The spiraculum is sinistral, only visible from below; it has a broad pouch and its opening is directed upward and backward, without a free tube. The vent is slightly on the right side of the tail base, with a short, broad pouch and a very large opening, which is continuous with the ventral tail fin. The tail is weakly developed, with a delicate fin; the muscular part is narrow. The stoutness of the body, produced by the thick intestine, and the weakly developed tail are closely correlated with the adaptation of the species to the quiet water of small pools and marshes.

The small mouth (fig. 81, B) is antero-ventral, with a row of papillae on each side of the upper lip and along the whole margin of the lower lip. These papillae have pigmented cores. Papillae without pigment are irregularly scattered inside of this row, except below the middle of the outermost row of lower labial teeth. Of twenty tadpoles examined, sixteen have the tooth formula I:2-2/ II:1-1, two have $I: 1-1 / I I: 1-1$, one has I:1-2/II:1-1, and one has I:2-2/ III :0 0. In most cases, the upper lip has three rows of teeth, the outermost row complete, the two inner rows interrupted, the innermost row very short and the segments widely separated, located at the ends of the upper mandible. On the lower lip, the three rows of teeth have only the innermost narrowly interrupted. All of the rows of labial teeth are placed on a fleshy base. The mandibles are weak and have finely serrated edges.

The young just after metamorphosis are generally from 10 to $12 \mathrm{~mm}$. in length.

\section{Nanorana pleskei: Measurements of Ten Tadpoles}

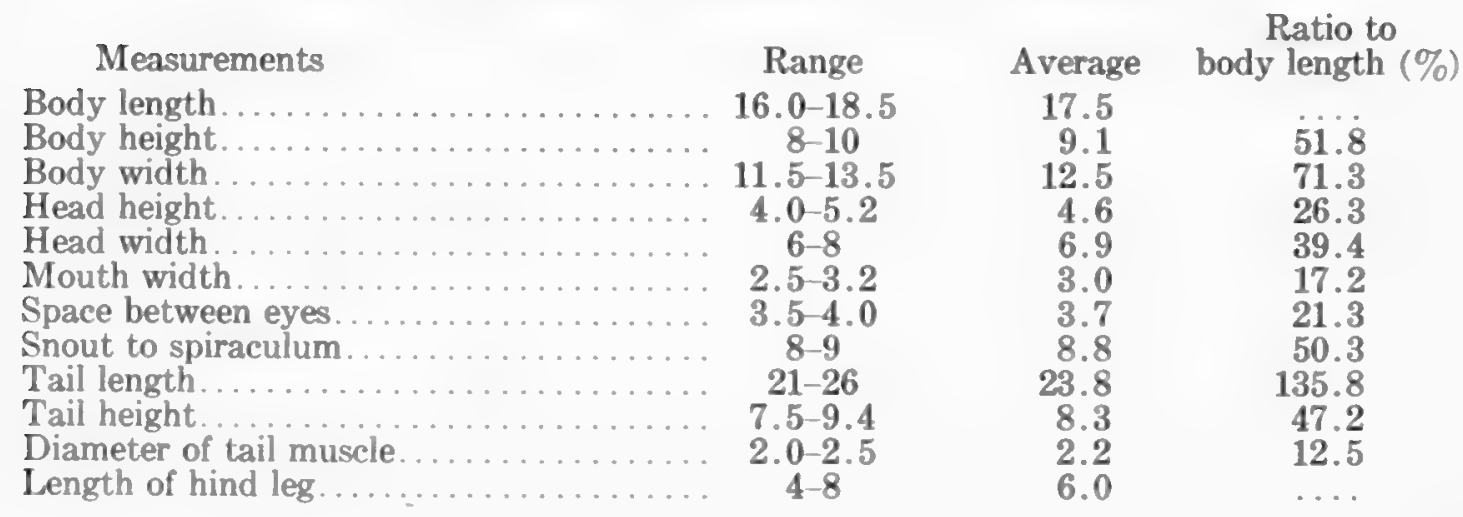




\section{Altirana parkeri Stejneger}

Rana pleskei Boulenger (not of Günther), 1920, Rec. Ind. Mus., 20: 107.

Altirana parkeri Stejneger, 1927, Jour. Wash. Acad. Sci., 17: 318-Tingri, 15,000 feet altitude, Tibet.

History of species.-In 1927 the United States National Museum received by exchange with the British Museum two specimens of frogs that had been identified by Boulenger as Rana pleskei, and reported upon by him in 1920 . When compared by Stejneger with true Nanorana pleskei, collected by D. C. Graham, it was immediately evident that the specimens named by Boulenger were quite different from Günther's pleskei. After further comparison with a specimen from Yatong, in the projecting angle of Himalayan Tibet between
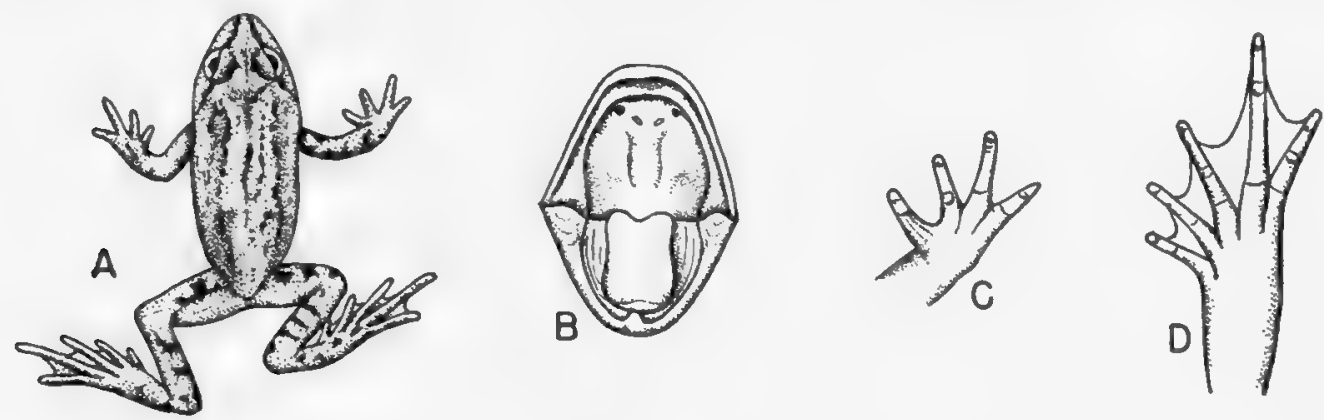

FIG. 82. Altirana parkeri. A. Adult $(\times 1)$. B. Oral cavity $(\times 2)$. C. Ventral view of hand $(\times 2)$. D. Ventral view of foot $(\times 2)$. Drawn by Dr. Doris M. Cochran.

Sikkim and Bhutan, Stejneger (1927) referred these Tibetan frogs to a new genus and species, Altirana parkeri (fig. 82).

Original description.- "Digits without terminal dilations and horizontal grooves; tympanum absent; outer metatarsals separated in their distal third; no dorso-lateral glandular fold; no long tooth-like protuberance in front of lower jaw; toes fully webbed; subarticular tubercles present but rather flat and indistinct; fifth toe slightly shorter than third; second and fourth fingers subequal; tibio-tarsal articulation reaching the shoulder.

"In view of Boulenger's careful account of the Himalayan specimens a detailed description of the type is not deemed necessary here, but I would call attention to the fact that Boulenger expressly states (p. 108) that males are 'without secondary sexual characters,' while the specimens before me clearly demonstrate the presence of a large nuptial pad-like swelling on the inner side of the first finger, which is covered with minute dark spinules, as are also the bases of the first and second fingers, a feature strongly developed in the Museum of Comparative Zoology specimen, and only slightly less in the type. The inference is that Boulenger's specimens were not collected during the breeding season."

Measurements (after Boulenger) of U.S.N.M. No. 72328, type, male adult, and M.C.Z. No. 11636, male adult (in parentheses): Tip of snout to vent 25.0 
mm. (34.0); tip of snout to anterior border of eye $5.5 \mathrm{~mm}$. (5.7); tip of snout to nostril $3.2 \mathrm{~mm}$. (3.7); nostril to eye $2.2 \mathrm{~mm}$. (2.2); longitudinal diameter of eye $3.6 \mathrm{~mm} .(4.0)$; distance between nostrils $3.0 \mathrm{~mm}$. (3.0); interorbital width 2.0 $\mathrm{mm}$. (2.0); width of upper eyelid $2.5 \mathrm{~mm}$. (3.0); width of head $12.2 \mathrm{~mm}$. (12.0); foreleg $16.0 \mathrm{~mm}$. (16.0); hind leg from vent to tip of fourth toe $44.0 \mathrm{~mm}$. (44.0); hind leg from groin to tip of fourth toe $43.0 \mathrm{~mm}$. (42.0); tibia $14.0 \mathrm{~mm}$. (14.0); foot from heel to tip of fourth toe $26.0 \mathrm{~mm}$. (23.0).

\section{Genus STAUROIS Cope}

\section{Key for Identification of Adults of Staurois in Western China}

I. Disk of first finger with distinct lateral grooves separating upper and lower surfaces.

A. Male without vocal sacs; tympanum obscure; tibio-tarsal articulation reaching beyond eye............................... ricketti minor.

AA. Male with vocal sacs; tympanum distinct; tibio-tarsal articulation reaching tip of snout.

B. Back with black spots or marbling or with grayish variegations... afghanus.

BB. Back with no black spots or marbling and no grayish variegations.

II. Disk of first finger without lateral grooves.

chunganensis.

A. Back with brown or dark medium-sized or large spots or blotches (preserved specimens best examined under liquid).

B. Back with brown spots enclosed by light green rings on dark green, in life; in preserved specimens, light brown on greenish black........... loloensis.

BB. Back with dark blotches irregularly arranged and with irregular outlines on light olive gray in life; in preserved specimens, with dark irregular spots on

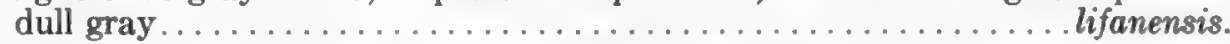

AA. Back without brown or dark medium-sized or large spots.

B. With conspicuous large flattened gland on under side of lower arm in female; disk of fourth toe as wide as fringes at base of disk in male. . kangtingensis.

BB. No gland on under side of lower arm in female; disk of fourth toe always wider than fringe at base of disk.................... mantzorum.

\section{KEY FOR IDENTIFICATION OF TADPOLES OF STAUROIS}

I. With extra papillae inside of marginal papillae of latero-posterior region of upper lip.

A. Some papillae beneath outermost row of labial teeth of lower lip.

B. Two sub-branchial muscles (M. diaphragmatobranchiamedialis) round, parallel, and not meeting the $M$. diaphragmatoprecordalis...... kangtingensis.

BB. Two sub-branchial muscles oval, converging anteriorly, and in contact with M. diaphragmatoprecordalis........................ lifanensis.

AA. Without papillae beneath outermost row of labial teeth of lower lip. .mantzorum.

II. Without extra papillae inside of marginal papillae of latero-posterior region of upper

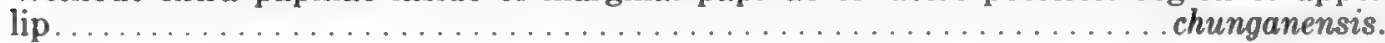

\section{Staurois mantzorum David}

Polypedates mantzorum David, 1871, Nouv. Arch. Mus. Hist. Nat. Paris, 7, Bull.: 95-Muping, Szechwan, China.

Rana jugans Stejneger, 1926, Proc. Biol. Soc. Wash., 39: 53-near Wenchwan, about $100 \mathrm{~km}$. northwest of Chengtu.

Staurois jugans Pope and Boring, 1940, Peking Nat. Hist. Bull., 15, pt. 1: 47; Liu, 1940, Peking Nat. Hist. Bull., 15, pt. 2: 162. 
History of species.-Père David collected some frogs from Muping in 1869 and described them as Polypedates mantzorum in 1871; no subsequent author seems to have cited this name. In 1924, Graham collected two adult females 1.5 miles beyond Muping, and these were identified by Stejneger as Rana jugans. From July 22 to August 22, 1939, I collected sixty-four specimens at Muping, which were identified as Staurois jugans by Pope and Boring. Not until 1947, with the library facilities of Chicago Natural History Museum available, was it discovered that David's description of Polypedates mantzorum is perfectly recognizable. Stejneger, who was usually meticulous in disposing of any early name, seems to have missed mantzorum altogether. The coloration described by David corresponds unmistakably with the watercolor drawing from life in my notes.

Distribution and collection data.-Staurois mantzorum is an endemic species of northwestern Szechwan, with a vertical distribution from 3,000 to 6,000 feet. In the Muping area I found it in streams outside of Muping City, near Yangtsun (3,200 feet altitude) and around Lungtung (3,400 feet). From April 22 to July 3, 1941, eighty-one females and fifty-six males were collected at Shuimokou, Chungkingchow, about twenty-five miles west of Kwanhsien City. Six females and four males were collected at Maliuwan and Yenhsingping, near Wenchwanhsien (the type locality of jugans); and three females and two males are from Lifan, northwest of Wenchwanhsien.

Comparison with related species.-Staurois mantzorum (pl. 7, figs. 2 and 6) is a cascade frog related in some characters to Staurois kangtingensis. The coloration of mantzorum differs from that of kangtingensis in its large rounded green spots on an ashy gold background; the latter species usually has small dark spots connected by brown lines to form a network on a bluish green background. After preservation, it is difficult to distinguish these species by coloration alone. The conspicuous gland on the postero-ventral median part of the arm in the female of kangtingensis can be used to distinguish that species. The female of mantzorum has no visible corresponding gland, though it is present in the skin and easily disclosed by a cut.

Original description (translation).- "Among the moist stones of the torrents of Muping live two frogs. They appear to be new. They have the toes elongated and terminating in large disks. I name them Polypedates mantzorum and Polypedates dugritei. The first has an ashy gold back, with rounded green spots. It has transverse stripes on the thighs and on the arms."

Description of topotype female.-Body stout. Head depressed, slightly broader than long, the top of the head flat, with a small round median white spot between the anterior corners of the eyes; snout rounded and projected beyond the mouth; nostril about mid-way between the tip of the snout and the anterior border of the eye; canthus rostralis rounded; loreal region oblique, with a horizontal groove from the nostril to the antero-ventral part of the lower eyelid; interorbital space narrower than internasal space and equal to the width 
of the upper eyelid; tympanum obscure, covered with skin; tongue large and deeply notched behind; vomerine tooth patches in two oblique series, their anterior ends in a line between the posterior edges of the choanae, separated by a space about one-half the length of one of the series, and the space from its antero-lateral end to the choana about equal to its own length.

Arm moderately long, with long fingers (fig. 83, A); the third finger the longest, the tip of the fourth finger reaching the base of the disk of the third finger, the

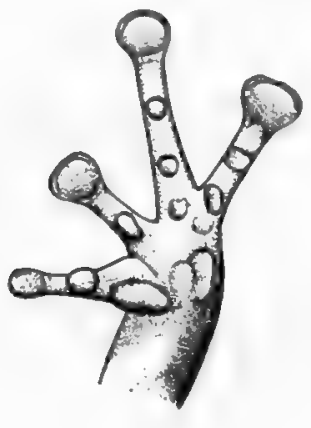

A

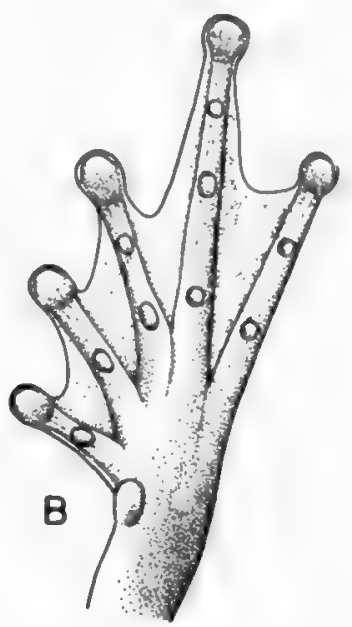

FIG. 83. Staurois mantzorum $(\times 2)$. A. Ventral view of hand. B. Ventral view of foot.

second finger shorter than the fourth and slightly longer than the first; large adhesive disks on the three outer fingers, the tip of the first finger dilated like a disk but with no horizontal groove; subarticular tubercles well developed, with large supernumerary tubercles at the bases of the two outer fingers; palmar tubercles fused and rather indistinct; an elongated pad developed on the lower and inner side of the first finger.

Legs long, the tibio-tarsal articulation reaching beyond the nostril; heels overlapping when placed at right angles to the body; the fourth toe the longest, the third and fifth about equal, the second much shorter than the third and much longer than the first; all toes provided with disks, which are smaller than those of the fingers; toes fully webbed except the fourth, in which the web reaches beyond the distal subarticular tubercle; subarticular tubercles well developed; inner metatarsal tubercle weak, oval and flattened; no outer metatarsal tubercle.

Skin smooth above and below, with a few tubercles on the sides of the body and behind the angle of the mouth; a few tubercles near the vent; a skin fold from the posterior corner of the eye to the shoulder.

Coloration in life.-Ashy golden brown on top of head and body, with large rounded dark green spots; snout more greenish than brown; sides of head and neck region and dorsal sides of limbs with green ground color; a dark band from the tip of the snout through the nostril to the anterior border of the eye, con- 
tinuing behind the eye on the skin fold to the shoulder; lateral to the ashy golden brown on the back, a row of elongated green spots of varying size extending from the posterior corner of the eye to the groin; sides of body washed with dusky and with green; irregular black stripes on arms and legs; web orange yellow; yellowish cream on the throat, belly, and under sides of limbs; clouded with gray on throat. After preservation, all the green color becomes a dull grayish blue.

Measurements of type of Staurois mantzorum (U.S.N.M. No. 67819, male; percentage of body length in parentheses).-Body length $52 \mathrm{~mm}$.; head length $17 \mathrm{~mm}$. (32.2); head width $17 \mathrm{~mm}$. (32.2); length of lower arm $27 \mathrm{~mm}$. (51.9); diameter of lower arm $6 \mathrm{~mm}$. (11.5); length of hand $16 \mathrm{~mm}$. (30.5); disk of third finger $3 \mathrm{~mm}$. (5.7); length of leg $91 \mathrm{~mm}$. (175.0); length of tibia $30 \mathrm{~mm}$. (57.6); length of foot and tarsus $39 \mathrm{~mm}$. (75.0); length of foot $26 \mathrm{~mm}$. (50.0); disk of fourth toe $2.5 \mathrm{~mm}$. (4.8).

Coloration.- Ninety females and sixty-two males were collected in the region of the type locality of mantzorum. In life, the color varies greatly but most specimens have a green or bluish green ground color on the body and the dorsal sides of the limbs and digits. Small round black spots cover the warts on the back and are connected by light brown to form a network; blackish or brownish irregular bars are present on the limbs. The throat and part of the thorax are generally marbled with dark gray. The belly and the ventral sides of the limbs are creamyellow. The webs are yellow, with an indication of orange. The pupil is black, enclosed by a golden ring, and the iris is golden stippled with black.

Sex dimorphism.-The length of the hind limb varies greatly. In the majority of the females, the tibio-tarsal articulation reaches beyond the nostril, and in the majority of males it reaches the tip of the snout.

Males are much smaller than females, with a strong nuptial pad developed on the inner and upper side of the first finger. There are no vocal sacs or lineae masculinae in the male, and the arm is stronger and the leg longer.

Habitat and habits.-Staurois mantzorum is a common cascade frog in mountain streams west of Kwanhsien and in the southwest part of Wenchwan. This species is usually found together with Rana margaretae and sometimes with Staurois lifanensis. Individuals are usually seen adhering to and flattened on the surfaces of rocks beside cascades, where the spray reaches them. In the daytime, the place chosen by this frog is usually shaded by bushes and other vegetation. Staurois mantzorum is known as the "flood frog" because the local people have observed that it suddenly appears in large numbers on the stones of the mountain stream after a heavy rain, especially when the water is very high. Under these conditions the frogs can not stay in their hiding places. The water also stimulates the frog to come out for breeding. I was fortunate to be able to study and collect this "flood frog" in Panch'angkou, Shuimokou, on the afternoon of April 22, 1941, after a very heavy rain. On that evening we collected sixty-two females and thirty-five males. Males as well as females were jumping from stone to stone, the males croaking with a sharp low voice like that of a 
Staurois mantzorum: Measurements of Fifteen Male and Twenty-five Female Adults from Muping

\begin{tabular}{|c|c|c|c|c|}
\hline Measurements & Sex & Range & Average & $\begin{array}{l}\text { Ratio to } \\
\text { body length }(\%)\end{array}$ \\
\hline Body length ................ & $\begin{array}{l}\sigma^{7} \\
\wp\end{array}$ & $\begin{array}{c}49.2-57.5 \\
59-72\end{array}$ & $\begin{array}{l}53.6 \\
68.1\end{array}$ & $\ldots$ \\
\hline Head width. & $\begin{array}{l}\sigma^{7} \\
8\end{array}$ & $\begin{array}{l}15.5-18.2 \\
18.3-24.5\end{array}$ & $\begin{array}{l}17.2 \\
22.3\end{array}$ & $\begin{array}{l}32.1 \\
32.7\end{array}$ \\
\hline Interorbital space........... & $\begin{array}{l}\sigma^{7} \\
\%\end{array}$ & $\begin{array}{l}4.3-6.5 \\
4.5-6.0\end{array}$ & $\begin{array}{l}5.0 \\
5.4\end{array}$ & $\begin{array}{l}9.3 \\
7.9\end{array}$ \\
\hline Diameter of lower arm. & $\begin{array}{l}0 \\
8 \\
\$\end{array}$ & $\begin{array}{l}4.3-7.0 \\
5.2-7.2\end{array}$ & $\begin{array}{l}6.0 \\
6.2\end{array}$ & $\begin{array}{r}11.1 \\
9.1\end{array}$ \\
\hline Length of hand. & $\begin{array}{l}0 \\
0 \\
8\end{array}$ & $\begin{array}{c}13.5-17.5 \\
18-22\end{array}$ & $\begin{array}{l}15.2 \\
20.2\end{array}$ & $\begin{array}{l}28.4 \\
29.7\end{array}$ \\
\hline Disk of third finger. & $\begin{array}{l}\sigma^{7} \\
9\end{array}$ & $\begin{array}{l}2.0-3.5 \\
3.0-4.1\end{array}$ & $\begin{array}{l}2.8 \\
3.7\end{array}$ & $\begin{array}{l}5.2 \\
5.4\end{array}$ \\
\hline Length of leg. & $\begin{array}{l}0 \\
9\end{array}$ & $\begin{array}{r}92-117 \\
114-130\end{array}$ & $\begin{array}{l}103.0 \\
122.0\end{array}$ & $\begin{array}{l}192.2 \\
179.1\end{array}$ \\
\hline Length of tibia. . & $\begin{array}{l}\sigma^{7} \\
\text { क }\end{array}$ & $\begin{array}{c}29.0-34.5 \\
36-43\end{array}$ & $\begin{array}{l}32.3 \\
38.9\end{array}$ & $\begin{array}{l}60.3 \\
57.1\end{array}$ \\
\hline Length of foot and tarsus. . & $\begin{array}{l}0^{7} \\
\circ\end{array}$ & $\begin{array}{l}41.5-48.5 \\
50.0-58.5\end{array}$ & $\begin{array}{l}45.3 \\
53.9\end{array}$ & $\begin{array}{l}84.5 \\
79.1\end{array}$ \\
\hline Length of foot. & $\begin{array}{l}9 \\
8 \\
9\end{array}$ & $\begin{array}{l}26-31 \\
31-37\end{array}$ & $\begin{array}{l}28.4 \\
34.4\end{array}$ & $\begin{array}{l}53.0 \\
50.7\end{array}$ \\
\hline Disk of fourth toe. & 8 & $1.8-3.0$ & 2.4 & 4.5 \\
\hline
\end{tabular}

Staurois mantzorum: Measurements of Thirty-five Male and Twenty-seven Female Adults from Wenchwan

\begin{tabular}{|c|c|c|c|c|}
\hline Measurements & $\operatorname{Sex}$ & Range & Average & $\begin{array}{l}\text { Ratio to } \\
\text { body length }(\%)\end{array}$ \\
\hline Body length...... & $\begin{array}{l}8 \\
9\end{array}$ & $\begin{array}{l}49.5-54.7 \\
65.0-71.8\end{array}$ & $\begin{array}{l}52.0 \\
68.1\end{array}$ & $\ldots$ \\
\hline Head length........ & $\begin{array}{l}0^{7} \\
9\end{array}$ & $\begin{array}{l}16-18 \\
21-26\end{array}$ & $\begin{array}{l}17.0 \\
22.4\end{array}$ & $\begin{array}{l}32.7 \\
32.9\end{array}$ \\
\hline Head width. & o & $\begin{array}{l}15.8-18.6 \\
20.0-25.7\end{array}$ & $\begin{array}{l}16.8 \\
23.5\end{array}$ & $\begin{array}{l}32.3 \\
34.5\end{array}$ \\
\hline Interorbital space ........... & $\begin{array}{l}0^{7} \\
q\end{array}$ & $\begin{array}{l}4.5-5.5 \\
5.4-6.5\end{array}$ & $\begin{array}{l}5.0 \\
5.9\end{array}$ & $\begin{array}{l}9.6 \\
8.7\end{array}$ \\
\hline Length of lower arm... & $\begin{array}{l}0^{7} \\
0\end{array}$ & $\begin{array}{l}26.5-29.8 \\
33.3-37.4\end{array}$ & $\begin{array}{l}28.1 \\
35.2\end{array}$ & $\begin{array}{l}54.1 \\
51.7\end{array}$ \\
\hline Diameter of lower arm. . & $\begin{array}{l}\sigma^{7} \\
8\end{array}$ & $\begin{array}{l}5.5-7.4 \\
5.7-7.1\end{array}$ & $\begin{array}{l}6.3 \\
6.5\end{array}$ & $\begin{array}{r}12.2 \\
9.6\end{array}$ \\
\hline Length of hand. & $\begin{array}{l}0^{7} \\
\text { q }\end{array}$ & $\begin{array}{l}12.5-14.3 \\
16.0-19.3\end{array}$ & $\begin{array}{l}13.3 \\
17.7\end{array}$ & $\begin{array}{l}25.6 \\
26.1\end{array}$ \\
\hline Disk of third finger. & $\begin{array}{l}0^{7} \\
8\end{array}$ & $\begin{array}{l}2.3-3.3 \\
3.2-4.2\end{array}$ & $\begin{array}{l}2.7 \\
3.9\end{array}$ & $\begin{array}{l}5.2 \\
5.7\end{array}$ \\
\hline Length of leg. & $\begin{array}{l}8 \\
9\end{array}$ & $\begin{array}{r}95-106 \\
117-134\end{array}$ & $\begin{array}{r}99.0 \\
122.7\end{array}$ & $\begin{array}{l}190.3 \\
180.3\end{array}$ \\
\hline Length of tibia. & o' & $\begin{array}{l}29.8-33.3 \\
36.8-41.0\end{array}$ & $\begin{array}{l}31.7 \\
38.7\end{array}$ & $\begin{array}{l}60.9 \\
56.9\end{array}$ \\
\hline Length of foot and tarsus...... & $\begin{array}{l}0 \\
9\end{array}$ & $\begin{array}{c}43.5-49.0 \\
54-59\end{array}$ & $\begin{array}{l}46.2 \\
56.2\end{array}$ & $\begin{array}{l}88.8 \\
82.6\end{array}$ \\
\hline Length of foot. & $\begin{array}{l}\text { o7 } \\
\text { ᄋ }\end{array}$ & $\begin{array}{c}25.2-28.5 \\
31-34\end{array}$ & $\begin{array}{l}27.0 \\
33.3\end{array}$ & $\begin{array}{l}51.9 \\
48.9\end{array}$ \\
\hline Disk of fourth toe... & $\begin{array}{l}0^{7} \\
\text { क }\end{array}$ & $\begin{array}{c}2-3 \\
2.6-3.3\end{array}$ & $\begin{array}{l}2.4 \\
2.9\end{array}$ & $\begin{array}{l}4.6 \\
4.3\end{array}$ \\
\hline
\end{tabular}


cricket. When I tried to approach one, it jumped into the flooded stream and disappeared. At night, however, with the help of a flashlight, it was easy to catch them by hand.

I failed to find paired individuals or egg-masses, although we worked for two more days searching for breeding pairs and for eggs, throughout the 200 meters of Panch'angkou where we got our specimens.

Tadpoles.-From April 20 to 25, 1941, tadpoles (fig. 84) of Staurois mantzorum with hind limb-buds were collected from the same mountain stream where many adult specimens were obtained. During the first three weeks of July, I visited the same mountain stream and saw a few adults and collected small tadpoles and tadpoles with hind legs. As I worked along that short mountain stream for about three weeks at two periods of time, and as the Staurois found was mantzorum, it seems certain that the Staurois tadpoles collected from that mountain stream are the tadpoles of that species.

The small tadpoles usually hide themselves between or beneath stones near the margins of pools and ponds, under cascades. The larger tadpoles were found singly, adhering tightly to the surface of slippery rocks where there is usually a thin film of water running through below or by the sides of a cascade. With its large adhesive disk (fig. 84, B), the tadpole clings tightly to the rock, with the tail directed sidewise by the current. It can slide upward or downward on the slippery surface of a vertical stone or boulder. If there is any disturbance, it releases itself instantly, and drops into the bubbling water.

The coloration of these tadpoles varies slightly on the body but greatly on the posterior half of the tail. The body is olive to olive brown. The round black pupil is enclosed by a golden iris, and this ring is bordered by olive brown. The tail has the same coloration, much lighter toward the tip. There are dorsal and ventral irregular ashy patches. In a few cases, the larger tadpoles have a light gray wash on the tail with scarlet on the posterior half of the tail. The belly is colorless.

\section{Staurois mantzorum: Measurements of Ten Tadpoles}

\begin{tabular}{|c|c|c|c|}
\hline Measurements & Range & Average & $\begin{array}{l}\text { Ratio to } \\
\text { body length (\%) }\end{array}$ \\
\hline Body length...... & $12.3-18.8$ & 14.9 & \\
\hline Body height. & $5.3-7.8$ & 6.5 & 43.8 \\
\hline Body width. & $6.8-9.7$ & 8.3 & 55.6 \\
\hline Head height. & $4.4-6.4$ & 5.4 & 36.3 \\
\hline Head width. & $8.2-10.3$ & 9.0 & 60.3 \\
\hline Tail length. & $21.0-28.5$ & 23.9 & 161.2 \\
\hline Tail height. & $5.8-9.0$ & 7.8 & 52.4 \\
\hline Diameter of tail muscle. & $2.8-5.2$ & 3.8 & 25.4 \\
\hline Length of hind limb. & $9.4-13.5$ & 11.1 & $\ldots$ \\
\hline
\end{tabular}

The average body length from snout to base of tail in ten tadpoles with hind limb-buds averaging $11 \mathrm{~mm}$., is $15 \mathrm{~mm}$. (see table). The body is dorsoventrally flattened, with the snout region depressed. The snout is rounded from above. The nostril, enclosed by a light-colored ring, is much nearer to the eye 


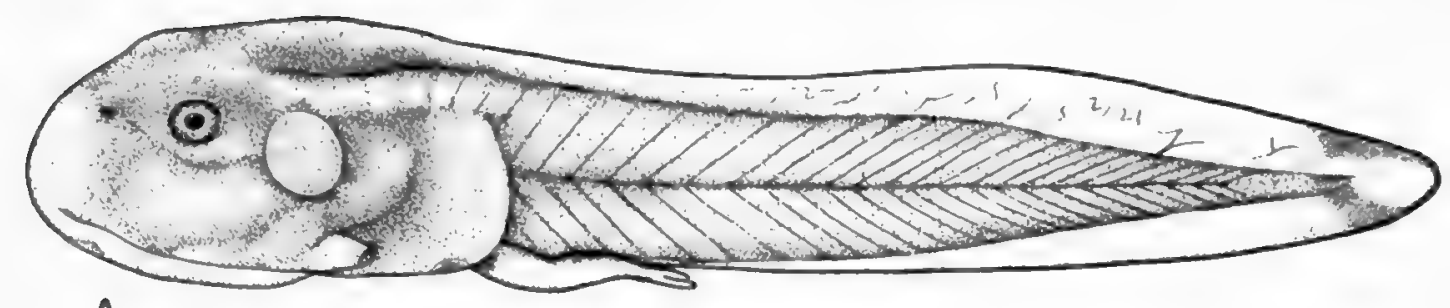

A

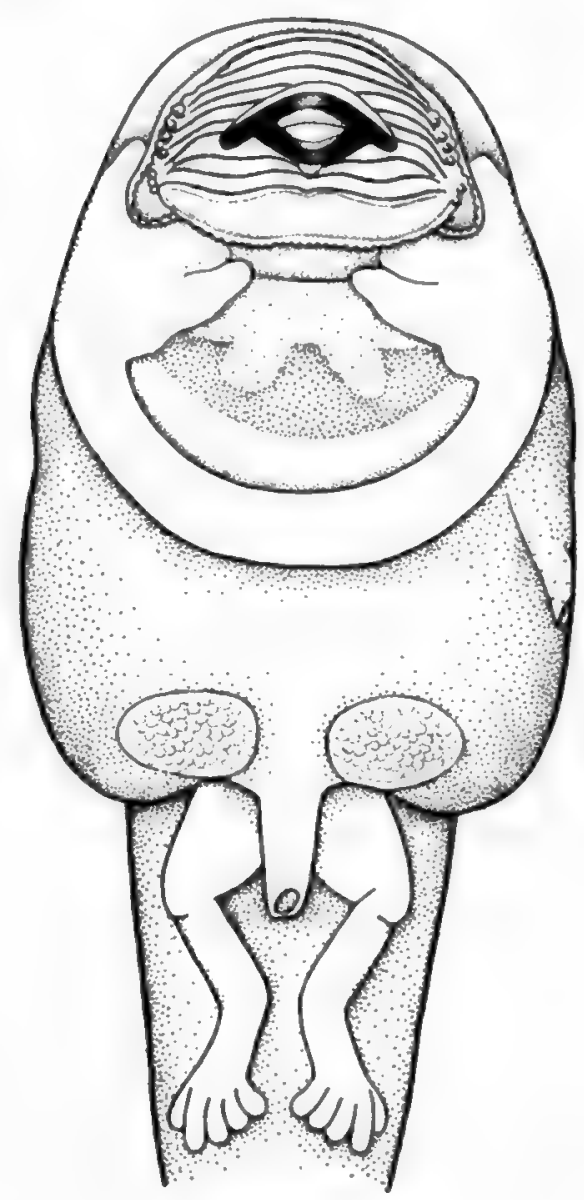

B

Fig. 84. Staurois mantzorum; tadpole. A. Lateral view $(\times 3)$. B. Ventral view $(\times 5)$.

than to the tip of the snout. The eye is latero-dorsal. The spiraculum is sinistral, directed upward and backward, ending in a short tube visible from above and below. There are two pairs of poison glands. The upper pair is symmetrically placed behind and below each eye, and the ventral pair is at the base of the belly. The ventral glands are larger, oval, and narrowly separated. The vent is median and tubular at the base, continuous with the ventral tail fin, with a short pointed free part.

The mouth (fig. 84, B) is ventral. The upper lip is narrow and horseshoeshaped, its long sides turning backward and interlocking with the corners of the 
lower lip, which is straight, broad, much thicker, and notched in the middle. This lower lip functions as the forward margin of the ventral disk. There are two rows of rounded papillae on the upper lip. The outer row is very regular on the margin of most of the lip and the inner row is more or less irregular, with additional papillae between the outer and inner rows. There are some additional papillae at the corners of the mouth. There is only a single row of smaller papillae on the posterior free margin of the lower lip. Labial teeth are well developed. In this species, there are seven rows of teeth on the upper lip; the first row is weak on its mid-margin, but continuous; the second and third rows are continuous and more strongly developed; the remaining four rows are all interrupted, with the innermost row the shortest. There are three rows on the lower lip, the innermost row interrupted and the two outer rows continuous. The mandible is moderately developed and has a serrated edge. There is no variation in the number of rows of labial teeth among the tadpoles of this species. An adhesive ventral disk with a thickened U-shaped rim is well developed behind the mouth; the lower lip forms its anterior part. The anterior tips of the rim are partially covered ventrally by the posterior ends of the upper lip. The ventral disk is broader than long, its width being 60 per cent and its length from the tip to the posterior edge of the rim 54 per cent of the length of the body.

\section{Staurois chunganensis Pope}

Rana chunganensis Pope, 1929, Amer. Mus. Nov., No. 352: 3-Kuatun village, northwestern Chunganhsien, Fukien, 4,500-5,000 feet altitude.

Staurois chunganensis Liu, 1940, Peking Nat. Hist. Bull., 15, pt. 4: 291; idem, 1940, Jour. West China Border Res. Soc., 12, (B): 32.

History of species. - Specimens of a frog collected by Pope at Kuatun village, Chunganhsien, Fukien, in August, 1926, were described by himself as Rana chunganensis in 1929. I found many pairs of these frogs on Mount Omei in July, 1940, and was able to watch the entire development from egg through metamorphosis. As the tadpoles have both the ventral sucker and the poison glands of Staurois tadpoles, it seems preferable to place chunganensis with Staurois instead of with Rana.

Distribution and collection data.-On August 5, 1938, a mated pair of chunganensis was collected in Heilungkiang ("Black Dragon River"), Mount Omei, at 3,400 feet altitude, as they were being carried down by the rapid current. During the next day the female laid 448 white medium-sized eggs in the bag in which the pair had been placed. Another female was obtained on the road at twilight on July 19, 1939, near Tsaochiaying, Tienchuan, Sikang, at an altitude of about 2,500 feet. From July 18 to July 20, 1940, 129 males and 89 females were collected from Shihsunkou, at Fuhusze on Mount Omei, at about 4,000 feet altitude. Other males were collected along the valley, as they were croaking on the stones in the stream, on the banks, or among vegetation not far from the stream. Single individuals are very hard to collect, as they are very active and jump into the water or retreat into the holes on the banks before one can 
reach them. Paired individuals are easy to collect for they are carried by the current to ponds below the cascades in a helpless condition and one can pick them up as they float along. During the summer of 1945, two pairs of chunganensis and six males were obtained from the same stream on Mount Omei. I found Staurois chunganensis in western Szechwan and Sikang, with a vertical distribution from 2,500 feet to 5,000 feet altitude.

Comparison with related species.-Staurois chunganensis (pl. 7, fig. 3) differs from all other Chinese Staurois in the small pointed disks of the fingers and toes (fig. 85), and is distinguished also from all other western Chinese forms by the

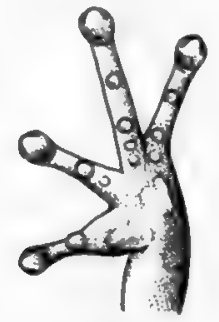

A

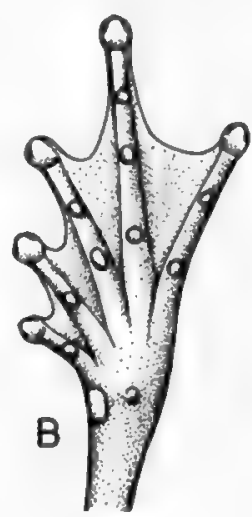

FIG. 85. Staurois chunganensis $(\times 2)$. A. Ventral view of hand. B. Ventral view of foot.

distinct tympanum and paired external vocal sacs in the male. Staurois chunganensis appears to be closely related to Rana montivaga Pope from the same mountain stream, collected at the same time as his chunganensis. They can easily be distinguished by secondary sex characters, as the male of montivaga lacks external vocal sacs and strong nuptial pads, and is much larger than the male of chunganensis.

Original description (as amplified, 1931).- "Vomerine teeth in oblique series, their anterior edges on a line with the centers of the choanae.

"Head scarcely longer than broad, depressed; snout rounded, slightly projecting beyond mouth, about as long as eye; canthus rostralis obtuse; loreal region feebly oblique, concave; nostril barely nearer tip of snout than eye; distance between nostrils as great as interorbital width, which equals that of eyelid; tympanum distinct, about three-fifths diameter of eye, separated from it by a distance equal to half the tympanic diameter.

"Fingers [fig. 85, A] long and slender; first barely as long as second and with a conspicuous nuptial pad on the inner side. Subarticular tubercles well developed, toes [fig. 85, B] with pads similar in form and size to those of fingers, webbed to base of pads on all but longest where webbing barely reaches beyond last subarticular tubercle; outer metatarsals separated nearly to base. Inner metatarsal tubercle oval, feebly prominent, no outer tubercle. 
"Hind limb long and slender, tibio-tarsal articulation reaching to end of snout; heels strongly overlapping when placed at right angles to the body; tibia contained 1.7 times in length of head and body; width of tibia 4.6 times in its length.

"Dorso-lateral fold feeble, especially posteriorly; a glandular fold from below tympanum to shoulder. Skin generally smooth and devoid of tubercles.

"The color is reddish brown above but light beneath, the back covered with very small inconspicuous speckles. A black stripe extends from the tip of the snout to the eye and from behind the eye, where it includes the tympanum, to the base of the thigh. Above, the stripe is bordered by the dorso-lateral fold and it rapidly grows narrow behind the line of the shoulder. A light stripe extends from below the nostril to the shoulder, passing just beneath the eye and tympanum. The limbs are boldly barred above. In life, the posterior region of the belly and ventral aspect of the limbs were light yellow. A large, external vocal sac is present on either side just anterior to the insertion of the forelimbs.

"The type measures $39 \mathrm{~mm}$. from snout to vent."

Staurois chunganensis: Measurements of Fifty Male and Fifty Female Adults

\begin{tabular}{|c|c|c|c|c|}
\hline Measurements & Sex & Range & Average & $\begin{array}{c}\text { Ratio to } \\
\text { body length (\%) }\end{array}$ \\
\hline Body length.... & $\begin{array}{l}\sigma^{7} \\
9\end{array}$ & $\begin{array}{l}34-39 \\
44-54\end{array}$ & $\begin{array}{l}36.5 \\
49.8\end{array}$ & $\ldots$ \\
\hline Head length. . & $\begin{array}{l}0^{7} \\
q\end{array}$ & $\begin{array}{c}12.0-15.5 \\
15-18\end{array}$ & $\begin{array}{l}13.3 \\
16.5\end{array}$ & $\begin{array}{l}36.5 \\
33.3\end{array}$ \\
\hline Head width. & $\begin{array}{l}0 \\
9 \\
q\end{array}$ & $\begin{array}{l}11.8-13.8 \\
15.4-18.0\end{array}$ & $\begin{array}{l}12.7 \\
16.5\end{array}$ & $\begin{array}{l}34.8 \\
33.2\end{array}$ \\
\hline Interorbital space. . & $\begin{array}{l}0^{\lambda} \\
\wp\end{array}$ & $\begin{array}{l}3.0-4.1 \\
3.4-5.0\end{array}$ & $\begin{array}{l}3.3 \\
4.4\end{array}$ & $\begin{array}{l}9.2 \\
8.8\end{array}$ \\
\hline Tympanum. & $\begin{array}{l}0^{7} \\
q\end{array}$ & $\begin{array}{l}2.0-2.8 \\
2.3-3.2\end{array}$ & $\begin{array}{l}2.3 \\
2.6\end{array}$ & $\begin{array}{l}6.3 \\
5.4\end{array}$ \\
\hline Length of lower arm. . & $\begin{array}{l}\sigma^{7} \\
\wp\end{array}$ & $\begin{array}{l}16.5-20.0 \\
22.5-27.0\end{array}$ & $\begin{array}{l}18.2 \\
25.1\end{array}$ & $\begin{array}{l}50.0 \\
50.5\end{array}$ \\
\hline Diameter of lower arm......... & $\begin{array}{l}0^{7} \\
q\end{array}$ & $\begin{array}{l}3.7-5.0 \\
3.3-4.8\end{array}$ & $\begin{array}{l}4.4 \\
4.2\end{array}$ & $\begin{array}{r}12.1 \\
8.5\end{array}$ \\
\hline Length of hand. . & $\begin{array}{l}\sigma^{7} \\
\wp\end{array}$ & $\begin{array}{r}9.5-12.5 \\
12.5-16.5\end{array}$ & $\begin{array}{l}11.0 \\
14.5\end{array}$ & $\begin{array}{l}30.2 \\
29.1\end{array}$ \\
\hline Disk of third finger. & $\begin{array}{l}\sigma^{7} \\
q\end{array}$ & $\begin{array}{l}1.3-1.8 \\
1.7-2.5\end{array}$ & $\begin{array}{l}1.6 \\
2.1\end{array}$ & $\begin{array}{l}4.4 \\
4.2\end{array}$ \\
\hline Length of leg. & $\begin{array}{l}0^{7} \\
\&\end{array}$ & $\begin{array}{l}62-74 \\
85-100\end{array}$ & $\begin{array}{l}66.5 \\
92.6\end{array}$ & $\begin{array}{l}182.4 \\
186.4\end{array}$ \\
\hline Length of tibia.. & $\begin{array}{l}\sigma^{7} \\
\text { q }\end{array}$ & $\begin{array}{c}20-24 \\
27.5-32.5\end{array}$ & $\begin{array}{l}21.4 \\
29.7\end{array}$ & $\begin{array}{l}58.7 \\
59.7\end{array}$ \\
\hline Length of foot and tarsus. . & $\begin{array}{l}\sigma^{7} \\
8\end{array}$ & $\begin{array}{c}28-33 \\
36.5-44.0\end{array}$ & $\begin{array}{l}29.6 \\
41.2\end{array}$ & $\begin{array}{l}81.2 \\
82.9\end{array}$ \\
\hline Length of foot. . & $\begin{array}{l}\sigma^{7} \\
8\end{array}$ & $\begin{array}{l}18.0-21.5 \\
23.5-29.0\end{array}$ & $\begin{array}{l}19.4 \\
26.4\end{array}$ & $\begin{array}{l}53.1 \\
53.2\end{array}$ \\
\hline Disk of fourth toe. & $\begin{array}{l}0^{7} \\
9\end{array}$ & $\begin{array}{l}1.2-1.7 \\
1.5-2.2\end{array}$ & $\begin{array}{l}1.4 \\
1.8\end{array}$ & $\begin{array}{l}3.9 \\
3.7\end{array}$ \\
\hline
\end{tabular}


Secondary sex characters.-Sex dimorphism in size is well marked in chunganensis, the average body length of fifty males being $36.5 \mathrm{~mm}$., and that of fifty females $50 \mathrm{~mm}$. The arm of the male is definitely stronger than that of the female. The male has two subgular external vocal sacs, with two round openings near the angles of the mouth, and has a well-developed nuptial pad with minutely granular surface on the inner dorsal side of the first finger. Lineae masculinae are not developed.

Habitat and habit.-Staurois chunganensis is only found in the water or on the banks near the water of mountain streams during the breeding season. Before and after the breeding season, it is found among or on vegetation on the hillsides far away from the water.

Breeding behavior.-According to Pope's observation in Fukien in 1926, there were two obvious periods of great sexual activity at Kuatun, the first reaching a peak from August 3 to 6, the second from approximately August 22 to 25. During these brief periods, and for a few days before, the males called in great numbers through the day as well as at night, but diligent search for several days revealed only one female and no mated pairs. My field observation of Staurois chunganensis on Mount Omei was somewhat similar. The breeding season is rather definite, easily determined by the croaking of the males. During the summer of 1938, it was about August 5, as paired individuals were collected at that time. During the summer of 1940, it extended altogether from July 18 to August 14. The peak of the breeding season was from July 18 to 20 , as 125 paired individuals were collected in a pond below a cascade of Shisunkou; on July 21, nine more pairs were obtained from the same place, and afterward only a few pairs could be collected in a day. No croaking was heard after August 14. During the breeding season the males of this species are very active. Their croaking is very beautiful, sometimes like a Chinese mountain bulbul's voice, sometimes like the music of a cricket, sometimes like a young chick peeping at twilight. Some males were found croaking on the twigs of bushes or trees on the banks of the mountain streams.

Sex recognition depends on the croaking and kicking of a male when another male tries to grasp him, while the female ready for egg-laying gives no repulsive reaction when a male attempts to clasp her. The amplexus is of the axillary type, with fingers curved up at the postero-lateral angle of the coracoid of the female. When paired, the female carries the male on her back, jumping from stone to stone in the stream. There are many tragedies. If a male tries to grasp already paired individuals, the mated female may escape from the second male by jumping into the water. If she jumps into the rapid current of the stream, the pair can not stop themselves and may be carried by the current as much as a mile, as I collected paired individuals far below the breeding site on the same stream. Dead females were found quite frequently, with the body wall ruptured and the egg-mass outside of the body cavity. This might be the result of the strong embrace during a struggle in the rapid water, as no dead males were found in the stream. 
The egg-laying process was observed in our field station from collected mated pairs. At the time of egg-laying the female raises her vent, with head pointed downward in the water. Then she presses her vent against the wall of the jar. This process may be repeated several times before egg-laying begins. At the time of egg-laying, the tibio-tarsal joint of the female is turned mediodorsad and the foot pointed latero-ventrad, with webs fully spread out, while the legs of the male are bent so that the tibio-tarsal joints meet medio-dorsally, with the feet separated. Thus a triangular space is formed to direct the sperm and enclose the eggs after they are laid. By pressure of the vent of the female, the eggs are attached to the substrate. It takes only half a minute to finish the egg-laying process. Eggs come out in groups, from our observation generally in five groups. The shape of the egg-masses is rather uniform, mostly an elongated flattened band with a concave center corresponding to the position of the vent of the female. Ten masses of eggs were measured, their length ranging from 50 to $78 \mathrm{~mm}$. (average $68 \mathrm{~mm}$.); their diameter from 24 to $31 \mathrm{~mm}$. (average $27 \mathrm{~mm}$.); and their thickness from 8 to $13 \mathrm{~mm}$. (average $11 \mathrm{~mm}$.). Four eggmasses counted contained 417, 420, 421, and 488 eggs, respectively. The eggs are rather large, with a diameter of $2.8 \mathrm{~mm}$., and are white. The whole egg-mass is firmly attached to the substrate by jelly, and the eggs are also connected with each other. There is only a single layer of jelly enveloping each egg.

After egg-laying the male remains on the back of the female. The female rids herself of the male by shaking her hind limbs up and down and elongating her body to decrease its diameter; if the male still will not release, the female arches her body downward, as described for Hyla andersonii by Aronson (1943). The male may croak and try different ways to hold the female, but at last he releases her. After egg-laying, females evidently hide themselves under stones or among the vegetation, as not a single female was found anywhere along the valley. The males tried to find a second and perhaps a third female with which to mate.

Egg-masses are found in stationary water back of large stones or at the bend of a stream where there is no rapid current. Scattered eggs are also found, which is perplexing, since we turned many stones and looked into many holes along the mountain stream where we collected so many paired individuals without finding egg-masses. Perhaps the egg-masses were attached to the under surface of stones in deep water where we could not reach them.

As Staurois chunganensis breeds in running water of large mountain streams, the eggs can hardly develop normally in stationary water or in a jar. More than thirty egg-masses were laid in our room, and one or two were kept in separate jars. The water, from clear streams, was changed every day. The early cleavage proceeded normally, as in other frogs, taking half a day to reach the sixteen cell stage, and about a day to the morula. After this the jelly became hardened and the development was abnormal. Very few of them reached the neural groove stage. Three egg-masses were placed in cases screened by cloth 
and supported by wire and put into streams of running water back of large stones outside of Taosze. The eggs developed normally, the incubation period being from twelve to fourteen days. Another three masses of eggs were placed back of the temple in a water reservoir with slow current. The incubation period was shorter than that in the stream, taking only from eight to ten days, but many of the embryos died, as the jelly hardened in the later stages of development. The lower temperature of the water in the stream accounts for the longer incubation period. The eggs in our cloth cages in the stream were attacked by large planaria, which ate up more than half of the embryos, though they were removed from the cages once or twice a day.

Just after hatching, the embryo is still helpless. It cannot swim around and it attaches itself to the bottom or lies on its side. It is absolutely white. As it hatches out in an early stage, only very short external gills and black pigment for the eye are to be seen. A day after hatching, black pigment is found on the dorsal side of the head and on the antero-dorsal part of the body. Four days after hatching, the ventral adhesive sucker is well differentiated and the body becomes much darker.

On the afternoon of August 20, 1940, hundreds of small tadpoles were collected from the same mountain stream where many paired individuals had been collected from July 18 to 20 of the same year. Most of them were found between or beneath small stones in shallow, comparatively slow-running water. Some were found attached to the free surface of the stones, with the body adhering tightly to the stone and the tail forced sidewise by the current. They are very sensitive to disturbance, releasing themselves and dropping into the current and disappearing in a moment.

Tadpole.-Mature tadpoles (fig. 86) are found in mountain streams attached to the free surfaces of large stones, or hiding themselves between or beneath small stones in comparatively shallow running water. When they adhere to a stone below a cascade, their snouts face the cascade and their tails wriggle sideways in the force of the current. If there is any disturbance they release themselves, drop into the current, and disappear. The tadpole can slide from place to place on the surface of the stone without releasing the body. This action is performed by the large ventral adhesive disk (fig. $86, \mathrm{~B}$ ), which operates together with the toothless part of the broad lower lip. The tadpoles are found in Heilungkiang and Shihsunkou and one tadpole was collected by $\mathrm{H}$. W. Chang from a mountain stream near Nanyaomiao, Wenchwan, about twenty miles northwest of Kwanhsien.

The coloration of the tadpoles varies greatly. There are two common types, one varying from light to dark gray and the other from light to dark brown. Besides these, there are some peculiar combinations and patterns. Some of the gray tadpoles have a white reversed $\mathrm{V}$-shaped mark from the nostril region to the eyes, and brown tadpoles occur with a similar brilliant brown mark. The pupil is round and black and is enclosed by a thin golden ring, which is 
surrounded by a wide iris whose color corresponds to the color of the body. Brown or gray tadpoles may have a wide black band behind the eye and a similar band at the base of the tail. The tail may be marbled near the middle by light patterns between the dorsal fin and the muscle; in a few cases this may extend the length of the tail. This character is rarely found in uniformly colored

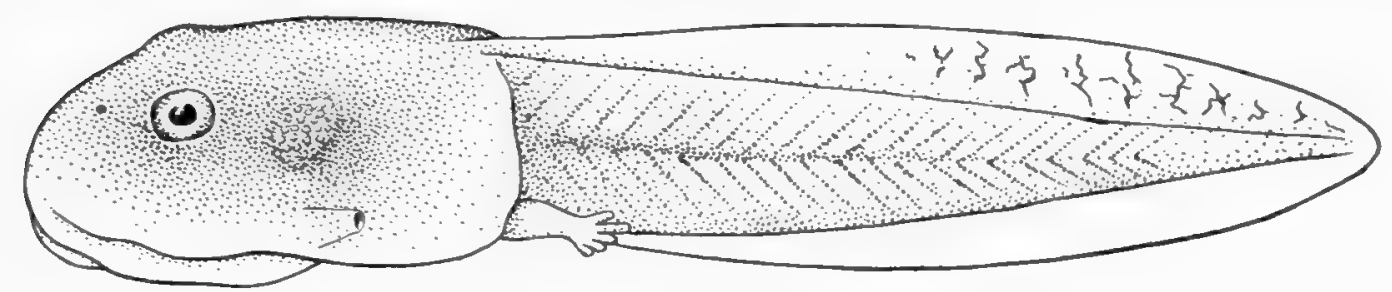

A

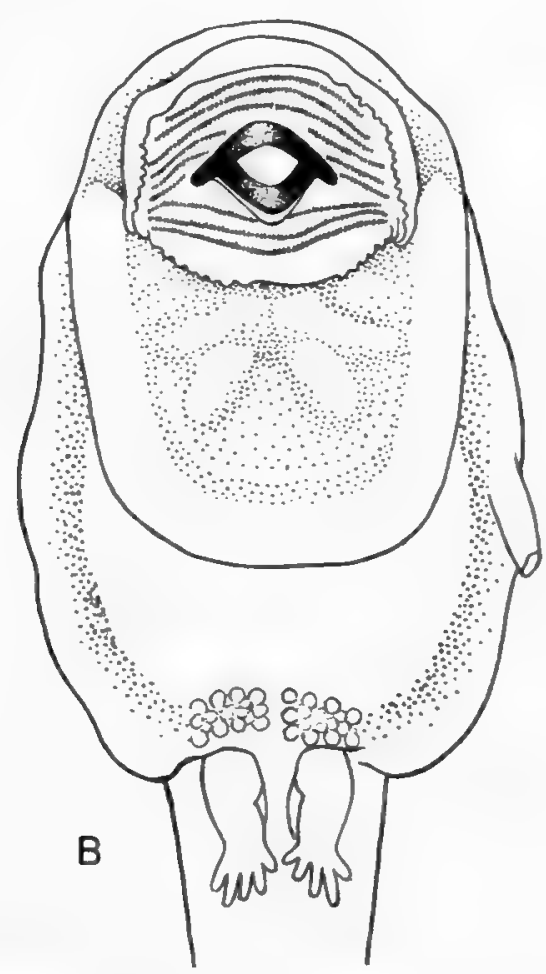

FIG. 86. Staurois chunganensis; tadpole. A. Lateral view $(\times 4)$. B. Ventral view $(\times 6)$.

tadpoles; it is common in those with the reversed V-shaped mark on the head. The throat and front of the belly are pinkish gray, giving way to whitish gray behind, the former being due to abundant blood and the latter to the color of the intestine.

Tadpoles with hind legs well differentiated are much smaller than those of Staurois mantzorum of equal age, the total length including body and tail being only $35 \mathrm{~mm}$. Measurements (with percentage of body length in parentheses) are: body length $12.6 \mathrm{~mm}$.; body height $6.0 \mathrm{~mm}$. (47.4); body width $8.0 \mathrm{~mm}$. (63.4); head height $5.4 \mathrm{~mm}$. (42.8); head width $7.8 \mathrm{~mm}$. (61.9); mouth width $5.4 \mathrm{~mm}$. (42.8); snout to spiraculum $9.3 \mathrm{~mm}$. (73.7); tail length $22.0 \mathrm{~mm}$. (174.5); 
tail height $6.7 \mathrm{~mm}$. (53.1); diameter of tail muscle $3.7 \mathrm{~mm}$. (29.3); length of hind limb $3.5 \mathrm{~mm}$.

The front of the body is flattened below, where the adhesive disk is developed. The snout is more or less square, and much more conspicuous in young tadpoles. The nostril is nearer to the eye than to the snout tip and is enclosed by a lightcolored ring. The eyes are more dorsal than lateral and nearer to the snout than to the base of the tail; the space between them is about one-third of the body length. In very young tadpoles this space contains two glands, which grow until they reach each other and fuse into one. The spiraculum is sinistral, ending with a tube directed upward and backward and visible from above and below. Its distance from the tip of the snout is 74 per cent of the body length. The vent is median and tubular, about one-third of its total length being free.

The mouth (fig. 86, B) is ventral, with a single interrupted row of papillae on the upper lip continued along the free margin of the lower lip. Six rows of teeth are developed in the upper lip, the outer three rows continuous, and the inner three rows interrupted; the outermost row is weakly developed on the free margin. On the lower lip, there are three rows of labial teeth, the innermost interrupted and the other two rows continuous. The mandible is moderately developed and has a fine serrate edge. Posterior to the mouth is the large adhesive ventral disk, which is horseshoe-shaped, with a central depression and a broad rim-fold of skin that forms the posterior and lateral margins of the disk. Anteriorly the rim ends at the mouth, with its inner edge overlapped by the corners of the upper lip. The broad free part of the lower lip closes the front of the disk. This disk is used by the tadpoles as a shallow vacuum cup with which to adhere to the stones in swift mountain streams. Its length and diameter are slightly more than half of the length of the body.

\section{Staurois lifanensis Liu}

Staurois lifanensis Liu, 1945, Jour. West China Border Res. Soc., 15, (B): 33-Nankou, Lifan City, Lifan, Szechwan.

History of species.-Ten females and six males were collected in Lifanhsien during the summer of 1941 and described as Staurois lifanensis in 1945.

Distribution and collection data.-Staurois lifanensis is an endemic form of northwestern Szechwan, with a vertical distribution ranging from 4,000 to 7,000 feet. From the end of July to the end of August, 1941, sixteen females and six males and tadpoles of different stages were collected from Nankou, Lifan City, and in the lower region of Mengtunkou in Lifan. Tadpoles and young adults were obtained in a stream near Tsakunao (6,000 feet altitude), Lifan, from August 1 to August 3, 1941. When we returned to Chengtu from this trip, $\mathrm{Mr}$. H. C. Chang collected a male specimen near Yenhsingping, Wenchwanhsien. A female was collected by Mr. K. F. Cheng from Tsaopo, Wenchwanhsien.

Eight specimens (U.S.N.M. Nos. 107460, 107461, 107514, 107515, and 107524, males; and 107458, 107459, and 107523, females) were collected by D. C. 
Graham at Kwanhsien and Weichow from July to August, 1938, and identified by Stejneger as Rana jugans. Examination of these specimens shows that they are typical Staurois lifanensis.

Comparison with related species.-Staurois lifanensis (pl. 7, fig. 5) differs from all other species of the genus in having dark blotches with irregular outlines on the back. These blotches are similar to those of Staurois himalayana, but with more diffused outline on a darker background. The male of lifanensis is
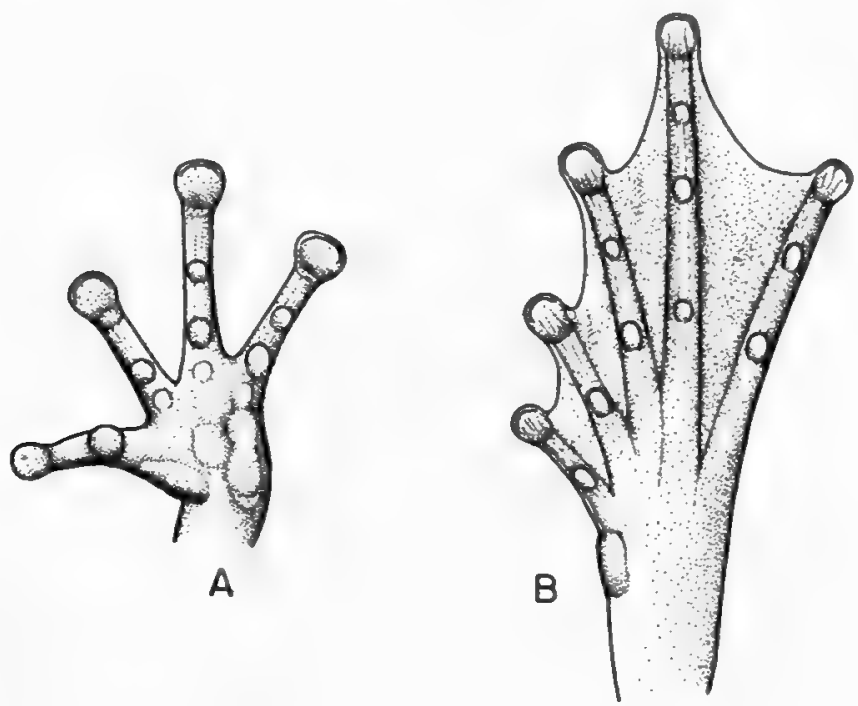

FIG. 87. Staurois lifanensis $\left(\times 1 \frac{1}{2}\right)$. A. Ventral view of hand. B. Ventral view of foot.

much smaller than that of himalayana, and has no vocal sac, whereas himalayana has a vocal sac. The tibio-tarsal articulation of lifanensis reaches beyond the nostril, and to beyond the snout in himalayana.

Original description. - "Vomerine teeth in oblique series, their latero-anterior ends on a line with the posterior border of the choanae.

"Head slightly longer than broad, depressed; snout rounded, projecting beyond the mouth, slightly shorter than the eye; canthus rostralis obtuse; loreal region strongly concave and oblique; nostrils mid-way between the eye and the tip of the snout; internasal space much greater than the interorbital width, which equals the width of the upper eyelid; tympanum distinct, about one-fourth the length of the eye, which in life is reddish in color below.

"The length of the lower arm about half of the body length; fingers [fig. 87, A] rather long, the first nearly as long as the second, and the fourth shorter than the third, but longer than the first and second; subarticular tubercles well developed; the finger disks wider than those of the toes, with distinct grooves separating the upper from the lower surfaces.

"Hind limb long and rather slender, the tibio-tarsal articulation reaching beyond the nostril; heels overlapping when femora are placed at right angles 
to the body; length of tibia about 65 per cent of the body length; toes [fig. 87, B] with distinct subarticular tubercles and their disks similar to those of the fingers but smaller; webs fully developed to the bases of all the disks; inner metatarsal tubercle oval; no outer metatarsal tubercle.

"No dorso-lateral fold, but a feeble glandular fold present from the posterior corner of the eye to the shoulder. Skin with glandular granules."

Coloration.--Color less variable than in mantzorum; male and female similar. Ground color of back from bluish gray to olive brown stippled with black; brown to black patterns on the body and limbs; eye with horizontally oval black pupil, the iris with the upper half golden, the lower half golden with red; throat and thoracic region ashy; belly white; ventral sides of limbs light gray-white; web stippled with ashy. Some specimens with ashy markings on anterior and lateroventral sides of body. In formalin, the color becomes dull and the brown markings are obscure on the gray ground color, and the reddish color of the lower eyeball is lost.

Staurois lifanensis: Measurements of Five Male and Ten Female Adults

\begin{tabular}{|c|c|c|c|c|}
\hline Measurements & Sex & Range & Average & $\begin{array}{c}\text { Ratio to } \\
\text { body length (\%) }\end{array}$ \\
\hline Body length....... & $\begin{array}{l}0^{7} \\
8\end{array}$ & $\begin{array}{l}52-56 \\
61-79\end{array}$ & $\begin{array}{l}54.2 \\
71.1\end{array}$ & $\ldots$ \\
\hline Head length. & $\begin{array}{l}\sigma^{7} \\
q\end{array}$ & $\begin{array}{l}18.0-19.5 \\
21-27\end{array}$ & $\begin{array}{l}18.7 \\
24.3\end{array}$ & $\begin{array}{l}34.4 \\
34.2\end{array}$ \\
\hline Head width...... & $\begin{array}{l}\sigma^{7} \\
\$\end{array}$ & $\begin{array}{c}18-19 \\
20.5-26.0\end{array}$ & $\begin{array}{l}18.5 \\
24.0\end{array}$ & $\begin{array}{l}34.1 \\
33.7\end{array}$ \\
\hline Interorbital space.... . & $\begin{array}{l}07 \\
8\end{array}$ & $\begin{array}{l}4.5-5.0 \\
5.0-6.8\end{array}$ & $\begin{array}{l}4.7 \\
5.7\end{array}$ & $\begin{array}{l}8.7 \\
8.0\end{array}$ \\
\hline Tympanum. & $\begin{array}{l}0 \\
8\end{array}$ & $\begin{array}{c}2-3 \\
1.2-2.2\end{array}$ & $\begin{array}{l}2.4 \\
1.8\end{array}$ & $\begin{array}{l}4.5 \\
2.6\end{array}$ \\
\hline Length of lower arm. . & $\begin{array}{l}07 \\
8\end{array}$ & $\begin{array}{l}25-27 \\
31-38\end{array}$ & $\begin{array}{l}26.4 \\
34.8\end{array}$ & $\begin{array}{l}48.7 \\
48.9\end{array}$ \\
\hline Diameter of lower arm. . & $\begin{array}{l}9 \\
9\end{array}$ & $\begin{array}{c}6.5-7.5 \\
6-8\end{array}$ & $\begin{array}{l}7.0 \\
7.0\end{array}$ & $\begin{array}{r}12.9 \\
9.8\end{array}$ \\
\hline Length of hand. . & $\begin{array}{l}07 \\
\$\end{array}$ & $\begin{array}{c}16-17 \\
19.0-23.5\end{array}$ & $\begin{array}{l}16.5 \\
21.7\end{array}$ & $\begin{array}{l}30.4 \\
30.5\end{array}$ \\
\hline Disk of third finger.... & $\begin{array}{l}7 \\
9\end{array}$ & $\begin{array}{l}2.4-3.0 \\
2.8-4.0\end{array}$ & $\begin{array}{l}2.7 \\
3.2\end{array}$ & $\begin{array}{l}5.0 \\
4.6\end{array}$ \\
\hline Length of leg. & $\begin{array}{l}0^{7} \\
\text { \& }\end{array}$ & $\begin{array}{r}94-103 \\
112-132\end{array}$ & $\begin{array}{r}97.4 \\
124.6\end{array}$ & $\begin{array}{l}179.7 \\
175.2\end{array}$ \\
\hline Length of tibia. & $\begin{array}{l}7 \\
9\end{array}$ & $\begin{array}{l}30-33 \\
37-44\end{array}$ & $\begin{array}{l}31.8 \\
40.5\end{array}$ & $\begin{array}{l}58.7 \\
57.0\end{array}$ \\
\hline Length of foot and tarsus....... & $\begin{array}{l}\text { o } \\
8\end{array}$ & $\begin{array}{l}42-46 \\
51-64\end{array}$ & $\begin{array}{l}43.6 \\
55.2\end{array}$ & $\begin{array}{l}80.4 \\
77.6\end{array}$ \\
\hline Length of foot. . & $\begin{array}{l}0^{7} \\
\text { \& }\end{array}$ & $\begin{array}{l}29-31 \\
35-40\end{array}$ & $\begin{array}{l}30.0 \\
38.5\end{array}$ & $\begin{array}{l}55.4 \\
54.1\end{array}$ \\
\hline Disk of fourth toe. & $\begin{array}{l}0^{x} \\
8\end{array}$ & $\begin{array}{l}2.0-2.8 \\
2.2-3.2\end{array}$ & $\begin{array}{l}2.4 \\
2.9\end{array}$ & $\begin{array}{l}4.5 \\
4.0\end{array}$ \\
\hline
\end{tabular}

Measurements of type (percentage of body length in parentheses).--Body length $72 \mathrm{~mm}$.; head length $25 \mathrm{~mm}$. (35); head width $25 \mathrm{~mm}$. (35); interorbital 
space $6 \mathrm{~mm}$. (8); tympanum $2 \mathrm{~mm}$. (3) ; length of lower arm $36 \mathrm{~mm}$. (50); diameter of lower arm $6.5 \mathrm{~mm}$. (9); length of hand $22 \mathrm{~mm}$. (30); disk of third finger $3 \mathrm{~mm}$. (4); length of leg $132 \mathrm{~mm}$. (183); length of tibia $42 \mathrm{~mm}$. (58); length of foot and tarsus $57 \mathrm{~mm}$. (79); length of foot $39 \mathrm{~mm}$. (54); inner metatarsal tubercle $4 \mathrm{~mm}$. (6); disk of fourth toe $3 \mathrm{~mm}$. (4).

Sex dimorphism.-Females of lifanensis are larger than males (see table). The arm of the male is distinctly stronger than that of the female, and there is a strong nuptial pad on the inner dorsal side of the first finger. No lineae masculinae or vocal sacs are developed.

Habitat and habits.-Staurois lifanensis is found on stones in the running water of mountain streams or by the sides of the streams. Near Lifan City, these frogs are found together with Staurois mantzorum. Occasionally lifanensis was found on stones in large streams, which is not true of mantzorum.

No eggs or paired individuals of lifanensis were found.

Tadpole.-Many tadpoles (pl. 10, fig. 12) and individuals at different stages through metamorphosis were found in the river of Mengtunkou and Nankou, Lifan. That these are tadpoles of Staurois lifanensis, not mantzorum, is shown by direct check of metamorphosed individuals.

The habitat of the tadpoles of lifanensis is similar to that of those of Staurois kangtingensis. I found them more abundant in the shallow running water of large mountain streams than under cascades. They are active and sensitive, hiding themselves between and beneath the stones like the torrent fish Hemimyzon.

The head and body are depressed, especially anteriorly, the back is rounded, and the ventral side flattened. The snout is depressed, broad and rounded in outline as seen from above and below. The nostril is dorsal, enclosed by a ring, and is about mid-way between the tip of the snout and the anterior corner of the eye. The eyes are more dorsal than lateral, and the interorbital space is slightly greater than the internasal space. The spiraculum is sinistral, directed upward and backward, with a short free tube visible from above and below. It is nearer to the base of the tail than to the tip of the snout. There are two pairs of poison glands, the post-otic rounded and about twice as large as the eye, and the post-abdominal oval, with a length of $5 \mathrm{~mm}$., and not meeting the gland on the other side. The tail is about twice as long as the body, and the muscular portion is strongly developed. The tail fin is low and thick, with a rounded tip. The tail fin decreases in height toward the base of the tail, and there is no fin dorsally and ventrally for about $4 \mathrm{~mm}$.

The tadpole of lifanensis is olive green above, the muscular portion of the tail being pigmented with black and yellow. The tail fin is light scarlet, with an intensively pigmented cardinal semicircular area near its tip. The belly is unpigmented. After preservation, the body is dull greenish black, as is the muscular portion of the tail, and the beautiful scarlet and cardinal colors disappear. 


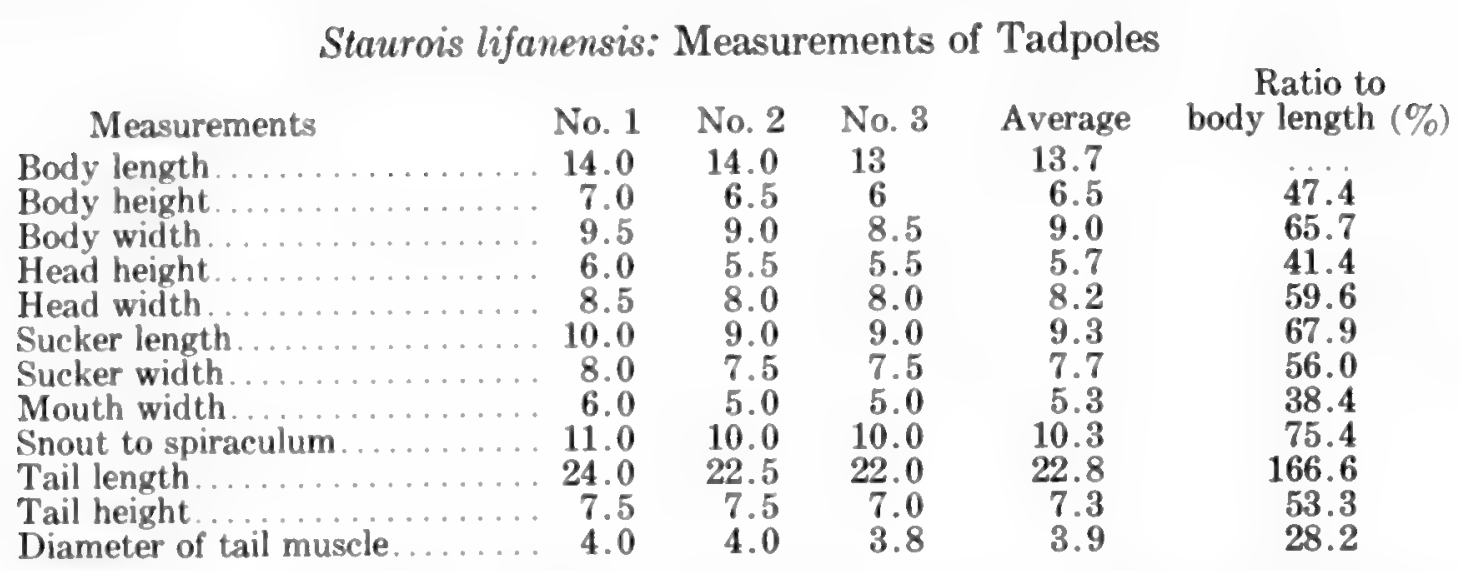

The mouth (fig. 88) is ventral. A single row of flattened papillae is developed on the margin of the latero-posterior portion of the upper lip, with a much

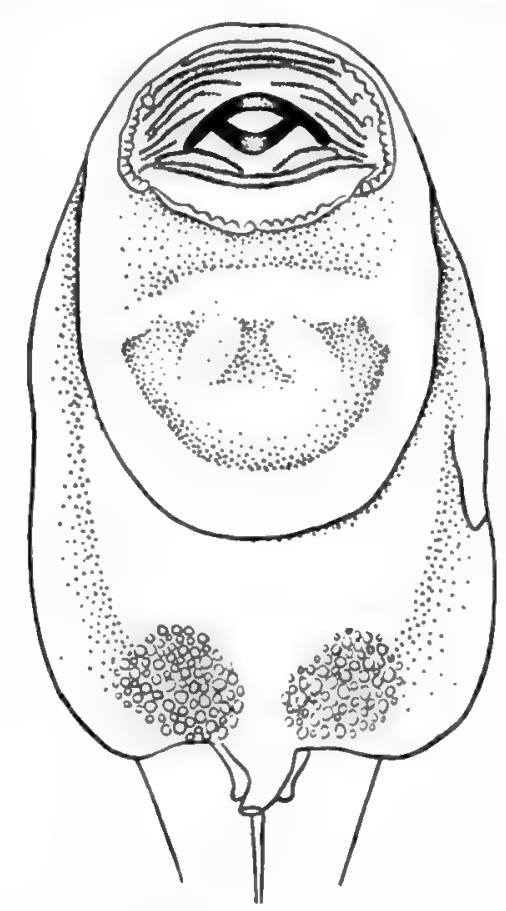

FIG. 88. Staurois lifanensis; ventral view of tadpole $(\times 5)$.

shorter inner row of rounded papillae near the posterior corners of the upper lip. The free margin of the lower lip has a row of flattened papillae and there are some extra large low papillae on the antero-inner portion of the lower lip. There are seven rows of labial teeth on the upper lip, the outermost row very weak opposite the margin of the upper lip, where it is free from papillae; the next two rows are better developed and continuous, and the four inner rows are interrupted. Three rows of labial teeth are developed in the lower lip, the innermost interrupted and the two outer rows continuous. The mandible is moderately developed, with a serrated edge. Behind the mouth is a large adhesive sucker 
enclosed by a horseshoe-shaped rim, the antero-lateral free ends of which are overlapped by the posterior corners of the upper lip. The diaphragmatobranchiamedialis muscles are oval, converging anteriorly to meet the diaphragmatoprecordalis anteriorly.

\section{Staurois kangtingensis sp. nov.}

Type.-No. 49412 Chicago Natural History Museum, from Kangting, Sikang, 8,000 feet altitude. Adult female, collected by C. T. Chin.

Diagnosis.-A distinct species of Staurois (pl. 7, fig. 4), distinguished by a visible large flattened gland on the postero-ventro-median part of the lower arm in the female; and in the male by the size of the disk of the fourth toe, which is usually without a complete horizontal groove and equal to the width of the toe and its lateral fringes near the base of the disk.

Description of type.-Body stout. Head nearly as broad as long; snout rounded, projecting beyond the mouth; nostril about mid-way between the tip of the snout and the anterior corner of the eye; canthus rostralis obtuse; loreal region oblique, with a deep groove from below and in front of the nostril to the upper anterior part of the lower eyelid; interorbital space smaller than internasal space and equal to the width of the upper eyelid; tympanum obscure, covered with ordinary skin with fine granules; an elevated light-colored spot on top of the head, in line with the anterior borders of the eyes; tongue large, deeply notched behind, and with many large rounded papillae above; vomerine tooth patches small, oblique, with teeth 4-4, separated by a space about one-third the length of one of the series; the outer ends of the tooth series about in line with the posterior corners of the choanae.

Arm rather strong, with long fingers (fig. 89, A); the third finger longest, the fourth finger reaching the base of the disk of the third finger, the second finger shorter than the fourth and reaching the anterior border of the distal subarticular tubercle of the third, the third finger equal to the second; the three outer fingers provided with large disks; the tip of the first finger enlarged and flattened, but without a horizontal groove; subarticular tubercles well developed, two supernumerary tubercles on the right hand and three on the left; a long outer and a rounded inner tubercle on the palm; the inner ventral basal part of the first finger provided with a long pad.

Legs long and strong, the tibio-tarsal articulation reaching beyond the eye; heels overlapping when placed at right angles to the body; toes (fig. 89, B) fully webbed, 4-5-3-2-1 in order of length, all with disks; the width of the disk of the fourth toe not wider than the toe and its lateral fringes near the base of the disk; subarticular tubercles well developed; inner metatarsal tubercle small, oval, and flat, without a free edge; no outer metatarsal tubercle.

Skin rugose laterally, small rounded warts scattered on top of the head and body, and many larger granules on the sides of the neck and body and around the vent; crowded larger granules on the base of the thighs at the rear; a very 
well-marked glandular fold extending obliquely from the posterior corner of the eye to the arm, where it meets another well-marked glandular fold extending from the angle of the mouth.

Coloration in alcohol.--Dark greenish blue above; small dark spots covering small round warts on the back, connected by light brown to form a network; irregular dark bars on the limbs; throat dark gray; thorax and sides of the belly marbled with gray; belly and ventral sides of the limbs light.

Coloration in life.--Deep dull yellow-green above, with small black spots covering the small rounded warts and connected by light brown to form a net-
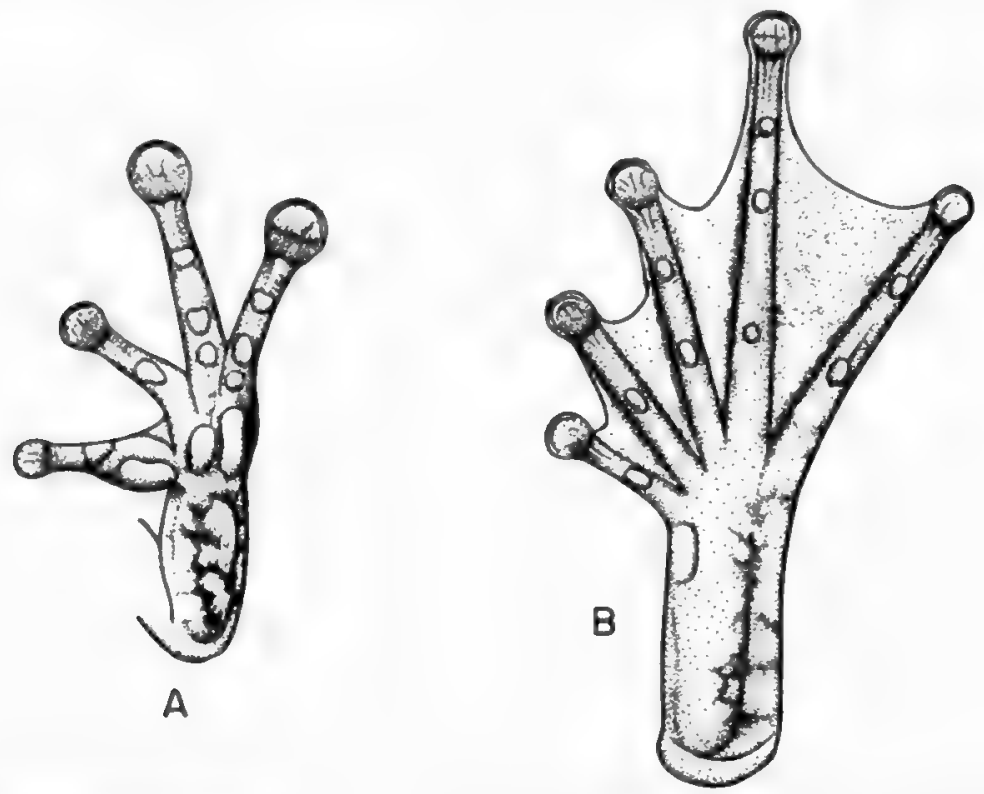

FIG. 89. Staurois kangtingensis $(\times 2)$. A. Ventral view of hand. B. Ventral view of foot.

work; sides marbled with black; irregular black bars on the limbs; throat dark gray; thorax and sides of the belly marbled with gray, belly and ventral sides of the limbs cream-yellow; webs yellowish-orange; pupil black, horizontally oval, enclosed by golden yellow, with red on its ventral half.

Measurements of type.-Body length $53 \mathrm{~mm}$.; head length $17 \mathrm{~mm}$.; head width $17 \mathrm{~mm}$.; length of lower arm $27 \mathrm{~mm}$.; length of hand $18 \mathrm{~mm}$.; disk of third finger $3 \mathrm{~mm}$.; length of leg $100 \mathrm{~mm}$.; length of tibia $33 \mathrm{~mm}$.; length of foot and tarsus $46 \mathrm{~mm}$.; length of foot $33 \mathrm{~mm}$.; disk of fourth toe $2 \mathrm{~mm}$.

Discussion of paratypes.-From July 17 to 20, 1942, five adult females, sixteen adult males and two young were collected with the type along the bank of the Yalakou, inside of Kangting City. Four specimens were obtained along the Tatu River, at 4,500 feet altitude, near Luting City, on July 5; one was collected from Chuwo, 11,000 feet altitude, Luhohsien, and one from Hsintuchiao, 11,200 feet altitude, Sikang. This new Staurois is an endemic form of Sikang Province, found from Luting to Luho, with a vertical distribution ranging from 4,500 to 11,200 feet altitude. 
Staurois kangtingensis: Measurements of Three Female Adults*

\begin{tabular}{|c|c|c|c|c|c|}
\hline Measurements & $\begin{array}{l}\text { No. } \\
582\end{array}$ & $\begin{array}{l}\text { No. } \\
581\end{array}$ & $\begin{array}{l}\text { No. } \\
937\end{array}$ & Average & $\begin{array}{l}\text { Ratio to } \\
\text { body length }(\%)\end{array}$ \\
\hline Body length. & 74.0 & 73.0 & 70.0 & 72.3 & \\
\hline Head length. & 24.0 & 23.0 & 23.0 & 23.3 & 32.2 \\
\hline Head width. & 25.0 & 24.5 & 23.5 & 24.3 & 33.6 \\
\hline Length of lower arm. & 37.0 & 38.0 & 36.0 & 37.0 & 51.1 \\
\hline Diameter of lower arm. & 7.5 & 7.5 & 7.0 & 7.3 & 9.9 \\
\hline Length of hand. & 25.0 & 24.0 & 24.0 & 24.3 & 33.6 \\
\hline Disk of third finger. & 4.5 & 4.0 & 4.0 & 4.1 & 5.6 \\
\hline Length of leg. & 135.0 & 137.0 & 129.0 & 133.6 & 184.8 \\
\hline Length of tibia. & 43.0 & 43.0 & 41.0 & 42.3 & 58.5 \\
\hline Length of foot and tarsus. & 58.0 & 60.0 & 56.0 & 58.0 & 80.2 \\
\hline Length of foot. & 42.0 & 42.0 & 40.0 & 41.3 & 57.1 \\
\hline Disk of fourth toe & 3.0 & 3.0 & 3.2 & 3.0 & 4.1 \\
\hline
\end{tabular}

* Liu Collection.

Staurois kangtingensis: Measurements of Four Male Adults*

$\begin{array}{lrrrrrc}\text { Measurements } & \text { No. } & \text { No. } & \text { No. } & \text { No. } & & \begin{array}{c}\text { Ratio to } \\ \text { Average }\end{array} \\ \text { body length }(\%)\end{array}$

* Liu Collection.

Sex dimorphism in size is clear, males being much smaller than females. Very strong nuptial pads are present on the inner dorsal side of the first finger of the male, and the arm is much stronger than that of the female. Males have no vocal sacs or lineae masculinae.

Habitat and habits.-Staurois kangtingensis is found along large and small mountain streams with swift water, but without cascades, the stream thus differing from the type in which mantzorum and lifanensis are generally found. We found all of our kangtingensis in the evening; other species of Staurois of western China were collected in the daytime as well as in the evening.

No eggs or breeding pairs were found.

Tadpoles.-Tadpoles were found in swift water but not at cascades. It is almost impossible to see this tadpole in the stream.

The body of the tadpole (fig. 90) is depressed, especially at the head. The snout is broad, depressed, and rounded from above and below. The nostril, enclosed by a ring, is dorsal and nearer to the eye than to the tip of the snout. The eyes are more dorsal than lateral, and the interorbital space is greater than the internasal space. The spiraculum is sinistral, directed upward and backward, and ending in a narrow free tube visible from above and below. It is nearer 
the base of the tail than the tip of the snout. The tail is long and strong, and the tail fin is rather thick, with a rounded tip, decreasing in height toward the base of the tail; there is no fin dorsally and ventrally for about $5 \mathrm{~mm}$. from the base of the tail. There are two pairs of poison glands. Of these the post-otic are rounded

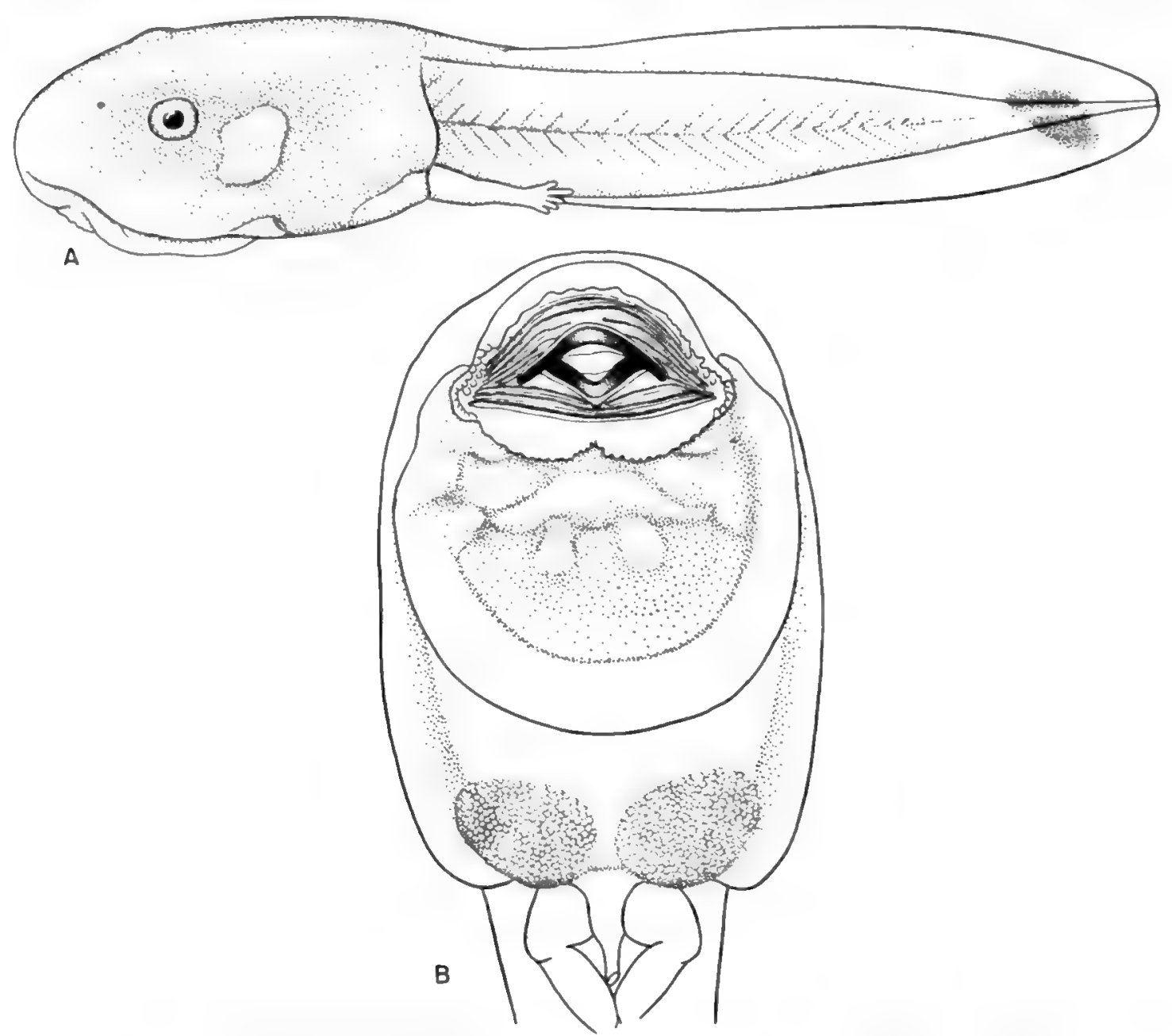
$(\times 4)$.

FIG. 90. Staurois kangtingensis; tadpole. A. Lateral view $\left(\times 2 \frac{1}{2}\right)$. B. Ventral view

and twice as large as the orbit. The post-abdominal poison gland is oval, $6 \mathrm{~mm}$. in length, and meets its fellow near the base of the vent.

The color on the body and the muscular portion of the tail is grayish olive green. The tail fin and the belly are cream-yellow, the fin being spotted with olive green. In a few cases, the tip of the tail has an intensively pigmented semicircular area, with a cardinal or yellowish orange tip continuous with the olive green muscular portion. After preservation, the back and the muscular portion of the tail are dull greenish black; the belly is colorless and there is some dull gray stippling on the tail. Near the tail tip, the semicircular dark color is still distinguishable. 
The mouth (fig. 90, B) is ventral. There is one row of somewhat flattened papillae on the latero-posterior portion of the margin of the upper lip, with another row of larger rounded papillae inside the marginal row near the corners. There is a single row of flattened papillae on the free margin of the lower lip, with a few large rounded low papillae on the inner dorsal side. There are seven rows of labial teeth in the upper lip, the outermost continuous and weakly developed on the margin of the lip, the next two rows continuous, and the four inner rows interrupted. On the lower lip, there are three rows, the innermost interrupted. The mandible is moderately developed, with serrated edges. Behind the mouth is a large adhesive sucker enclosed behind and at the sides by an elevated rim. In front, the free ends of the rim are overlapped by the posterior corners of the upper lip. Across the anterior region of the sucker is the muscle referred to as the diaphragmatoprecordalis, and back of this are two rounded muscles known as the diaphragmatobranchiamedialis. There is no contact between these two groups of muscles.

\section{Staurois kangtingensis: Measurements of Two Tadpoles}

\begin{tabular}{|c|c|c|c|c|}
\hline Measurements & No. 1 & No. 2 & Average & $\begin{array}{c}\text { Ratio to } \\
\text { body length (\%) }\end{array}$ \\
\hline Body length. & 20.0 & 19.0 & 19.5 & \\
\hline Body height. & 9.5 & 8.0 & 8.7 & 44.9 \\
\hline Body width. & 7.5 & 6.0 & 6.7 & 34.6 \\
\hline Head height. . & 7.0 & 7.5 & 7.2 & 37.2 \\
\hline Head width. . & 8.0 & 7.5 & 7.7 & 39.7 \\
\hline Sucker length. & 14.2 & 14.0 & 14.1 & 72.3 \\
\hline Sucker width. & 12.4 & 11.4 & 11.9 & 61.0 \\
\hline Mouth width. . & 8.2 & 7.5 & 7.8 & 40.0 \\
\hline Snout to spiraculum. & 15.2 & 14.2 & 14.7 & 75.4 \\
\hline Tail length........ & 40.0 & 36.0 & 38.0 & 194.9 \\
\hline Tail height. & 9.5 & 9.0 & 9.2 & 47.4 \\
\hline Diameter of tail muscle & 6.0 & 6.0 & 6.0 & 30.8 \\
\hline Length of hind limb... & 5.0 & 3.0 & 4.0 & .. \\
\hline
\end{tabular}

Staurois loloensis sp. nov.

Type.-No. 49408 Chicago Natural History Museum, from Lolokou, Chaochiaohsien, Sikang, 10,000 feet altitude. Adult female, collected May 5, 1942, by Ch'eng-chao Liu.

Diagnosis.-A distinct Staurois (pl. 7, fig. 1), differing from other species of the same genus by having large rounded brown spots (enclosed by light green in life and by dark brown in preservation) on the back of the head and body; and with zigzag brown cross-bars, edged by the same color as the dorsal spots, on the legs and arms.

Description of type.-Body depressed and moderately stout. Head depressed, as long as broad, flat above; snout rounded and projecting beyond the mouth; nostril about midway between the tip of the snout and the anterior border of the eye; interorbital space about equal to the internasal space but greater than the width of the upper eyelid; tympanum small, more or less distinct, and covered 
with fine granules; canthus rostralis obscure; loreal region oblique, with a horizontal groove from below the nostril to the anterior side of the lower eyelid; a small white spot on top of the head in a line near the anterior corners of the eyes; tongue (fig. 91, A) deeply notched behind; no vomerine teeth, but with long oblique vomerine ridges, the outer ends of which originate near the inner median corners of the choanae, separated by a small space.

Arm moderately developed, with long fingers (fig. 91, B); the third finger the longest; the tip of the fourth finger reaching the base of the disk of the third
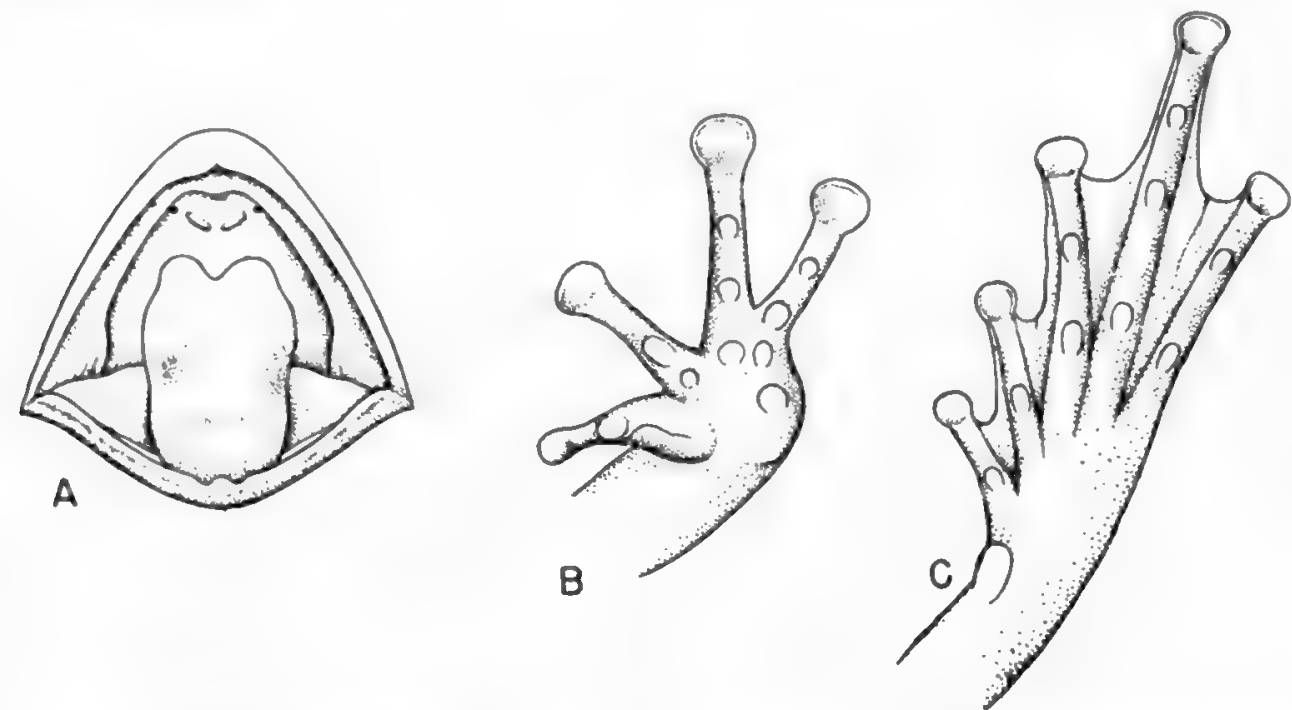

FIG. 91. Staurois loloensis $(\times 11 / 2)$. A. Oral cavity.

B. Ventral view of hand

C. Ventral view of foot.

finger; the tip of the second finger reaching beyond the distal subarticular tubercle of the third finger; the first finger subequal to the second; the three outer fingers provided with large disks, and the tip of the first finger dilated like a disk but without a horizontal groove; subarticular tubercles well developed; large supernumerary tubercles at the bases of the two outer fingers; an elongated outer and a rounded inner palmar tubercle confluent at the base of the palm; an elongated pad on the ventral outer side of the first finger.

Leg long and strong, the tibio-tarsal articulation extending to beyond the eye; heels overlapping when placed at right angles to the body; toes (fig. 91, C) flattened, the fourth toe the longest, the third and fifth subequal, nearly reaching the distal subarticular tubercle of the fourth, the second nearly reaching the distal subarticular tubercle of the third, and the first reaching the distal subarticular tubercle of the second; toes fully webbed except the fourth, on which the web reaches the distal subarticular tubercle, with fringes continuing to the base of the disk; subarticular tubercles well developed; inner metatarsal tubercle elongated, flat and very small; no outer metatarsal tubercle.

Skin smooth on the head, the back, and the dorsal sides of the limbs; lightcolored small spinules on the sides of the body, with an accumulation of spinules 
to the rear of the angles of the mouth; a weak skin fold from the eye to the shoulder; larger groups of spinules on the basal posterior portion of the thighs; the throat, belly and ventral sides of the limbs smooth.

Coloration in life.- The ground color of the head, back, and sides of the body, and of the dorsal sides of the limbs, is dark green with large brown spots enclosed by light green rings on the head and back and with a few smaller ones on the sides of the body. Four brown bars with light green margin and more or less zigzag in outline are found on each segment of the hind limbs. Two or three bars of the same color are developed on the upper and lower arms. There are indistinct brown bars on the outer toes and fingers. The throat, thorax, most of the belly and the ventral sides of the limbs are yellowish dusky. After preservation, the dark green ground color becomes iron gray, and the brown spots and bars become lighter, with darker diffuse margins.

Measurements of type (percentage of body length in parentheses).-Body length $76 \mathrm{~mm}$.; head length $23.5 \mathrm{~mm}$. (31); head width $24 \mathrm{~mm}$. (32); length of lower arm $36 \mathrm{~mm}$. (47); diameter of lower arm $8 \mathrm{~mm}$. (10.5); length of hand 23 $\mathrm{mm}$. (30); disk of third finger $3.5 \mathrm{~mm}$. (4.6); length of leg $133 \mathrm{~mm}$. (175); length of tibia $42 \mathrm{~mm}$. (55); length of foot and tarsus $59 \mathrm{~mm}$. (78); length of foot $40 \mathrm{~mm}$. (53); disk of fourth toe $3 \mathrm{~mm}$. (3.9).

\section{Staurois loloensis: Measurements of Ten Adult Females}

\begin{tabular}{|c|c|c|c|}
\hline Measurements & Range & Average & $\begin{array}{c}\text { Ratio to } \\
\text { body length }(\%)\end{array}$ \\
\hline Body length....... & $67-77$ & 72.1 & \\
\hline Head length. & $23-25$ & 23.6 & 32.7 \\
\hline Head width. & $22-24$ & 22.8 & 31.7 \\
\hline Interorbital space. & $5.5-6.0$ & 5.7 & 7.9 \\
\hline Length of lower arm. & $32-37$ & 33.7 & 46.7 \\
\hline Width of lower arm. & $7.0-8.5$ & 7.8 & 10.9 \\
\hline Length of hand.... & $21-25$ & 22.4 & 31.8 \\
\hline Disk of third finger. & $3.2-4.0$ & 3.6 & 5.0 \\
\hline Length of leg. & $110-135$ & 120.5 & 167.1 \\
\hline Length of tibia. & $37-43$ & 39.6 & 54.9 \\
\hline Length of foot and tarsus & $49-59$ & 54.0 & 74.9 \\
\hline Length of foot. & $31-40$ & 36.8 & 51.1 \\
\hline Disk of fourth toe & $2.5-3.2$ & 3.0 & 4.2 \\
\hline
\end{tabular}

Discussion of paratypes.-Eleven adult females were collected from the type locality, Lolokou, from May 5 to June 14, 1942. Except as to the number and distribution of the brown spots on the body and of the bars on the limbs, the series is very uniform. All have the characteristic coloration. The texture of the skin varies slightly. The length of the hind limb is uniform, all specimens having the tibio-tarsal articulation reaching beyond the eye. The vomerine teeth vary greatly. In addition to the type, five specimens were examined. One specimen has two long oblique vomerine ridges without teeth and with their outer ends nearly touching the median corners of the choanae; one has a single tooth at the inner end of each vomerine ridge, the ridges being widely separated; one has two short oblique vomerine tooth patches with teeth 3-2; one has two 
long oblique vomerine tooth patches with teeth $3-4$; and one has a long vomerine tooth patch on the left side with five teeth and a very short patch on the right with two teeth. Rhacophorus bambusicola has the same variation in this respect, and both are high mountain forms.

Two adult females of this species in the United States National Museum had been identified as Rana jugans by Stejneger. These two specimens (Nos. 79707 and 93857) were collected by Graham from Yaochin (8,000 feet altitude), Paohsing, on July 14, 1927. During the summer of 1938, Mr. H. C. Chang of West China Union University collected an adult female near Tupakou $(8,500$ feet altitude), Paohsing. From May 5 to June 14, 1942, eleven adult females were collected from Lolokou (10,000 feet altitude), Chaochiao, Sikang. This cascade frog is an endemic form of eastern Sikang, with a vertical distribution ranging from 8,000 to 10,000 feet.

Habitat and habits.-Staurois loloensis is found sitting on the rocks near the margin of the water of small mountain streams from 7,000 to 11,000 feet altitude. The specimens collected are all females, contrary to my experience, which has been to find a preponderance of males in such collecting.

No tadpoles or eggs have been found.

\section{Staurois ricketti minor subsp. nov.}

Type.-No. 49411 Chicago Natural History Museum, from Mapien, about 3,000 feet altitude, Szechwan. Adult male, collected by Mr. Tang.

Diagnosis.-Closely related to ricketti ricketti; tympanum depressed, obscure, its membrane like the skin surrounding it, and partly covered by granules; distinct and not covered by granules in ricketti; dorsum smoother and with fewer warts, especially behind the tympanic region in ricketti minor; ricketti minor much smaller than ricketti ricketti, especially the male; sex dimorphism in size very great in ricketti minor, and much less in ricketti ricketti.

Description of type.-Body (fig. 92) stout and depressed. Head much depressed, as long as broad, flat above; snout strongly projecting beyond the mouth, rounded, flat above; canthus rostralis distinct, its well-defined ridge extending anteriorly around the snout; loreal region nearly vertical, with a horizontal groove from the nostril to the eye; nostril lateral and about mid-way between the tip of the snout and the anterior corner of the eye; a small round white spot on top of the head in a line about halfway between the nostril and the eye; interorbital space about two-thirds of the internasal space; upper eyelid narrower than the interorbital space, with many small warts, especially near the posterior part; tympanum obscure and depressed, with membrane like the adjacent skin and partly covered with granules; tongue notched behind; vomerine teeth in two groups, very oblique, in a line to the rear of the choanae, the space between them about one-half the width of the space from a vomerine tooth patch to the choana. 
Arm short, with very short fingers; the third finger longer than the fourth by the length of the disk; the fourth finger slightly longer than the first and second, which are about equal in length; all fingers provided with disks, that of the third the largest, and of the first the smallest; white nuptial spines on the inner dorsal side of the first finger; subarticular tubercles distinct, with supernumerary tubercles on the bases of the three outer fingers; two palmar tubercles fused at their bases; an elongated pad on the outer part of the ventral side of the first finger.

Legs short, the tibio-tarsal articulation reaching beyond the eye; the heels slightly overlapping when placed at right angles to the body; toes $4-5-3-2-1$ in

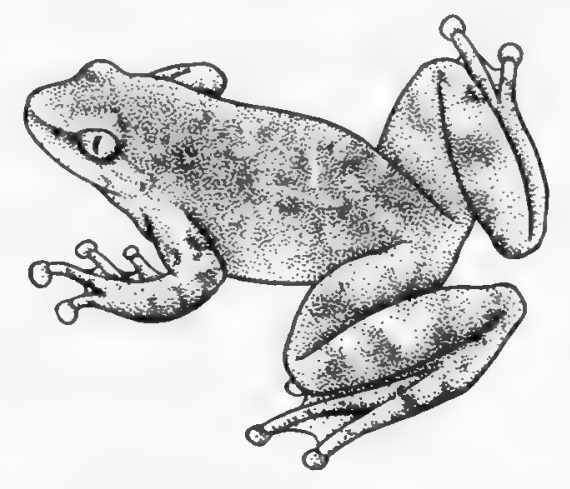

FIG. 92. Staurois ricketti minor; adult male $(\times 1)$.

order of length, all provided with disks but smaller than the disk of the third finger; webs thin, reaching to the bases of the disks; subarticular tubercles well developed; inner metatarsal tubercle oval and flat, without free cutting edge; no outer metatarsal tubercle.

Staurois ricketti ricketti and Staurois ricketti minor: Measurements of Adults

\begin{tabular}{|c|c|c|c|c|c|c|c|c|}
\hline & \multicolumn{4}{|c|}{ Males } & \multicolumn{4}{|c|}{ Females } \\
\hline & r. min & $\begin{array}{l}r \text { (type) } \\
\text { hwan }\end{array}$ & $\begin{array}{r}r_{0} r \\
\dot{F}^{2}\end{array}$ & $\begin{array}{l}\text { cketti } \\
\text { kien }\end{array}$ & & $\begin{array}{l}\text { minor } \\
\text { echwan }\end{array}$ & & $\begin{array}{l}\text { icketti } \\
\text { kien }\end{array}$ \\
\hline Measurements & MM. & $\begin{array}{l}\text { Ratio } \\
\text { to body } \\
\text { length } \\
(\%)\end{array}$ & MM. & $\begin{array}{l}\text { Ratio } \\
\text { to body } \\
\text { length } \\
(\%)\end{array}$ & MM. & $\begin{array}{c}\text { Ratio } \\
\text { to body } \\
\text { length } \\
(\%)\end{array}$ & MM. & $\begin{array}{c}\text { Ratio } \\
\text { to body } \\
\text { length } \\
(\%)\end{array}$ \\
\hline Body length. & 44.0 & & 57.0 & & 52 & & 59.0 & \\
\hline Head length. & 15.5 & 35.2 & 19.0 & 33.3 & 18 & 34.6 & 19.5 & 33.0 \\
\hline Head width. & 15.0 & 33.8 & 19.0 & 33.3 & 18 & 34.6 & 19.5 & 33.0 \\
\hline Length of lower arm. & 19.0 & 43.1 & 24.0 & 42.1 & 23 & 44.2 & 25.0 & 42.3 \\
\hline Diameter of lower arm. & 4.5 & 10.2 & 6.0 & 10.5 & 5 & 9.6 & 5.0 & 8.4 \\
\hline Length of hand. & 11.5 & 26.0 & 15.0 & 26.3 & 15 & 28.8 & 16.0 & 27.1 \\
\hline Disk of third finger. & 2.8 & 6.3 & 3.5 & 6.1 & 3 & 5.7 & 3.3 & 5.5 \\
\hline Length of leg..... & 73.0 & 165.9 & 90.0 & 157.8 & 82 & 157.6 & 88.0 & 149.1 \\
\hline Length of tibia. & 24.0 & 54.5 & 29.5 & 51.7 & 27 & 51.9 & 30.0 & 50.8 \\
\hline Length of foot and tarsus. & 32.0 & 72.7 & 39.0 & 68.4 & 38 & 73.0 & 39.0 & 66.0 \\
\hline Length of foot. & 21.0 & 47.7 & 26.5 & 46.4 & 26 & 50.0 & 26.0 & 44.0 \\
\hline Disk of fourth toe & 2.7 & 6.0 & 3.0 & 5.2 & 3 & 5.7 & 3.0 & 5.0 \\
\hline
\end{tabular}


Skin shagreen-like above, with very few scattered small flat warts, especially on the upper eyelid; a fold above the tympanic region; a large light-colored wart posterior to the angle of the jaw; the belly smooth, with only indistinct granules near the hip.

Coloration in formalin.-Yellowish olive above, much marbled with black; black bars on limbs; more finely and more darkly marbled on the posterior aspects of the thighs; whitish beneath.

Remarks.-Besides the type, there is a mature female paratype, collected at the type locality. The male is much smaller than the female, with white nuptial spines on the first finger. The arm of the male is definitely stronger than that of the female. The male has no vocal sacs.

\section{Staurois afghanus Günther}

Polypedates afghana Günther, 1858, Cat. Batr. Sal., Brit. Mus., p. 81-Afghanistan; idem, 1864, Rept. Brit. Ind., p. 432.

Amolops afghanus Cope, 1865, Nat. Hist. Rev., 1865: 117.

Ixalus kakhienensis Anderson, 1879, Anat. Zool. Res. Yunnan, p. 845, pl. 78, fig. 6Yunnan.

Polypedates marmoratus Anderson, 1879, Anat. Zool. Res. Yunnan, p. 842 - Yunnan.

Rana afghana Boulenger, 1882, Cat. Batr. Ecaud., p. 69; idem, 1887, Ann. Mus. Genova, (2), 5: 420; Annandale, 1912, Rec. Ind. Mus., 8: 24, pl. 4, fig. 3.

Rana latopalmata Boulenger, 1890, Fauna British India, Rept., p. 462.

Staurois afghanus Pope and Boring, 1940, Peking Nat. Hist. Bull., 15, pt. 1: 47.

History of species.-In China, Staurois afghanus is found only in Yunnan. The history of the species is complicated, as indicated by the synonymy. Günther (1858) described this new frog from an adult female presented by a Mr. Griffith, and two larvae, all supposed to be from Afghanistan. Boulenger (1882) transferred the species to Rana, and in 1890 put it in the synonymy of Rana latopalmata, stating that the types were not collected in Afghanistan; in his monograph in 1920 he continued to refer to it as latopalmata, with afghana in synonymy. Anderson's Ixalus kakhienensis and Polypedates marmoratus from Yunnan were placed in the synonymy of latopalmata by Boulenger in 1920. In 1940, Pope and Boring put kakhienensis in the synonymy of afghanus, without mention of marmoratus. On account of the ventral sucking disk of the tadpoles, Pope and Boring refer this species to the redefined genus Staurois.

Original description.- "Fingers quite free. Vomerine teeth in a straight line, on a level with the hinder edge of the inner nostrils, interrupted in the middle. Skin smooth; tympanum very small, as large as the disk of the finger; toes very broadly webbed to the disk.

“a. Adult female. Afghanistan. Presented by Mr. Griffith.

“a, b. Larvae. Afghanistan. Presented by the East India Company.

"To the above-mentioned characters may be added:- Habit as in $P$. maculatus; snout angular, rather high; nostril on the canthus rostralis in the middle 
between the eye and the top of snout; tympanum distant from the eye; inner nostrils moderate; eustachian tubes rather larger; disks rather large. Subarticular tubercles very conspicuous, oblong; metatarsus with a very small blunt tubercle. Above brown, variegated with greyish. Length of body 3 inches; length of front extremity $2 \frac{1}{3}$ inches; length of hinder one 6 inches."

\section{Genus RHACOPHORUS Kuhl and van Hasselt}

\section{Species of Western China}

Although the species representing the genus Rhacophorus in western China form only a small group, they present a remarkable amphibian nomenclatural puzzle. In 1871, David described a tree frog from Paohsing (Muping) as Polypedates dugritei; in 1877, Sauvage described the same material as Polypedates davidi, and Boulenger, in the Catalogue of the Batrachia Salientia (1882), followed Sauvage in the use of the specific name, referring to it as Rhacophorus davidi. In 1912, Barbour described Hyla monticola from a male specimen from Washan, Szechwan, collected by W. R. Zappey, and in 1920 he renamed the same form Hyla bambusicola, Hyla monticola Barbour 1912 being preoccupied by Hyla monticola Peters from Costa Rica. In 1924, Stejneger described a new tree frog from Mount Omei, Szechwan, as Polypedates omeimontis; and in the same year Vogt described another new tree frog as Rhacophorus pleurostictus batangensis, from Batang, Sikang. Pope and Boring, in 1940, placed bambusicola, pleurostictus batangensis, and omeimontis in the synonymy of davidi. I myself described still other tree frogs of this type as Rhacophorus hui and chenfui in 1945.

With the library facilities of Chicago Natural History Museum; with Mr. Pope's unpublished notes on the types of the above-mentioned species of Rhacophorus other than hui; and after renewed study of the types of monticola in the Museum of Comparative Zoology, of the type of omeimontis and a paratype of batangensis in the United States National Museum, and with my own material from Chaochiao, Sikang, and specimens collected by Mr. Tung from Shaping, Opienhsien, Szechwan, I believe that I can disentangle this whole complex of names.

Rhacophorus davidi is clearly a synonym of Rhacophorus dugritei, David's original description having been curiously missed, even by the meticulous Stejneger. Rhacophorus bambusicola is closely related to dugritei but differs in having much smaller digital disks, in its smaller size, and in the higher altitudes at which it is found. Rhacophorus pleurostictus batangensis, from Batang, Sikang, collected by Weigold, is a synonym of bambrusicola. According to Pope's measurements of the paratypes of pleurostictus batangensis collected by Weigold at Washan, Szechwan, these are to be referred to dugritei and not to bambusicola, their size being much larger. A study of the size of the digital disks in relation to the size of the tympanum of these Washan specimens is required to confirm this reference. Rhacophorus hui is definitely a synonym of bambusicola. Rhacophorus dugritei and bambusicola are short-legged tree frogs found mostly on 
ground, on or under stones, and occasionally on bushes; they lay their eggs in holes in the ground or under stones.

Rhacophorus omeimontis is a valid species with longer legs and very large digital disks; specimens of this species are found on trees and houses and lay their eggs in nests formed by the leaves of trees or other vegetation, near ponds and pools. Rhacophorus chenfui, a species I described in 1945 , is totally different from all other western Chinese tree frogs in having a uniform green back. It is endemic on Mount Omei. The tropical tree frog, Rhacophorus leucomystax, is widely distributed in western China and can be easily distinguished from other species by its extremely long legs and the absence of webs between the fingers.

\section{KEy FOR IdENTIFICATION OF AdUlts of Rhacophorus of WeStern China}

I. Fingers not webbed; tibio-tarsal articulation reaching snout .......... leucomystax.

II. Fingers webbed; tibio-tarsal articulation not reaching snout.

A. Tibio-tarsal articulation reaching eye; inner metatarsal tubercle weak.

B. Back uniform green; a slight web between first and second fingers; size smaller (male $37 \mathrm{~mm}$; female $50 \mathrm{~mm}$.).....................

BB. Back green and brown; a strong web between first and second fingers; size larger (male $59 \mathrm{~mm}$.; female $76 \mathrm{~mm}$.) ................. omeimontis.

AA. Tibio-tarsal articulation not reaching eye; inner metatarsal tubercle strong.

B. Disks smaller; disk of third finger not larger than tympanum . . . bambusicola.

BB. Disks larger; disk of third finger larger than tympanum..........dugritei.

Key for Identification of TAdpoles of Rhacophorus of Western China

I. Labial teeth of upper lip mostly $\mathrm{I}: 3-3$.

A. Body stout; tail fin high and marbled, with a light-colored painted tip. leucomystax.

AA. Body more or less cylindrical; tail fin lower, uniform in color, the more blunt tail tip dark. ................................. bambusicola.

II. Labial teeth of upper lip mostly $I: 4-4$.

A. Size smaller (13 mm.); yellowish gray-green; tail length about 165 per cent of

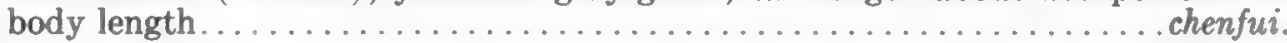

AA. Size larger $(15 \mathrm{~mm}$.$) ; black or dark gray; tail length about 210$ per cent of body length.

omeimontis.

\section{Rhacophorus leucomystax Gravenhorst}

Hyla leucomystax Gravenhorst, 1829, Delic. Mus. Vratislav., p. 26-Java.

Polypedates megacephalus Hallowell, 1860, Proc. Acad. Nat. Sci. Philadelphia, 12: $507-$ Hongkong, China.

Polypedates maculatus var. unicolor Müller, 1878, Verh. Naturf. Ges. Basel, (4), 6: 585.

Rhacophorus maculatus Boulenger (not of Gray), 1882, Cat. Batr. Sal., Brit. Mus., p. 83.

Rhacophorus leucomystax Boulenger, 1889, Proc. Zool. Soc. London, 1889: 29; Pope and Boring, 1940, Peking Nat. Hist. Bull., 15, pt. 1: 69.

Rhacophorus leucomystax megacephalus Stejneger, 1925, Proc. U. S. Nat. Mus., 66, art. 25: 30 . 
Distribution and collection data.-Rhacophorus leucomystax (fig. 93) is the commonest tree frog in China and one with a wide Indo-Malaysian distribution. Within China there are records from Szechwan, Sikang, Yunnan, Kwangsi, Kwangtung, Fukien, and Chekiang. The vertical distribution in western China is from about 1,000 feet to 5,000 feet altitude. Adults, egg-foams, and tadpoles

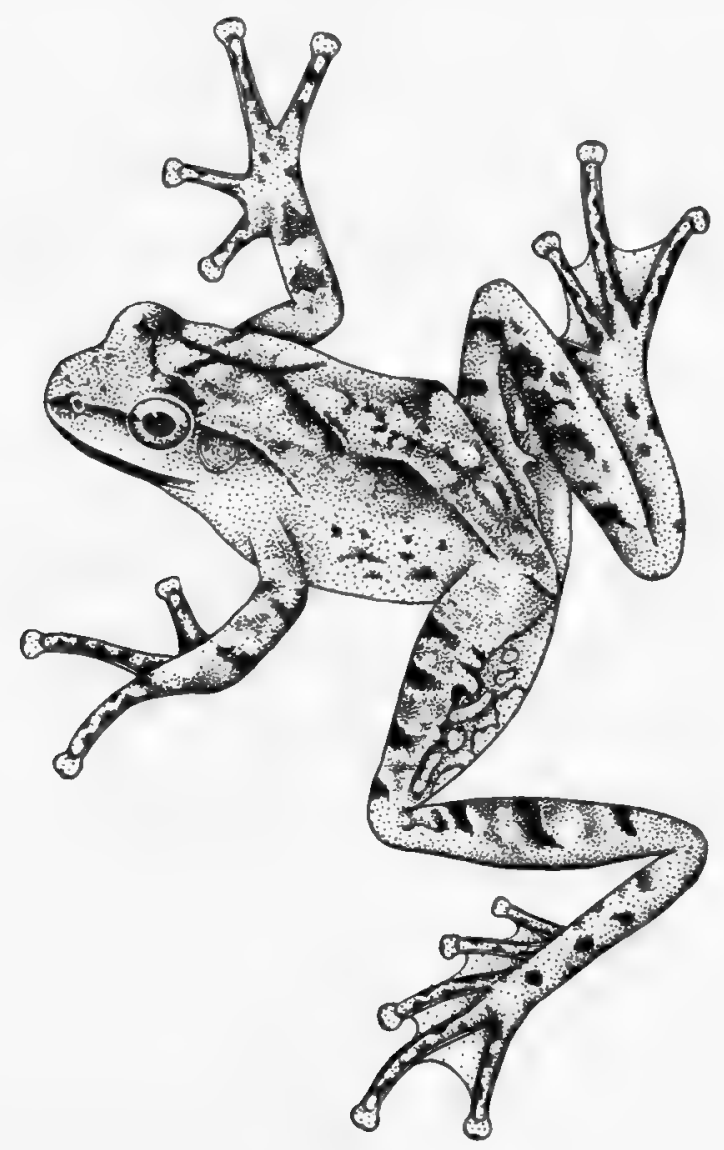

FIG. 93. Rhacophorus leucomystax; adult female ( $\times 1)$.

at different stages were collected from Kiating, Mount Omei, Kwanhsien, and Wenchwan, of Szechwan; and from Yaan, Tienchuan, and Paohsing, of Sikang.

Comparison with related species.-Rhacophorus leucomystax can easily be distinguished from all other species of the genus in western China by the absence of webs between the fingers. Rhacophorus oxycephalus, which has rudimentary webs or an indication of webs between the fingers, is from Hainan. The tibiotarsal articulation barely reaches the snout in leucomystax and extends beyond it in oxycephalus.

Original description (translation).- - "Toes half webbed, abdomen and femur granulated below, rusty in color above, margin of the upper jaw and the lateral border of the anterior feet with white."

Description.-Adult female, No. 137, Mount Omei, July, 1940, collected by Ch'eng-chao Liu. Body stout, broad and somewhat depressed. Head depressed, 
as long as broad, sloping anteriorly and projecting beyond the mouth; distance of the nostril from the tip of the snout about one-half its distance from the anterior border of the eye; canthus rostralis well marked, loreal region oblique and concave; interorbital space wide and flat, equal to the length of the eye; tympanum circular and distinct, about equal to the upper eyelid and a little more than half the length of the eye; a sharply defined skin fold from the posterior corner of the upper eyelid to the shoulder; vomerine teeth in two strong oblique rows, originating from the inner anterior corner of each choana and extending inward and backward to the line of the posterior lateral corners of the choanae; the two vomerine tooth rows separated by a space as wide as the choana; tongue large and very deeply notched.

Arm moderately strong, fingers very long, 3, 4, 2, 1 in order of length; no webs between the fingers; digital disks well developed on the third and fourth fingers, smaller on the second finger and smallest on the first finger; the disk of the third finger smaller than the tympanum; subarticular tubercles well developed; supernumerary tubercles at the bases of the fingers; a small outer and a large inner palmar tubercle.

Leg long and rather weak, the tibio-tarsal articulation reaching between the nostril and the eye; the heels slightly overlapping when placed at right angles to the body; the toes 4, 5, 3, 2, 1 in order of length; the first two toes about half webbed, the third and fifth two-thirds webbed, the web reaching beyond the second subarticular tubercle of the fourth toe; digital disks well developed on all toes, but smaller than the disks of the three outer fingers; subarticular tubercles well developed but no tubercles on the soles like those of the palms; inner metatarsal tubercle weak, oval, and with a free edge; no outer metatarsal tubercle.

Skin rough, with smaller granules on the back and dorsal sides of the head and limbs; the throat, the ventral aspect of the arm and femur, and especially the belly, coarsely granulated, the skin elsewhere smooth; a strongly developed skin fold from the eye to the shoulder.

Coloration in formalin.--Grayish brown above, with four obscure longitudinal black bands; the upper side of the head and limbs also grayish brown; dark bars on the arms and legs and on the outer fingers and toes; dark and light lines on the upper jaw; the sides lighter than the back and marbled near the groin; a light-colored ridge from the elbow extending to the base of the outer side of the fourth finger, a similar ridge extending from the tibio-tarsal joint along the dorsolateral side of the tarsus posteriorly, and along the outer side of the fifth toe to the base of its disk; the posterior aspect of the femur marbled with a black network on creamy gray; the throat and the ventral sides of the limbs marked with dark gray; the belly uniformly flesh-colored.

Coloration in life.-The coloration of this species in life varies greatly. From observation of specimens under natural conditions and from living specimens in jars, the color is seen to vary from light pinkish yellow to dark dirty brown. When in the dark it changes to brown or even dark brown. Individuals 
placed against light and dry backgrounds become yellowish, pinkish, or light gray in color on the back. In most cases there are four dark longitudinal bands on the back; the inner two begin at the nostrils, and the lateral pair extend backward from the front of the upper eyelids. Another dark band starts at the snout, extends through the nostril to the anterior border of the eye, and from the posterior border of the eye to the postero-dorsal side of the shoulder, sometimes extending backward to the groin. Individuals with no dark longitudinal stripes, but with only an interorbital cross-bar and an X-shaped mark on the back (fig. 93) in the shoulder region are not uncommon. There are three dark cross-bars on each leg, the middle one being broadest on the thigh and the tibia. Two bars are found on each arm, and the fingers and digits have dark spots or bars. These bands, bars, and spots are changeable in color according to the coloration of the habitat. The area posterior to the thigh and at the vent is much marbled with yellowish brown and purplish gray or brown. The throat and belly are creamy buff, and the throat is usually marbled or spotted with dark.

Rhacophorus leucomystax: Measurements of Fifty Male and Twenty-five Female Adults

\begin{tabular}{|c|c|c|c|c|}
\hline Measurements & Sex & Range & Average & $\begin{array}{c}\text { Ratio to } \\
\text { body length }(\%)\end{array}$ \\
\hline Body length...... & $\begin{array}{l}0^{7} \\
0\end{array}$ & $\begin{array}{l}40.5-48.0 \\
57-65\end{array}$ & $\begin{array}{l}44.5 \\
60.9\end{array}$ & $\cdots$ \\
\hline Head length. & $\begin{array}{l}07 \\
0\end{array}$ & $\begin{array}{l}13.5-17.3 \\
19.8-22.0\end{array}$ & $\begin{array}{l}15.7 \\
20.6\end{array}$ & $\begin{array}{l}35.2 \\
33.8\end{array}$ \\
\hline Head width. & $\begin{array}{l}0^{7} \\
9\end{array}$ & $\begin{array}{c}13.4-16.9 \\
20-23\end{array}$ & $\begin{array}{l}15.8 \\
21.3\end{array}$ & $\begin{array}{l}35.5 \\
34.9\end{array}$ \\
\hline Interorbital space........... & $\begin{array}{l}0^{7} \\
0\end{array}$ & $\begin{array}{l}5.0-6.3 \\
6.5-8.0\end{array}$ & $\begin{array}{l}5.6 \\
7.0\end{array}$ & $\begin{array}{l}12.5 \\
11.5\end{array}$ \\
\hline Tympanum. & $\begin{array}{l}\sigma^{7} \\
\text { क }\end{array}$ & $\begin{array}{l}2.9-3.7 \\
3.84 .8\end{array}$ & $\begin{array}{l}3.3 \\
4.3\end{array}$ & $\begin{array}{l}7.4 \\
7.1\end{array}$ \\
\hline Length of lower arm. . & $\begin{array}{l}0^{7} \\
0\end{array}$ & $\begin{array}{l}25.0-32.7 \\
37-44\end{array}$ & $\begin{array}{l}29.9 \\
40.0\end{array}$ & $\begin{array}{l}65.5 \\
65.7\end{array}$ \\
\hline Diameter of lower arm. & $\begin{array}{l}\sigma^{7} \\
9\end{array}$ & $\begin{array}{l}2.8-4.1 \\
4.0-5.5\end{array}$ & $\begin{array}{l}3.8 \\
4.7\end{array}$ & $\begin{array}{l}8.5 \\
7.7\end{array}$ \\
\hline Length of hand. & $\begin{array}{l}0^{7} \\
0\end{array}$ & $\begin{array}{l}11.0-13.5 \\
12.4-18.4\end{array}$ & $\begin{array}{l}12.3 \\
16.4\end{array}$ & $\begin{array}{l}27.6 \\
27.0\end{array}$ \\
\hline Width of third-finger disk...... & $\begin{array}{l}0 \\
0 \\
9\end{array}$ & $\begin{array}{l}1.7-2.4 \\
2.3-3.5\end{array}$ & $\begin{array}{l}2.0 \\
3.0\end{array}$ & $\begin{array}{l}4.6 \\
4.9\end{array}$ \\
\hline Length of hind leg. & $\begin{array}{l}0^{7} \\
q\end{array}$ & $\begin{array}{l}65-82 \\
91-111\end{array}$ & $\begin{array}{r}75.8 \\
102.8\end{array}$ & $\begin{array}{l}170.4 \\
168.7\end{array}$ \\
\hline Length of tibia... & $\begin{array}{l}0^{7} \\
q\end{array}$ & $\begin{array}{l}22.7-36.0 \\
27.5-46.5\end{array}$ & $\begin{array}{l}33.5 \\
38.5\end{array}$ & $\begin{array}{l}75.2 \\
63.2\end{array}$ \\
\hline Length of foot. . & $\begin{array}{l}\sigma^{7} \\
\varnothing\end{array}$ & $\begin{array}{c}16.3-20.8 \\
24-27\end{array}$ & $\begin{array}{l}18.6 \\
25.4\end{array}$ & $\begin{array}{l}41.7 \\
41.6\end{array}$ \\
\hline Width of fourth-toe disk. & $\begin{array}{l}0^{x} \\
\wp\end{array}$ & $\begin{array}{l}1.5-2.2 \\
2.2-3.0\end{array}$ & $\begin{array}{l}1.8 \\
2.5\end{array}$ & $\begin{array}{l}4.0 \\
4.1\end{array}$ \\
\hline
\end{tabular}

Sex dimorphism.-Mature males are much smaller than females (see table), and the body of the female is stouter. The male has an internal median subgular vocal sac with two rounded openings near the angle of the mouth. 
Light-colored nuptial pads are developed on the inner dorsal sides of the three inner fingers, that at the base of the inner dorsal side of the third finger very small. A pink linea masculina is present in preserved male specimens.

Discussion of species. - Rhacophorus leucomystax is a very widely distributed tree frog in the tropical region of Asia and the East Indies, and in southern, southeastern and southwestern China. An adequate study of its geographic variation remains to be made. For the present study, I mention only the differences and similarities of Chinese specimens from Szechwan and Fukien, comparing them with specimens from Indo-China, the Philippines, and North Borneo.

Rhacophorus leucomystax from Szechwan essentially agrees with Fukien specimens except that all the Fukien specimens examined have distinct vestigial webs between the first and second fingers, 25 per cent having a trace of web between the second and third fingers, while Szechwan specimens very rarely have even a trace of web between the first and second fingers. All the specimens from Indo-China, the Philippines, and Borneo have slightly better developed webs between the first and second, and the second and third fingers. Two specimens from Indo-China are without webs between the third and fourth fingers, but there is a trace of web between these fingers in frogs of this species from the more southern localities.

The length of the hind limbs and the condition of the webs between the toes must also be discussed. In most Chinese leucomystax, the tibio-tarsal articulation reaches between the eye and the nostril, and to the nostril only in two cases. In the Philippine and Indo-Chinese material, most of the specimens have the tibio-tarsal articulation reaching nearer to the nostril, and in a higher percentage reaching the nostril. The Bornean specimens all have the tibio-tarsal articulation reaching the nostril. Stejneger (1907) reports an adult female from Formosa with the tibio-tarsal articulation reaching beyond the tip of the snout. The webs between the toes are much better developed in individuals from Borneo, the Philippines and Indo-China, than in Chinese specimens.

The skin on top of the head is free in Chinese and Bornean specimens, but connected to the skull in individuals from Indo-China and the Philippines. The space anterior to the interorbital space and posterior to the internasal space is flat in Chinese and Bornean forms, whereas in specimens from Indo-China and the Philippines it is concave. The snout of the male in Philippine specimens is pointed and strongly projecting beyond the mouth; in Indo-Chinese and Bornean specimens the snout in males is moderately pointed and projects moderately beyond the mouth; in Chinese specimens the snout in the male is rounded and projects only slightly beyond the mouth. The tympanum is very close to the eye in Bornean specimens and is well separated from the eye in individuals from China, Indo-China, and the Philippines. A wide black mark from the posterior corner of the eye to the shoulder covers the whole tympanum in the specimens from Borneo, the Chinese specimens having only a narrow black line 
along the ventral margin of the skin fold from eye to shoulder, which never involves the tympanum. This is true also of some specimens from Indo-China and the Philippines. Some individuals have a diffuse marking, never black, at the tympanic region.

The most interesting variation in the available specimens of Rhacophorus leucomystax from China, Indo-China, the Philippines and Borneo lies in the development of the webs of the fingers and toes, and the length of the hind limbs. Specimens from Borneo appear to have better-developed webs and longer legs than specimens from the Philippines and Indo-China. The Chinese forms have almost no webs at all between the fingers, poorly developed webs between the toes, and shorter legs. All specimens have dermal ridges on the lateral sides of each finger, extending from the base to the disk. This is possibly the last sign of the highly developed webs of the tropical flying frogs and the well-developed webs of the arboreal tree frogs in general. The Chinese form, with the least indication of web between the first and second fingers of only a very few specimens, may be considered as derived from the more tropical Rhacophorus leucomystax. This assumes that the large webs are characteristic of the genus Rhacophorus. That $R$. leucomystax with its relatively small amount of web is a recently evolved species is indicated by its extremely wide continuous range and large populations.

Habitat and habits.-Rhacophorus leucomystax in Szechwan and Sikang is a montane form, no specimens of this species having been found at Chengtu. It is commonly known as the "bamboo-climbing frog," as it is sometimes found on bamboos; but this is usually not the case, as it is commonly found among other vegetation, under stones, or on trees near houses. During the breeding season, the adults are found near small ponds and old manure pools, and in rice fields with water. They usually hide themselves in the daytime and come out during twilight and evening. If it is raining, they may croak during the daytime. When they are found on trees or bamboos in daytime, the color is rather light, with distinct brown marks; specimens from under stones are darker in color. They are easy to find during the evening, as they migrate to ponds and pools, especially during the breeding season. When a specimen has been seen, one can nearly always get it by hand or with a net.

The breeding season of leucomystax is quite long, as egg-foam was collected around Taosze, Mount Omei, from the end of May to the latter part of August in 1938, 1940, and 1945. Mr. P. L. Luh of Wu Han University at Kiating, Szechwan, reported that it bred on April 27, 1939. I collected egg-foam as well as young tadpoles of this species from pools and ponds near Paohsing, on July 19, 1939. The studies of three summers on Mount Omei indicate that the time for breeding is mostly in July, when there is most rain.

Breeding behavior.-Breeding places include small dirty pools, the walls of unused old manure pools (usually near an old house or temple), and sometimes the crops in flooded fields. If there is no suitable pool or other water, egg-foam may be laid on the ground during rainy evenings. 
Near the time of egg-laying, the males croak near or on the banks of the pool or on vegetation around the breeding place to guide the females to the proper place for mating. The male croaks in two ways: the first type is a low broad sound, quite unpleasant, like the coughing of a baby; the second is very much like the noise made by a rooster calling a hen when he is picking up and dropping a worm or a seed. The notes are slow and more or less separated, and gradually increase in speed and pitch. Males will clasp an individual of any species that approaches. The position of amplexus differs. Before egg-laying, the hands of the male are usually above the armpits of the female, and the male lies close to her body, with his snout at the occipital region of her head. Sometimes the hands of the male may reach the armpits of the female. Up to the time of egg-laying, the female seems uneasy and moves around, trying to find a favorable location for egg-laying. The first indication she gives of egg-laying is to flatten her body and move her legs medially and laterally. This action causes the male to bend down his vent and move his hands to the armpits of the female, the first and second fingers being pointed backward and downward; the third and the fourth fingers curve antero-ventrad, and the feet and tarsi lie between the thighs of the female. In a jar, when a female is ready for egg-laying, the process of ovulation goes on, even without a male.

During the process of egg-laying the female does most of the work of producing a foam mass. Before the eggs appear she produces a small amount of fluid, and she beats this by moving her feet medially and laterally and turning them as they cross at the mid-line. When the primary foam for holding the eggs has been prepared, eggs and fluid come out together. Each time, as the eggs and fluid appear, the female beats the fluid into foam with her tarsi and feet, especially the latter. The foam beating is not continuous, the intervals being from twenty-five seconds to a minute, the number of beats in a series ranging from five to nine. Sometimes the female raises her vent as the eggs come out, and she also bends her thighs to raise the posterior part of the body. This seems to be done to insure fertilization. During egg-laying, the male is passive, with his eyes half closed, and his body closely applied to the back of the female. The groin region is bent down with the anal opening near that of the female and the folded thighs and tibiae fitting into the groin and above and behind the thighs of the female, the tarsi and feet lying lateral to the anal opening and between her thighs. Sometimes the male moves his feet up and down, especially when the eggs appear. Keeping the tarsi and feet in such a position may help to form a temporary canal to direct the sperm towards the eggs for fertilization. When the egg-laying process has been finished, the female generally stands up on her fore-limbs, and the male tries first to get away from the foam in which the distal ends of his hind limbs are buried. The adhesive pads of the hands help in his release. The female usually gets away from the foam later, by moving her legs and body sidewise with the help of her finger disks.

The color of the foam is white at the beginning, but after three to five minutes it gradually changes to light brown, while at the same time it becomes very 
sticky. It is generally oval in shape, with a flat bottom attached to the substrate. Sometimes it has a larger fundus region, a body, and a narrower neck region where the female left the foam after egg-laying.

The egg-foam may be attached to the walls of unused manure pools, or to the vegetation on the wall or near the margin of the water. Sometimes it is floating on the surface of the water, and it may even be on the ground near a pool. The distance from egg-foam to water varies greatly. It is rarely on the surface of water, and when so found it must have been washed down by rain, as it is impossible for the female to beat the foam on the surface of the water. On July 8 and 9, 1940, five masses of egg-foam were collected from the surface of the earth, on vegetation and stones. These were not connected with water but were near a stony basin. Two egg-foams on stones were dried up, and the three other masses on earth had well-developed embryos; in one case tadpoles had hatched out on the earth and the foam had liquefied. Egg-foam is mostly laid in manure pools and on vegetation in rice fields, as these are the favorite breeding places; those in manure pools are mostly infected and spoiled by maggots, which eat up all the eggs in the foam. If there is no rain or not very much during the breeding season, much egg-foam is dried up before the hatching of the tadpoles, so that the percentage of spoiled embryos is high.

The eggs are absolutely white. They are scattered in the egg-foam singly or in groups, but mostly near the basal part of the foam, where it is attached to the substrate. Very few eggs are on the surface and the upper part of the foam. They are heavier than the bubbles of the foam so that they gradually sink down into it. The few eggs on the surface dry up with the foam. Before the embryo is well differentiated it is very difficult to remove an egg or an embryo from the foam, as it is very sticky. When the embryo is well differentiated (as when the tail-bud has appeared) the foam around it is liquefied and loses its stickiness, and a layer of brownish fluid appears around each embryo. Eggs are very small, ranging from 1.8 to $2 \mathrm{~mm}$. in diameter, with an average of $1.9 \mathrm{~mm}$., but the size of the egg-foam masses varies greatly and is difficult to measure. The egg capsule is simple, as it is protected by sticky foam. There is only one thin jelly envelope immediately outside each egg.

Tadpole.-Incubation period varies with temperature. On Mount Omei and at Kiating, incubation takes from six to seven days. The tadpoles hatch at different stages of development. Some newly hatched individuals have external gills fully exposed, and have a limited amount of pigment scattered on head, body, and tail and on the dorso-lateral sides of the yolk, so that it is gray. The belly is white. Sometimes the newly hatched specimens have the external gills partially covered up, especially the gills on the right side, with a much darker body, and the white area of the belly very much limited. The process of hatching is very simple. Near the time of hatching, the foam surrounding the embryos begins to liquefy. The active movement of fully developed embryos in the liquefied foam drops them into the water below, and the dried remains of the foam are left behind on the substrate. Sometimes the whole egg-foam, with 
embryos fully developed, may be washed down to the water by rain. When liquefied foam drops into water the bubbles disappear and the tadpoles swim actively in the water.

External gills are covered up within one or two days after hatching. On the dorsal and dorso-lateral parts of the body there is a greenish-yellow background with scattered black and silver and golden dots. The tail is lighter in color as there are fewer pigment granules there and the tail fins are yellowish. The throat is darker in color and this lightens towards the posterior region of the belly, where white predominates.

Tadpoles (pl. 10, fig. 14) of this species are found in artificial pools, in unused manure pools (and even in used ones), near houses, on parts of the plain very near to the hills, or on the mountain sides. They are generally found together with tadpoles of Rana adenopleura and sometimes with those of Rhacophorus omeimontis on Mount Omei. Rhacophorus leucomystax is very abundant around Taosze. No tadpoles of this species are ever found in running water of any kind, or in large ponds. They feed on decayed vegetation or dead animals in the pools.

The coloration varies greatly according to the condition of the pool. If there is no living or dead vegetation in the pool, and the water is clear, the tadpole is greenish yellow on the body and the base of the tail. This color is lighter toward the latero-ventral side of the body and the tip of the muscular part of the tail. The tail crest is light yellowish gray, especially toward the tip. The crest and the posterior region of the muscular part of the tail are finely marbled with gray, but near the tip the crest is free from marbling. The belly is opaque creamy white. Tadpoles collected from a pool with much dead or decaying vegetation, or with dirty water, are darker in color. The back and sides of the body are olive green, shading lower down through greenish yellow to creamy yellow, and finally to creamy white on the belly. Near the base, the tail is dark brownish, ashy or olive green, lighter toward the tip. The tail crest is a light purplish brown, dark buff at the base and also lighter toward the tip. In the middle, the tail is much marbled with umber. The sides of the body are creamy yellow and the belly is creamy white. The eye has a round black pupil ringed with a reddish golden iris. A small creamy-colored round spot on the tip of the snout is characteristic of the tadpoles of this species.

\section{Rhacophorus leucomystax: Measurements of Ten Tadpoles}

\begin{tabular}{|c|c|c|c|}
\hline Measurements & Range & Average & $\begin{array}{c}\text { Ratio to } \\
\text { body length (\%) }\end{array}$ \\
\hline Body length...... . & $12.6-13.7$ & 13.2 & \\
\hline Body height. & $8.2-9.1$ & 8.6 & 65.2 \\
\hline Body width. & $8.2-9.5$ & 8.4 & 63.8 \\
\hline Head height. & $4.6-5.5$ & 5.1 & 38.5 \\
\hline Head width. & $7.5-8.6$ & 8.0 & 60.7 \\
\hline Mouth width. & $3.2-3.7$ & 3.5 & 26.4 \\
\hline Snout to spiraculum. & $8.2-9.4$ & 8.7 & 66.1 \\
\hline Tail length.......... & $20.5-27.0$ & 24.4 & 185.0 \\
\hline Tail height. & $8.9-10.0$ & 9.5 & 72.0 \\
\hline Diameter of tail muscle & $2.8-4.4$ & 3.4 & 25.9 \\
\hline Length of hind leg. & $3.2-7.0$ & 4.9 & . \\
\hline
\end{tabular}


The size and form of the tadpoles are greatly influenced by the condition of the water in which they live. If food stuff is abundant, the tadpole is much larger and clumsy and the abdomen is very large. For the present study, the tadpoles from the same pool were measured at a stage with hind leg-buds present; these averaged $5 \mathrm{~mm}$., ranging from 3.2 to $7.0 \mathrm{~mm}$. The average total length from snout to tip of tail was $38 \mathrm{~mm}$. (see table). The tail fin is relatively the highest to be found among the tadpoles of frogs of western China. The muscular

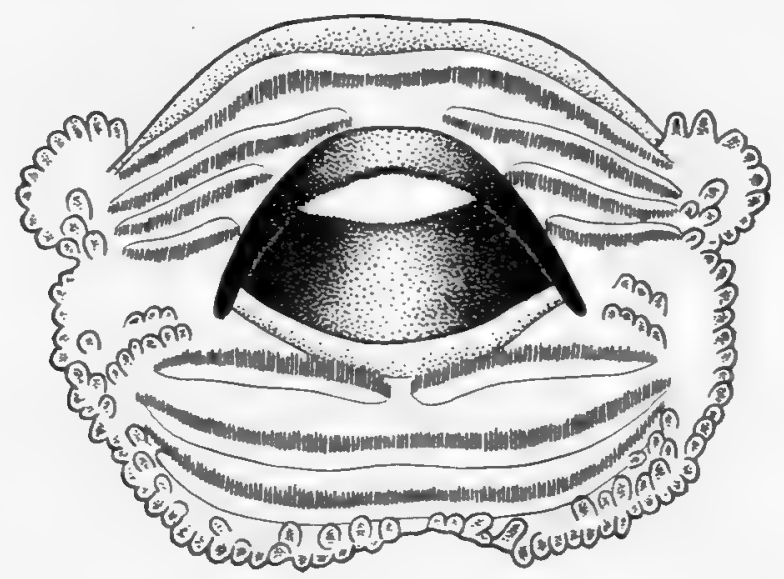

FIG. 94. Rhacophorus leucomystax; mouth of tadpole $(\times 20)$.

part of the tail is moderately developed. Just after metamorphosis, the young frog measures about $27 \mathrm{~mm}$. from snout to vent.

The head region is dorso-ventrally depressed, with the nostril nearer to the snout than to the eye. It is directed forward and sidewise and connected with the eye by a very conspicuous lachrymal canal. The eyes are lateral, with an interorbital space more than half the body length. The spiraculum is sinistral, directed upward and backward, without a tube, and barely visible from above and below. It is nearer to the base of the tail than to the tip of the snout, as from snout to spiraculum is 66 per cent of the body length. The vent is dextral, with the anal opening at the inner side of the right hind leg and at the base of the ventral tail crest. The tail is weakly developed, with a delicate pointed tip. The tail fin is very thin, especially near the tip of the tail.

The mouth (fig. 94) is antero-ventral in position, its width about 26 per cent of the body length. There is a single row of papillae at the lateral corner of the upper lip and on the free edge of the lower lip, a small ventro-median area being free from papillae. Three or more extra papillae are located at the ventral border of the upper lip inside the outer row. At the latero-ventral sides of the lower lip there is a somewhat irregular row of papillae inside the outer row. In some specimens, there are a few additional papillae between the outer and the inner rows. Above the lateral ends of the innermost row of lower labial teeth, there are two oblique folds with indistinctly separated papillae at each side of the corner of the mouth. Every papilla has a pigmented core. On the upper 
lip there are normally four rows of labial teeth, the outermost row complete, the other three rows all interrupted. The number of rows of labial teeth on the lower lip is constantly three, the innermost narrowly interrupted and the two outer rows complete, the middle row the longest. Twenty-six tadpoles studied for variation of rows of labial teeth exhibit the following variation: twenty-three have the tooth formula $\mathrm{I}: 3-3 / \mathrm{II}: 1-1$; two have I:4-4/II:1-1; and one has $I: 3-4 / I I: 1-1$. The upper mandible is moderately developed but the lower mandible is much the stronger; both have serrated edges.

\section{Rhacophorus dugritei David}

Polypedates dugritei David, 1871, Nouv. Arch. Mus. Hist. Nat. Paris, 7: 95-Mupin. Polypedates davidi Sauvage, 1877, Bull. Soc. Phil. Paris, (7), 1: 117-Mupin.

Rhacophorus davidi Boulenger, 1882, Cat. Batr. Sal., Brit. Mus., ed. 2, p. 83; Pope and Boring, 1940, Peking Nat. Hist. Bull., 15, pt. 1: 70 (in part).

Rhacophorus pleurostictus batangensis Vogt, 1924, Zool. Anz., 60: 341 (in part; Washan specimens only).

History of species.-Rhacophorus dugritei was collected from Paohsing (Muping), during Abbé David's second voyage, which lasted from May, 1868, to June, 1870. David (1871) described one of his frogs as Polypedates dugritei, named after M. Dugrité, a missionary who lived in western China for a long time. Herpetologists have uniformly followed Sauvage (1877) and Boulenger (1882) in using the name davidi for this tree frog. Pope and Boring (1940) placed all the west China tree frogs except leucomystax, namely, bambusicola, batangensis, and omeimontis, as synonyms of davidi. In 1940, I followed Pope and Boring in my life history of Rhacophorus davidi, but it is now clear that I was describing omeimontis and not the true davidi=dugritei. In 1945, I mentioned the similarity and differences of eight specimens collected from Shaping, Opienhsien, Szechwan, and identified them as Rhacophorus hui; now I know definitely that these are dugritei. My recent studies clearly show that davidi of Sauvage and Boulenger is an exact synonym of dugritei David.

Distribution and collection data.-David (1871) writes that he collected Rhacophorus dugritei from moist stones of the torrents of Paohsing, with another cascade frog, Staurois mantzorum; he fails to mention the altitude of the type locality of this tree frog. Paohsing is a district with an altitude ranging from about 3,000 to 13,000 feet, but the altitude of the type locality of Rhacophorus dugritei may well be about 3,000 feet, as I found Staurois mantzorum only around Paohsing City, in the lowest region of the Paohsing district. A female and seven males collected by Mr. Tang (1940) near Shaping, Opien, at an altitude of about 4,500 feet, indicate that the vertical distribution of dugritei is from about 3,000 to about 5,500 feet altitude.

Comparison with related species.-Rhacophorus dugritei (fig. 95) is closely related to bambusicola, differing in its greater body length, larger digital disks, and lower altitude range. The disk of the third finger is always larger than the 
tympanum in dugritei and never larger in bambusicola. The strong inner metatarsal tubercles and the short hind legs of dugritei distinguish this species from omeimontis, chenfui, and leucomystax.

Original description (translation).- "Among the moist stones of the torrents of Mouping live two frogs. They appear to be new. They have the toes elongated and terminating in large disks. I name them Polypedates Mantzorum and

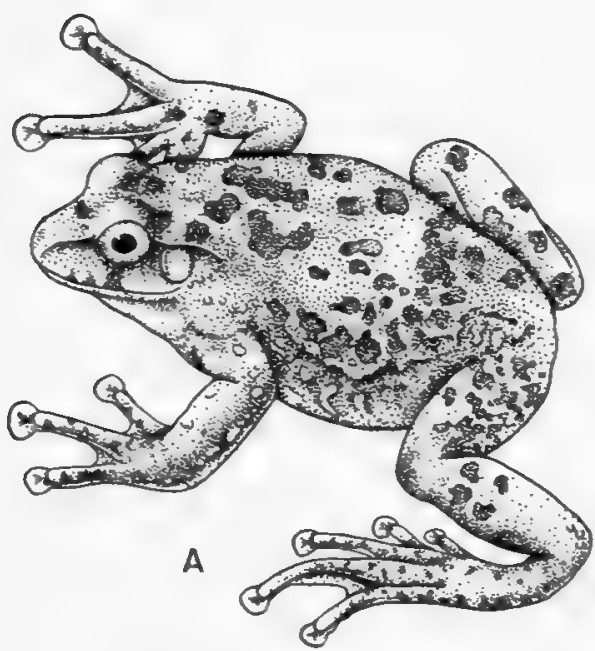

Fig. 95. Rhacophorus dugritei. A. Adult female $(\times 5 / 6)$ $\left(\times 1 \frac{1}{2}\right)$. C. Ventral view of foot $(\times 11 / 2)$.
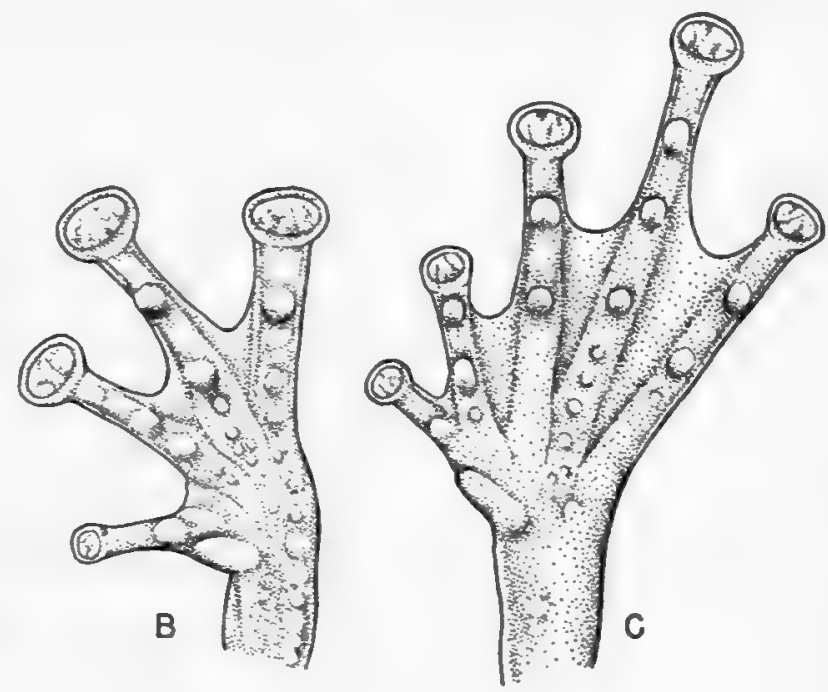

B. Ventral view of hand

Polypedates Dugritei. The second is a very beautiful species, slightly smaller in size. Above, it is of a beautiful green color, with round spots of metallic ashy gold. Yellow below, also spotted with metallic greenish. I give this latter animal the name of M. Dugrité in memory of the service I received from this missionary, who has lived for a long time in western China."

Description of adult male.-A typical adult male of this species, No. 536 Liu Collection, Shaping, Opien, altitude 4,500 feet, collected by Mr. Tang in 1940 , may be described. Body stout, $46 \mathrm{~mm}$. from snout to vent. Head broader than long, the snout bluntly pointed, sloping off in front, concave above, and slightly projecting; nostrils about midway from the snout to the eye; canthus rostralis well defined and extending to the tip of the snout; loreal region steep and concave; concave internasal space equal to the flat interorbital space; tympanum circular and about half the length of the eye; skin of the top of the head free; vomerine teeth in two transverse series, obliquely converging, separated posteriorly by a space about equal to the length of one tooth series, and their outer anterior ends on a line with the anterior corners of the choanae, from which they are narrowly separated; tongue free behind, widely notched, with numerous papillae on its upper surface.

Arm strong, with large hand; fingers $3,4,2,1$ in order of length; large digital disks on the second, third and fourth fingers, the first finger with a very 
small but distinct disk, the disk of the third finger larger than the tympanum; fingers 2, 3, and 4 about one-fourth webbed; the first finger with a vestigial web; subarticular tubercles very prominent, with additional tubercles at the bases of the fingers and palms; light-colored nuptial pads on the inner dorsal side of the first finger, and a very small narrow pad near the base of the inner dorsal side of the second finger.

Legs short and weak, the tibio-tarsal articulation reaching the tympanum; the heels widely separated when placed at right angles to the body; the toes (fig. 95, C) about one-third webbed, all provided with disks, but the disks smaller than those of the second, third, and fourth fingers; subarticular tubercles well developed, with additional tubercles at the bases of the toes and on the sole; the inner metatarsal tubercle shovel-like, strongly developed, with a free cutting edge; no outer metatarsal tubercle.

Skin rough, covered by fine granules on the back and coarse granules on the belly; skin on the top of the head free; skin on the throat loose and wrinkled by the median subgular external vocal sac; a sharply defined skin fold from the posterior corner of the eye to the shoulder.

Rhacophorus dugritei: Measurements of One Female and Seven Male Adults

\begin{tabular}{|c|c|c|c|c|}
\hline Measurements & Sex & Range & Average & $\begin{array}{c}\text { Ratio to } \\
\text { body length }(\%)\end{array}$ \\
\hline Body length...... & $\begin{array}{l}0^{7} \\
0\end{array}$ & $\begin{array}{c}44-47 \\
66\end{array}$ & $\begin{array}{l}45.4 \\
66.0\end{array}$ & $\ldots$ \\
\hline Head length. & $\begin{array}{l}0^{7} \\
\wp\end{array}$ & $\begin{array}{c}14-16 \\
21\end{array}$ & $\begin{array}{l}15.2 \\
21.0\end{array}$ & $\begin{array}{l}33.5 \\
31.8\end{array}$ \\
\hline Head width. & $\begin{array}{l}0^{7} \\
\text { \& }\end{array}$ & $\begin{array}{c}16-17 \\
23\end{array}$ & $\begin{array}{l}16.4 \\
23.0\end{array}$ & $\begin{array}{l}36.1 \\
34.9\end{array}$ \\
\hline Interorbital space. . & $\begin{array}{l}0^{7} \\
\text { \% }\end{array}$ & $\begin{array}{c}4.9-5.0 \\
7\end{array}$ & $\begin{array}{l}5.0 \\
7.0\end{array}$ & $\begin{array}{l}11.0 \\
10.6\end{array}$ \\
\hline Length of eye.. & $\begin{array}{l}\sigma^{7} \\
\text { 9 }\end{array}$ & $\begin{array}{c}4.5-6.0 \\
7\end{array}$ & $\begin{array}{l}5.5 \\
7.0\end{array}$ & $\begin{array}{l}12.1 \\
10.6\end{array}$ \\
\hline Tympanum. . & $\begin{array}{l}9 \\
9\end{array}$ & $\begin{array}{l}2.0-2.8 \\
3.8\end{array}$ & $\begin{array}{l}2.5 \\
3.8\end{array}$ & $\begin{array}{l}5.5 \\
5.8\end{array}$ \\
\hline Length of lower arm.... & $\begin{array}{l}9 \\
9\end{array}$ & $\begin{array}{c}23-25 \\
39\end{array}$ & $\begin{array}{l}24.3 \\
39.0\end{array}$ & $\begin{array}{l}53.5 \\
59.0\end{array}$ \\
\hline Diameter of lower arm.. & $\begin{array}{l}\sigma^{7} \\
\text { \& }\end{array}$ & $\begin{array}{c}4-6 \\
7\end{array}$ & $\begin{array}{l}5.0 \\
7.0\end{array}$ & $\begin{array}{l}11.0 \\
10.6\end{array}$ \\
\hline Length of hand......... & $\begin{array}{l}0^{7} \\
\text { \& }\end{array}$ & $\begin{array}{c}14.8-16.5 \\
23\end{array}$ & $\begin{array}{l}15.4 \\
23.0\end{array}$ & $\begin{array}{l}33.9 \\
34.9\end{array}$ \\
\hline Width of third-finger disk...... & $\begin{array}{l}0^{7} \\
q\end{array}$ & $\begin{array}{l}3 \\
5\end{array}$ & $\begin{array}{l}3.0 \\
5.0\end{array}$ & $\begin{array}{l}6.5 \\
7.6\end{array}$ \\
\hline Length of hind leg...... & $\begin{array}{l}\sigma^{7} \\
q\end{array}$ & $\begin{array}{c}57-64 \\
90\end{array}$ & $\begin{array}{l}61.0 \\
90.0\end{array}$ & $\begin{array}{l}134.4 \\
136.4\end{array}$ \\
\hline Length of tibia. & $\begin{array}{l}0 \\
9 \\
9\end{array}$ & $\begin{array}{c}16.8-18.0 \\
26\end{array}$ & $\begin{array}{l}17.2 \\
26.0\end{array}$ & $\begin{array}{l}37.9 \\
39.4\end{array}$ \\
\hline Length of foot and tarsus...... & $\begin{array}{l}0^{7} \\
\text { क }\end{array}$ & $\begin{array}{c}27-32 \\
44\end{array}$ & $\begin{array}{l}29.6 \\
44.0\end{array}$ & $\begin{array}{l}65.2 \\
66.7\end{array}$ \\
\hline Width of fourth-toe disk... & $\begin{array}{l}0^{7} \\
0\end{array}$ & $\begin{array}{c}2.0-2.8 \\
4\end{array}$ & $\begin{array}{l}2.4 \\
4.0\end{array}$ & $\begin{array}{l}5.3 \\
6.1\end{array}$ \\
\hline $\begin{array}{l}\text { Length of inner metatarsal } \\
\text { tubercle......................... }\end{array}$ & $\begin{array}{l}7 \\
8\end{array}$ & $\begin{array}{c}2.7-3.4 \\
5.5\end{array}$ & $\begin{array}{l}3.1 \\
5.5\end{array}$ & $\begin{array}{l}6.8 \\
8.3\end{array}$ \\
\hline
\end{tabular}


Deep greenish black on the back and the upper sides of the limbs (green in life), with small round brown spots on the back; sides of the body and posterior sides of the hind limbs much marbled with cream-yellow on the same ground color; throat dark; belly and ventral sides of the limbs cream-yellow, spotted by dark gray; upper sides of the digits much lighter, especially the two inner fingers and the three inner toes.

Sex dimorphism.- Sex dimorphism in size is marked, body length of males averaging $45 \mathrm{~mm}$.; that of a single female is $66 \mathrm{~mm}$. The male has an external median subgular vocal sac, with two slit-like openings at the side of the angle of the jaw. Cream-colored nuptial pads are developed on the inner dorsal sides of the first and second fingers of the male, and the lineae masculinae are well developed. The arms are longer and the digital disks are larger in the female.

Variation.-That the coloration varies greatly was noted by Pope when he studied the types in the Paris Museum. The only female specimens in my collection have very large brown spots enclosed by dark rims on the back; the throat and the belly are marbled with gray. The belly of the male is spotted or marbled in five specimens, and nearly without spots or marbling in two.

The vomerine tooth patches vary greatly, and some specimens appear to have only bony ridges, without teeth. No. 537 has two curved weak bony ridges between the choanae; No. 534 has stronger patches provided with teeth; No. 535 has very strong toothed ridges; in No. 538 a very short but strong left patch is provided with teeth, and the right one is a long, but weak and toothless, bony ridge; and Nos. 539, 515, and 533 have long, weak, bony ridges without teeth.

\section{Rhacophorus bambusicola Barbour}

Hyla monticola Barbour, 1912, Mem. Mus. Comp. Zool., 40 : 127-Washan, Szechwan (not of Peters).

Hyla bambusicola Barbour, 1920, Copeia, No. 85: 98 (substitute name for H. monticola, preoccupied).

Rhacophorus pleurostictus batangensis Vogt, 1924, Zool. Anz., 60 : 341-Batang, Sikang (in part).

Rhacophorus davidi Pope and Boring, 1940, Peking Nat. Hist. Bull., 15, pt. 1: 70 (in part).

Rhacophorus hui Liu, 1945, Jour. West China Border Res. Soc., 15, (B): 37-Yenwot'ang, Chaochiao, Sikang; idem, op. cit.: 65.

History of species.-In 1912, Barbour described Hyla monticola from a male specimen collected by W. R. Zappey at Washan, Szechwan, at an altitude of 10,500 feet. The name monticola being preoccupied in Hyla, Barbour substituted the name bambusicola in 1920. Pope and Boring (1940) placed bambusicola as a synonym of Rhacophorus davidi. In 1924, Vogt described another tree frog from Batang, Sikang, as Rhacophorus pleurostictus batangensis. From Mr. Pope's notes on the cotypes in the Berlin Museum, the specimens collected from Batang are referable to bambusicola; Rhacophorus hui, described by myself in 1945, is certainly also a synonym of bambusicola. 
Distribution and collecting data.-Rhacophorus bambusicola is a high mountain form found from 8,000 to 12,000 feet altitude. The species is endemic in the western part of Szechwan and in Sikang, being known mainly from four localities: the type locality, Washan, and Mount Omei, Szechwan; and Yenwot'ang, Chaochiao, and Batang, Sikang. It is possible that this species is generally distributed in high mountains of western Szechwan and Sikang.

I found my first specimen of $R$. bambusicola at 2 P.M., May 4, 1942, by attending to its croak, which is very much like the sound produced by $R$. ome $i$ montis. By turning stones near ditches, where we heard the croaking, Mr. Y.W. Kao found two males and eggs in foam-masses buried in the ground, with a small portion exposed. On June 14, 1942, fourteen males and a female were obtained at the time of pairing, and egg-masses and young tadpoles were collected from the same locality, Yenwot'ang. On June 15, 1945, adults, eggmasses and tadpoles were collected from Mount Omei, from 8,000 feet to the top of the mountain.

Comparison with related species.-Rhacophorus bambusicola (pl. 8, figs. 4, 5) is closely related to $R$. dugrite $i$, but it is smaller and the disk of its third finger is not larger than the tympanum, whereas in $R$. dugritei the disk of the third finger is always larger than the tympanum. The vertical distribution of bambusicola is from 8,000 to 12,000 feet altitude, and that of $R$. dugrite $i$ is from 3,000 to about 5,500 feet. $R$. bambusicola can easily be distinguished from $R$. leucomystax, omeimontis, and chenfui by its shorter leg and strongly developed inner metatarsal tubercle, the tibio-tarsal articulation reaching only beyond the shoulder in bambusicola, reaching the snout in leucomystax, and reaching at least to the eye in omeimontis and chenfui.

Original description.- "Vomerine teeth in two elongate series, well separated, converging backward, beginning between the middle of the extremely small choanae and extending considerably posterior to them. Tongue large and long, deeply nicked behind. Nostrils midway between eye and tip of snout, their distance from each other much greater than their distance from the labial margin. Interorbital space much greater than width of upper eyelid. Tympanum almost circular, its diameter less than half that of the eye. Fingers distinctly webbed at base, slender, terminating in very small disks. Feet with rather slightly developed webs, tarso-metatarsal joint reaching tip of snout. Toes long, disks slightly larger than those of fingers. Subarticular tubercles very weak; a weak inner and no outer metatarsal tubercle. Skin above smooth, below smooth on chest, but granular on throat and strongly granular on belly. An external vocal sac in male. Color in alcohol:-blue above with ocelli of dark brown, their centers brick-red. Throat dusky gray. Belly and inner side of limbs white, with many dark spots. Color in life:- 'green above, with ocelli of brown, with reddish centers. Inner side of thighs buff. Lower surfaces chrome-yellow.'"

The type specimen is not in good condition, and the original description is inadequate and contains some misinterpretations. It is to be corrected and supplemented as follows: 
Fingers (fig. 96, A), except the first, about one-fourth webbed; the disk of the third finger about two-thirds the diameter of the tympanum; subarticular tubercles distinct; toes (fig. 96, B) one-third webbed, the disks smaller than those of the fingers; subarticular tubercles distinct; the bases of the outer three toes with a row of small white tubercles on the ventral side; inner metatarsal tubercle shovel-like, strongly developed and with a free cutting edge; outer metatarsal tubercle indicated, flat; skin above finely granulated; a strong supratympanic fold from the posterior corner of the eye to the shoulder.

Variation.-The vomerine tooth patches in $R$. bambusicola, like those of dugritei, are extremely variable. In four specimens, one has teeth on the left

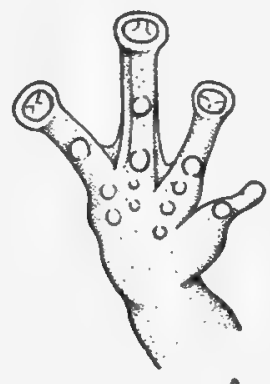

A

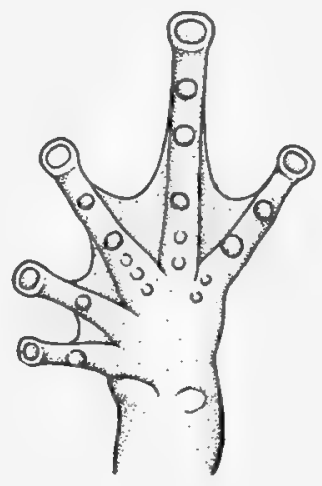

B of foot.

FIG. 96. Rhacophorus bambusicola $(\times 2)$. A. Ventral view of hand. B. Ventral view

patch and only a bony ridge on the right; two have two long ridges without teeth; and one has two widely separated tooth patches.

The coloration also varies greatly. The ground color, on the dorsal side of the head and the body, varies from light to dark green, to light olive-green and even to greenish-brown. Spots of varying size are found on the head and body, enclosed by light brown margins. The color and number of the spots vary greatly. Light green specimens have golden spots, whereas brownish golden or brown spots are found on dark green, olive green, or greenish brown individuals. The brown spots of the greenish brown specimens are lighter in color than the ground color and are sometimes inconspicuous. Some individuals have cream spots on the back, and these spots are much smaller than those of other types. The dorso-lateral sides of the body are lighter than the back. The sides are much marbled with black and cream. Near the armpit and groin, the color is much darker than the middle region of the body. The margin of the jaw is pale golden, with or without dark or light bars. The black pupil is horizontally oval, enclosed by a golden ring outside of which the iris is pinkish golden with fine black stippling. The upper sides of the limbs are like the back, but lighter towards the digits. The posterior aspects of the limbs are much marbled with brown or black, especially on the hind limbs, the concealed parts of which have 
black and cream marbling. The belly is cream yellow, marbled or spotted with brown or dark gray. The only female we collected is creamy-white on the belly, without spots or marbling. In the very few young specimens the back is green with a few black spots, the belly light yellow, and the vent region slightly marbled.

Sex dimorphism in size is considerable, the average body length of the adult males being $40 \mathrm{~mm}$., ranging from 34 to $43 \mathrm{~mm}$., whereas the only female in my collection measures $51 \mathrm{~mm}$. The type male measures $40 \mathrm{~mm}$. The body lengths of two gravid females collected at Batang and measured by Pope are $51 \mathrm{~mm}$. The hind limbs of females are longer than those of males. The snout is much more pointed in the male than in the female. Well-developed gray granular nuptial pads cover the basal inner dorsal sides of the first and second fingers of the male. The male has a median subgular external vocal sac, with two long slits as openings near the angles of the jaws. Lineae masculinae are present.

Rhacophorus bambusicola: Measurements of One Female and Ten Male Adults

\begin{tabular}{|c|c|c|c|c|}
\hline Measurements & Sex & Range & Average & $\begin{array}{c}\text { Ratio to } \\
\text { body length (\%) }\end{array}$ \\
\hline Body length....... & $\begin{array}{l}\sigma^{9} \\
0\end{array}$ & $\begin{array}{c}34-43 \\
51\end{array}$ & $\begin{array}{l}40.0 \\
51.0\end{array}$ & $\ldots$ \\
\hline Head length..... & $\begin{array}{l}0^{x} \\
\varnothing\end{array}$ & $\begin{array}{c}11.5-14.8 \\
16.5\end{array}$ & $\begin{array}{l}13.7 \\
16.5\end{array}$ & $\begin{array}{l}34.3 \\
32.3\end{array}$ \\
\hline Head width. & $\begin{array}{l}0 \\
9\end{array}$ & $\begin{array}{c}12.5-15.8 \\
18.5\end{array}$ & $\begin{array}{l}14.8 \\
18.5\end{array}$ & $\begin{array}{l}37.0 \\
36.2\end{array}$ \\
\hline Interorbital space... & $\begin{array}{l}\sigma^{7} \\
q\end{array}$ & $\begin{array}{c}4.2-5.0 \\
6.0\end{array}$ & $\begin{array}{l}4.6 \\
6.0\end{array}$ & $\begin{array}{l}11.5 \\
11.7\end{array}$ \\
\hline Tympanum................ & $\begin{array}{l}7 \\
9\end{array}$ & $\begin{array}{c}2.5-3.0 \\
3.4\end{array}$ & $\begin{array}{l}2.7 \\
3.4\end{array}$ & $\begin{array}{l}6.7 \\
6.6\end{array}$ \\
\hline Length of lower arm. . & $\begin{array}{l}0^{x} \\
9\end{array}$ & $\begin{array}{c}19-24 \\
30\end{array}$ & $\begin{array}{l}21.3 \\
30.0\end{array}$ & $\begin{array}{l}53.4 \\
58.8\end{array}$ \\
\hline Diameter of lower arm. & $\begin{array}{l}\sigma^{7} \\
q\end{array}$ & $\begin{array}{c}4.0-5.2 \\
5.5\end{array}$ & $\begin{array}{l}4.7 \\
5.5\end{array}$ & $\begin{array}{l}11.8 \\
10.7\end{array}$ \\
\hline Length of hand...... & $\begin{array}{l}0^{7} \\
9\end{array}$ & $\begin{array}{c}12.0-15.2 \\
19\end{array}$ & $\begin{array}{l}13.9 \\
19.0\end{array}$ & $\begin{array}{l}34.7 \\
37.2\end{array}$ \\
\hline Width of third-finger disk. & $\begin{array}{l}0 \\
9\end{array}$ & $\begin{array}{c}1.5-2.2 \\
2.5\end{array}$ & $\begin{array}{l}2.0 \\
2.5\end{array}$ & $\begin{array}{l}5.0 \\
4.9\end{array}$ \\
\hline Length of hind leg. . & $\begin{array}{l}0 \\
0 \\
9\end{array}$ & $\begin{array}{c}46-57 \\
71\end{array}$ & $\begin{array}{l}52.2 \\
71.0\end{array}$ & $\begin{array}{l}130.5 \\
139.1\end{array}$ \\
\hline Length of tibia. & $\begin{array}{l}0 \\
9\end{array}$ & $\begin{array}{c}13.0-15.7 \\
20.5\end{array}$ & $\begin{array}{l}14.6 \\
20.5\end{array}$ & $\begin{array}{l}36.6 \\
40.1\end{array}$ \\
\hline Length of foot.... & $\begin{array}{l}0^{x} \\
8\end{array}$ & $\begin{array}{l}14.5-20.0 \\
25\end{array}$ & $\begin{array}{l}17.9 \\
25.0\end{array}$ & $\begin{array}{l}44.7 \\
49.0\end{array}$ \\
\hline Width of fourth-toe disk. & $\begin{array}{l}0^{7} \\
9\end{array}$ & $\begin{array}{c}1.3-1.9 \\
2\end{array}$ & $\begin{array}{l}1.6 \\
2.0\end{array}$ & $\begin{array}{l}4.1 \\
3.9\end{array}$ \\
\hline
\end{tabular}

Habitat and habits.-Rhacophorus bambusicola is more terrestrial than arboreal, being found under stones, or in grass, and near ditches on the top of the mountains of 11,000 feet altitude between Hsuanshenpa and Lolokou, Chaochiao, Sikang. On Mount Omei we found this species under roots of vegetation near the edges of ponds and pools and on low bushes on the hillsides 
at from 8,000 to 11,000 feet altitude. The male sings like a bird, its voice being similar to that of Rhacophorus omeimontis. No specimens of bambusicola have been found on trees, on roofs of houses, or in water.

Breeding behavior. - The breeding season of this tree frog seems to be from the beginning of May to the end of June, as we found egg-foams and paired individuals on May 4, and egg-foams, tadpoles, and paired individuals again on June 16 of the same year, at Chaochiao. On June 15, 1945, egg-foams, tadpoles, and adults were found on the top of Mount Omei.

The male holds the female in axillary embrace. The egg-laying is much like that of leucomystax, according to my observations.

Eggs.--The eggs are buried in a single foam mass (fig. 97, A) that she forms by beating the fluid secreted with the eggs, and the shape of the mass varies greatly, according to the situation. The egg-foams are usually laid in holes near side pools, ponds, or ditches, or under stones, logs, or even roots of vegetation near any body of water. Occasionally they are found under stones on hillsides far away from water. Egg-foams laid in holes are usually elongated or oval, according to the shape of the holes; those under stones or roots of vegetation vary greatly in shape. One egg-foam, laid in a hole, was measured in the field as 65 by $70 \mathrm{~mm}$. The freshly laid egg-foam is white and the older ones are light brown.

The eggs are white. They are scattered singly or in groups mostly inside the foam, with only a very few at the surface. Each egg is enclosed by two layers of jelly, of which the outer layer is much thicker, the inner being directly applied to the surface of the egg. The egg-foam is a common protective sticky substance. Before the embryos are well differentiated, it is very difficult to remove the egg or the embryo from the foam, as the foam and the jelly capsules of the eggs are firmly stuck together. When the embryo is well differentiated, the foam around the jelly capsule of each embryo liquefies and loses its stickiness, a layer of brownish fluid appearing around each embryo. The eggs are small, ranging from 2 to $2.2 \mathrm{~mm}$. in diameter, with an average of $2.1 \mathrm{~mm}$.

Tadpole.-The process and fashion of development resemble those of omeimontis and leucomystax, the embryos lying on a large yolk mass. Just after hatching, the young tadpole has three groups of external gill filaments on each side of the neck. The filaments are long, flattened antero-posteriorly, and without pigment. Dark pigment granules are scattered on the back and the belly is creamish white. The tail of the newly hatched tadpole, in proportion to the body length, is much longer than that of the mature tadpole. The total length from the tip of the snout to the tip of the tail of the newly hatched individual is $8.8 \mathrm{~mm}$., with a body length of $2.8 \mathrm{~mm}$. and a tail length of $6 \mathrm{~mm}$.; the length of the tail at this stage is 214 per cent of the body length. When the tadpole (fig. 97, B) has its hind limb-bud developed, the total length is 32 mm., of which the body length is $13 \mathrm{~mm}$. and the tail is $19 \mathrm{~mm}$.; the tail length amounts to 146 per cent of the body length. 

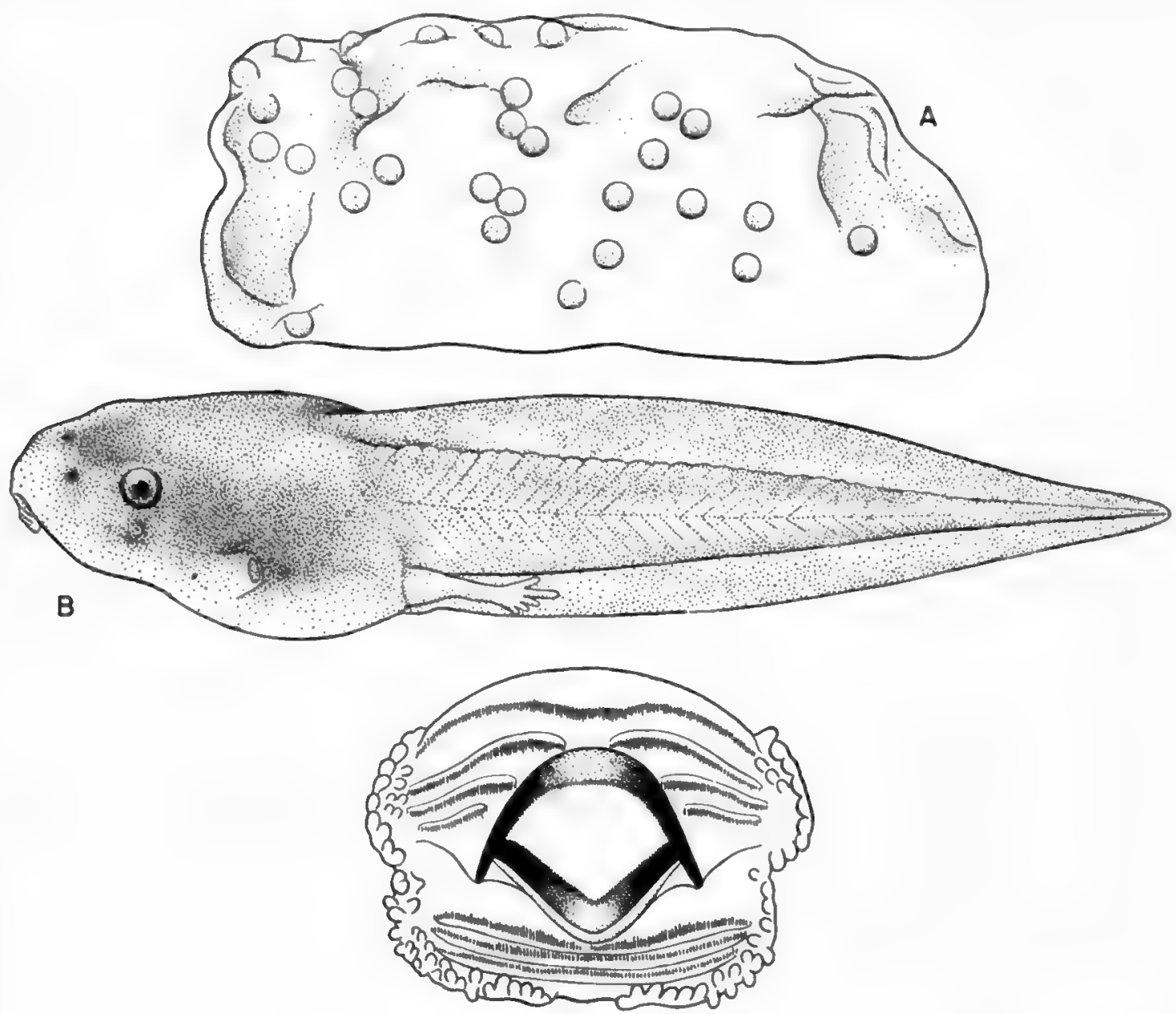

C

FIG. 97. Rhacophorus bambusicola. A. Egg-mass $\left(\times 1 \frac{1}{2}\right)$. B. Lateral view of tadpole $\left(\times 4 \frac{1}{4}\right)$. C. Mouth of tadpole $(\times 21)$.

The general shape of the body and the form of the tail are very much like those of the tadpoles of omeimontis. The coloration varies according to age and environment. Under natural conditions, the tadpoles are darker on a rainy day and lighter on a bright day, and those raised in the laboratory are much darker than those under natural conditions. The young tadpole with hind limbbuds is cream-yellow to yellowish olive green; the head is somewhat transparent and lighter in color than the body. As the hind legs develop, the color of the head and body become olive-green and the head remains lighter than the body. The tail is stippled with dark, especially at the margin and at the tip of the fin. The dark tail tip can be used as a field character to distinguish bambusicola tadpoles from those of omeimontis. The belly is stippled with gold. The round pupil is black; the iris is formed by an inner gold ring and an outer dark one.

The mouth (fig. 97, C) of the tadpole is ventral rather than anterior. The sides of the upper lip are provided with a row of large papillae, with some extra 
small papillae on the inside of the outer row. There is a small space free from papillae in the ventral middle region of the lower lip. On the free margin of the lower lip, except for the space mentioned, there is a single row of papillae. Inside this row, some extra papillae are developed, especially at the latero-ventral corners. The labial teeth are constant. There are four rows on the upper lip, the outermost continuous, the three inner rows interrupted, and the innermost row the shortest. The lower lip bears three rows of labial teeth, the innermost row narrowly interrupted, the two outer rows continuous, and the second row the longest. The mandibles are rather weak, with finely denticulate margins.

\section{Rhacophorus omeimontis Stejneger}

Polypedates omeimontis Stejneger, 1924, Occ. Pap. Boston Soc. Nat. Hist., 5: 120 Mount Omei; idem, 1925, Proc. U. S. Nat. Mus., 66, art. 25: 31.

Rhacophorus davidi Pope and Boring, 1940, Peking Nat. Hist. Bull., 15, pt. 1: 70 (in part); Liu, 1941, Peking Nat. Hist. Bull., 15, pt. 3: 243.

History of species.-D. C. Graham collected a specimen of this species on Mount Omei and Stejneger described it as a new species, Polypedates omeimontis, in 1924. Pope and Boring (1940) put Polypedates omeimontis Stejneger in the synonymy of Rhacophorus davidi. I find the species entirely distinguishable. Unfortunately, my notes on the life history of omeimontis were published under the name davidi.

Distribution and collection data.-Rhacophorus omeimontis is limited to western Szechwan and eastern Sikang, with a vertical distribution ranging from 3,000 to 6,500 feet altitude. Many adults and tadpoles of different stages were collected from Mount Omei during the summers of 1938, 1940, and 1945. Adults as well as egg-nests and tadpoles of different stages were obtained from Yaan and Tienchuan, in Sikang, during the summers of 1939 and 1943; and from Tsingch'engshan, Kwanhsien, and Panlungshan, Szechwan, during the spring and summer of 1939, 1940, and 1941.

Comparison with related species.-Rhacophorus omeimontis (pl. 8, fig. 3) is more closely related to the large handsome green tree frog, dennysi, endemic to southeastern China, than to the other species of Rhacophorus of western China. Rhacophorus omeimontis can easily be separated from dennysi. In omeimontis there are irregular brown markings on the back, and the third and fourth fingers are about half webbed, whereas dennysi is usually uniform green on the back with rounded brown spots in some individuals, and the third and fourth fingers are two-thirds webbed; omeimontis is much smaller than dennysi. Webs are not developed between the fingers of $R$. leucomystax, but the fingers of omeimontis are all webbed. The hind leg is considerably longer in omeimontis and much shorter in bambusicola and dugritei, as the tibio-tarsal articulation reaches the eye in omeimontis and only the shoulder region in dugritei and bambusicola. Rhacophorus chenfui is uniform green on the back and has only slight webbing between the first and second fingers. In omeimontis, irregular brown markings 
are always developed on the back, and the web is well developed between the first and second fingers.

Original description.- "Fingers half-webbed; head without spines; nocutaneous folds along legs; no dermal flap at heel; vomerine teeth in two slightly oblique series between the choanae; tympanum distinct, more than half the width of eye; upper and lower surfaces, except of hands and feet, granular; interorbital space slightly broader than upper eyelid; largest digital disc nearly as large as tympanum; tibio-tarsal joint reaching posterior angle of eye."

Description of adult female.-Body moderately stout and somewhat depressed. Head slightly broader than long; above view of snout somewhat pointed,

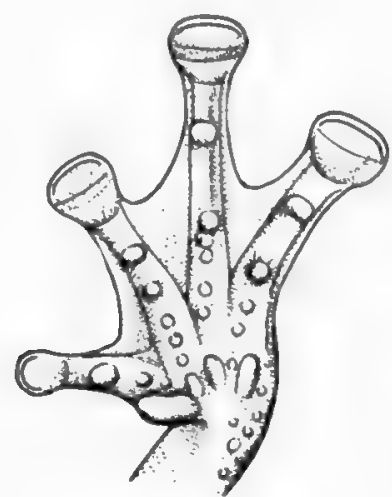

A

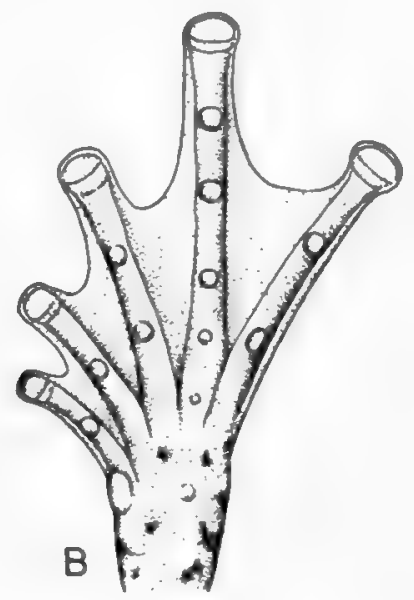
of foot.

FIG. 98. Rhacophorus omeimontis $(\times 2)$. A. Ventral view of hand. B. Ventral view

profile of snout conspicuously declivous and almost angulate at the nostril; canthus rostralis sharp, overhanging the concave loreal region; nostrils slightly nearer to the tip of the snout than to the anterior corner of the eye; internasal space equal to the width of the upper eyelid, which is about two-thirds the width of the interorbital space; tympanum nearly circular, about one-half of the interorbital space; vomerine teeth in two long, strong and slightly oblique series starting near the inner anterior corner of the choanae, extending backward and inward, separated with a space about equal to half of one vomerine tooth series; tongue large and deeply notched behind, with distinct papillae on the dorsum.

Arms long, with very large hands and long broad fingers; the lower arm more than half the length of the body; the length of the hand about one-third of the body length; fingers (fig. 98, A) 3, 4, 2, 1 in order of length; one-half webbed between the third and fourth fingers; about one-half webbed between the second and third fingers; very large disks on the second, third and fourth fingers and a small one on the tip of the first finger; the width of the disk of the third finger about the same as the diameter of the tympanum; subarticular tubercles strongly developed, especially the distal ones; smaller tubercles developed on the palm 
and arranged in rows in a line with the third and fourth fingers; prohallux well developed.

Legs moderately long but slender, the tibio-tarsal articulation reaching the middle of the eye; tibia about half of the length of the body; toes (fig. 98, B) flattened, the fourth the longest, the fifth and third about equal, the second and first the shortest; toes nearly fully webbed, the webs reaching the bases of the disks of the first, second, third, and fifth toes; disks of the toes about two-thirds of the size of those of the fingers but all well developed; subarticular tubercles well developed, with small tubercles on sole and arranged in rows continuing the lines of the outer toes; inner metatarsal tubercle weakly developed and without outer metatarsal tubercle.

Skin rough, with small scattered granules on the upper side of the head, body and limbs; larger rounded granules crowded on the ventral side of the body and the hind limbs; scattered granules or tubercles on hands and feet; skin otherwise smooth; a sharp narrow dermal fold from the eye over the tympanum to the shoulder.

Rhacophorus omeimontis: Measurements of Eighteen Male and Seven Female Adults

\begin{tabular}{|c|c|c|c|c|}
\hline Measurements & Sex & Range & Average & $\begin{array}{c}\text { Ratio to } \\
\text { body length }(\%)\end{array}$ \\
\hline Body length...... & $\begin{array}{l}\sigma^{x} \\
0\end{array}$ & $\begin{array}{l}52.0-65.5 \\
70.0-79.5\end{array}$ & $\begin{array}{l}59.0 \\
75.7\end{array}$ & $\ldots$ \\
\hline Head length. & $\begin{array}{l}\sigma^{7} \\
\varnothing\end{array}$ & $\begin{array}{l}15.5-21.7 \\
18.6-24.7\end{array}$ & $\begin{array}{l}19.0 \\
22.7\end{array}$ & $\begin{array}{l}32.3 \\
30.0\end{array}$ \\
\hline Head width & $\begin{array}{l}0^{7} \\
q\end{array}$ & $\begin{array}{l}18.0-22.5 \\
24.5-29.0\end{array}$ & $\begin{array}{l}19.9 \\
25.8\end{array}$ & $\begin{array}{l}33.8 \\
34.1\end{array}$ \\
\hline Interorbital space. & $\begin{array}{l}0^{7} \\
\text { o }\end{array}$ & $\begin{array}{l}6.4-8.0 \\
8.2-9.6\end{array}$ & $\begin{array}{l}7.1 \\
8.6\end{array}$ & $\begin{array}{l}12.0 \\
11.3\end{array}$ \\
\hline Tympanum. & $\begin{array}{l}0^{7} \\
q\end{array}$ & $4.6-5-5.4$ & $\begin{array}{l}4.4 \\
5.1\end{array}$ & $\begin{array}{l}7.4 \\
6.8\end{array}$ \\
\hline Length of lower arm. & $\begin{array}{l}0 \\
9\end{array}$ & $\begin{array}{c}30.0-44.5 \\
48-59\end{array}$ & $\begin{array}{l}37.1 \\
54.0\end{array}$ & $\begin{array}{l}62.9 \\
71.3\end{array}$ \\
\hline Diameter of lower arm. & $\begin{array}{l}0^{7} \\
\text { o }\end{array}$ & $\begin{array}{l}4.8-6.7 \\
6.5-7.8\end{array}$ & $\begin{array}{l}5.7 \\
7.3\end{array}$ & $\begin{array}{l}9.6 \\
9.7\end{array}$ \\
\hline Length of hand. . & $\begin{array}{l}0^{7} \\
\text { o }\end{array}$ & $\begin{array}{l}17.0-23.6 \\
23.5-25.5\end{array}$ & $\begin{array}{l}20.2 \\
24.5\end{array}$ & $\begin{array}{l}34.2 \\
32.4\end{array}$ \\
\hline Width of third-finger disk. & $\begin{array}{l}0^{7} \\
\$\end{array}$ & $\begin{array}{l}3.7-5.5 \\
5.3-6.5\end{array}$ & $\begin{array}{l}4.2 \\
5.7\end{array}$ & $\begin{array}{l}7.2 \\
7.5\end{array}$ \\
\hline Length of hind leg. & $\begin{array}{l}0^{7} \\
\text { o }\end{array}$ & $\begin{array}{r}83-114 \\
117-130\end{array}$ & $\begin{array}{r}99.2 \\
121.3\end{array}$ & $\begin{array}{l}168.1 \\
160.2\end{array}$ \\
\hline Length of tibia. & $\begin{array}{l}0^{7} \\
q\end{array}$ & $\begin{array}{l}26.6-32.5 \\
36.0-40.5\end{array}$ & $\begin{array}{l}29.9 \\
37.9\end{array}$ & $\begin{array}{l}50.6 \\
50.1\end{array}$ \\
\hline Length of foot.... & $\begin{array}{l}0^{7} \\
q\end{array}$ & $\begin{array}{l}23.3-29.8 \\
31.0-32.8\end{array}$ & $\begin{array}{l}26.5 \\
32.2\end{array}$ & $\begin{array}{l}44.9 \\
42.5\end{array}$ \\
\hline Width of fourth-toe disk. & $\begin{array}{l}0^{7} \\
8\end{array}$ & $\begin{array}{l}2.7-4.0 \\
3.5-4.5\end{array}$ & $\begin{array}{l}3.2 \\
4.1\end{array}$ & $\begin{array}{l}5.4 \\
5.4\end{array}$ \\
\hline
\end{tabular}

Coloration in life.-The ground color is grass green with large brown markings on the back and the dorsal side of the limbs. The form and size of the brown marks vary greatly and some specimens may have darker brown marks or spots 
on the brown marks. The dorsal sides of the three inner fingers and the two inner toes are much lighter. The ventral side is cream in color, with the throat stippled with dark. The sides of the body are mottled by dark brown. The webs are gray, spotted with dark gray, and the dorsal sides of the disks are yellowish gray. The coloration of the living animals varies greatly and is changeable under different conditions. If its surroundings are dark and wet, the animal will have a deeper color; otherwise it will be light. In general the coloration of this tree frog is very much like the bark of a tree partially covered by lichen and moss, and the frog is usually found in this situation. After the specimens are preserved in formalin, the green ground color becomes dark bluish and the brown markings and dark brown marbling become indistinct on the back, but they remain conspicuous on the sides of the body and the anterior and posterior sides of the hind legs.

Secondary sex characters.-Sex dimorphism in size is clearly shown in this species of tree frogs, the average body length being about $59 \mathrm{~mm}$. in the male and $76 \mathrm{~mm}$. in the female. Males are provided with two patches of white nuptial pads, the larger on the inner dorsal side of the first finger and the smaller on the inner dorso-distal portion of the first segment of the second finger. The male has an internal median subgular vocal sac with two slit-like openings inside of the mouth near the angles of the jaws. Lineae masculinae are present.

Habitat and habits.-Adults of Rhacophorus omeimontis are found in grass, on trees and other vegetation, under stones by the side of ponds and pools, and on the roofs and walls of houses and temples on the hillside. For this reason the animal is commonly known as the tree climbing frog or "sky frog." Rhacophorus omeimontis is a montane form with a vertical distribution from 3,000 to 6,000 feet. These frogs usually come out during the evenings, especially during or just after rains. They are more abundant during the breeding season.

Breeding behavior.-The breeding season of Rhacophorus omeimontis around Tsingch'engshan, Kwanhsien, is from the end of April to May; on Mount Omei it is later. During the breeding season, the males sit on branches of trees or on stones near the margins of small pools, which are the most favorable breeding situation. Such small pools, shaded by trees, were located along the small valley near the temple where I stayed, and along the road. During twilight the croaking of the males could be heard for about one hundred yards. The voice is very much like the noise made by a cricket, sometimes like a sharp low whistle. As one approaches, the croaking stops.

The spawning process was not observed, but paired individuals were collected. The embrace is axillary, the male grasping the female by the armpit with his forearms. Sometimes the second finger of the male may be placed on the dorsal basal part of the arm of the female. Egg-laying takes place at night.

The breeding places vary. According to my observations, this frog prefers to lay its eggs in leaves on trees that overhang water. If there are no trees overhanging the margins of ponds or pools, the females may lay their eggs in 
low vegetation on the slopes of small stationary bodies of water. On the night of April 28, 1940, I first heard the croaking from a pool behind Tenshitung, Tsingch'engshan, Kwanhsien. Here I first collected an egg-mass from the leaves on a tree. On the evening of May 10 of the same year, three masses of eggs were found in their leaf-nests on the same tree. From another small pool, by the side of an old temple on the mountain, eighteen masses of eggs were collected on May 10. Eight were found in leaf-nests on a peach tree, and the other ten were on plants at the edge of the same pool. All the branches of the peach tree were occupied, and the remaining frogs seem to have been driven to the less preferable places for egg-laying. The embryos in the eight masses of eggs on the tree were somewhat more advanced than those from the masses on the plants at the side of the pool.

Eggs.-The egg-nests on trees (pl. 9) are different from those on the plants of the sloping banks of a pool. On trees they are oval, with a narrow base, and the lower end is rounded. They are all at the tips of twigs, and involve a number of leaves. The first nest collected on the early morning of April 29 was formed by three twigs and nine leaves, two on the right side, three on the left and four at the back. An opaque white leathery elastic secretion bound the egg-mass firmly to the leaves, especially at the top of the nest, where the secretion was much more abundant. Eggs at the lower anterior side of the nest were exposed, with only a thin layer of secretion over them where they were not covered by leaves. The nest was about five feet above a small pool and was on the twigs of a small tree.

The egg-masses from the sides of the pool may be completely covered by leaves or partly exposed on the bottom. Egg-masses found on slopes of the pool tend to have the greater part exposed. These egg-masses may be oval, elongated, or irregularly flattened. Such nests may be formed by grasses, Polygonum, Selaginella, Acorus gramineus, Begonia, or Polygonatum. There is no selection of plants growing at the edge of the pool. The exposed part of egg-masses is covered by a thin layer of foam, the common coat for all the eggs. Eggs are greenish in color and may be clearly seen, as the foam is thin. The color of the eggs closely resembles the color of the leaves.

Each egg is large, with a diameter of $4.3 \mathrm{~mm}$. with the jelly and $3.3 \mathrm{~mm}$. without it. The capsule consists of three layers of membrane, one of jelly, and one of liquid. The outer layer is a white opaque elastic membrane, which is porous. This is a common coat covering all the eggs and connecting the eggmass to the leaves. It is very thick at the top of the egg-mass where there are no eggs, but it becomes thinner toward the lower portion, where most of the eggs are accumulated. The second coat is a thin white elastic membrane directly under the first coat. Inside this membrane is a thick layer of light-brown, very sticky jelly. A very delicate elastic membrane is found inside of the jelly. This is the third coat. Just after egg-laying, the third membrane is closely applied to the egg with a small amount of liquid inside. As the embryo develops, 
the liquid increases constantly so that the innermost layer becomes very conspicuous, and the embryo can move around inside of the third membrane. With three membranes, one jelly layer and one aqueous layer, the egg or the embryo is well protected from injury or evaporation. The duration of incubation partly depends upon the situation of the egg-mass. Eggs near the margin of temporary pools generally have a short incubation period and take a shorter time for metamorphosis. Even in the same egg-mass, the embryos on the surface develop much more quickly than those in the interior. During the early stages of development, the external coat of the capsule is tough and opaque white, and the aqueous layer inside the inner coat is very thin. As the embryo develops this inner layer increases in thickness by liquefaction of the jelly of the layer inside the second coat. At the time of hatching, the inner layer becomes so thick that the embryo nearly touches the second coat, and the embryo can turn freely in its "private pond."

In eggs laid on the night of April 28, the blastula stage was reached at 6 P.M. of the next day. Neural grooves and neural tubes were formed on April 30. In the early morning (7 A.M.) of May 1 , body regions were differentiated. The tip of the tail was bent ventrad and then turned anteriorly and to the left. The pronephros was distinct. Embryos grow very quickly, as at 7.50 A.M., on May 2, black eyes and external gills with long finger-like projections were well developed, with the tail bent ventro-anteriorly. Pigment was conspicuously developed on - the head and body, especially latero-posterior to the head region. On May 3, the embryo was much more advanced in development, its head larger and its eyes and external nasal openings well formed. The external gills reached the middle region of the body. The tail overlapped the snout region.

In eggs laid on the night of April 28 all the embryos were fully developed and some were hatched out by the morning of May 6 ; all were hatched by the afternoon of the same day. Eggs laid on the night of May 9 were hatched out on the fifteenth of the same month. The incubation period in the laboratory is from six to eight days, but under natural conditions it may be shorter, with the proper amount of sunshine and the normal amount of moisture from dew or rain. The first egg-mass was treated to imitate natural conditions by hanging the twig with the egg-nest in a large glass jar in which a small amount of water was placed, and covering the jar with a piece of cloth. The other end of the twig was placed in a small bottle containing water so that the leaves would not wilt. Every morning water was showered on the nest.

Near the time of hatching, the embryo becomes very dark except on the belly. The external gills are partially covered over. The external, opaque coat becomes liquefied and the original white color nearly disappears, so that the median coats of different eggs are in contact with each other. Thus the connection between the eggs becomes very loose. By this time the embryos find it very easy to drop out of the nest singly or in groups. A fully developed embryo can move around inside the capsule by moving its tail and body sidewise. This movement may be caused by any disturbance. 
Capsules containing fully developed embryos may drop into the water singly or in groups if shaken by the wind. After dropping into the water, the embryo inside the capsule moves its body and tail vigorously at intervals. Such random movements may make a hole in the capsule, through which the young tadpole emerges. After emergence it swims quickly for a short time and then stops and lies quietly on its side. The rapidity of hatching is caused by the action of the tadpole and the contraction of the membrane of the capsule. The head generally comes out first, but in some cases the tail may emerge while the body and head are still in the capsule. In this case the tadpole has to struggle for a long time to free its body and head. Sometimes it will draw its tail back into the capsule again, and, by turning its body, come out normally head first. By vigorous random movements, a tadpole may hatch out in the egg-nest on the trees. In that case, it swings sidewise by its body and tail in the liquefied jelly and drops or slides into the water.

Tadpole.-Tadpoles hatched in the nest have the external gills of the right side covered up by an overgrowth of skin fold and a part or only the tips of the external gills of the left side exposed. Ventral suckers are still present as two round conspicuous white tubercles postero-lateral to the mouth. When the eggs drop into the water before hatching, the embryos may hatch from their capsules as smaller tadpoles, light in color, with external gills exposed on both sides. Their movements are very awkward, the head being bent downward on account of the large yolk.

The tadpoles grow very rapidly after hatching. Ten tadpoles just after hatching in the egg-nest and ten one day after and three days after hatching were measured from the snout to the tip of the tail. Just after hatching, the average length was $11.9 \mathrm{~mm}$., ranging from 11.5 to $12.5 \mathrm{~mm}$.; tadpoles one day after hatching had an average length of $14.8 \mathrm{~mm}$., with a range from 14.1 to $15.5 \mathrm{~mm}$. ; the average length of tadpoles three days after hatching was $16.3 \mathrm{~mm}$., ranging from 15.2 to $17.7 \mathrm{~mm}$. The growth rate just after hatching is rather uniform and much faster than later on.

Rhacophorus omeimontis: Measurements of Twenty Tadpoles

\begin{tabular}{|c|c|c|c|}
\hline Measurements & Range & Average & $\begin{array}{c}\text { Ratio to } \\
\text { body length }(\%)\end{array}$ \\
\hline Body length....... & $13.3-15.3$ & 14.5 & \\
\hline Body height. & $7.0-8.5$ & 7.7 & 52.8 \\
\hline Body width. & $7.8-9.5$ & 8.7 & 60.0 \\
\hline Head height. & $5.0-6.4$ & 5.8 & 40.3 \\
\hline Head width. & $7.2-8.1$ & 7.7 & 53.4 \\
\hline Snout to spiraculum. & $8.8-10.0$ & 9.6 & 66.3 \\
\hline Tail length........ & $27.2-32.4$ & 30.3 & 209.1 \\
\hline Tail height. & $8.0-9.3$ & 8.7 & 59.8 \\
\hline Diameter of tail muscle. & $4.3-5.3$ & 4.8 & 32.9 \\
\hline Length of hind leg..... & $3.5-6.8$ & 4.9 & 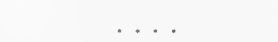 \\
\hline
\end{tabular}

The tadpoles (fig. 99) of Rhacophorus omeimontis are found in clear pools with dead leaves; they rarely occur in the old manure pools inhabited by the 
tadpoles of Rana adenopleura and Rhacophorus leucomystax. Tadpoles of omeimontis are bottom feeders, eating decayed vegetation in the pools, but they come up to the surface of the water now and then for oxygen and immediately go back to the bottom. They are very sensitive to disturbance, and hide themselves under vegetation immediately. The size, color, and general shape of the body are greatly influenced by the environment.

In clear water and in springs where dead leaves cover the bottom the coloration of the tadpoles is moderately dark. Such tadpoles are dark on the body with many small golden spots. The tail fin is purplish black, and the muscular axis dark brown. The belly is dark gray. Tadpoles that were collected from a clear pool containing dead vegetation were moderate in size, with lower tail crests;

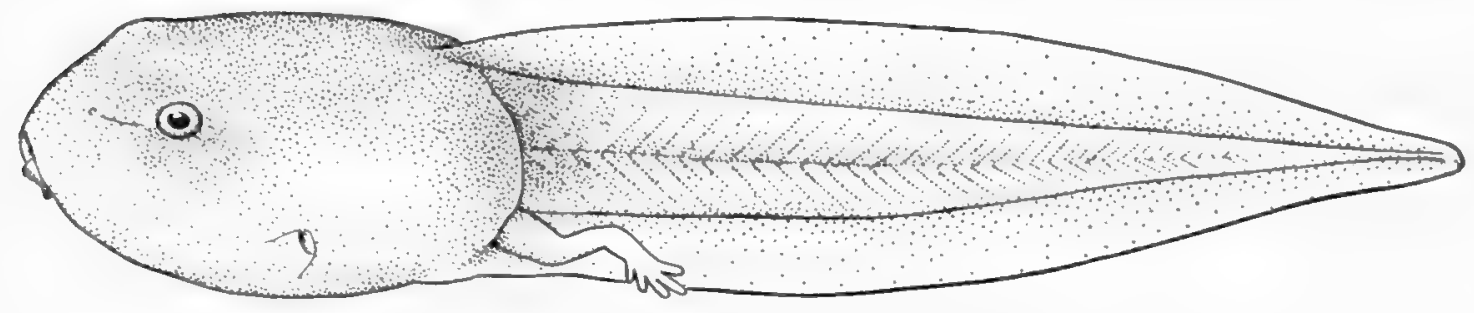

FiG. 99. Rhacophorus omeimontis; tadpole $(\times 3)$.

those from an old manure pit were larger, with higher tail fins. Twenty tadpoles collected from a leaf-bottomed clear pool were measured (see table). The average length, from tip of snout to tip of tail, of the twenty tadpoles, with hind legs averaging $5 \mathrm{~mm}$., was $44.8 \mathrm{~mm}$., ranging from 40 to $48 \mathrm{~mm}$. Tadpoles from an unused manure pool were much larger; a single specimen had a total length (snout to tip of tail) of $53 \mathrm{~mm}$., body length $18 \mathrm{~mm}$., and tail $35 \mathrm{~mm}$. The height of the tail crest was 76 per cent of the body length in this specimen, while for tadpoles collected from ponds or pools it was only about 60 per cent.

In tadpoles of omeimontis the snout is rounded; each nostril is enclosed by a light-colored ring, and the nostrils, directed antero-laterally, lie about midway from eye to snout. The eyes are dorso-lateral, with a space 40 per cent of the body length between them. The spiraculum is sinistral and without a free tube, directed upwards and backwards, and not visible from below. The vent is dextral and located near the base of the inner side of the right leg. The tail is long and bluntly pointed, with the ventral crest slightly deeper than the dorsal.

The mouth is antero-ventral. The average width is $39 \mathrm{~mm}$., which is 27 per cent of the body length. The sides of the upper lip are provided with one row of papillae, much larger than the rest, and inside this row there are six or more additional papillae between the first and fifth rows of the upper labial teeth. There is a small space free from papillae at the ventral middle region of the lower lip. On the free margin of the lower lip there is a row of closely set papillae, and inside this row there is another row extending latero-dorsally to the tips of the outermost row of labial teeth on the lower lip. At each corner of 
the mouth there is a fold with indistinctly separated papillae. In twenty-five tadpoles, twenty specimens have the tooth formula I:4-4/II:1-1; one has I:4-5/ $\mathrm{II}: 1-1$; two have I:5-4/II:1-1; and two have I:5-5/II:1-1. The rows of teeth on the lower lip are constant but those of the upper lip vary slightly, 80 per cent of the individuals having five rows. The outermost row of the upper lip is complete and the other four rows are interrupted. On the lower lip, the innermost row is narrowly interrupted and the two outer rows are complete, with the middle row longest. The mandible is moderately developed and has a serrated edge. The lower mandible is much stronger and shorter than the upper mandible.

After the fore limbs are freed, the color of the tadpole begins to change. The dorsal side of the body becomes green, and the tail and belly remain dark except for the adhesive disks, which are yellowish. Near the time of metamorphosis, the tail fin becomes black and absorption begins. From hatching to metamorphosis takes forty-two days; after metamorphosis the juvenile frog is green on the back and on the upper parts of the limbs, and yellowish green on the upper jaw. A black line runs from the tip of the snout through the nostril to the anterior border of the eye, and from the hind corner of the eye over the tympanum to the groin. Ventral to this line from the head region to the base of the arm, the color is light bluish green. The throat is yellowish gray. The ventral side of the body and limbs is light gray. Adhesive disks are yellowish and occasionally show a blood color that is due to an accumulation of blood in this region. The young adults of this species are frequently mistaken for Hyla. Just after metamorphosis the young have a body length of $17 \mathrm{~mm}$. A young adult with a body length of $18 \mathrm{~mm}$. may be grayish green to dark green above, the coloration varying according to the environment. The upper jaw from the tip of the snout to the posterior angle of the mouth is bluish green, very narrow in front but widening behind. There is an ill-defined black or dark gray band from the tip of the snout through the nostril and the eye to just above the base of the arm. The tympanum is dark gray. Black pigment accumulates on the margin of the dark marbling. The sides of the body are purplish gray, the color decreasing in intensity toward the light gray belly. The dorsal sides of the limbs are the same color as the back, and beneath they are the same color as the sides of the body. The adhesive disks are light yellow or pinkish yellow. Until the young frog is about $23 \mathrm{~mm}$. in length, there is not very much change in coloration except that the black marks on the margin of the upper and lower jaws become much more conspicuous and a yellowish-green band develops at the vent and at the external lateral sides of the tibia and tarsal regions. The head is larger in proportion to the body, which is considerably elongated, so that at this time it is more like the adult than before. When the young adult measures about $27 \mathrm{~mm}$., the green back and the dorsal sides of the limbs are much marbled by black, and the black band from the tip of the snout to the middle part of the body is more conspicuous. The black mark from the jaw to the eye is complete, and the margin of the jaw is yellowish white. The ventral sides of the limbs 
are yellow, and the belly is grayish, with well-developed granules. The throat, near the margin of the jaw, is yellowish green. Adhesive disks are yellowish green in color.

\section{Rhacophorus chenfui Liu}

Rhacophorus chenfui Liu, 1945, Jour. West China Border Res. Soc., 15, (B): 35Mount Omei, Szechwan, China.

History of species.-The first specimen of this tree frog was obtained near Huitingsze, Mount Omei, Szechwan, July 25, 1938, and the species was described as new in 1945.

Distribution and collection data.-During the summer of 1938, on July 25, a female, two males, young individuals, and many tadpoles at various stages were collected at Huitingsze (3,850 feet altitude), Mount Omei. In March, 1940, two females and a male were obtained near P'ilutien, on the same mountain, and from July to the middle part of August of the same year five males and a female were collected at the original locality. From mid-May to mid-July, 1945, a female and two males were collected from the same locality.

Rhacophorus chenfui has been found only on Mount Omei, with a vertical distribution ranging from 3,800 to 4,500 feet.

Comparison with related species.-The uniform green color on the back of Rhacophorus chenfui (pl. 8, figs. 1 and 2) distinguishes it from all other species of the genus of western China. The tibio-tarsal articulation reaches the eye in chenfui and only to the shoulder region or to the tympanum in bambusicola and dugritei. Rhacophorus chenfui can be distinguished from omeimontis by its much smaller size and by the slight amount of webbing between the first and second fingers (fig. 100, A). Rhacophorus leucomystax is larger in size, is brown, and is entirely without webs between the fingers.

Original description. - "Head equal in length and width, sloping anteriorly; snout pointed, sloping from the internasal space and projecting beyond the mouth. Tongue deeply notched posteriorly, and with many rounded papillae on its upper surface; two long rows of vomerine teeth nearly joining the anterior edges of choanae and converging posteriorly. Nostril closer to eye than to tip of snout; canthus rostralis obtuse; loreal region oblique and slightly concave; interorbital space slightly convex and greater than internasal space; eye with horizontal pupil much larger than eyelid; tympanum small, distinct, and about half the interorbital space.

"Length of fore limb about 60 per cent of body length with a diameter of lower arm 10.4 per cent of the body length. First finger is the smallest and shortest, with a very small disk; second finger shorter than the fourth; third finger the longest, with a disk about 5 per cent of the body length; disks well developed and somewhat squarish at the free ends of the three outer fingers; webs well developed between second, third, and fourth fingers, and feebly indicated between first and second fingers; subarticular tubercles well developed. 
"Hind limb moderate, with tibio-tarsal articulation reaching the center of the eye; heels do not meet when placed at right angles to the body; tibia about one-third of the leg length; toes provided with disks similar in form but smaller than those of the fingers; webs extending slightly beyond the subarticular tubercles nearest to the disk; inner metatarsal tubercle oval, prominent; outer metatarsal tubercle small.

"Skin with granules above; a glandular fold from the posterior corner of the eye to the shoulder; the belly and the ventral side of the thighs with large polygonal glandular granules and the throat with smaller ones.

"Color in life.-Uniform leaf-green on the upper sides of the head, body, and parts of limbs exposed when folded, and on the third and fourth fingers and

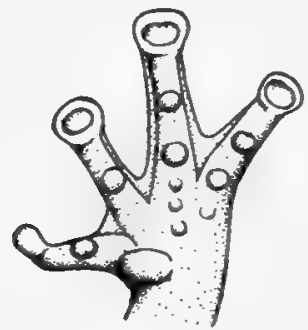

A

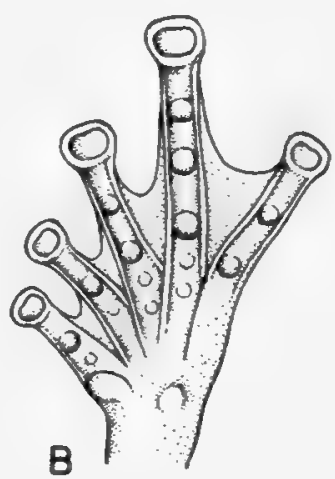

FIG. 100. Rhacophorus chenfui $(\times 2)$. A. Ventral view of hand. B. Ventral view of foot.

the fourth and fifth toes; sides of the body light green; a creamy line extending from the anterior region of the lower jaw posteriorly to the groin, where it becomes inconspicuous. Similar lines on the exposed parts of the posterior margin of the free areas of the arms and legs, not on the anterior margins of those green areas; a conspicuous creamy line above and to the sides of the anus. Ventral to this cream-colored line, color is fleshy purple, with light fine chestnut granules, darker near the light line, lighter toward ventral side. Throat darker at its margin; the belly golden yellow; the ventral sides of limbs, webs and disks fleshy brownish yellow. Eye with black pupil and orange golden iris, with indications of green. The color change under different conditions is not great, but when kept in a bag or in a dark place the leaf-green changes into dark green. After preservation in formalin, the back is dark purplish blue and the belly is pinkish gray.

"Sex dimorphism in size is marked. Females are much larger than males, and the legs of the former sex are longer, especially the tarsus and foot. The male has an external median subgular vocal sac with two short slit-like openings near the angle of the jaw. A cream-colored nuptial pad is present on the inner dorsal side of the first finger. Lineae masculinae are conspicuous, white in the living male and pink in specimens preserved in formalin." 
Rhacophorus chenfui: Measurements of Eight Male and Four Female Adults

\begin{tabular}{|c|c|c|c|c|}
\hline Measurements & Sex & Range & Average & $\begin{array}{l}\text { Ratio to } \\
\text { body length }(\%)\end{array}$ \\
\hline Body length...... & $\begin{array}{l}0^{7} \\
9\end{array}$ & $\begin{array}{l}35-38 \\
48-55\end{array}$ & $\begin{array}{l}36.9 \\
49.7\end{array}$ & $\ldots$ \\
\hline Head length...... & $\begin{array}{l}0 \\
8 \\
8\end{array}$ & $\begin{array}{c}12.0-13.5 \\
17-19\end{array}$ & $\begin{array}{l}12.9 \\
17.5\end{array}$ & $\begin{array}{l}34.9 \\
35.2\end{array}$ \\
\hline Head width. & $\begin{array}{l}8 \\
8\end{array}$ & $\begin{array}{c}12.2-13.8 \\
17-19\end{array}$ & $\begin{array}{l}13.0 \\
18.0\end{array}$ & $\begin{array}{l}35.2 \\
36.2\end{array}$ \\
\hline Interorbital space............ & $\begin{array}{l}\sigma^{7} \\
9\end{array}$ & $\begin{array}{l}4.6-5.0 \\
4.5-6.0\end{array}$ & $\begin{array}{l}4.8 \\
5.0\end{array}$ & $\begin{array}{l}13.0 \\
10.0\end{array}$ \\
\hline Length of eye.... & $\begin{array}{l}\sigma^{7} \\
9\end{array}$ & $4.2-5.0$ & $\begin{array}{l}4.5 \\
5.4\end{array}$ & $\begin{array}{l}12.1 \\
10.8\end{array}$ \\
\hline Tympanum.......... & $\begin{array}{l}07 \\
9\end{array}$ & $\begin{array}{l}2.0-2.5 \\
2.5-3.0\end{array}$ & $\begin{array}{l}2.2 \\
2.8\end{array}$ & $\begin{array}{l}5.9 \\
5.6\end{array}$ \\
\hline Length of lower arm.... & $\begin{array}{l}0^{7} \\
8\end{array}$ & $\begin{array}{c}7-8 \\
10-12\end{array}$ & $\begin{array}{r}7.7 \\
10.8\end{array}$ & $\begin{array}{l}20.9 \\
21.8\end{array}$ \\
\hline Diameter of lower arm. . & $\begin{array}{l}\text { o } \\
\text { क }\end{array}$ & $\begin{array}{l}3.2-3.8 \\
3.5-5.0\end{array}$ & $\begin{array}{l}3.5 \\
4.6\end{array}$ & $\begin{array}{l}9.4 \\
9.2\end{array}$ \\
\hline 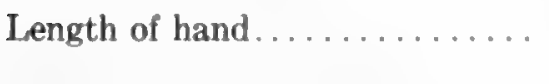 & $\begin{array}{l}0^{7} \\
8\end{array}$ & $\begin{array}{c}10.5-12.0 \\
15-17\end{array}$ & $\begin{array}{l}11.2 \\
15.9\end{array}$ & $\begin{array}{l}30.4 \\
32.0\end{array}$ \\
\hline Width of third-finger disk. & $\begin{array}{l}\text { or } \\
8\end{array}$ & $\begin{array}{l}1.8-2.4 \\
2.4-3.0\end{array}$ & $\begin{array}{l}2.0 \\
2.7\end{array}$ & $\begin{array}{l}5.4 \\
5.4\end{array}$ \\
\hline Length of hind leg. & $\begin{array}{l}97 \\
8\end{array}$ & $\begin{array}{l}48-54 \\
66-75\end{array}$ & $\begin{array}{l}50.1 \\
71.0\end{array}$ & $\begin{array}{l}135.7 \\
142.8\end{array}$ \\
\hline Length of tibia... & $\begin{array}{l}\sigma^{7} \\
8\end{array}$ & $\begin{array}{l}15-17 \\
21-23\end{array}$ & $\begin{array}{l}15.9 \\
22.0\end{array}$ & $\begin{array}{l}43.0 \\
44.2\end{array}$ \\
\hline Length of foot. . & $\begin{array}{l}\text { or } \\
\text { क }\end{array}$ & $\begin{array}{l}15-17 \\
21-23\end{array}$ & $\begin{array}{l}16.0 \\
22.1\end{array}$ & $\begin{array}{l}43.3 \\
44.4\end{array}$ \\
\hline Width of fourth-toe disk........ & $\begin{array}{l}\sigma^{7} \\
8\end{array}$ & $\begin{array}{l}1.4-2.0 \\
2.0-2.7\end{array}$ & $\begin{array}{l}1.7 \\
2.3\end{array}$ & $\begin{array}{l}4.6 \\
4.6\end{array}$ \\
\hline $\begin{array}{l}\text { Length of inner metatarsal } \\
\text { tubercle........................ }\end{array}$ & $\begin{array}{l}0^{7} \\
0\end{array}$ & $\begin{array}{l}1.5-2.0 \\
2.3-2.8\end{array}$ & $\begin{array}{l}1.8 \\
2.5\end{array}$ & $\begin{array}{l}4.8 \\
5.0\end{array}$ \\
\hline
\end{tabular}

Habitat and habits.-Rhacophorus chenfui is a mountain form found mostly on leaves of Musa near small ditches and pools, and also under stones near water. During rainy days these frogs croak with a high interrupted note, very much like the croaking of Hyla arborea. When they are sitting on leaves it is difficult to locate them, as the color on the back and the dorsal sides of the exposed parts of the limbs and digits is closely similar to that of the leaves.

Breeding behavior.--My assistants and I have failed during three summers to observe the mating and egg-laying of chenfui, but tadpoles in various stages were found in a small pool back of Huitingsze, the type locality.

Tadpoles.-Tadpoles of chenfui were found in small ponds on Mount Omei, near the temples where the adults were found, during the middle part of July, 1938. The living tadpole is grayish yellow-green, with darker body; the color of the foodstuff in the alimentary canal darkens the belly. The tip of the tail is dark as in the tadpoles of $R$. bambusicola. After preservation in formalin, the tadpole is yellowish gray, with a much darker belly. The form of the body and 
the shape of the tail in the tadpoles of chenfui are very much like those of omeimontis and bambusicola. The tadpoles of chenfui are smaller than those of the latter two species, their color is much lighter than those of omeimontis, and they have much more green than those of bambusicola.

Rhacophorus chenfui: Measurements of Ten Tadpoles

\begin{tabular}{|c|c|c|c|}
\hline Measurements & Range & Average & $\begin{array}{c}\text { Ratio to } \\
\text { body length (\%) }\end{array}$ \\
\hline Body length. & $11.5-13.0$ & 12.5 & \\
\hline Body height. & $5.8-6.0$ & 6.0 & 47.6 \\
\hline Body width. & $6.5-7.0$ & 6.9 & 55.6 \\
\hline Head height. & $4.2-5.0$ & 4.6 & 37.1 \\
\hline Head width. & $6.5-7.0$ & 6.8 & 54.8 \\
\hline Mouth width. & $3.5-4.0$ & 3.6 & 28.8 \\
\hline Snout to spiraculum. & $7-8$ & 7.4 & 59.6 \\
\hline Tail length........ & $18-22$ & 20.8 & 166.7 \\
\hline Tail height. & $6.5-7.5$ & 6.9 & 55.2 \\
\hline Diameter of tail muscle. & $2.5-3.2$ & 3.0 & 23.9 \\
\hline Length of hind leg. .... & $2-6$ & 4.1 & \\
\hline
\end{tabular}

The snout is rounded; the nostril is about midway between the tip of the snout and the border of the eye, and is enclosed by a light-colored ring and directed latero-anteriorly. The eyes are dorso-lateral. The spiraculum is sinistral and without a free tube, directed upward and backward and visible from below but not from above. The vent is dextral, near the base of the right side of the ventral tail fin. The tail length is proportionately shorter than in omeimontis or in other species of Rhacophorus of western China. The tail is bluntly pointed, with the dorsal and ventral tail fins about equally developed, and the muscle is rather weak.

The mouth is more ventral than anterior, and rather small. The papillae on the lips vary greatly. Generally there is one row of papillae on the sides of the upper lip and the corners of the mouth with a few extra ones inside of this row. In most cases, there are two rows of papillae on the lower lip except at the mid-ventral region, where there may be a small space without papillae. Of ten specimens, nine have the tooth formula $I: 4-4 / I I: 1-1$ and one has $I: 5-5 /$ II:1-1. The mandibles are moderately developed, with a serrated edge, the upper stronger than the lower. 


\section{REFERENCES}

ANDERSON, JOHN

1871. Description of a new genus of newts from western Yunnan. Proc. Zool. Soc. Lond., 1871 : $423-425$.

1878. Anatomical and zoological researches: comprising an account of the zoological results of the two expeditions to western Yunnan in 1868 and 1875. London, Quaritch. 2 vols., illus.

\section{AnNandale, Nelson}

1911. Contributions to the fauna of Yunnan. Part VI. Batrachia and reptiles. Rec. Indian Mus., 6: 215-218.

1917. The occurrence of Rana pleskei Günther, in Kashmir. Rec. Indian Mus., 13: 417-418, figs. $1-2$.

Aronson, L. R.

1943. The "release" mechanism and sex recognition in Hyla andersonii. Copeia, 1943, No. 4: 246-249.

\section{BARBOUR, THOMAS}

1909. Notes on Amphibia and Reptilia from eastern Asia. Proc. New England Zool. Club, 4 : 53-78, pls. 6-7.

1912. Some Chinese vertebrates. Amphibia and Reptilia. Mem. Mus. Comp. Zool., 40: $125-136$, pls. $1-2$.

1920. A preoccupied name in Hyla. Copeia, 88: 98.

BEDRIAGA, JACQUES VON

1898. Amphibien und Reptilien. Lfg. 1, Caudata, Ecaudata. Wiss. Res. Przewalski Centr. Asien Reisen, Zool. Theil, 3, Ábt. 1: 1-69, pl. 1.

\section{BOETTGER, OSKAR}

1885. Materialien zur herpetologischen Fauna von China I. Ber. Offenbacher Ver. Naturk., 24-25: 115-170.

1892. Katalog der Batrachier-sammlung der Senckenbergischen naturforschenden Gesellschaft in Frankfurt-am-Main. Frankfurt a/M., Gebrüder Knauer. 10:73.

BORING, A. M.

1936. The Amphibia of Hong Kong. Part III. Hong Kong Nat., 7: 11-14, figs. 17-18.

1938. Studies in variation among Chinese Amphibia. II. Variation in five wideranging common Salientia. Peking Nat. Hist. Bull., (B), 13: 89-110.

\section{BOULenger, G. A.}

1878. Description de deux genres nouveaux de la famille des salamandrides. Bull. Soc. Zool. France, 1878: 71-72.

1882a. Catalogue of the Batrachia Gradientia s. Caudata and Batrachia Apoda in the collection of the British Museum. London, British Museum. viiit $127 \mathrm{pp.}$ 9 pls. 
1882b. Catalogue of the Batrachia Salientia s. Ecaudata in the collection of the British Museum. London, British Museum. xvi+503 pp., 30 pls., text figs.

1887a. An account of the batrachians obtained in Burma by M. L. Fea, of the Genoa Civic Museum. Ann. Mus. Civ. Stor. Nat. Genova, (2), 5: 422, pl. 4, fig. 3.

1887b. On a rare Himalayan toad, Cophophryne sikkimensis, Blyth. Ann. Mag. Nat. Hist., (5), $20: 405-407$.

1904. Descriptions of new frogs and snakes from Yunnan. Ann. Mag. Nat. Hist., (7), $13: 130-134$.

1905. On some rare batrachians and reptiles from Tibet. Ann. Mag. Nat. Hist., (7), 15: $378-379$.

1908. A revision of the Oriental pelobatid batrachians (genus Megalophrys). Proc. Zool. Soc. London, 1908: 407-430, pls. 22-25, text fig. 78.

1909. Descriptions of four new frogs and a new snake discovered by Mr. H. Sauter in Formosa. Ann. Mag. Nat. Hist., (8), 4: 492-495.

1917. Descriptions of new frogs of the genus Rana. Ann. Mag. Nat. Hist., (8), 20 : 413-418.

1919. On Aelurophryne mammata Gthr., an addition to the batrachian fauna of Kashmir. Rec. Indian Mus., 16: 469-470.

1920. A monograph of the South Asian, Papuan, Melanesian and Australian frogs of the genus Rana. Rec. Indian Mus., 20:1-226.

BRown, J. C.

1910. Contributions to the fauna of Yunnan based upon the collections of J. Coggin Brown. Introduction. Rec. Indian Mus., 5: 193-195.

Chang, Mangven L. Y.

1932. Notes on a collection of reptiles from Szechuan. Contr. Biol. Lab. Sci. Soc. China, Zool., 8: 9-95, figs. 1-28.

1936. Contribution a l'etude morphologique, biologique, et systematique des amphibiens urodeles de la Chine. Paris, Librairie Picart. pp. 1-156, 5 pls., 20 text figs., 3 maps.

Chang, Mangven L. Y. and Hsü, H. F.

1932. Study of some amphibians from Szechuan. Contr. Biol. Lab. Sci. Soc. China, Zool., 8, No. 5: 161-165, figs. 8 and 9.

\section{DAVID, ARMand}

1871. Journal d'un voyage en Mongolie et en Chine fait en 1866-68. Nouv. Arch. Mus. Nat. Paris, 7, (Bull.): 75-100.

1875. Journal de mon troisième voyage d'exploration dans l'Empire Chinois. Paris, Librairie Hachette. 2 vols.

DUNN, E. R.

1923. The salamanders of the family Hynobiidae. Proc. Amer. Acad. Arts Sci., 58: $445-523$.

\section{GÜNTHER, AlberT}

1858. Catalogue of the Batrachia Salientia in the collection of the British Museum. London, British Museum. xvi+160 pp., 12 pls.

1892. List of the species of reptiles and fishes collected by Mr. A. E. Pratt on the upper Yang-tze-kiang and in the province Sze-chuen, with description of the new species, in A. E. PRATT, To the snows of Tibet through China. London, Longmans, Green and Co. pp. 238-250.

1896. Report on collections of reptiles, batrachians and fishes made by Messrs. Potanin and Berezowski in the Chinese Provinces Kansu and Szechuen. Ann. Mus. Zool. Acad. Sci. St. Petersburg, 1: 199-219, 2 pls. 
LIU, CH'ENG-CHAO

1931. Sexual behavior in the Siberian toad, Bufo raddei, and the pond frog, Rana. nigromaculata. Peking Nat. Hist. Bull., 6: 43-60, 1 pl.

1935a. The "linea masculina," a new secondary sex character in Salientia. Jour. Morph., 57 : 131-142, pl. 1 .

1935b. Types of vocal sac in the Salientia. Proc. Boston Soc. Nat. Hist., 41: 19-40, pls. 4-8, text figs. 1-8.

1935c. Rana boulengeri, with a discussion of the allied species in China. Peking Nat. Hist. Bull., 10 : 55-60, pl. 1.

1936. Secondary sex characters in Chinese frogs and toads. Field Mus. Nat. Hist., Zool. Ser., 22: 115-156, pls. 1-12.

1940a. Natural history studies of West China Amphibia. I. Adaptations in tadpoles and adults. Peking Nat. Hist. Bull., 15: 161-174, 2 pls.

1940b. Natural history studies of West China Amphibia. II. Life history of Rhacophorus davidi (Sauvage). Peking Nat. Hist. Bull., 15: 243-251, 1 pl.

1940c. Natural history studies of West China Amphibia. III. Life history of Rana boulengeri. Peking Nat. Hist. Bull., 15: 253-259, 3 text figs.

1940d. Natural history studies of West China Amphibia. IV. Life history of Rana adenopleura (Rana musica?). Peking Nat. Hist. Bull., 15: 285-290, 4 text figs.

1940e. Natural history studies of West China Amphibia. V. Life history of Staurois chunganensis. Peking Nat. Hist. Bull., 15: 291-295, 3 text figs.

1940f. Tadpoles of West China Salientia. Jour. West China Border Res. Soc., 12, (B): 7-62, 4 pls.

1943a. Two new scutigers from Chaochiaohsien, Sikang. Jour. West China Border Res. Soc., 14, (B): 35-38, 9 text figs.

1943b. Natural history studies of West China Amphibia. VI. Life history of Kaloula rugifera. Jour. West China Border Res. Soc., 14, (B): 39-42.

1943c. Natural history studies of West China Amphibia. VII. Life history of Rhacophorus leucomystax. Jour. West China Border Res. Soc., 14, (B): 43-50.

1943d. Natural history studies of West China Amphibia. VIII. Life history of Scutiger sikkimensis with a discussion of its allied species in China. Jour. West China Border Res. Soc., 14, (B): 51-76, 2 pls.

1945a. Life history of Rhacophorus hui. Jour. West China Border Res. Soc., 15, (B): $65-68,2$ pls.

1945b. Life history of Kaloula macroptica. Jour. West China Border Res. Soc., 15, (B): $61-64,1 \mathrm{pl}$.

1945c. Life history of Bombina maxima. Jour. West China Border Res. Soc., 15, (B): $56-60,1 \mathrm{pl}$.

1945d. New frogs from West China. Jour. West China Border Res. Soc., 15, (B): $28-43,2$ pls.

1945e. Life history of Batrachuperus pinchonii. Jour. West China Border Res. Soc., 15 , (B): 45-55, 1 pl.

1947. Two new frogs of the genus Scutiger from West China. Copeia, 1947: 123-126.

MELL, RICHARD

1922. Beiträge zur Fauna sinica. I. Die Vertebraten Südchinas; Feldlisten und Feldnoten der Säuger, Vögel, Reptilien, Batrachier. Arch. Naturg., 88, Abt. A, Heft 10: 1-146, 4 pls., 1 map.

MOCQUARD, F.

1910. Voyage de M. de Dr. Louis Vaillant dans l'Asie Centrale (Mission Pelliot). Reptiles et batraciens. Bull. Mus. Nat. Hist. Nat. Paris, 16: 145-153.

NiKoLSKY, A. M.

1918. Amphibiens (Amphibia). Faune de la Russie. Petrograd, 309 pp., 4 pls., 62 text figs. 
Noble, G. K.

1926. The importance of larval characters in the classification of South African Salientia. Amer. Mus. Nov., 237: 1-10, 6 text figs.

1931. The biology of the Amphibia. New York, McGraw-Hill. xiii+577 pp., 174 text figs.

OKADA, YAICHIRO

1931. The tailless batrachians of the Japanese empire. Japan, Imperial Agricultural Experiment Station, 215 pp., 29 pls., 97 text figs.

PARKER, H. W.

1925. A collection of reptiles and batrachians from Tonkin. Ann. Mag. Nat. Hist., (9), $15: 300-306$.

1934. A monograph of the frogs of the family Microhylidae. London, British Museum. viii+208 pp., 67 text figs.

PETERS, WILhelm

1867. Herpetologische Notizen. Monatsber. Akad. Wiss. Berlin, 1867: 13-37.

PoPe, C. H.

1931. Notes on amphibians from Fukien, Hainan, and other parts of China. Bull. Amer. Mus. Nat. Hist., 61 : 397-611, pls. 13-22, 39 text figs., 1 map.

1947. A new pelobatid frog from Fukien Province, China. Copeia, 1947: 109-112.

Pope, C. H. and Boring, A. M.

1940. A survey of Chinese Amphibia. Peking Nat. Hist. Bull., 15: 13-86, 1 map.

Procter, J. B.

1922. On a new toad, Cophophryne alticola, collected on the Mt. Everest Reconnaissance Expedition, 1921. Ann. Mag. Nat. Hist., (9), 9: 583-587.

SAUVAge, H. E.

1877. Sur quelques batraciens de Chine. Bull. Soc. Phil. Paris, (7), 1: 115-118.

Schmid, K. P.

1925. New Chinese amphibians and reptiles. Amer. Mus. Nov., 175: 1-3.

1927. Notes on Chinese amphibians. Bull. Amer. Mus. Nat. Hist., 54: 553-575, pls. 31-32.

1938a. A geographic variation gradient in frogs. Field Mus. Nat. Hist., Zool. Ser., 20: $377-382$.

1938b. A note on the linea masculina of frogs. Copeia, 1938: 199.

Schmidt, K. P. and Ch'ENG-CHAo LiU

1940. A new toad from West China. Field Mus. Nat. Hist., Zool. Ser., 24: 151-154, text fig. 16.

SClater, W. L.

1892. On some specimens of frogs in the Indian Museum, Calcutta, with descriptions of several new species. Proc. Zool. Soc. London, 1892: 341-348, pl. 24.

SHAW, TSEN-HWANG

1929. The amphibians of Peiping. Bull. Fan Mem. Inst. Biol., 1: 75-97, 14 text figs.

Smith, M. A.

1923. On a collection of reptiles and batrachians from the Island of Hainan. Jour. Nat. Hist. Soc. Siam, 6: 195-212, 2 text figs.

1926. The function of the "funnel" mouth of the tadpoles of Megalophrys, with a note on $M$. aceras Boulenger. Proc. Zool. Soc. London, 1926: 983-988. 
STEJNEGER, LEONHARD

1907. Herpetology of Japan and adjacent territory. Bull. U. S. Nat. Mus., 58: xx+ 577 pp., 35 pls., 409 text figs.

1925. Chinese amphibians and reptiles in the United States National Museum. Proc. U. S. Nat. Mus., 66, art. 25: 1-115, 6 text figs.

1926. Two new tailless amphibians from western China. Proc. Biol. Soc. Wash., 39: $53-54$.

1927. A new genus and species of frog from Tibet. Jour. Wash. Acad. Sci., 17: 317-319.

VAN Kampen, P. N.

1923. The amphibia of the Indo-Australian Archipelago. Leiden, Brill. xii+304 pp., 29 text figs.

\section{VOGT, THEODOR}

1924. Reptilien und Amphibien aus Szetschwan, Osttibet, und Fschili. Zool. Anz., 60 : $337-344$.

\section{Werner, Franz}

1924. Ergebnisse der Expeditions Dr. Handel-Mazzettis nach China 1914 bis 1918 auf Kosten der Akademie der Wissenschaften in Wien. Úber Reptilien und Amphibien aus Süd-China. Denkschr. Akad. Wiss. Wien, math.-natur., 99: 39-58.

WiEgmanN, A. F. A.

1834. Siebente Abteilung: Amphibien, in Meyen, F. J. F., Nova Acta Acad. Leop. Carol., 17: 183-268, 268a-d, 10 pls.

\section{ZAREVSKY, S.}

1925. Notes on some batrachians from Palaearctic regions. Ann. Mus. Zool. Acad. Sci. USSR, 26: 73-78. 


\section{INDEX}

adenopleura, Rana, 253-260

Aelurophryne, 117-120

Aelurophryne brevipes, 125-132

Aelurophryne glandulata, 137-144

Aelurophryne maculata, 136-137

Aelurophryne mammata, 120-125

Aelurophryne tainingensis, $132-136$

afghana, Polypedates, 358

afghana, Rana, 358

afghanus, Amolops, 358

afghanus, Staurois, 358-359

ahli, Montorana, 323

alticola, Cophophryne, 146

alticola, Scutiger, 168

Altirana parkeri, $329-330$

Amolops afghanus, 358

amurensis, Rana, 280

andersonii, Rana, 297-303

annectans, Hyla, 224-231

annectans, Polypedates, 224

annectens, Hyla, 224

asiatica, Bufo vulgaris, 220

asiatica, Rana, 280

asiatica, Rana temporaria, 280

asiaticus, Bufo bufo, 220

bambusicola, Hyla, 373

bambusicola, Rhacophorus, 373-379

bankorensis, Bufo, 214, 220

batangensis, Rhacophorus pleurostictus, 370 , 373

Batrachuperus, $80-82$

Batrachuperus cochranae, 101-102

Batrachuperus karlschmidti, 87-96

Batrachuperus pinchonii, 82-87

Batrachuperus sinensis, 82

Batrachuperus tibetanus, 96-99

Batrachuperus yenyuanensis, 99-101

Batrachyperus, 80

boettgeri, Megophrys, 185

Bombina maxima, 110-117

Bombinator maximus, 110

Bombinator sikkimensis, 145

boringii, Vibrissaphora, 176-180

boulengeri, Leptobrachium, 181

boulengeri, Megophrys, 181-185

boulengeri, Microhyla, 252

boulengeri, Rana, 263-272

brevipes, Áelurophryne, 125-132

brevipes, Bufo, 203

Bufo, 201-203
Bufo bankorensis, 214, 220

Bufo brevipes, 203

Bufo bufo asiaticus, 220

Bufo bufo gargarizans, 220-224

Bufo bufo minshanicus, 212-214

Bufo bufo wrighti, 214-219

Bufo gargarizans, 220

Bufo japonicus, 220

Bufo mammata, 117

Bufo melanostictus, 203

Bufo minshanicus, 212

Bufo nouettei, 203

Bufo raddei, 203-206, 207

Bufo raddei pleskei, 203

Bufo raddei przewalskii, 203

Bufo raddii, 203

Bufo tibetanus, 207-212

Bufo tuberculatus, 207

Bufo vulgaris, 207, 220

Bufo vulgaris asiatica, 220

Bufo vulgaris japonicus, 220

burkilli, Rana tigrina, 322

butleri, Microhyla, 252-253

caldwelli, Rana, 253

Calluela, 321

Calluella ocellata, 232-235

Calluella yunnanensis, 232

Callula verrucosa, 246

Calophrynus pleurostigma sinensis, 247

carinense, Leptobrachium, 196

carinensis, Megalophrys, 196

carinensis, Megophrys, 196-197

carnaticum, Diplopelma, 248

Ceratophryne, 180

Ceratophryne nasuta, 180

Ceratophrys, 180

chaochiaoensis, Rana, 292-297

chenfui, Rhacophorus, 388-391

chensinensis, Rana, 279

chensinensis, Rana temporaria, 279-285

chinensis, Rana, 309

chinensis, Rana esculenta, 309

chunganensis, Rana, 337

chunganensis, Staurois, 337-344

cochranae, Batrachuperus, 101-102

Cophophryne, 145

Cophophryne alticola, 146

Cophophryne sikkimensis, 145

Cryptobranchus maximus, 69

Cynops wolterstorffi, 109 
daunchina, Rana, 253

davidiana, Sieboldia, 69

davidianus, Megalobatrachus, 69-77

davidianus, Megalobatrachus japonicus, 69

davidi, Hoplobatrachus, 69

davidi, Megalobatrachus japonicus, 69

davidi, Polypedates, 370

davidi, Rhacophorus, $370,373,379$

davidi, Sieboldia, 69

Dermodactylus pinchonii, 82

Diplopelma carnaticum, 248

Diplopelma ornatum var. B., 248

dugritei, Polypedates, 370

dugritei, Rhacophorus, 370-373

Engystoma interlineatum, 247

Engystoma ornatum, 248

eremita, Microhyla, 248

esculenta var., Rana, 309

feae, Rana, 277-278

fissipes, Microhyla, 248

gargarizans, Bufo, 220

gargarizans, Bufo bufo, 220-224

glandulata, Aelurophryne, 137-144

gracilis, Rana, 315

grahami, Microhyla, 252

grahami, Rana, 297

guentheri, Rana, 318-321

hainanensis, Microhyla, 252

hasseltii, Leptobrachium, 180

Hoplobatrachus davidi, 69

Hoplobatrachus reinhard tii, 309

hui, Rhacophorus, 373

Hydrostentor pantherinus, 322

Hyla annectans, 224-231

Hyla annectens, 224

Hyla bambusicola, 373

Hyla leucomystax, 360

Hyla monticola, 373

Hylorana malabarica, 318

Hynobius shihi, 77-80

Hypselotriton wolterstorffi, 109

interlineatum, Engystoma, 247

interlineatus, Kalophrynus pleurostigma, 247-248

Ixalus kakhienensis, 358

Ixalus lateralis, 180

japonica, Rana, 280

japonica, Rana, 285-292

japonica, Rana esculenta, 309

japonica, Rana temporaria, 285

japonicus, Bufo, 220

japonicus, Bufo vulgaris, 220

japonicus, Megalobatrachus, 69, 73, 76

jugans, Rana, 330

jugans, Staurois, 330

kakhienensis, Ixalus, 358

Kalophrynus, 231
Kalophrynus pleurostigma, 247

Kalophrynus pleurostigma interlineatus, $247-248$

Kaloula, 232

Kaloula macroptica, 241-246

Kaloula rugifera, 235-241

Kaloula verrucosa, 246-247

kangtingensis, Staurois, 349-353

karlschmidti, Batrachuperus, 87-96

keyserlingii, Salamandrella, 82

kuhlii, Rana, 322

kweichowensis, Tylototriton, 102-106

lateralis, Ixalus, 180

lateralis, Megophrys, 180-181

latopalmata, Rana, 358

Leptobrachium, 180

Leptobrachium boulengeri, 181

Leptobrachium carinense, 196

Leptobrachium hasseltii, 180

leucomystax, Hyla, 360

leucomystax, Rhacophorus, $360-370$

lifanensis, Staurois, 344-349

limnocharis, Rana, 315-318

loloensis, Staurois, 353-356

longicrus, Rana, 285

longipes, Megophrys, 180

macrodon, Rana, 297

macroptica, Kaloula, 241-246

maculata, Aelurophryne, 136-137

maculatus, Rhacophorus, 360

major, Megalophrys, 180

malabarica, Hylorana, 318

mammata, Aelurophryne, 120-125

mammata, Bufo, 117

mantzorum, Polypedates, 330

mantzorum, Staurois, 330-337

margaretae, Rana, 303-309

marmorata, Rana esculenta, 309

marmoratus, Polypedates, 358

maxima, Bombina, 110-117

maximus, Bombinator, 110

maximus, Cryptobranchus, 69

maximus, Megalobatrachus, 69

megacephalus, Polypedates, 360

megacephalus, Rhacophorus leucomystax, 360

Megalobatrachus davidianus, $69-77$

Megalobatrachus japonicus, $69,73,76$

Megalobatrachus japonicus davidi, 69

Megalobatrachus japonicus davidianus, 69

Megalobatrachus maximus, 69

Megalobatrachus sligoi, 69

Megalophrys, 180

Megalophrys carinensis, 196

Megalophrys major, 180

Megalophrys nasuta, 180

Megophrys, 180

Megophrys boettgeri, 185

Megophrys boulengeri, 181-185

Megophrys carinensis, 196-197 
Megophrys lateralis, 180-181

Megophrys longipes, 180

Megophrys minor, 185-191

Megophrys omeimontis, 191-194

Megophrys oshanensis, 197-201

Megophrys shapingensis, 194-196

Megophrys weigoldi, 182

melanostictus, Bufo, 203

melli, Rana, 298

Microhyla, 232

Microhyla boulengeri, 252

Microhyla butleri, 252-253

Microhyla eremita, 248

Microhyla fissipes, 248

Microhyla grahami, 252

Microhyla hainanensis, 252

Microhyla ornata, 248-252

Microhyla sowerbyi, 252

Microhyla sp., 252

Microhylidae, 231-232

minor, Megophrys, 185-191

minor, Staurois ricketti, 356-358

minshanicus, Bufo, 212

minshanicus, Bufo bufo, 212-214

Molge wolterstorffi, 109

mongolia, Rana nigromaculata, 309

monticola, Hyla, 373

monticola, Xenophrys, 180

Montorana ahli, 323

musica, Rana, 253

Nannorana pleskei, 323

Nanorana pleskei, $323-328$

nasuta, Ceratophryne, 180

nasuta, Megalophrys, 180

nigromaculata, Rana, 309-313

nigromaculata, Rana esculenta, 309

nigromaculata, Rana nigromaculata, 309

nouettei, Bufo, 203

Nyctibatrachus sinensis, 322

ocellata, Calluella, 232-235

omeimontis, Megophrys, 191-194

omeimontis, Polypedates, 379

omeimontis, Rhacophorus, 379-388

ornata, Microhyla, 248-252

ornatum, Engystoma, 248

oshanensis, Megophrys, 197-201

pantherina, Rana tigrina, 322

pantherinus, Hydrostentor, 322

parkeri, Altirana, 329-330

Pelobatrachus, 180

phrynoides, Rana, 272-277

pinchonii, Batrachuperus, 82-87

pinchonii, Dermodactylus, 82

pingii, Scutiger, 146-151

pleskei, Bufo raddei, 203

pleskei, Nannorana, 323

pleskei, Nanorana, 323-328

pleskei, Rana, 118, 323, 329

pleuraden, Rana, 260-262 pleurostigma, Kalophrynus, 247

Polypedates afghana, 358

Polypedates annectans, 224

Polypedates davidi, 370

Polypedates dugritei, 370

Polypedates maculatus unicolor, 360

Polypedates mantzorum, 330

Polypedates marmoratus, 358

Polypedates megacephalus, 360

Polypedates omeimontis, 379

Polypedates yunnanensis, 297

popei, Scutiger, 154-162

przewalskii, Bufo raddei, 203

raddei, Bufo, 203-206, 207

raddii, Bufo, 203

Rana adenopleura, 253-260

Rana afghana, 358

Rana amurensis, 280

Rana andersonii, 297-303

Rana asiatica, 280

Rana boulengeri, 263-272

Rana caldwelli, 253

Rana chaochiaoensis, 292-297

Rana chensinensis, 279

Rana chinensis, 309

Rana chunganensis, 337

Rana daunchina, 253

Rana esculenta chinensis, 309

Rana esculenta japonica, 309

Rana esculenta marmorata, 309

Rana esculenta nigromaculata, 309

Rana esculenta var., 309

Rana feae, 277-278

Rana gracilis, 315

Rana grahami, 297

Rana guentheri, 318-321

Rana japonica, $280,285-292$

Rana jugans, 330

Rana kuhlii, 322

Rana latopalmata, 358

Rana limnocharis, 315-318

Rana longicrus, 285

Rana macrodon, 297

Rana margaretae, 303-309

Rana melli, 298

Rana musica, 253

Rana nigromaculata, 309-313

Rana nigromaculata mongolia, 309

Rana nigromaculata nigromaculata, 309

Rana nigromaculata reinhardtii, 309

Rana phrynoides, 272-277

Rana pleskei, 118, 323, 329

Rana pleuraden, 260-262

Rana reinhardti, 309

Rana rugosa, 322

Rana rugulosa, 321

Rana schmackeri, 297, 298

Rana shuchinae, 313-315

Rana silvatica, 285

Rana spinosa, 263

Rana spinosa group, 262 
Rana temporaria, 285

Rana temporaria asiatica, 280

Rana temporaria chensinensis, 279-285

Rana temporaria group, 278-279

Rana temporaria japonica, 285

Rana tibetana, 263

Rana tigerina, 322

Rana tigerina rugulosa, 321-322

Rana tigrina burkilli, 322

Rana tigrina pantherina, 322

Rana tigrina rugulosa, 322

Rana vittigera, 315,322

Rana weigoldi, 280

Ranina symetrica, 248

reinhardtii, Hoplobatrachus, 309

reinhardtii, Rana nigromaculata, 309

reinhardti, Rana, 309

Rhacophorus, 359-360

Rhacophorus bambusicola, 373-379

Rhacophorus chenfui, 388-391

Rhacophorus davidi, $370,373,379$

Rhacophorus dugritei, $370-373$

Rhacophorus hui, 373

Rhacophorus leucomystax, 360-370

Rhacophorus leucomystax megacephalus, 360

Rhacophorus maculatus, 360

Rhacophorus omeimontis, 379-388

Rhacophorus pleurostictus batangensis, 370 , 373

ricketti minor, Staurois, 356

ricketti, Staurois ricketti, 357

rugifera, Kaloula, 235-241

rugosa, Rana, 322

rugosa, Scutiger, 151-154

rugulosa, Rana, 321

rugulosa, Rana tigerina, 321-322

rugulosa, Rana tigrina, 322

Salamandrella keyserlingii, 82

Salamandrella sinensis, 80,82

schmackeri, Rana, 297, 298

schmidti, Scutiger, 162-168

Scutiger, 144-146

Scutiger alticola, 168

Scutiger pingii, 146-151

Scutiger popei, 154-162

Scutiger rugosa, 151-154

Scutiger schmidti, 162-168

Scutiger sikkimensis, 154

Scutiger sp. from Lungtung, Paohsinghsien, 175-176

Scutiger sp. from Mount Omei, 171-175

Scutiger sp. from Panlungshan, 168-171

shapingensis, Megophrys, 194-196

shihi, Hynobius, 77-80

shuchinae, Rana, 313-315

Sieboldia davidi, 69

Sieboldia davidiana, 69

sikkimensis, Bombinator, 145

sikkimensis, Cophophryne, 145

sikkimensis, Scutiger, 154 silvatica, Rana, 285

sinensis, Batrachuperus, 82

sinensis, Calophrynus pleurostigma, 247

sinensis, Nyctibatrachus, 322

sinensis, Salamandrella, 80, 82

sligoi, Megalobatrachus, 69

sowerbyi, Microhyla, 252

spinosa group, Rana, 262

spinosa, Rana, 263

Staurois, 330

Staurois afghanus, 358-359

Staurois chunganensis, 337-344

Staurois jugans, 330

Staurois kangtingensis, 349-353

Staurois lifanensis, 344-349

Staurois loloensis, 353-356

Staurois mantzorum, 330-337

Staurois ricketti minor, 356-358

Staurois ricketti ricketti, 357

symetrica, Ranina, 248

tainingensis, Aelurophryne, 132-136

taliangensis, Tylototriton, 106-107

temporaria group, Rana, 278 279

temporaria, Rana, 285

tibetana, Rana, 263

tibetanus, Batrachuperus, 96-99

tibetanus, Bufo, 207-212

tigerina, Rana, 322

Triturus wolterstorffi, 109-110

tuberculatus, Bufo, 207

Tylototriton kweichowensis, 102-106

Tylototriton taliangensis, 106-107

Tylototriton verrocosa, 108

Tylototriton verrucosa, 108

Tylototriton verrucosus, 108-109

unicolor, Polypedates maculatus, 360

verrocosa, Tylototriton, 108

verrucosa, Callula, 246

verrucosa, Kaloula, 246-247

verrucosa, Tylototriton, 108

verrucosus, Tylototriton, 108-109

Vibrissaphora boringii, 176-180

vittigera, Rana, 315,322

vulgaris, Bufo, 207, 220

weigoldi, Megophrys, 182

weigoldi, Rana, 280

wolterstorffi, Cynops, 109

wolterstorff, Hypselotriton, 109

wolterstorff, Molge, 109

wolterstorffi, Triturus, 109-110

wrighti, Bufo bufo, 214-219

Xenophrys, 180

Xenophrys monticola, 180

yenyuanensis, Batrachuperus, 99-101

yunnanensis, Calluella, 232

yunnanensis, Polypedates, 297 
PLATES 


\section{EXPLANATION OF PLATE 1}

\section{Salamanders of Western China}

FIG. 1. Batrachuperus tibetanus.

FIG. 2. Batrachuperus tibetanus; view of head from above.
FIG. 3. Batrachuperus tibetanus; view of head from below.

FIG. 4. Batrachuperus pinchonii; view of head from above.

FIG. 5. Batrachuperus pinchonii; view of head from below. 


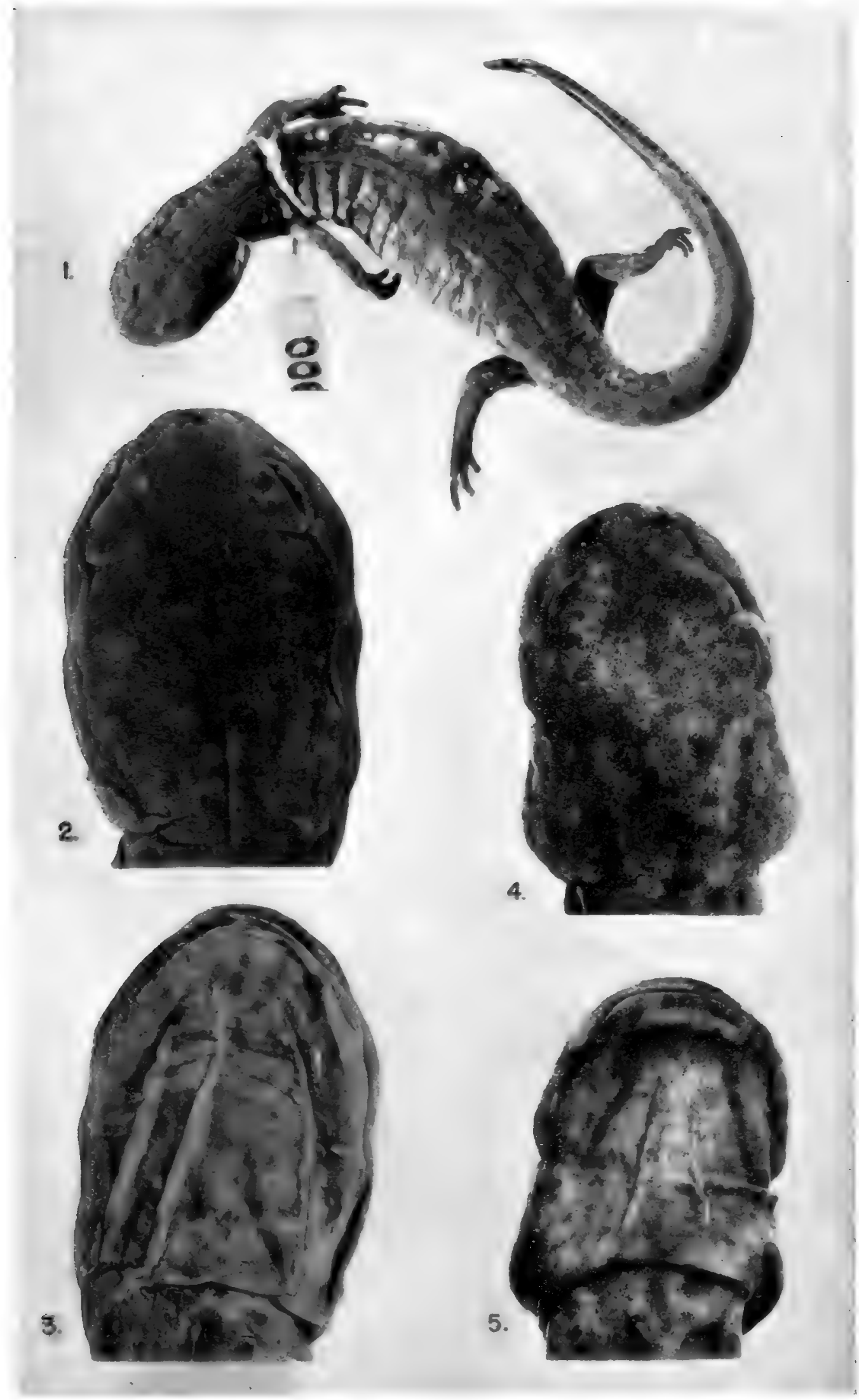




\section{EXPLANATION OF PLATE 2}

\section{Salamanders of Western China}

FIG. 1. Tylototriton kweichowensis; variation FIG. 2. Tylototriton kweichowensis; lateral in dorsal coloration $(\times 2)$. view $(\times 1)$.

FIG. 3. Tylototriton kweichowensis; ventral view $(\times 1)$. 
Fieldiana: Zoology Memoirs, Volume 2

Plate 2
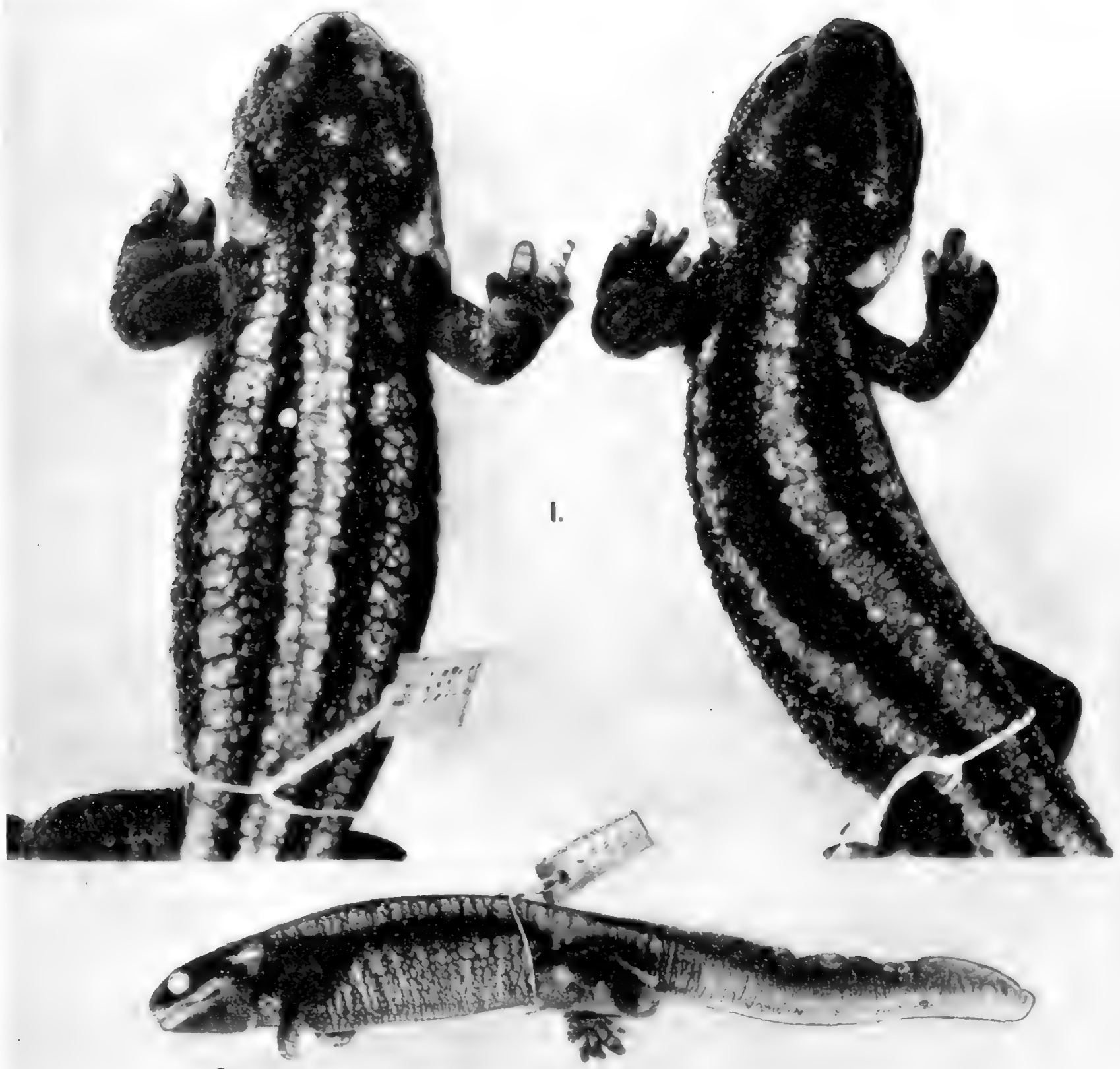

2.

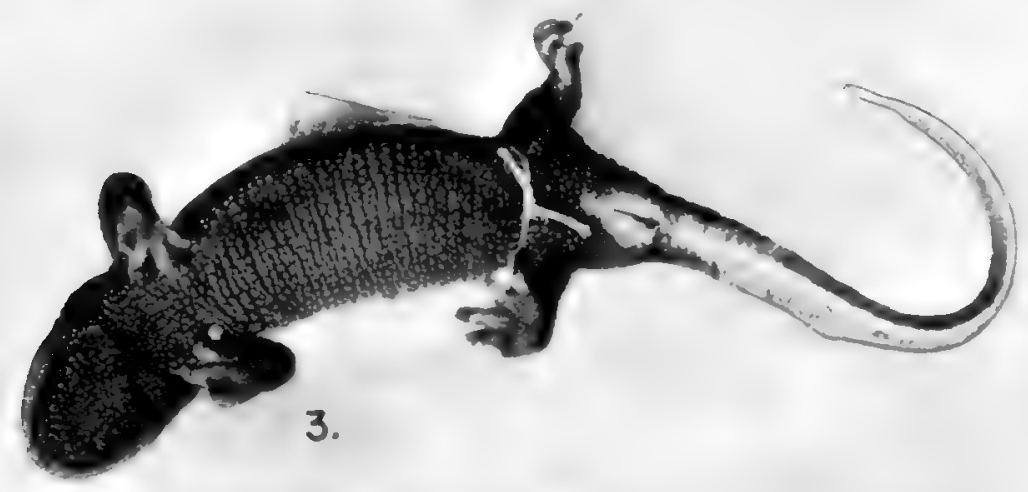




\section{EXPLANATION OF PLATE 3}

\section{Salamanders of Western China}

FIG. 1. Batrachuperus pinchonii.

FIG. 2. Triturus wolterstorffi.

FIG. 3. Tylototriton taliangensis. 
Fieldiana: Zoology Memoirs, Volume 2

Plate 3
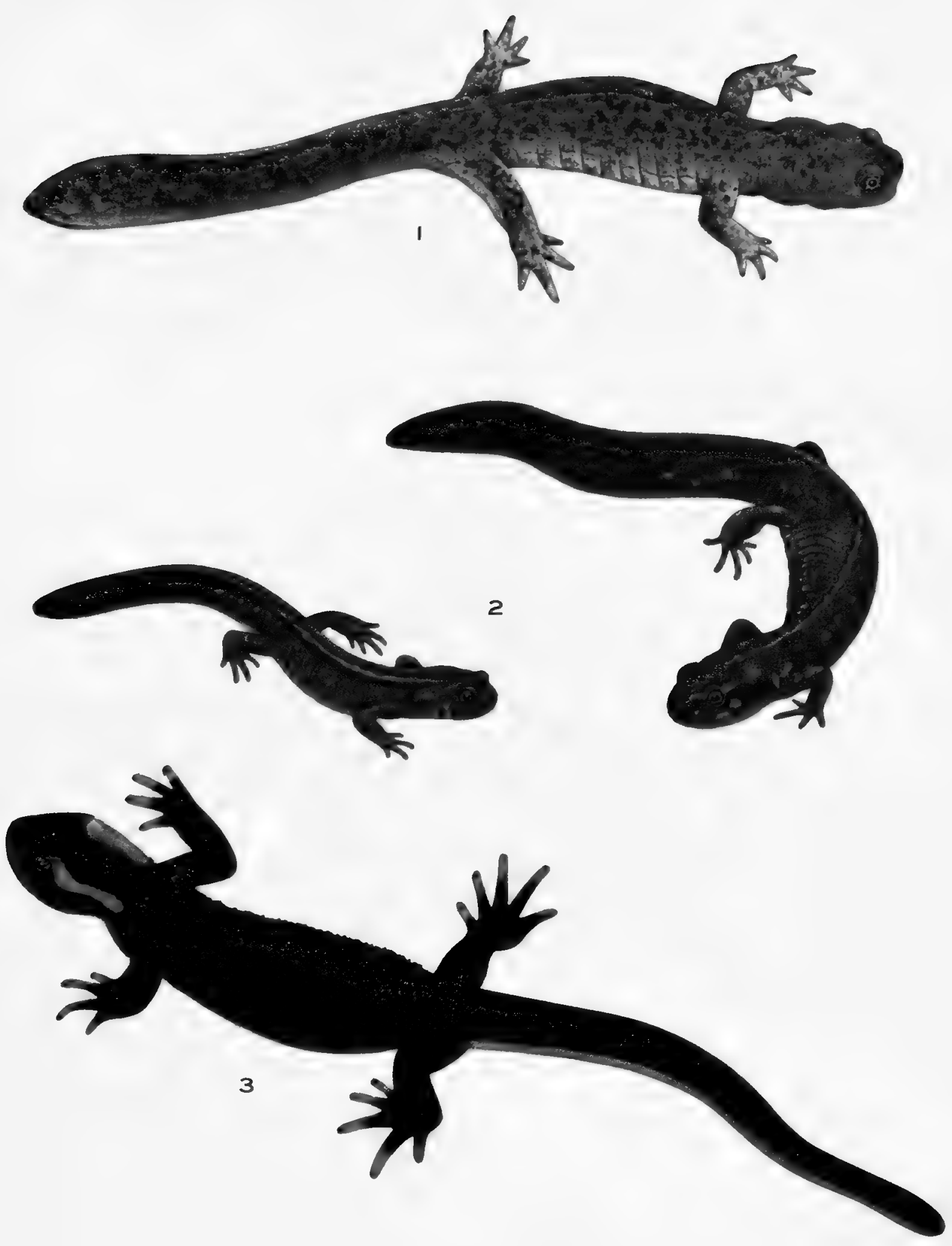


\section{EXPLANATION OF PLATE 4}

\section{Pelobatid Frogs of Western China}

FIG. 1. Scutiger pingii; female.

FIG. 2. Megophrys omeimontis; male.

FIG. 3. Vibrissaphora boringii; male.
FIG. 4. Aelurophryne tainingensis.

FIG. 5. Megophrys minor; male.

FIG. 6. Aelurophryne glandulata. 
Fieldiana: Zoology Memoirs, Volume 2

Plate 4
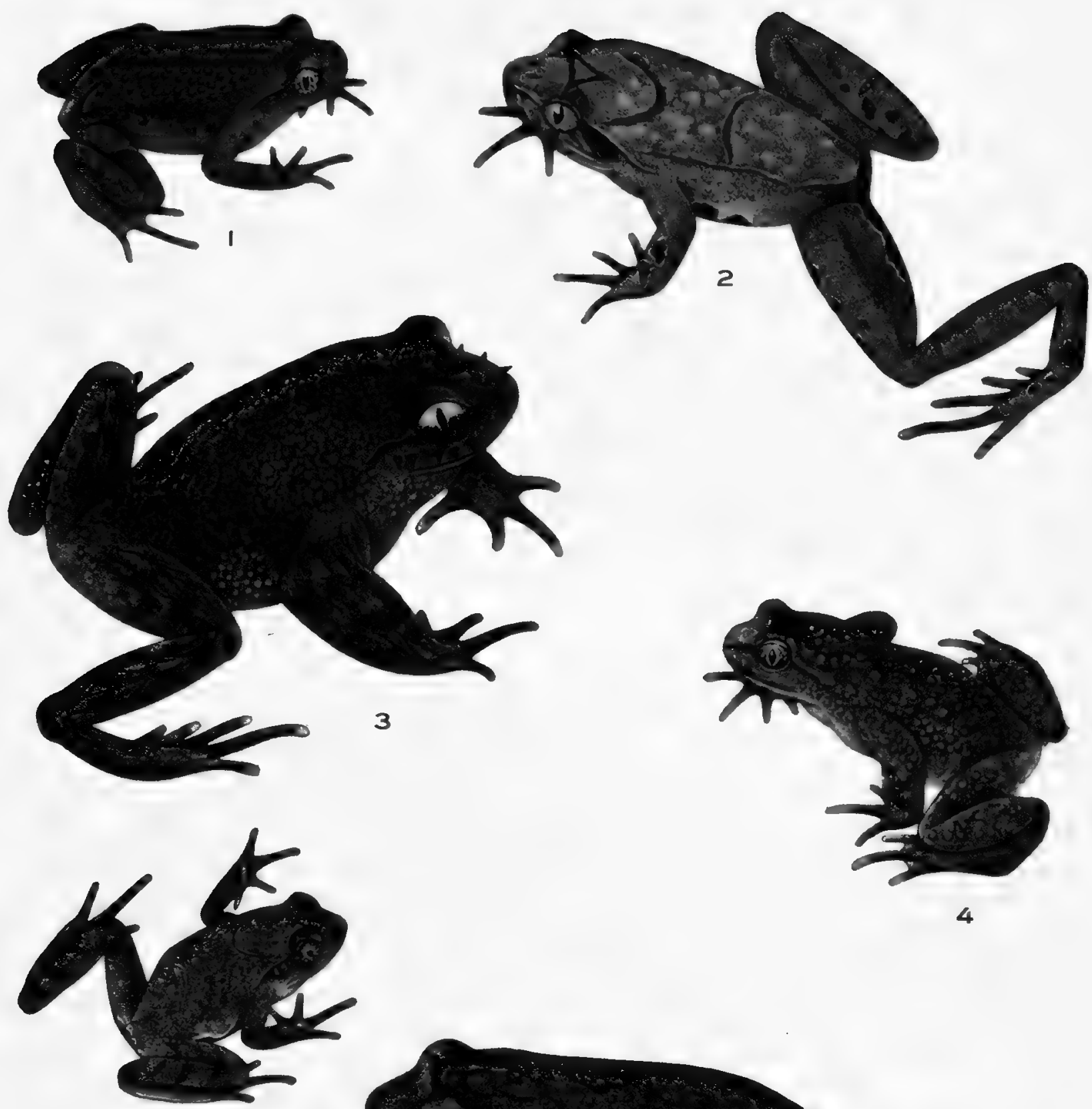

4

5

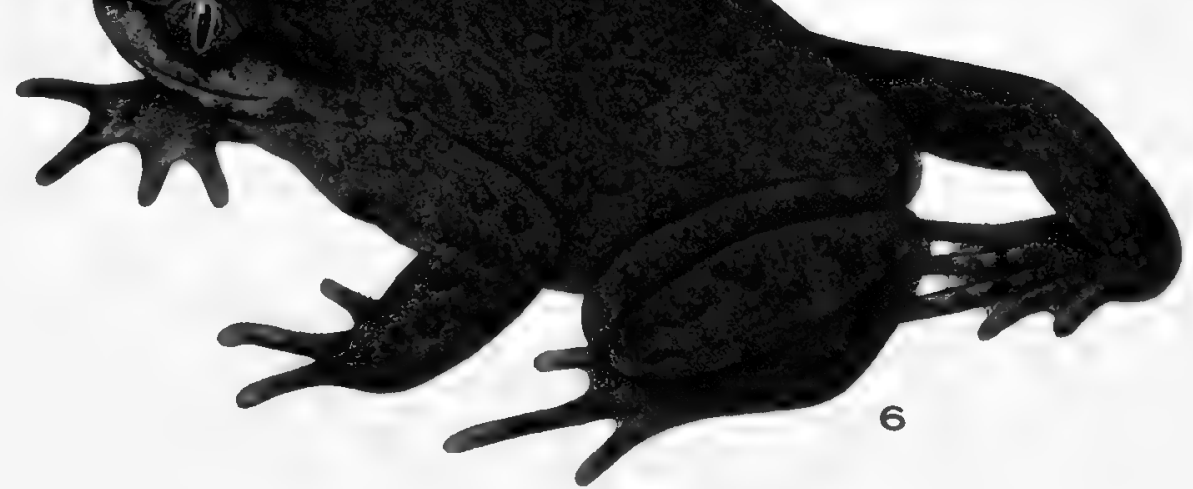




\section{EXPLANATION OF PLATE 5}

\section{Pelobatid Frogs of Western China}

FIG. 1. Scutiger schmidti; female.

FIG. 3. Megophrys shapingensis.

FIG. 2. Scutiger schmidti; male.

FIG. 4. Megophrys boulengeri.

FIG. 5. Scutiger popei. 
Fieldiana: Zoology Memoirs, Volume 2

Plate 5
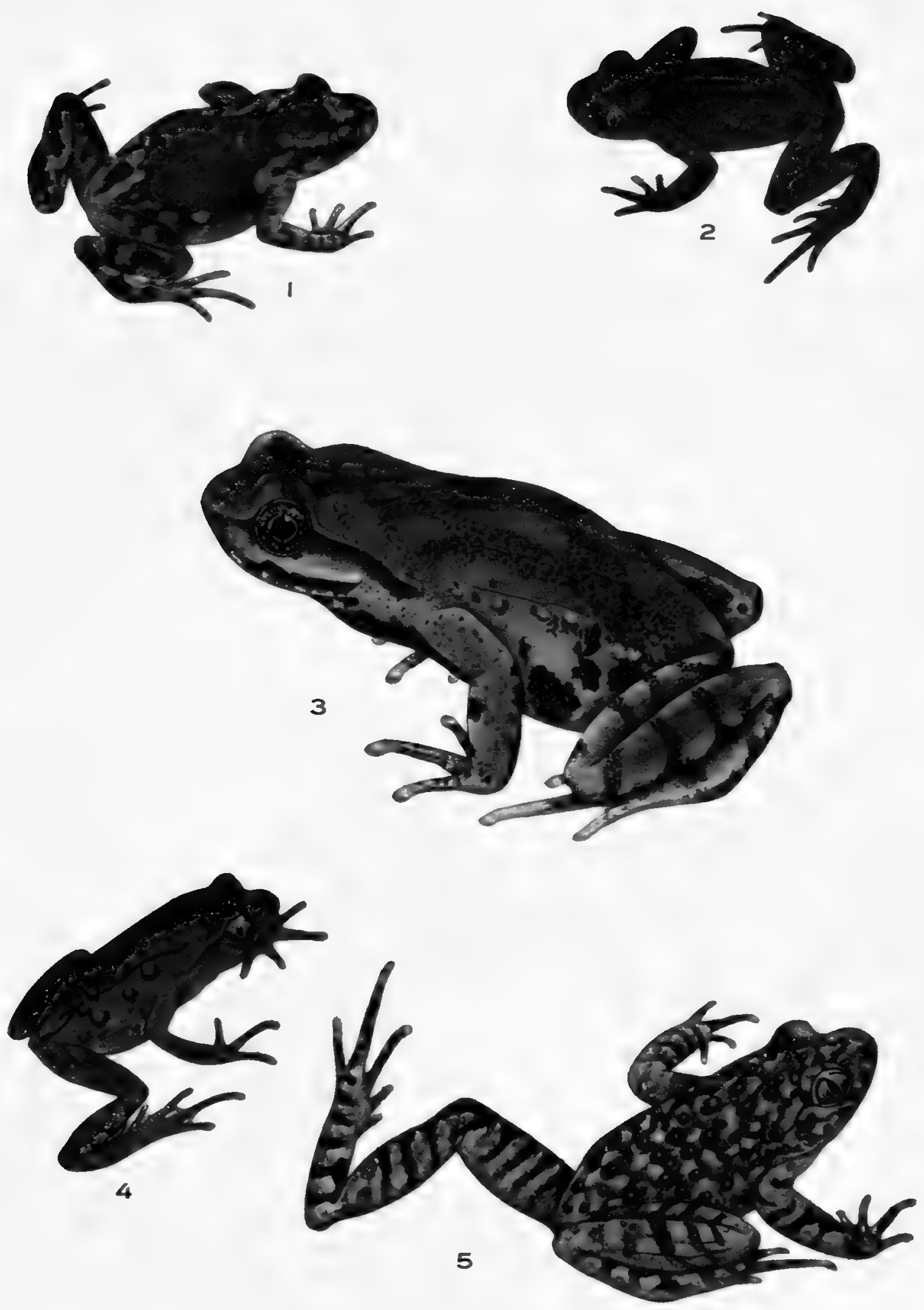


\section{EXPLANATION OF PLATE 6}

\section{Frogs of Western China}

FIG. 1. Rana nigromaculata.

Fig. 2. Rana chaochiooensis.

FIG. 3. Rana andersonii.
FIG. 4. Rana shuchinae.

FIG. 5. Nanorana pleskei.

Fig. 6. Rana margaretae. 

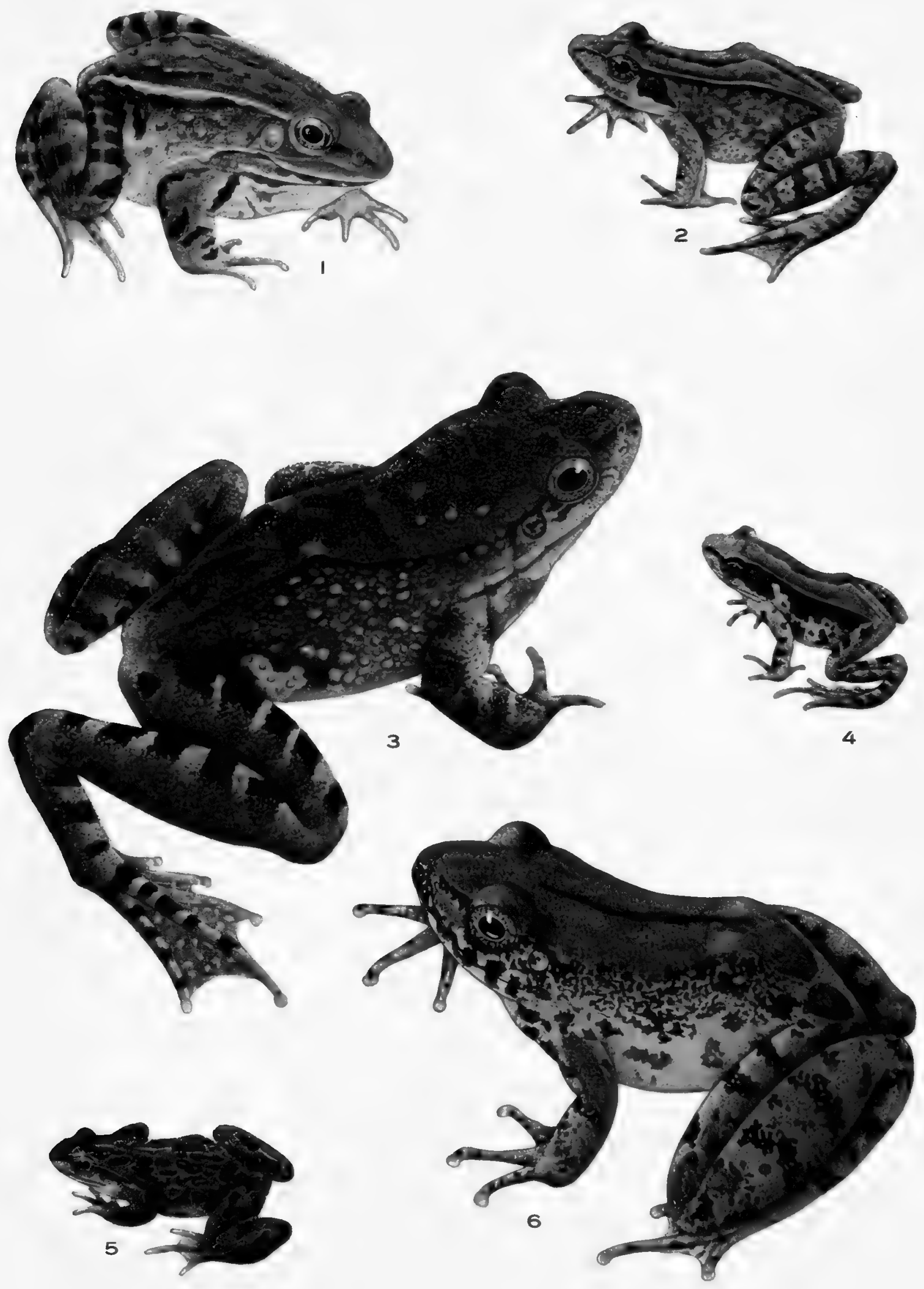


\section{EXPLANATION OF PLATE 7}

\section{Cascade Frogs of Western China}

FIG. 1. Staurois loloensis.

Fig. 2. Staurois mantzorum.

FIG. 3. Staurois chunganensis.
FIG. 4. Staurois kangtingensis.

FIG. 5. Staurois lifanensis.

FIG. 6. Staurois mantzorum; variant. 

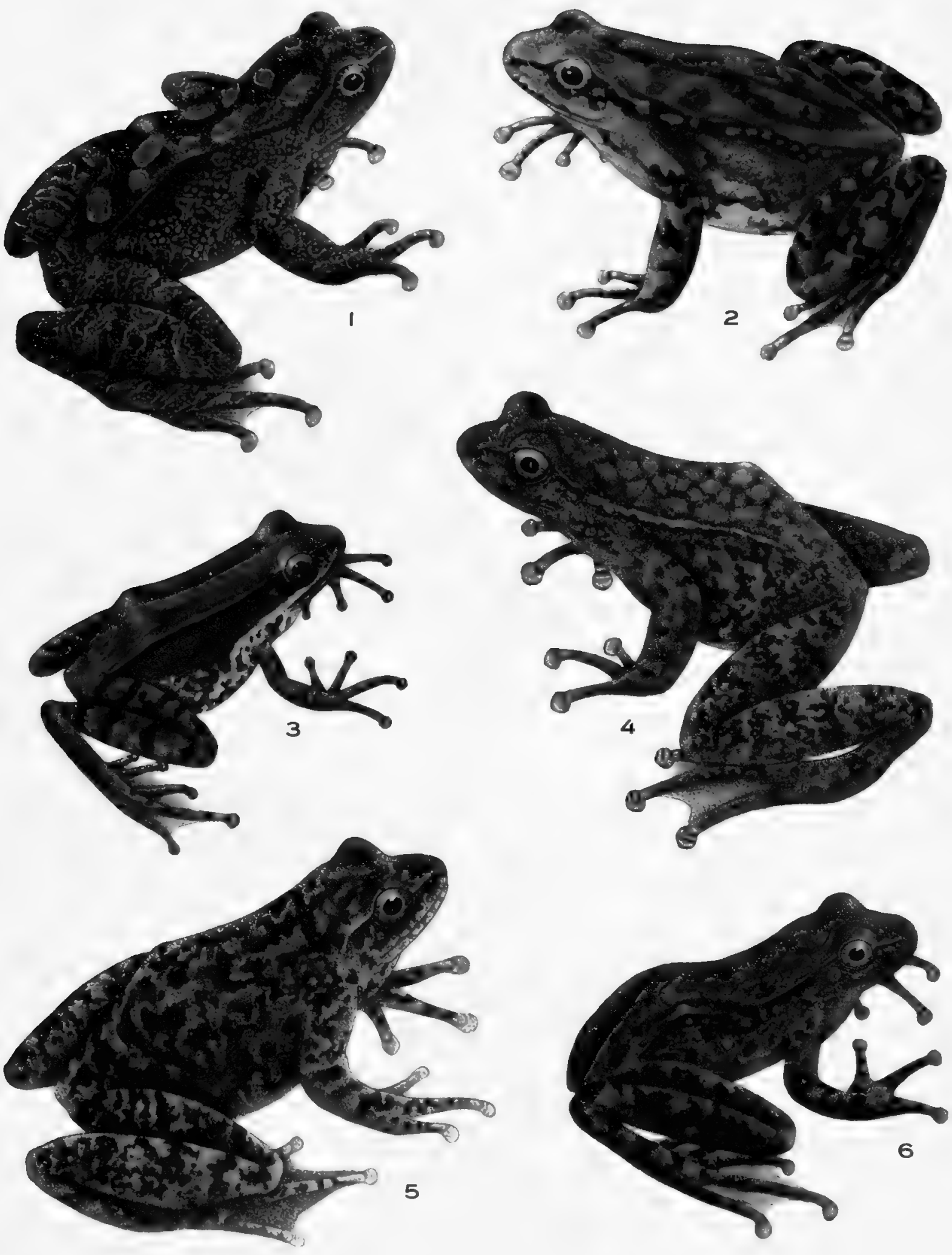


\section{EXPLANATION OF PLATE 8}

\section{Tree Frogs of Western China}

FIG. 1. Rhacophorus chenfui; male.

FIG. 2. Rhacophorus chenfui; female.
FIG. 3. Rhacophorus omeimontis; male.

FIG. 4. Rhacophorus bambusicola; female.

Fig. 5. Rhacophorus bambusicola; male. 
Fieldiana: Zoology Memoirs, Volume 2

Plate 8
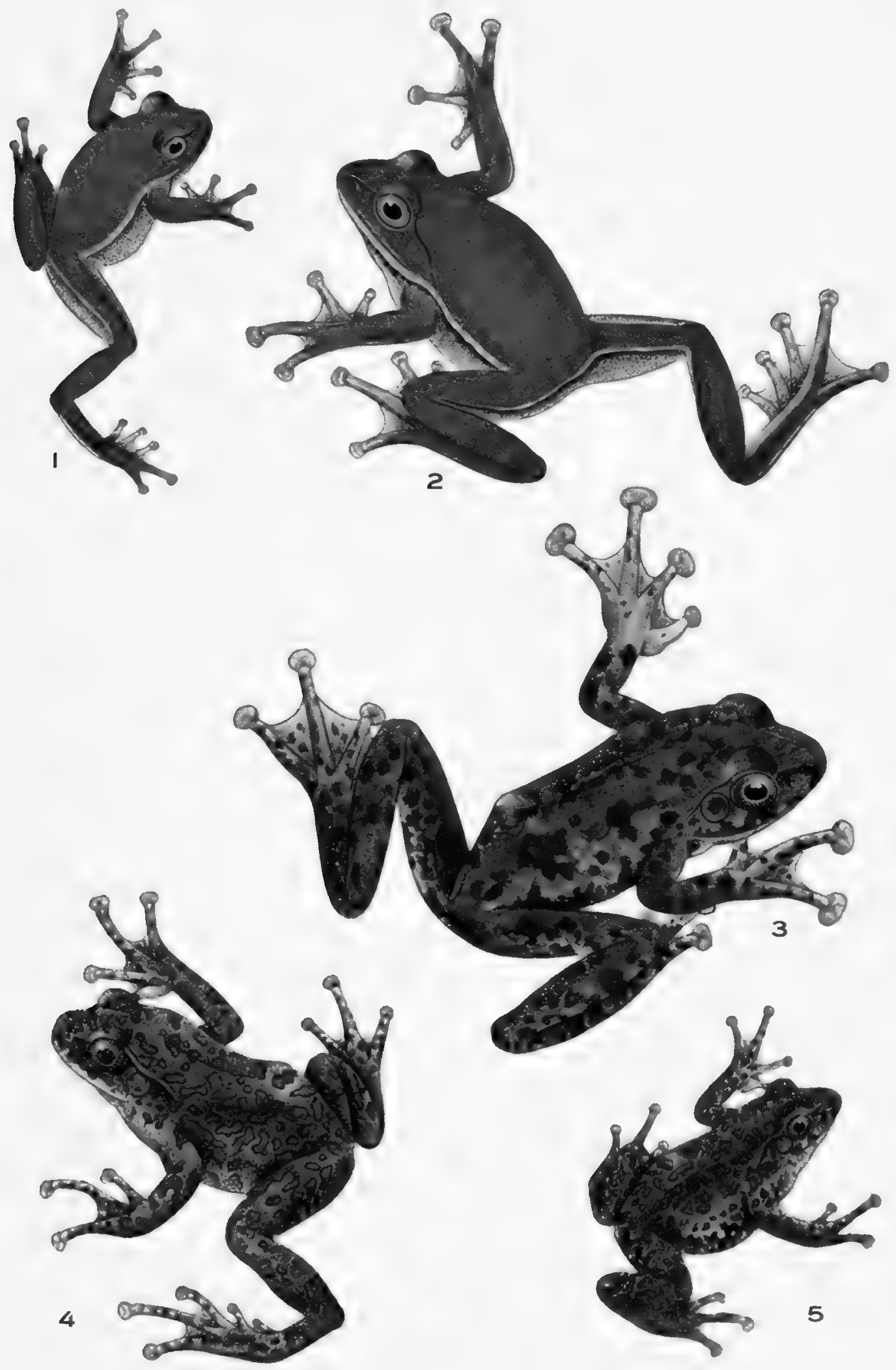
EXPLANATION OF PLATE 9

Aerial Egg-Mass of Tree Frog

Egg-mass of Rhacophorus omeimontis 
Fieldiana: Zoology Memoirs, Volume 2

Plate 9

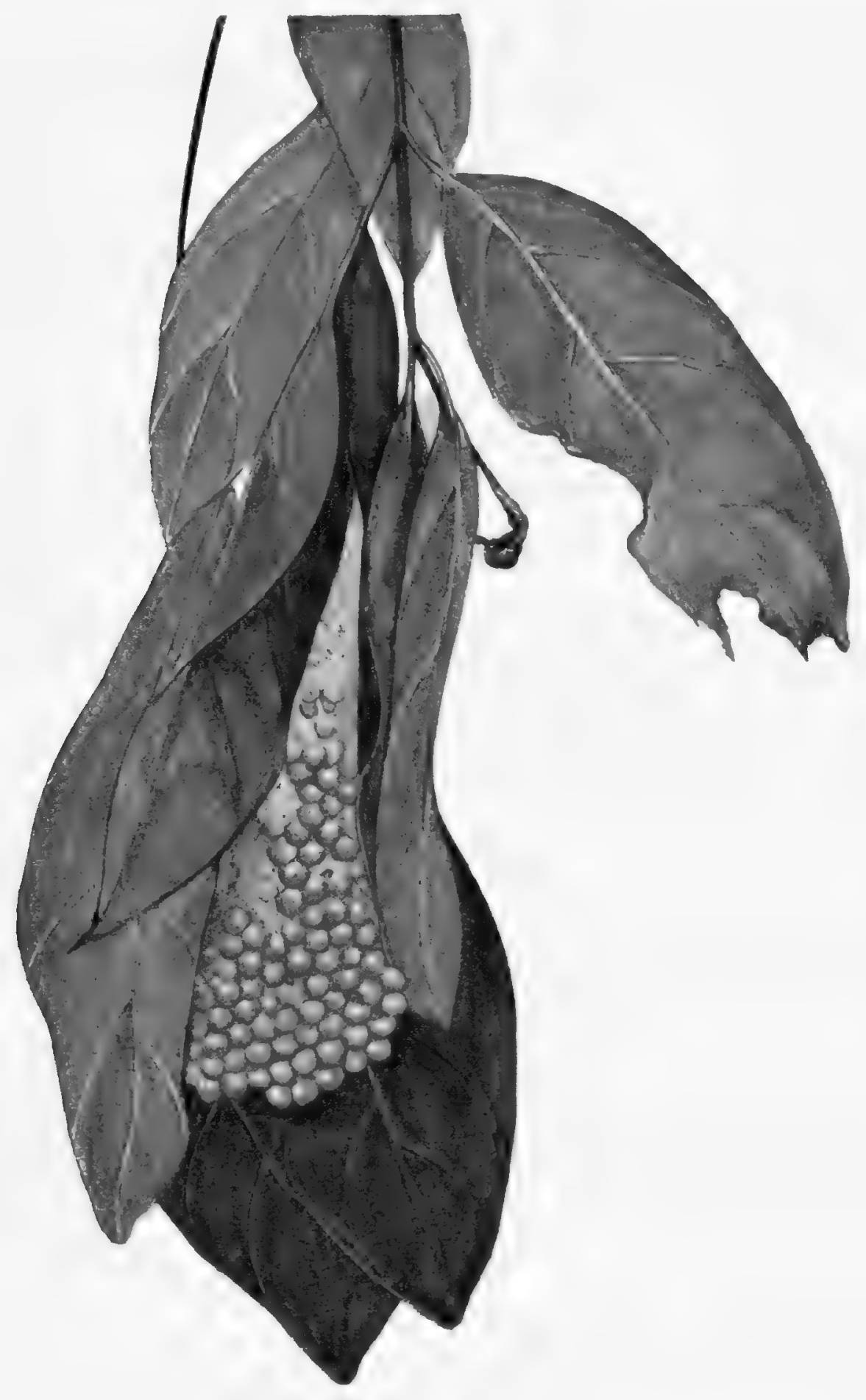




\section{EXPLANATION OF PLATE 10}

\section{Tadpoles of Salientians of Western China}

FIG. 1. Megophrys minor; dorsal view.

FIG. 2. Megophrys minor; lateral view.

FIG. 3. Scutiger rugosa.

FIG. 4. Megophrys oshanensis.

FIG. 5. Microhyla ornata.

FIG. 6. Rana boulengeri.

FIG. 7. Aelurophryne glandulata.
FIG. 8. Bombina maxima.

FIG. 9. Rana adenopleura.

FIG. 10. Hyla annectans.

FIG. 11. Kaloula macroptica.

FIG. 12. Staurois lifanensis.

FIG. 13. Scutiger schmidti.

FIG. 14. Rhacophorus leucomystax. 
Fieldiana: Zoology Memoirs, Volume 2

Plate 10
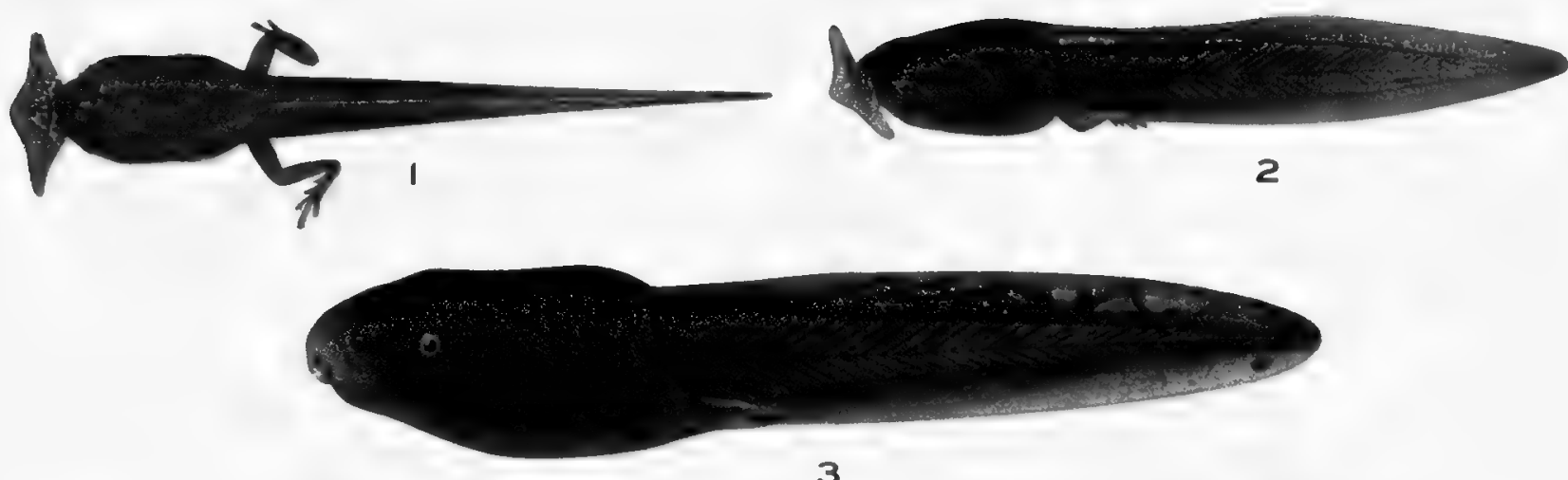

3
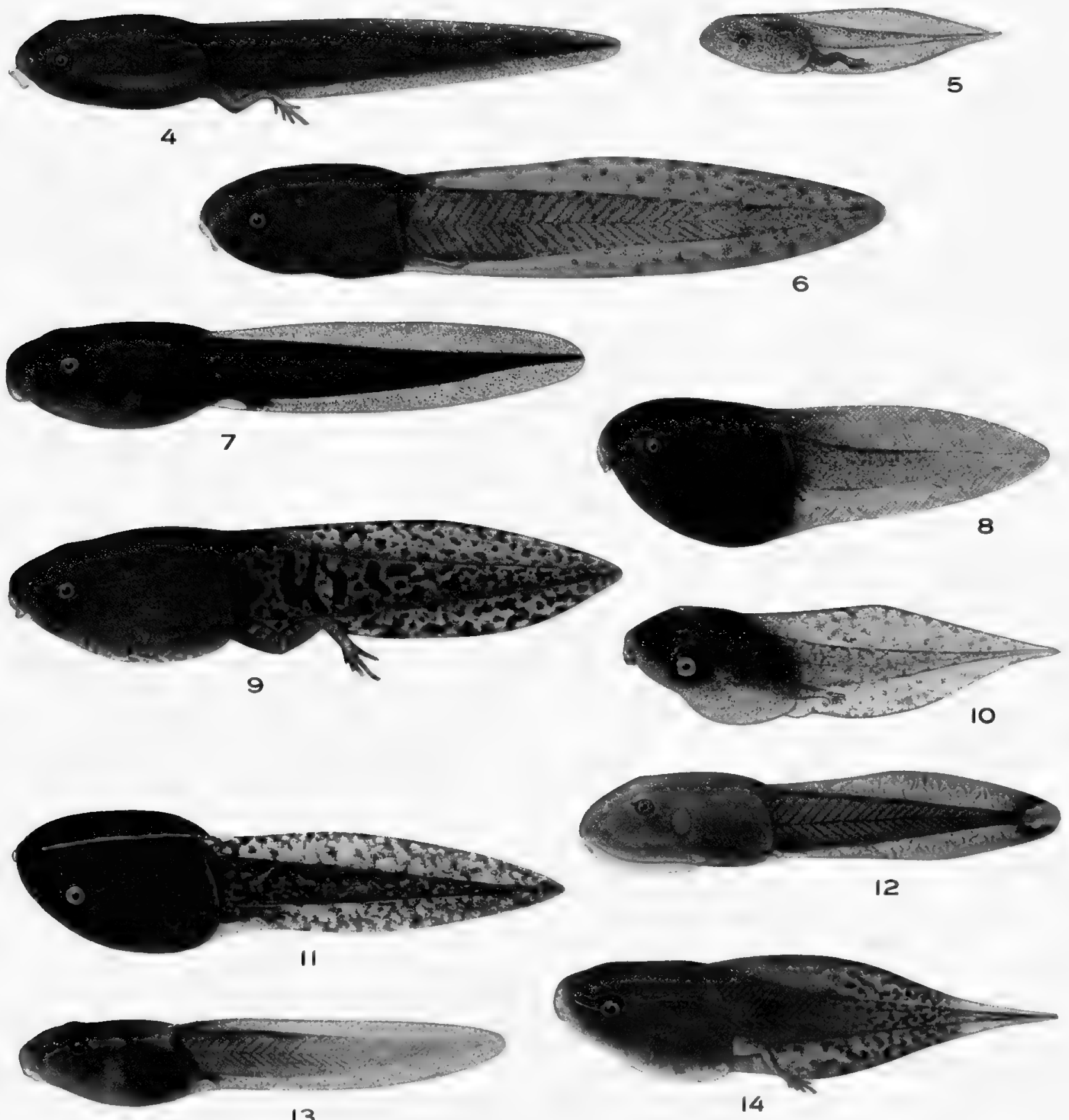





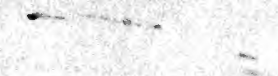


